\section{Pacific Northwest}

National Laboratory

Operated by Battelle for the

U.S. Department of Energy

\title{
Hanford Immobilized LAW \\ Product Acceptance Testing: Tanks Focus Area Results
}

\author{
J. D. Vienna \\ A. Jiricka \\ P. Hrma \\ D. E. Smith \\ Pacific Northwest National Laboratory \\ Richland, Washington 99352 \\ T. H. Lorier \\ R. L Schulz \\ I. A. Reamer \\ Savannah River Technology Center, \\ Aiken, South Carolina 29808
}

December 2001

Prepared for the U.S. Department of Energy under Contract DE-AC06-76RL01830 


\title{
Hanford Immobilized LAW Product Acceptance Testing: Tanks Focus Area Results
}

\author{
J. D. Vienna \\ A. Jiricka \\ P. Hrma \\ D. E. Smith \\ Pacific Northwest National Laboratory, \\ Richland, W ashington 99352 \\ T. H. Lorier \\ R. L. Schulz \\ I. A. Reamer \\ Savannah River Technology Center, \\ Aiken, South Carolina 29808
}

December 2001

Prepared for the U.S. Department of Energy under Contract DE-AC06-76RL01830 


\title{
Hanford Immobilized LAW Product Acceptance Testing: Tanks Focus Area Results
}

\author{
J. D. Vienna \\ A. Jiricka \\ P. Hrma \\ D. E. Smith \\ Pacific Northwest National Laboratory, \\ Richland, Washington 99352
}

\author{
T. H. Lorier \\ R. L. Schulz \\ I. A. Reamer \\ Savannah River Technology Center, \\ Aiken, South Carolina 29808
}

December 2001

Prepared for the U.S. Department of Energy under Contract DE-AC06-76RL01830

Pacific Northwest National Laboratory

Richland, Washington 99352 


\section{Summary}

This report provides the results of a continuing study to help determine the composition range of lowactivity waste (LAW) glasses that will meet performance expectations of the Hanford site burial facility. This is a continuation of the Hanford Immobilized Low Activity Waste Product Acceptance: Tanks Focus Area Testing Data Package II (Schulz et al. 2000). In addition to the completion of Phase I testing (glasses HLP-01 through -55), new product consistency test (PCT), vapor hydration test (VHT), and alteration products data for Phase II (glasses HLP-58 through -77) are included to use when comparing the response of the various glasses to different test conditions.

An original test matrix of 55 glasses (Phase I) was developed to identify the impact of glass composition on long-term corrosion behavior and to develop an acceptable composition region for Hanford LAW glasses. Of the 55 glasses, 45 were designed to systematically vary the glass composition, and 10 were selected because large and growing databases on their corrosion characteristics had accumulated. A second matrix (Phase II) was developed, consisting of 20 glasses, to help determine the influence on the test responses of key glass components that were not varied systematically in Phase I. All glasses were fabricated according to standard procedures and heat treated to simulate the slowest cooling that will occur in a portion of the waste glass after vitrification in the planned treatment facility at Hanford.

A series of VHTs was performed at temperatures from $90^{\circ} \mathrm{C}$ to $300^{\circ} \mathrm{C}$. The amount of glass converted to alteration products, $m_{a}$, is listed along with test time, $t$, and temperature in Appendix C; these are discussed in Sections 3.5 and 4.0. The alteration rates, determined from the linear portion of the $m_{a^{-}}-t$

function, are also listed in Appendix C. The rates were determined for most test-matrix glasses at $200^{\circ} \mathrm{C}$; they range from 0.00 to $1708 \mathrm{~g} / \mathrm{m}^{2} / \mathrm{d}$ (covering five orders of magnitude). The glasses with the five highest rates (in $\mathrm{g} / \mathrm{m}^{2} / \mathrm{d}$ ) at $200^{\circ} \mathrm{C}$ are HLP-63 (1708), HLP-66 (1337), HLP-52 (1219), HLP-53Q (553), and HLP-02 (265). The glasses with the lowest rates at $200^{\circ} \mathrm{C}$ are HLP-42 (0.00), HLP-19 (0.01), HLP34 (0.04), and HLP-32 (0.18). The major crystalline alteration products were identified. The most prevalent crystalline alteration products include analcime, sodium aluminum-silicate-hydrate (or sodium aluminum silicate boron hydroxide hydrate with a similar crystal structure), and clinopyroxene. A combination of X-ray diffraction (XRD) and scanning electron microscopy/energy dispersive spectroscopy (SEM/EDS) analyses revealed that a majority of the alteration products are amorphous materials with compositions similar to those of the unreacted glass, and crystalline alteration products generally appear on the surface of the reacted specimens. The impact of inverse temperature on the logarithm of the VHT rate was found to be nearly linear with slopes, $E_{a}$, ranging from 80 to $102 \mathrm{~kJ} / \mathrm{mol}$. A correlation was found between the alteration rate measured by VHT at $200^{\circ} \mathrm{C}$ and glass composition. This correlation showed that alkali, divalent components, and aluminum oxides increase VHT rate while $\mathrm{SiO}_{2}, \mathrm{TiO}_{2}, \mathrm{ZrO}_{2}, \mathrm{~B}_{2} \mathrm{O}_{3}$, and $\mathrm{Fe}_{2} \mathrm{O}_{3}$ decrease $\mathrm{VHT}$ rate. Glass redox was found to have little effect on VHT rate. Correlations were found between the time required to reach an acceleration in rate by VHT at $200^{\circ} \mathrm{C}$ and by PCT-B performed at $99^{\circ} \mathrm{C}$ with a $20000 \mathrm{~m}^{-1}$ glass surface area to solution volume ratio (S/V) and between the VHT rate at $200^{\circ} \mathrm{C}$ with pressurized unsaturated flow-through test rates. It was found that although conservative for short time tests, single-point VHT measurements may be useful for meeting contract specifications for Hanford LAW glasses. 
The testing (via PCT) of Phase I glasses was complete with the 10000 -h tests. This modified PCT (PCT-B) was performed at $90^{\circ} \mathrm{C}$ with a S/V of approximately $20000 \mathrm{~m}^{-1}$. The normalized release rates for the 10000 -h tests ranged from $2.13 \times 10^{-4}$ to $1.52 \times 10^{-1} \mathrm{~g} /\left(\mathrm{m}^{2} \cdot \mathrm{d}\right)$ for boron and $4.33 \times 10^{-4}$ to $8.55 \times$ $10^{-2} \mathrm{~g} / \mathrm{m}^{2} /$ day for sodium. The glasses with the highest boron release rates were HLP-02, $-29,-46,-27$, and -53 at $10000 \mathrm{~h}$, while those with the highest release rates for sodium were HLP-27, -53, 46, -29, and -52. The twenty glasses of Phase II were subject to the same test conditions of the PCT as the Phase I glasses (thus far up to $5000 \mathrm{~h}$ complete). The Phase II glasses with the largest release for boron were HLP-71, -66, -73, -63, and -64 at $1000 \mathrm{~h}$, and HLP-70, -66, -73, -67, and -64 at $5000 \mathrm{~h}$. At $5000 \mathrm{~h}$, the release rates for boron ranged from $2.66 \times 10^{-4}$ to $1.50 \times 10^{-1} \mathrm{~g} / \mathrm{m}^{2} /$ day. In the case of sodium release, the glasses with the largest releases were HLP-71, -63, -66, -73, and -67 at $1000 \mathrm{~h}$, and HLP-70, -66, -67, -64, and -73 at $5000 \mathrm{~h}$. At $5000 \mathrm{~h}$, the release rates for sodium ranged from $3.73 \times 10^{-4}$ to $8.62 \times 10^{-2}$

$\mathrm{g} / \mathrm{m}^{2} /$ day. The data gathered thus far for the Phase II glasses indicate that they follow the same general trends as the Phase I glasses - the release rates decrease steadily up to $1000 \mathrm{~h}$ and then either level off or continue a gradual decrease up to the 5000-h time period. It appeared from all supplied data (Phases I and II) that some of the least durable glasses were HLP-02, -33, -39, -70, and -71, and that some of the most durable were HLP-30, -49, -59, -62, and -69. For PCT as a function of glass composition, it appeared that glasses with higher alumina and silica contents did not have large release rates for sodium or boron. Also, glasses with relatively high concentrations of sodium were typically among those with the largest shortterm releases of sodium. It should be noted that these trends were based on single data points, and further testing is required before conclusions can be drawn with any certainty.

According to specifications established in Hanford Contract DE-AC27-01RV14136, Section C (DOE 2000), all glasses must pass a PCT-A limit of $2.0 \mathrm{~g} / \mathrm{m}^{2}$ and a VHT limit of $50 \mathrm{~g} /\left(\mathrm{m}^{2} \cdot \mathrm{d}\right)$. Of all the HLP glasses tested, only 20 did not pass these criteria by at least one test. The glasses that failed typically had low concentrations of $\mathrm{ZrO}_{2}$ and high concentrations of alkali oxides. More thorough evaluations of composition effects on PCT-A releases and VHT rates are required before an acceptable glass composition region can be clearly defined. However, the work presented in this report provides a starting point.

The final section of the main document provides a summary of the results obtained thus far, as well as recommendations for future study. In addition, the Appendices contain additional useful information that was too extensive to be included in the main text of this report.

\section{References}

Schulz, R. L., T. H. Lorier, D. K. Peeler, K. G. Brown, I. A. Reamer, J. D. Vienna, A. Jiricka, B. M. Jorgenson, and D. E. Smith. 2000. Hanford Immobilized LAW Product Acceptance: Tanks Focus Area Testing Data Package II, PNNL-13344, Pacific Northwest National Laboratory, Richland, Washington.

U.S. Department of Energy (DOE). 2000. Design, Construction, and Commissioning of the Hanford Tank Waste Treatment and Immobilization Plant, Section C, Modification No. M008; DOE Office of River Protection, Richland, Washington 99352; Contract with Bechtel National, Inc., San Francisco, California 94105, Contract No.: DE-AC27-01RV14136, Issued August 31, 2000. 


\section{Glossary}

Accelerated tests

AES

AGCR

Alteration

products

Amount of glass

dissolved

ANSI

ARM

ASTM

Behavior

Corrosion

Corrosion layer

Corrosion rate

Dissolution

DIW

DOE

DOE-EM

EA

$E_{a}$

EDS

HLP

IA

ICP

ILAW

LAW

LRM

$m_{a}$ tests conducted to attain certain conditions faster than it would be possible under natural conditions or tests conducted under conditions that increase the reaction rate atomic emission spectroscopy acceptable glass composition region

thermodynamically more stable phases formed during glass corrosion. These phases may incorporate constituents from glass and other species from the solution, atmosphere, and barrier materials.

mass of glass dissolved, calculated from the thickness of glass reacted, which is determined by subtracting the remaining glass layer thickness (determined by OM/IA) from initial glass thickness

American National Standards Institute

Analytical Reference Material

American Society for Testing and Materials

the response of a material to its environment, specifically to the temperature and solution chemistry

the process of glass dissolution and conversion to alteration products

layer of alteration products formed on the surface of bulk glass

the rate at which glass is dissolved or converted to alteration products

the process of dissolving solid material into the solution

deionized water

U.S. Department of Energy

DOE's Office of Environmental Management

Environmental Assessment

apparent activation energy

energy dispersive spectroscopy

Hanford LAW product acceptance (glass nomenclature)

image analysis

inductively coupled plasma

immobilized low-activity waste

low-activity waste

low-activity waste reference material

mass of glass converted to alteration products in $\mathrm{g} / \mathrm{m}^{2}$ 


\begin{tabular}{|c|c|}
\hline NIST & National Institute for Standards and Technology \\
\hline $\mathrm{OM}$ & optical microscopy \\
\hline ORP & Office of River Protection \\
\hline PA & performance assessment \\
\hline PCT & Product Consistency Test \\
\hline PCT-A & method A of the PCT as defined in ASTM (1998) \\
\hline PCT-B & method B of the PCT as defined in ASTM (1998) \\
\hline PDF & powder diffraction file \\
\hline Performance & $\begin{array}{l}\text { the ability of the burial system, primarily waste form in this work, to meet regulatory } \\
\text { limits on release of radioactive and hazardous components }\end{array}$ \\
\hline PNNL & Pacific Northwest National Laboratory \\
\hline PUF & Pressurized Unsaturated Flow-Through (test) \\
\hline$r$ & alteration rate in $\mathrm{g} / \mathrm{m}^{2} / \mathrm{d}$ \\
\hline repeated glasses & multiple glasses with the same target composition, fabricated and tested separately \\
\hline RH & relative humidity \\
\hline RSD & relative standard deviation \\
\hline $\mathrm{S} / \mathrm{V}$ & glass surface area to solution volume ratio \\
\hline SEM & scanning electron microscopy \\
\hline SRTC & Savannah River Technology Center \\
\hline$t$ & Time \\
\hline TBD & to be determined \\
\hline TDS & Total Dissolved Solids \\
\hline TFA & Tanks Focus Area \\
\hline VHT & Vapor Hydration Test \\
\hline WTP & Waste Treatment Plant \\
\hline XRD & $\mathrm{X}$-ray diffraction \\
\hline$\rho$ & density in $\mathrm{g} / \mathrm{cm}^{3}$ \\
\hline$\sigma$ & standard deviation \\
\hline
\end{tabular}




\section{Acknowledgments}

The authors would like to acknowledge the following individuals for their contribution to this work:

- E. W. Holtzscheiter for management and guidance

- D. E. Clark, P. M. Dove, W. L. Ebert, J. A. Gentilucci, C. M. Jantzen, B. P. McGrail, I. L. Pegg, J. D. Rimstidt, J. H. Simmons, D. M. Strachan, T. Weber, M. C. Weinberg, G. G. Wicks, and F. E. Woolley for project review and guidance

- W. L. Ebert, B. P. McGrail, and D. M. Strachan for assistance in crafting the VHT procedure and frequent advise

- C. A. Babel, B. R. Johnson, F. M. Mann, D. K. Peeler, L. M. Peurrung, Jacob Reynolds, and D. M. Strachan for careful review of the document

- K. G. Brown and S. L. Marra for helpful discussions and advice

- S. K. Cooley, T. B. Edwards, and G. F. Piepel, for statistical analyses

- W. C. Buchmiller, J. V. Crum, and Y. Su for assistance in VHT alteration phase identification

- B. W. Arey, J. E. Coleman, J. V. Crum, B. R. Johnson, and J. S. Young for SEM/EDS analyses

- I. L. Pegg for supplying relevant glass compositions and for reviewing glass-composition ranges

- A. C. Buechele, W. L. Ebert, and B. P. McGrail, for supplying useful data

- T. B. Edwards for assistance in design of the second phase test matrix

- B. R. Allen, W. C. Buchmiller, J. V. Crum, B. R. Johnson, B. M. Jorgensen, M. J. Schweiger, and R. J. Workman for assistance in fabrication, sample preparation, and testing of HLP glasses

- D. R. Best, D. J. Pittman, M. L. Thomas, and P. A. Toole for chemical analyses of HLP glasses

- W. C. Cosby for assistance in editing and formatting this document.

This study was funded by the U.S. Department of Energy's Offices of Science and Technology (through the Tanks Focus Area) and River Protection. Pacific Northwest National Laboratory is operated for the U.S. Department of Energy by Battelle under Contract DE-AC06-76RL01830. 


\section{Contents}

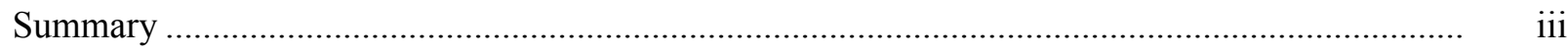

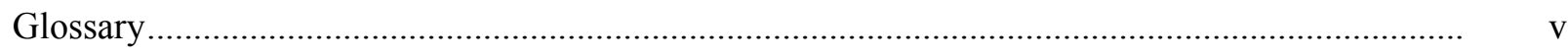

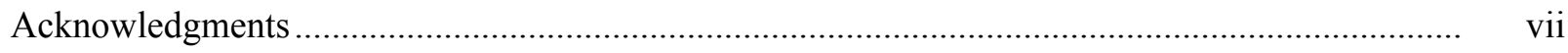

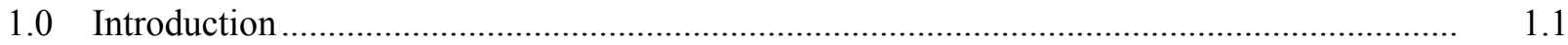

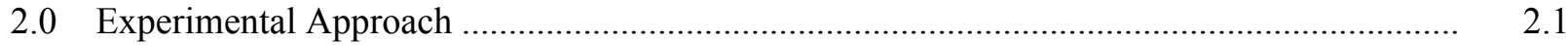

$2.1 \quad$ Test Matrix Design.......................................................................................... 2.1

2.2 Glass Fabrication and Heat Treatment .................................................................... 2.5

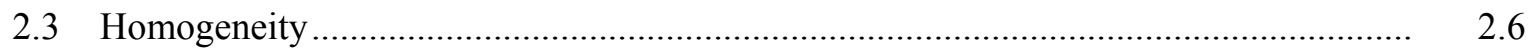

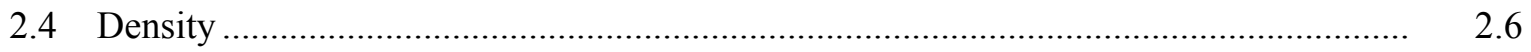

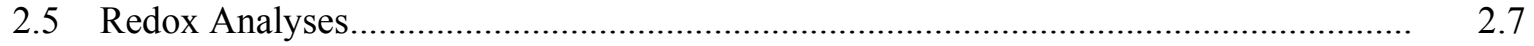

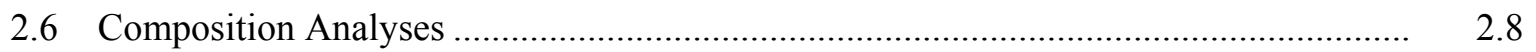

2.6.1 $\mathrm{Na}_{2} \mathrm{O}_{2} / \mathrm{NaOH} / \mathrm{HCl}$ Fusion Preparation ......................................................... 2.9

2.6.2 $\mathrm{LiBO}_{2} / \mathrm{HNO}_{3}$ Fusion Preparation ............................................................... 2.9

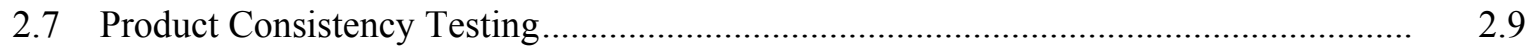

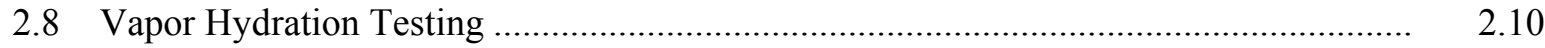

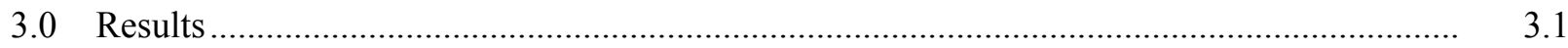

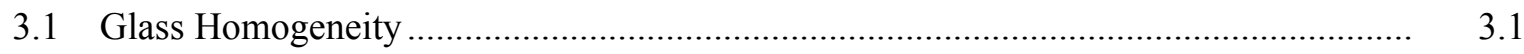

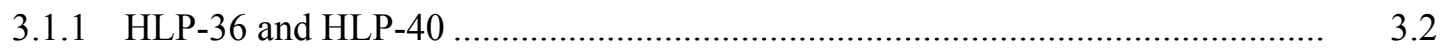

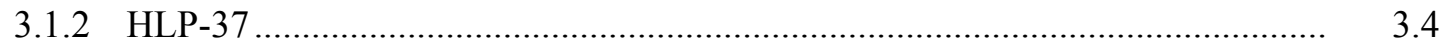

3.1.3 HLP-38 and HLP-42 ............................................................................... 3.5

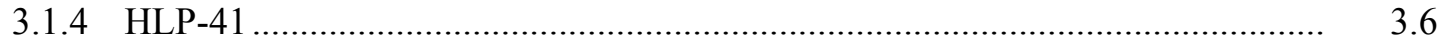

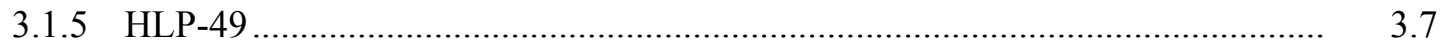

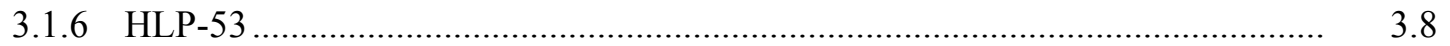

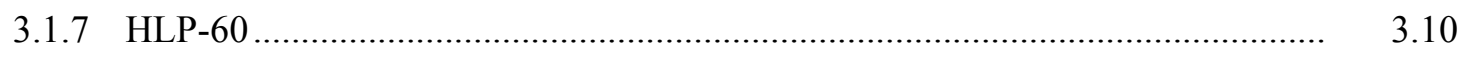

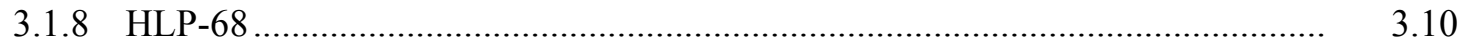

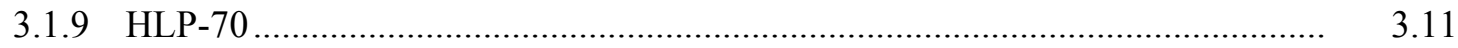

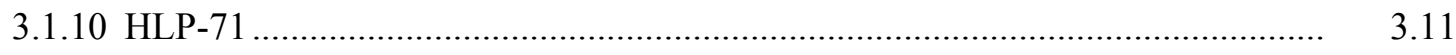

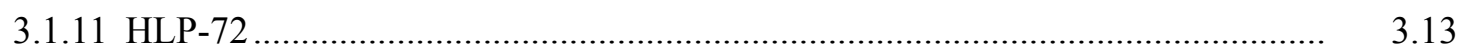

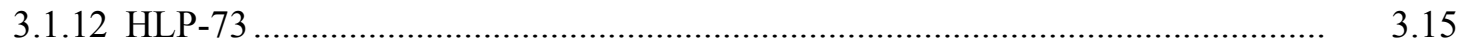

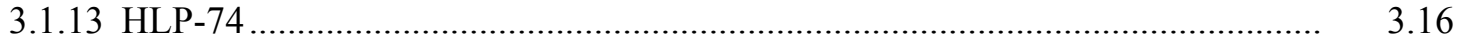




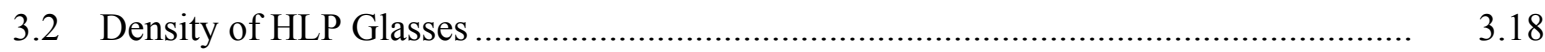

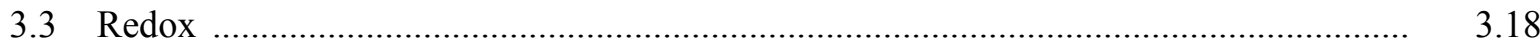

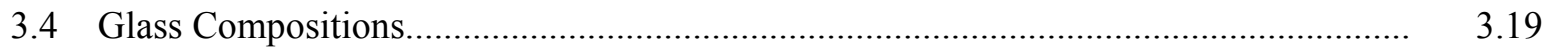

3.4.1 Compositions of Replicate Glasses ............................................................ $\quad 3.20$

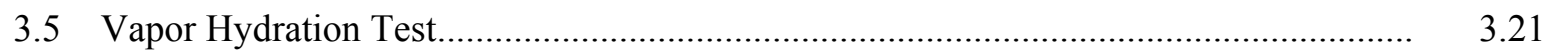

3.5.1 VHT Method Development ........................................................................ 3.21

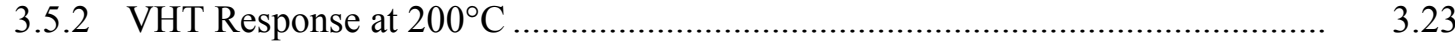

3.5.3 Alteration Products.................................................................................. 3.27

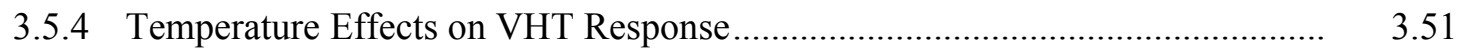

3.5.5 Reproducibility of VHT Measurements ....................................................... 3.51

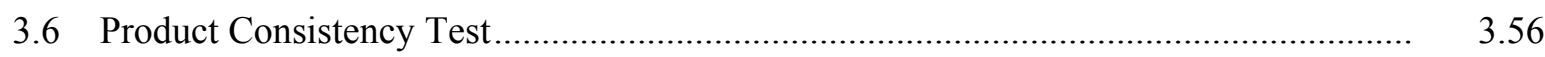

3.6.1 10 000-h Testing of Phase I Glasses ................................................................. 3.56

3.6.2 Phase II Glasses.................................................................................... 3.60

3.6.3 Alteration Products on PCT Samples ........................................................... 3.62

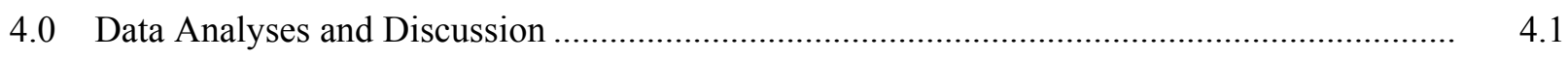

4.1 General LAW Glass Alteration Behavior ...............................................................

4.2 VHT Response as a Function of Temperature ............................................................

4.3 VHT Response as a Function of Glass Composition .................................................. 4.8

4.4 Comparison of VHT Response with Literature VHT Data .......................................... 4.13

4.5 Comparison of VHT and Other Test Methods ........................................................... 4.15

4.6 PCT Response as a Function of Time .................................................................... 4.17

4.7 PCT Response as a Function of Glass Composition .................................................... 4.19

4.8 Effect of Iron Redox on PCT and VHT Responses .................................................. 4.19

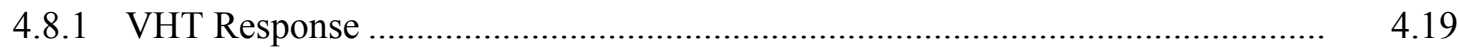

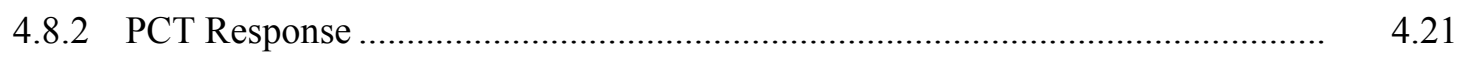

4.9 Comparison of Test Responses to Hanford Contract Specifications and Glass “Acceptability" .......................................................................................... 4.23

5.0 Conclusions and Recommendations.................................................................... 5.1

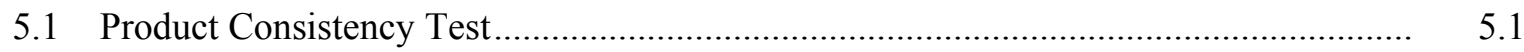

5.2 Vapor Hydration Test........................................................................................ 5.1

5.3 Glass Composition .................................................................................... 5.3

5.4 Recommendations for Future Studies ....................................................................... 5.3 


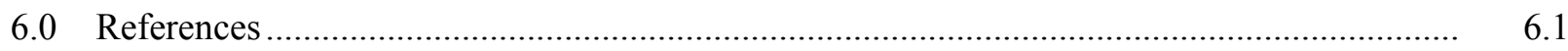

Appendix A: Target and Measured Compositions of the HLP Glasses .......................................... A.1

Appendix B: PCT-A and PCT-B Data for the HLP Glasses .................................................. B.1

Appendix C: VHT Data for the HLP Glasses .................................................................... C.1

Appendix D: VHT Data from Literature ........................................................................... D. 1

Appendix E: XRD Spectra from VHT Samples .............................................................. E.1

\section{Figures}

2.1. Computed Thermal Cooling Curve for 1.2 x 1.2 x 1.8 m Waste Package............................ 2.7

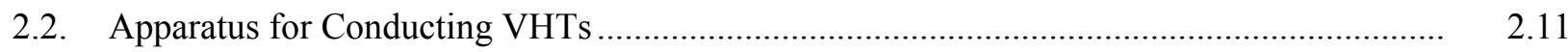

2.3. OM/IA Measurement of HLP-51 after 2 days of VHT at $300^{\circ} \mathrm{C}$ in Combination of Transmitted and Reflected Light .................................................................................. 2.11

3.1. XRD Pattern of Inhomogeneous Phase I Glasses …........................................................

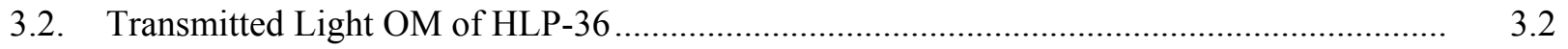

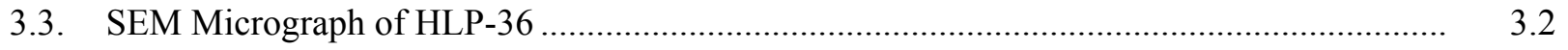

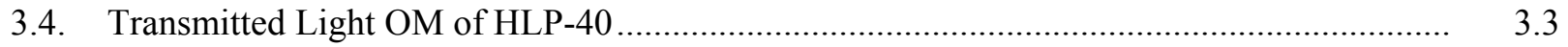

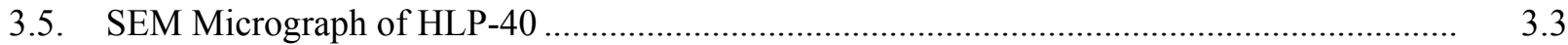

3.6. EDS Spectrum of Zinc Iron Oxide .................................................................................

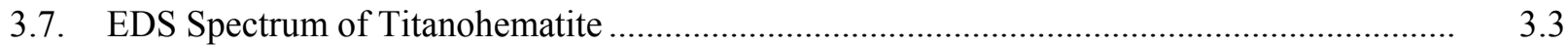

3.8. EDS Spectrum of Iron Titanium Oxide ........................................................................... 3.3

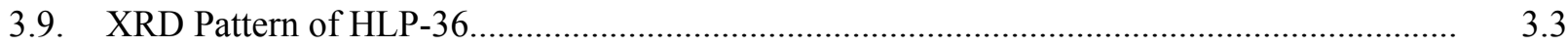

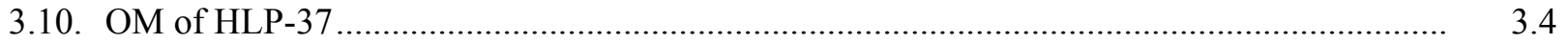

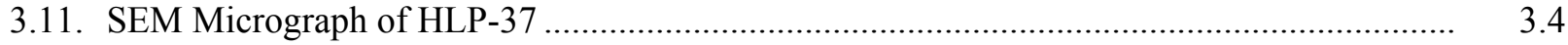

3.12. EDS Spectrum of Carnegieite Low $\left[\mathrm{Na}\left(\mathrm{AlSiO}_{4}\right)\right]$ - Dark Gray Phase .................................. 3.4

3.13. EDS Spectrum of Carnegieite Low $\left[\mathrm{Na}\left(\mathrm{AlSiO}_{4}\right)\right]$ - Light Gray Phase ................................. 3.4

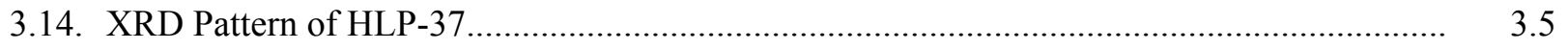

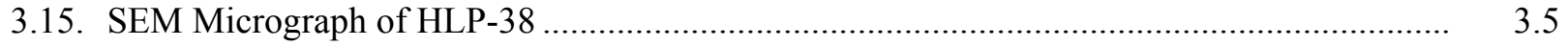

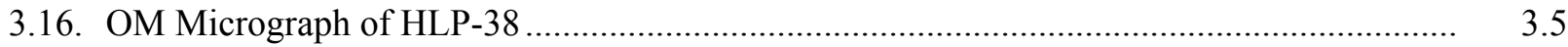

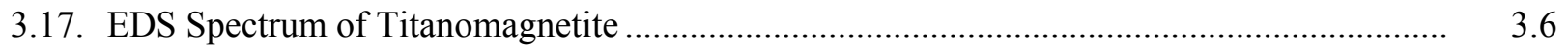

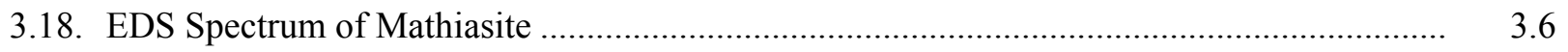

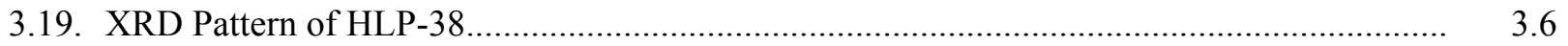


3.20. OM of HLP-41 ................................................................................................

3.21. EDS Spectrum of a Crystal in HLP-41 …………………………………………..... 3.6

3.22. OM of Augite in HLP-49 .................................................................................... 3.7

3.23. SEM Micrograph of Augite and Zinc Iron Oxide (on top) in HLP-49 ……………............. 3.7

3.24. EDS Spectrum of Augite …………………………………........................................ 3.7

3.25. EDS Spectrum of Zinc Iron Oxide......................................................................... 3.7

3.26. SEM Micrograph of Pt, Augite (background), and Zinc Iron Oxide in HLP-49 .................. 3.8

3.27. EDS Spectrum of a Pt particle in HLP-49 ................................................................ 3.8

3.28. Photograph of HLP-53 Glass Monolith after Heat Treatment ............................................ 3.8

3.29. OM of HLP-53 Bulk ................................................................................... 3.8

3.30. OM of HLP-53 Surface …………………………………………………….

3.31. XRD Pattern of HLP-53 Surface ……………………………………………………....... 3.9

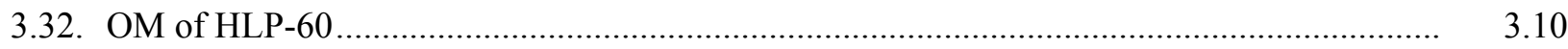

3.33. XRD Pattern of HLP-60........................................................................................... 3.10

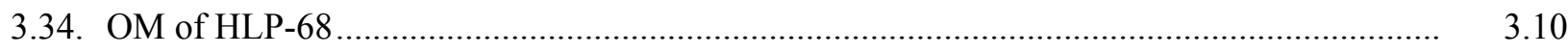

3.35. XRD Pattern of HLP-68 ............................................................................................. 3.10

3.36. OM of HLP-70

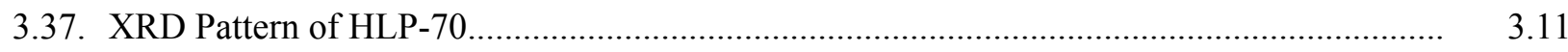

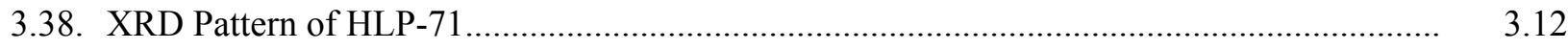

3.39. Transmitted Light Micrograph of HLP-71 ................................................................... 3.12

3.40. SEM Micrograph of HLP-71 Glass with BSE and Al, Ca, Na, Si, and Zr EDS Images ....... 3.12

3.41. Backscatter Electron Micrograph of HLP-71 ................................................................. 3.13

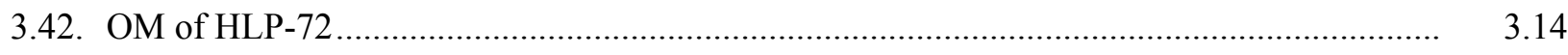

3.43. XRD Pattern of HLP-72 ……………………………………………………….... 3.14

3.44. Scanning Electron Micrograph of HLP-72 ……………………………………………..... 3.14

3.45. Photograph of HLP-73 Glass Monolith after Heat Treatment ............................................ 3.15

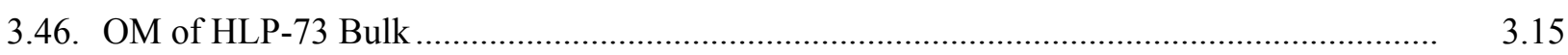

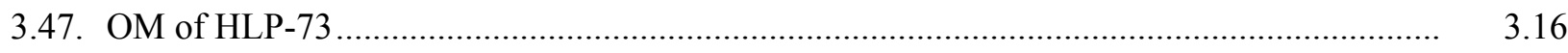

3.48. XRD Pattern of HLP-73 ……………………………………………………..... 3.16

3.49. SEM Micrograph of HLP-73 Glass with BSE and Al, $\mathrm{Fe}, \mathrm{Mg}$, Si, and Na EDS Images ....... 3.16

3.50. Photograph of HLP-74 Glass Monolith after Heat Treatment ............................................. 3.17

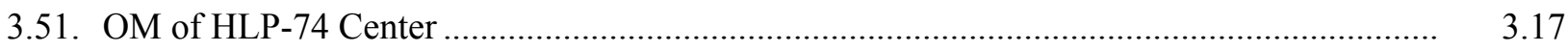


3.52. OM of HLP-74...

3.53. XRD Pattern of HLP-74.

3.54. Effect of $\mathrm{pO} 2$ on Measured Glass Redox

3.55. Results from VHT on the HLP- 46 Glass at $175^{\circ} \mathrm{C}$

3.56. The ma as a Function of $\mathrm{t}$ for HLP- 08 at $200^{\circ} \mathrm{C}$

3.57. The ma as a Function of $\mathrm{t}$ for HLP- 64 at $200^{\circ} \mathrm{C}$

3.58. The ma as a Function of $t$ for HLP- 56 at $200^{\circ} \mathrm{C}$

3.59. Location of EDS Spectra for HLP-06 Subjected to VHT at $200^{\circ} \mathrm{C}$ for 9 Days.

3.60. Locations of EDS Measurements for HLP-09 Subjected to VHT at $300^{\circ} \mathrm{C}$ for 3 Days

3.61. OM of HLP-09 Subjected to VHT at $300^{\circ} \mathrm{C}$ for 3 Days

3.62. Locations of EDS Measurements for HLP-09 Subjected to VHT at $250^{\circ} \mathrm{C}$ for 6 days .......... 3.35

3.63. Locations of EDS Measurements for HLP-12 Subjected to VHT at $200^{\circ} \mathrm{C}$ for 95 Days ....... 3.36

3.64. Location of EDS Measurements for HLP-47 Glass Subjected to VHT at $200^{\circ} \mathrm{C}$ for 20 Days.

3.65. Location of EDS Spectra for HLP-48 Glass Subjected to VHT at $150^{\circ} \mathrm{C}$ for 87 Days .......... 3.38

3.66. Location of EDS Spectra for HLP-48 Glass Subjected to VHT at $200^{\circ} \mathrm{C}$ for 10 Days .......... 3.39

3.67. Location of EDS Measurements for HLP-51 Subjected to VHT at $200^{\circ} \mathrm{C}$ for 20 Days......... $\quad 3.40$

3.68. Location of EDS Measurements for HLP-51 Glass Subjected to VHT at $150^{\circ} \mathrm{C}$ for 215 Days

3.69. Locations of EDS Measurements for HLP-12 Subjected to VHT at $200^{\circ} \mathrm{C}$ for 95 Days .......

3.70. Locations of EDS Measurements for HLP-31 Subjected to VHT at $200^{\circ} \mathrm{C}$ for 5 Days ......... $\quad 3.43$

3.71. Locations of EDS Measurements for HLP-43 Subjected to VHT at $250^{\circ} \mathrm{C}$ for 2 Days ......... 3.44

3.72. Location of EDS Measurements for HLP-48 Subjected to VHT at $175^{\circ} \mathrm{C}$ for 42 Days......... $\quad 3.45$

3.73. Locations of EDS Measurements for HLP-56 Subjected to VHT at $250^{\circ} \mathrm{C}$ for 2 Days ......... $\quad 3.47$

3.74. Location of EDS Spectra for HLP-64 Glass Subjected to VHT at $200^{\circ} \mathrm{C}$ for 44 days .......... 3.48

3.75. Location of EDS Spectra for HLP-69 Glass Subjected to VHT at $200^{\circ} \mathrm{C}$ for 28 days ........... 3.49

3.76. Location of EDS Spectra for HLP-70 Glass Subjected to VHT at $200^{\circ} \mathrm{C}$ for 28 days ........... 3.50

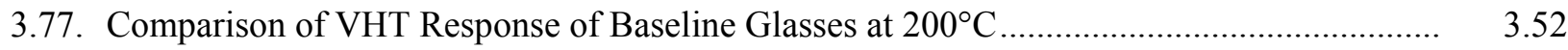

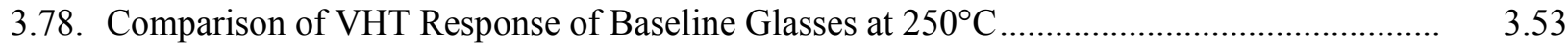

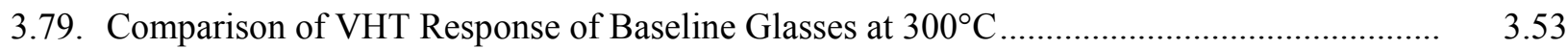

3.80. Comparison of VHT Responses for HLP-48 Glass .......................................................... 3.54

3.81. Comparison of VHT Responses for HLP-47, -76, and -77 Glasses.................................... 3.56 
3.82. A) Release Rate Versus Time for Selected Glasses Representing the Largest Release Rates of Sodium. B) Release Rate Versus Time for Selected Glasses Representing the Largest Release Rates for Boron. With the exception of HLP-05, the same glasses represent both elements with similar trends.

3.83. A) Release Rate Versus Time for Selected Glasses Representing the Smallest Release Rates for Sodium. B) Release Rate Versus Time for Selected Glasses Representing the Smallest Release Rates for Boron. Note that the same glasses are represented for both elements with similar trends.

3.84. Normalized Releases Versus Time for Boron, Sodium, and Silicon for Glasses HLP-76 and HLP-77

4.1. General Alteration Curve (after Jiricka et al. 2001)

4.2. Typical Glass Alteration Curve Generated from Equation (2) with (a) HLP-55 PCT-B data and (b) HLP-46 $175^{\circ} \mathrm{C}$ VHT data

4.3. Effect of Temperature on the Alteration Rate of LAW Glasses

4.4. Effect of Alkali Oxide Mole Fraction $(\mathrm{R} \equiv \mathrm{Li}, \mathrm{Na}, \mathrm{K})$ on $\ln [\mathrm{r}]$ for $\mathrm{VHT}$ at $200^{\circ} \mathrm{C}$

4.5. Scatter-Plot Matrix of Component Concentrations Used for VHT-Composition Calculations

4.6. Predicted vs. Measured $\ln [\mathrm{r}]$ for $200^{\circ} \mathrm{C}$ VHT

4.7. Comparison of VHT Results Reported in this Study with Those Reported in Literature for Glasses with the Same Target Compositions

4.8. Time to Acceleration Comparison ......

4.9. Comparison of VHT and PUF Alteration Rates for Selected Glasses

4.10. VHT Response of Reduced and Oxidized Baseline Glasses

4.11. Optical Light Micrographs of HLP-01 and HLP-45 Sample Cross-sections after VHT

4.12. Normalized Loss of $\mathrm{Na}$ and $\mathrm{B}$ from Reduced and Oxidized Baseline Glasses from PCT-A

4.13. Normalized Loss of B from Reduced and Oxidized Baseline Glasses from PCT-B

4.14. VHT Results for HLP Glasses Measured at $200^{\circ} \mathrm{C}$ with (a) Complete Time Scale and (b) 50-Day Time Scale.

4.15. Scatter-Plot Matrix of HLP Glass with Red Symbols for Glasses that do not Meet one or both Contract Specifications and Green Symbols for Glasses that meet both Contract Specifications 


\section{Tables}

2.1. Target Compositions (in mass $\%$ of oxides) of the Hanford LAW

Product-Acceptance Glasses ............................................................................................ 2.2

2.2. Melting Parameters for HLP-44 and HLP-45 ............................................................ 2.7

2.3. Elemental Analysis Based on Dissolution Procedure and Analytical Technique.................. 2.8

3.1. List of Phases Identified in HLP-36 and -40 with XRD .................................................. 3.2

3.2. List of Phases Identified in HLP-37 ......................................................................................

3.3. Phases Identified in HLP-38 and HLP-42 with XRD ......................................................... 3.5

3.4. List of Phases Identified in HLP-49 with XRD ................................................................. 3.7

3.5. Comparison of Composition for Different Samples of HLP-53 …..................................... 3.9

3.6. List of Phases Identified in HLP-70 ............................................................................... 3.11

3.7. List of Crystalline Phases Identified in HLP-71 with XRD ................................................. 3.11

3.8. Semiquantitative Composition Estimate of Phases in HLP-71 by EDS ............................. 3.13

3.9. List of Phases Identified in HLP-72 _............................................................................. 3.14

3.10. Semiquantitative Composition Estimate of Phases in HLP-72 by EDS ............................. 3.15

3.11. Semiquantitative Composition Estimate of Phases in HLP-73 by EDS ............................. 3.17

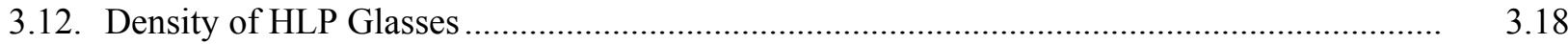

3.13. Melting Oxygen Partial Pressure and Measured Redox of HLP-26, -44, and -45 ............... 3.19

3.14. Target Compositions (in mass $\%$ of oxides) and Measured Compositions (in mass $\%$ of oxides) for the Replicate HLP "Baseline” Glasses .......................................................... 3.21

3.15. Comparison of Three Current Test Methods .................................................................... 3.22

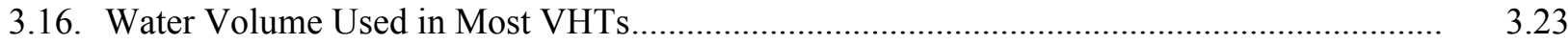

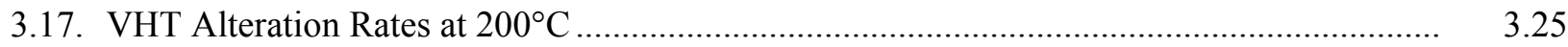

3.18. Crystalline Phases Identified in VHT Samples with XRD …............................................... 3.28

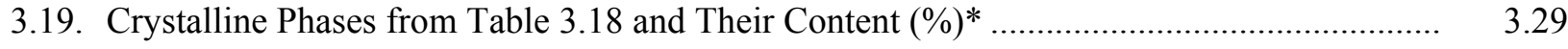

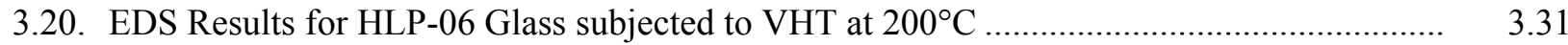

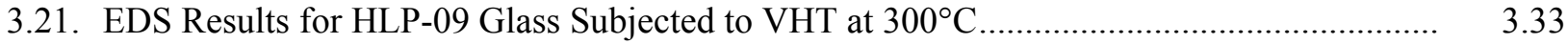

3.22. EDS Results for HLP-09 Glass Subjected to VHT at $250^{\circ} \mathrm{C}$ for 6 days.................................. 34

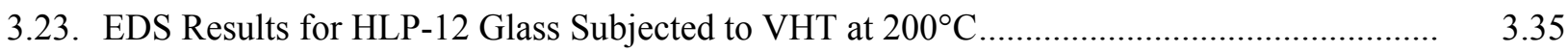

3.24. EDS Results for HLP-47 Glass subjected to VHT at $200^{\circ} \mathrm{C} \mathrm{\ldots ..........................................} 3.36$

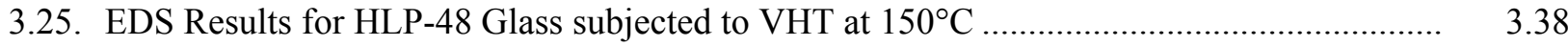

3.26. EDS Results for HLP-48 Glass Subjected to VHT at $200^{\circ} \mathrm{C}$ for 10 days............................ 3.39 
3.27. EDS Results for HLP-51 Glass Subjected to VHT at $200^{\circ} \mathrm{C}$

3.28. EDS Results for HLP-51 Glass Subjected to VHT at $150^{\circ} \mathrm{C}$

3.29. EDS Results for HLP-12 Glass Subjected to VHT at $200^{\circ} \mathrm{C}$

3.30. EDS Results for HLP-31 Glass Subjected to VHT at $200^{\circ} \mathrm{C}$

3.31. EDS Results for HLP-43 Glass Subjected to VHT at $250^{\circ} \mathrm{C}$

3.32. EDS Results for HLP-48 Glass Subjected to VHT at $175^{\circ} \mathrm{C}$

3.33. EDS Results for HLP-56 Glass Subjected to VHT at $250^{\circ} \mathrm{C}$

3.34. EDS Results for HLP-64 Glass Subjected to VHT at $200^{\circ} \mathrm{C}$ for 44 days.

3.35. EDS Results for HLP-69 Glass Subjected to VHT at $200^{\circ} \mathrm{C}$ for 28 days......

3.36. EDS Results for HLP-70 Glass Subjected to VHT at $200^{\circ} \mathrm{C}$ for 28 Days

3.37. Comparison of alteration rates measured at $200^{\circ} \mathrm{C}, 250^{\circ} \mathrm{C}$, and $300^{\circ} \mathrm{C}$ for the baseline glass

3.38. Comparison of Alteration Rates Measured for the HLP-48 Glass

3.39. Comparison of Alteration Rates Measured for the HLP-47, HLP-76, and HLP-77 Glasses

3.40. Ordering of Release Rates for the Phase I HLP Glasses Based Upon $10000 \mathrm{~h}$ PCT-B Data.

3.41. Sodium and Boron Release Rates for Four Glasses with the Same Composition

3.42. Ordering of Release Rates for the Phase II HLP Glasses Based Upon PCT-B Data

3.43. Summary of Glass Surface Alteration on PCT Samples.

4.1. Corrosion Parameters used to Generate Figure 4.2.

4.2. VHT Rate as a Function of Temperature for HLP Glasses

4.3. Pair-wise Correlations Between Components in Glasses Used for VHT-Composition Calculations

4.4. Summary of First-order Expansion Results .....

4.5. Estimated Time to Acceleration (ta)

4.6. Ordering of Release Rates for All HLP Glasses Based Upon PCT-B Data.

4.7. Comparison of VHT Alteration Rates for Reduced and Oxidized Baseline Glasses 


\subsection{Introduction}

The U.S. Department of Energy (DOE), Office of River Protection (ORP) intends to immobilize Hanford's low-activity waste (LAW) in the form of borosilicate glass for storage and disposal. The LAW glass will be disposed of in a shallow land-burial facility. It must be demonstrated that the disposal system will adequately retain the radionuclides and prevent contamination of the surrounding environment. Waste-form performance is the first line of defense against releases of contaminants after disposal and an integral part of the multiple-engineered barrier system. Mann et al. (2001) found that the release of radionuclides from the waste form via interaction/reaction with water is the prime threat to the environment surrounding the disposal site. The two major dose contributors in Hanford LAW glass that must be retained are ${ }^{99} \mathrm{Tc}$ and ${ }^{129} \mathrm{I}$ (Mann et al. 2001).

McGrail et al. (2000) described the strategy for testing and modeling to determine/assess the radionuclide release rates from LAW glass. This strategy requires extensive testing and modeling for each glass considered. The program includes, for example, in situ testing, tests with waste-package components, tests that simulate the hydrology and geochemistry of the burial site, and coupled flowreaction modeling. The resources required to perform such a thorough study on a large number of glasses are not practical. The Tanks Focus Area (TFA) Immobilization Program, DOE-EM ${ }^{(\mathrm{a})}$ Office of Science and Technology, has outlined a task to help determine the composition range of LAW glasses that will meet performance expectations.

A methodology is needed to determine the range of LAW glass compositions that satisfy performance requirements for the burial facility at Hanford. Following the high-level waste glass experiences at the West Valley Demonstration Project, the Defense Waste Processing Facility, and Hanford, this methodology will be based on acceptable glass composition regions (AGCRs) determined by process and product property limits and property-composition relationships. This report summarizes the preliminary results of a study aimed at developing a series of short-term tests, test data, property restrictions, propertycomposition models, and ultimately an AGCR for Hanford LAW glass.

The work performed in this study was planned and conducted with the aid of an expert panel to assure that program direction and progress were founded on a solid and defensible foundation and to avoid expending resources on approaches with low chances of successfully meeting the program needs. Vienna et al. (1999) described the initial program plan and accounted for the expert panel suggestions on implementation strategy. Vienna et al. (2000) provided an initial data package from this study. Brown et al. (2000) summarized the mid-program review by the expert panel and described the plan for the second phase of study. Schulz et al. (2000) gave an updated data package of results from the first phase of the study. Ebert et al. (2001) gave a detailed account of alteration products formed on some of the study glasses during vapor hydration tests (VHTs) and product consistency tests (PCTs). Muller et al. (2001) gave the results of VHT and PCT evaluations of glasses recently formulated for Hanford LAW.

This document, which is a follow-up to the initial data packages (Vienna et al. 2000; Schulz et al. 2000), provides additional information on long-term PCT-B ${ }^{(\text {b) }}$ tests, VHTs, and alteration products formed

(a) The U.S. Department of Energy's Office of Environmental Management.

(b) Method B of the PCT as defined in ASTM (1998). 
on selected glasses subjected to durability testing. Much of the initial data and background information from the original documents was retained in this document to allow the current report to stand-alone. 


\subsection{Experimental Approach}

During the first phase of this study, 45 glasses were designed with systematically varying compositions along with 10 additional glasses, including glasses similar to those being considered by the Waste Treatment Plant (WTP) at Hanford (Vienna et al. 1999). An additional 20 glasses were statistically designed to backfill the initial 55 glasses and expand the composition region as a second phase of the study (Brown et al. 2000). In total, 75 glasses were fabricated and heat treated to simulate the slowest cooling that is expected to occur during plant operation. The homogeneity, density, and chemical composition of test glasses were measured. The responses of each glass to the VHT and the PCT (both PCT-A and PCT-B) were measured.

\subsection{Test Matrix Design}

A matrix of 75 glasses was developed and tested with the aim to identify the relationship between glass composition and response to the PCT and VHT (Vienna et al. 1999; Brown et al. 2000). The target compositions of these Hanford LAW product-acceptance (HLP) glasses are listed in Table 2.1. They are split into five groups of glasses:

1. The first 24 glasses contained variations in nine components- $\mathrm{SiO}_{2}, \mathrm{Al}_{2} \mathrm{O}_{3}, \mathrm{~B}_{2} \mathrm{O}_{3}, \mathrm{Fe}_{2} \mathrm{O}_{3}, \mathrm{TiO}_{2}, \mathrm{ZnO}$, $\mathrm{ZrO}_{2}, \mathrm{MgO}$, and waste (primarily $\mathrm{Na}_{2} \mathrm{O}$ ) - one-at-a-time (HLP-01 through -24) from a central composition (HLP-01). These glasses give a direct indication of the impact of each of these oxides on the behavior of glasses in the testing program. Glasses HLP-44 and -45 have the same target composition as HLP-01, but were melted and heat treated under reducing atmospheres to increase the ratio of divalent to total iron $(\mathrm{Fe}(\mathrm{II}) / \mathrm{Fe})$.

2. Four glasses (HLP-01, $-25,-26$, and -43 ) have the same target composition and were fabricated and tested separately to assess the reproducibility of the glass fabrication and test procedures.

3. Sixteen glasses (HLP-27 through -42) varied four components at a time- $-\mathrm{SiO}_{2}, \mathrm{Al}_{2} \mathrm{O}_{3}, \mathrm{~B}_{2} \mathrm{O}_{3}$, and waste (primarily $\mathrm{Na}_{2} \mathrm{O}$ ) - to assess the interactive effects of the components expected to have the largest effect on glass behavior in corrosion testing.

4. Ten glasses (HLP-46 through -56) (see below) were included because large and growing databases on their corrosion characteristics had accumulated:

- HLP-46 is the LD6-5412 glass that was characterized by Kim et al. (1995), Feng et al. (1996), and McGrail et al. (1997a,b). ${ }^{\text {(a) }}$ This glass expands the composition ranges of test glasses to higher concentrations of $\mathrm{SiO}_{2}, \mathrm{CaO}$, and $\mathrm{K}_{2} \mathrm{O}$.

- HLP-47 is the low-activity waste reference material (LRM) glass that was characterized by Wolf et al. (1998) and Ebert and Wolf (1999). This glass increases the range of $\mathrm{SiO}_{2}, \mathrm{~K}_{2} \mathrm{O}, \mathrm{Cl}^{-}$, and $\mathrm{F}^{-}$ concentrations in the test glasses.

- HLP-48 is the LAW-A33 glass that was characterized by McGrail et al. (1999) and Muller et al. (2001). This glass represents a nominal composition that may be processed by the WTP.

(a) W. L. Ebert, A. J. Bakel, D. M. Strachan, and S. F. Wolf. 1998. Laboratory Testing of LD6-5412 Glass, DRAFT, Argonne National Laboratory, Argonne, Illinois. 
Table 2.1. Target Compositions (in mass\% of oxides) of the Hanford LAW Product-Acceptance Glasses

\begin{tabular}{|c|c|c|c|c|c|c|c|c|c|c|c|c|c|c|c|c|c|c|c|c|c|c|}
\hline Glass ID $^{\mathrm{a}}$ & Description $^{b}$ & $\mathbf{A l}_{2} \mathbf{O}_{3}$ & $\mathbf{B}_{2} \mathbf{O}_{3}$ & $\mathrm{CaO}$ & $\mathrm{Cl}$ & $\mathrm{Cr}_{2} \mathrm{O}_{3}$ & $\mathbf{F}$ & $\mathrm{Fe}_{2} \mathrm{O}_{3}{ }^{\mathrm{j}}$ & $\mathrm{K}_{2} \mathrm{O}$ & $\mathrm{La}_{2} \mathrm{O}_{3}$ & $\mathbf{L i}_{2} \mathbf{O}$ & MgO & $\mathrm{MoO}_{3}$ & $\mathrm{Na}_{2} \mathrm{O}$ & $\mathbf{P}_{2} \mathbf{O}_{5}$ & $\mathbf{R e O}_{2}$ & $\mathrm{SO}_{3}$ & $\mathrm{SiO}_{2}$ & $\mathrm{TiO}_{2}$ & $\mathrm{ZnO}$ & $\mathrm{ZrO}_{2}$ & Total \\
\hline HLP-01 & Baseline & 7.00 & 10.00 & 0.01 & 0.28 & 0.08 & 0.01 & 5.50 & 0.41 & 0.00 & 0.00 & 1.50 & 0.00 & 20.00 & 0.06 & 0.01 & 0.07 & 49.07 & 3.00 & 1.50 & 1.50 & 100.00 \\
\hline HLP-02 & $\mathrm{L} \mathrm{Si}$ & 8.79 & 12.57 & 0.02 & 0.35 & 0.09 & 0.01 & 6.92 & 0.52 & 0.00 & 0.00 & 1.88 & 0.00 & 25.14 & 0.07 & 0.01 & 0.09 & 36.00 & 3.77 & 1.88 & 1.88 & 99.99 \\
\hline HLP-03 & $\mathrm{H} \mathrm{Si}$ & 6.60 & 9.43 & 0.01 & 0.26 & 0.07 & 0.01 & 5.19 & 0.39 & 0.00 & 0.00 & 1.41 & 0.00 & 18.85 & 0.05 & 0.01 & 0.07 & 52.00 & 2.82 & 1.41 & .41 & 9.99 \\
\hline HLP-04 & I Si & 8.24 & 11.78 & 0.01 & 0.33 & 0.09 & 0.01 & 6.48 & 0.49 & 0.00 & 0.00 & 1.77 & 0.00 & 23.57 & 0.07 & 0.01 & 0.09 & 40.00 & 3.53 & 1.77 & 1.77 & 100.01 \\
\hline HLP-05 & $\mathrm{L} \mathrm{Al}$ & 4.00 & 10.32 & 0.01 & 0.29 & 0.08 & 0.01 & 5.68 & 0.43 & 0.00 & 0.00 & 1.55 & 0.00 & 20.65 & 0.06 & 0.01 & 0.08 & 50.65 & 3.09 & 1.55 & 1.55 & 100.01 \\
\hline HLP-06 & $\mathrm{H} \mathrm{Al}$ & 11.94 & 9.47 & 0.01 & 0.26 & 0.07 & 0.01 & 5.21 & 0.39 & 0.00 & 0.00 & 1.42 & 0.00 & 18.94 & 0.05 & 0.01 & 0.07 & 46.46 & 2.84 & 1.42 & 1.42 & 99.99 \\
\hline HLP-07 & I Al & 9.00 & 9.79 & 0.01 & 0.27 & 0.07 & 0.01 & 5.38 & 0.40 & 0.00 & 0.00 & 1.47 & 0.00 & 19.57 & 0.05 & 0.01 & 0.07 & 48.01 & 2.93 & 1.47 & 1.47 & 99.98 \\
\hline HLP-08 & L B & 7.31 & 6.00 & 0.01 & 0.29 & 0.08 & 0.01 & 5.75 & 0.43 & 0.00 & 0.00 & 1.57 & 0.00 & 20.89 & 0.06 & 0.01 & 0.08 & 51.25 & 3.13 & 1.57 & 1.57 & 100.01 \\
\hline HLP-09 & H B & 6.84 & 12.00 & 0.01 & 0.27 & 0.07 & 0.01 & 5.38 & 0.40 & 0.00 & 0.00 & 1.47 & 0.00 & 19.56 & 0.05 & 0.01 & 0.07 & 47.98 & 2.93 & 1.47 & 1.47 & 99.99 \\
\hline HLP-10 & I B & 7.15 & 8.00 & 0.01 & 0.28 & 0.08 & 0.01 & 5.63 & 0.42 & 0.00 & 0.00 & 1.53 & 0.00 & 20.45 & 0.06 & 0.01 & 0.07 & 50.16 & 3.06 & 1.53 & 1.53 & 99.98 \\
\hline HLP-11 & $\mathrm{L} \mathrm{Fe}$ & 7.41 & 10.58 & 0.01 & 0.29 & 0.08 & 0.01 & 0.00 & 0.44 & 0.00 & 0.00 & 1.59 & 0.00 & 21.17 & 0.06 & 0.01 & 0.08 & 51.93 & 3.17 & 1.59 & 1.59 & 100.01 \\
\hline HLP-12 & $\mathrm{HFe}$ & 6.74 & 9.63 & 0.01 & 0.27 & 0.07 & 0.01 & 9.00 & 0.40 & 0.00 & 0.00 & 1.44 & 0.00 & 19.26 & 0.05 & 0.01 & 0.07 & 47.25 & 2.89 & 1.44 & 1.44 & 99.98 \\
\hline HLP-13 & $\mathrm{I} \mathrm{Fe}$ & 7.18 & 10.27 & 0.01 & 0.28 & 0.08 & 0.01 & 3.00 & 0.42 & 0.00 & 0.00 & 1.54 & 0.00 & 20.53 & 0.06 & 0.01 & 0.08 & 50.37 & 3.08 & 1.54 & .54 & 100.00 \\
\hline HLP-14 & $\mathrm{L} \mathrm{Ti}$ & 7.21 & 10.31 & 0.01 & 0.29 & 0.08 & 0.01 & 5.67 & 0.43 & 0.00 & 0.00 & 1.55 & 0.00 & 20.62 & 0.06 & 0.01 & 0.08 & 50.59 & 0.00 & 1.55 & 1.55 & 100.02 \\
\hline HLP-15 & $\mathrm{H} \mathrm{Ti}$ & 6.78 & 9.69 & 0.01 & 0.27 & 0.07 & 0.01 & & 0.40 & & 0.00 & & 0.00 & & 0.05 & 0.01 & 0.07 & & 6.00 & 1.45 & 1.45 & 99.98 \\
\hline HLP-16 & $\mathrm{L} \mathrm{Zn}$ & 7.10 & 10.15 & 0.01 & 0.28 & 0.08 & 0.01 & 5.59 & 0.42 & 0.00 & 0.00 & 1.52 & 0.00 & 20.31 & 0.06 & 0.01 & 0.07 & 49.82 & 3.04 & 0.00 & 1.52 & 99.99 \\
\hline HLP-17 & $\mathrm{H} \mathrm{Zn}$ & 6.82 & 9.75 & 0.01 & 0.27 & 0.07 & 0.01 & 5.36 & 0.40 & 0.00 & 0.00 & 1.46 & 0.00 & 19.50 & 0.05 & 0.01 & 0.07 & 47.82 & 2.92 & 4.00 & 1.46 & 99.98 \\
\hline HLP-18 & $\mathrm{L} \mathrm{Zr}$ & 7.10 & 10.15 & 0.01 & 0.28 & 0.08 & 0.01 & 5.59 & 0.42 & 0.00 & 0.00 & 1.52 & 0.00 & 20.31 & 0.06 & 0.01 & 0.07 & 49.82 & 3.04 & 1.52 & 0.00 & 99.99 \\
\hline HLP-19 & $\mathrm{H} \mathrm{Zr}$ & 6.68 & 9.55 & 0.01 & 0.26 & 0.07 & 0.01 & & & & 0.00 & & 0.00 & & 0.05 & 0.01 & 0.07 & & 2.86 & 1.43 & 6.00 & 99.99 \\
\hline HLP-20 & $\mathrm{L} \mathrm{Mg}$ & 7.10 & 10.15 & 0.01 & 0.28 & 0.08 & 0.01 & 5.59 & 0.42 & 0.00 & 0.00 & 0.00 & 0.00 & 20.31 & 0.06 & 0.01 & 0.07 & 49.82 & 3.04 & 1.52 & .52 & 99.99 \\
\hline HLP-21 & $\mathrm{H} \mathrm{Mg}$ & 6.82 & 9.75 & 0.01 & 0.27 & 0.07 & 0.01 & 5.36 & 0.40 & 0.00 & 0.00 & 4.00 & 0.00 & 19.50 & 0.05 & 0.01 & 0.07 & 47.82 & 2.92 & 1.46 & 1.46 & 99.98 \\
\hline HLP-22 & $\mathrm{L} \mathrm{Na}$ & 7.37 & 10.53 & 0.01 & 0.22 & 0.06 & 0.01 & 5.79 & 0.33 & 0.00 & 0.00 & 1.58 & 0.00 & 16.00 & 0.04 & 0.01 & 0.06 & 51.67 & 3.16 & 1.58 & 1.58 & 100.00 \\
\hline HLP-23 & $\mathrm{H} \mathrm{Na}$ & 6.72 & 9.61 & 0.01 & 0.32 & 0.09 & 0.01 & 5.29 & 0.47 & 0.00 & 0.00 & 1.44 & 0.00 & 23.00 & 0.06 & 0.01 & 0.08 & 47.13 & 2.88 & 1.44 & 1.44 & 100.00 \\
\hline HLP-24 & I Na & 7.18 & 10.27 & 0.01 & 0.25 & 0.07 & 0.01 & 5.65 & 0.37 & 0.00 & 0.00 & 1.54 & 0.00 & 18.00 & 0.05 & 0.01 & 0.07 & 50.37 & 3.08 & 1.54 & 1.54 & 00.01 \\
\hline HLP-25 & Baseline & 7.00 & 10.00 & 0.01 & 0.28 & 0.08 & 0.01 & 5.50 & 0.41 & 0.00 & 0.00 & 1.50 & 0.00 & 20.00 & 0.06 & 0.01 & 0.07 & 49.07 & 3.00 & 1.50 & 1.50 & 100.00 \\
\hline HLP-26 & Baseline & 7.00 & 10.00 & 0.01 & 0.28 & 0.08 & 0.01 & 5.50 & 0.41 & 0.00 & 0.00 & 1.50 & 0.00 & 20.00 & 0.06 & 0.01 & 0.07 & 49.07 & 3.00 & 1.50 & 1.50 & 100.00 \\
\hline HLP-27 & $\mathrm{HHHH}^{\mathrm{c}}$ & 1.94 & 12.00 & 0.01 & 0.32 & 0.09 & 0.01 & 0.00 & 0.47 & 0.00 & 0.00 & 0.00 & 00 & 23 & 0.06 & 0.01 & 0.08 & 0 & 0.00 & 0.00 & 0.00 & 9.99 \\
\hline HLP-28 & $\mathrm{HHHL}^{\mathrm{c}}$ & 11.94 & 12.00 & 0.01 & 0.22 & 0.06 & 0.01 & 3.10 & 0.33 & 0.00 & 0.00 & 0.84 & 0.00 & 16.00 & 0.04 & 0.01 & 0.06 & 52.00 & 1.69 & 0.84 & 0.84 & 99.99 \\
\hline HLP-29 & $\mathrm{HHLH}^{\mathrm{c}}$ & 11.94 & 6.00 & 0.01 & 0.32 & 0.09 & 0.01 & 2.54 & 0.47 & 0.00 & 0.00 & 0.69 & 0.00 & 23.00 & 0.06 & 0.01 & 0.08 & 52.00 & 1.38 & 0.69 & 0.69 & 99.98 \\
\hline HLP-30 & HHLL $^{c}$ & 11.94 & 6.00 & 0.01 & 0.22 & 0.06 & 0.01 & 5.64 & 0.33 & 0.00 & 0.00 & 1.54 & 0.00 & 16.00 & 0.04 & 0.01 & 0.06 & 52.00 & 3.07 & 1.54 & 1.54 & 100.01 \\
\hline HLP-31 & $\mathrm{HLHH}^{\mathrm{c}}$ & 4.00 & 12.00 & 0.01 & 0.32 & 0.09 & 0.01 & 3.36 & 0.47 & 0.00 & 0.00 & 0.92 & 0.00 & 23.00 & 0.06 & 0.01 & 0.08 & 52.00 & 1.83 & 0.92 & 0.92 & 100.00 \\
\hline
\end{tabular}


Table 2.1 (Contd)

\begin{tabular}{|c|c|c|c|c|c|c|c|c|c|c|c|c|c|c|c|c|c|c|c|c|c|c|}
\hline Glass ID ${ }^{\mathrm{a}}$ & Description & $\mathbf{A l}_{\mathbf{2}} \mathbf{O}_{3}$ & ${ }_{2} \mathrm{O}_{3}$ & $\mathrm{CaO}$ & Cl & $\mathrm{Cr}_{2} \mathrm{O}_{3}$ & $\mathbf{F}$ & $\mathrm{Fe}_{2} \mathrm{O}_{3}{ }^{\mathrm{j}}$ & $\mathbf{K}_{2} \mathbf{O}$ & $\mathrm{La}_{2} \mathrm{O}_{3}$ & $\mathbf{L i}_{2} \mathbf{O}$ & MgO & $\mathrm{MoO}_{3}$ & $\mathrm{Na}_{2} \mathrm{O}$ & $\mathbf{P}_{2} \mathbf{O}_{5}$ & $\mathrm{ReO}_{2}$ & $\mathrm{O}_{3}$ & $\mathrm{SiO}_{2}$ & $\mathrm{TiO}_{2}$ & nO & $\mathrm{ZrO}_{2}$ & Total \\
\hline HLP-32 & $\mathrm{HLHL}^{\mathrm{c}}$ & 4.00 & 12.00 & 0.01 & 0.22 & 0.06 & 0.01 & 6.46 & 0.33 & 0.00 & 0.00 & 1.76 & 0.00 & 16.00 & 0.04 & 0.01 & 0.06 & 52.00 & 3.52 & 1.76 & 1.76 & 100.00 \\
\hline HLP-33 & HLLH $^{\mathrm{c}}$ & 4.00 & .00 & 0.01 & 0.32 & 0.09 & 0.01 & 5.90 & 0.47 & 0.00 & 0.00 & 1.61 & 0.00 & 23.00 & 0.06 & 0.01 & 0.08 & 52.00 & 3.21 & 1.61 & 1.61 & 99.99 \\
\hline HLP-34 & HLLL $^{\mathrm{c}}$ & 4.00 & 6.00 & 0.01 & 0.22 & 0.06 & 0.01 & 9.00 & 33 & .00 & .00 & 2.45 & .00 & 6.00 & .04 & .01 & .06 & 52.00 & 4.90 & .45 & .45 & 9.99 \\
\hline HLP-35 & $\mathrm{LHHH}^{\mathrm{c}}$ & 11.94 & 12.00 & 0.01 & 0.32 & 0.09 & 0.01 & 6.77 & 0.47 & 0.00 & 0.00 & 1.85 & 0.00 & 23.00 & 0.06 & 0.01 & .08 & 36.00 & 3.69 & .85 & 1.85 & 100.00 \\
\hline HLP-36 & $\mathrm{LHHL}^{\mathrm{c}}$ & 11.94 & 12.00 & 0.01 & 0.22 & 0.06 & 0.01 & 9.87 & 0.33 & 0.00 & 0.00 & 2.69 & 0.00 & 16.00 & 0.04 & 0.01 & 0.06 & 36.00 & 5.38 & 2.69 & 2.69 & 100.00 \\
\hline HLP & $\mathrm{LHLH}^{\mathrm{c}}$ & 1 & 6.00 & 0.01 & 0.32 & 0.09 & 0.01 & 9.31 & 0.47 & 0.00 & 0.00 & 2.54 & 0.00 & 3.00 & 0.06 & 0.01 & 0.08 & 36.00 & 5.07 & 2.54 & 2.54 & 99.99 \\
\hline HLP-38 & $\mathrm{LHLL}^{\mathrm{c}}$ & 11.94 & 6.00 & 0.01 & 0.22 & 0.06 & 0.01 & 12.41 & 0.33 & 0.00 & 0.00 & 3.38 & 0.00 & 16.00 & 0.04 & 0.01 & 0.06 & 36.00 & 6.76 & 3.38 & 3.38 & 99.99 \\
\hline HLP-39 & $\mathrm{LLHH}^{\mathrm{c}}$ & 4.00 & 12.00 & 0.01 & 0.32 & 0.09 & 0.01 & 10.13 & 0.47 & 0.00 & 0.00 & 2.76 & 0.00 & 23.00 & 0.06 & 0.01 & 0.08 & 36.00 & 5.52 & 2.76 & 2.76 & 99.98 \\
\hline HLP. & $\mathrm{LLHL}^{\mathrm{c}}$ & & 12.00 & 0.01 & & 0.06 & & & & & & & & & & & 0.06 & & 7.21 & 3.61 & 3.61 & \\
\hline HLP-41 & $\operatorname{LLLH}^{\mathrm{c}}$ & 4.00 & 6.00 & 0.01 & 0.32 & 0.09 & 0.01 & 12.67 & 0.47 & 0.00 & 0.00 & 3.45 & 0.00 & 23.00 & 0.06 & 0.01 & 0.08 & 36.00 & 6.90 & 3.45 & 3.45 & 99.97 \\
\hline HLP-42 & LLLL $^{\mathrm{c}}$ & 4.00 & 6.00 & 0.01 & 0.22 & 0.06 & 0.01 & 15.77 & 0.33 & 0.00 & 0.00 & 4.30 & 0.00 & 16.00 & 0.04 & 0.01 & 0.06 & 36.00 & 8.59 & 4.30 & 4.30 & 100.00 \\
\hline HLP-43 & Baseline & 7.00 & 10.00 & 0.01 & 0.28 & 0.08 & 0.01 & 5.50 & 0.41 & 0.00 & 0.00 & 1.50 & 0.00 & 20.00 & 0.06 & 0.01 & 0.07 & 49.07 & 3.00 & 1.50 & 1.50 & 100.00 \\
\hline HLP-44 & reduced $^{\mathrm{d}}$ & 7.00 & 10.00 & 0.01 & 0.28 & 0.08 & 0.01 & 5.50 & 0.41 & 0.00 & 0.00 & 1.50 & 0.00 & 20.00 & 0.06 & 0.01 & 0.07 & 49.07 & 3.00 & 1.50 & 1.50 & 100.00 \\
\hline HLP-45 & reduced $^{\mathrm{d}}$ & 7.00 & 10.00 & 0.01 & 0.28 & 0.08 & 0.01 & 5.50 & 0.41 & 0.00 & 0.00 & 1.50 & 0.00 & 20.00 & 0.06 & 0.01 & 0.07 & 49.07 & 3.00 & .50 & 1.50 & 100.00 \\
\hline HLP-46 & LD6-5412 ${ }^{\mathrm{f}}$ & 12.00 & 5.00 & 4.00 & 0.35 & 0.04 & 0.29 & 0.00 & 1.46 & 0.00 & 0.00 & 0.00 & 0.15 & 20.00 & 0.19 & 0.00 & 0.22 & 55.91 & 0.00 & 0.00 & 0.00 & 99.61 \\
\hline HLP-47 & $\mathrm{LRM}^{\mathrm{g}}$ & & 8.00 & 0 & 0.80 & 0.20 & & & & & & & 0.00 & & & & 0.20 & & 0.10 & 0.00 & 1.00 & \\
\hline HLP-48 & $\mathrm{LAW}-\mathrm{A} 33^{\mathrm{e}}$ & 11.97 & 8.85 & 0.00 & 0.58 & 0.02 & 0.04 & 5.77 & 3.10 & 0.00 & 0.00 & 1.99 & 0.00 & 20.00 & 0.08 & 0.00 & 0.10 & 38.25 & 2.49 & 4.27 & 2.49 & 100.00 \\
\hline HLP-49 & LAW-B29 & & 8.07 & 7.03 & & 0.10 & 0.00 & & & & & & 0.00 & & & & & & 0.00 & & 3.04 & 99.98 \\
\hline HLP-51 & LAW-ABP1 & 10.00 & 9.25 & 0.00 & 0.58 & 0.02 & 0.04 & 2.50 & 2.20 & 2.00 & 0.00 & 1.00 & 0.00 & 20.00 & 0.08 & 0.00 & 0.10 & 41.89 & 2.49 & 2.60 & 5.25 & 100.00 \\
\hline HLP-52 & $\mathrm{HAN}-28^{\mathrm{e}}$ & 10.15 & 0.00 & 2.59 & 0.13 & 0.08 & 0.31 & 2.53 & 1.96 & 0.00 & 0.00 & 1.18 & 0.00 & 28.62 & 1.90 & 0.00 & 0.30 & 44.46 & 0.38 & 0.00 & 5.00 & 99.59 \\
\hline HLP-53 & $\mathrm{LAW}-\mathrm{A} 23^{\mathrm{e}}$ & 9.86 & 4.23 & 4.38 & 0.36 & 0.01 & 0.12 & 7.30 & 3.10 & 0.00 & 2.04 & 2.04 & 0.00 & 20.00 & 0.08 & 0.00 & 0.04 & 40.15 & 0.00 & 3.28 & 2.99 & 99.98 \\
\hline HLP-54 & & 12.00 & 9.00 & 0.00 & 0.09 & 0.04 & 0.21 & 0.00 & 0.33 & & 0.00 & 0.00 & 0.00 & 20.00 & 1.19 & 0.00 & 0.32 & 56.78 & 0.00 & .00 & 0.00 & 99.97 \\
\hline HLP-55 & L4-99 & 9.00 & 9.00 & 0.00 & 0.09 & 0.04 & 0.21 & 0.00 & 0.33 & 0.01 & 0.00 & 0.00 & 0.00 & 20.00 & 1.19 & 0.00 & 0.32 & 59.78 & 0.00 & 0.00 & 0.00 & 99.97 \\
\hline HLP-56 & LAW-A $44^{\mathrm{e}}$ & 6.20 & 8.90 & 1.99 & 0.65 & 0.02 & 0.01 & 6.98 & 0.50 & 0.00 & 0.00 & 1.99 & 0.01 & 20.00 & 0.03 & 0.10 & 0.10 & 44.55 & 1.99 & 2.96 & 2.99 & 99.97 \\
\hline HLP-58 & I Ca & 6.86 & 9.80 & 2.00 & 0.27 & 0.08 & 0.01 & 5.39 & 0.40 & 0.00 & 0.00 & 1.47 & 0.00 & 19.60 & 0.06 & 0.01 & 0.07 & 48.09 & 2.94 & 1.47 & 1.47 & 99.99 \\
\hline HLP-59 & $\mathrm{H} \mathrm{Ca}$ & 6.65 & 9.50 & 5.00 & 0.27 & 0.08 & 0.01 & 5.23 & 0.39 & 0.00 & 0.00 & 1.43 & 0.00 & 19.00 & 0.06 & 0.01 & 0.07 & 46.62 & 2.85 & 1.43 & 1.43 & 100.03 \\
\hline HLP-60 & $M C^{\mathrm{h}, \mathrm{i}}$ & 11.94 & 12.57 & 0.01 & 0.35 & 0.09 & 0.01 & 1.71 & 0.33 & 0.00 & 0.00 & 4.30 & 0.00 & 16.00 & 2.00 & 0.01 & 0.09 & 36.00 & 8.59 & 0.00 & 6.00 & 100.00 \\
\hline HLP-61 & $\mathrm{MC}^{\mathrm{h}, \mathrm{i}}$ & 4.00 & 12.57 & 5.00 & 0.35 & 0.09 & 0.01 & 0.00 & 5.00 & 0.00 & 0.00 & 4.30 & 0.00 & 16.00 & 0.04 & 0.01 & 0.09 & 39.65 & 8.59 & 4.30 & 0.00 & 100.00 \\
\hline HLP-62 & $M C^{i}$ & 4.00 & 12.57 & 5.00 & 0.35 & 0.09 & 0.01 & 0.00 & 0.33 & 0.00 & 0.00 & 0.00 & 0.00 & 16.00 & 0.04 & 0.01 & 0.09 & 46.92 & 8.59 & 0.00 & 6.00 & 100.00 \\
\hline
\end{tabular}


Table 2.1 (Contd)

\begin{tabular}{|c|c|c|c|c|c|c|c|c|c|c|c|c|c|c|c|c|c|c|c|c|c|c|}
\hline Gla & Descri & $\mathbf{A l}_{2} \mathbf{O}_{3}$ & $\mathbf{B}_{2} \mathbf{O}_{3}$ & $\mathrm{aO}$ & Cl & $\mathbf{r}_{2} \mathbf{O}_{3}$ & $\mathbf{F}$ & $\mathrm{Fe}_{2} \mathrm{O}_{3}{ }^{\mathrm{j}}$ & $\mathbf{K}_{2} \mathrm{O}$ & $\mathrm{La}_{2} \mathbf{O}_{3}$ & $\mathbf{L i}_{\mathbf{2}} \mathbf{O}$ & gO & $\mathrm{MoO}_{3}$ & $\mathbf{a}_{2} \mathbf{O}$ & $\mathbf{P}_{2} \mathbf{O}_{5}$ & $\mathrm{ReO}_{2}$ & $\mathrm{SO}_{3}$ & $\mathrm{iO}_{2}$ & $\mathrm{TiO}_{2}$ & nO & $\mathrm{rO}_{2}$ & Total \\
\hline ILP-63 & $\mathrm{MC}^{\mathrm{h}, \mathrm{i}}$ & 4.00 & 6.00 & 0.01 & 0.35 & 0.09 & 0.01 & 15.04 & .33 & 0.00 & 0.00 & 4.30 & 0.00 & 5.14 & 0.04 & 0.01 & 0.09 & 36.00 & .59 & .00 & 00 & 00.00 \\
\hline HLP-64 & $\mathrm{MC}^{\mathrm{i}}$ & 4.00 & 6.00 & 0.01 & 0.35 & 0.09 & 0.01 & 0.00 & 5.00 & 0.00 & 0.00 & 4.30 & 0.00 & 16.00 & 2.00 & 0.01 & 0.09 & 52.00 & 0.00 & 4.14 & 6.00 & 00.00 \\
\hline LP-65 & & 4.00 & 6.00 & 5.00 & 0.35 & 0.09 & 0.01 & 9.82 & 0.33 & 0.00 & 0.00 & 4.30 & 0.00 & 16.00 & 2.00 & 0.01 & 0.09 & 52.00 & 0.00 & 0.00 & 0.00 & 00.00 \\
\hline & & 00 & 12.57 & 0.01 & 0.35 & .09 & 0.01 & 5.36 & & & & & & & & & 09 & & 0.00 & .00 & .00 & \\
\hline HLP-67 & $M C^{\mathrm{i}}$ & 4.00 & 12.57 & 0.01 & 0.35 & 0.09 & 0.01 & 4.43 & 5.00 & 0.00 & 0.00 & 0.00 & 0.00 & 25.14 & 2.00 & 0.01 & 0.09 & 36.00 & 0.00 & 4.30 & .00 & .00 \\
\hline HLP-68 & $\mathrm{MC}^{\mathrm{i}}$ & 9.64 & 6.00 & 5.00 & 0.35 & 0.09 & 0.01 & 15.77 & 5.00 & 0.00 & 0.00 & 0.00 & 0.00 & 16.00 & 0.04 & 0.01 & 0.09 & 36.00 & 0.00 & 0.00 & 6.00 & .00 \\
\hline HLP-69 & $\mathrm{MC}^{\mathrm{i}}$ & 11.94 & 6.00 & 0.01 & 0.35 & 0.09 & 0.01 & 0.24 & 0.33 & 0.00 & 0.00 & 0.00 & 0.00 & 16.00 & 0.04 & 0.01 & 0.09 & 52.00 & 8.59 & 4.30 & 0.00 & 00.00 \\
\hline HLP-70 & $M C^{\mathrm{i}}$ & 11.94 & 6.00 & 4.78 & 0.35 & 0.09 & 0.01 & 0.00 & 5.00 & 0.00 & 0.00 & 0.00 & 0.00 & 5.14 & 2.00 & 0.01 & 0.09 & 36.00 & 8.59 & 0.00 & 0.00 & 00.00 \\
\hline HLP-71 & $\mathrm{MC}^{\mathrm{i}}$ & 11.94 & 6.00 & 5.00 & 0.35 & 0.09 & 0.01 & 0.40 & 0.33 & 0.00 & 0.00 & 4.30 & 0.00 & 5.14 & 0.04 & 0.01 & 0.09 & 36.00 & 0.00 & 4.30 & 5.00 & 00.00 \\
\hline LP-72 & $\mathrm{MC}^{\mathrm{h}, \mathrm{i}}$ & 00 & 6.00 & 0.01 & 0.35 & 0.09 & 0.01 & 15.77 & 33 & 0.00 & 0.00 & 0.00 & .00 & 00 & 2.00 & .01 & .09 & & 8.59 & 30 & .00 & 00 \\
\hline HLP-73 & $\mathrm{MC}^{\mathrm{i}}$ & 11.94 & 12.57 & 0.01 & 0.35 & 0.09 & 0.01 & 13.59 & 5.00 & 0 . & 0.00 & 4.30 & 0 & & 0.04 & 0.01 & 09 & & 0.00 & 00 & .00 & 00 \\
\hline HLP-74 & $M C^{\mathrm{i}}$ & 11.94 & 12.57 & 5.00 & 0.35 & 0.09 & 0.01 & 11.31 & 0.33 & 0.00 & 0.00 & 0.00 & 0.00 & 6.00 & 2.00 & 0.01 & 0.09 & 36.00 & 0.00 & 4.30 & 0.00 & 100.00 \\
\hline HLP-75 & $\mathrm{MC}^{\mathrm{i}}$ & 7.43 & 8.93 & 2.31 & 0.35 & 0.09 & 0.01 & 5.54 & 2.49 & 0.00 & 0.00 & 2.00 & 0.00 & 19.84 & 0.99 & 0.01 & 0.09 & 41.55 & 3.68 & 2.00 & .70 & 100.01 \\
\hline HLP-76 & $\mathrm{LRM}^{\mathrm{g}}$ & 10.00 & 8.00 & 0.50 & 0.80 & 0.20 & 1.00 & 1.00 & 1.50 & 0.01 & 0.10 & 0.10 & 0.00 & 20.00 & 0.50 & 0.00 & 0.20 & 54.37 & 0.10 & 0.00 & .00 & 99.38 \\
\hline HLP-77 & LRM $^{\mathrm{g}}$ & 10.00 & 8.00 & 0.50 & 0.80 & 0.20 & 1.00 & 1.00 & 1.50 & O & 0.10 & 0.10 & 00 & .00 & 0.50 & 0.00 & 20 & 7 & 0.10 & .00 & .00 & 38 \\
\hline Min & & 4.00 & 0.00 & 0.00 & 0.00 & 0.01 & 0.00 & 0.00 & 0.33 & & 0.00 & 0.00 & 0.00 & 0 & 0.01 & 0.00 & 02 & & 0.00 & .00 & 0.00 & \\
\hline Max & & 12.17 & 12.57 & 7.03 & 0.80 & 0.20 & 1.00 & 15.77 & 5.00 & 2.00 & 4.08 & 4.30 & & & 2. & 0 & & 8 & .59 & .30 & .00 & \\
\hline \multicolumn{23}{|c|}{ (a) Glass HLP-50 is reserved for a suitable natural analog glass to be tested once identified. } \\
\hline \multirow{4}{*}{\multicolumn{23}{|c|}{ 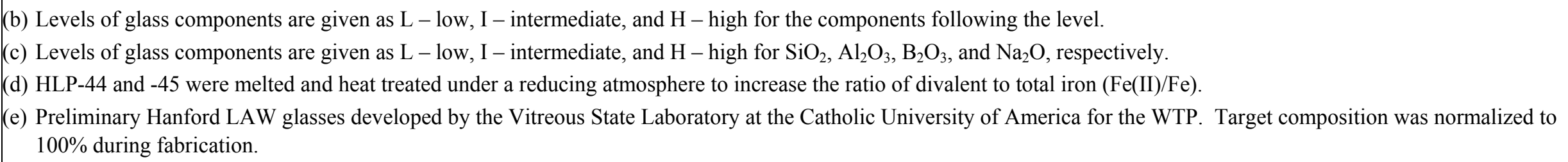 }} \\
\hline & & & & & & & & & & & & & & & & & & & & & & \\
\hline & & & & & & & & & & & & & & & & & & & & & & \\
\hline & & & & & & & & & & & & & & & & & & & & & & \\
\hline \multirow{2}{*}{\multicolumn{23}{|c|}{$\begin{array}{l}\text { (f) HLP-46, or LD6-5412, contains additional components (target mass \%): } \mathrm{SrO}(0.11), \mathrm{I}(0.13), \mathrm{Cs}_{2} \mathrm{O}(0.15) \text {, and } \mathrm{MnO}(0.003) \text {, see Feng et al. }(1996) \text { for details. } \\
\text { (g) HLP-47, -76, and -77; or LRM; contains additional components (target mass } \%) \text { : } \mathrm{BaO}(0.005), \mathrm{CdO}(0.2), \mathrm{I}(0.002) \text {, MnO (0.1), } \mathrm{NiO}(0.1) \text {, and PbO (0.1), see Ebert and } \\
\text { Wolf } 1999 \text { for details. }\end{array}$}} \\
\hline & & & & & & & & & & & & & & & & & & & & & & \\
\hline \multicolumn{23}{|c|}{ (h) Target glass compositions for HLP-60, $-61,-63$, and -72 were changed from those listed in Brown et al. 2000 to reflect those compositions fabricated. } \\
\hline \multicolumn{23}{|c|}{ (i) Multiple-component change glasses that were statistically designed to back-fill the composition region are listed as MC. } \\
\hline \multicolumn{23}{|c|}{ (j) The entire $\mathrm{Fe}$ concentration is listed as $\mathrm{Fe}_{2} \mathrm{O}_{3}$; except where otherwise noted, no attempt was made to control the oxidation state of Fe. } \\
\hline
\end{tabular}


- HLP-49 is the LAW-B, also known as LAW-B29, that was characterized by Ferrara et al. (1998) and Muller et al. (2001). It expands the composition ranges of the study to lower $\mathrm{Na}_{2} \mathrm{O}$ concentrations and higher $\mathrm{CaO}$ and $\mathrm{Li}_{2} \mathrm{O}$ concentrations and represents a nominal composition that may be processed in the WTP.

- HLP-51 is the LAW-ABP1 glass that was characterized by McGrail et al. (1999 and 2001). This glass introduces $\mathrm{La}_{2} \mathrm{O}_{3}$ as a glass component.

- HLP-52 is the HAN-28 glass that was characterized by McGrail et al. (1999). This glass expands the composition ranges to lower $\mathrm{B}_{2} \mathrm{O}_{3}$ and $\mathrm{Fe}_{2} \mathrm{O}_{3}$ concentrations and higher $\mathrm{Na}_{2} \mathrm{O}$ and $\mathrm{P}_{2} \mathrm{O}_{5}$ concentrations.

- HLP-53 is the LAW-A23 glass that was characterized by McGrail et al. (1999 and 2001) and Muller et al. (2001). This glass represents a composition that may be processed in the WTP and expands the range of composition to higher $\mathrm{CaO}$ concentrations.

- HLP-54 is the L4-912 glass that was characterized by Kim et al. (1995) and Feng et al. (1996). ${ }^{(a)}$ This glass expands the composition ranges to higher concentrations of $\mathrm{Al}_{2} \mathrm{O}_{3}$ and $\mathrm{SiO}_{2}$ and lower concentrations of many glass components.

- HLP-55 is the L4-99 glass that was characterized by Kim et al. (1995) and Feng et al. (1996). ${ }^{\text {(a) }}$ This glass expands the composition ranges to higher $\mathrm{SiO}_{2}$ concentration and lower concentrations of many glass components.

- HLP-56 is the LAW-A44 glass that was characterized by McGrail et al. (1999) and Muller et al. (2001). This glass is the current baseline composition for the nominal envelope A LAWs to be processed in the WTP during the current contract.

5. The final 20 glasses contained variations in twelve components- $\mathrm{Al}_{2} \mathrm{O}_{3}, \mathrm{~B}_{2} \mathrm{O}_{3}, \mathrm{CaO}, \mathrm{Fe}_{2} \mathrm{O}_{3}, \mathrm{~K}_{2} \mathrm{O}$, $\mathrm{MgO}, \mathrm{Na}_{2} \mathrm{O}, \mathrm{P}_{2} \mathrm{O}_{5}, \mathrm{SiO}_{2}, \mathrm{TiO}_{2}, \mathrm{ZnO}$, and $\mathrm{ZrO}_{2}$ - many-at-a-time (HLP-58 through -75) from a central composition (HLP-75). These glasses were statistically chosen to backfill the existing test matrix of 55 glasses (Brown et al. 2000). Glasses HLP-76 and -77 are the same glass as HLP-47 (LRM) but, unlike HLP-47, the samples were heat-treated as described in Section 2.2.

\subsection{Glass Fabrication and Heat Treatment}

Matrix glasses were batched from single metal oxide or carbonate precursors for all components except $\mathrm{SO}_{3}, \mathrm{P}_{2} \mathrm{O}_{5}, \mathrm{~F}$, and $\mathrm{Cl}$, which were added as sodium salts, and $\mathrm{B}_{2} \mathrm{O}_{3}$, which was added as $\mathrm{H}_{3} \mathrm{BO}_{3}$. Batches sufficient to produce $500 \mathrm{~g}$ of glass were melted in covered $\mathrm{Pt} / \mathrm{Rh}$ crucibles for $1 \mathrm{~h}$, quenched on a steel plate, ground in a tungsten carbide mill, and remelted in a covered $\mathrm{Pt} / \mathrm{Rh}$ crucible for $1 \mathrm{~h}$. After the second melt, a portion of the melt was quenched on a steel plate. The remainder of the melt was transferred directly into a preheated furnace (in Pt or Pt/Rh containers) and heat treated according to the

\footnotetext{
(a) W. L. Ebert, A. J. Bakel, D. M. Strachan, and S. F. Wolf. 1998. Laboratory Testing of LD6-5412 Glass, DRAFT, Argonne National Laboratory, Argonne, Illinois.
} 
WTP box interior cooling schedule shown in Figure 2.1. (a) This cooling schedule was used to simulate the slowest cooling that can be expected during plant operation. Glasses HLP-46, -47, -52, -54, and -55 were not heat treated (to maintain the same thermal history of the glasses previously tested with the same compositions), but bars were cast and annealed for $2 \mathrm{~h}$ at roughly $10^{\circ} \mathrm{C}$ above the glass-transition temperature and slow cooled to room temperature. Glasses HLP-44 and -45 were batched with a targeted ratio of $\mathrm{FeO}$ to $\mathrm{Fe}_{2} \mathrm{O}_{3}$ and melted and heat treated in a controlled atmosphere furnace with $\mathrm{CO} / \mathrm{CO}_{2}$ ratios described in Table 2.2. Glasses HLP-13 through HLP-25 and glasses HLP-58 through HLP-75 were fabricated at the Savannah River Technology Center (SRTC). Glasses HLP-46 (LD6-5412, Feng et al. 1996) and HLP-47, -76, and -77 (LRM, Ebert and Wolf 1999) were previously fabricated as standard glasses and were used "as-received" in this study. Glasses HLP-76 and -77 were heat treated according to the WTP box interior cooling schedule used in this study while HLP-47 was not. All remaining glasses were fabricated at Pacific Northwest National Laboratory (PNNL) according to the same procedure as used at SRTC.

\subsection{Homogeneity}

Heat-treated glasses were examined in transmitted-light optical microscopy (OM) at magnifications up to 70×. Selected glasses were examined at high magnification (up to 1000×) OM, scanning electron microscopy (SEM) with energy dispersive spectroscopy (EDS), and X-ray diffraction (XRD). Crystalline fractions of any glass in which secondary crystalline phases were identified with OM were obtained with semiquantitative XRD. The crystal content of Phase I glasses was estimated according to the direct comparison method, while those of Phase II glasses were estimated according to the reference intensity ratio (RIR) method (Cullity 1978). Both these methods yield relative uncertainties of $\pm 50 \%$ or less.

\subsection{Density}

Densities of all glasses were measured with a gas pycnometer (AccuPyc 1330), which uses ultra pure Helium and is equipped with a $1-\mathrm{cm}^{3}$ cell. Heat-treated glass samples were ground in a tungsten carbide mill for 1 min to reduce the impact of bubbles on density. The device was calibrated with a tungsten carbide calibration ball before each set of measurements to check the calibration and exclude possible contamination of the instrument by glass powder. ${ }^{(b)}$

(a) Although the WTP no longer plans to cast glass into a box, an updated cooling schedule was not available at the time of this testing. The impacts of a different cooling schedule will have to be assessed after the final schedule is available. However, the impacts are not expected to be significant.

(b) Certificate of Calibration, 98-046490, traceable to National Institute for Standards and Technology (NIST) Test No. 821 25B 592-97 according to the American National Standards Institute ANSI/NCSL 2640-1-94 and ISO 10012-1-92, Precision Ball \& Gauge Co., Alvadore, Oregon (1998). 
Table 2.2. Melting Parameters for HLP-44 and HLP-45

\begin{tabular}{|l|c|c|c||}
\hline Fabrication Step & Ratio & HLP-44 & HLP-45 \\
\hline Batching & $\mathrm{FeO} / \mathrm{Fe}_{2} \mathrm{O}_{3}$ & $1.65 / 3.67$ & $3.87 / 1.23$ \\
\hline Melting & $\mathrm{CO} / \mathrm{CO}_{2}$ & $0.64 / 99.36$ & $16.66 / 82.7$ \\
\hline Heat Treatment & $\mathrm{CO} / \mathrm{CO}_{2}$ & $0 / 100$ & $0.02 / 99.97$ \\
\hline
\end{tabular}

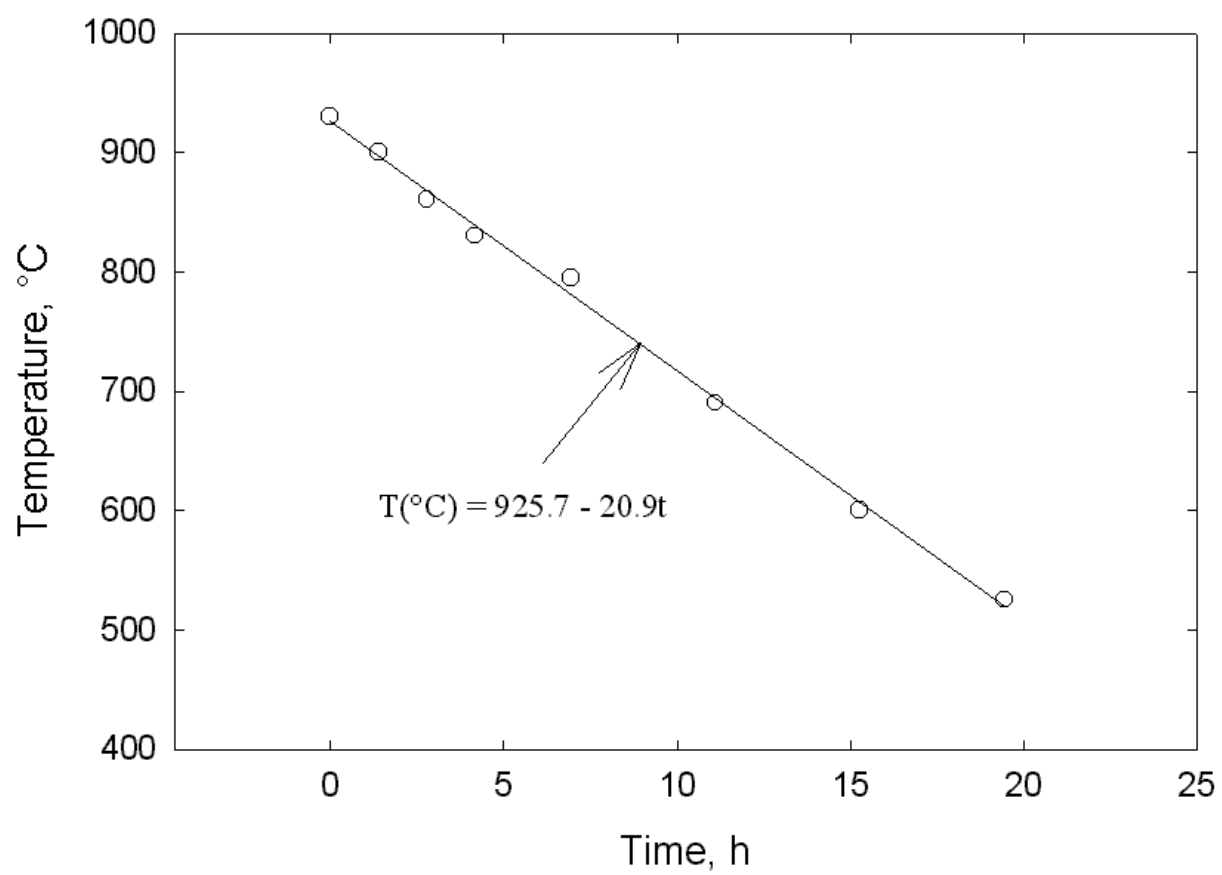

Figure 2.1. Computed Thermal Cooling Curve for $1.2 \times 1.2 \times 1.8 \mathrm{~m}$ Waste Package

Once the sample was loaded, ten purge cycles were performed in roughly $30 \mathrm{~min}$. The average of 10 -volume-displacement measurements on the same sample was used to calculate the density of each glass. A standard deviation was calculated from the 10-volume-displacement measurements. This procedure was found to yield a precision from 0.04 to $0.01 \%$ (relative) when multiple measurements of the same glass were made over a period of roughly 4 months, which is consistent with the reported precision for this instrument.

\subsection{Redox Analyses}

The Fe(II)/Fe ratio or redox of selected matrix glasses (HLP-26, -44, and -45) was measured according to the colorimetric method. The redox of both quenched and heat-treated samples was measured. For the measurement, roughly $0.1 \mathrm{~g}$ of powder (ground in a tungsten carbide mill) was mixed with $2.5 \mathrm{~mL}$ of concentrated $\mathrm{H}_{2} \mathrm{SO}_{4}(95$ to $98 \%$ ) and then with $7.5 \mathrm{~mL}$ of concentrated $\mathrm{HF}$ (48 to $51 \%$ ). Within $15 \mathrm{sec}$ after the powder was mixed with HF, a $250-\mathrm{mL}$ reagent solution composed of phenanthroline, boric acid, and potassium hydrogen phthalate was immediately added to stabilize the $\mathrm{Fe}(\mathrm{II})$. The solution was diluted to $500 \mathrm{~mL}$ with DIW, and the absorbance of Fe(II) was measured using 
an ultra-violet/visible/near infrared spectrophotometer. The spectrophotometer was calibrated, and an $\mathrm{Fe}$ (II) concentration was calculated from calibration data. The total iron was determined with inductively coupled plasma-emission spectroscopy of the solution.

\subsection{Composition Analyses}

To confirm that the "as-fabricated" glass compositions corresponded to the defined targeted compositions (see Table 2.1), a sample from each HLP glass was analyzed. Due to limited quantities of glass, fines (-200 mesh powder) produced during the PCT sample-preparation procedure were submitted for analysis. Therefore, the composition analyses were, in each case, performed on samples of the glasses used in PCT analyses. Concentrations (as mass \%) for the cations of interest were measured with inductively coupled plasma-atomic emission spectroscopy (ICP-AES) after preparing the samples with one of two fusion techniques: 1) $\mathrm{Na}_{2} \mathrm{O}_{2} / \mathrm{NaOH} / \mathrm{HCl}$ or 2) $\mathrm{LiBO}_{2} / \mathrm{HNO}_{3}$. Table 2.3 identifies the elements analyzed, methods of analysis, and typical reportable limits. ${ }^{(a)}$ The target and measured concentrations will be compared below.

Table 2.3. Elemental Analysis Based on Dissolution Procedure and Analytical Technique

\begin{tabular}{|c|c|c|c|}
\hline Element & Dissolution Technique & Analytical Technique & Typical Reportable Limit $(\mu \mathrm{g} / \mathrm{mL})$ \\
\hline $\mathrm{Al}$ & $\mathrm{Na}_{2} \mathrm{O}_{2} / \mathrm{NaOH} / \mathrm{HCl}$ & ICP-AES & $<0.200$ \\
\hline B & $\mathrm{Na}_{2} \mathrm{O}_{2} / \mathrm{NaOH} / \mathrm{HCl}$ & ICP-AES & $<0.180$ \\
\hline $\mathrm{Ca}$ & $\mathrm{LiBO} / \mathrm{HNO}_{3}$ & ICP-AES & $<0.010$ \\
\hline $\mathrm{Cr}$ & $\mathrm{LiBO}_{2} / \mathrm{HNO}_{3}$ & ICP-AES & $<0.030$ \\
\hline $\mathrm{Fe}$ & $\mathrm{LiBO}_{2} / \mathrm{HNO}_{3}$ & ICP-AES & $<0.020$ \\
\hline $\mathrm{K}$ & $\mathrm{LiBO}_{2} / \mathrm{HNO}_{3}$ & ICP-AES & $<0.600$ \\
\hline $\mathrm{Li}$ & $\mathrm{Na}_{2} \mathrm{O}_{2} / \mathrm{NaOH} / \mathrm{HCl}$ & ICP-AES & $<0.020$ \\
\hline $\mathrm{Mg}$ & $\mathrm{LiBO}_{2} / \mathrm{HNO}_{3}$ & ICP-AES & $<0.001$ \\
\hline $\mathrm{Na}$ & $\mathrm{LiBO}_{2} / \mathrm{HNO}_{3}$ & ICP-AES & $<0.530$ \\
\hline $\mathrm{Ni}$ & $\mathrm{LiBO}_{2} / \mathrm{HNO}_{3}$ & ICP-AES & $<0.060$ \\
\hline $\mathrm{Si}$ & $\mathrm{Na}_{2} \mathrm{O}_{2} / \mathrm{NaOH} / \mathrm{HCl}$ & ICP-AES & $<0.180$ \\
\hline $\mathrm{Ti}$ & $\mathrm{LiBO}_{2} / \mathrm{HNO}_{3}$ & ICP-AES & $<0.001$ \\
\hline $\mathrm{Zn}$ & $\mathrm{LiBO}_{2} / \mathrm{HNO}_{3}$ & ICP-AES & $<0.400$ \\
\hline $\mathrm{Zr}$ & $\mathrm{LiBO}_{2} / \mathrm{HNO}_{3}$ & ICP-AES & $<0.080$ \\
\hline
\end{tabular}

Glass standards were not run with these samples, as this practice is not required by the applicable procedures (Procedures 1.4, 1.5, and 1.16 in the SRTC Procedural Manual L28). ${ }^{(\mathrm{b})}$ Instead, a matrix-

(a) The reportable limits are obtained from a two-point calibration, followed by the analyses of a blank five times with five replicates. The average standard deviation for each element, or detection limit, is then calculated from these results. The reportable limit is the detection limit multiplied by 10 .

(b) SRTC Mobile Lab Procedure Manual (U). Procedure 1.4: Dissolution of Glass, Sludge, and Slurry Samples Using Lithium Metaborate, Manual L28.

SRTC Mobile Lab Procedure Manual (U). Procedure 1.5: Dissolution of Glass, Sludge, and Slurry Samples Using $\mathrm{Na}_{2} \mathrm{O}_{2} / \mathrm{NaOH} / \mathrm{HCl}$, Manual L28.

SRTC Mobile Lab Procedure Manual (U). Procedure 1.16: Inductively Coupled Plasma-Atomic Emission Spectrometer Varian Vista AX, Manual L28. 
matched calibration standard was run at the beginning and end of the test blocks as well as after each 10 samples. For the analyses of the calibration standard, the expected differences are $\pm 5 \%$.

\subsection{1 $\mathrm{Na}_{2} \mathrm{O}_{2} / \mathrm{NaOH} / \mathrm{HCl}$ Fusion Preparation}

Approximately $0.25 \pm 0.01 \mathrm{~g}$ of crushed glass was fused with $1.5 \mathrm{~g} \mathrm{Na}_{2} \mathrm{O}_{2}$ and $1.0 \mathrm{~g} \mathrm{NaOH}$ at $600^{\circ} \mathrm{C}$ for $15 \mathrm{~min}$ in a Pt crucible. The fused sample was dissolved in water and $25 \mathrm{~mL}$ of $\mathrm{HCl}$. The fused sample was diluted to $250 \mathrm{~mL}$ with deionized water. An ICP-AES was used to measure the concentrations of $\mathrm{B}, \mathrm{Si}, \mathrm{Al}$, and $\mathrm{Li}$ in the $\mathrm{Na}_{2} \mathrm{O}_{2} / \mathrm{NaOH} / \mathrm{HCl}$ fusion preparation. Before running the solution through the ICP-AES, a $1 / 10$ dilution on the final $250-\mathrm{mL}$ solution was performed. Calibration standards were matrix matched.

\subsection{2 $\mathrm{LiBO}_{2} / \mathrm{HNO}_{3}$ Fusion Preparation}

Approximately $0.1 \pm 0.01 \mathrm{~g}$ of crushed glass was fused with $0.3 \mathrm{~g}$ of $\mathrm{LiBO}_{2}$ at $900^{\circ} \mathrm{C}$ for $15 \mathrm{~min}$ in a Pt crucible. The fused sample was dissolved in a $4 \% \mathrm{HNO}_{3}$ solution. The dissolved sample was diluted to a final volume of $250 \mathrm{~mL}$. No further dilutions were made before running this solution through the ICP-AES. Again, calibration standards were matrix matched.

\subsection{Product Consistency Testing}

Both PCT-A and PCT-B were performed on each test-matrix glass to assess chemical durability as defined in American Society for Testing and Materials (ASTM) C 1285 (ASTM 1998). The PCT-A was conducted in triplicate for each of the HLP glasses. Duplicate blank tests with ASTM Type I water were also run within each test block. Samples were ground, washed, and prepared according to procedure. For PCT-A, $15 \mathrm{~mL}$ of water were added to $1.5 \mathrm{~g}$ of glass in stainless steel vessels resulting in a surface area to volume ratio $(\mathrm{S} / \mathrm{V})$ of approximately $2000 \mathrm{~m}^{-1}$. (For this initial examination of the data, small variations in $\mathrm{S} / \mathrm{V}$ resulting from minor density differences were not considered.) The vessels were closed, sealed, and placed into an oven at $90 \pm 2{ }^{\circ} \mathrm{C}$ where they remained for 7 days $\pm 3 \mathrm{~h}$. After the 7-day test, vessels were removed from the oven and allowed to cool to room temperature. The final masses of each vessel and the solution $\mathrm{pH}$ were recorded on the data sheet. Test solutions were then filtered through a $0.45-\mu \mathrm{m}$ pore-size filter. Six $\mathrm{mL}$ of each test solution were then acidified with $4 \mathrm{~mL}$ of $0.4 \mathrm{M} \mathrm{HNO}_{3}$ to keep cations in solution. Test solutions and blanks were then analyzed for $\mathrm{Si}, \mathrm{B}, \mathrm{Na}$, and $\mathrm{Li}$ concentrations with ICP-AES. A multi-element solution standard was also submitted with the PCT solutions for control purposes. Data sheets were used to record the vessel identification number, sample ID, mass of vessel (empty), mass of vessel with glass, and the mass of vessel with glass and water.

The PCT-B series was conducted at an S/V value of approximately $20000 \mathrm{~m}^{-1}$ and a temperature of $90^{\circ} \mathrm{C}$ in Teflon ${ }^{\circledR}$ vessels ${ }^{(a)}$ as defined by Vienna et al. (1999). The durations for the PCT-B tests were 10,

(a) When Teflon ${ }^{\circledR}$ vessels are used, $\mathrm{CO}_{2}$ diffuses into the test solution so that secondary reactions are not limited by $\mathrm{CO}_{2}$ concentration. Also for these long-test durations, the vessel mass must be tracked and water added when the water mass loss exceeds $10 \%$. 
$100,1000,5000$ (or a time to be determined [TBD]), and $10000 \mathrm{~h}$ (or a time TBD). ${ }^{(a)}$ Samples were ground, washed, and prepared according to procedure. Ten mL of ASTM Type I water were added to $10.0 \mathrm{~g}$ of glass in Teflon vessels, resulting in an S/V value of approximately $20000 \mathrm{~m}^{-1}$. The vessels were closed, sealed, and placed into an oven at $90 \pm 2{ }^{\circ} \mathrm{C}$. During the 5000 and 10000 -h tests, the vessels were removed from the oven at randomly chosen time intervals and weighed to assess the potential for water loss over the extended test period. If the mass of the entire vessel differed more than $1 \mathrm{~g}$ from the original mass, then enough water was added back to the vessel to bring the mass back to the original mass. After the specified test duration, the vessels were removed from the oven and were allowed to cool to room temperature. The final mass of each vessel and the solution $\mathrm{pH}$ were recorded on the data sheet. Test solutions were then filtered through a $0.45-\mu \mathrm{m}$ pore-size filter. Generally, $6 \mathrm{~mL}$ of each test solution were then acidified with $4 \mathrm{~mL}$ of $0.4 \mathrm{M} \mathrm{HNO}_{3}$ to keep cations in solution. Test solutions and blanks were then analyzed for Si, B, Na, and Li concentrations with ICP-AES. A multi-element solution standard was also submitted with the PCT solutions for control purposes. Data sheets were used to record the vessel identification number, sample ID, mass of vessel (empty), mass of vessel with glass, and the mass of vessel with glass and water. Selected glass samples from the PCT-B tests are being evaluated for the formation of secondary phases via electron microscopy.

\subsection{Vapor Hydration Testing}

In the VHT, monolithic samples were exposed to water vapor at elevated temperatures (typically $90^{\circ} \mathrm{C}$ to $300^{\circ} \mathrm{C}$ ) in a sealed vessel as shown schematically in Figure 2.2. This environment greatly accelerates the progression of glass corrosion by water and can result in the formation of alteration phases. The principal uses of the test are 1) as a screening tool to quickly determine if a glass is likely to corrode at an extreme rate, 2) as a convenient means of generating alteration phases for analysis within a short period, and 3) for a measure of the alteration rate during the latter stages of the glass corrosion process at elevated temperatures.

The VHTs were performed according to technical procedure. ${ }^{(b)}$ Samples with dimensions of $10 \times 10$ $\times 1.5 \mathrm{~mm}$ were prepared from heat-treated glass bars with a diamond-impregnated saw. All sides were polished to 600-grit surface finishes with silicon carbide paper. Samples, stainless steel vessels, lids, and supports were cleaned, and samples were suspended from stainless steel supports on Pt wire. An amount of deionized water (DIW), predetermined to be appropriate for the vessel size, the temperature, and the number of samples in the vessel, was added to the vessel. The sealed vessel was held at constant temperature in a convection oven for a preset time, removed, weighed, and quenched in water.

After the test termination, specimens were removed from the vessel and divided into two parts with a diamond-impregnated saw. One part was used for OM/image analysis (IA) evaluation of the specimen cross section, and the other part was used for phase identification with XRD and/or SEM with EDS. The remaining glass thickness was determined by performing at least 10 measurements equally distributed

(a) A sixth sample was initiated and will be used as a "pulse-flow" test in which solution concentrations are monitored on, at least, a monthly basis to determine the appropriate times to pull the two TBD tests. Samples will be terminated at a time determined upon review of initial data.

(b) Vapor-phase Hydration Test Procedure, GDL-VHT, Rev. 1, Pacific Northwest National Laboratory, Richland, Washington (1999). 
across the crack-free areas of the specimen as shown in Figure 2.3. This step yielded the average thickness of the remaining glass and the standard deviation of the measurements.

If the cross-section cut is not exactly perpendicular to the specimen surface, an increase in measured thickness will occur. A cut of $20^{\circ}$ off perpendicular would increase the measured thickness by roughly $6 \%$. The cut is not perpendicular if the thickness measured under transmitted light is different than that measured under reflected light. However, unless the cut is substantially different from $90^{\circ}$, the resulting error is negligible.

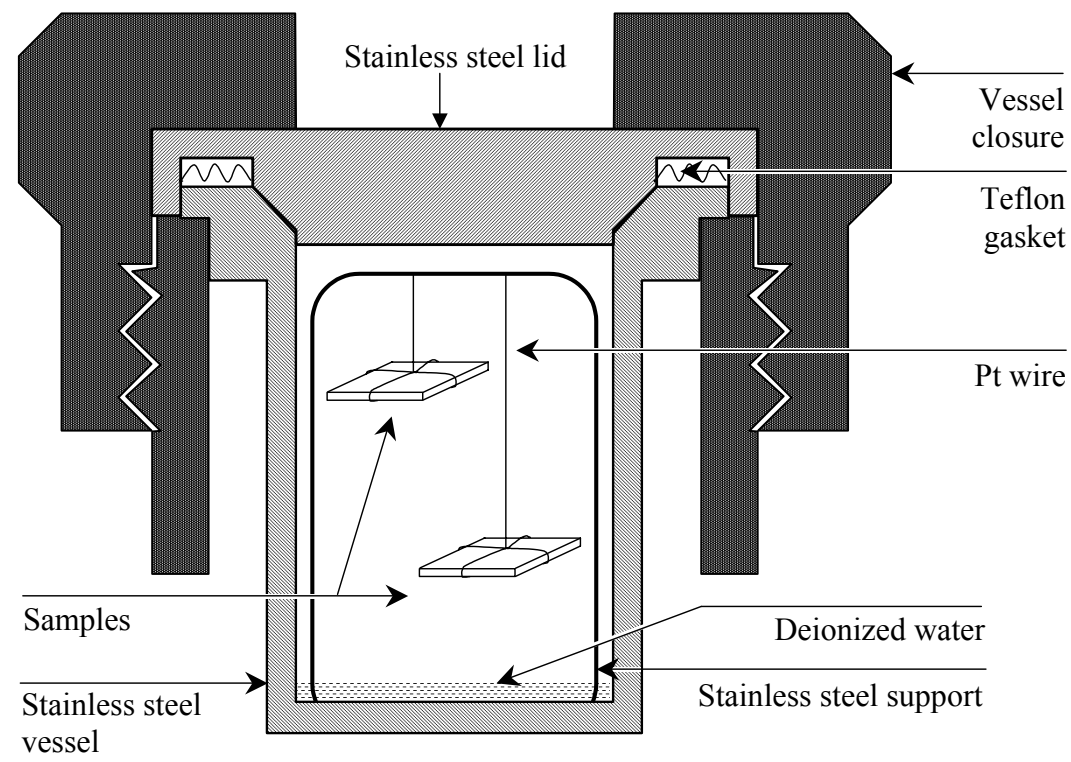

Figure 2.2. Apparatus for Conducting VHTs

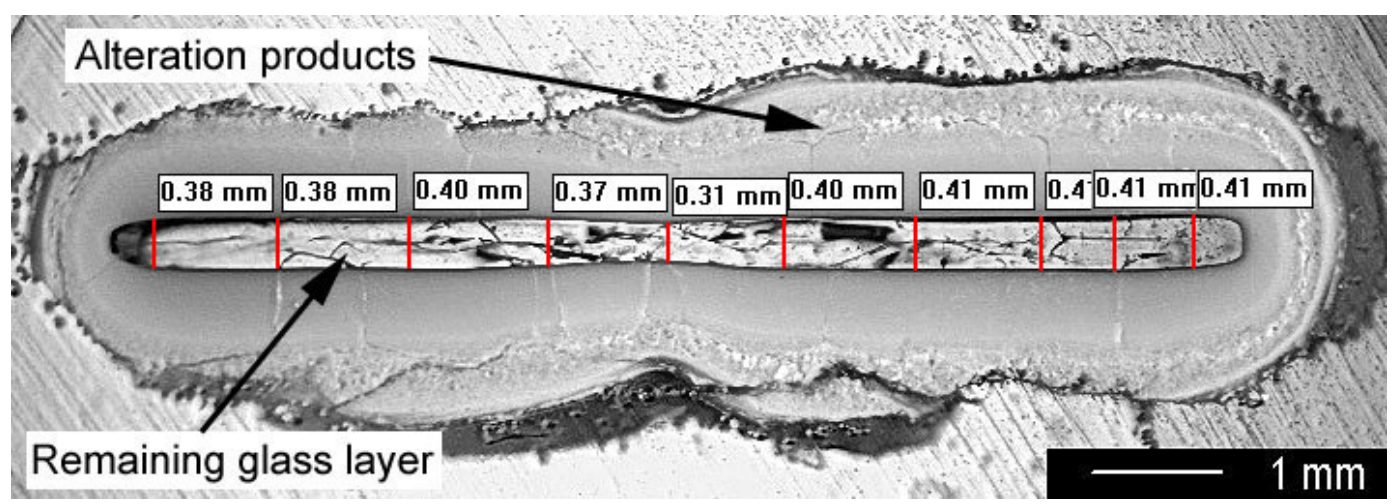

Figure 2.3. OM/IA Measurement of HLP-51 after 2 days of $\mathrm{VHT}$ at $300^{\circ} \mathrm{C}$ in Combination of Transmitted and Reflected Light (thickness of remaining glass is displayed above each measurement) 
The initial dimensions of the specimens were measured with calipers. The thickness of unaltered glass was measured with the IA system connected to the OM. To confirm that both measurements were accurate, both devices were calibrated with standards. Calipers were calibrated with a National Institute for Standards and Technology (NIST)-traceable calibration gage block with a precision of $0.025 \mathrm{~mm}$. The OM with IA was calibrated with an Olympus micrometric calibration ruler with the resolution of $\leq 0.01 \mathrm{~mm}$. A calibration check was performed by measuring a series of pretest specimens with both methods. There was good agreement between the two methods (less than $3.5 \%$ relative difference for multiple measurements).

The mass of glass altered or converted into alteration products $\left(m_{a}\right)$ per unit surface area is calculated with the following formula,

$$
m_{a}=\frac{1}{2} d_{i} \rho\left(1-\frac{d_{r}}{d_{i}}\right)=\frac{m_{i}}{2 w_{i} l_{i}}\left(1-\frac{d_{r}}{d_{i}}\right)
$$

where

$$
\begin{aligned}
d_{i} & =\text { initial glass thickness } \\
\rho & =\text { bulk density } \\
d_{r} & =\text { thickness of the remaining glass } \\
w_{i} \text { and } l_{i} & =\text { initial specimen width and length, respectively } \\
m_{i} & =\text { initial specimen mass. }
\end{aligned}
$$




\subsection{Results}

The testing program described above is still in progress. This section summarizes the current results. The homogeneity of test glasses after heat treatment is discussed in Section 3.1, glass density is given in Section 3.2, Sections 3.3 and 3.4 present the glass redox and compositions, VHT results are given in Section 3.5, and PCT results are presented in Section 3.6.

\subsection{Glass Homogeneity}

Fourteen of the 75 matrix glasses formed significant amounts of a crystalline phase during the heat treatment. All other glasses appeared to be homogeneous or single phase with OM. Selected glasses were examined with SEM and XRD to confirm their homogeneity. These methods are capable of detecting crystalline inhomogeneities with concentrations of roughly 1 mass $\%$ or greater streaks, inclusions, and macroscopic inhomogeneities that can be seen under reflected/transmitted light microscopy up to $1000 \times$ magnifications. However, these methods are not capable of detecting a number of phase-separation types and microscopic inhomogeneities. Of the glasses that formed additional phases-HLP-36, -37, -38, -40, -41, -42, -49, -53, -60, -70, -71, -72, -73, and -74-six were fourcomponent-at-a-time change glasses with low $\mathrm{SiO}_{2}$, two were proposed WTP glasses, and six were multicomponent change glasses with low $\mathrm{SiO}_{2}$. Examination of the XRD traces of each glass, shown in Figure 3.1 for Phase I glasses, suggests that they all contain crystalline inclusions with the possible exception of HLP-41. Further examination suggests that glasses HLP-38 and -42 have similar patterns. The phase characterization for each of these glasses is described in Sections 3.1.1 through 3.1.13.

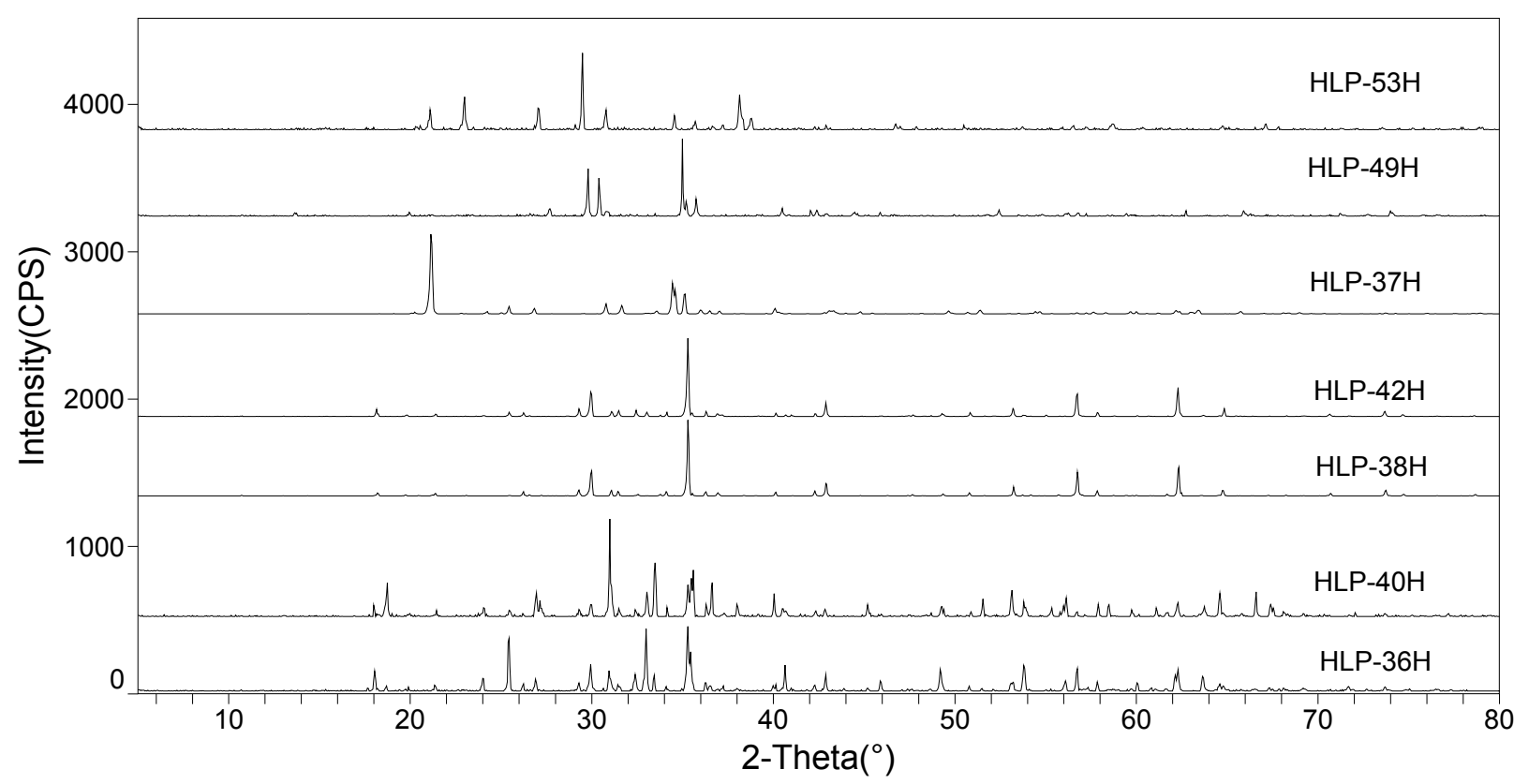

Figure 3.1. XRD Pattern of Inhomogeneous Phase I Glasses (with the "amorphous hump" subtracted) 


\subsubsection{HLP-36 and HLP-40}

Glasses HLP-36 and -40 have the same target concentrations of $\mathrm{SiO}_{2}, \mathrm{Na}_{2} \mathrm{O}$, and $\mathrm{B}_{2} \mathrm{O}_{3}$ with a different concentration of $\mathrm{Al}_{2} \mathrm{O}_{3}$ and form the same crystalline phases. The phases identified in these glasses along with their estimated concentrations are listed in Table 3.1. Hematite was found in two modifications with a different content of Ti substituting for Fe (Titanohematite). Micrographs of these phases, both OM and SEM, are shown in Figure 3.2 and Figure 3.3 for HLP-36 and Figure 3.4 and Figure 3.5 for HLP-40. The EDS spectra of typical crystals are shown in Figure 3.6 through Figure 3.8. Both zinc iron oxide and iron titanium oxide form smaller crystals located usually on the surface of hematite. An additional phase was found in HLP-36 with SEM/EDS; this phase has a high Ti concentration and a smaller Mg concentration. It likely accounts for the Loveringite structure found with XRD (See Figure 3.9) with Mg substituted for Ca.

Table 3.1. List of Phases Identified in HLP-36 and -40 with XRD

\begin{tabular}{|l|l|c|c||}
\hline \hline$\#^{(\mathbf{a})}$ & \multicolumn{1}{|c|}{ Phase } & Concentration in HLP-36 & Concentration in HLP-40 \\
\hline 1 & Zinc Iron Oxide $\left(\mathrm{ZnFe}_{2} \mathrm{O}_{4}\right)$ & 2 mass\% & 0.4 mass\% \\
\hline 2 & Hematite $\left(\mathrm{Fe}_{2} \mathrm{O}_{3}\right)$ & 2 & 1.5 \\
\hline 3 & Iron Titanium ${\mathrm{Oxide}\left(\mathrm{Fe}_{2} \mathrm{TiO}_{5}\right)}_{2}$ & 2 & 10 \\
\hline 4 & Loveringite $\left(\mathrm{CaTi}_{21} \mathrm{O}_{38}\right)$ & 5 & 1 \\
\hline
\end{tabular}

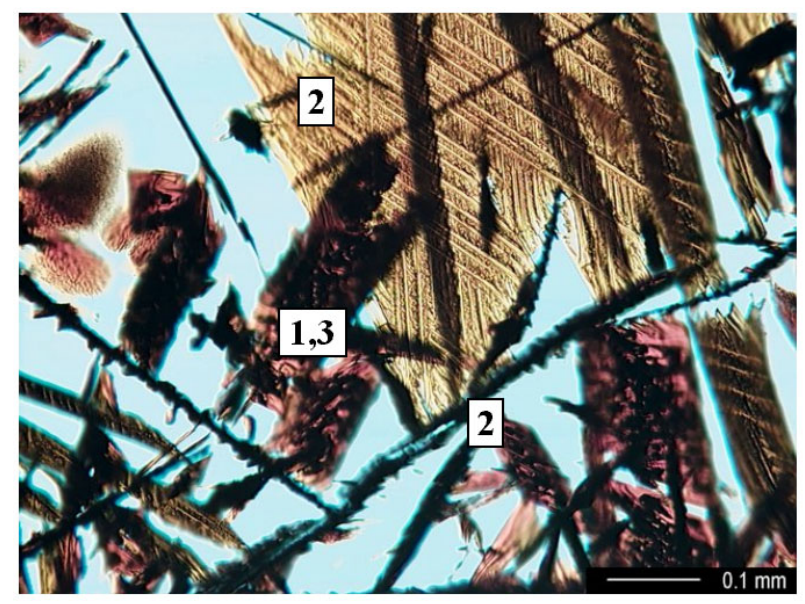

Figure 3.2. Transmitted Light $\mathrm{OM}$ of HLP-36 (200 $\times)$

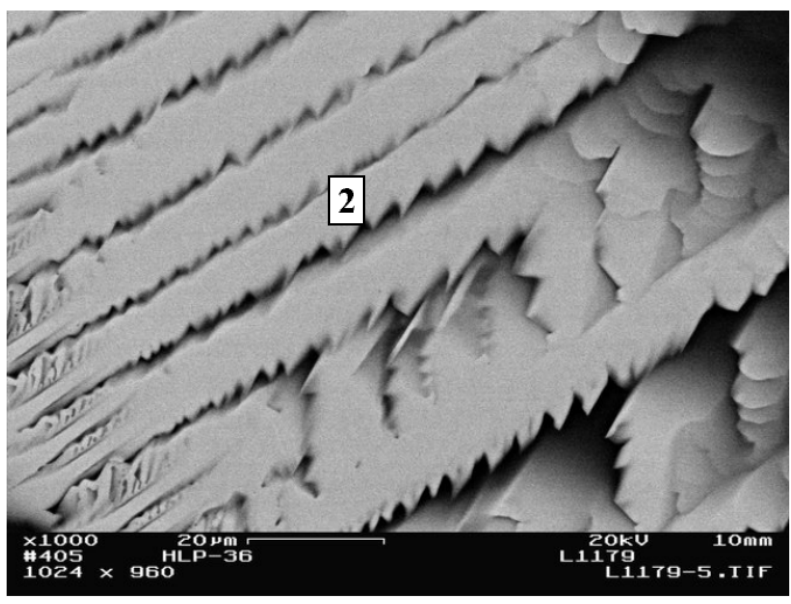

Figure 3.3. SEM Micrograph of HLP-36 


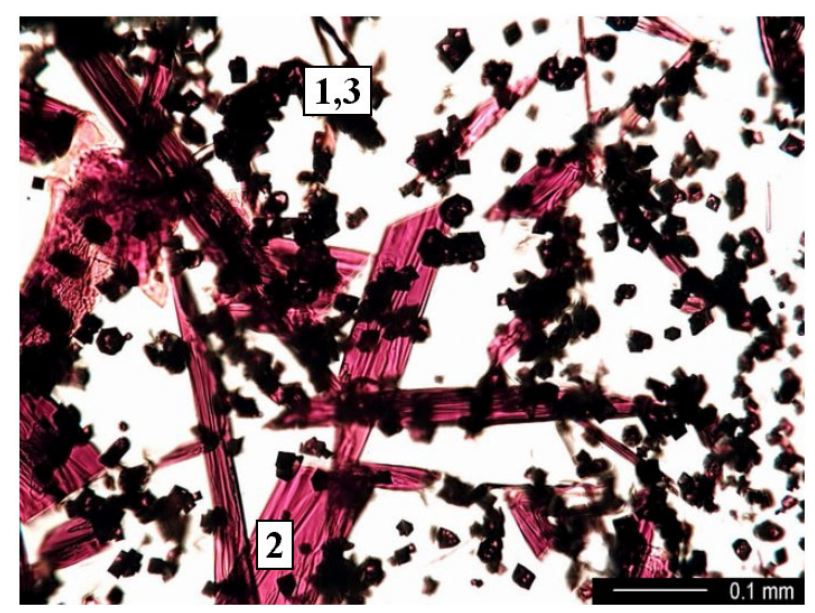

Figure 3.4. Transmitted Light OM of HLP-40 (200×)

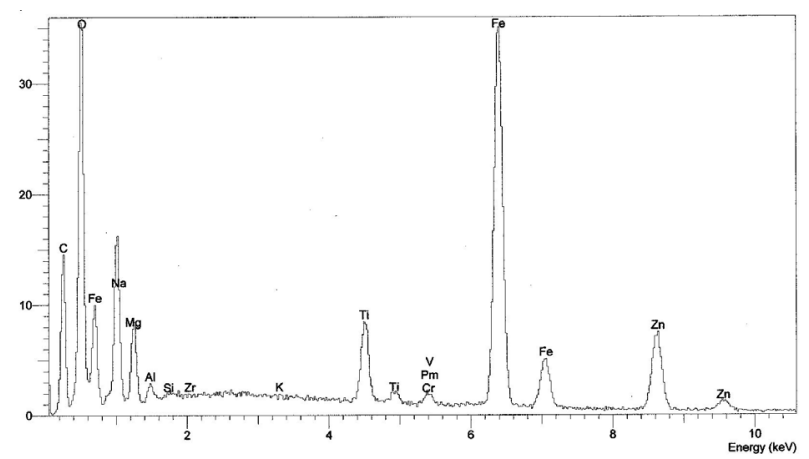

Figure 3.6. EDS Spectrum of Zinc Iron Oxide $\left(\mathrm{ZnFe}_{2} \mathrm{O}_{4}\right)$

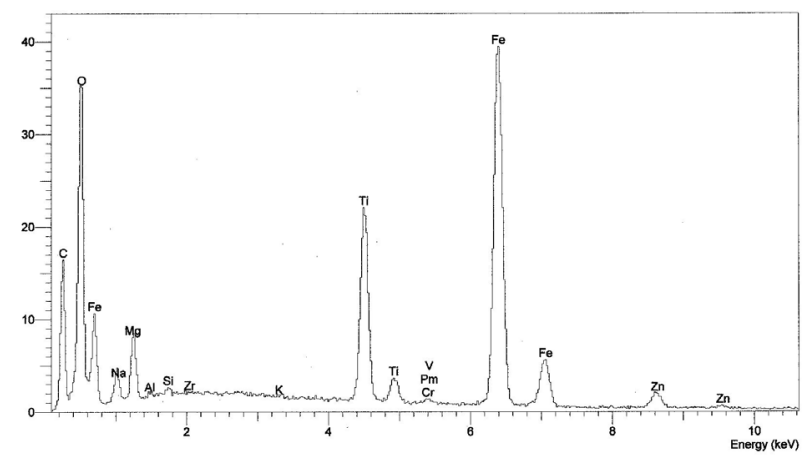

Figure 3.8. EDS Spectrum of Iron Titanium Oxide $\left(\mathrm{Fe}_{2} \mathrm{TiO}_{5}\right)$

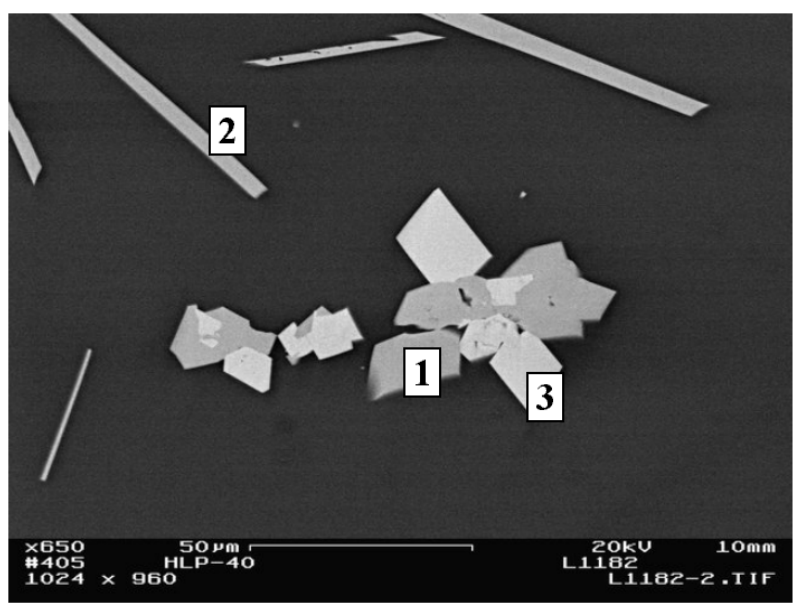

Figure 3.5. SEM Micrograph of HLP-40

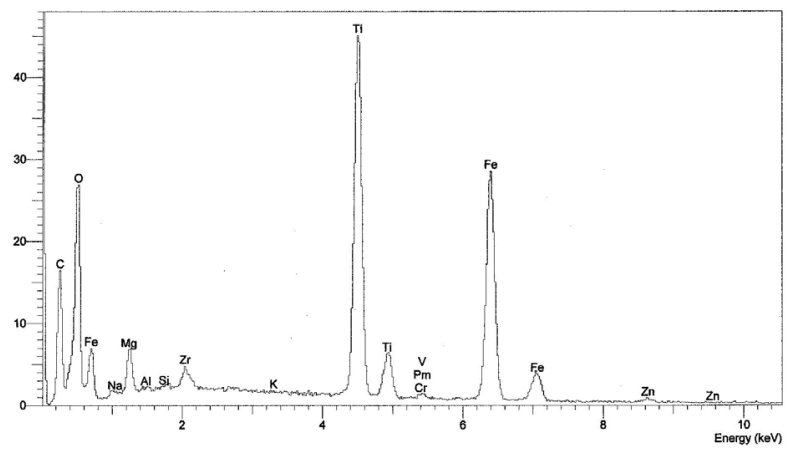

Figure 3.7. EDS Spectrum of Titanohematite

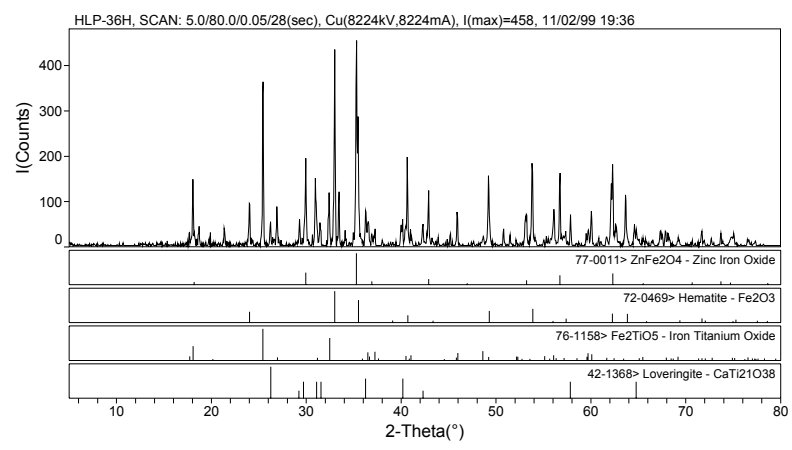

Figure 3.9. XRD Pattern of HLP-36 


\subsubsection{HLP-37}

Carnegeite and chromite were identified in HLP-37 glass, with concentrations listed in Table 3.2. The leaf-like crystals in Figure 3.10 were identified as two distinct carnegieite phases. The light gray phase in Figure 3.11 has higher Si concentration, while the darker phase has higher concentrations of Al and $\mathrm{Na}$ as shown in Figure 3.12. The second phase was identified with OM as spinel. An EDS spectra (Figure 3.13) of this phase indicates high concentrations of $\mathrm{Cr}$ and $\mathrm{Fe}$, likely chromite. This structure cannot be verified by XRD (Figure 3.14) because of its minor content in glass.

Table 3.2. List of Phases Identified in HLP-37

\begin{tabular}{||c|l|c||}
\hline$\#^{(\mathbf{a})}$ & \multicolumn{1}{|c|}{ Phase } & Concentration \\
\hline 1 & Carnegieite low $\left(\mathrm{Na}\left(\mathrm{AlSiO}_{4}\right)\right)$ & 49 mass $\%$ \\
\hline 2 & Chromite $\left(\mathrm{FeCr}_{2} \mathrm{O}_{4}\right)$ & $\geq 0.5$ \\
\hline \multicolumn{2}{|l|}{ (a) Numbers refer to the labels in figures. } \\
\hline
\end{tabular}

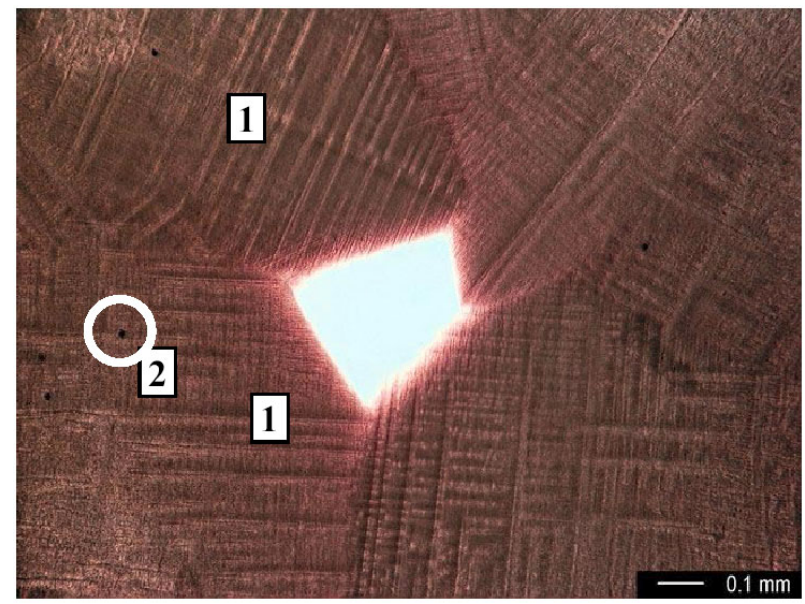

Figure 3.10. OM of HLP-37 (100 $\times)$

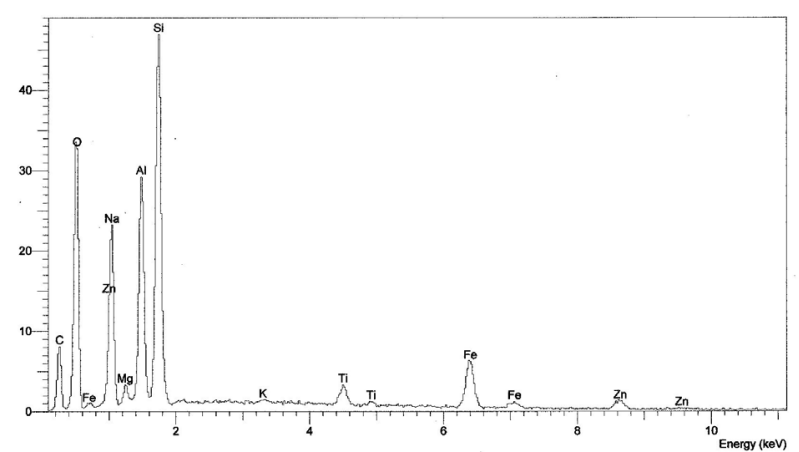

Figure 3.12. EDS Spectrum of Carnegieite Low $\left[\mathrm{Na}\left(\mathrm{AlSiO}_{4}\right)\right]$ - Dark Gray Phase

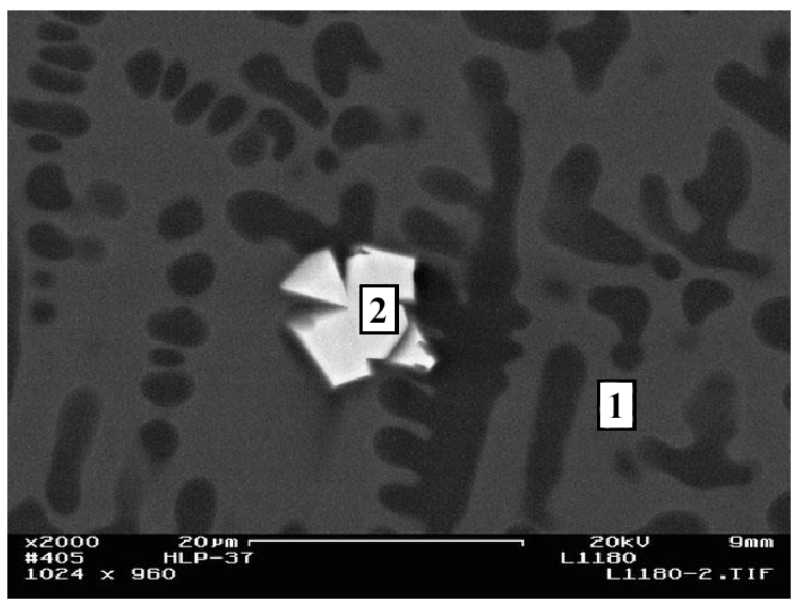

Figure 3.11. SEM Micrograph of HLP-37

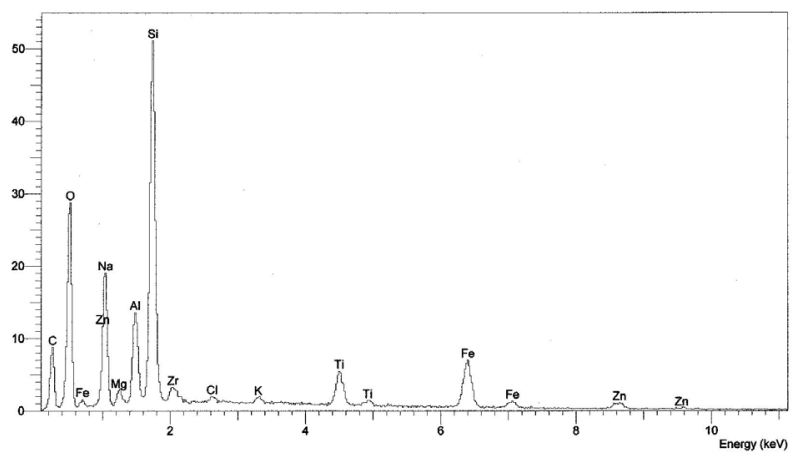

Figure 3.13. EDS Spectrum of Carnegieite Low $\left[\mathrm{Na}\left(\mathrm{AlSiO}_{4}\right)\right]$ - Light Gray Phase 


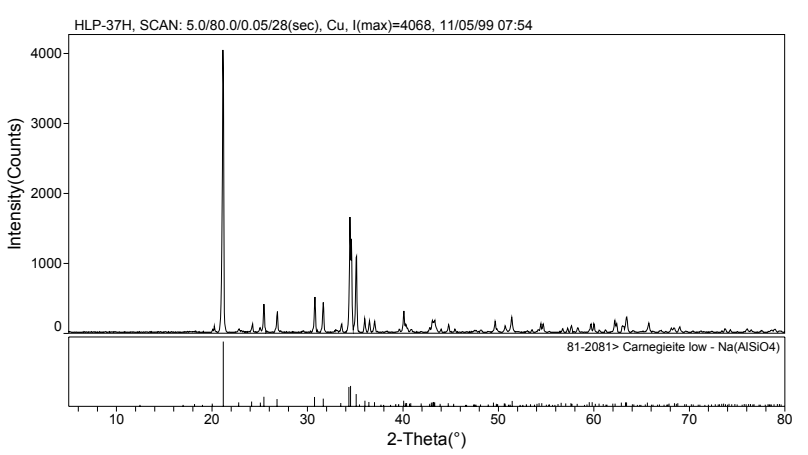

Figure 3.14. XRD Pattern of HLP-37

\subsubsection{HLP-38 and HLP-42}

Like glasses HLP-36 and -40, HLP-38 and -42 have the same target concentrations of $\mathrm{SiO}_{2}, \mathrm{Na}_{2} \mathrm{O}$, and $\mathrm{B}_{2} \mathrm{O}_{3}$ with a different concentration of $\mathrm{Al}_{2} \mathrm{O}_{3}$ and form the same crystalline phases. Titanomagnetite and mathiasite were identified in these glasses with their estimated concentrations listed in Table 3.3. Figure 3.15 and Figure 3.16 show SEM micrographs of these phases in HLP-38. The EDS spectra for these phases are shown in Figure 3.17 and Figure 3.18, and the XRD pattern is given in Figure 3.19.

Table 3.3. Phases Identified in HLP-38 and HLP-42 with XRD

\begin{tabular}{|c|l|c|c|}
\hline \hline$\#^{(\mathbf{a})}$ & \multicolumn{1}{|c|}{ Phase } & Concentration in HLP-38 & Concentration in HLP-42 \\
\hline 1 & Titanomagnetite $\left(\mathrm{Fe}_{2.50} \mathrm{Ti}_{0.50} \mathrm{O}_{4}\right)$ & 13 mass $\%$ & 13 mass $\%$ \\
\hline 2 & Mathiasite $\left[(\mathrm{K}, \mathrm{Ba})(\mathrm{Ti}, \mathrm{Cr}, \mathrm{Fe}, \mathrm{Mg})_{21} \mathrm{O}_{38}\right]$ & 6 & 5 \\
\hline \multicolumn{2}{|l}{ (a) Numbers refer to the labels in figures. } \\
\hline
\end{tabular}

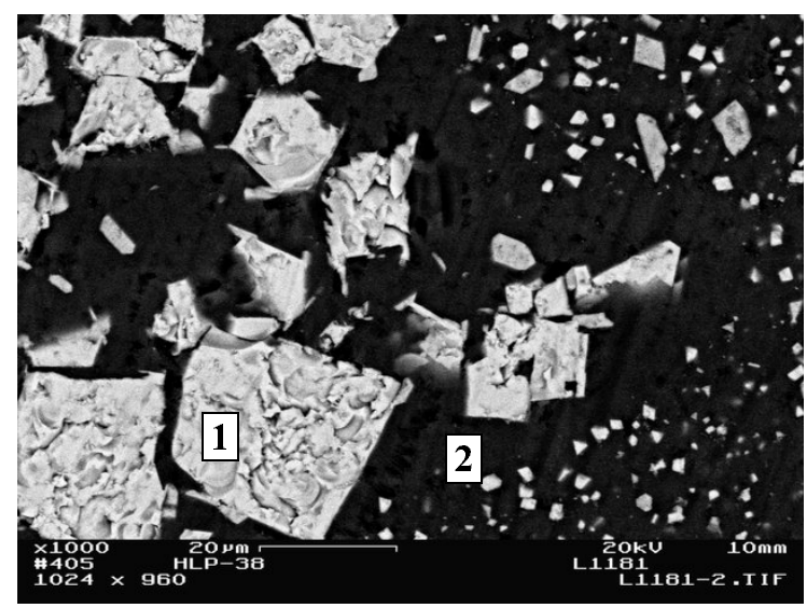

Figure 3.15. SEM Micrograph of HLP-38

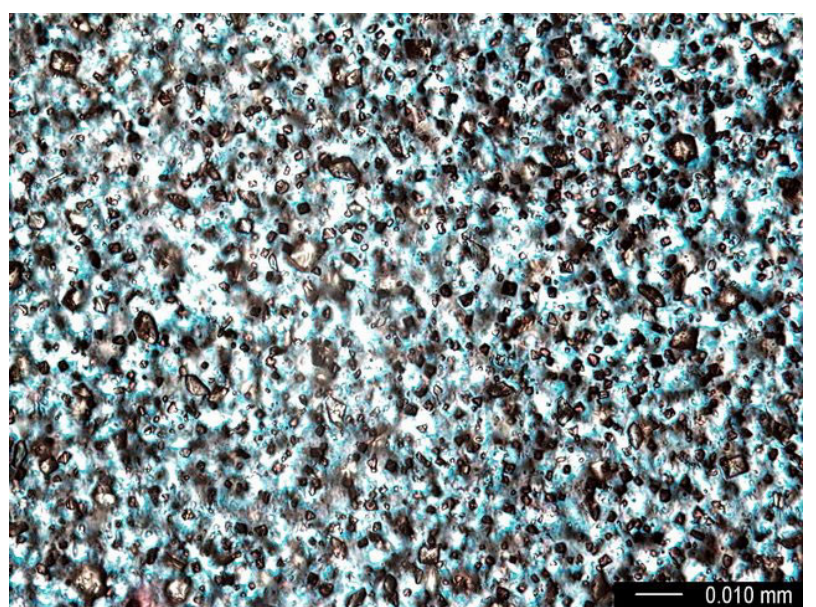

Figure 3.16. OM Micrograph of HLP-38 


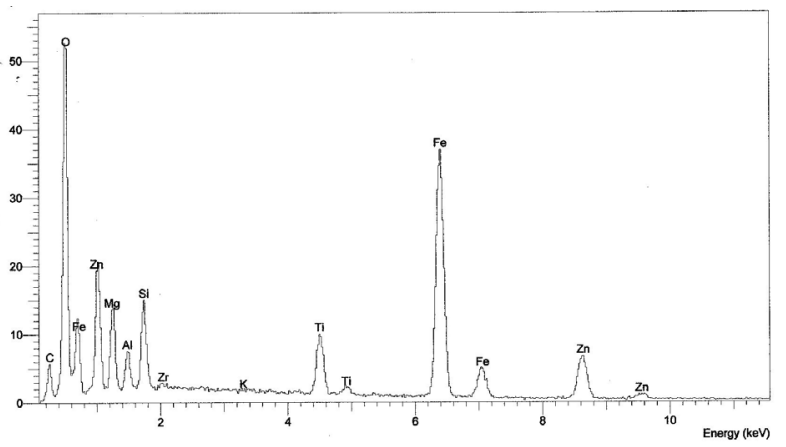

Figure 3.17. EDS Spectrum of Titanomagnetite $\left(\mathrm{Fe}_{2.50} \mathrm{Ti}_{0.50} \mathrm{O}_{4}\right)$

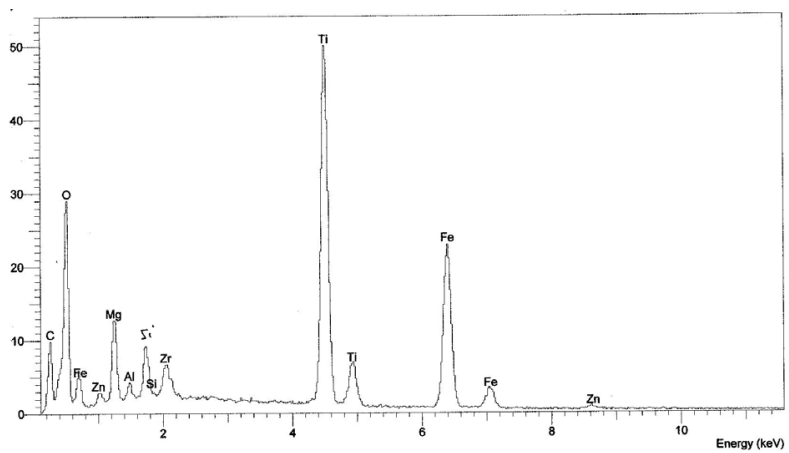

Figure 3.18. EDS Spectrum of Mathiasite $\left[(\mathrm{K}, \mathrm{Ba})(\mathrm{Ti}, \mathrm{Cr}, \mathrm{Fe}, \mathrm{Mg})_{21} \mathrm{O}_{38}\right]$

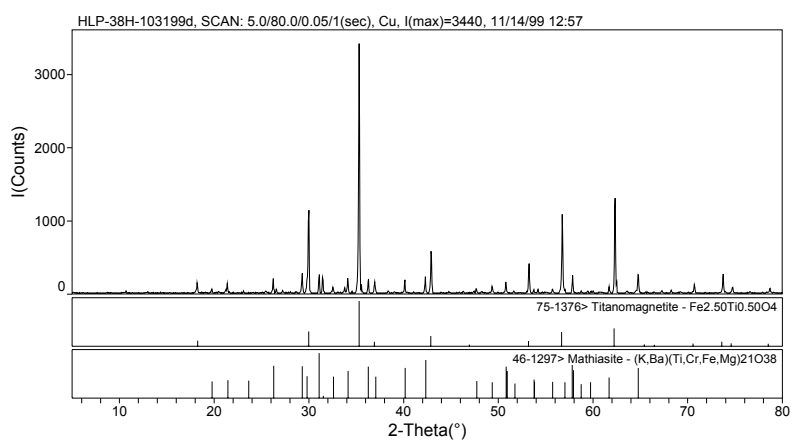

Figure 3.19. XRD Pattern of HLP-38

\subsubsection{HLP-41}

Zinc iron oxide $\left(\mathrm{ZnFe}_{2} \mathrm{O}_{4}\right)$ was identified in HLP-41 with a combination of OM, which showed spinel-like crystals as shown in Figure 3.20, and EDS, which showed high concentrations of $\mathrm{Fe}$ and $\mathrm{Zn}$ as shown in Figure 3.21. We were not able to identify the crystalline phases with XRD because of the low concentration of crystals. The detection limit of crystalline phases by the XRD method used was estimated at roughly 0.5 mass $\%$.

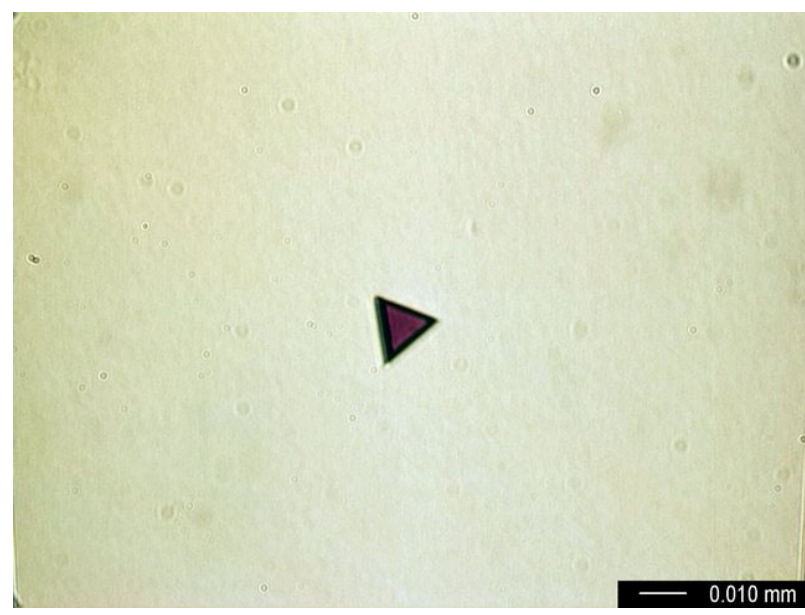

Figure 3.20. OM of HLP-41 (500 $\times)$

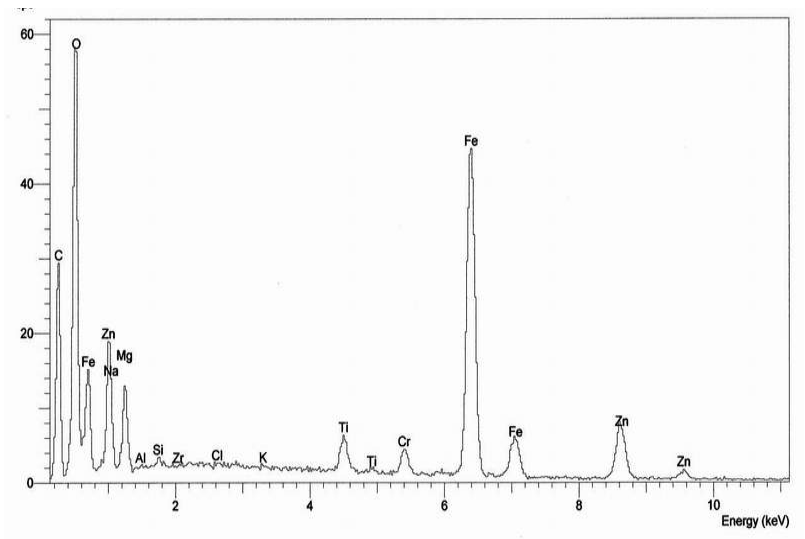

Figure 3.21. EDS Spectrum of a Crystal in HLP-41 


\subsubsection{HLP-49}

The phases identified in HLP-49 glass with XRD are listed in Table 3.4. Only one type of crystal was identified in HLP-49 with OM as shown in Figure 3.22. The composition of the crystal was calculated from the semiquantitative SEM/EDS results to be $\mathrm{Ca}_{0.88} \mathrm{Mg}_{0.49} \mathrm{Fe}_{0.49}\left(\mathrm{SiO}_{3}\right)_{2}$, which is very close to a Caclinopyroxene named augite. Some Zr impurities were also found via SEM/EDS of these crystals (see Figure 3.23 through Figure 3.25). Two types of these clinopyroxene phases were identified from the XRD pattern with a different ratio of Fe substituting for Mg. Further SEM investigation identified chromite at the center of a clinopyroxene crystal and $\mathrm{Pt}$ in the center of one chromite crystal (see Figure 3.26 and Figure 3.27). Platinum may have dissolved into the glass from the crucible in which the glass was melted and likely served as a nucleation center for growth of the chromite, which in turn may have served as a nucleation site for the growth of clinopyroxene.

Table 3.4. List of Phases Identified in HLP-49 with XRD

\begin{tabular}{||c|l|c|}
\hline$\#^{(\mathbf{a})}$ & \multicolumn{1}{|c|}{ Phase } & Concentration \\
\hline 1 & Calcium Magnesium Silicate $\left[\mathrm{Ca}_{0.8} \mathrm{Mg}_{1.2}\left(\mathrm{SiO}_{3}\right)_{2}\right]$ & 2 mass\% \\
\hline 2 & Augite $\left[\mathrm{Ca}_{0.61} \mathrm{Mg}_{0.76} \mathrm{Fe}_{0.49}\left(\mathrm{SiO}_{3}\right)_{2}\right]$ & 4 \\
\hline 3 & Zinc Iron Oxide $\left(\mathrm{ZnFe}_{2} \mathrm{O}_{4}\right)$ & $\leq 0.5$ \\
\hline (a) Numbers refer to the labels in figures. & \\
\hline
\end{tabular}

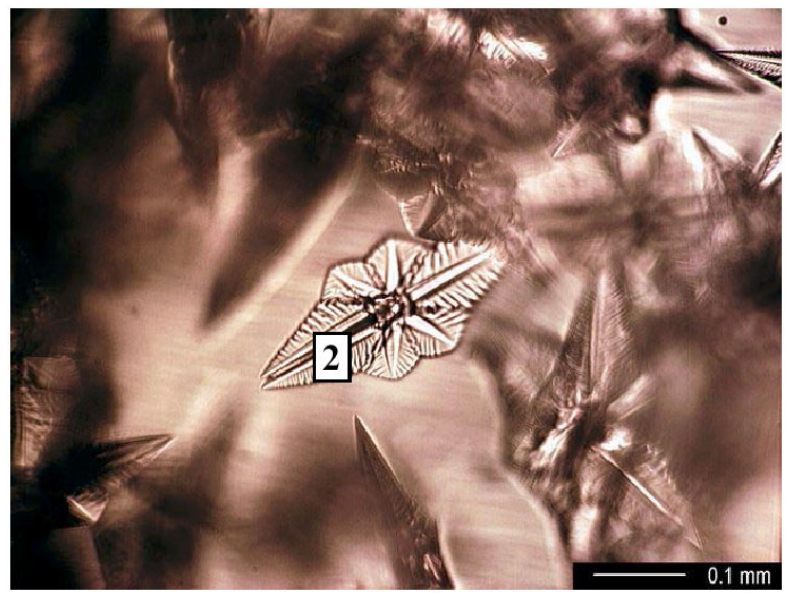

Figure 3.22. OM of Augite in HLP-49 (200 $\times)$

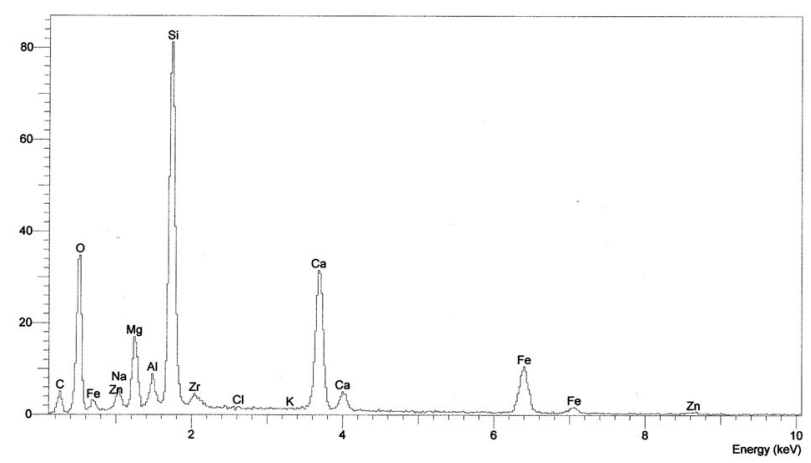

Figure 3.24. EDS Spectrum of Augite

$\left[\mathrm{Ca}_{0.61} \mathrm{Mg}_{0.76} \mathrm{Fe}_{0.49}\left(\mathrm{SiO}_{3}\right)_{2}\right]$

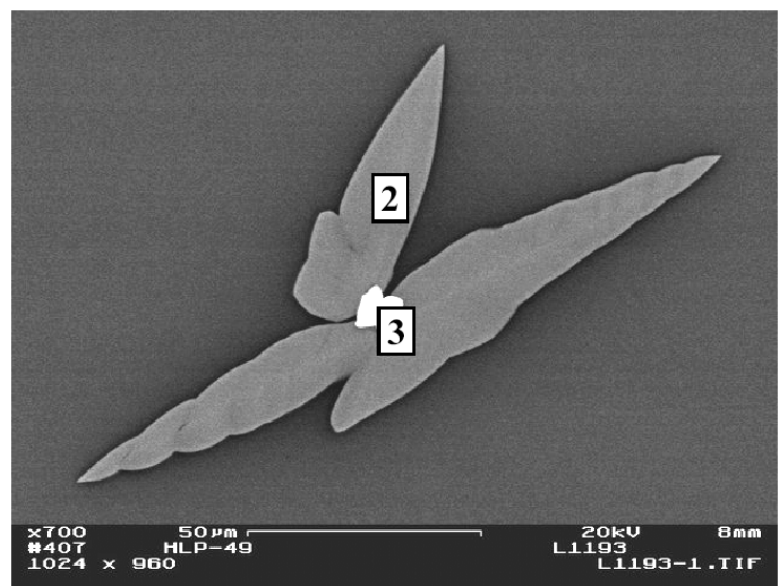

Figure 3.23. SEM Micrograph of Augite and Zinc Iron Oxide (on top) in HLP-49

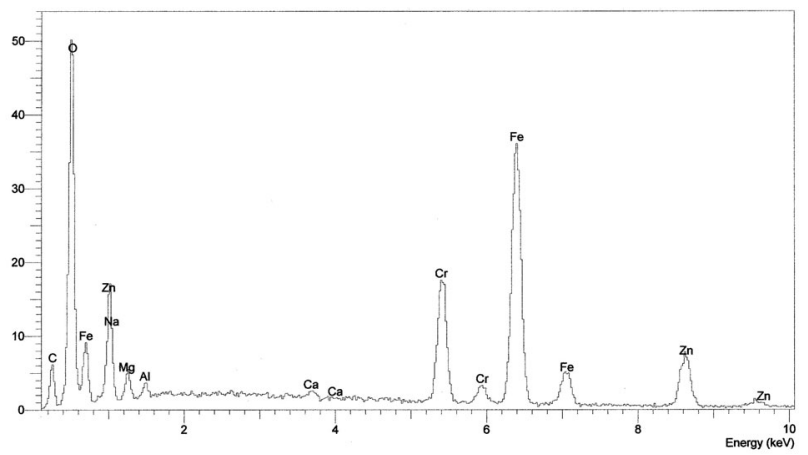

Figure 3.25. EDS Spectrum of Zinc Iron Oxide $\left(\mathrm{ZnFe}_{2} \mathrm{O}_{4}\right)$ 


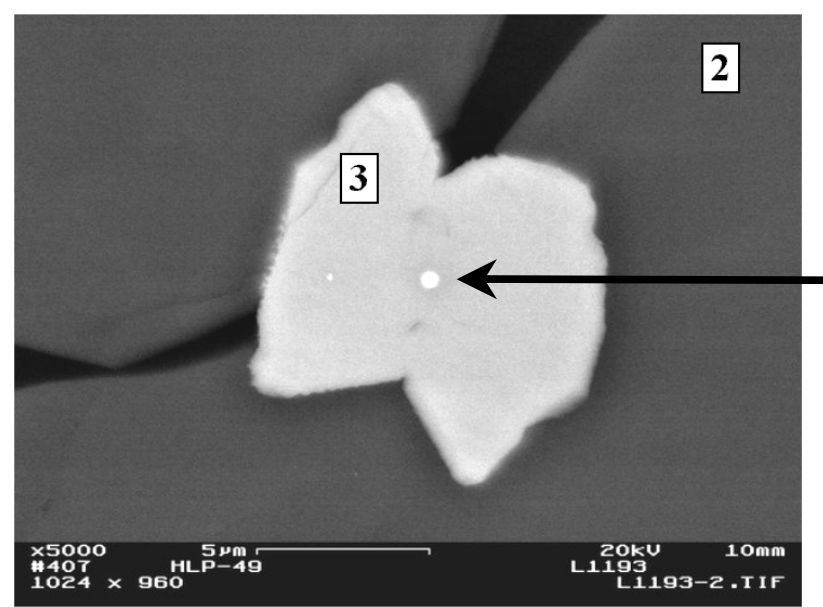

Figure 3.26. SEM Micrograph of Pt, Augite (background), and Zinc Iron Oxide in HLP-49

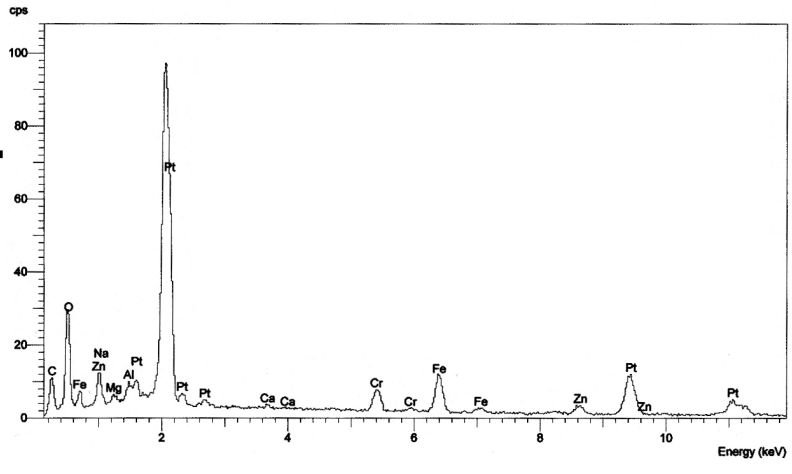

Figure 3.27. EDS Spectrum of a Pt particle in HLP-49

\subsubsection{HLP-53}

During the heat treatment of HLP-53, a second phase appeared to segregate on all surfaces of the melt (for example, see Figure 3.28 and Figure 3.29). The segregated materials or "phases" were easy to mechanically separate. Optical microscopy analyses of each individual "phase" (given in Figure 3.30 and Figure 3.31) showed densely packed small crystals on the surface phase and a few large crystals in the bulk phase. Only nepheline $\left(\mathrm{NaAlSiO}_{4}\right)$ was identified in the XRD patterns for both the surface and bulk. The measured compositions of the bulk-quenched glass and the surface layer and bulk layer of the heattreated glass are compared in Table 3.5. The differences are too small to suggest that the two layers are of different composition. These data suggest massive surface crystallization of nepheline in HLP-53 during heat treatment. The inhomogeneity of this sample precluded the testing of heat-treated samples by VHT; however, a sample representative of the material was ground and used for PCT-A and PCT-B along with a quenched sample. The content of nepheline measured in HLP-53 glass with XRD was 2.11 mass\%.

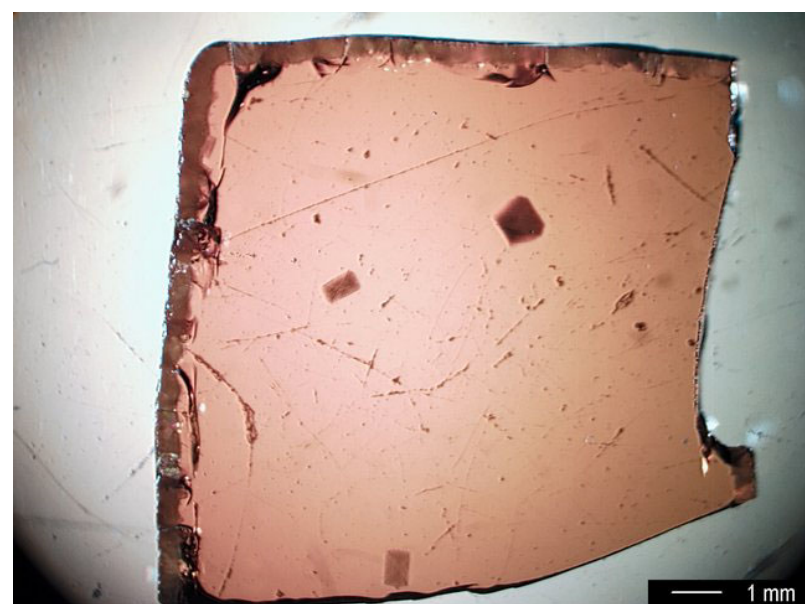

Figure 3.28. Photograph of HLP-53 Glass Monolith after Heat Treatment

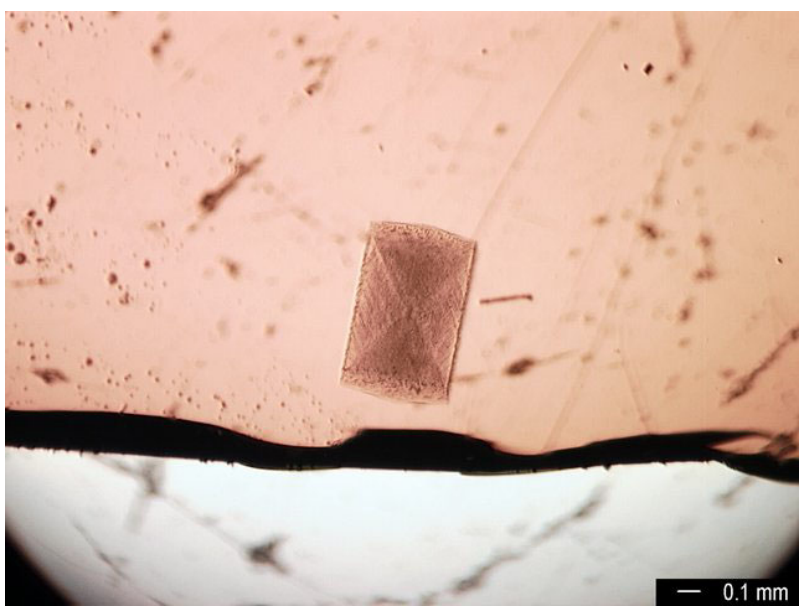

Figure 3.29. OM of HLP-53 Bulk (70 $\times)$ 


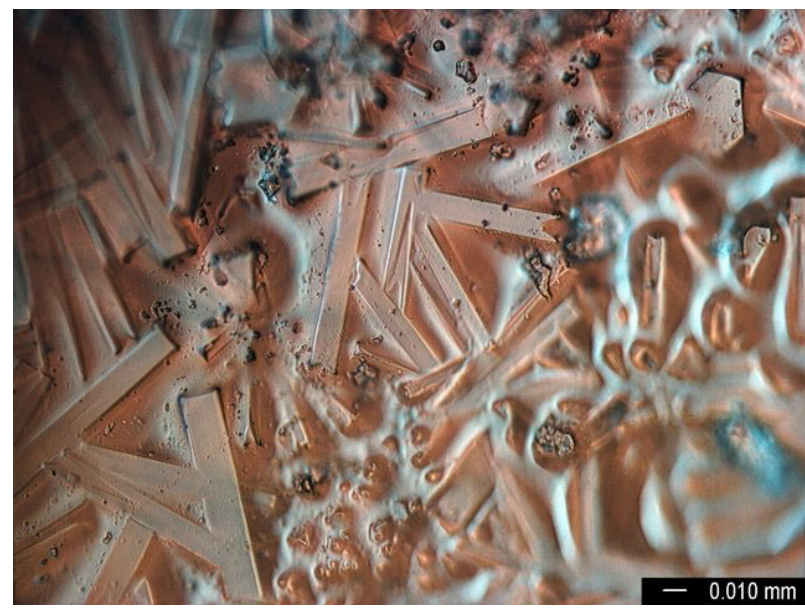

Figure 3.30. OM of HLP-53 Surface $(500 \times)$

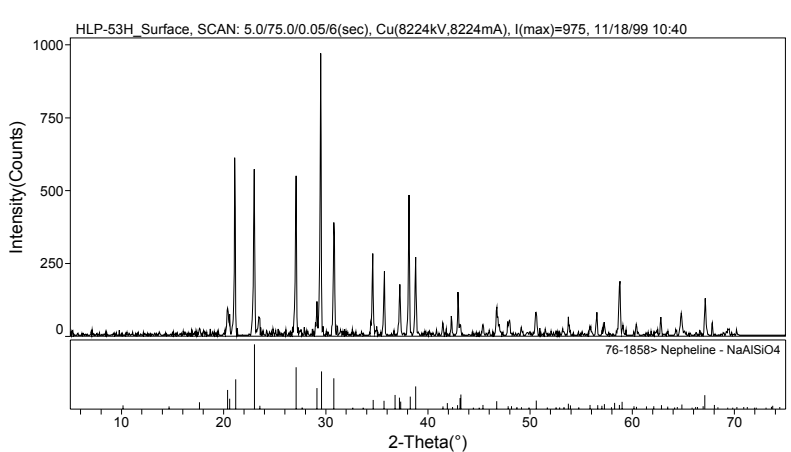

Figure 3.31. XRD Pattern of HLP-53 Surface

Table 3.5. Comparison of Composition for Different Samples of HLP-53 (mass \%)

\begin{tabular}{|l|c|c|c|c|c||}
\hline & Target & Quench & HT (PCT) & Bulk & Surface \\
\hline $\mathrm{SiO}_{2}$ & 40.15 & 40.8 & 39.5 & 42.2 & 43.5 \\
\hline $\mathrm{Al}_{2} \mathrm{O}_{3}$ & 9.86 & 9.79 & 9.31 & 9.59 & 9.49 \\
\hline $\mathrm{B}_{2} \mathrm{O}_{3}$ & 4.23 & 4.54 & 5.46 & 4.34 & 4.26 \\
\hline $\mathrm{Fe}_{2} \mathrm{O}_{3}$ & 7.30 & 7.52 & 7.67 & 7.99 & 8.12 \\
\hline $\mathrm{ZnO}^{2}$ & 3.28 & 3.24 & 3.09 & 3.07 & 3.26 \\
\hline $\mathrm{ZrO}_{2}$ & 2.99 & 2.82 & 2.76 & 2.79 & 2.67 \\
\hline $\mathrm{MgO}^{2}$ & 2.04 & 1.84 & 1.93 & 1.85 & 1.89 \\
\hline $\mathrm{Li}_{2} \mathrm{O}$ & 2.04 & 2.13 & 2.29 & 2.11 & 2.09 \\
\hline $\mathrm{Na}_{2} \mathrm{O}$ & 20.00 & 20.4 & 18.6 & 18.7 & 19.3 \\
\hline $\mathrm{K}_{2} \mathrm{O}$ & 3.10 & 3.08 & 2.75 & 2.98 & 2.93 \\
\hline $\mathrm{CaO}^{2} \mathrm{4} .38$ & 4.33 & 4.21 & 4.27 & 4.32 \\
\hline $\mathrm{Cl}^{-}$ & 0.36 & NM & NM & NM & NM \\
\hline $\mathrm{SO}_{3}$ & 0.04 & NM & NM & NM & NM \\
\hline $\mathrm{P}_{2} \mathrm{O}_{5}$ & 0.08 & NM & NM & NM & NM \\
\hline $\mathrm{Cr}_{2} \mathrm{O}_{3}$ & 0.01 & $\mathrm{BD}$ & 0.14 & BD & BD \\
\hline $\mathrm{F}^{-}$ & 0.12 & NM & NM & NM & NM \\
\hline $\mathrm{Total}^{2}$ & 99.98 & 100.49 & 97.71 & 100.19 & 101.83 \\
\hline $\mathrm{NM}^{-}$not measured, BD = below detection limits. \\
\hline \hline
\end{tabular}




\subsubsection{HLP-60}

Iron titanium oxide $\left(\mathrm{Fe}_{2} \mathrm{TiO}_{5}\right)$ was identified in HLP-60 glass, with a concentration of roughly 12 mass\%. The plate-like appearance of these crystals is shown in Figure 3.32. The XRD pattern used to identify the phase as $\mathrm{Fe}_{2} \mathrm{TiO}_{5}$ is shown in Figure 3.33 (with the amorphous hump subtracted).

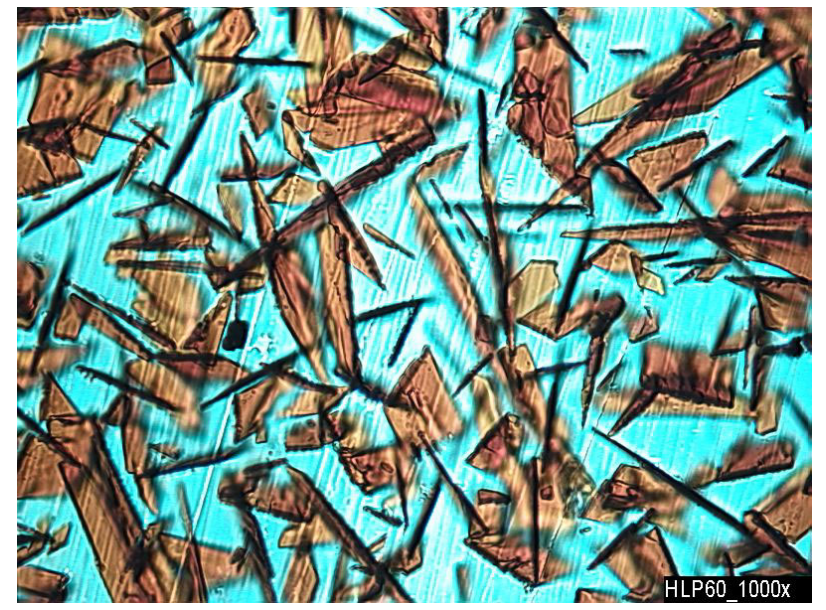

Figure 3.32. OM of HLP-60 (1000 $\times)$

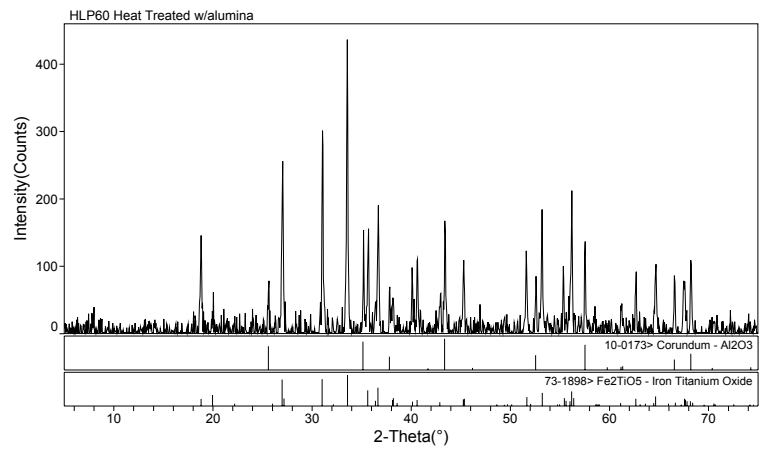

Figure 3.33. XRD Pattern of HLP-60 $\left(\mathrm{Al}_{2} \mathrm{O}_{3}\right.$ was added as standard)

\subsubsection{HLP-68}

Nepheline $\left(\mathrm{K}(\mathrm{Na}, \mathrm{K})_{3} \mathrm{Al}_{4} \mathrm{Si}_{4} \mathrm{O}_{16}\right)$ was identified in HLP-68 glass, with concentration of roughly 0.6 mass \%. The diamond-like appearance of these crystals is shown in Figure 3.34. The XRD pattern used to identify the phase as nepheline is shown in Figure 3.35 (with the amorphous hump subtracted). All peeks seen in the XRD pattern other than those marked as the nepheline belong to the $\mathrm{Al}_{2} \mathrm{O}_{3}$ standard added for semiquantitative analysis.

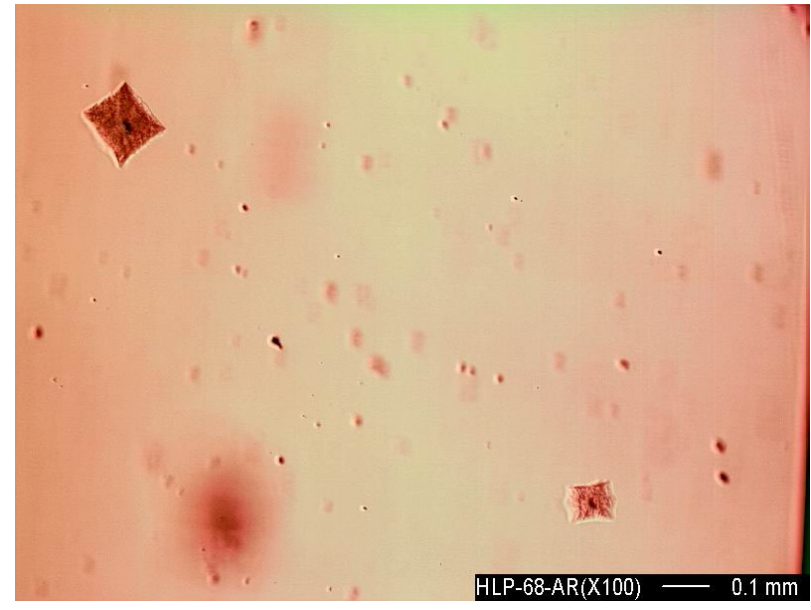

Figure 3.34. OM of HLP-68 (100 $\times)$

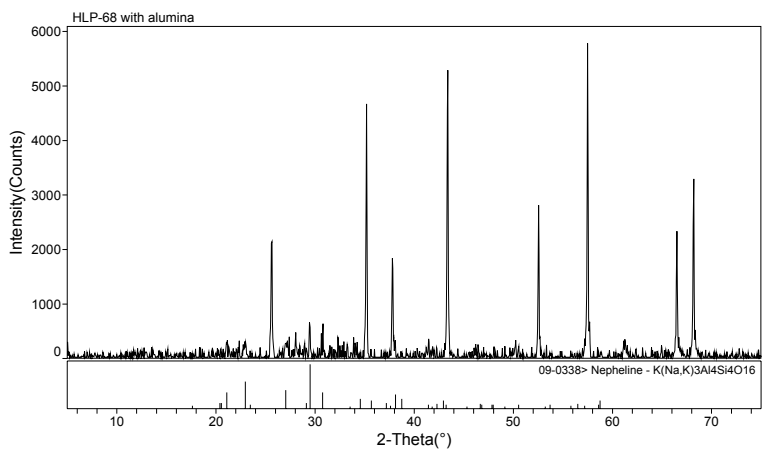

Figure 3.35. XRD Pattern of HLP-68 $\left(\mathrm{Al}_{2} \mathrm{O}_{3}\right.$ was added as standard) 


\subsubsection{HLP-70}

Nepheline and combeite were identified in HLP-70 glass, with concentrations listed in Table 3.6. A transmitted light optical micrograph of the heat-treated glass is shown in Figure 3.36. Figure 3.37 shows the XRD pattern of the heat-treated glass (with the amorphous hump subtracted).

Table 3.6. List of Phases Identified in HLP-70

\begin{tabular}{|c|l|c||}
\hline$\#$ & \multicolumn{1}{|c|}{ Phase } & Concentration \\
\hline 1 & Nepheline $\left(\mathrm{K}(\mathrm{Na}, \mathrm{K})_{3} \mathrm{Al}_{4} \mathrm{Si}_{4} \mathrm{O}_{16}\right)$ & 12 mass $\%$ \\
\hline 2 & Combeite $\left(\mathrm{Na}_{6} \mathrm{Ca}_{3} \mathrm{Si}_{6} \mathrm{O}_{18}\right)$ & 6 \\
\hline
\end{tabular}

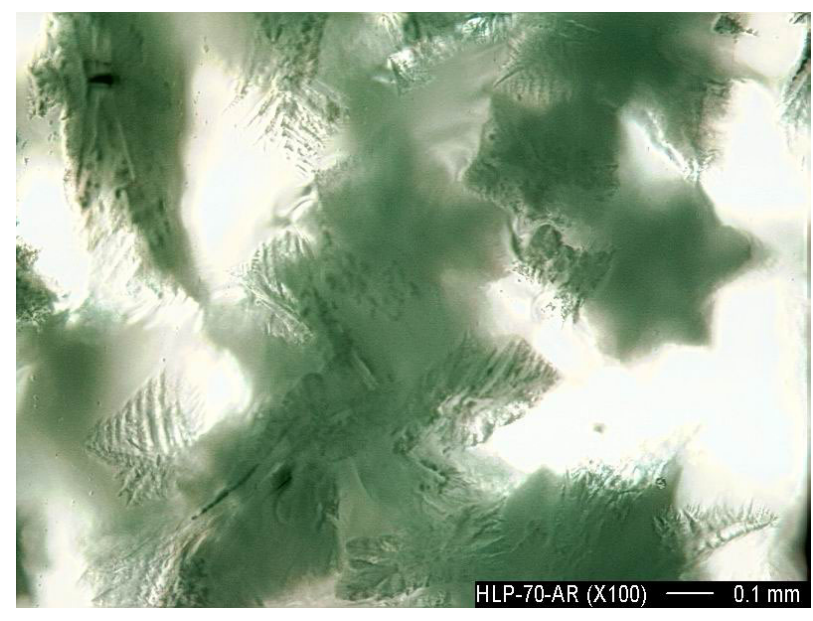

Figure 3.36. OM of HLP-70 (60 $\times)$

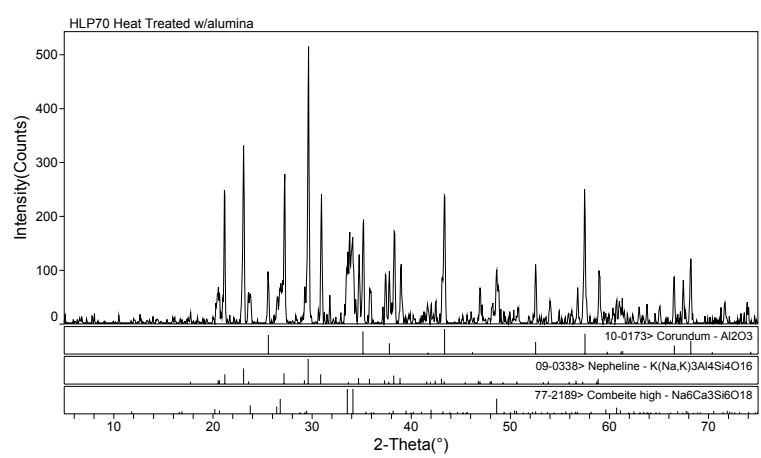

Figure 3.37. XRD Pattern of HLP-70 $\left(\mathrm{Al}_{2} \mathrm{O}_{3}\right.$ was added as a standard)

\subsubsection{HLP-71}

The phases identified in HLP-71 glass with XRD are listed in Table 3.7 (see Figure 3.38). Two distinct crystal morphologies can be seen by OM in Figure 3.39. The SEM micrograph with EDS dotmaps is shown in Figure 3.40. Four distinct phases can be seen in the SEM/EDS images. A closer view of the phases is shown in the backscatter electron (BSE) micrograph in Figure 3.41 with EDS results listed in Table 3.8. The bright, elongated crystal phase is the sodium zirconium silicate phase identified with XRD. The sodium aluminum silicate makes up a large fraction of the figure and appears as smooth, rounded, mid-gray phase in the BSE micrograph. The remaining two phases appear as a relatively lightand dark-gray background surrounding the two crystalline phases. The lighter gray phase is high in $\mathrm{SiO}_{2}$ and $\mathrm{CaO}$ and contains little or no $\mathrm{ZrO}_{2}$ and $\mathrm{Al}_{2} \mathrm{O}_{3}$. The darker gray matrix phase contains higher $\mathrm{Na}_{2} \mathrm{O}$ and lower $\mathrm{SiO}_{2}$ and $\mathrm{CaO}$ than the lighter phase. These two matrix phases are likely amorphous due to their morphology and the lack of XRD pattern.

Table 3.7. List of Crystalline Phases Identified in HLP-71 with XRD

\begin{tabular}{|l|c|}
\hline \multicolumn{1}{|c|}{ Phase } & Concentration \\
\hline Sodium Aluminum Silicate $\left(\mathrm{Na}_{1.55} \mathrm{Al}_{1.55} \mathrm{Si}_{0.45} \mathrm{O}_{4}\right)$ & 58 mass\% \\
\hline Sodium Zirconium Silicate $\left(\mathrm{Na}_{4} \mathrm{Zr}_{2} \mathrm{Si}_{3} \mathrm{O}_{12}\right)$ & 4 \\
\hline
\end{tabular}




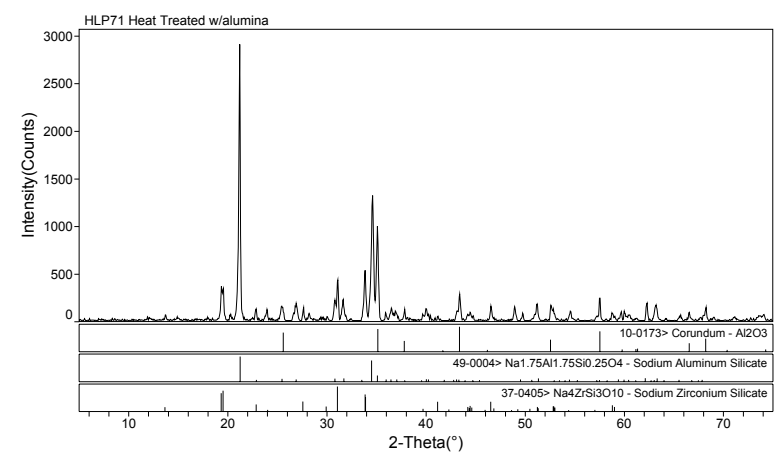

Figure 3.38. XRD Pattern of $\mathrm{HLP}-71\left(\mathrm{Al}_{2} \mathrm{O}_{3}\right.$ was added as a standard)

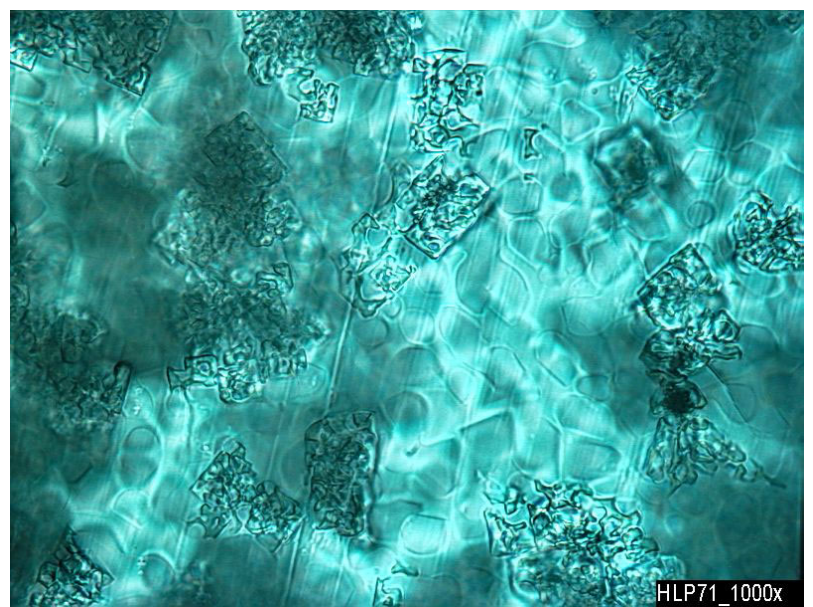

Figure 3.39. Transmitted Light Micrograph of HLP-71 (1000 $\times)$

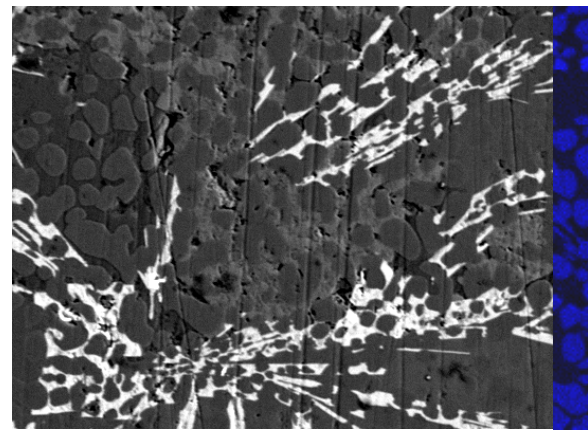

BEC Image

Al map

Ca map

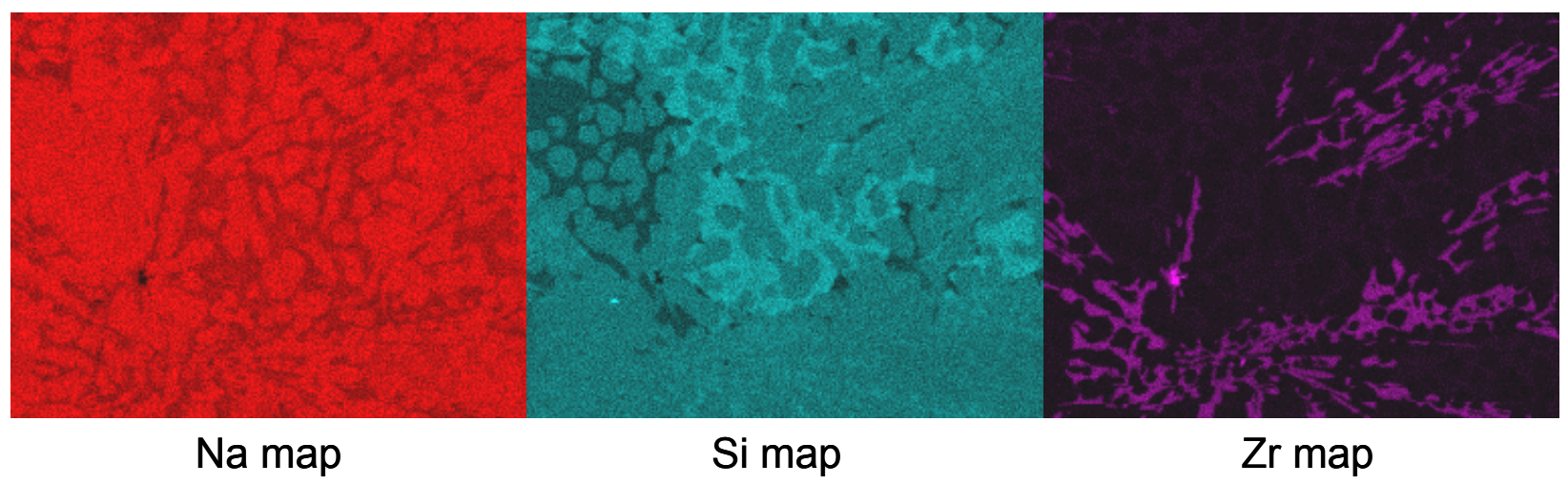

Figure 3.40. SEM Micrograph of HLP-71 Glass with BSE and Al, Ca, Na, Si, and $\mathrm{Zr}$ EDS Images 


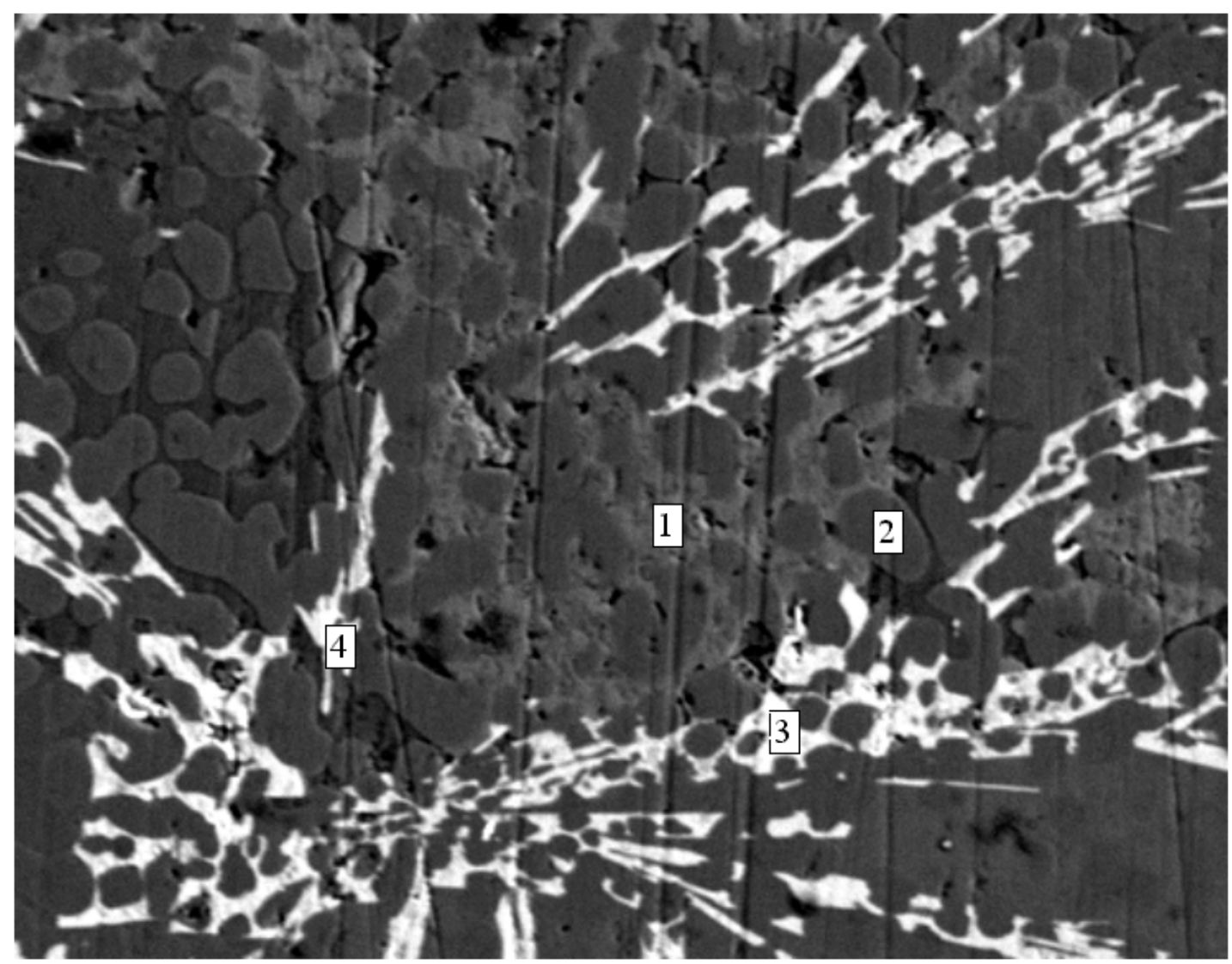

Figure 3.41. Backscatter Electron Micrograph of HLP-71 (at 1400 $\times$ )

Table 3.8. Semiquantitative Composition Estimate of Phases in HLP-71 by EDS (in mass\% of oxides)

\begin{tabular}{|c|l|c|c|r|r|r|r|r|r||}
\hline \hline$\#^{(\mathbf{a})}$ & Phase & $\mathbf{N a}_{2} \mathbf{O}$ & $\mathbf{M g O}$ & $\mathbf{A l}_{2} \mathbf{O}_{3}$ & $\mathbf{S i O}_{2}$ & $\mathbf{Z r O}_{2}$ & $\mathbf{C a O}$ & $\mathbf{Z n O}$ & $\mathbf{K}_{2} \mathbf{O}$ \\
\hline 1 & Light gray matrix & 21.2 & 1.5 & 1.9 & 50.8 & 2.9 & 21.6 & 0.0 & 0.0 \\
\hline 2 & Sodium Aluminum Silicate & 22.5 & 5.7 & 22.8 & 41.3 & 0.0 & 1.9 & 5.8 & 0.0 \\
\hline 3 & Sodium Zirconium Silicate & 16.7 & 1.2 & 3.6 & 35.5 & 42.1 & 0.9 & 0.0 & 0.0 \\
\hline 4 & Sodium Zirconium Silicate & 14.7 & 1.1 & 3.7 & 41.1 & 38.1 & 1.3 & 0.0 & 0.0 \\
\hline (a) Numbers refer to the labels in figures. \\
\hline
\end{tabular}

\subsubsection{HLP-72}

Rutile and Baddeleyite were identified in HLP-72 glass, with concentrations listed in Table 3.9. A transmitted light optical micrograph of the heat-treated glass is shown in Figure 3.42. Figure 3.43 shows the XRD pattern of the heat-treated glass (with the amorphous hump subtracted). The elongated crystals are rutile while the clustered phase at the center of rutile "stars" is baddeleyite. Figure 3.44 shows a SEM image of these phases, with the EDS spectra tabulated in Table 3.10. 
Table 3.9. List of Phases Identified in HLP-72

\begin{tabular}{|c|l|c|}
\hline \hline$\#$ & \multicolumn{1}{|c|}{ Phase } & Concentration \\
\hline 1 & Rutile $\left(\mathrm{TiO}_{2}\right)$ & 8 mass $\%$ \\
\hline 2 & Baddeleyite $\left(\mathrm{ZrO}_{2}\right)$ & 3 \\
\hline
\end{tabular}

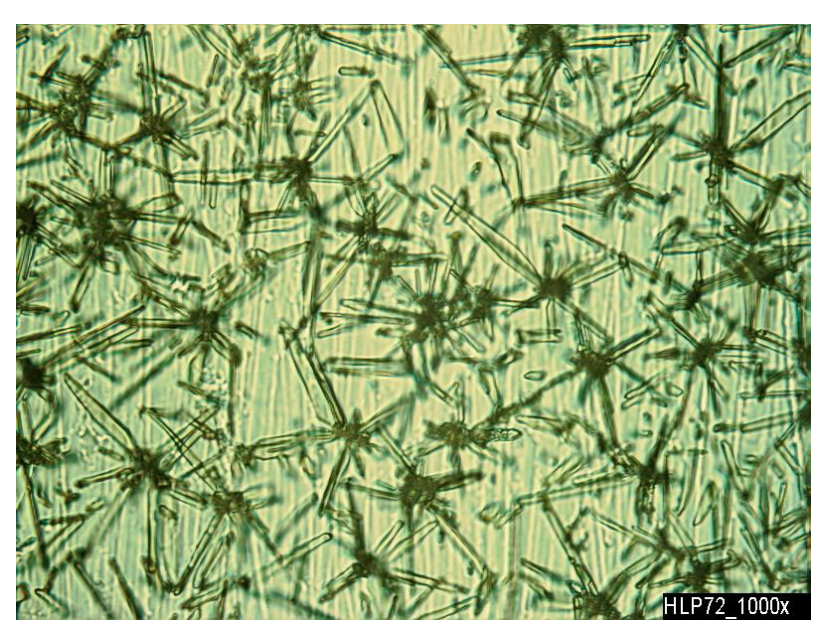

Figure 3.42. OM of HLP-72 (1000 $\times)$

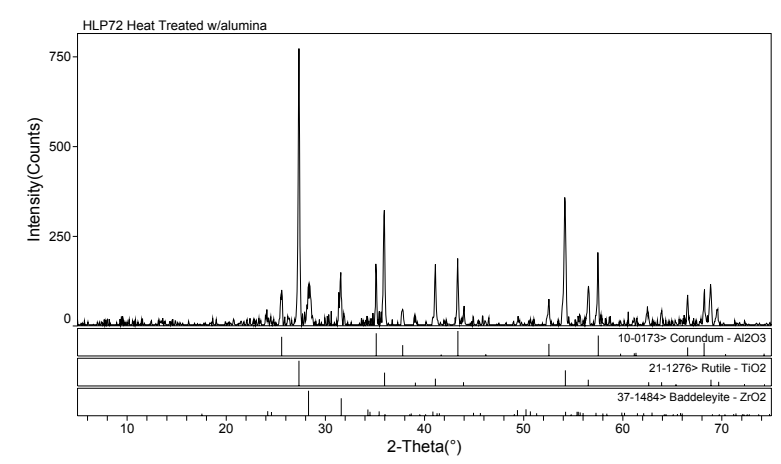

Figure 3.43. XRD Pattern of HLP-72 $\left(\mathrm{Al}_{2} \mathrm{O}_{3}\right.$ was added as a standard)

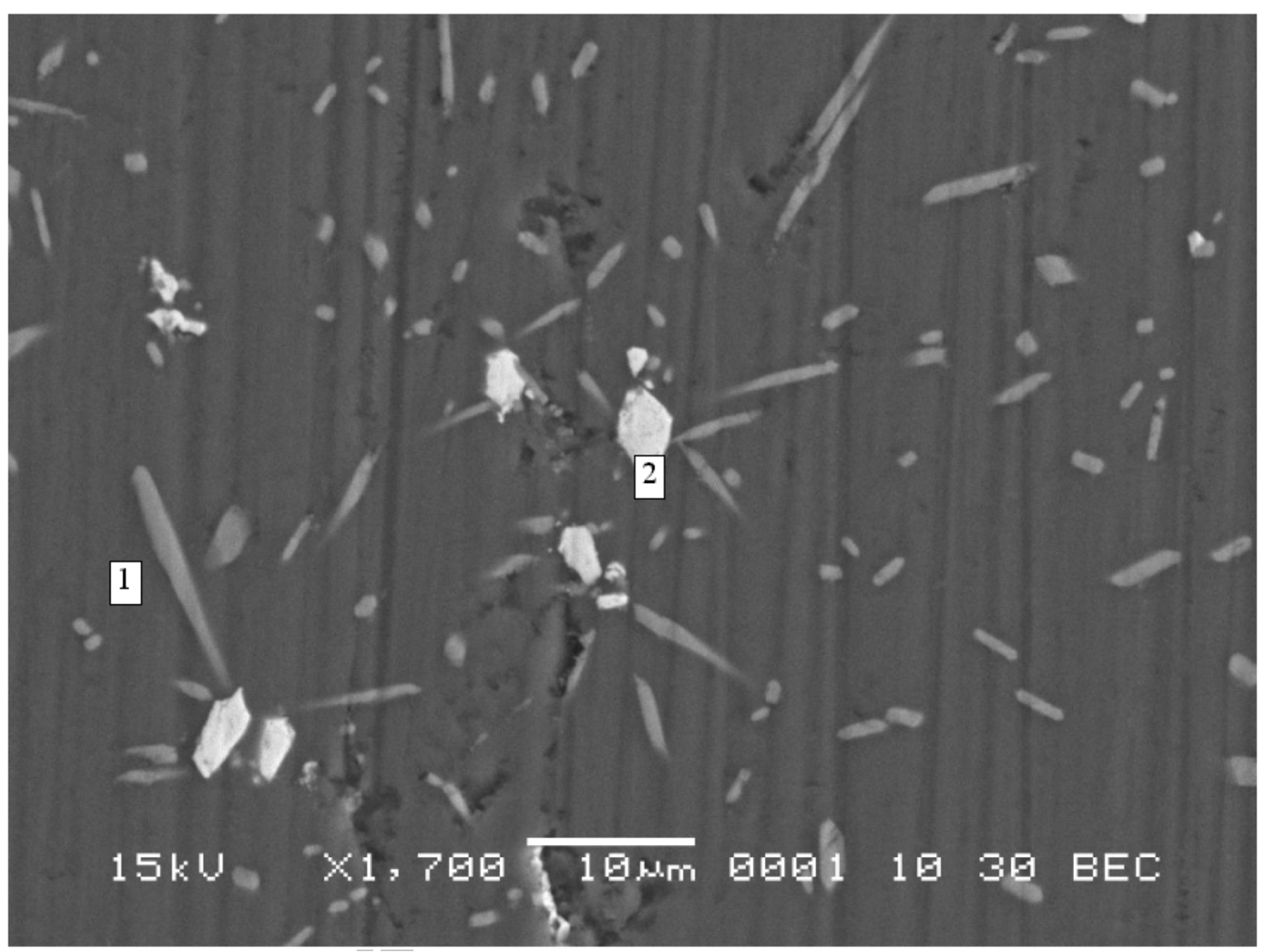

Figure 3.44. Scanning Electron Micrograph of HLP-72 
Table 3.10. Semiquantitative Composition Estimate of Phases in HLP-72 by EDS (in mass \% of oxides)

\begin{tabular}{||c|l|c|c|c|c|c|c||}
\hline \hline$\#^{(\mathbf{a})}$ & Phase & $\mathbf{N a}_{2} \mathbf{O}$ & $\mathbf{M g O}$ & $\mathbf{A l}_{\mathbf{2}} \mathbf{O}_{\mathbf{3}}$ & $\mathbf{S i O}_{2}$ & $\mathbf{Z r O}_{2}$ & $\mathbf{T i O}_{\mathbf{2}}$ \\
\hline 1 & Rutile + glass & 2.9 & 1.8 & 4.1 & 9.4 & 8.2 & 73.5 \\
\hline 2 & Baddeleyite & 0 & 0 & 0 & 0 & 100 & 0 \\
\hline
\end{tabular}

\subsubsection{HLP-73}

Like HLP-53, a second phase appeared to segregate on all surfaces of the melt during the heat treatment of HLP-73 (for example, see Figure 3.45). Optical microscopy analyses of the segregated phase (given in Figure 3.46 and Figure 3.47) showed densely packed angular crystals on the surface with a few clusters of them in the bulk. X-ray diffraction analyses identified only nepheline in both the surface and the bulk (see Figure 3.48). These data suggest massive surface crystallization of nepheline in HLP-73 as during heat treatment as was seen in HLP-53. The inhomogeneity of this sample precluded the testing of heat-treated samples by VHT, but was ground and included in PCT analyses. The content of nepheline measured in HLP-73 glass with XRD was roughly 10 mass\%.

Figure 3.49 shows a BSE micrograph of a portion of the HLP-73 sample along with EDS element maps for $\mathrm{Al}, \mathrm{Fe}, \mathrm{Mg}, \mathrm{Si}$, and $\mathrm{Na}$. There appear to be thin lines of iron rich areas surrounded on both sides by bands of aluminum and silicon rich (and magnesium poor) material—presumably the nepheline identified with XRD. Sodium appears to be dispersed uniformly through the matrix and nepheline, dropping in concentration only in the iron rich lines. A semiquantitative composition analyses of the nepheline and glass phase are given in Table 3.11.

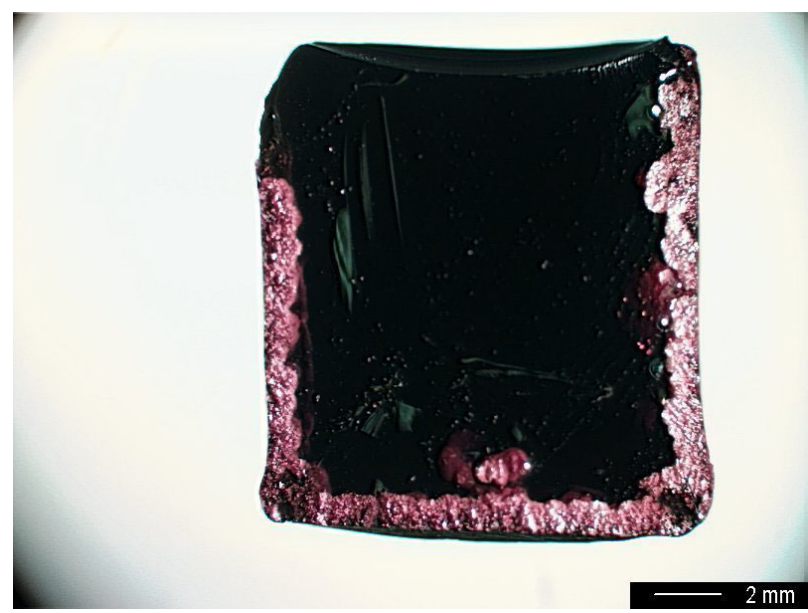

Figure 3.45. Photograph of HLP-73 Glass Monolith after Heat Treatment

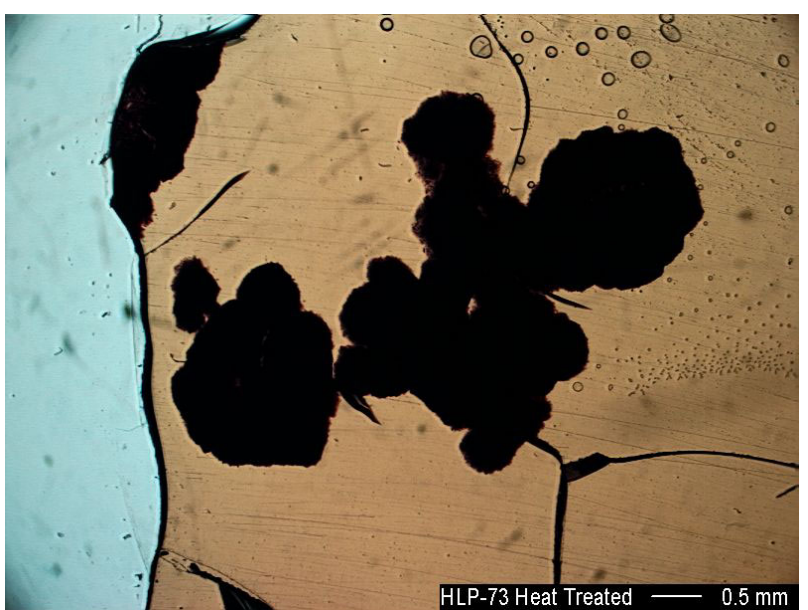

Figure 3.46. OM of HLP-73 Bulk (70 $\times)$ 


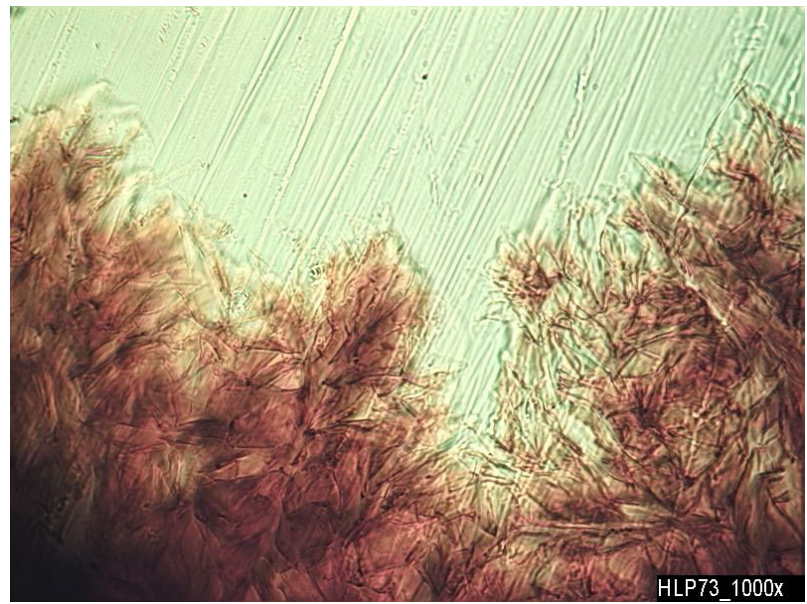

Figure 3.47. OM of HLP-73 (1000 $\times)$

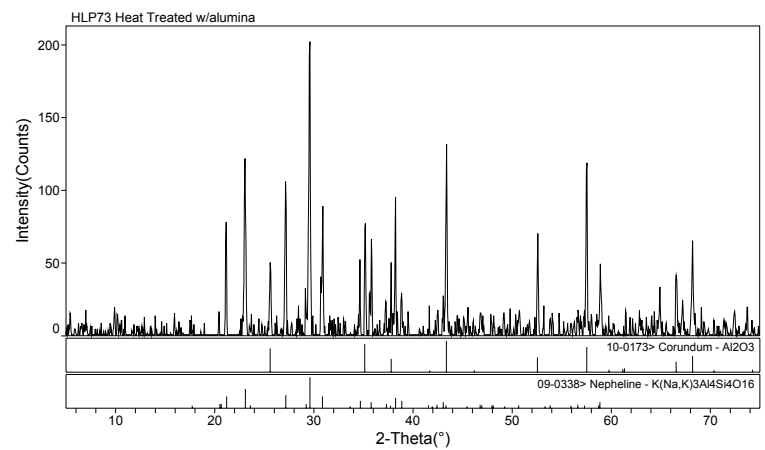

Figure 3.48. XRD Pattern of HLP-73 (with $\mathrm{Al}_{2} \mathrm{O}_{3}$ added as a standard)

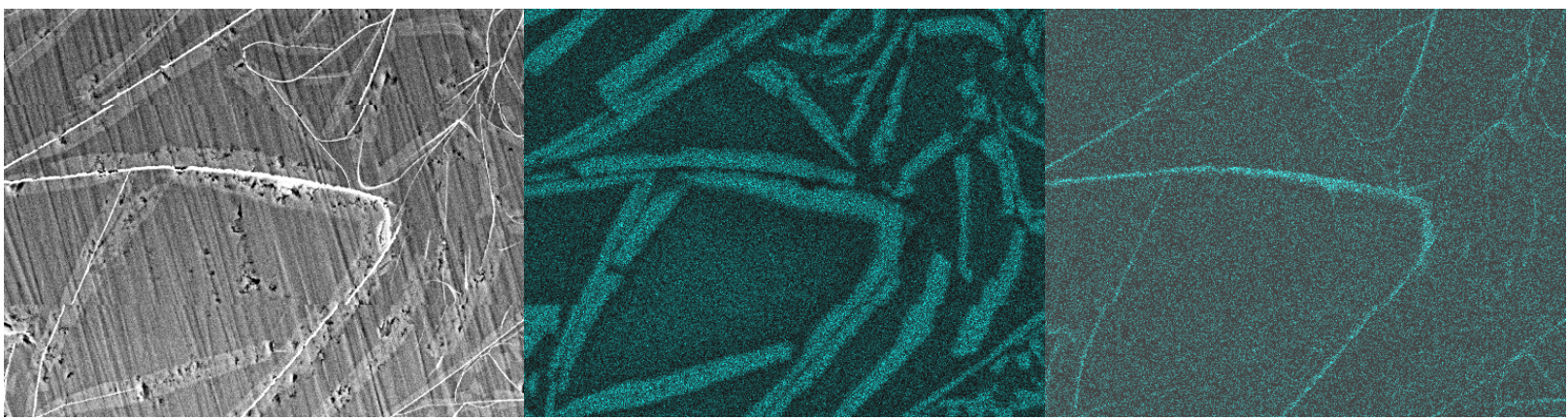

BEC Image

Al map

Fe map

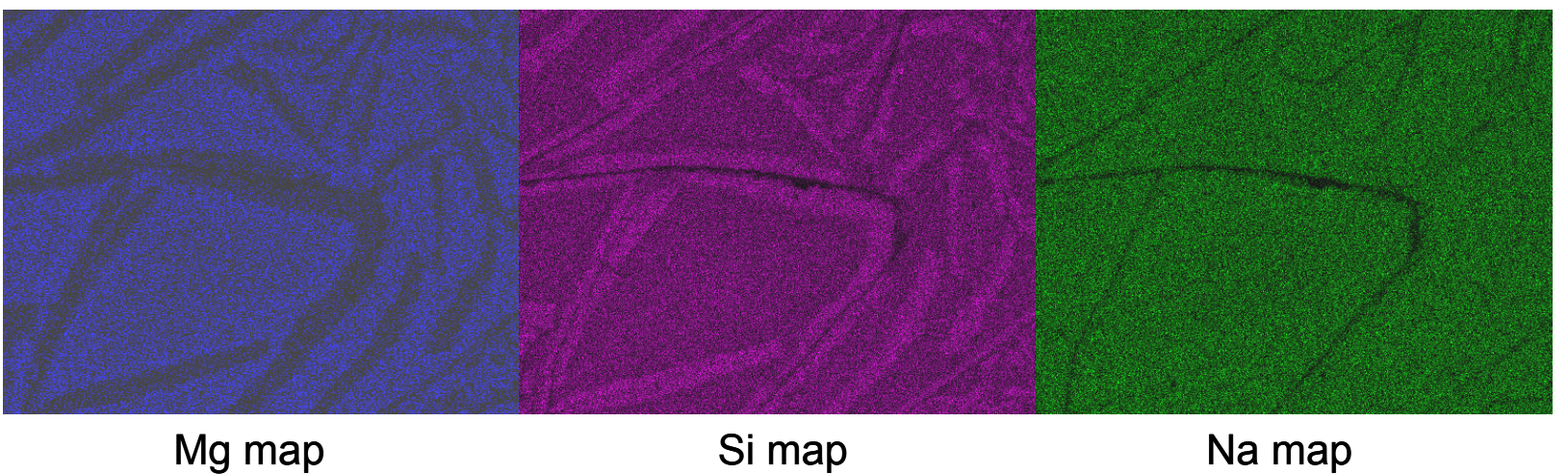

Figure 3.49. SEM Micrograph of HLP-73 Glass with BSE and Al, Fe, Mg, Si, and Na EDS Images

\subsubsection{HLP-74}

Like HLP-53 and -73, a second phase appeared to segregate on all surfaces of the melt during the heat treatment of HLP-74, (for example, see Figure 3.50). Optical microscopy analyses of the bulk or center phase (given in Figure 3.51 and Figure 3.52) shows two distinct crystal morphologies - a small dark material with low aspect ratio and a transparent dendritic phase growing from the dark phase. X-ray diffraction analyses identified only fluorellestadite at roughly 2 mass $\%$ in the sample (see Figure 3.53 ). It 
is still unclear what phase exists on the sample surface and which phase seen by OM is the fluorellestadite identified by XRD. The inhomogeneity of this sample precluded the testing of heat-treated samples by VHT, but the sample was ground and subjected to PCT.

Table 3.11. Semiquantitative Composition Estimate of Phases in HLP-73 by EDS (in mass\% of oxides)

\begin{tabular}{||l|c|c|c|c|c|c||}
\hline \hline Phase & $\mathbf{N a}_{2} \mathbf{O}$ & $\mathbf{M g O}$ & $\mathbf{A l}_{2} \mathbf{O}_{3}$ & $\mathbf{S i O}_{2}$ & $\mathbf{K}_{\mathbf{2}} \mathbf{O}$ & $\mathbf{F e}_{\mathbf{2}} \mathbf{O}_{\mathbf{3}}$ \\
\hline Glass matrix & 16.75 & 5.36 & 15.61 & 43.17 & 5.23 & 13.52 \\
\hline Glass matrix & 13.05 & 7.1 & 12.55 & 47.51 & 5.82 & 13.1 \\
\hline Nepheline & 13.73 & 2.04 & 24.06 & 46.88 & 4.54 & 8.75 \\
\hline \hline
\end{tabular}

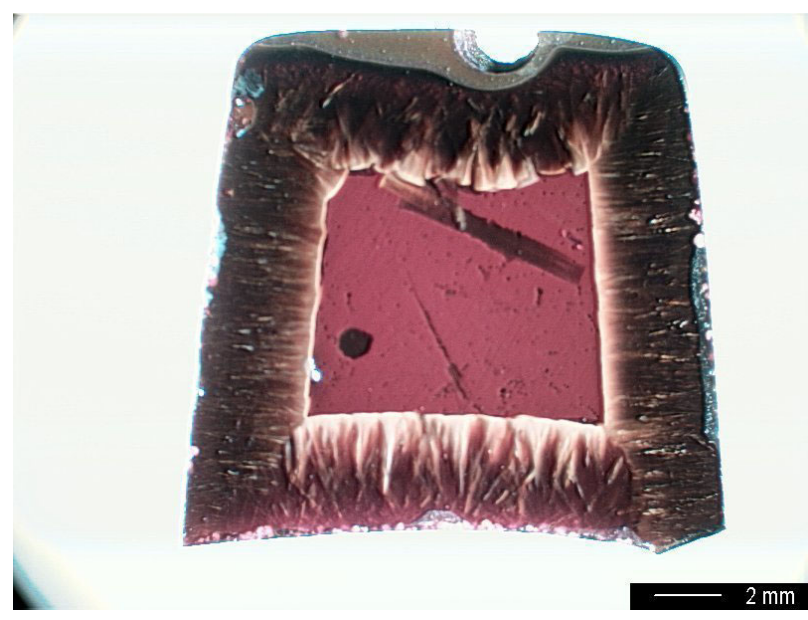

Figure 3.50. Photograph of HLP-74 Glass Monolith after Heat Treatment

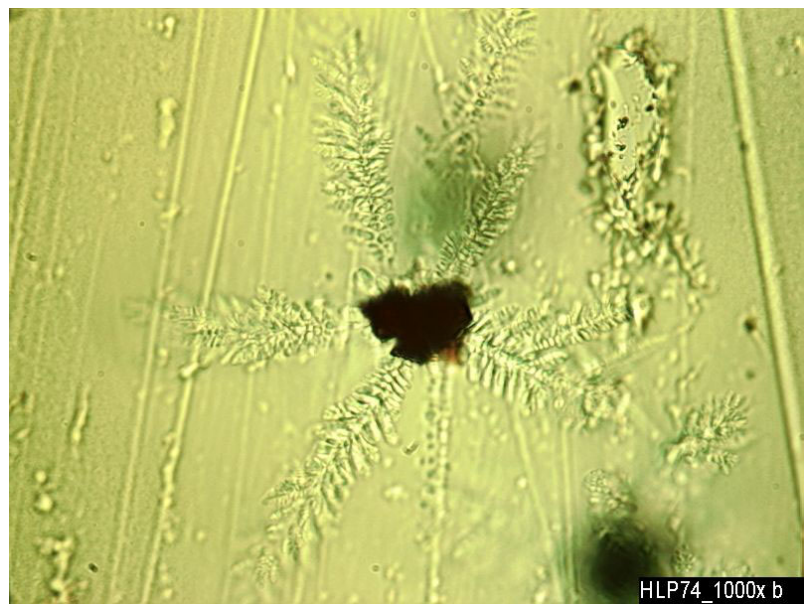

Figure 3.52. OM of HLP-74 (1000 $\times)$

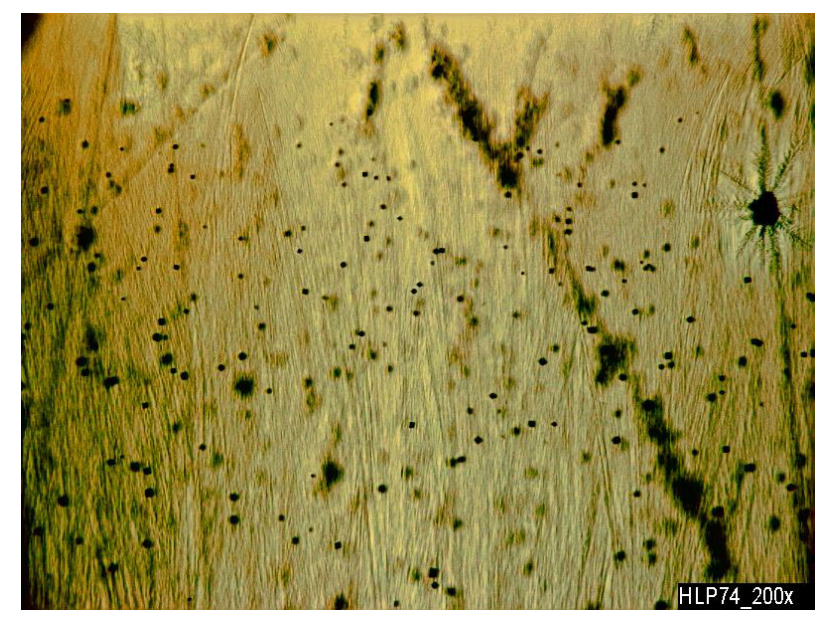

Figure 3.51. OM of HLP-74 Center $(70 \times)$

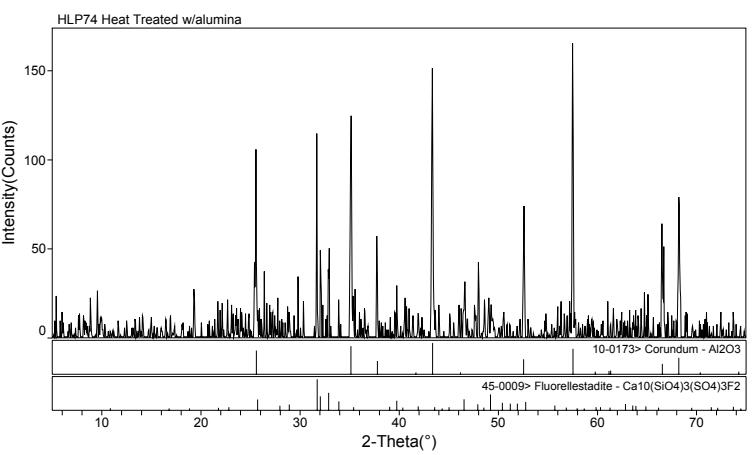

Figure 3.53. XRD Pattern of HLP-74 (with $\mathrm{Al}_{2} \mathrm{O}_{3}$ added as a standard) 


\subsection{Density of HLP Glasses}

The measured glass densities $(\rho)$ are listed in Table 3.12 along with standard deviations. The densities of all matrix glasses range from $2.45 \mathrm{~g} / \mathrm{cm}^{3}$ to $2.95 \mathrm{~g} / \mathrm{cm}^{3}$. (a) However, on average, the crystallized glasses have higher densities, ranging from $2.61 \mathrm{~g} / \mathrm{cm}^{3}$ to $2.95 \mathrm{~g} / \mathrm{cm}^{3}$ as compared to the homogeneous glasses, which range in density from $2.45 \mathrm{~g} / \mathrm{cm}^{3}$ to $2.79 \mathrm{~g} / \mathrm{cm}^{3}$.

Table 3.12. Density of HLP Glasses (heat treated and powdered unless otherwise noted)

\begin{tabular}{|c|c|c|c|c|c|c|c|c|c|c|c|}
\hline $\operatorname{lass}^{\mathrm{a}}$ & $\rho\left(\mathrm{g} / \mathrm{cm}^{3}\right)$ & $\left.\mathrm{g} / \mathrm{cm}^{3}\right)$ & lass ${ }^{\mathrm{a}}$ & $\overline{\left(\mathrm{g} / \mathrm{cm}^{3}\right)}$ & $\overline{\sigma \sigma\left(\mathrm{g} / \mathrm{cm}^{3}\right)}$ & " Glass $^{\mathrm{a}}$ & 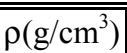 & $\overline{\left(\mathrm{g} / \mathrm{cm}^{3}\right)}$ & & $\rho(g / c$ & \\
\hline HLP-01 & 2.6493 & 0.0020 & HLP-22 & 2.5900 & 0.0018 & HLP-42 & 20 & 0.0012 & \begin{tabular}{|l|} 
HLP-60G \\
\end{tabular} & 2.9320 & 0.0002 \\
\hline LP-02 & 7022 & 0020 & LP-23 & 3 & & LLP-43 & & & \begin{tabular}{|l} 
HLP-61G \\
\end{tabular} & 6494 & 0008 \\
\hline $\mathrm{P}-03$ & $\overline{6364}$ & D011 & P-24 & 37 & 0006 & $\mathrm{~L}$ & 391 & 018 & $\overline{\mathrm{G}}$ & .6795 & .0006 \\
\hline LP-04 & 6828 & & 25 & & & 15 & & & 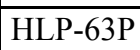 & 308 & 008 \\
\hline HLP-05 & 6756 & & 26 & & & $P$ & & & $\mathrm{P}$ & 7793 & 009 \\
\hline HLP-06 & 5609 & 0.0025 & HLP-27 & 5048 & 0.0008 & HLP-47Q & 5233 & 15 & HLP-63G & 2.7393 & .0007 \\
\hline HLP-07 & 6027 & 0.0015 & ILP-27QP & 4869 & 0.0 & HLP-48 & 2.6872 & & HLP-64G & .6331 & .0005 \\
\hline HLP-08 & 6915 & 0.0030 & HLP-28 & 2.5165 & 0.0021 & ILP-48HG & 2.6556 & 07 & HLP & 2.6494 & .0007 \\
\hline P-09 & 6014 & $\overline{0.0}$ & 29 & 6691 & 28 & $\mathrm{P}$ & 2.6515 & 15 & $\mathrm{HL}$ & 34 & .0002 \\
\hline HLP-10 & 6229 & 0009 & P-30 & 0 & 0.0006 & HLP-4 & 2.6428 & 09 & HLP-66G & .5818 & .0003 \\
\hline HLP-11 & 5630 & 5 & 1 & 6244 & 1 & HLP-49 & 2.7712 & 06 & \begin{tabular}{|l|} 
HLP-67G \\
\end{tabular} & 2.7122 & .0006 \\
\hline HLP-12 & 6819 & 0 . & P-32 & 2.6249 & 0.0 & ILP-51Q & 2.7218 & 0.0006 & HLP-68G & 2.7948 & 0.0006 \\
\hline HLP-13 & 6074 & 0 . & P-33 & 6351 & $\overline{0.0}$ & HLP-5 & 2.6 & & HLP-69G & 6048 & 0.0009 \\
\hline HLP-14 & 5880 & 30 & CP-34 & 6729 & 0 & PP- & 2.6539 & 107 & \begin{tabular}{|l|} 
HLP-70G \\
\end{tabular} & 2.6384 & .0005 \\
\hline HLP-15 & 5275 & 0032 & -35 & 37 & 0060 & HLP_- & 58 & 0.0007 & HLP-71G & 2.7159 & .0021 \\
\hline HLP-16 & 5919 & 0.0034 & -36 & 7437 & 0.0 & LP-54Q & 2.4897 & 0.0030 & HLP-72G & 2.6629 & 0.0007 \\
\hline HLP-17 & 2.6574 & 0.0039 & HLP-37 & 2.7056 & 0.0 & HLP-55Q & 2.4545 & 0.0025 & HLP-73G & 2.6123 & 0.0007 \\
\hline HLP-18 & 5997 & 0.0027 & HLP-38 & .7828 & 0.0020 & LP-56 & 2.6804 & 0.0015 & HLP-74G & 2.6800 & 0.0008 \\
\hline HLP-19 & 2.6692 & 0.0012 & HLP-39 & 2.7304 & 0.0018 & HLP-56G & 2.6810 & 0.0008 & \begin{tabular}{|l|} 
HLP-75G \\
\end{tabular} & 2.6806 & 0.0004 \\
\hline $\mathrm{P}-20$ & 2.6258 & & 40 & & & 3G & 2.6217 & & HLI & 2.5537 & 0.0006 \\
\hline ILP-21 & 2.6148 & 0.0009 & HLP-41 & 2.8140 & 0.0015 & HLP-59G & 2.6452 & 006 & HLP-77G & .5613 & $\overline{0.000}$ \\
\hline
\end{tabular}

\subsection{Redox}

Glasses HLP-44 and -45 have the same target composition as the baseline glass (HLP-01). However, they were melted and heat treated under reducing conditions to progressively increase the redox (ratio of divalent to total iron- $\mathrm{Fe}(\mathrm{II}) / \mathrm{Fe})$ as discussed in Section 2.2. The measured redox of these glasses is compared to that of HLP-26 in Table 3.13. The redox of these heat-treated glasses ranges from $1 \%$ to nearly $59 \%$, which is expected to bracket the redox of glasses to be produced in the WTP.

Figure 3.54 shows the relationship between the natural logarithm of oxygen partial pressure above the glass melt and the measured redox of the quenched glasses. Our measurements show that $\ln [\mathrm{Fe}(\mathrm{II}) / \mathrm{Fe}(\mathrm{III})]$ is related to $\ln \left[\mathrm{p}_{\mathrm{O} 2}\right]$ by a straight line with slope of 0.253 , which closely matches the expected slope of 0.25 . This relationship allows the reader the ability to interpolate the effects of $\mathrm{p}_{\mathrm{O} 2}$ on

(a) The units of $\mathrm{g} / \mathrm{cm}^{3}$ are used in this report to allow direct comparison with existing data on glass density. To convert to the SI units of $\mathrm{kg} / \mathrm{m}^{3}$, the reader can multiply reported values by 1000 . 
corrosion characteristics of the glass. However, as shown in Section 4.8, the effects of iron redox on VHT and PCT responses are still uncertain.

Table 3.13. Melting Oxygen Partial Pressure and Measured Redox of HLP-26, -44, and -45

\begin{tabular}{|l|c|l|l|l||}
\hline Sample $^{(\mathbf{a})}$ & $-\ln \left(\mathbf{p}_{\mathbf{O} 2}\right)$ & $\mathbf{F e}(\mathbf{I I}) / \mathbf{F e}$ & $\mathbf{F e}(\mathbf{I I}) / \mathbf{F e}$ & Ave. \\
\hline HLP-26Q & 1.56 & 0.0115 & 0.0119 & 0.0117 \\
\hline HLP-26H & & 0.0099 & 0.0102 & 0.0101 \\
\hline HLP-44Q & 13.8 & 0.195 & 0.1856 & 0.1903 \\
\hline HLP-44H & & 0.2029 & 0.2066 & 0.2048 \\
\hline HLP-45Q & 20.7 & 0.6199 & 0.5924 & 0.6062 \\
\hline HLP-45H & & 0.581 & 0.59 & 0.5855 \\
\hline SRM-278 & & 0.711 & 0.686 & 0.6985 \\
\hline b & & &
\end{tabular}

(a) $\mathrm{Q}=$ quenched and $\mathrm{H}=$ heat treated

(b) Obsidian Rock with certified $\mathrm{Fe}(\mathrm{II}) / \mathrm{Fe}=0.74$ \pm 0.01 (a) $^{(a)}$

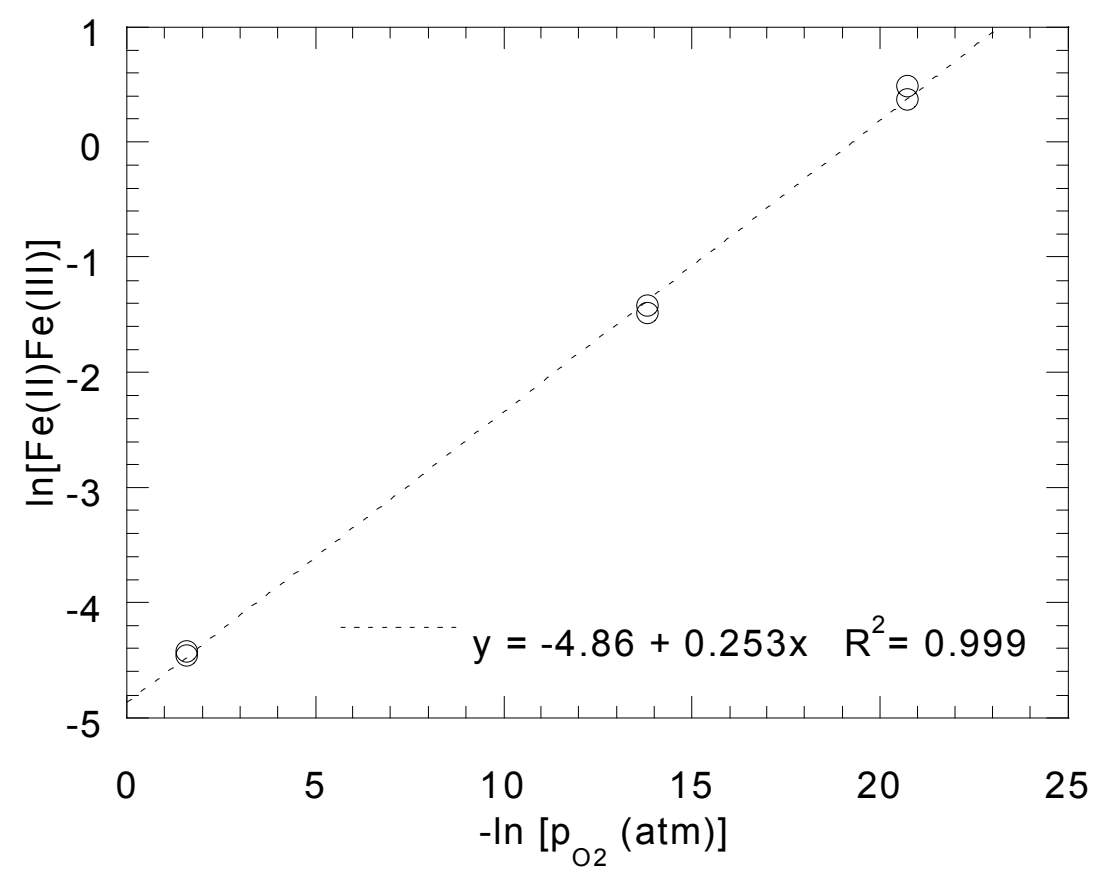

Figure 3.54. Effect of $p_{02}$ on Measured Glass Redox

\subsection{Glass Compositions}

The targeted and measured glass compositions are shown in Table A.1. Comparison of the targeted and measured compositions indicates that there were few significant differences. That is, the differences

(a) Standard Reference Material \#278-Obsidian Rock, National Bureau of Standards, Washington, D. C., 1992. 
between the target and measured concentrations for most of the major components (i.e., $\mathrm{SiO}_{2}, \mathrm{Al}_{2} \mathrm{O}_{3}$, $\mathrm{B}_{2} \mathrm{O}_{3}$, and $\mathrm{Na}_{2} \mathrm{O}$ ) were less than $5 \%$. For those glasses that had component(s) with percent differences larger than 5\%, analytical errors (ICP drift or incomplete dissolution) and/or small batching errors (possibly due to waters of hydration) may have occurred. It is believed that those errors were not great enough to invalidate results. Furthermore, the initial review of these data suggested that no gross laboratory-to-laboratory variation in glass preparation appeared to have occurred.

It should be noted that the measured values for $\mathrm{Fe}_{2} \mathrm{O}_{3}$ and $\mathrm{Cr}_{2} \mathrm{O}_{3}$ concentrations were higher than the targeted values for all the glasses. Since a significant amount of glass was needed for testing (i.e., VHT, PCT-A, and PCT-B), only ground PCT fines (-200 mesh) were available for composition analyses. Therefore, contamination from the stainless steel grinding vessel is suspected to be the primary cause of the elevated $\mathrm{Fe}_{2} \mathrm{O}_{3}$ and $\mathrm{Cr}_{2} \mathrm{O}_{3}$ values. This contamination has the effect of relatively decreasing the other measured concentrations for the glass.

The sum of the oxides was greater than $95 \%{ }^{(a)}$ for all but one glass (i.e., HLP-46). For another four glasses (HLP-09, HLP-11, HLP-26 and HLP-32), the sum of the oxides was approximately 95\%. The resulting lower-than-expected sums of oxides may be either the result of an analytical bias or normal random variation in the measured concentrations.

In almost all cases, the measured $\mathrm{Na}_{2} \mathrm{O}$ values were lower than targeted. The maximum deviation was observed in HLP-11 where the measured $\mathrm{Na}_{2} \mathrm{O}$ value was $14 \%$ lower than targeted. There is currently insufficient data to resolve the source(s) of these differences; further examination is necessary.

\subsubsection{Compositions of Replicate Glasses}

The chemical compositions of the four repeated or "baseline" glasses (HLP-01, HLP-25, HLP-26 and HLP-43) were measured and are provided in Table 3.14. Analysis of the variance or standard deviation in the measured compositional values provides insight into reproducibility of the batching and analytical measurements. Comparisons among the mean-measured compositional values to the targeted values provide an indication of how well the targeted composition was reproduced. Examination of the differences among component measurements and targeted concentrations (on a glass-by-glass basis) can provide some insight into the possibility of either gross batching or measurement errors.

The relative differences for the major oxide components presented in Table 3.14 indicate that reasonably good agreement between batching and chemical analysis was achieved. For the majority of the oxide components, the mean concentration was consistent with the targeted value (i.e., the relative difference was $5.33 \%$ or less). This was not the case with $\mathrm{Fe}_{2} \mathrm{O}_{3}$ and $\mathrm{Cr}_{2} \mathrm{O}_{3}$ where contamination from the grinding vessel was indicated, and the measured values were significantly higher than targeted. This was also not the case for $\mathrm{Na}_{2} \mathrm{O}$ where the relative difference between the mean measured and targeted concentrations was approximately $8 \%$. Further examination of this and the compositional data for the other glasses, however, indicates that the $\mathrm{Na}_{2} \mathrm{O}$ measurement values may be biased low since in almost all cases, measured $\mathrm{Na}_{2} \mathrm{O}$ values were lower than targeted. The measured $\mathrm{SiO}_{2}$ concentrations were also

(a) A sum of oxides greater than $95 \%$ is a heuristic metric used to assure that the measured glass compositions are valid. 
consistently lower than the target values, although the difference (in means) was only approximately $2.6 \%$. A more detailed analysis of variance is planned for these "replicate" glasses.

An examination of the relative standard deviations for the major constituents of the four glasses represented in Table 3.14 indicates that there was good precision in the measured glass concentrations relative to the results from the LRM round-robin study (Ebert and Wolf 1999). That is, despite the fact that these batches were fabricated in separate batches in different laboratories, the relative standard deviations in the measured glass concentrations for these four glasses are generally lower than those from the LRM study (Ebert and Wolf 1999). Considering the likely errors in the concentration measurements, it would be difficult to distinguish among these glasses based upon their measured compositions.

Table 3.14. Target Compositions (in mass\% of oxides) and Measured Compositions (in mass\% of oxides) for the Replicate $\mathrm{HLP}$ "Baseline" Glasses $\left(\mathrm{Li}_{2} \mathrm{O}, \mathrm{Cl}, \mathrm{SO}_{3}, \mathrm{P}_{2} \mathrm{O}_{5}, \mathrm{~F}, \mathrm{ReO}_{2}\right.$, and $\mathrm{MoO}_{3}$, not included here, can be found in Appendix A)

\begin{tabular}{|c|c|c|c|c|c|c|c|c|c|c|c|c|c|c|}
\hline \begin{tabular}{|l|} 
Glass ID \\
\end{tabular} & Description & $\mathrm{SiO}_{2}$ & $\mid \mathbf{A l}_{2} \mathbf{O}_{3}$ & $\overline{\mathrm{B}_{2} \mathrm{O}_{3}}$ & $\overline{\mathrm{Fe}_{2} \mathrm{O}_{3}}$ & $\mathrm{TiO}_{2}$ & $\mathrm{ZnO}$ & $\overline{\mathrm{ZrO}_{2}}$ & MgO & $\mathrm{Na}_{2} \mathrm{O}$ & $\mathrm{K}_{2} \mathrm{O}$ & $\mathrm{CaO}$ & $\mathrm{Cr}_{2} \mathrm{O}_{3}$ & $\mathbf{L a}_{2} \mathbf{O}_{3}$ \\
\hline HLP-01 & Measured & 48.8 & 7.04 & 8.92 & 6.52 & 3.00 & 1.46 & 1.54 & 1.41 & 18.4 & 0.40 & 0.01 & 0.25 & 0.02 \\
\hline HLP-25 & Measured & 47.2 & 6.76 & 10.1 & 6.27 & 2.66 & 1.49 & 1.48 & 1.54 & 18.5 & 0.41 & 0.01 & 0.21 & 0.02 \\
\hline HLP-26 & Measured & 46.8 & 6.68 & 9.43 & 5.97 & 2.86 & 1.40 & 1.50 & 1.45 & 18.2 & 0.43 & $\mathrm{BD}$ & 0.21 & $\mathrm{BD}$ \\
\hline HLP-43 & Measured & 48.4 & 6.69 & 9.85 & 6.23 & 2.86 & 1.40 & 1.50 & 1.33 & 18.5 & 0.47 & 0.01 & 0.23 & $\mathrm{BD}$ \\
\hline Mean & Measured (M) & 47.8 & 6.79 & 9.58 & 6.25 & 2.84 & 1.44 & 1.50 & 1.43 & 18.4 & 0.43 & & 0.22 & \\
\hline Target & Baseline (C) & 49.07 & 7.00 & 10.00 & 5.50 & 3.00 & 1.50 & 1.50 & 1.50 & 20.00 & 0.41 & 0.01 & 0.08 & 0.00 \\
\hline Diff & $\Delta=\mathrm{C}-\mathrm{M}$ & 1.27 & 0.21 & 0.42 & -0.75 & 0.16 & 0.06 & 0 & 0.07 & 1.6 & -0.02 & 0.01 & -0.14 & \\
\hline Diff (\%) & $100 \%(\Delta / C)$ & 2.59 & 3.00 & 4.20 & -13.64 & 5.33 & 4.00 & 0 & 4.67 & 8.00 & -4.88 & & -175 & \\
\hline Std Dev & Measured & 0.82 & 0.15 & 0.45 & 0.20 & 0.12 & 0.04 & 0.02 & 0.08 & 0.12 & 0.03 & & 0.02 & \\
\hline \begin{tabular}{|c|} 
Rel Std \\
Dev (\%)
\end{tabular} & $\begin{array}{c}\text { Mean } \\
\text { Measured }\end{array}$ & 1.7 & 2.2 & 4.7 & 3.2 & 4.2 & 2.8 & 1.3 & 5.3 & 0.65 & 6.3 & & 7.7 & \\
\hline $\begin{array}{c}\text { Rel Std } \\
\text { Dev (\%) }\end{array}$ & $\begin{array}{c}\text { LRM } \\
\text { (Ebert and } \\
\text { Wolf 1999) }\end{array}$ & 2.62 & 3.75 & 4.37 & 13.48 & 13.00 & $\mathrm{n} / \mathrm{a}$ & 6.99 & 9.00 & 6.07 & 33.04 & 15.93 & 11.58 & \\
\hline & & & & & & & & & & & & & & \\
\hline
\end{tabular}

\subsection{Vapor Hydration Test}

The resistance of matrix glasses to corrosion in the VHT was measured over the temperature range from $90^{\circ} \mathrm{C}$ to $300^{\circ} \mathrm{C}$. Some key aspects of methods development are presented in Section 3.5.1.

Preliminary rates at $200^{\circ} \mathrm{C}$ are reported for most glasses in Section 3.5.2. The alteration products are reported for many VHT samples in Section 3.5.3, and the impacts of temperature on rate are discussed in Section 3.5.4 for selected glasses. The reproducibility of VHT response is discussed in Section 3.5.5.

\subsubsection{VHT Method Development}

The VHT was first performed by Friedman and Long (1976) to date obsidian samples and was first applied to waste-glass corrosion studies by Bates and colleagues (Bates et al. 1984; Abrajano et al. 1986; Abrajano et al. 1989; Ebert and Bates 1990; Ebert and Bates 1991). There is currently a handful of laboratories/researchers actively publishing VHT data on waste glasses (for examples: this study; Muller et al. 2001; Luo et al. 1997). These data seem to follow three basic sets of procedures for convenience; 
these basic procedures are labeled A, B, and C. Table 3.15 compares some of the features of these procedures.

Table 3.15. Comparison of Three Current Test Methods

\begin{tabular}{|c|c|c|c|}
\hline Procedure & 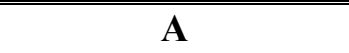 & (B & $\mathbf{C}$ \\
\hline Reference (example) & Luo et al. 1997 & Vienna et al. 2000 & Muller et al. 2001 \\
\hline Specimen shape & $\begin{array}{l}\text { Core drilled cylinder } \\
\text { cut to wafers }\end{array}$ & $\begin{array}{l}\text { Cut square faced } \\
\text { rectangle }\end{array}$ & $\begin{array}{l}\text { Cut rectangle with fracture } \\
\text { surface as one face }\end{array}$ \\
\hline $\begin{array}{l}\text { Typical specimen } \\
\text { dimensions }(\mathrm{cm})\end{array}$ & $\begin{aligned} \text { diameter } & =1.0 \\
\text { thickness } & =0.1\end{aligned}$ & $\begin{array}{c}\text { width }=1.0 \\
\text { length }=1.0 \\
\text { thickness }=0.15\end{array}$ & $\begin{array}{c}\text { width }=1.0 \\
\text { length }=1.0 \\
\text { thickness }=0.2\end{array}$ \\
\hline Bulk surface area $\left(\mathrm{cm}^{2}\right)$ & 1.89 & 2.60 & 2.80 \\
\hline Surface finish & $\begin{array}{l}\text { One side polished to } \\
600 \text { grit }\end{array}$ & $\begin{array}{l}\text { All sides polished to } \\
600 \text { grit }\end{array}$ & $\begin{array}{l}\text { All cut surfaces polished } \\
\text { to } 200 \text { grit or better }\end{array}$ \\
\hline $\begin{array}{l}\text { Mass of typical } \\
\text { specimen }(\mathrm{g})\end{array}$ & 0.20 & 0.39 & 0.52 \\
\hline $\begin{array}{l}\mathrm{m}_{\mathrm{a}}=\text { mass of glass per } \\
\text { unit surface area }\left(\mathrm{g} / \mathrm{m}^{2}\right)\end{array}$ & 1300 & 1950 & 2600 \\
\hline \multicolumn{4}{|c|}{ Volume of water added to $22-\mathrm{mL}$ vessel with two specimens at given temperature in $\mathrm{mL}\left(\mu \mathrm{L} / \mathrm{cm}^{2}\right)$} \\
\hline $\mathrm{T}=150^{\circ} \mathrm{C}$ & $0.15(40)$ & $0.15(29)$ & $0.19(34)$ \\
\hline $\mathrm{T}=200^{\circ} \mathrm{C}$ & $0.25(66)$ & $0.25(48)$ & $0.29(52)$ \\
\hline Evaluation method & $\begin{array}{l}\text { Thickness of } \\
\text { alteration layer }\end{array}$ & $\begin{array}{l}\text { Thickness of } \\
\text { remaining glass }\end{array}$ & $\begin{array}{c}\text { Thickness of alteration } \\
\text { layer }\end{array}$ \\
\hline
\end{tabular}

Jiricka et al. (2001) performed a thorough analysis of the influence of test parameters on the VHT response. The factors evaluated by Jiricka et al. (2001) included specimen preparation, surface finish, specimen-holder configuration, amount of water, evaluation method, and measurement precision. The factors that appeared to have the strongest influence on VHT response and reproducibility are the amount of water used and the evaluation method. These factors are discussed below.

\subsubsection{Volume of Water}

Selecting the appropriate water volume is of fundamental importance for establishing suitable and reproducible conditions in the VHT. If the relative humidity $(\mathrm{RH})$ inside the vessel is too low, little reaction will occur. Abrajano et al. (1989) observed a negligible reaction below $70 \% \mathrm{RH}$ at $202^{\circ} \mathrm{C}$. If the volume of water inside the vessel is too high, a reflux can occur, allowing the transport of soluble species from the surface of the specimen to the solution at the bottom of the vessel. Our aim was to obtain the volume of water needed to conduct the tests at temperatures up to $300^{\circ} \mathrm{C}$ at a maximum alteration rate with no reflux. Tests up to $175^{\circ} \mathrm{C}$ were conducted with the volume of water calculated from steam tables plus $0.05 \mathrm{~mL}$ of excess water per specimen in the vessel. The $\mathrm{pH}$ of the residual liquid in the vessel at the completion of the test was selected as a measure of reflux or dripping from the specimen. The $\mathrm{pH}$ could only be estimated by the use of $\mathrm{pH}$ paper because of the small volume of residual liquid. Since the tests up to $175^{\circ} \mathrm{C}$ did not show elevated $\mathrm{pH}$, or any other indication of possible reflux, tests with a different volume of water were conducted at $200^{\circ} \mathrm{C}, 250^{\circ} \mathrm{C}$, and $300^{\circ} \mathrm{C}$. The volume of water in excess of $100 \%$ relative humidity was calculated from steam tables for the vessel size and temperature. Vienna et al. 
(2000), Schulz et al. (2000), and Jiricka et al. (2001) reported results from these tests. Ultimately, it was determined that the highest amount of water that did not cause a $\mathrm{pH}$ rise on test termination (a sign of possible reflux) would be used. This volume of water differs from the $100 \% \mathrm{RH}$ in the range from $+0.05 \mathrm{~mL}$ for $\mathrm{T} \leq 150^{\circ} \mathrm{C}$ to $-0.54 \mathrm{~mL}$ for $300^{\circ} \mathrm{C}$. It was further shown that the volume of water used to conduct the test does not have a significant impact on the alteration rate itself, but affects the intercept and time that is needed to achieve the same reaction extent (Jiricka et al. 2001). Table 3.16 summarizes the amount of water used for most of the VHTs in this study.

Table 3.16. Water Volume Used in Most VHTs (performed in 22-mL vessels)

\begin{tabular}{|c|c|c|}
\hline \# of Samples & T $\left({ }^{\circ} \mathbf{C}\right)$ & Water Vol. $(\mathbf{m L})$ \\
\hline 1 & 90 & 0.069 \\
\hline 1 & 125 & 0.08 \\
\hline 1 & 150 & 0.10 \\
\hline 2 & 150 & 0.15 \\
\hline 1 & 175 & 0.14 \\
\hline 1 & 200 & 0.20 \\
\hline 2 & 200 & 0.25 \\
\hline 1 & 250 & 0.45 \\
\hline 1 & 275 & 0.62 \\
\hline 1 & 300 & 0.80 \\
\hline
\end{tabular}

\subsubsection{Specimen Evaluation Method}

To determine the amount of glass converted into alteration products, it is possible to measure the remaining glass thickness or the thickness of alteration layers. Jiricka et al. (2001) performed detailed analyses of the relative merits of each technique. The data demonstrated overwhelming evidence that measurement of the remaining glass thickness is more accurate and appropriate for samples with relatively small alteration thicknesses. In measuring the alteration layer, the layer density is lower than that of the glass and varies widely with glass composition and test condition; additionally, the alteration layers are non-uniform in thickness and density. In measuring the remaining glass thickness, the precision of measurement of a relatively small difference in thickness can have low measurement precision. The exact thickness at which the precision of remaining glass measurement becomes preferable depends on the specific equipment used to measure samples. For the analyses and equipment used in this study, measurement of the alteration layer would be preferable to measuring the remaining glass thickness only when the alteration-layer thickness was $\leq 10 \mu \mathrm{m}$. However, in this study, we have primarily focused on the measurement of alteration in the latter stages of the corrosion process (e.g., > $10 \mu \mathrm{m}$ of alteration); hence, all measurements were performed on the remaining glass thickness.

Further details of the VHT procedure used in this study were previously published (Vienna et al. 2000 and Schulz et al. 2000).

\subsubsection{VHT Response at $200^{\circ} \mathrm{C}$}

The amount of glass converted to alteration products, $m_{a}$, was calculated from measured VHT data according to Equation 1 (Section 2.8). An example of a typical $m_{a}-t$ relationship observed in VHT is 
shown in Figure 3.55. For this sample, no observable alteration occurred in less than 1 day. This was followed by a period in which there is high scatter in the $m_{a}-t$ data (between 1 and 2 days), an abrupt increase in $m_{a}$ (between 2 and 3 days), and finally, a nearly linear $m_{a}-t$ relationship ( $>3$ days). These phenomena are described in more detail in Section 4.1.

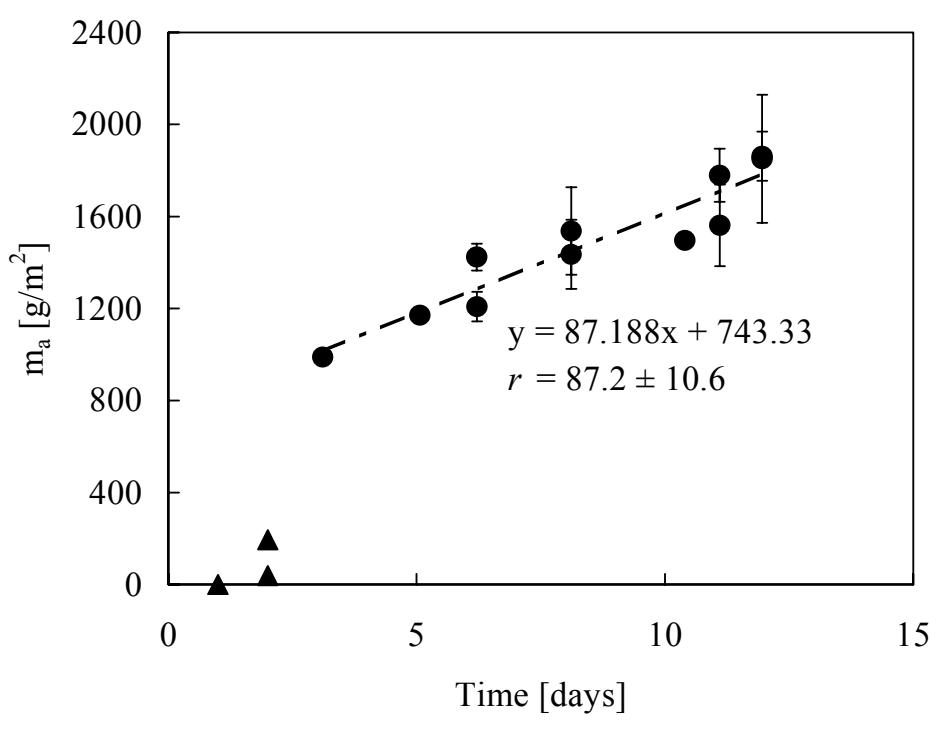

\section{Figure 3.55. Results from VHT on the HLP-46 Glass at $175^{\circ} \mathrm{C}$ (data represented by triangles were omitted from the linear fit)}

The $m_{a}-t$ relationship and experimental data for glasses tested in this study are reported in Appendix C. Three characteristics of the $m_{a}-t$ relationship are listed for each glass in Table C-2:

1. The slope of the linear portion of the $m_{a}-t$ relationship $\left(r=\mathrm{d} m_{a} / \mathrm{d} t\right)$, reported in $\mathrm{g} / \mathrm{m}^{2}$.

2. The time required to reach the abrupt increase in $m_{a}$ with $t$ or time to acceleration, which can be used to relate VHT data to long-term PCT or other static dissolution tests; this is discussed in Section 4.5.

3. The intercept formed by extrapolating the linear portion of the $m_{a}-t$ relationship to zero time, which gives an indication of the amount of glass dissolved before the linear alteration stage is reached.

The alteration rate, or the rate at which glass is converted to the alteration products, $r$, was determined from the linear portion of $m_{a}-t$ curves. Typically, the range from $400 \mathrm{~g} / \mathrm{m}^{2}$ to $1800 \mathrm{~g} / \mathrm{m}^{2}$ was considered for the calculation. In this range, the alteration layers are well developed and cover the entire specimen. Fully converted specimens were generally excluded from the evaluation since the exact time at which the reaction is complete is generally unknown. The alteration rates for all matrix glasses were measured at $200^{\circ} \mathrm{C}$. The VHT alteration rates measured at $200^{\circ} \mathrm{C}$, sorted according to glass ID, are given in Table 3.17. The rates range from 0.00 to 1708 with a mean value of $92.4 \mathrm{~g} / \mathrm{m}^{2} / \mathrm{d}$ and a median value of $7.6 \mathrm{~g} / \mathrm{m}^{2} / \mathrm{d}$.

A typical example of an alteration curve for LAW glasses is displayed in Figure 3.56. The alteration rate was determined using above-mentioned criteria, the rate is determined from several data points, and the alteration curve is roughly linear with a positive intercept. The alteration rate at $200^{\circ} \mathrm{C}$ could not be determined precisely for 38 of the 75 glasses tested. These glasses fall into five categories, marked with 
a, b, c, d, and e in Table 3.17 and Appendix C. For glasses in the first category, the experimental data are insufficient for the determination of the alteration rate at $200^{\circ} \mathrm{C}$. Six glasses are found in this category, marked with "a." Additional data may be used to improve the estimates of $r$ for glasses in this category. An example of such a glass is shown in Figure 3.57.

A sufficient reaction extent for the rate determination (alteration extent greater than $800 \mathrm{~g} / \mathrm{m}^{2}$ ) was not achieved for 19 glasses, marked with "b" in Table 3.17 and Appendix C. An example of such a glass is displayed in Figure 3.58. The water loss (as determined by vessel mass loss) is increasing with increasing reaction time. This water loss often results in a nearly constant reaction extent after roughly 200 days at $200^{\circ} \mathrm{C}$. Additional data at $200^{\circ} \mathrm{C}$ will do little to improve rate estimates for glasses in this category.

Table 3.17. VHT Alteration Rates at $200^{\circ} \mathrm{C}$

\begin{tabular}{|c|c|c|c|c|c|c|c|c|}
\hline $\mid$\begin{tabular}{|l} 
Glass ID \\
\end{tabular} & $r\left(\mathrm{~g} / \mathrm{m}^{2} / \mathrm{d}\right)$ & Note & Glass ID & 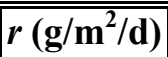 & Note & Glass ID & $\bar{~} r\left(\mathrm{~g} / \mathrm{m}^{2} / \mathrm{d}\right)$ & Note \\
\hline HLP-01 & 4.3 & $\mathrm{~b}$ & HLP-26 & 1.2 & $\mathrm{~b}$ & HLP-51 & 4.0 & $\mathrm{~b}$ \\
\hline HLP-02 & 264.7 & & HLP-27 & 67.4 & & HLP-52 & 1219.4 & \\
\hline HLP-03 & 0.9 & b & HLP-28 & 6.7 & & HLP-53Q & 552.6 & $\mathrm{e}$ \\
\hline HLP-04 & 53.0 & & HLP-29 & 56.6 & & HLP-54 & 21.4 & \\
\hline HLP-05 & 2.7 & $\mathrm{~b}, \mathrm{f}$ & HLP-30 & 10.0 & $\mathrm{f}$ & HLP-55 & 42.1 & \\
\hline HLP-06 & 2.1 & $\mathrm{a}, \mathrm{f}$ & HLP-31 & 100.5 & $\mathrm{c}$ & HLP-56 & 1.9 & $\mathrm{~b}$ \\
\hline HLP-07 & 13.8 & & HLP-32 & 0.2 & $\mathrm{~b}$ & HLP-58 & 2.2 & $\mathrm{~b}$ \\
\hline HLP-08 & 7.2 & & HLP-33 & 22.3 & & HLP-59 & 4.5 & $\mathrm{a}$ \\
\hline HLP-09 & 1.2 & $\mathrm{~b}$ & HLP-34 & 0.0 & $\mathrm{~b}$ & HLP-60 & 5.6 & $c, g$ \\
\hline HLP-10 & 11.7 & & HLP-35 & 13.0 & & HLP-61 & 10.0 & $\mathrm{f}$ \\
\hline HLP-11 & 6.0 & & HLP-36 & 13.8 & $\mathrm{~g}$ & HLP-62 & 1.7 & $\mathrm{c}$ \\
\hline HLP-12 & 13.6 & & HLP-37 & 2.0 & $\mathrm{~g}$ & HLP-63 & 1707.6 & e \\
\hline HLP-13 & 2.1 & & HLP-38 & 8.4 & $\mathrm{~g}$ & HLP-64 & 12.4 & $\mathrm{a}$ \\
\hline HLP-14 & 18.4 & & HLP-39 & 8.4 & $c, f$ & HLP-65 & 4.3 & \\
\hline HLP-15 & 1.4 & $\mathrm{~b}$ & HLP-40 & 1.5 & $\mathrm{~g}$ & HLP-66 & 1336.9 & $\mathrm{~d}$ \\
\hline HLP-16 & 7.6 & b & HLP-41 & 9.9 & $\mathrm{~g}$ & HLP-67 & 230.5 & \\
\hline HLP-17 & 2.4 & & HLP-42 & 0.0 & $\mathrm{c}, \mathrm{g}$ & HLP-68 & 5.7 & \\
\hline HLP-18 & 16.7 & & HLP-43 & 4.6 & $\mathrm{~b}$ & HLP-69 & 3.8 & \\
\hline HLP-19 & 0.0 & $\mathrm{~b}$ & HLP-44 & 4.9 & & HLP-70 & & $\mathrm{c}, \mathrm{g}$ \\
\hline HLP-20 & 1.5 & $\mathrm{~b}$ & HLP-45 & 5.2 & $\mathrm{c}$ & HLP-71 & & $\mathrm{c}, \mathrm{g}$ \\
\hline HLP-21 & 7.2 & & HLP-46 & 254.6 & & HLP-72 & 9.6 & $\mathrm{a}, \mathrm{g}$ \\
\hline HLP-22 & 0.3 & $\mathrm{~b}$ & HLP-47 & 60.7 & $\mathrm{c}$ & HLP-74 & 8.0 & $\mathrm{~g}$ \\
\hline HLP-23 & 19.9 & & HLP-47-S & 67.2 & $\mathrm{c}$ & HLP-75 & 7.9 & \\
\hline HLP-24 & 1.7 & $\mathrm{~b}$ & HLP-48 & 50.5 & & HLP-76 & 140.9 & $\mathrm{a}, \mathrm{c}$ \\
\hline HLP-25 & 4.2 & $\mathrm{~b}$ & HLP-49 & 2.4 & $\mathrm{~b}, \mathrm{~g}$ & HLP-77 & 176.4 & $\mathrm{a}, \mathrm{c}$ \\
\hline \multicolumn{9}{|c|}{$\begin{array}{l}\text { a Not enough data to accurately determine the alteration rate. } \\
\text { b Sufficient alteration was not achieved before significant water loss. } \\
\text { c Sample analyses difficulties. } \\
\text { d Rate based on single value. } \\
\text { e Rate based on two values. } \\
\text { f Outlying data point(s) were removed from fit. } \\
\text { g Grossly crystallized glass. }\end{array}$} \\
\hline
\end{tabular}


Ten glasses in Table 3.17 are marked with, "c." Difficulties arose in analyzing samples of these glasses because the original glasses cracked or crystallized. Finally, two glasses are marked with a "d" and one with an "e," indicating that the rate was determined from only one or two data points, respectively.

Data marked with a "f" indicate that outlying data were removed from the linear fit to determine rate, and data marked with a "g" indicate glasses that contained gross crystallinity after heat treatment as described in Section 3.1.

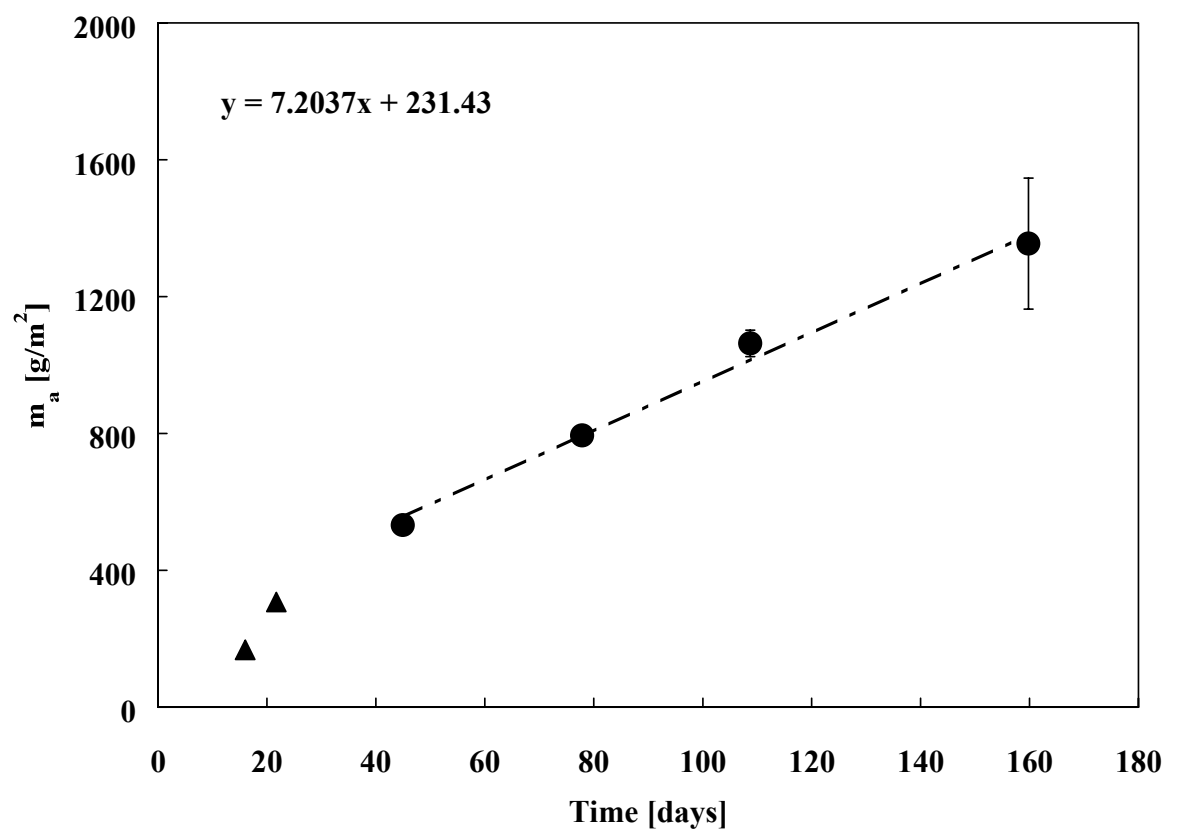

Figure 3.56. The $m_{a}$ as a Function of $t$ for HLP-08 at $200^{\circ} \mathrm{C}$ (data represented by triangles were omitted from the linear fit) 


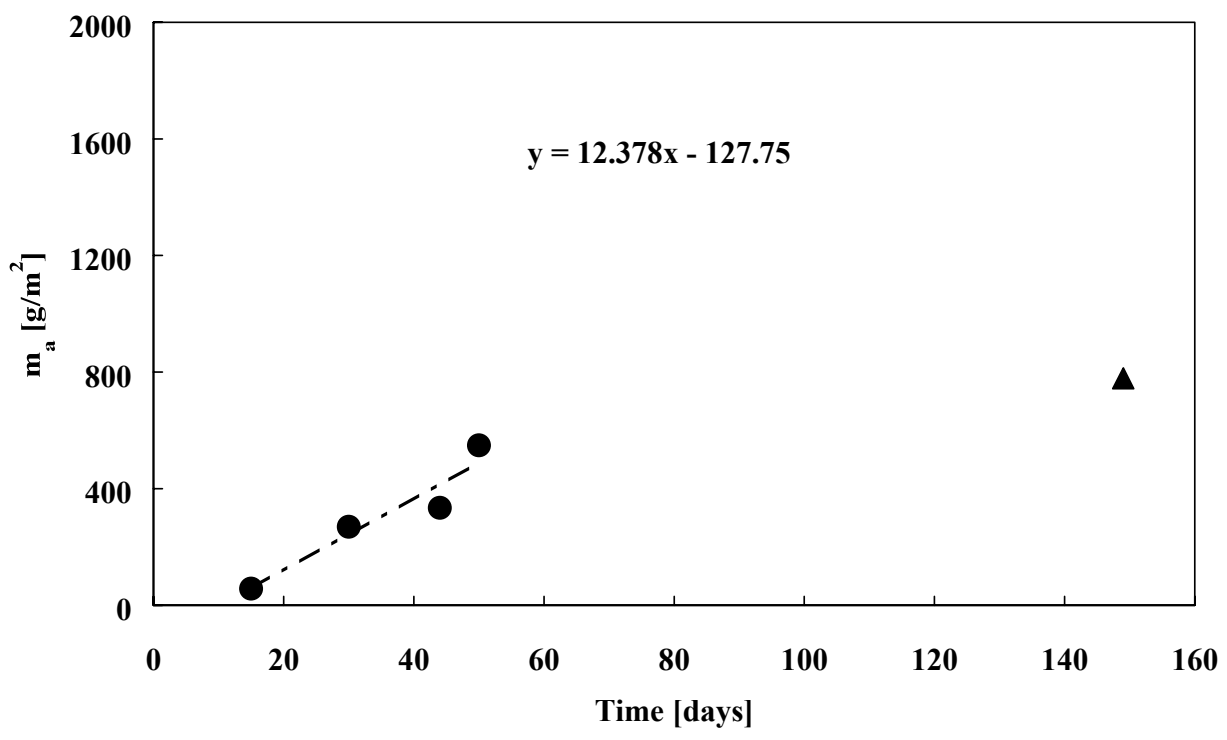

Figure 3.57. The $m_{a}$ as a Function of $t$ for HLP- 64 at $200^{\circ} \mathrm{C}$ (data represented by triangles were omitted from the linear fit)

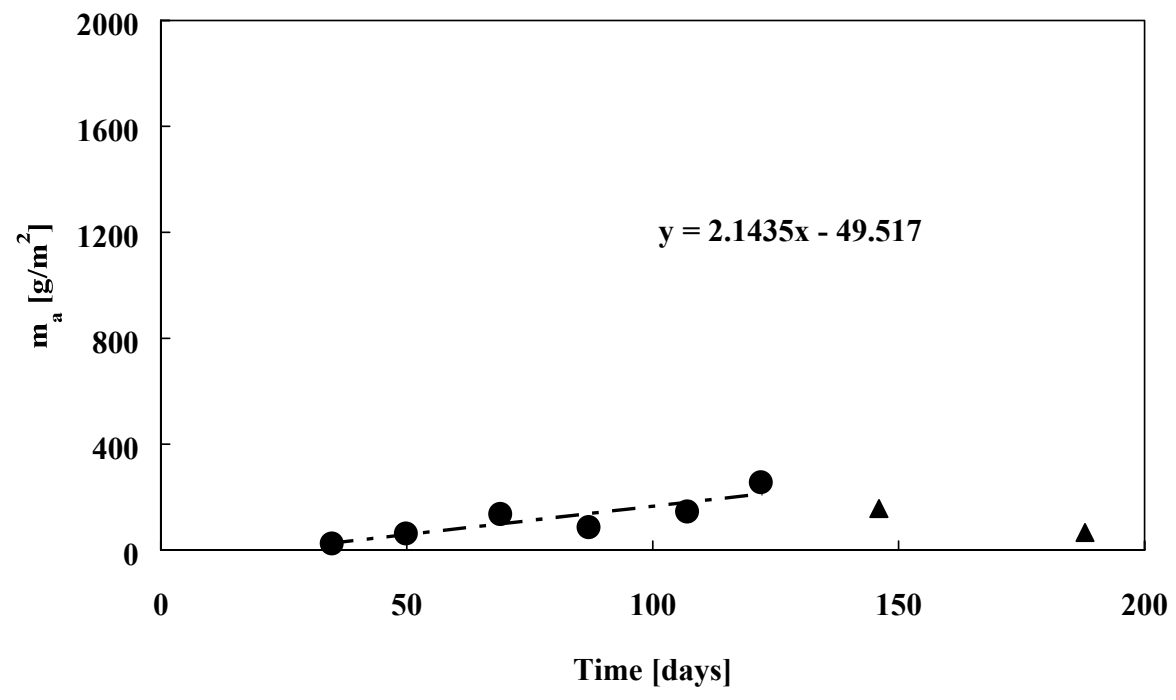

Figure 3.58. The $m_{a}$ as a Function of $t$ for HLP-56 at $200^{\circ} \mathrm{C}$ (data represented by triangles were omitted from the linear fit due to excessive water loss)

\subsubsection{Alteration Products}

The alteration products formed during VHT of selected glasses were characterized with XRD and SEM/EDS. X-ray diffraction was performed to identify the crystalline phases formed during corrosion, and SEM/EDS was performed to determine the chemical composition and microstructure of the alteration products - both crystalline and non-crystalline. 


\subsubsection{XRD Identification}

Appendix E gives a series of XRD scans grouped in categories of samples with similar alteration products. Table 3.18 lists the crystalline alteration products identified in VHT specimens, and Table 3.19 gives their measured concentrations by glass, test time, temperature, and analysis method. Most of the specimens tended to form analcime $\left(\mathrm{NaAlSi}_{2} \mathrm{O}_{6} \cdot \mathrm{H}_{2} \mathrm{O}\right)$, sodium titanium silicate $\left(\mathrm{NaTi}_{2} \mathrm{SiO}_{6}\right)$, and sodium aluminum silicate hydrate $\left(\mathrm{Na}_{6}\left[\mathrm{AlSiO}_{4}\right]_{6} \cdot 4 \mathrm{H}_{2} \mathrm{O}\right)$, all ideal chemical formulae. Since no elements are released from solution during vapor hydration testing, all components were available for reaction. The typical soluble component used to characterize glass dissolution was boron. Although boron alteration products were expected, only two boron-containing phases were identified (6 and 12 in Table 3.18). Another boron-containing phase is sodium-aluminum-silicate-boron-hydroxide hydrate. However, its XRD pattern is practically identical to sodium-aluminum-silicate hydrate, so its presence has not yet been confirmed.

Table 3.18. Crystalline Phases Identified in VHT Samples with XRD

\begin{tabular}{|c|c|c|c|c|}
\hline (\# & Phase & Formula & PDF\# ${ }^{(\mathbf{a})}$ & Formed in Glasses \\
\hline 1 & Analcime-C & $\mathrm{NaAlSi}_{2} \mathrm{O}_{6} \cdot \mathrm{H}_{2} \mathrm{O}$ & $41-1478$ & All Except 52, 53, 69-72 \\
\hline 2 & Sodium titanium silicate & $\mathrm{NaTiSi}_{2} \mathrm{O}_{6}$ & $29-1280$ & $\begin{array}{c}\text { All Except } 06,11,12,21,23,27, \\
29,31,35-38,46,48-55\end{array}$ \\
\hline & $\begin{array}{c}\text { Sodium aluminum } \\
\text { silicate hydrate }\end{array}$ & $\mathrm{Na}_{6}\left[\mathrm{AlSiO}_{4}\right]_{6} \cdot 4 \mathrm{H}_{2} \mathrm{O}$ & $42-216$ & \multirow[b]{2}{*}{$02,19,29,35,38,48,51,53-55$} \\
\hline 3 & \begin{tabular}{|c|}
$\begin{array}{c}\text { Sodium aluminum } \\
\text { silicate boron } \\
\text { hydroxide hydrate }\end{array}$ \\
\end{tabular} & $\mathrm{Na}_{7.55}\left(\mathrm{AlSiO}_{4}\right)_{6}\left(\mathrm{~B}(\mathrm{OH})_{4}\right)_{1.685}\left(\mathrm{H}_{2} \mathrm{O}\right)_{1.97}$ & $83-550$ & \\
\hline \multirow{2}{*}{4} & Sodium aluminum & \multirow{2}{*}{$\mathrm{Na}_{6} \mathrm{Al}_{6} \mathrm{Si}_{10} \mathrm{O}_{32} \cdot 12 \mathrm{H}_{2} \mathrm{O}$} & $39-219$ & \multirow{2}{*}{23,51} \\
\hline & silicate hydrate & & $44-103$ & \\
\hline 5 & $\begin{array}{c}\text { Sodium aluminum } \\
\text { silicate hydrate }\end{array}$ & $\mathrm{Na}_{5.7} \mathrm{Al}_{5.7} \mathrm{Si}_{10.3} \mathrm{O}_{32} \cdot 12 \mathrm{H}_{2} \mathrm{O}$ & $34-524$ & 27 \\
\hline 6 & Tincalconite & $\mathrm{Na}_{2} \mathrm{~B}_{4} \mathrm{O}_{7} \cdot 5 \mathrm{H}_{2} \mathrm{O}$ & $7-277$ & 30,36 \\
\hline 7 & Spinel & {$[\mathrm{Fe}, \mathrm{Zn}, \mathrm{Ni}][\mathrm{Fe}, \mathrm{Ti}, \mathrm{Cr}]_{2} \mathrm{O}_{4}$} & $86-509$ & 38,42 \\
\hline 8 & Gobbinsite & $\mathrm{Ca}_{0.6} \mathrm{Na}_{2.6} \mathrm{~K}_{2.2} \mathrm{Al}_{6} \mathrm{Si}_{10} \mathrm{O}_{32}\left(\mathrm{H}_{2} \mathrm{O}\right)_{12}$ & $75-1464$ & 46 \\
\hline 9 & $\begin{array}{c}\text { Sodium aluminum } \\
\text { silicate hydrate }\end{array}$ & $\mathrm{Na}_{3} \mathrm{Al}_{3} \mathrm{Si}_{3} \mathrm{O} 12\left(\mathrm{H}_{2} \mathrm{O}\right)_{2}$ & $84-590$ & 09 \\
\hline 10 & $\begin{array}{c}\text { Sodium aluminum } \\
\text { silicon oxide }\end{array}$ & $\mathrm{Na}_{2.12} \mathrm{Al}_{2} \mathrm{Si}_{2} \mathrm{O}_{8.06}$ & $47-716$ & 56 \\
\hline 11 & Phillipsite & $(\mathrm{K}, \mathrm{Na})_{2}(\mathrm{Si}, \mathrm{Al})_{8} \mathrm{O}_{16} \cdot 4 \mathrm{H}_{2} \mathrm{O}$ & $46-1427$ & 51 \\
\hline 12 & Pinakiolite & $(\mathrm{Mg}, \mathrm{Mn})_{2} \mathrm{Mn}\left(\mathrm{BO}_{3}\right)_{2}$ & $36-413$ & $04,37,43,48$ \\
\hline 13 & $\begin{array}{l}\text { Calcium silicate } \\
\text { hydroxide hydrate }\end{array}$ & $\mathrm{Ca}_{4.5} \mathrm{Si}_{6} \mathrm{O}_{15}(\mathrm{OH})_{3} \cdot 2 \mathrm{H}_{2} \mathrm{O}$ & $43-1488$ & 53 \\
\hline 14 & $\begin{array}{l}\text { Sodium zirconium } \\
\text { silicate }\end{array}$ & $\mathrm{Na}_{14} \mathrm{Zr}_{2} \mathrm{Si}_{10} \mathrm{O}_{31}$ & 29-1459 & 52 \\
\hline 15 & $\begin{array}{c}\text { Hydroxycancrinite } \\
\text { Sodium aluminum } \\
\text { silicate hydrate }\end{array}$ & $\begin{array}{c}\mathrm{Na}_{8} \mathrm{Al}_{6} \mathrm{Si}_{6} \mathrm{O}_{24}(\mathrm{OH})_{2} \cdot 2 \mathrm{H}_{2} \mathrm{O} \\
\mathrm{Na}_{14} \mathrm{Al}_{12} \mathrm{Si}_{13} \mathrm{O}_{51} \cdot 6 \mathrm{H}_{2} \mathrm{O}\end{array}$ & $\begin{array}{l}46-1457 \\
28-1036\end{array}$ & 52 \\
\hline 16 & Aegirine & $\mathrm{NaFe}\left(\mathrm{SiO}_{3}\right)_{2}$ & $34-0185$ & $05,12,14,44,45$ \\
\hline 17 & Zirconium oxide & $\mathrm{Zr}_{0.94} \mathrm{O}_{2}$ & $81-1322$ & 39 \\
\hline 18 & Catapleite & $\mathrm{Na}_{2} \mathrm{ZrSi}_{3} \mathrm{O}_{9}\left(\mathrm{H}_{2} \mathrm{O}\right)_{2}$ & $72-2020$ & 39 \\
\hline 19 & $\begin{array}{l}\text { Acmite } \\
\text { Acmite-augite }\end{array}$ & $\begin{array}{c}\mathrm{NaFe}\left(\mathrm{Si}_{2} \mathrm{O}_{6}\right) \\
(\mathrm{Na}, \mathrm{Ca}) \mathrm{FeSi}_{2} \mathrm{O}_{6}\end{array}$ & \begin{tabular}{|l|}
$71-1491$ \\
$18-1221$ \\
\end{tabular} & $19,40,56$ \\
\hline 20 & $\begin{array}{l}\text { Unidentified, or other } \\
\text { phases }\end{array}$ & - & -- & $\begin{array}{c}04,21,22,49,59,61,64,65,69- \\
72,74\end{array}$ \\
\hline
\end{tabular}


Table 3.19. Crystalline Phases from Table 3.18 and Their Content (\%)*

\begin{tabular}{|c|c|c|c|c|c|c|c|c|c|c|c|c|c|c|c|c|c|c|c|c|c|c|c|c|}
\hline \multirow{2}{*}{$\begin{array}{c}\text { Glass } \\
\text { ID } \\
\end{array}$} & \multirow{2}{*}{$\begin{array}{c}\text { Temp } \\
\left({ }^{\circ} \mathrm{C}\right)\end{array}$} & \multirow{2}{*}{$\begin{array}{c}t \\
\text { (d) }\end{array}$} & \multirow[b]{2}{*}{ Type } & \multicolumn{20}{|c|}{ Crystalline Phase } & \multirow[b]{2}{*}{ SEM } \\
\hline & & & & 1 & 2 & 3 & 4 & 5 & 6 & 7 & 8 & 9 & 10 & 11 & 12 & 13 & 14 & 15 & 16 & 17 & 18 & 19 & 20 & \\
\hline HLP-01 & 200 & 125 & surf & 97 & 3 & & & & & & & & & & & & & & & & & & & \\
\hline HLP-02 & 200 & 30 & bulk & 16 & 15 & 69 & & & & & & & & & & & & & & & & & & \\
\hline HLP-03 & 200 & 125 & surf & 90 & 10 & & & & & & & & & & & & & & & & & & & \\
\hline HLP-04 & 200 & 16 & bulk & 46 & 44 & & & & & & & & & & 10 & & & & & & & & & \\
\hline HLP-05 & 300 & 8 & surf & & & & & & & & & & & & & & & & 96 & & & & 4 & \\
\hline HLP-06 & 200 & 106 & surf & 100 & & & & & & & & & & & & & & & & & & & & $X$ \\
\hline HLP-07 & 200 & 100 & bulk & 94 & 6 & & & & & & & & & & & & & & & & & & & \\
\hline HLP-08 & 200 & 100 & surf & 95 & 5 & & & & & & & & & & & & & & & & & & & \\
\hline HLP-09 & 300 & 5 & surf & 93 & 4 & & & & & & & 3 & & & & & & & & & & & & $\mathrm{X}$ \\
\hline HLP-10 & 200 & 129 & surf & 98 & 2 & & & & & & & & & & & & & & & & & & & \\
\hline HLP-11 & 200 & 68 & surf & 100 & & & & & & & & & & & & & & & & & & & & \\
\hline HLP-12 & 200 & 105 & bulk & 82 & & & & & & & & & & & & & & & 18 & & & & & $\mathrm{X}$ \\
\hline HLP-12 & 300 & 2 & bulk & 45 & 55 & & & & & & & & & & & & & & & & & & & \\
\hline HLP-13 & 200 & 80 & surf & 97 & 3 & & & & & & & & & & & & & & & & & & & \\
\hline HLP-14 & 200 & 101 & bulk & 57 & & & & & & & & & & & & & & & 43 & & & & & \\
\hline HLP-15 & 200 & 75 & surf & 99 & 1 & & & & & & & & & & & & & & & & & & & \\
\hline HLP-16 & 200 & 75 & surf & 98 & 2 & & & & & & & & & & & & & & & & & & & \\
\hline HLP-17 & 200 & 75 & surf & 98 & 2 & & & & & & & & & & & & & & & & & & & \\
\hline HLP-18 & 200 & 32 & bulk & 93 & 7 & & & & & & & & & & & & & & & & & & & \\
\hline HLP-19 & 300 & 3 & bulk & 30 & & 10 & & & & & & & & & & & & & & & & 60 & & \\
\hline HLP-20 & 200 & 75 & surf & 87 & 13 & & & & & & & & & & & & & & & & & & & \\
\hline HLP-21 & 200 & 32 & surf & 85 & & & & & & & & & & & & & & & & & & & 15 & \\
\hline HLP-22 & 200 & 32 & surf & 71 & & & & & & & & & & & & & & & & & & & 29 & \\
\hline HLP-23 & 200 & 7 & surf & 95 & & & 5 & & & & & & & & & & & & & & & & & \\
\hline HLP-24 & 200 & 32 & surf & 95 & 5 & & & & & & & & & & & & & & & & & & & \\
\hline HLP-27 & 200 & 4 & bulk & 88 & & & & 12 & & & & & & & & & & & & & & & & \\
\hline HLP-27 & 200 & 100 & bulk & 100 & & & & & & & & & & & & & & & & & & & & \\
\hline HLP-28 & 200 & 300 & surf & 100 & & & & & & & & & & & & & & & & & & & & \\
\hline HLP-29 & 200 & 13 & bulk & 39 & 60 & 1 & & & & & & & & & & & & & & & & & & \\
\hline HLP-30 & 200 & 23 & surf & 94 & & & & & 6 & & & & & & & & & & & & & & & \\
\hline HLP-31 & 200 & 2 & surf & 100 & & & & & & & & & & & & & & & & & & & & $X$ \\
\hline HLP-31 & 200 & 10 & bulk & 68 & 32 & & & & & & & & & & & & & & & & & & & \\
\hline HLP-32 & 200 & 24 & surf & 85 & 15 & & & & & & & & & & & & & & & & & & & \\
\hline HLP-33 & 200 & 129 & surf & 93 & 7 & & & & & & & & & & & & & & & & & & & \\
\hline HLP-33 & 300 & 5 & bulk & 29 & 71 & & & & & & & & & & & & & & & & & & & $\mathrm{X}$ \\
\hline HLP-34 & 300 & 8 & surf & 8 & & 46 & & & & & & & & 46 & & & & & & & & & & \\
\hline HLP-35 & 200 & 21 & bulk & 61 & & 39 & & & & & & & & & & & & & & & & & & \\
\hline HLP-36 & 200 & 32 & surf & 86 & & & & & 14 & & & & & & & & & & & & & & & \\
\hline
\end{tabular}


Table 3.19 (Contd)

\begin{tabular}{|c|c|c|c|c|c|c|c|c|c|c|c|c|c|c|c|c|c|c|c|c|c|c|c|}
\hline \multirow{2}{*}{$\begin{array}{c}\text { Glass } \\
\text { ID } \\
\end{array}$} & \multirow{2}{*}{$\begin{array}{c}\text { Temp } \\
\left({ }^{\circ} \mathrm{C}\right)\end{array}$} & \multirow{2}{*}{$\begin{array}{c}t \\
\text { (d) }\end{array}$} & \multirow[b]{2}{*}{ Type } & \multicolumn{19}{|c|}{ Crystalline Phase } & \multirow[b]{2}{*}{ SEM } \\
\hline & & & & 1 & 2 & 3 & 4 & 5 & 6 & 7 & \begin{tabular}{|l|l}
8 & 9 \\
\end{tabular} & \begin{tabular}{|l|l}
10 \\
\end{tabular} & 11 & 12 & 13 & 14 & 15 & 16 & 17 & 18 & 19 & 20 & \\
\hline HLP-37 & 200 & 24 & surf & 76 & & & & & & & & & & 24 & & & & & & & & & \\
\hline HLP-38 & 200 & 24 & bulk & 38 & & 2 & & & & 60 & & & & & & & & & & & & & \\
\hline HLP-38 & 200 & 64 & bulk & 24 & & 10 & & & & 66 & & & & & & & & & & & & & \\
\hline HLP-39 & 300 & 5 & bulk & & & & & & & & & & & & & & & 58 & 26 & 16 & & & \\
\hline HLP-40 & 275 & 5 & bulk & 5 & & 33 & & & & & & & & & & & & & & & 62 & & \\
\hline HLP-41 & 200 & 120 & surf & 90 & 10 & & & & & & & & & & & & & & & & & & \\
\hline HLP-42 & 200 & 68 & surf & 33 & 5 & & & & & 62 & & & & & & & & & & & & & \\
\hline HLP-43 & 200 & 33 & bulk & 53 & 6 & & & & & & & & & 41 & & & & & & & & & \\
\hline HLP-44 & 300 & 3 & bulk & 79 & & & & & & & & & & & & & & 21 & & & & & \\
\hline HLP-45 & 300 & 3 & bulk & 65 & & & & & & & & & & & & & & 35 & & & & & \\
\hline HLP-46 & 200 & 1 & bulk & 97 & & & & & & & 3 & & & & & & & & & & & & $\mathrm{X}$ \\
\hline HLP-46 & 200 & 4 & bulk & 95 & & & & & & & 5 & & & & & & & & & & & & \\
\hline HLP-47 & 200 & 24 & bulk & 97 & 3 & & & & & & & & & & & & & & & & & & $X$ \\
\hline HLP-48 & 200 & 20 & bulk & 41 & & 51 & & & & & & & & 8 & & & & & & & & & $X$ \\
\hline HLP-49 & 200 & 50 & surf & 47 & & & & & & & & & & & & & & & & & & 53 & \\
\hline HLP-51 & 150 & 187 & surf & 13 & & & & & & & & & 87 & & & & & & & & & & \\
\hline HLP-51 & 200 & 75 & bulk & 19 & & & 81 & & & & & & & & & & & & & & & & $X$ \\
\hline HLP-51 & 250 & 3 & surf & 70 & & 30 & & & & & & & & & & & & & & & & & \\
\hline HLP-52 & 200 & 13 & bulk & & & & & & & & & & & & & 38 & 62 & & & & & & \\
\hline HLP-53 & 200 & 3 & bulk & & & 94 & & & & & & & & & 6 & & & & & & & & \\
\hline HLP-54 & 200 & 41 & bulk & 65 & & 45 & & & & & & & & & & & & & & & & & \\
\hline HLP-55 & 200 & 14 & bulk & 40 & & 60 & & & & & & & & & & & & & & & & & \\
\hline HLP-56 & 250 & 7 & surf & 71 & 20 & & & & & & & & & & & & & & & 9 & & & \\
\hline HLP-56 & 250 & 5 & surf & 96 & 4 & & & & & & & & & & & & & & & & & & \\
\hline HLP-56 & 300 & 3 & bulk & 21 & 72 & & & & & & & 7 & & & & & & & & & & & $X$ \\
\hline HLP-58 & 200 & 101 & bulk & $X$ & & & & & & & & & & & & & & & & & & & \\
\hline HLP-59 & 200 & 44 & bulk & $X$ & & & & & & & & & & & & & & & & & & $X$ & \\
\hline HLP-61 & 200 & 149 & bulk & $X$ & & & & & & & & & & & & & & & & & & $X$ & \\
\hline HLP-64 & 200 & 44 & bulk & & & & & & & & & & & & & & & & & & & $X$ & $X$ \\
\hline HLP-65 & 200 & 28 & bulk & $X$ & & & & & & & & & & & & & & & & & & $X$ & \\
\hline HLP-65 & 200 & 43 & bulk & $\mathrm{X}$ & & & & & & & & & & & & & & & & & & & \\
\hline HLP-68 & 200 & 28 & bulk & $X$ & & & & & & & & & & & & & & & & & & & \\
\hline HLP-69 & 200 & 42 & bulk & & & & & & & & & & & & & & & & & & & $\mathrm{X}$ & $\mathrm{X}$ \\
\hline HLP-70 & 200 & 28 & bulk & & & & & & & & & & & & & & & & & & & $X$ & $X$ \\
\hline HLP-71 & 200 & 28 & bulk & & & & & & & & & & & & & & & & & & & $X$ & \\
\hline HLP-72 & 200 & 50 & bulk & & & & & & & & & & & & & & & & & & & $X$ & \\
\hline HLP-72 & 200 & 151 & bulk & $\mathrm{X}$ & & & & & & & & & & & & & & & & & & $X$ & \\
\hline HLP-74 & 200 & 29 & bulk & $X$ & & & & & & & & & & & & & & & & & & $X$ & \\
\hline HLP-75 & 200 & 28 & bulk & $\mathrm{X}$ & & & & & & & & & & & & & & & & & & & \\
\hline
\end{tabular}


Table 3.19 (Contd)

\begin{tabular}{|c|c|c|c|c|c|c|c|c|c|c|c|c|c|c|c|c|c|c|c|c|c|c|c|}
\hline \multirow{2}{*}{$\begin{array}{c}\text { Glass } \\
\text { ID } \\
\end{array}$} & \multirow{2}{*}{$\begin{array}{c}\text { Temp } \\
\left({ }^{\circ} \mathrm{C}\right)\end{array}$} & \multirow{2}{*}{$\begin{array}{c}t \\
\text { (d) }\end{array}$} & \multirow[b]{2}{*}{ Type } & \multicolumn{19}{|c|}{ Crystalline Phase } & \multirow[b]{2}{*}{ SEM } \\
\hline & & & & 1 & 2 & 3 & 4 & 5 & 6 & 7 & 8 & $\begin{array}{l}9 \\
\end{array}$ & 10 & 11 & 12 & 13 & 14 & 151 & 16 16 1 & \begin{tabular}{l|l}
17 & 1 \\
\end{tabular} & 18 19 & $\begin{array}{l}9 \\
9\end{array}$ & \\
\hline HLP-75 & 200 & 42 & bulk & $\mathrm{X}$ & & & & & & & & & & & & & & & & & & & \\
\hline HLP-76 & 200 & 42 & bulk & $\mathrm{X}$ & & & & & & & & & & & & & & & & & & & \\
\hline HLP-77 & 200 & 42 & bulk & $\mathrm{X}$ & & & & & & & & & & & & & & & & & & & \\
\hline
\end{tabular}

\subsubsection{SEM/EDS Identification}

\section{Specimen Cross-Section}

Specimen cross-sections were analyzed on selected samples to help determine the location and composition of the alteration products. A portion of these results is highlighted below.

The EDS results for HLP-06 are given in normalized atomic\% of elements in Table 3.20. The location of EDS measurements is displayed in Figure 3.59. Generally, it can be concluded that the content of sodium is systematically lower in EDS scans from areas showing preferential leaching. All other elements, except aluminum, are present in the amounts comparable to the target glass composition. The content of aluminum is higher because a solution with aluminum oxide was used to polish this cross section before analysis. Based on this observation, we can conclude that the fibers observed in the HLP-06 specimen after the VHT test were created by preferential leaching, and the composition of altered glass was depleted of sodium (roughly about $10 \mathrm{~mol} \%$ ). A slight increase in silica concentration (roughly $3 \mathrm{~mol} \%$ ) was also observed.

Table 3.20. EDS Results for HLP-06 Glass subjected to VHT at $200^{\circ} \mathrm{C}$

\begin{tabular}{||c|c|c|c|c|c|c|c|c|c||}
\hline \hline & Location & Na & $\mathbf{M g}$ & $\mathbf{A l}$ & $\mathbf{S i}$ & $\mathbf{K}$ & $\mathbf{T i}$ & $\mathbf{F e}$ & $\mathbf{Z n}$ \\
\hline Target & Glass & 36.46 & 2.10 & 7.76 & 46.14 & 0.49 & 2.12 & 3.89 & 1.04 \\
\hline EDS-01 & Glass & 33.96 & 1.47 & 12.98 & 44.65 & 0.49 & 1.89 & 3.51 & 1.04 \\
\hline EDS-02 & Fiber & 26.54 & 2.02 & 14.87 & 49.57 & 0.40 & 1.72 & 3.83 & 1.06 \\
\hline EDS-05 & Fiber & 28.38 & 1.70 & 14.16 & 48.40 & 0.43 & 2.03 & 3.86 & 1.05 \\
\hline EDS-06 & Glass & 34.17 & 1.49 & 13.03 & 44.34 & 0.45 & 1.91 & 3.52 & 1.10 \\
\hline EDS-08 & Glass & 30.26 & 1.71 & 13.92 & 47.16 & 0.51 & 1.90 & 3.55 & 0.98 \\
\hline EDS-09 & Fiber & 27.35 & 1.95 & 14.53 & 48.87 & 0.40 & 2.05 & 3.80 & 1.04 \\
\hline \hline
\end{tabular}




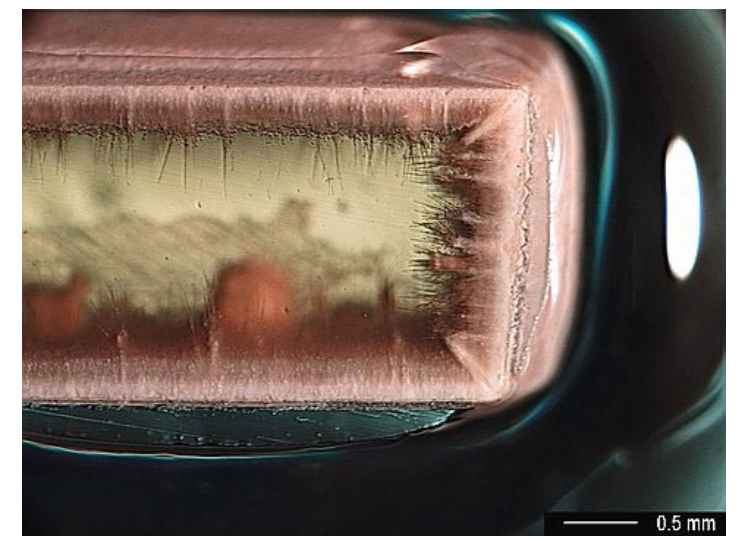

OM Micrograph of HLP-06 Cross Section after 9 Days at $200^{\circ} \mathrm{C}$

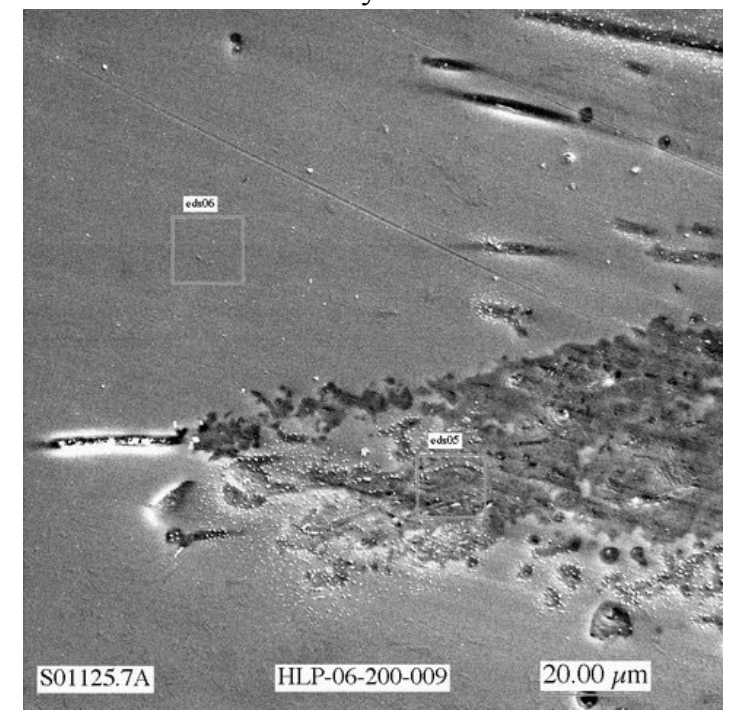

HLP-06 Location of EDS Measurements

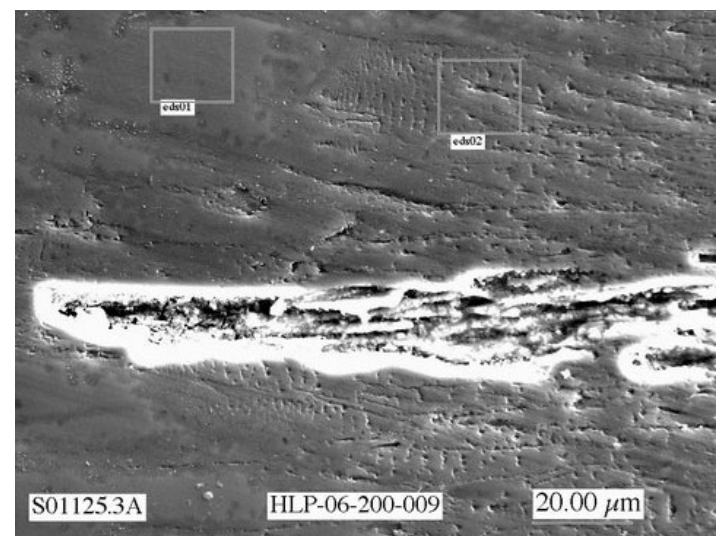

HLP-06 Location of EDS Measurements

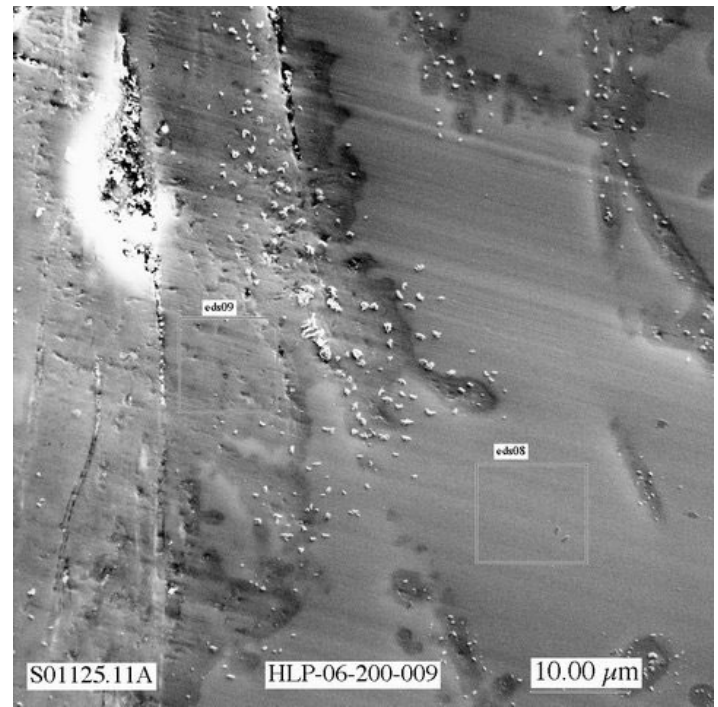

HLP-06 Location of EDS Measurements

Figure 3.59. Location of EDS Spectra for HLP-06 Subjected to VHT at $200^{\circ} \mathrm{C}$ for 9 Days

The EDS results for HLP-09 are given in Table 3.21 in normalized mass $\%$ of elements. The locations of EDS analyses are indicated in the electron micrograph shown in Figure 3.60. It is apparent that the alteration products form at least three layers. These layers can also be identified with OM, as shown in Figure 3.61.

It can be assumed that no components from the glass are removed from the specimen surface during testing because of the nature of the VHT. Therefore, the differences in concentration of individual elements indicate component migration or component incorporation in alteration products. From the analyzed components, silicon, aluminum, sodium, and magnesium show the highest differences in concentration between the alteration layers.

The highest concentration of sodium was found in EDS-03, which is located under the surface alteration layer. The lowest concentration of sodium was found in the surface alteration layer (EDS-04). The content of sodium, aluminum, and silicon in EDS-04 yields $\mathrm{Na}_{1.1} \mathrm{Al}_{0.9} \mathrm{Si}_{2.9}$, which roughly corresponds to the composition of analcime $\left(\mathrm{NaAlSi}_{2} \mathrm{O}_{6} \cdot \mathrm{H}_{2} \mathrm{O}\right)$. Analcime was the major alteration 
product identified with XRD as shown in Appendix E (see Figure 3.61). The third layer, analyzed as EDS-06, appears from OM and SEM to be an intermediate between layers two and four (EDS-02 and EDS-03); the EDS composition estimates confirm this assignment.

Table 3.21. EDS Results for HLP-09 Glass Subjected to VHT at $300^{\circ} \mathrm{C}$ (normalized mass \% of elements)

\begin{tabular}{|c|c|c|r|c|c|c|c|c|c|}
\hline ID & Na & Mg & \multicolumn{1}{|c|}{ Al } & Si & K & Ti & Fe & Zn & $\mathbf{Z r}$ \\
\hline Target & 29.3 & 1.8 & 7.3 & 45.2 & 0.7 & 3.5 & 7.6 & 2.4 & 2.2 \\
\hline EDS-01 & 24.3 & 1.0 & 13.3 & 51.9 & 0.7 & 2.3 & 4.3 & 1.1 & 1.1 \\
\hline EDS-02 & 24.4 & 0.7 & 13.3 & 51.7 & 1.1 & 2.4 & 4.1 & 1.1 & 1.2 \\
\hline EDS-03 & 33.1 & 2.5 & 2.8 & 47.7 & 0.9 & 3.8 & 6.1 & 1.8 & 1.2 \\
\hline EDS-04 & 17.7 & 0.6 & 17.0 & 56.1 & 0.3 & 2.1 & 3.9 & 1.1 & 1.2 \\
\hline EDS-06 & 30.7 & 1.1 & 11.8 & 46.3 & 1.0 & 2.6 & 4.5 & 1.2 & 0.8 \\
\hline
\end{tabular}

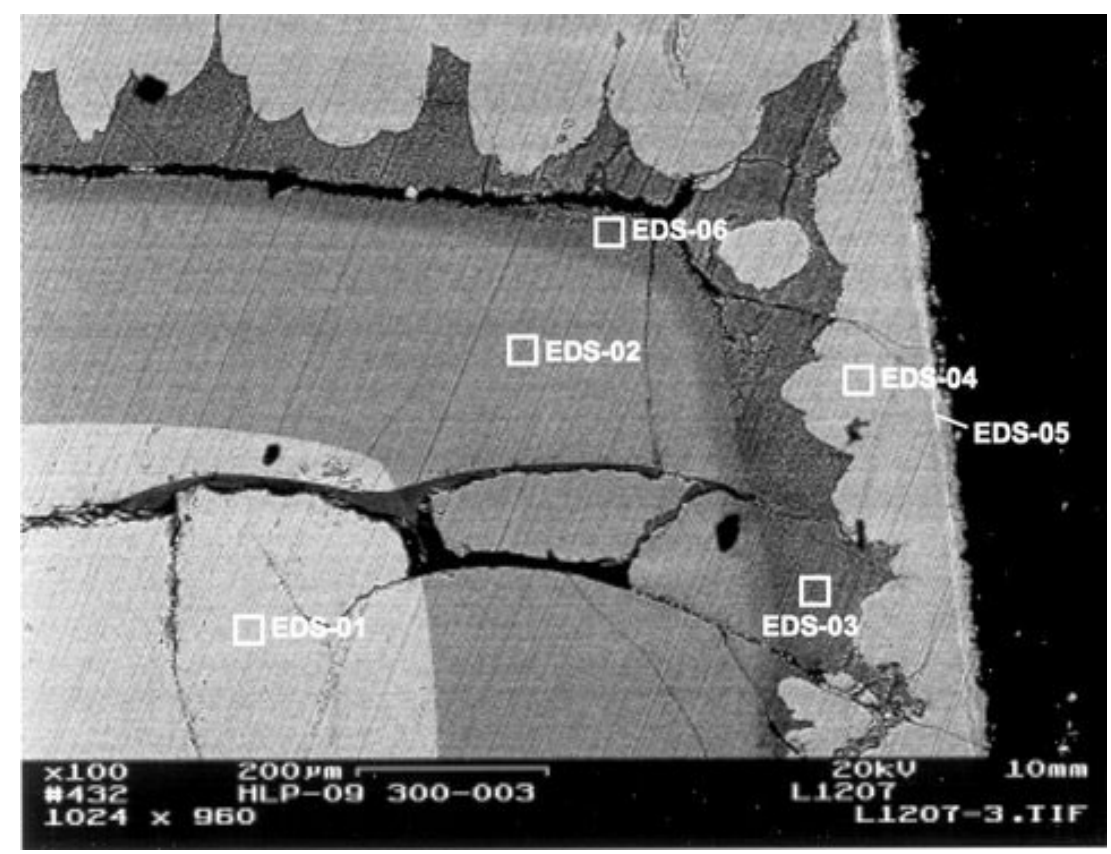

Figure 3.60. Locations of EDS Measurements for HLP-09 Subjected to VHT at $300^{\circ} \mathrm{C}$ for 3 Days 


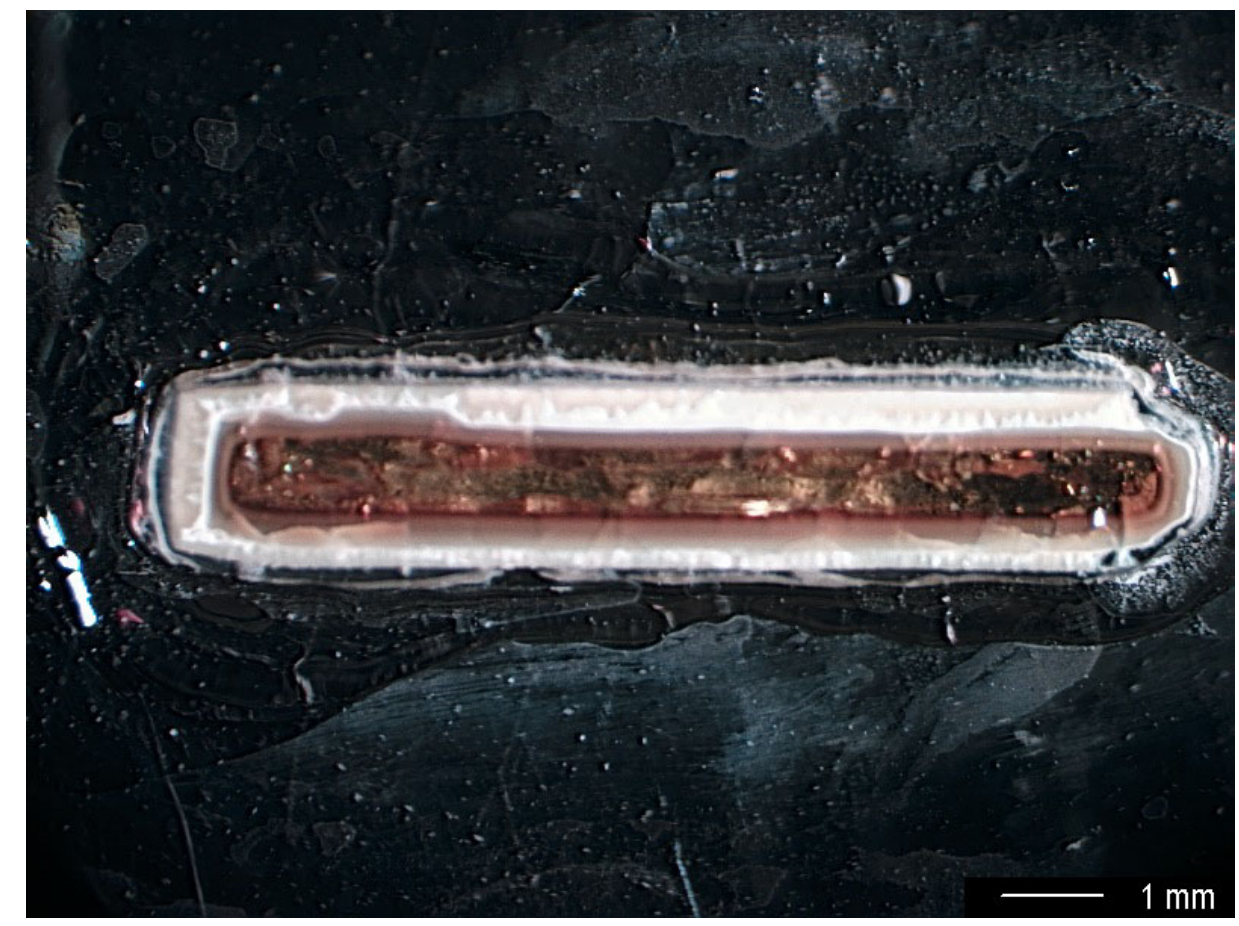

Figure 3.61. OM of HLP-09 Subjected to VHT at $300^{\circ} \mathrm{C}$ for 3 Days

For comparison, the cross section of HLP-09 subjected to VHT at $250^{\circ} \mathrm{C}$ was analyzed. The EDS results for HLP-09-250-06 are given in Table 3.22 in normalized mass $\%$ of elements. The locations of EDS analyses are indicated in the electron micrograph shown in Figure 3.62. The layered structure seen in the $300^{\circ} \mathrm{C}$ tested sample is apparent in the $250^{\circ} \mathrm{C}$ sample. However, more of the fine structure of these layers is evident in the analyses of the $250^{\circ} \mathrm{C}$ sample.

Table 3.22. EDS Results for HLP-09 Glass Subjected to VHT at $250^{\circ} \mathrm{C}$ for 6 days (normalized mass\% of elements)

\begin{tabular}{|c|c|c|c|c|c|c|c|c|c|c|c|c|c|c||}
\hline ID & Na & $\mathbf{M g}$ & \multicolumn{1}{|c|}{$\mathbf{A l}$} & $\mathbf{S i}$ & $\mathbf{P}$ & $\mathbf{Z r}$ & $\mathbf{S}$ & $\mathbf{C l}$ & $\mathbf{K}$ & $\mathbf{C a}$ & $\mathbf{T i}$ & $\mathbf{C r}$ & $\mathbf{F e}$ & $\mathbf{Z n}$ \\
\hline Target & 29.06 & 1.78 & 7.25 & 44.91 & 0.04 & 2.18 & 0.06 & 0.54 & 0.66 & 0.01 & 3.52 & 0.10 & 7.53 & 2.36 \\
\hline EDS-01 & 26.81 & 3.05 & 4.00 & 45.77 & 0.64 & 2.13 & 0.82 & 1.02 & 0.75 & 0.21 & 3.79 & 0.14 & 8.09 & 2.77 \\
\hline EDS-02 & 24.24 & 2.37 & 8.42 & 48.32 & 0.34 & 1.68 & - & 0.34 & 0.78 & - & 3.22 & 0.14 & 7.16 & 2.98 \\
\hline EDS-03 & 17.98 & 2.15 & 13.26 & 51.49 & 0.14 & 2.65 & - & 0.21 & 0.39 & 0.15 & 2.68 & - & 6.34 & 2.56 \\
\hline EDS-04 & 23.13 & 3.34 & 2.93 & 46.43 & 0.88 & 2.58 & 0.94 & 1.13 & 0.78 & 0.71 & 4.85 & - & 9.85 & 2.43 \\
\hline EDS-05 & 15.74 & 2.54 & 10.12 & 52.06 & 0.27 & 1.89 & - & 0.24 & 0.19 & 0.27 & 3.94 & - & 10.17 & 2.57 \\
\hline EDS-06 & 24.69 & 2.44 & 8.63 & 47.66 & 0.62 & 1.75 & - & 0.31 & 0.93 & - & 3.23 & 0.15 & 6.95 & 2.64 \\
\hline EDS-07 & 25.15 & 2.49 & 8.36 & 47.47 & 0.35 & 2.33 & - & 0.45 & 0.78 & - & 3.11 & 0.22 & 6.78 & 2.53 \\
\hline EDS-08 & 13.79 & 1.61 & 7.81 & 51.19 & 0.50 & 2.49 & 0.81 & 0.44 & 1.06 & - & 4.85 & 0.47 & 11.20 & 3.77 \\
\hline
\end{tabular}




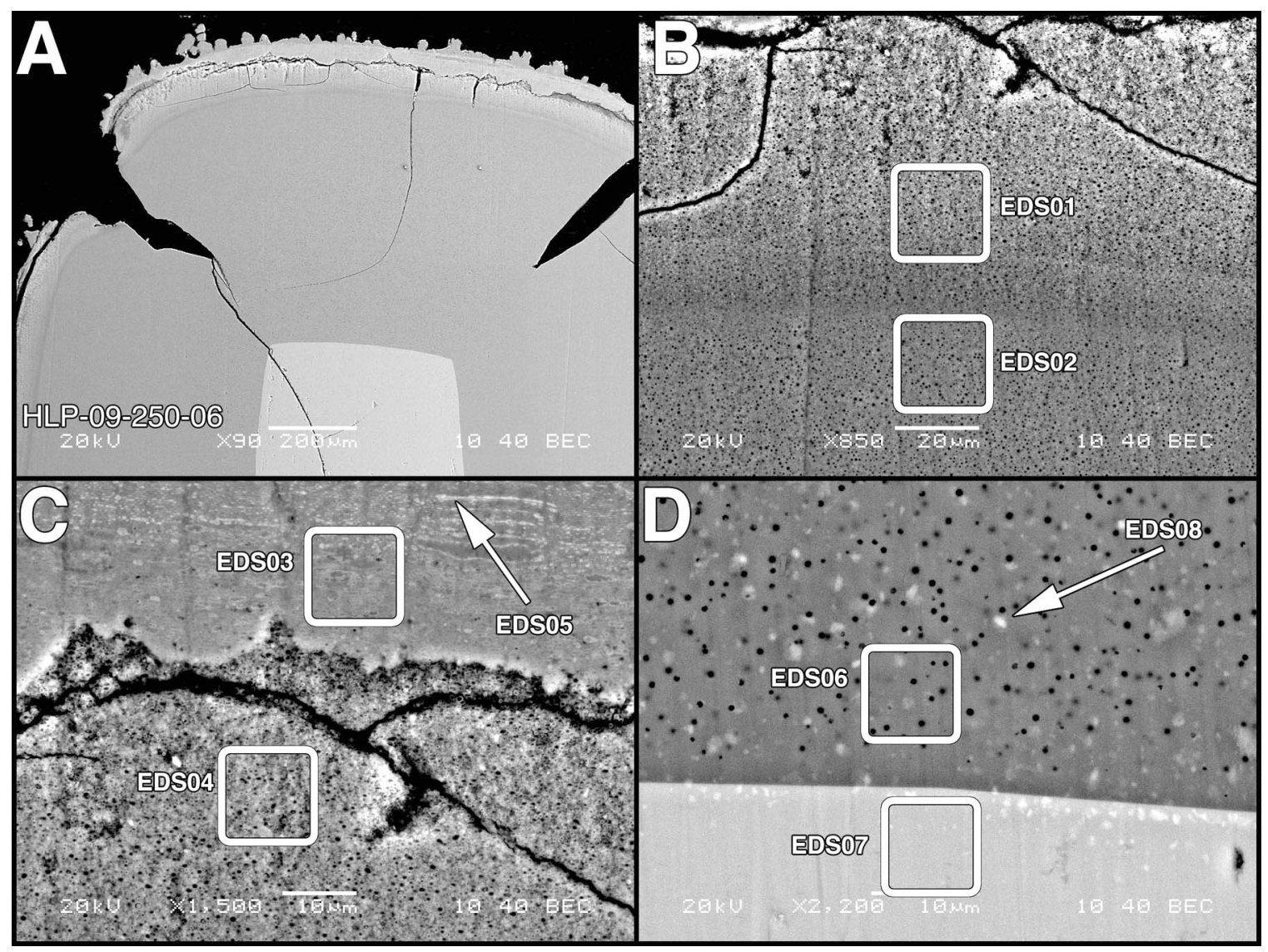

Figure 3.62. Locations of EDS Measurements for HLP-09 Subjected to VHT at $250^{\circ} \mathrm{C}$ for 6 days

The EDS results for HLP-12 are given in Table 3.23 in normalized mass $\%$ of elements. The locations of EDS measurements are indicated in the electron micrograph shown in Figure 3.63. The content of sodium in the alteration layers is almost constant. The biggest difference in concentration is observed for aluminum, which shows the highest concentration under the surface alteration layer and is practically depleted in the surface alteration layer. Sodium and silicon are the major components found in the surface alteration layer, which is also enriched with titanium and iron. This would indicate the presence of aegirine $\left(\mathrm{NaFe}\left(\mathrm{SiO}_{3}\right)_{2}\right)$ or sodium titanium silicate $\left(\mathrm{NaTiSi}_{2} \mathrm{O}_{6}\right)$. Analcime $\left(\mathrm{NaAlSi}_{2} \mathrm{O}_{6} \cdot \mathrm{H}_{2} \mathrm{O}\right)$ and Naclinopyroxene aegirine $\left(\mathrm{NaFe}\left(\mathrm{SiO}_{3}\right)_{2}\right)$ were identified as the major crystalline phases. A large solid solution range exists between $\mathrm{Na}-\mathrm{Fe}$ and $\mathrm{Na}$-Ti clinopyroxenes. The EDS results from specimen cross section are not suitable for determination of likely mineral phase.

Table 3.23. EDS Results for HLP-12 Glass Subjected to VHT at $200^{\circ} \mathrm{C}$ (normalized mass $\%$ of elements)

\begin{tabular}{|c|c|c|r|c|c|c|c|c|c|}
\hline ID & Na & $\mathbf{M g}$ & \multicolumn{1}{c|}{$\mathbf{A l}$} & $\mathbf{S i}$ & $\mathbf{K}$ & $\mathbf{T i}$ & $\mathbf{F e}$ & $\mathbf{Z n}$ & $\mathbf{Z r}$ \\
\hline Target & 27.8 & 1.7 & 6.9 & 43.0 & 0.6 & 3.4 & 12.2 & 2.3 & 2.1 \\
\hline EDS-08 & 25.2 & 0.0 & 9.6 & 45.6 & 0.5 & 3.3 & 11.1 & 2.5 & 2.3 \\
\hline EDS-07 & 24.3 & 0.0 & 12.0 & 46.7 & 0.7 & 2.3 & 9.5 & 2.4 & 2.1 \\
\hline EDS-09 & 27.1 & 0.0 & 1.2 & 43.3 & 0.4 & 5.7 & 17.3 & 2.7 & 2.3 \\
\hline \hline
\end{tabular}




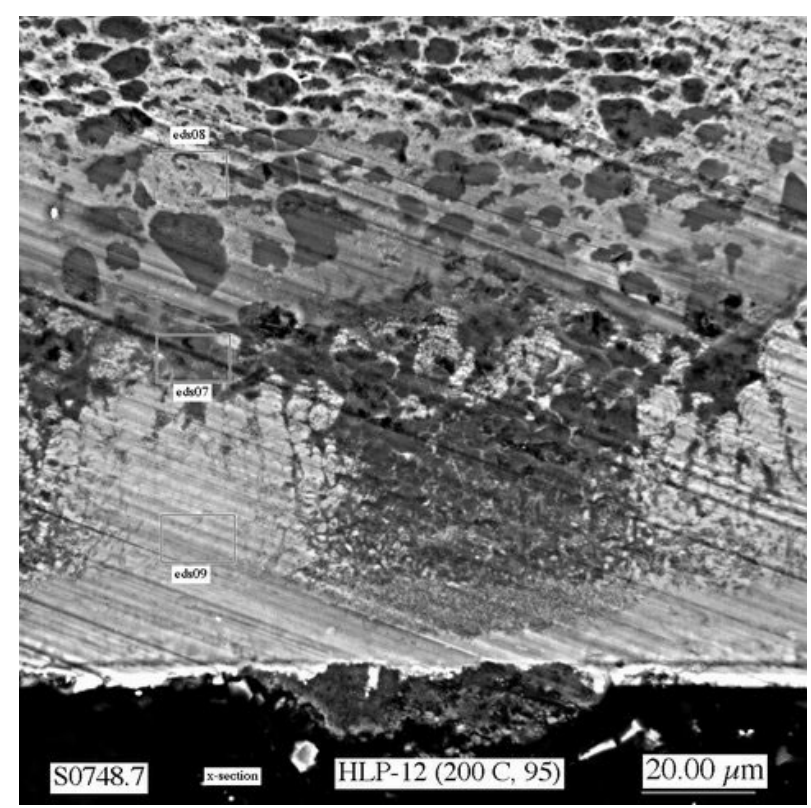

Figure 3.63. Locations of EDS Measurements for HLP-12 Subjected to VHT at $200^{\circ} \mathrm{C}$ for 95 Days

The EDS results for HLP-47 are given in normalized atomic\% of elements in Table 3.24. The location of EDS measurements is displayed in Figure 3.64. A translucent alteration layer develops during the alteration of HLP-47 glass. Surprisingly, the SEM/EDS analysis reveals that the composition of this translucent alteration layer is almost identical to the target glass composition (EDS-04, 06, and 10), showing slight depletion of sodium and possibly slight silica enrichment. Crystals that were white and almost transparent were observed inside this layer. The SEM/EDS analysis reveals high sodium content (above $80 \mathrm{~mol} \%$ ) and about $10 \mathrm{~mol} \%$ of silica. This phase was not identified yet.

Table 3.24. EDS Results for HLP-47 Glass subjected to VHT at $200^{\circ} \mathrm{C}$

\begin{tabular}{|c|c|c|r|c|c|c|c||}
\hline & Location & Na & \multicolumn{1}{c|}{ Al } & Si & K & Fe & $\mathbf{Z r}$ \\
\hline Target & Glass & 35.88 & 10.90 & 50.30 & 1.77 & 0.70 & 0.45 \\
\hline EDS-03 & Particle & 81.82 & 3.16 & 14.24 & 0.46 & 0.17 & 0.14 \\
\hline EDS-04 & Glass & 29.85 & 11.40 & 54.99 & 2.05 & 1.03 & 0.67 \\
\hline EDS-06 & Glass & 29.74 & 11.49 & 55.21 & 1.99 & 1.03 & 0.53 \\
\hline EDS-07 & Particle & 85.93 & 2.64 & 10.83 & 0.31 & 0.17 & 0.11 \\
\hline EDS-09 & Particle & 83.40 & 3.06 & 12.85 & 0.35 & 0.17 & 0.17 \\
\hline EDS-10 & Glass & 28.94 & 11.70 & 55.49 & 2.03 & 1.09 & 0.76 \\
\hline
\end{tabular}




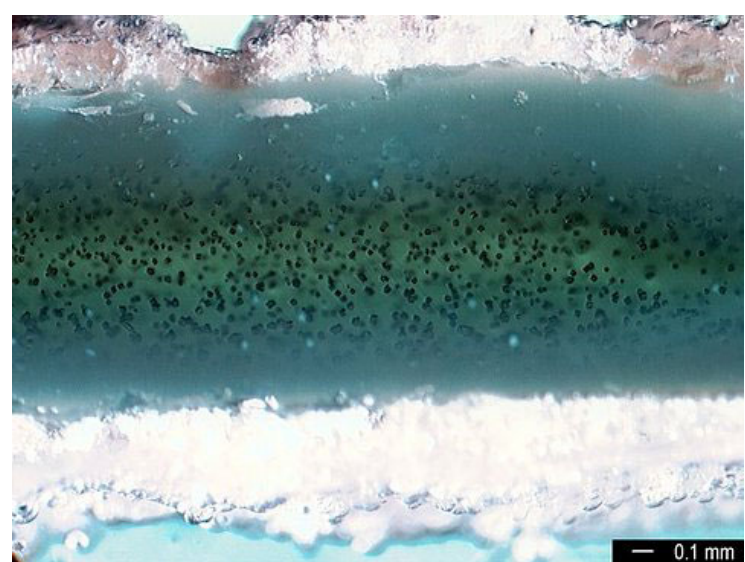

OM Micrograph HLP-47 Cross Section after

20 Days at $200^{\circ} \mathrm{C}$

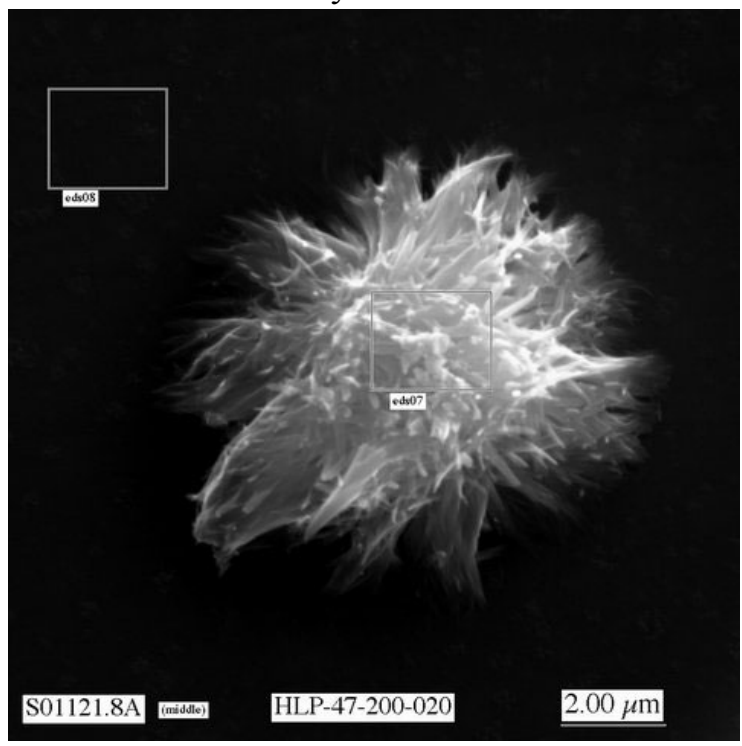

HLP-47 Location of EDS Measurements

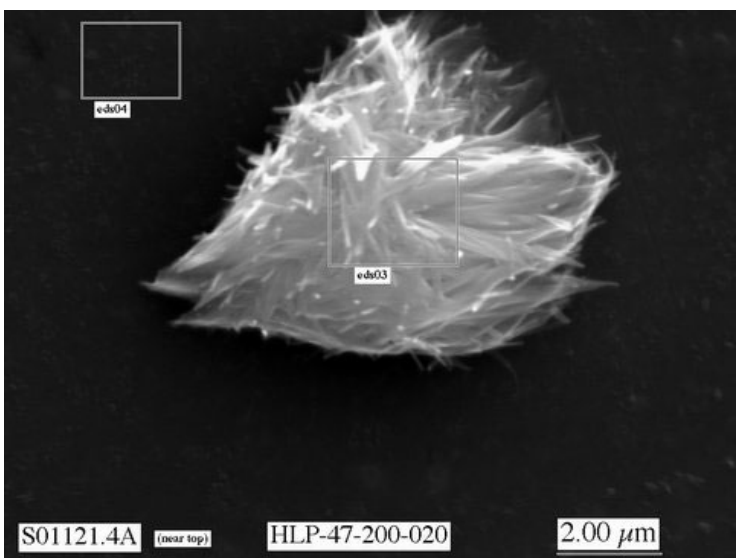

HLP-47 Location of EDS Measurements

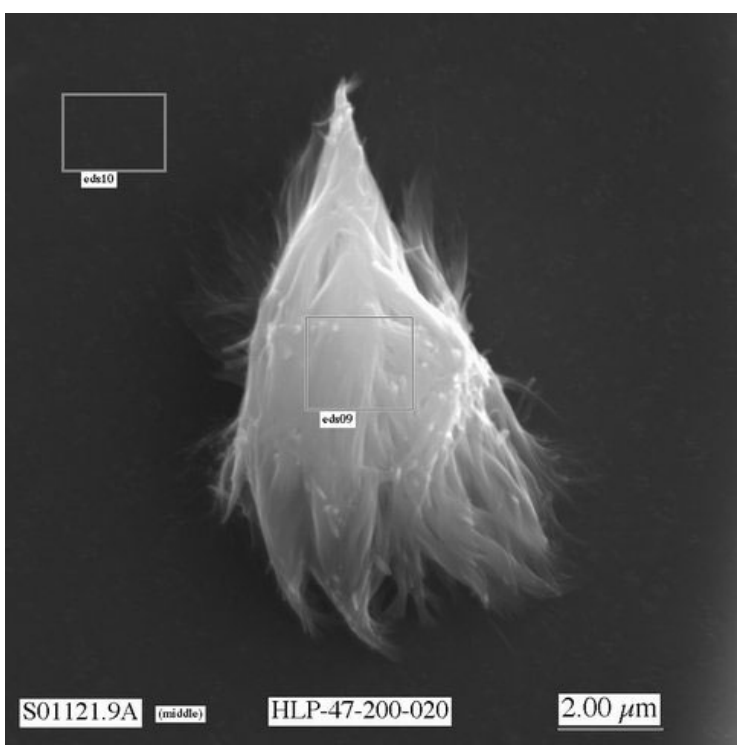

HLP-47 Location of EDS Measurements

Figure 3.64. Location of EDS Measurements for HLP-47 Glass Subjected to VHT at $200^{\circ} \mathrm{C}$ for 20 Days

The EDS results for HLP-48 tested at $150^{\circ} \mathrm{C}$ are given in normalized atomic\% of elements in Table 3.25. The location of EDS measurements is displayed in Figure 3.65. The surface layers are depleted of sodium and aluminum when compared to the inside layers and target glass composition (however, $\mathrm{Al}$ concentration may be effected by polishing of the sample). The content of silica does not change significantly. All other elements are present in the surface layer in concentrations higher than in the target glass composition. Although EDS-04 is located in the area that shows preferential leaching, its composition is comparable to EDS-05 (target glass), probably because the area of the measurement does not have sufficient resolution to reveal the composition of preferentially leached areas. The EDS- 12 reveals that the preferentially leached areas of the specimen are depleted of sodium (roughly $10 \mathrm{~mol} \%$ when compared to EDS-14, and roughly $17 \mathrm{~mol} \%$ when compared to the target glass composition). EDS-12 also shows an increase in silica concentration (roughly $10 \mathrm{~mol} \%$ ) when compared to the target glass composition and possibly an increase in magnesium concentration. 
Table 3.25. EDS Results for HLP-48 Glass subjected to VHT at $150^{\circ} \mathrm{C}$

\begin{tabular}{|c|l|c|c|r|c|c|c|c|c|c||}
\hline & Location & $\mathbf{N a}$ & $\mathbf{M g}$ & \multicolumn{1}{c|}{$\mathbf{A l}$} & $\mathbf{S i}$ & $\mathbf{K}$ & $\mathbf{T i}$ & $\mathbf{F e}$ & $\mathbf{Z n}$ & $\mathbf{Z r}$ \\
\hline Target & Glass & 35.69 & 2.73 & 12.99 & 35.21 & 3.64 & 1.72 & 4.00 & 2.90 & 1.12 \\
\hline EDS-01 & Layer 1 & 28.46 & 6.20 & 3.55 & 32.84 & 6.10 & 4.54 & 9.25 & 6.87 & 2.19 \\
\hline EDS-02 & Layer 2 & 29.69 & 5.69 & 4.17 & 34.20 & 5.69 & 5.28 & 8.45 & 4.04 & 2.79 \\
\hline EDS-03 & Layer 3 & 32.72 & 2.81 & 14.97 & 36.15 & 2.96 & 1.38 & 3.84 & 3.66 & 1.52 \\
\hline EDS-04 & Fibers & 35.80 & 2.87 & 11.95 & 35.03 & 3.35 & 1.97 & 4.45 & 3.11 & 1.46 \\
\hline EDS-05 & Glass & 36.48 & 2.27 & 12.67 & 35.19 & 3.54 & 1.66 & 3.96 & 3.01 & 1.21 \\
\hline EDS-12 & Fibers & 18.46 & 3.22 & 15.54 & 44.43 & 4.70 & 2.35 & 5.64 & 4.16 & 1.51 \\
\hline EDS-13 & Both & 23.84 & 2.42 & 15.46 & 41.91 & 4.11 & 1.90 & 4.69 & 4.14 & 1.50 \\
\hline EDS-14 & Glass & 29.08 & 2.48 & 13.88 & 39.29 & 4.10 & 1.91 & 4.47 & 3.53 & 1.28 \\
\hline
\end{tabular}

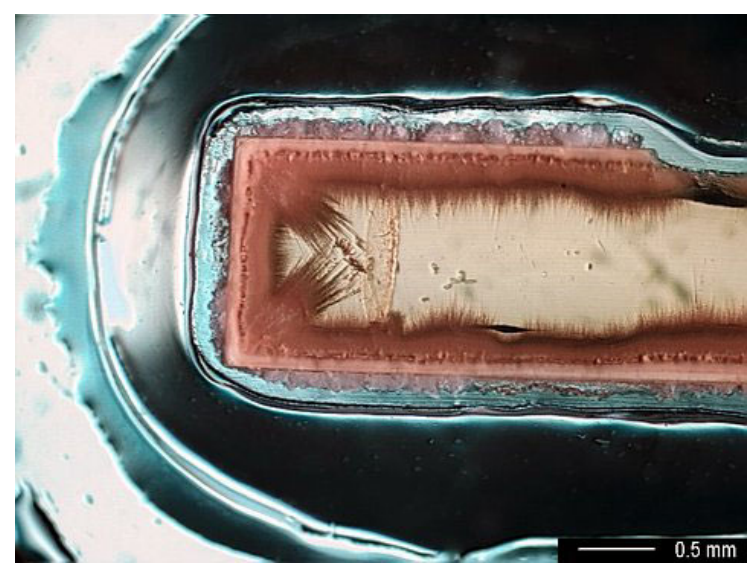

OM Micrograph of HLP-48 Cross Section after 87 Days at $150^{\circ} \mathrm{C}$

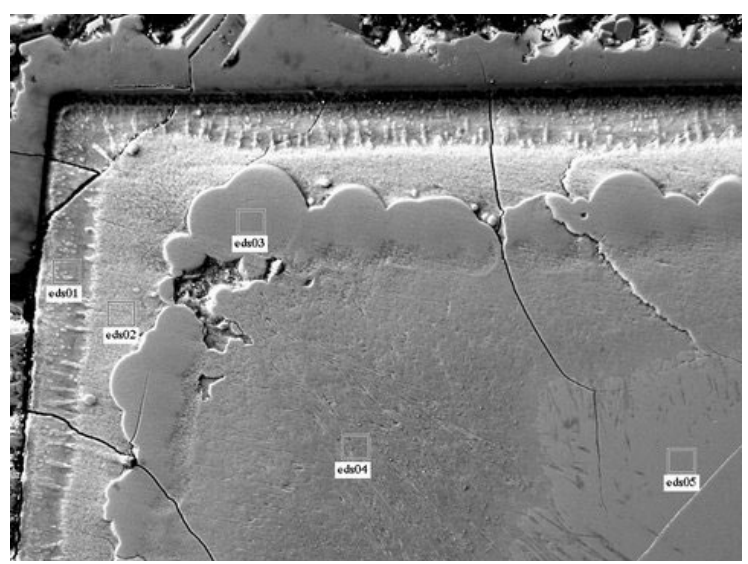

HLP-48 Location of EDS Measurements

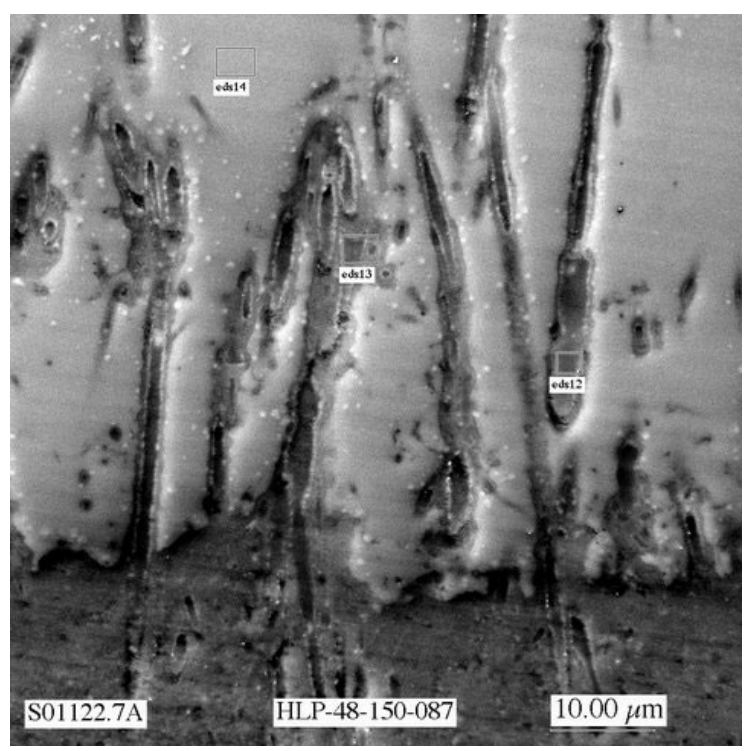

HLP-48 Location of EDS measurements

Figure 3.65. Location of EDS Spectra for HLP-48 Glass Subjected to VHT at $150^{\circ} \mathrm{C}$ for 87 Days 
The fiber-like alteration patterns seen in samples of HLP-48 tested at $150^{\circ} \mathrm{C}$ were not as prevalent in samples tested at $200^{\circ} \mathrm{C}$. Figure 3.66 shows a BSE micrograph of the cross section of HLP-48 sample tested at $200^{\circ} \mathrm{C}$ for 10 days. There is clear distinction between five layers of the sample. Table 3.26 give the EDS results taken in each of the five layers (with EDS-05 and EDS-06 being taken at two points in the remaining glass layer). A faint fiber-like pattern is seen on the right side of the micrograph, growing into the unaltered glass layer. The outermost layer (EDS-01) is the highest in Si and Al and the lowest in $\mathrm{Na}, \mathrm{K}, \mathrm{Fe}, \mathrm{Zn}$, and $\mathrm{Zr}$. The concentration of $\mathrm{Na}$ is significantly lower in all layers than the target value with the highest concentration being in the remaining glass. The $\mathrm{Na}$ was likely removed during sample polishing.

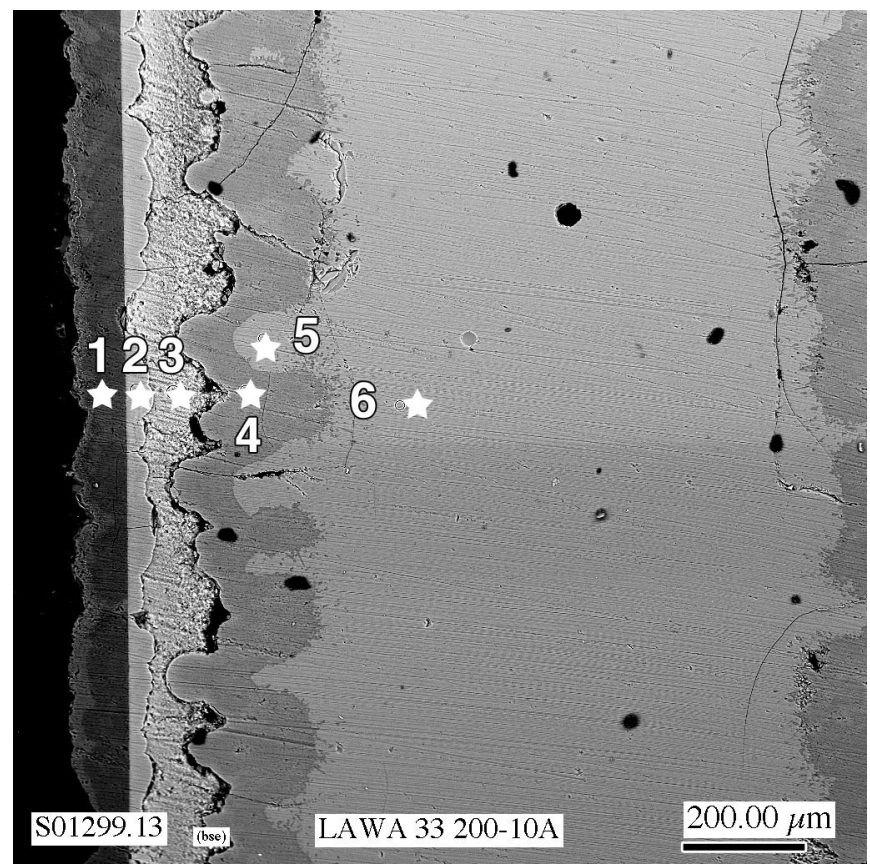

Figure 3.66. Location of EDS Spectra for HLP-48 Glass Subjected to VHT at $200^{\circ} \mathrm{C}$ for 10 Days

Table 3.26. EDS Results for HLP-48 Glass Subjected to VHT at $200^{\circ} \mathrm{C}$ for 10 days (normalized mass\% of elements)

\begin{tabular}{|c|c|c|c|c|c|c|c|c|c|c||}
\hline ID & Na & $\mathbf{M g}$ & $\mathbf{A l}$ & $\mathbf{S i}$ & $\mathbf{C l}$ & $\mathbf{K}$ & $\mathbf{T i}$ & $\mathbf{F e}$ & $\mathbf{Z n}$ & $\mathbf{Z r}$ \\
\hline Target & 26.15 & 2.12 & 11.17 & 31.47 & 1.02 & 7.76 & 2.63 & 7.03 & 7.40 & 3.25 \\
\hline EDS-01 & 10.65 & & 11.26 & 23.12 & 0.03 & 0.33 & & 1.03 & 0.97 & 0.28 \\
\hline EDS-02 & 11.44 & 0.95 & 6.61 & 16.42 & 0.16 & 2.36 & 1.84 & 4.37 & 4.62 & 2.37 \\
\hline EDS-03 & 10.86 & 2.30 & 1.67 & 15.10 & 0.50 & 4.01 & 2.55 & 6.95 & 5.26 & 3.13 \\
\hline EDS-04 & 12.38 & 1.02 & 6.94 & 17.21 & 0.18 & 2.06 & 0.96 & 3.43 & 3.67 & 2.43 \\
\hline EDS-05 & 14.19 & 0.85 & 6.12 & 17.86 & 0.52 & 2.45 & 1.42 & 3.79 & 3.33 & 1.88 \\
\hline EDS-06 & 14.65 & 0.89 & 6.08 & 17.54 & 0.49 & 2.49 & 1.37 & 3.64 & 3.30 & 1.92 \\
\hline
\end{tabular}

The EDS results for HLP-51 are given in Table 3.27 in normalized mass $\%$ of elements. The locations of EDS analyses are indicated in the electron micrograph shown in Figure 3.67. Analysis of the surface layer at EDS-01 suggests an atomic ratio of $\mathrm{Na}_{1.1} \mathrm{Al}_{1.0} \mathrm{Si}_{2.1}$. The layer under the surface layer was depleted 
of sodium and aluminum. Although the layers marked with EDS-03 and EDS-04 are distinguishable with both OM and SEM/EDS, their compositions are similar, showing significant variation only in the content of sodium and aluminum. Initial glass composition corresponds to that of EDS-05, but shows lower sodium concentration.

Table 3.27. EDS Results for HLP-51 Glass Subjected to VHT at $200^{\circ} \mathrm{C}$ (normalized mass\% of elements)

\begin{tabular}{||c|c|c|r|c|c|c|c|c|c|c||}
\hline ID & Na & $\mathbf{M g}$ & \multicolumn{1}{c|}{ Al } & Si & K & La & Ti & $\mathbf{F e}$ & $\mathbf{Z n}$ & $\mathbf{Z r}$ \\
\hline Target & 28.0 & 1.1 & 10.0 & 36.9 & 3.4 & 3.2 & 2.8 & 3.3 & 3.9 & 7.3 \\
\hline EDS-01 & 20.4 & 0.0 & 22.2 & 48.0 & 1.0 & 0.0 & 0.1 & 2.3 & 4.5 & 1.5 \\
\hline EDS-02 & 9.4 & 2.1 & 2.6 & 39.3 & 7.2 & 9.1 & 7.7 & 7.5 & 6.3 & 8.8 \\
\hline EDS-03 & 16.6 & 1.6 & 3.4 & 38.5 & 7.0 & 4.8 & 4.1 & 3.6 & 4.6 & 16.0 \\
\hline EDS-04 & 13.6 & 0.6 & 10.2 & 43.2 & 7.4 & 3.5 & 3.1 & 3.4 & 4.5 & 10.5 \\
\hline EDS-05 & 19.1 & 0.5 & 9.9 & 41.8 & 4.2 & 3.4 & 3.1 & 3.3 & 4.3 & 10.2 \\
\hline \hline
\end{tabular}

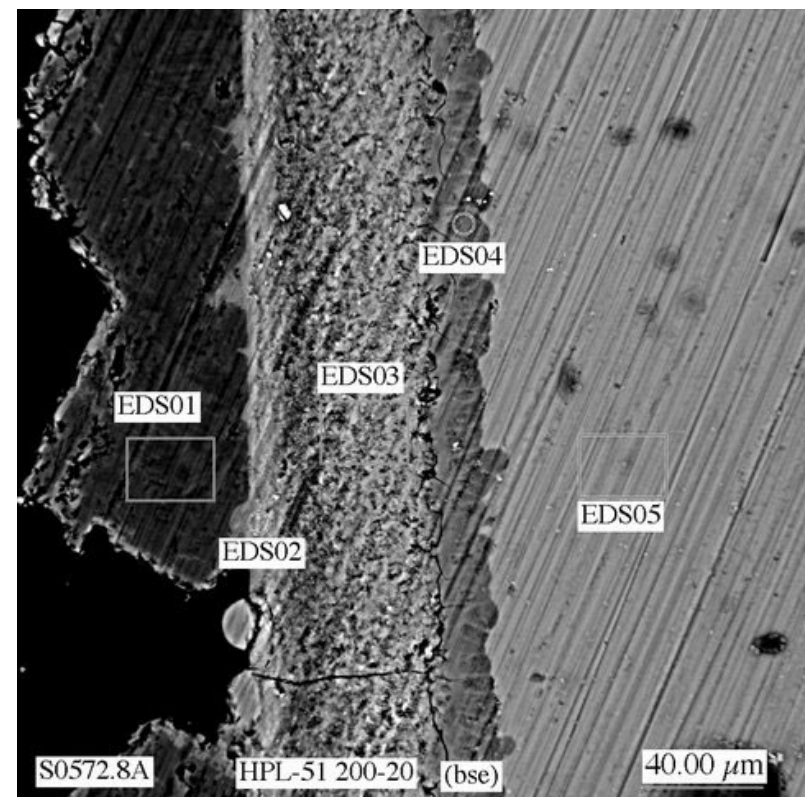

Figure 3.67. Location of EDS Measurements for HLP-51 Subjected to VHT at $200^{\circ} \mathrm{C}$ for 20 Days

The EDS results (in normalized atomic\% of elements) for the HLP-51 specimen exposed to VHT conditions at $200^{\circ} \mathrm{C}$ are given in Table 3.27 , and for specimens subjected to VHT at $150^{\circ} \mathrm{C}$, the results are given in Table 3.28. The location of EDS measurements is displayed in Figure 3.67 and Figure 3.68. Three different compositions were observed in the areas with preferential leaching. The first composition matches the target glass composition and is shown in EDS-08 and EDS-11. The second composition (EDS-10) shows depletion of sodium (roughly $9 \mathrm{~mol} \%$ ) and enrichment of silica ( $8 \mathrm{~mol} \%$ ) and magnesium (1.5 mol\%). The third composition (EDS-09) shows no magnesium and an enrichment of aluminum (4 mol\%), and possibly silica ( $2 \mathrm{~mol} \%$ ) (however, polishing the sample may affect $\mathrm{Al}$ concentration). 
Table 3.28. EDS Results for HLP-51 Glass Subjected to VHT at $150^{\circ} \mathrm{C}$

\begin{tabular}{|c|c|c|c|c|c|c|c|c|c|c|}
\hline & Location & Na & Mg & Al & Si & K & Ti & Fe & Zn & SUM \\
\hline Target & Glass & 37.86 & 1.46 & 11.51 & 40.90 & 2.74 & 1.83 & 1.84 & 1.87 & 100.00 \\
\hline EDS-01 & Glass & 38.03 & 1.05 & 11.13 & 41.98 & 2.75 & 1.28 & 1.73 & 2.04 & 100.00 \\
\hline EDS-08 & Glass & 35.29 & 1.16 & 11.60 & 43.82 & 2.83 & 1.33 & 1.82 & 2.14 & 100.00 \\
\hline EDS-09 & Fiber & 36.66 & 0.00 & 15.59 & 42.59 & 1.10 & 0.87 & 1.00 & 2.19 & 100.00 \\
\hline EDS-10 & Fiber & 28.79 & 2.92 & 10.35 & 47.89 & 2.88 & 1.80 & 2.88 & 2.49 & 100.00 \\
\hline EDS-11 & Glass & 35.48 & 1.19 & 11.73 & 43.79 & 2.73 & 1.31 & 1.80 & 1.97 & 100.00 \\
\hline
\end{tabular}

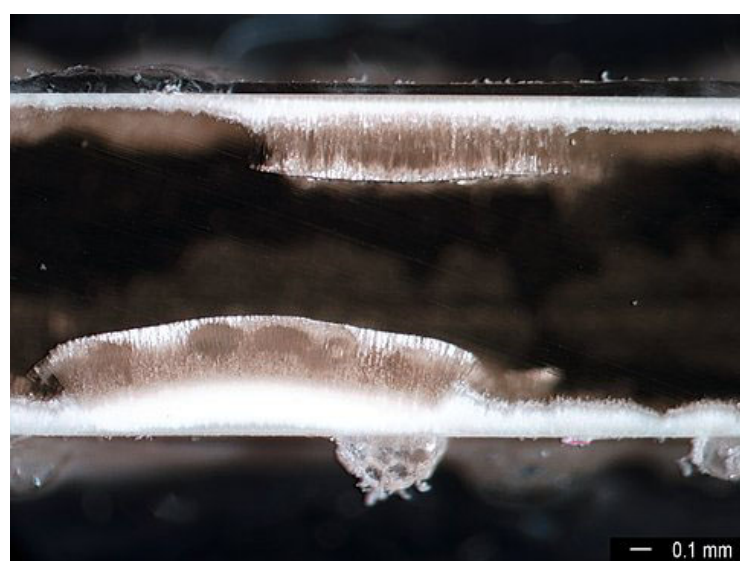

OM Micrograph of HLP-51 Cross Section after 215 Days at $150^{\circ} \mathrm{C}$

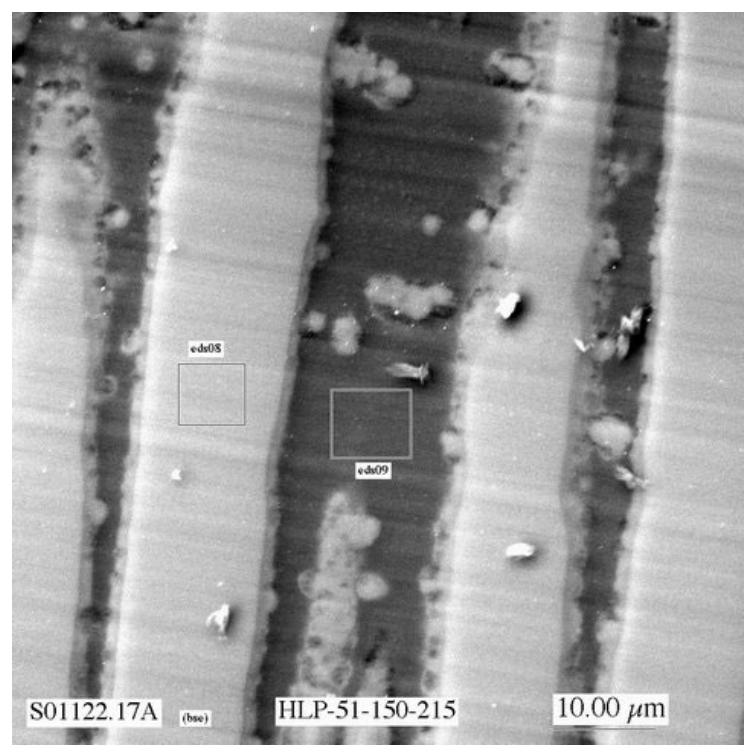

HLP-51 Location of EDS measurements

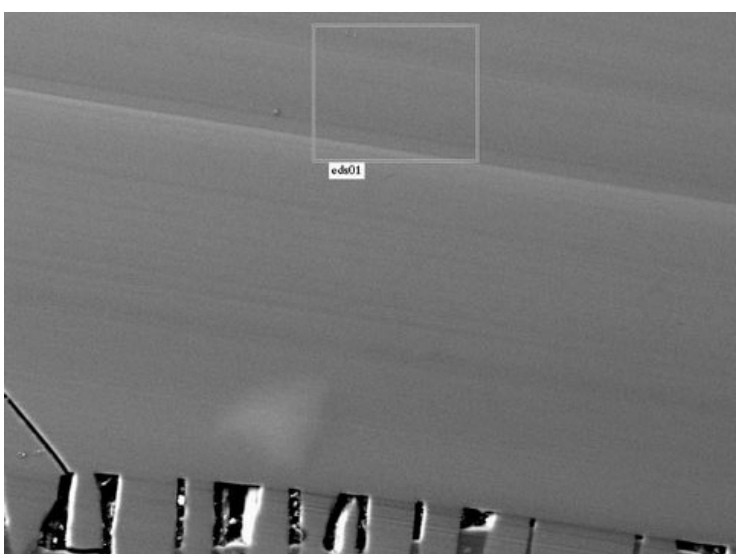

HLP-51 Location of EDS Measurements

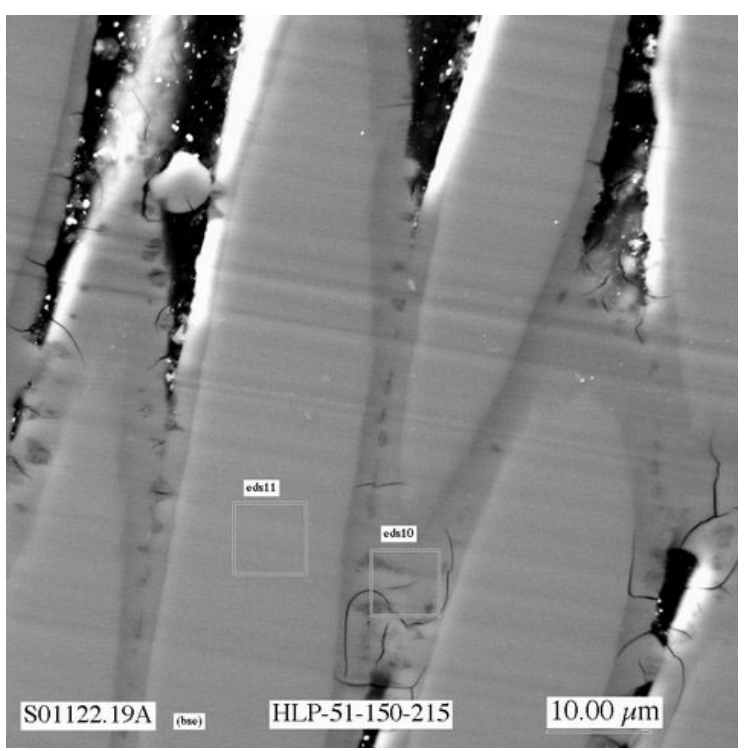

HLP-51 Location of EDS measurements

Figure 3.68. Location of EDS Measurements for HLP-51 Glass Subjected to VHT at $150^{\circ} \mathrm{C}$ for 215 Days 


\section{Specimen Surface}

The EDS results for HLP-12 are given in Table 3.29 in normalized mass $\%$ of elements. The locations of EDS measurements are indicated in the electron micrograph shown in Figure 3.69. Analyses of EDS spectra taken at EDS-09 and EDS-11 show similar composition, yielding the atomic ratios of $\mathrm{Na}_{1.6} \mathrm{Al}_{1.0} \mathrm{Si}_{2.8}$, which approximately corresponds to analcime $\left(\mathrm{NaAlSi}_{2} \mathrm{O}_{6} \cdot \mathrm{H}_{2} \mathrm{O}\right)$. EDS-10 shows significant amounts of sodium, silicon, and iron, indicating the presence of aegirine $\left(\mathrm{NaFe}\left(\mathrm{SiO}_{3}\right)_{2}\right)$.

Aegirine was observed to a form wide range of composition, yielding possibly augite $\left(\mathrm{Ca}\left(\mathrm{Mg}, \mathrm{Fe}^{2+}\right) \mathrm{Si}_{2} \mathrm{O}_{6}\right)$ and its intermediate mineral aegirine-augite. It was also observed to contain minor amounts of titanium (Bates 1984) and aluminum that is substituting for silicon up to 10\% (Nesse 1991). Analyses of the EDS spectra taken at EDS-10 yield the atomic ratios of $\mathrm{Na}_{1.4} \mathrm{Fe}_{0.2} \mathrm{Al}_{0.3} \mathrm{Si}_{1.6}$ that might correspond to one of the aegirine compositions. Analcime $\left(\mathrm{NaAlSi}_{2} \mathrm{O}_{6} \cdot \mathrm{H}_{2} \mathrm{O}\right)$ and Na-clinopyroxene aegirine $\left(\mathrm{NaFe}\left(\mathrm{SiO}_{3}\right)_{2}\right)$ were identified as the major crystalline phases in the XRD pattern.

Table 3.29. EDS Results for HLP-12 Glass Subjected to VHT at $200^{\circ} \mathrm{C}$ (normalized mass $\%$ of elements)

\begin{tabular}{||c|c|c|r|r|c|c|r|c|c||}
\hline ID & Na & $\mathbf{M g}$ & \multicolumn{1}{|c|}{ Al } & \multicolumn{1}{c|}{$\mathbf{S i}$} & $\mathbf{K}$ & $\mathbf{T i}$ & $\mathbf{F e}$ & $\mathbf{Z n}$ & $\mathbf{Z r}$ \\
\hline Target & 27.8 & 1.7 & 6.9 & 43.0 & 0.6 & 3.4 & 12.2 & 2.3 & 2.1 \\
\hline EDS-09 & 23.2 & 0.0 & 17.0 & 49.6 & 0.2 & 0.5 & 7.3 & 2.2 & 0.0 \\
\hline EDS-10 & 31.1 & 0.0 & 6.9 & 43.9 & 0.2 & 1.2 & 13.6 & 3.1 & 0.0 \\
\hline EDS-11 & 25.7 & 0.0 & 13.5 & 47.6 & 0.3 & 0.6 & 9.6 & 2.8 & 0.0 \\
\hline
\end{tabular}

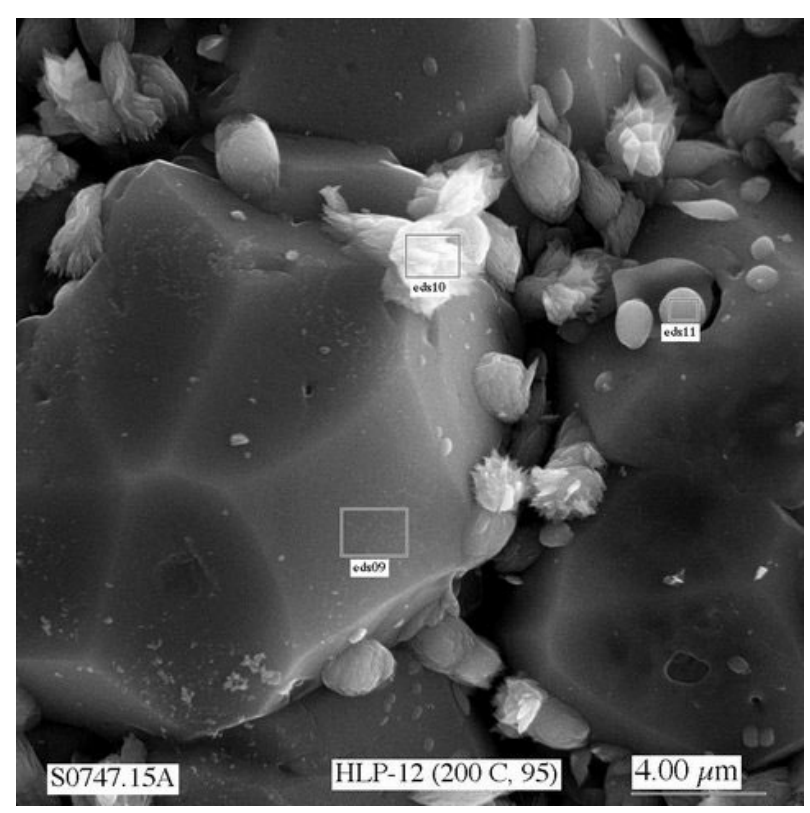

Figure 3.69. Locations of EDS Measurements for HLP-12 Subjected to VHT at $200^{\circ} \mathrm{C}$ for 95 Days 
The EDS results for HLP-31 are given in Table 3.30 in normalized mass $\%$ of elements. The locations of EDS measurements are indicated in the electron micrograph shown in Figure 3.70. EDS-09 is not displayed, but its location approximately corresponds to EDS-01. Analyses of the EDS spectra at EDS-01 and EDS-09 yield the atomic ratios of $\mathrm{Na}_{1.0} \mathrm{Al}_{0.4} \mathrm{Fe}_{0.1} \mathrm{Si}_{1.8}$. Its morphology does not correspond to analcime $\left(\mathrm{NaAlSi}_{2} \mathrm{O}_{6} \cdot \mathrm{H}_{2} \mathrm{O}\right)$, which was identified as a major crystalline phase, and it does not contain enough titanium to form sodium titanium silicate $\left(\mathrm{NaTiSi}_{2} \mathrm{O}_{6}\right)$, which was identified as a second alteration product. Therefore, it must be concluded that this crystalline phase is a clinopyroxene solid solution with the composition closer to Na-Fe clinopyroxene and the crystal structure closer to Na-Ti clinopyroxene.

Table 3.30. EDS Results for HLP-31 Glass Subjected to VHT at $200^{\circ} \mathrm{C}$ (normalized mass\% of elements)

\begin{tabular}{|c|c|c|r|r|c|c|c|c|c|c||}
\hline ID & $\mathbf{N a}$ & $\mathbf{M g}$ & \multicolumn{1}{c|}{$\mathbf{A l}$} & $\mathbf{S i}$ & $\mathbf{K}$ & $\mathbf{C a}$ & $\mathbf{T i}$ & $\mathbf{F e}$ & $\mathbf{Z n}$ & $\mathbf{Z r}$ \\
\hline Target & 34.6 & 1.1 & 4.3 & 49.3 & 0.8 & 0.0 & 2.2 & 4.8 & 1.5 & 1.4 \\
\hline EDS-01 & 18.6 & 0.0 & 15.3 & 52.5 & 0.2 & 0.0 & 1.5 & 7.4 & 2.5 & 1.8 \\
\hline EDS-02 & 33.9 & 1.1 & 7.4 & 48.9 & 0.4 & 0.0 & 1.7 & 3.9 & 1.2 & 1.5 \\
\hline EDS-09 & 42.5 & 0.0 & 11.1 & 39.8 & 0.0 & 0.0 & 0.7 & 3.3 & 1.1 & 1.4 \\
\hline
\end{tabular}

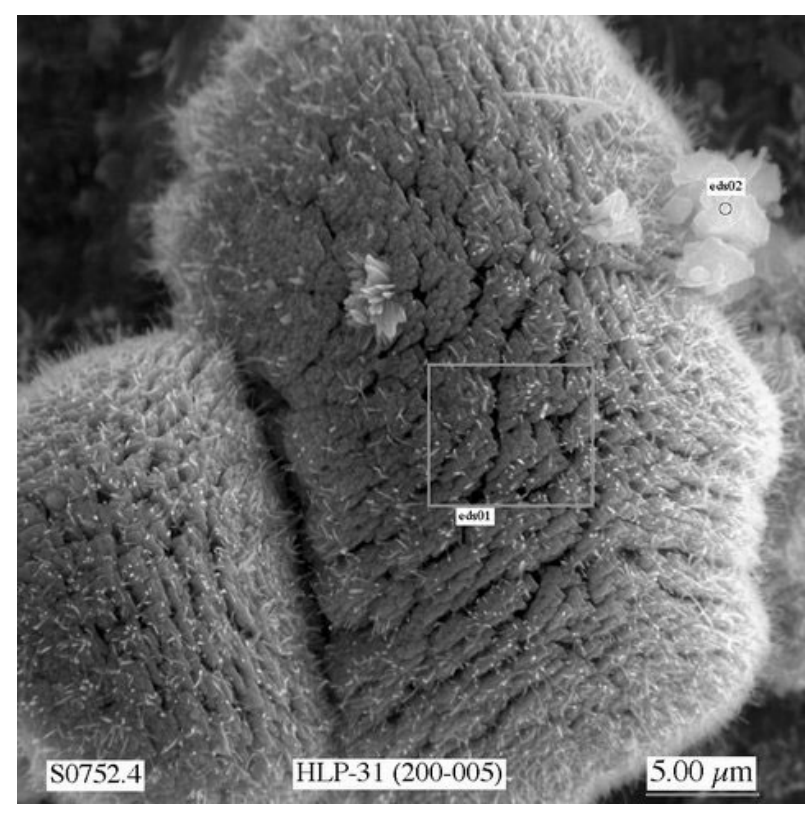

Figure 3.70. Locations of EDS Measurements for HLP-31 Subjected to VHT at $200^{\circ} \mathrm{C}$ for 5 Days

The EDS results for HLP-43 are given in Table 3.31 in mass\% of elements. The locations of EDS measurements are indicated in the electron micrograph shown in Figure 3.71. Analyses of the EDS spectra at EDS-01 and EDS-02 yield the atomic ratios of $\mathrm{Na}_{1.4} \mathrm{Al}_{1.0} \mathrm{Si}_{2.5}$ and $\mathrm{Na}_{3.0} \mathrm{Al}_{1.0} \mathrm{Si}_{4.4}$, respectively. Both compositions are roughly equal to analcime $\left(\mathrm{NaAlSi}_{2} \mathrm{O}_{6} \cdot \mathrm{H}_{2} \mathrm{O}\right)$, but this phase (EDS-02) is depleted of aluminum. Analyses of the phase at EDS- 07 yield the atomic ratio of $\mathrm{Na}_{1.3} \mathrm{Al}_{1.0} \mathrm{Si}_{2.6}$, which roughly equates to analcime $\left(\mathrm{NaAlSi}_{2} \mathrm{O}_{6} \cdot \mathrm{H}_{2} \mathrm{O}\right)$ as well. The shape of these analcime crystals, created at $250^{\circ} \mathrm{C}$, suggests that the crystals are in their cubic configuration and were created by rapid growth. Spots labeled 
Table 3.31. EDS Results for HLP-43 Glass Subjected to VHT at $250^{\circ} \mathrm{C}$ (normalized mass \% of elements)

\begin{tabular}{|c|r|r|r|r|c|c|c|c|c|}
\hline ID & Na & $\mathbf{M g}$ & \multicolumn{1}{|c|}{$\mathbf{A l}$} & \multicolumn{1}{c|}{$\mathbf{S i}$} & $\mathbf{K}$ & $\mathbf{T i}$ & $\mathbf{F e}$ & $\mathbf{Z n}$ & $\mathbf{Z r}$ \\
\hline Target & 29.3 & 1.8 & 7.3 & 45.3 & 0.7 & 3.5 & 7.6 & 2.4 & 2.2 \\
\hline EDS-01 & 14.4 & 0.0 & 20.2 & 58.3 & 0.0 & 0.1 & 2.3 & 4.2 & 0.5 \\
\hline EDS-02 & 27.4 & 0.0 & 10.6 & 48.4 & 0.3 & 0.1 & 4.6 & 8.7 & 0.0 \\
\hline EDS-05 & 3.5 & 0.0 & 3.3 & 3.9 & 0.1 & 8.3 & 57.4 & 23.5 & 0.1 \\
\hline EDS-11 & 5.6 & 0.0 & 3.3 & 5.6 & 0.2 & 11.0 & 54.3 & 19.8 & 0.2 \\
\hline
\end{tabular}
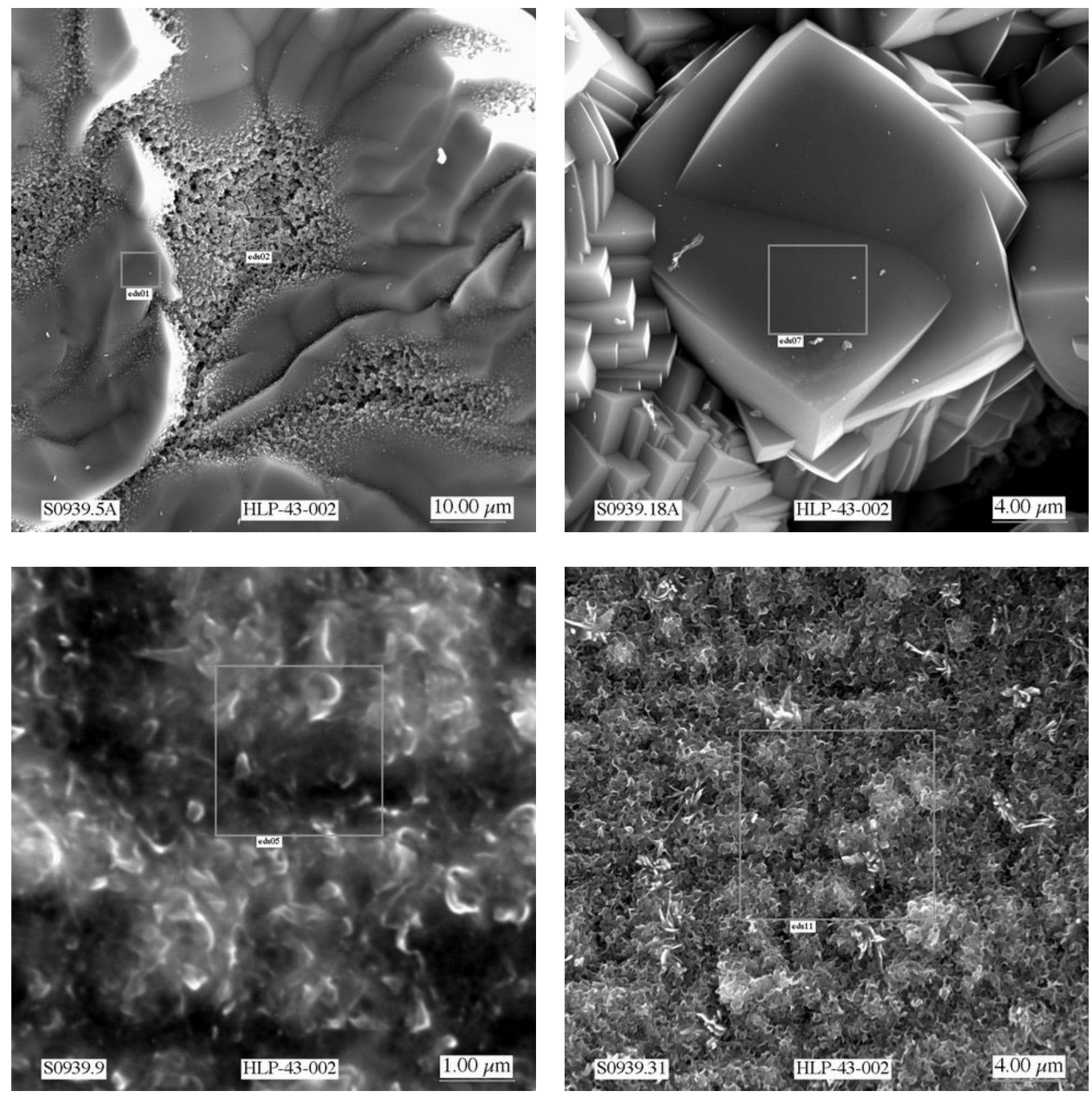

Figure 3.71. Locations of EDS Measurements for HLP-43 Subjected to VHT at $250^{\circ} \mathrm{C}$ for 2 Days 
EDS-05 and EDS-11 show the specimen surface between the crystalline phases. Their composition is similar. These surface layers show depletion of sodium, magnesium, silicon, potassium, and zirconium. They are rich in titanium $(2 \times$ higher content than in the initial glass), iron ( $8 \times$ higher), and zinc (10× higher), indicating the presence of zinc iron titanium oxide $\left(\mathrm{ZnFeTiO}_{4}\right)$. However, this observation was not confirmed in the XRD pattern for this specimen.

The EDS results for HLP-48 are given in Table 3.32 in normalized mass $\%$ of elements. The locations of EDS measurements are indicated in the electron micrograph shown in Figure 3.72. Crystals marked with EDS-22 were identified as sodium chloride with the atomic ratios of $\mathrm{Na}_{1.0} \mathrm{Cl}_{1.1}$. The surface layer marked with EDS-23 is enriched with titanium, iron, and zinc when compared to the target glass composition. The crystalline phase was not identified. Analysis of EDS-26 yields analcime $\mathrm{Na}_{1.0} \mathrm{Al}_{1.0} \mathrm{Si}_{2.4}$. An unknown crystalline phase, marked with EDS-25, is located on top of analcime crystals. This phase is rich in zirconium and sodium and also contains silicon and aluminum.

Table 3.32. EDS Results for HLP-48 Glass Subjected to VHT at $175^{\circ} \mathrm{C}$ (normalized mass $\%$ of elements)

\begin{tabular}{|c|r|r|r|r|r|r|r|r|r|r||}
\hline ID & \multicolumn{1}{|c|}{ Na } & $\mathbf{M g}$ & \multicolumn{1}{|c|}{ Al } & \multicolumn{1}{c|}{ Si } & K & Cl & \multicolumn{1}{c|}{ Ti } & Fe & Zn & \multicolumn{1}{|c|}{$\mathbf{r r}$} \\
\hline Target & 20.0 & 0.0 & 12.0 & 38.3 & 3.1 & 0.6 & 2.5 & 5.8 & 4.3 & 2.5 \\
\hline EDS-22 & 35.9 & 0.0 & 0.4 & 0.9 & 0.3 & 61.1 & 0.3 & 0.6 & 0.6 & 0.1 \\
\hline EDS-23 & 3.8 & 0.0 & 1.0 & 1.4 & 1.2 & 0.8 & 27.1 & 38.6 & 25.8 & 0.4 \\
\hline EDS-25 & 51.7 & 0.0 & 3.6 & 12.3 & 0.6 & 1.2 & 0.0 & 0.4 & 0.7 & 29.6 \\
\hline EDS-26 & 18.6 & 0.0 & 21.0 & 52.5 & 1.0 & 0.2 & 0.1 & 1.9 & 2.6 & 2.1 \\
\hline
\end{tabular}
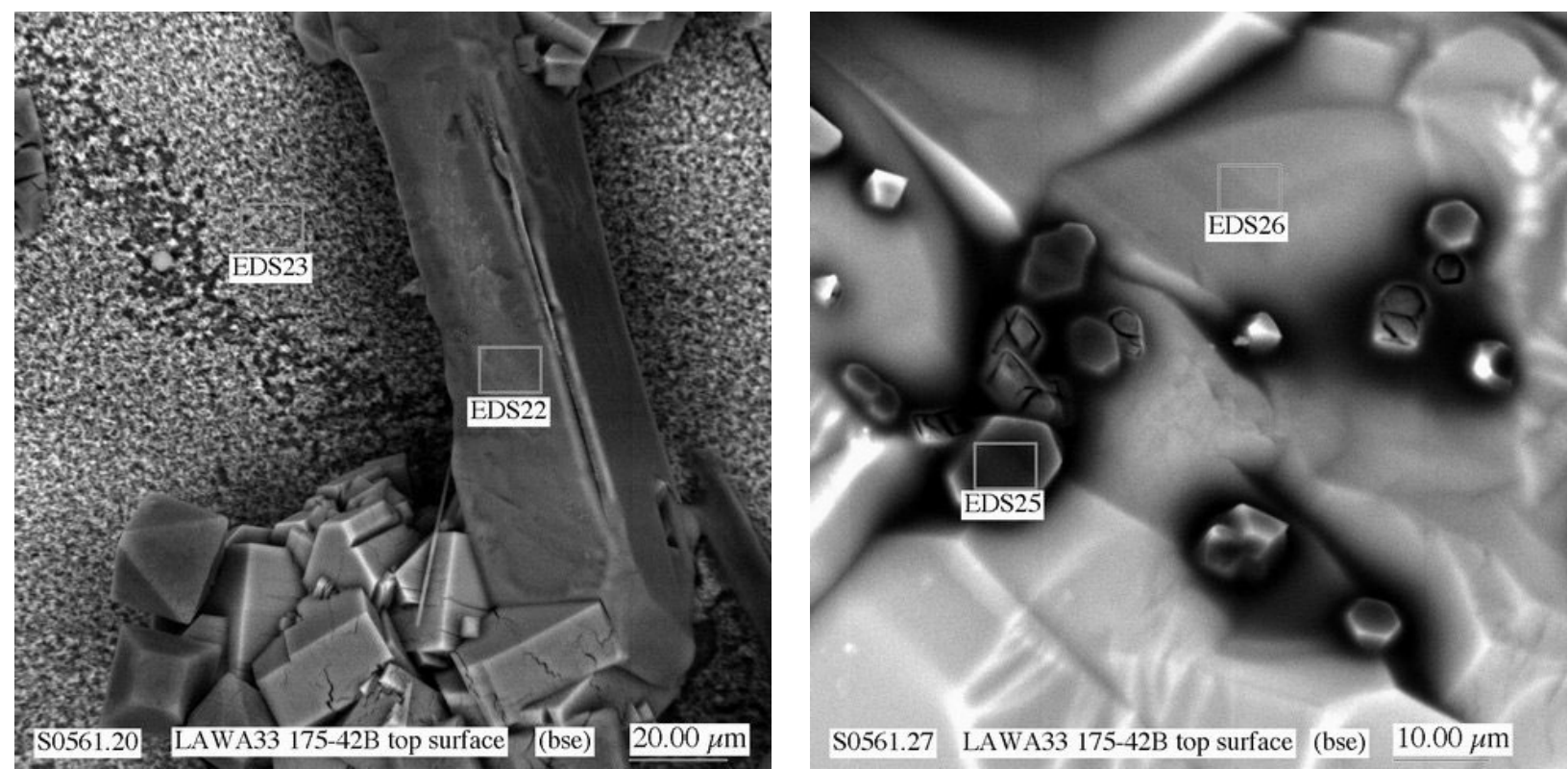

Figure 3.72. Location of EDS Measurements for HLP-48 Subjected to VHT at $175^{\circ} \mathrm{C}$ for 42 Days 
The EDS results for HLP-56 are given in Table 3.33 in normalized mass\% of elements. The locations of EDS measurements are indicated in the electron micrograph shown in Figure 3.73. Analyses of EDS-01 and EDS-04 yield $\mathrm{Na}_{1.4} \mathrm{Al}_{1.0} \mathrm{Si}_{2.5}$, corresponding to analcime $\left(\mathrm{NaAlSi}_{2} \mathrm{O}_{6} \cdot \mathrm{H}_{2} \mathrm{O}\right)$. Analysis of EDS-02 yields $\mathrm{Na}_{1.5} \mathrm{Fe}_{0.5} \mathrm{Ti}_{0.1} \mathrm{Si}_{2.0}$, corresponding to acmite-augite $\left((\mathrm{Na}, \mathrm{Ca}) \mathrm{FeSi}_{2} \mathrm{O}_{6}\right)$. Both phases were also identified with XRD.

Table 3.33. EDS Results for HLP-56 Glass Subjected to VHT at $250^{\circ} \mathrm{C}$ (normalized mass $\%$ of elements)

\begin{tabular}{||c|c|c|c|c|c|c|c|c|c|c|c||}
\hline \hline Initial Glass & $\mathbf{N a}$ & $\mathbf{M g}$ & $\mathbf{A l}$ & $\mathbf{S i}$ & $\mathbf{K}$ & $\mathbf{C a}$ & $\mathbf{T i}$ & $\mathbf{F e}$ & $\mathbf{Z n}$ & $\mathbf{Z r}$ & $\mathbf{R e}$ \\
\hline Target & 28.45 & 2.31 & 6.29 & 39.93 & 0.40 & 2.73 & 2.29 & 9.36 & 3.82 & 4.25 & 0.16 \\
\hline EDS-01 & 22.26 & 0.00 & 19.24 & 49.76 & 0.04 & 0.11 & 0.11 & 3.00 & 4.54 & 0.94 & 0.00 \\
\hline EDS-04 & 29.36 & 0.00 & 18.72 & 45.61 & 0.02 & 0.02 & 0.02 & 2.24 & 3.65 & 0.35 & 0.00 \\
\hline EDS-02 & 24.62 & 0.36 & 0.53 & 38.97 & 0.08 & 2.35 & 4.74 & 20.47 & 5.43 & 2.45 & 0.00 \\
\hline
\end{tabular}

The EDS results for HLP-64 are given in Table 3.34 in normalized mass\% of elements. The locations of EDS measurements are indicated in the electron micrograph shown in Figure 3.74. Crystals marked with EDS-03 and EDS-04 are high in Na, Zn, and Zr while the phases marked with EDS-01 and EDS-02 are high in $\mathrm{Si}$ ad K. No phases could be matched to the XRD pattern taken on the sample surface (see Appendix E).

Table 3.34. EDS Results for HLP-64 Glass Subjected to VHT at $200^{\circ} \mathrm{C}$ for 44 days (normalized mass\% of elements)

\begin{tabular}{||c|c|c|c|c|c|c|c|c||}
\hline ID & Na & Mg & Al & Si & K & Ca & Zn & Zr \\
\hline Target & 22.48 & 4.91 & 4.01 & 46.02 & 7.86 & 0.01 & 6.30 & 8.41 \\
\hline EDS-01 & 22.53 & - & 5.75 & 46.64 & 8.96 & - & 3.76 & 12.36 \\
\hline EDS-02 & 19.77 & 5.81 & 3.55 & 44.96 & 8.38 & - & 7.76 & 9.77 \\
\hline EDS-03 & 37.07 & 0.83 & - & 1.67 & - & 6.96 & 22.19 & 31.29 \\
\hline EDS-04 & 60.49 & 0.52 & - & 1.96 & 0.19 & 0.15 & 9.87 & 26.82 \\
\hline
\end{tabular}



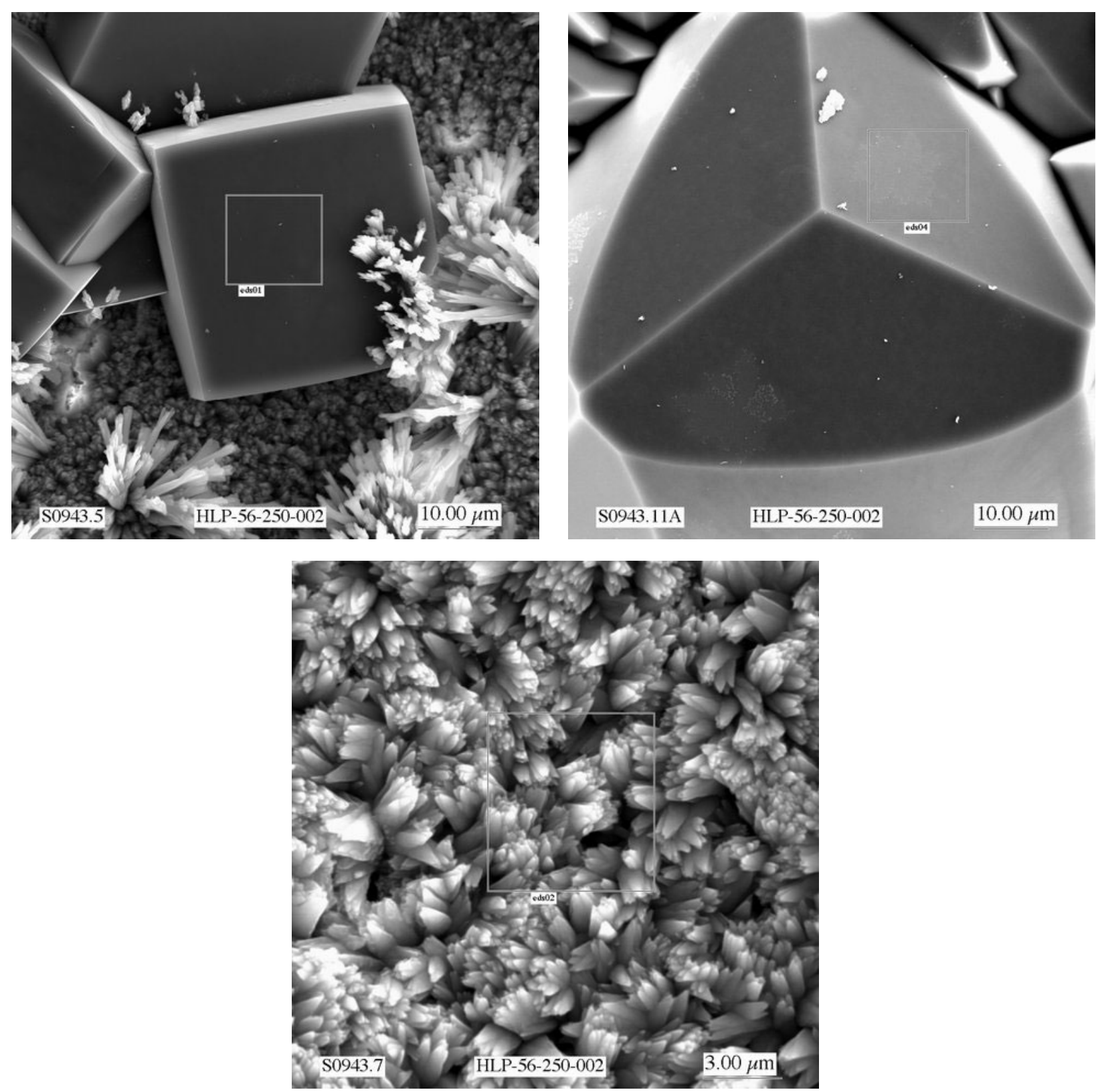

Figure 3.73. Locations of EDS Measurements for HLP-56 Subjected to VHT at $250^{\circ} \mathrm{C}$ for 2 Days 


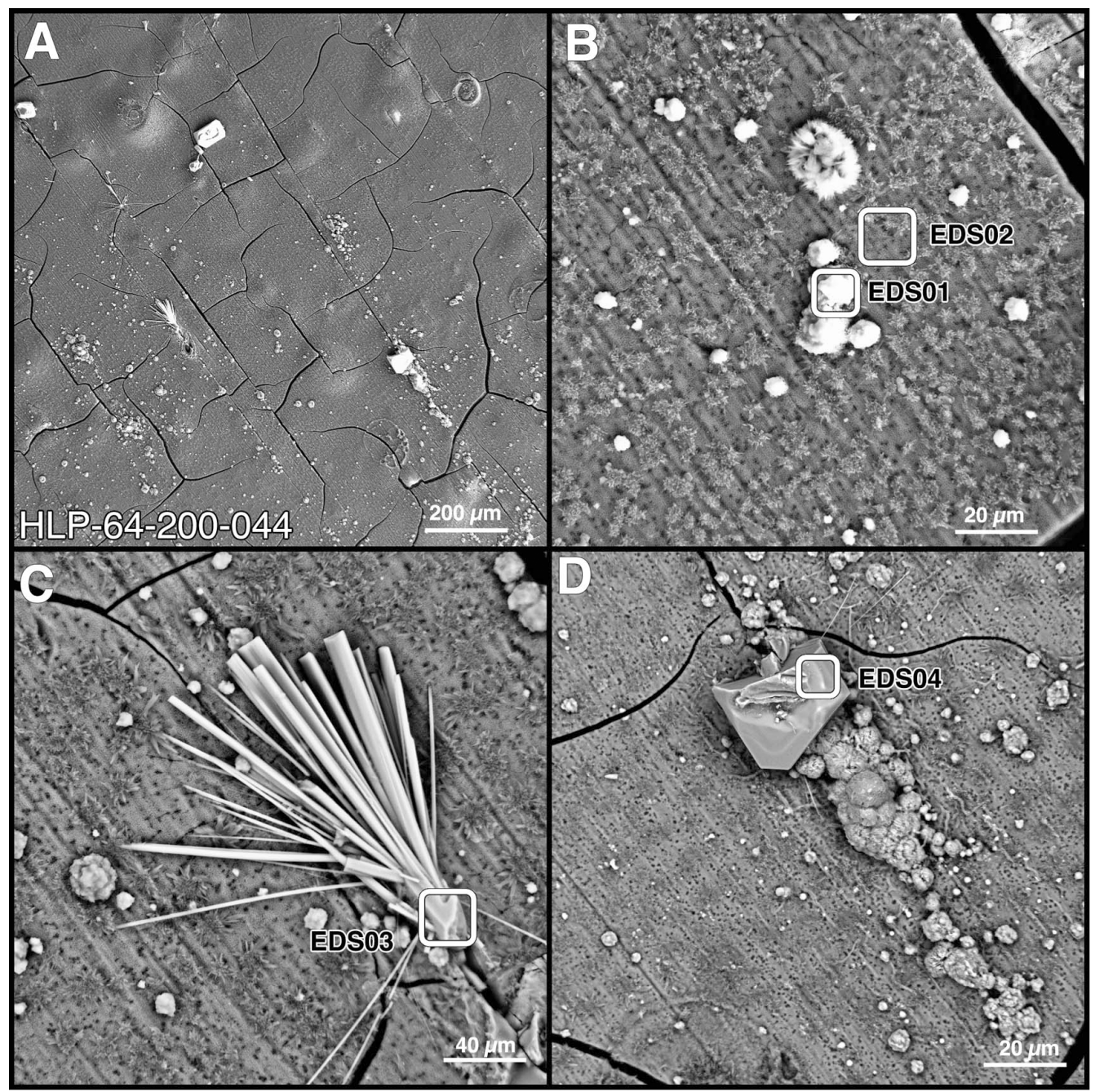

Figure 3.74. Location of EDS Spectra for HLP-64 Glass Subjected to VHT at $200^{\circ} \mathrm{C}$ for 44 days

The EDS results for HLP-69 are given in Table 3.35 in normalized mass\% of elements. The locations of EDS measurements are indicated in the electron micrograph shown in Figure 3.75. There are relatively high Ca concentrations in all EDS spectra for this sample, which is surprising because of the low target $\mathrm{Ca}$ concentration in the glass (which was confirmed in chemical analyses of glass samples). Analyses of EDS-01, -02, -03, and -04 suggests a sodium salt, calcium silicate, a sodium-iron mineral, and sodiumpotassium-iron-silicate (possibly clinopyroxene), respectively.

Table 3.35. EDS Results for HLP-69 Glass Subjected to VHT at $200^{\circ} \mathrm{C}$ for 28 days (normalized mass\% of elements)

\begin{tabular}{|c|r|l|c|r|c|c|c||}
\hline ID & \multicolumn{1}{|c|}{ Na } & Mg & Al & \multicolumn{1}{c|}{ Si } & K & Ca & Fe \\
\hline Target & 27.64 & 0 & 14.71 & 56.6 & 0.638 & 0.017 & 0.391 \\
\hline EDS-01 & 90.48 & 0.27 & - & 3.48 & 1.89 & 2.06 & 1.82 \\
\hline EDS-02 & 7.43 & - & 3.89 & 39.56 & 7.17 & 37.13 & 4.81 \\
\hline EDS-03 & 21.21 & - & 0.52 & 5.93 & 2.19 & 0.74 & 69.42 \\
\hline EDS-04 & 8.89 & - & 2.77 & 24.96 & 10.9 & 2.28 & 50.2 \\
\hline
\end{tabular}




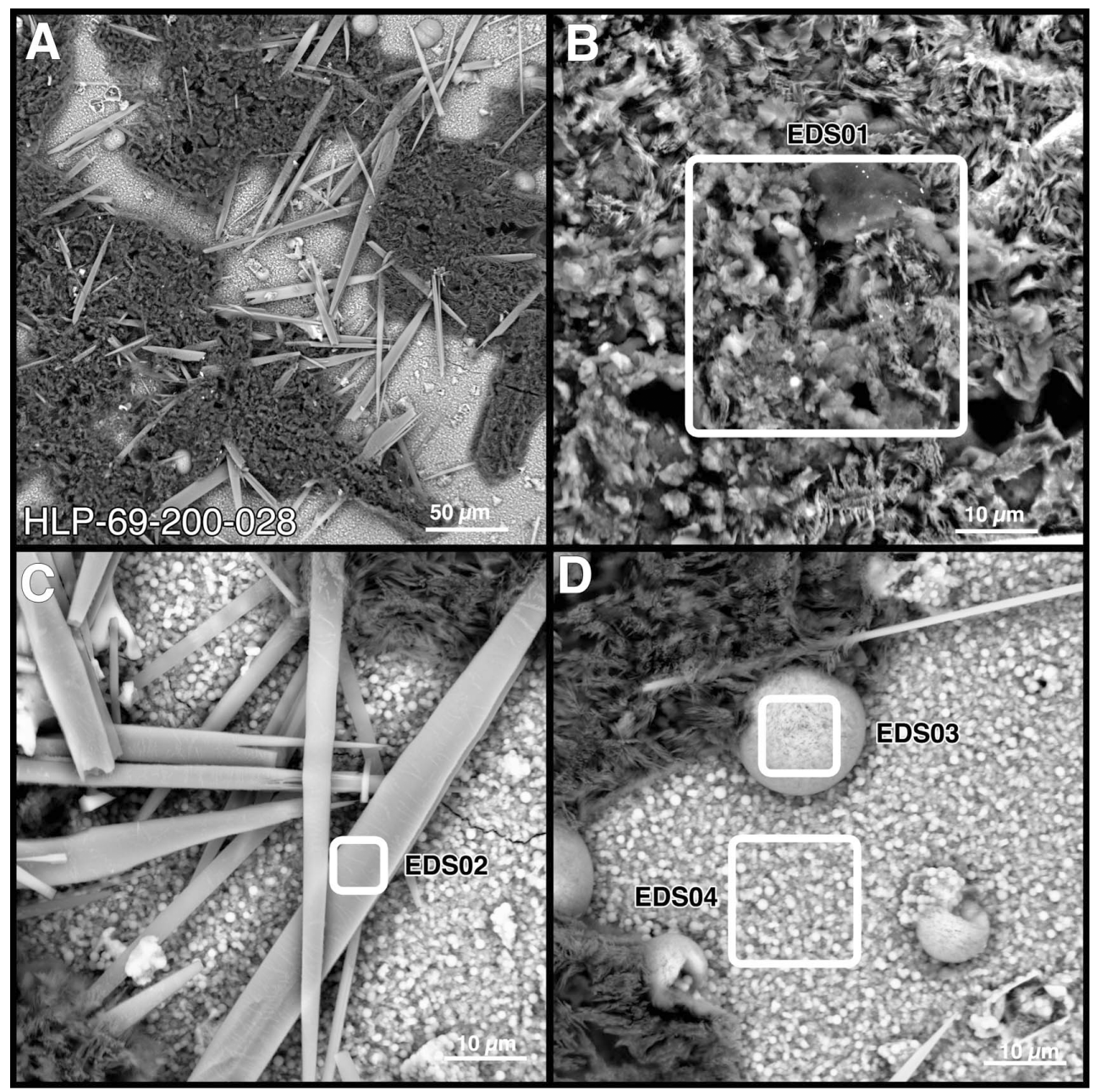

Figure 3.75. Location of EDS Spectra for HLP-69 Glass Subjected to VHT at $200^{\circ} \mathrm{C}$ for 28 days

The EDS results for HLP-70 are given in Table 3.36 in normalized mass $\%$ of elements. The locations of EDS measurements are indicated in the electron micrograph shown in Figure 3.76. There are relatively low Ti concentrations in all EDS spectra for this sample. The phase marked by EDS-01 is an alkalialuminosilicate with estimated stoichiometry of $\mathrm{Na}_{3} \mathrm{Al}_{2} \mathrm{Si}_{2} \mathrm{O}_{\mathrm{x}}$. The phases marked by EDS-03 and -04 are sodium-calcium-silicates with estimated stoichiometries of $(\mathrm{Na}, \mathrm{K})_{8}(\mathrm{Al}, \mathrm{Si})_{5} \mathrm{Ca}_{2} \mathrm{O}_{\mathrm{x}}$ and $(\mathrm{Na}, \mathrm{K})_{8}(\mathrm{Al}, \mathrm{Si})_{2} \mathrm{Ca}_{1} \mathrm{O}_{\mathrm{x}}$, respectively. The phase marked by EDS-05 is an alkali-silicate.

Table 3.36. EDS Results for HLP-70 Glass Subjected to VHT at $200^{\circ} \mathrm{C}$ for 28 Days (normalized mass\% of elements)*

\begin{tabular}{|c|c|c|c|c|c|c|c|c||}
\hline ID & Na & Al & Si & Cl & K & Ca & Ti & Fe \\
\hline Target & 33.99 & 11.52 & 30.67 & 0.64 & 7.57 & 6.23 & 9.39 & 0.00 \\
\hline EDS-01 & 33.32 & 25.99 & 32.19 & 0.87 & 4.81 & 1.83 & 0.94 & 0.04 \\
\hline EDS-03 & 39.49 & 7.52 & 20.35 & 0.23 & 0.91 & 16.51 & 0.85 & - \\
\hline EDS-04 & 55.94 & 0.16 & 15.38 & - & 0.39 & 12.78 & 0.32 & - \\
\hline EDS-05 & 46.99 & 0.80 & 22.24 & 0.94 & 19.29 & 0.75 & 0.19 & 0.17 \\
\hline * EDS-02 was a carbon article from coating the specimen. \\
\hline
\end{tabular}




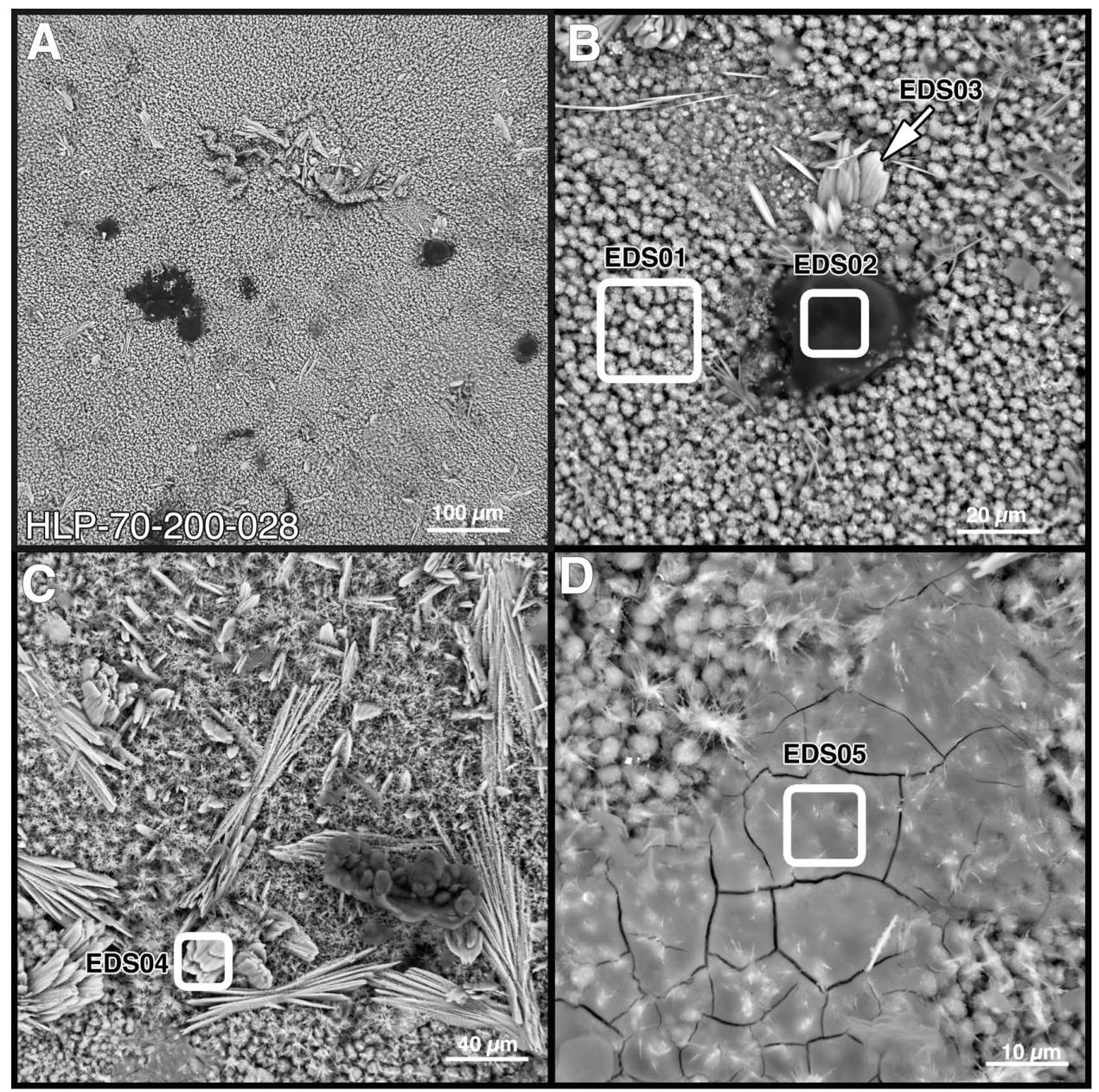

Figure 3.76. Location of EDS Spectra for HLP-70 Glass Subjected to VHT at $200^{\circ} \mathrm{C}$ for 28 days

\subsubsection{SEM/EDS Summary}

The SEM/EDS analyses reveal additional alteration products that cannot be detected with XRD. These alteration products are usually not present in amounts sufficient for the XRD identification. However, these phases may play an important role in the alteration process, and their identification is necessary if the alteration process is to be modeled with geochemical codes (McGrail et al. 2000). The combination of SEM/EDS and XRD analyses suggests that the density of alteration layers is decreasing from the middle of the specimen towards the surface, except the surface layer, which consists of crystalline phases. It also reveals that most of the alteration layers are amorphous or contain only a small amount of crystalline phases and that they contain all elements present in the initial glass in levels similar to the target glass compositions.

Although SEM/EDS was shown to be more suitable for analyzing the surface of the specimen, it revealed that the fiber-like shaped abnormalities, observed in some cross sections of LAW glasses subjected to the VHT, could be described as preferentially leached areas. These areas contain channels that show primarily a depletion of sodium (roughly $10 \mathrm{~mol} \%$ when compared to the glass composition). Enrichment in silica and magnesium was also observed. 


\section{Additional Analyses}

Ebert et al. (2001) performed complimentary and more detailed analyses of alteration products on some VHT samples.

\subsubsection{Temperature Effects on VHT Response}

The effect of temperature on the corrosion of glass in general and more specifically, if and how VHT data can be extrapolated to disposal conditions, is of primary interest to this study. Selected VHTs were started at temperatures ranging from $90^{\circ} \mathrm{C}$ to $300^{\circ} \mathrm{C}$ to determine the impact of temperature on the alteration rate and to identify any clear changes in alteration behavior that may exist. However, these low-temperature tests are still in progress, and results at temperatures ranging from $90^{\circ} \mathrm{C}$ to $150^{\circ} \mathrm{C}$ are still imprecise. Alteration rates, $r$ (as determined from the slope of the linear portion of $m_{a}$ vs. $t$ ), are tabulated for each glass and temperature tested in Appendix C. Section 4.2 discusses these results and their significance on the alteration process.

\subsubsection{Reproducibility of VHT Measurements}

Four glasses (HLP-01, -25, -26, and -43) with the same target composition were fabricated for testing the reproducibility of the entire process from glass fabrication, heat treatment, and laboratory; sample preparation; and measurement. As discussed in Section 3.4.1, no detectable, statistically significant, difference in composition was observed for these glasses. The alteration rates are summarized in Table 3.37 .

Table 3.37. Comparison of alteration rates measured at $200^{\circ} \mathrm{C}, 250^{\circ} \mathrm{C}$, and $300^{\circ} \mathrm{C}$ for the baseline glass

\begin{tabular}{|c|c|c|c|}
\hline Glass ID & $\begin{array}{l}\text { Alteration rate at } \\
200^{\circ} \mathrm{C}\left(\mathrm{g} / \mathrm{m}^{2} / \mathrm{d}\right)\end{array}$ & $\begin{array}{c}\text { Alteration rate at } \\
250^{\circ} \mathrm{C}\left(\mathrm{g} / \mathrm{m}^{2} / \mathrm{d}\right)\end{array}$ & $\begin{array}{l}\text { Alteration rate at } \\
300^{\circ} \mathrm{C}\left(\mathrm{g} / \mathrm{m}^{2} / \mathrm{d}\right)\end{array}$ \\
\hline HLP-01 & $4.26 \pm 0.75$ & $264 \pm 19$ & $929 \pm 0.3$ \\
\hline HLP-25 & $4.20 \pm 0.97$ & $292 \pm 23$ & $737 \pm 88$ \\
\hline HLP-26 & $1.19 \pm 0.42$ & $224 \pm 14$ & $761 \pm 60$ \\
\hline HLP-43 & $4.56 \pm 1.07$ & $234 \pm 8$ & $832 \pm 92$ \\
\hline Combined & $2.92 \pm 0.45$ & $253 \pm 12$ & $777 \pm 44$ \\
\hline$\% \mathrm{RSD}^{(\mathrm{a})}$ & $45 \%$ & $12 \%$ & $11 \%$ \\
\hline
\end{tabular}

(a) Percent relative standard deviation accounts for differences in multiple measurements of each specimen, differences in points from the $m_{a}-t$ line, and differences between glasses.

Comparison of the $m_{a}-t$ data at $200^{\circ} \mathrm{C}$ for the baseline glass (from Appendix C) is shown in Figure 3.77. The rates do not show a good agreement and range from $1.2 \mathrm{~g} / \mathrm{m}^{2} / \mathrm{d}$ to $4.6 \mathrm{~g} / \mathrm{m}^{2} / \mathrm{d}$. It is apparent that although the rates show a $45 \%$ relative standard deviation, the $m_{a}$ values are comparable. In other words, comparing $m_{a}$ values for the four glasses suggests that they behave similarly; however, the fitted rates vary between glasses. The main reasons for the differences in rate are the number and position of 
measured data points. This glass shows a high resistance to VHT at $200^{\circ} \mathrm{C}$, so it was not possible to dissolve more than $800 \mathrm{~g} / \mathrm{m}^{2}$ before significant loss of water in the test vessel occurred.

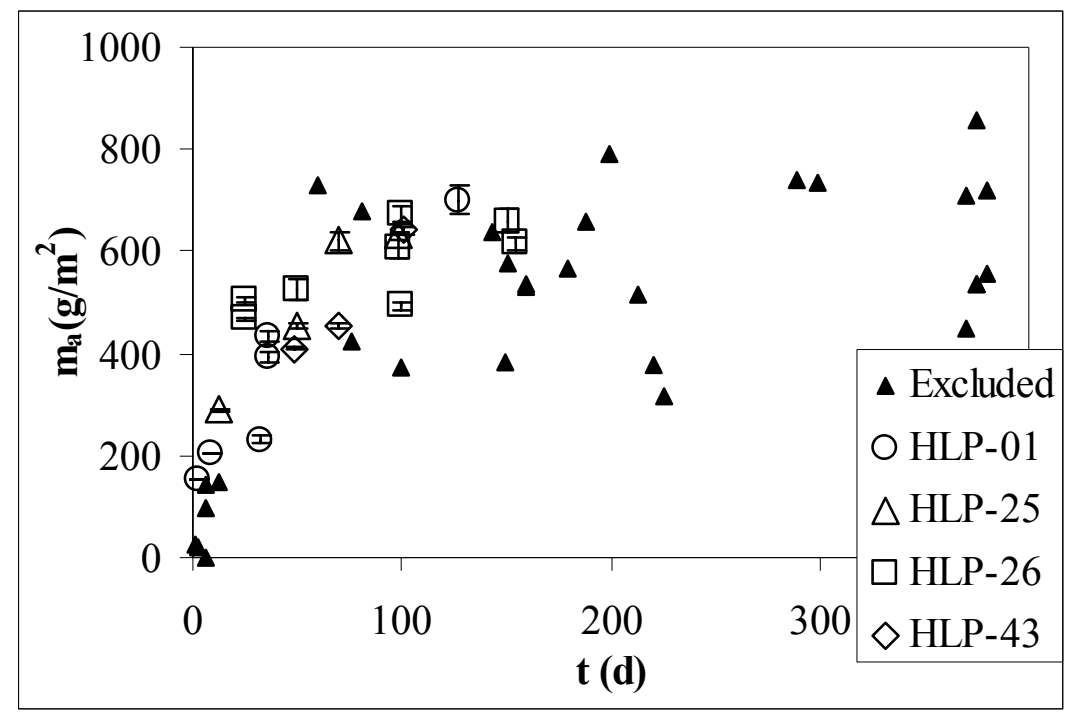

Figure 3.77. Comparison of VHT Response of Baseline Glasses at $200^{\circ} \mathrm{C}$ (some points were excluded due to either insufficient reaction or excess water loss as described in Section 3.5)

The alteration rates measured at $250^{\circ} \mathrm{C}$ for the baseline glasses are compared in Table 3.37 and plotted in Figure 3.78. The lowest alteration rate, measured for HLP-26, is $224 \mathrm{~g} / \mathrm{m}^{2} / \mathrm{d}$. The highest alteration rate, measured for HLP-25, is $292 \mathrm{~g} / \mathrm{m}^{2} / \mathrm{d}$. The combined alteration rate was calculated as $253 \pm 12 \mathrm{~g} / \mathrm{m}^{2} / \mathrm{d}$. The percent relative standard deviation (\%RSD) for the thickness variability of a single specimen, the 10 measurements performed on each specimen, is 3\%. The variability in the measured $m_{a}$ values over the 2 months is $8 \%$ RSD. The variability of the rate over the 2 months for these tested glasses is $12 \% \mathrm{RSD}$.

The alteration rates measured at $300^{\circ} \mathrm{C}$ for the baseline glasses are compared in Table 3.37 and plotted in Figure 3.79. The combined alteration rate was calculated as $777 \pm 44 \mathrm{~g} / \mathrm{m}^{2} / \mathrm{d}$, and the percent relative standard deviation is $11 \%$.

As discussed above, the lowest testing temperature, $200^{\circ} \mathrm{C}$, shows the highest uncertainty in alteration rate. This is caused mainly by the relatively high resistance of the baseline glass to VHT at $200^{\circ} \mathrm{C}$ where the test vessel loses a significant amount of water during the test before the $m_{a}$ value of $800 \mathrm{~g} / \mathrm{m}^{2}$ can be reacted. The number and distribution of the measured data points also influences the alteration rate, which further increases the uncertainty. Higher temperatures enable the specimens to fully react before a significant amount of water is lost, thus yielding more consistent and reproducible results. The effect of temperature on the corrosion is discussed in Section 4.2. 


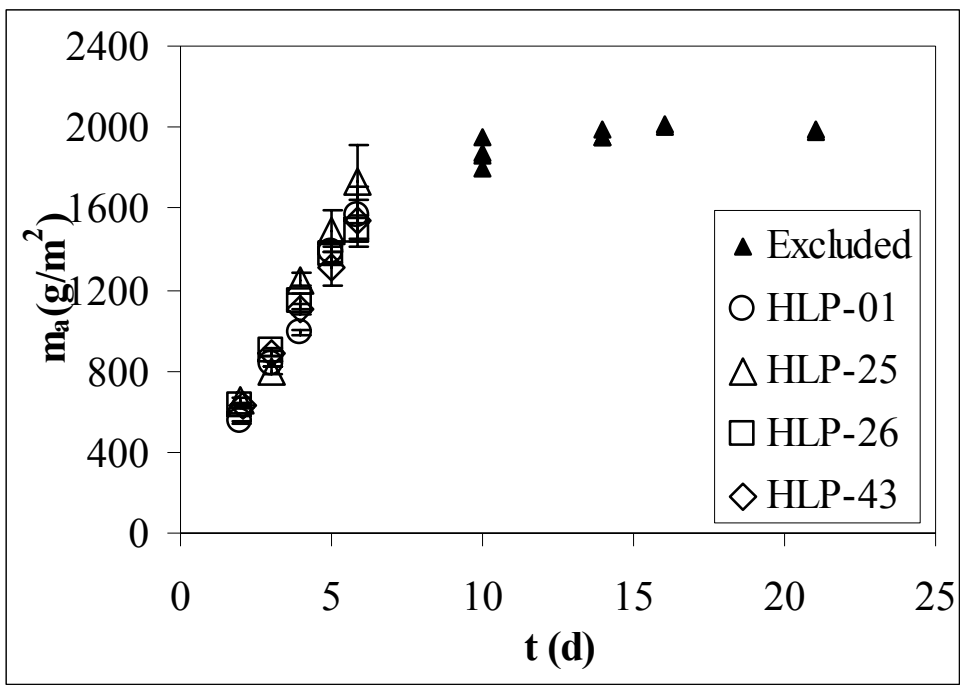

Figure 3.78. Comparison of VHT Response of Baseline Glasses at $250^{\circ} \mathrm{C}$ (some points were excluded due to complete dissolution of the sample as described in Section 3.5)

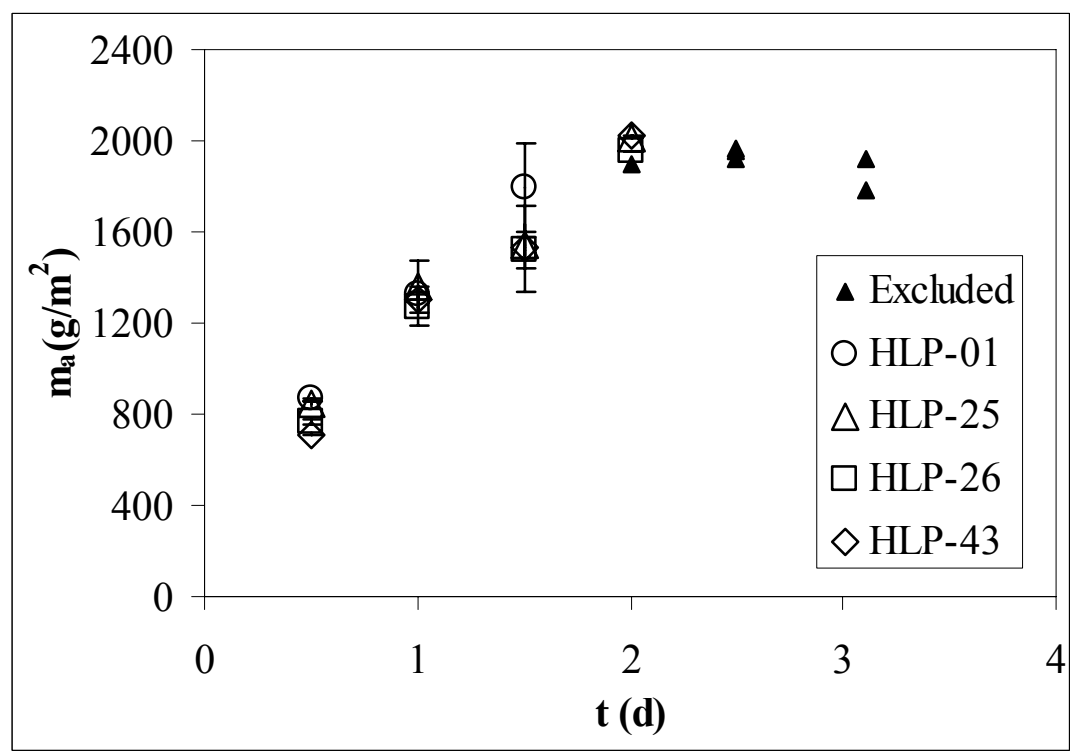

Figure 3.79. Comparison of VHT Response of Baseline Glasses at $300^{\circ} \mathrm{C}$ (some points were excluded due to complete dissolution of the sample as described in Section 3.5)

To test this hypothesis, we selected a glass that more fully dissolves before complications with water loss can affect the measurements-HLP-48. The alteration rate of HLP-48 was measured with two samples per vessel, starting in December 1999. The VHT response of this glass was again measured, starting in May 1999 with only one sample per vessel. The glass was refabricated in late 1999 and was tested in two laboratories as part of a mini-round robin (RR) type test where the two participating laboratories each prepared eight samples and tested four of the samples they prepared along with four samples that the other lab prepared. The rates measured for each of these four sets of measurements are compared in Table 3.38 . 
Table 3.38. Comparison of Alteration Rates Measured for the HLP-48 Glass

\begin{tabular}{||l|c||}
\hline Glass ID & $\boldsymbol{r}\left(\mathbf{g} / \mathbf{m}^{\mathbf{2}} / \mathbf{d}\right)$ \\
\hline Dec-99 & $51.1 \pm 4.1$ \\
\hline May-99 & $50.5 \pm 6.1$ \\
\hline RR-Lab A & $49.3 \pm 13.7$ \\
\hline RR-Lab B & $47.5 \pm 5.8$ \\
\hline Combined & $46.9 \pm 6.5$ \\
\hline \%RSD $^{(a)}$ & 3.2 \\
\hline
\end{tabular}

(a) Percent relative standard deviation accounts for differences in multiple measurements of each specimen, differences in points from the $m_{a}-t$ line, differences between glasses, and differences between laboratories.

Comparison of the four data sets for the HLP-48 glass is shown in Figure 3.80. The rates range from $47.5 \mathrm{~g} / \mathrm{m}^{2} / \mathrm{d}$ to $51.1 \mathrm{~g} / \mathrm{m}^{2} / \mathrm{d}$ and agree within the uncertainties listed in Table 3.38 . With a \%RSD of only 3.2 , it is clear that the reproducibility of rate for HLP-48 is far higher than that of the baseline glass, especially at $200^{\circ} \mathrm{C}$.

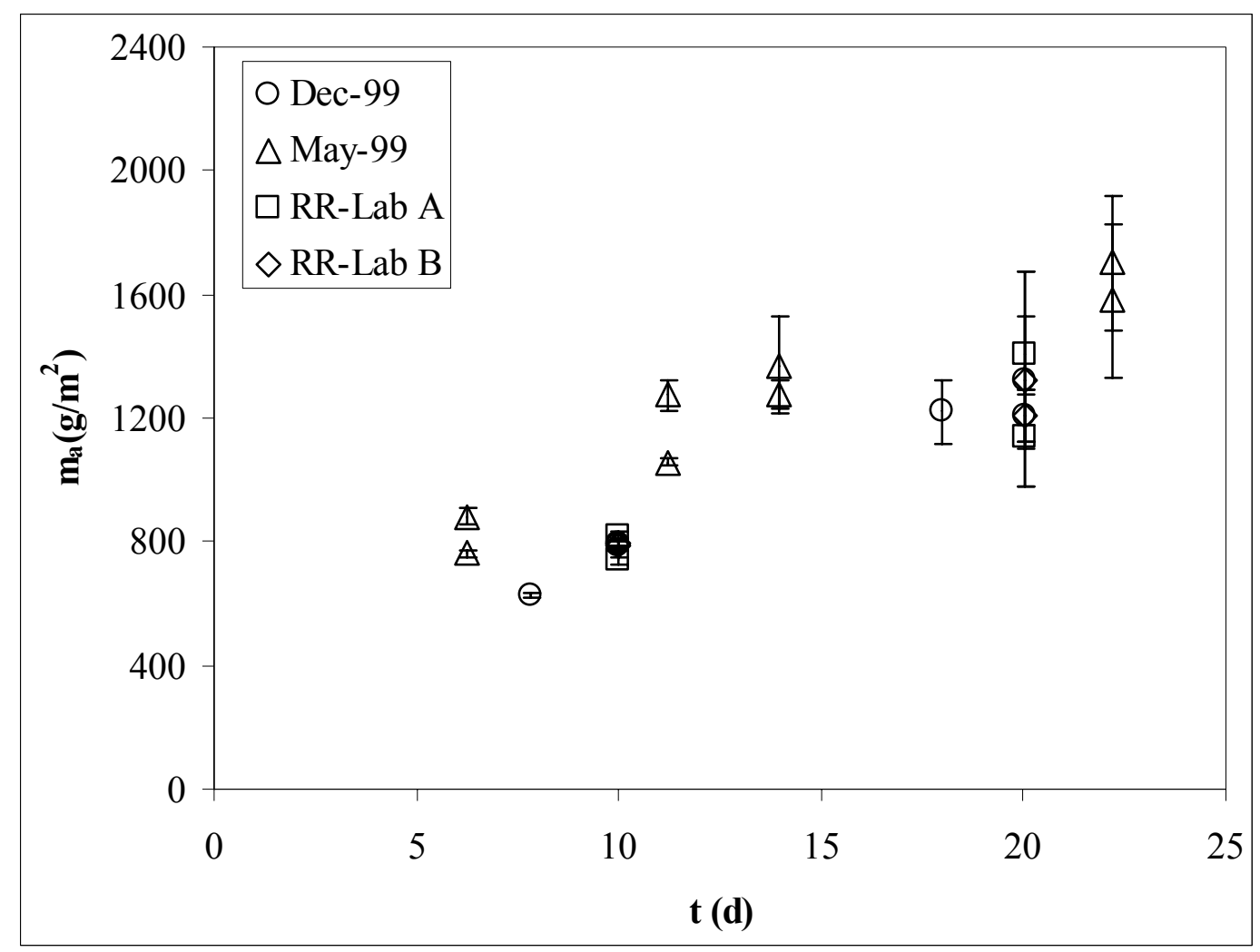

Figure 3.80. Comparison of VHT Responses for HLP-48 Glass

This difference in \%RSD prompted us to perform a similar set of tests on a glass. To help bracket the uncertainty in VHT measurement, we chose a glass labeled "c" for difficult to analyze-HLP-47. HLP-47 was measured using two samples per vessel starting in December 1999. The VHT response of this glass was again measured starting in September 1999 using only one sample per vessel. The VHT 
response of this glass was again measured starting in June 2000, using one sample per vessel, and again by staff from two different laboratories. Finally, HLP-76 and HLP-77 were added to the matrix as blind samples and measured. The rates measured for each of these four sets of measurements are compared in Table 3.39.

Comparison of the six data sets for the HLP-47, -76, and -77 glasses is shown in Figure 3.81. The rates do not show a good agreement (with 50\%RSD) and can be broken into two sets: 1) sets with $r<100 \mathrm{~g} / \mathrm{m}^{2} / \mathrm{d}$, including Sep-99, Dec-99, and Jun-00-A with rates ranging from 49 to $67 \mathrm{~g} / \mathrm{m}^{2} / \mathrm{d}$ and 2) sets with $r>100 \mathrm{~g} / \mathrm{m}^{2} / \mathrm{d}$, including Jun-00-B, HLP-76, and HLP-77 with $129 \leq r \leq 176 \mathrm{~g} / \mathrm{m}^{2} / \mathrm{d}$. Like the baseline glass at $200^{\circ} \mathrm{C}$, the $m_{a}$ values are comparable, although the rates vary by $50 \% \mathrm{RSD}$. In other words, comparing $m_{a}$ values for the six data sets suggests that they behave similarly; however, the fitted rates vary between glasses. The main reasons for the differences in rate are the number and position of measured data points and the difficulty in measurement for this particular glass.

\section{Table 3.39. Comparison of Alteration Rates Measured for the HLP-47, HLP-76, and HLP-77 Glasses}

\begin{tabular}{||c|c|}
\hline Glass ID & $\boldsymbol{r}\left(\mathbf{g} / \mathbf{m}^{2} / \mathbf{d}\right)$ \\
\hline Sep-99 & $60.7 \pm 6.4$ \\
\hline Dec-99 & $48.9 \pm 0.0$ \\
\hline Jun-00-A & $67.2 \pm 5.1$ \\
\hline Jun-00-B & $128.5 \pm 13.3$ \\
\hline HLP-76 & $140.9 \pm 3.0$ \\
\hline HLP77 & $67.9 \pm 9.7$ \\
\hline combined & 50 \\
\hline \multicolumn{2}{|c|}{ \%RSD } \\
\hline (a) & $\begin{array}{l}\text { (a) Percent relative standard deviation accounts for } \\
\text { differences in multiple measurements of each specimen, } \\
\text { differences in points from the } m_{a}-t \text { line, differences } \\
\text { between glasses, and differences between laboratories. }\end{array}$ \\
\hline
\end{tabular}

We conclude, based on the results of the three sets of glasses for which we were able to generate statistical analysis of the VHT response, that

- the repeatability of the rate measurement is strongly dependent on the following factors:

- the amount of corrosion that can occur before water loss causes measurement difficulties

- the difficulty in measuring the amount of reaction in the glass

- the temperature of measurement

- for those glasses not marked by "a," "b," "c," "d," or "e" in Appendix C or Section 3.5.2, we expect the $\%$ RSD to be roughly 10 , and we expect the $\%$ RSD to be below 50 for the remaining glasses. 


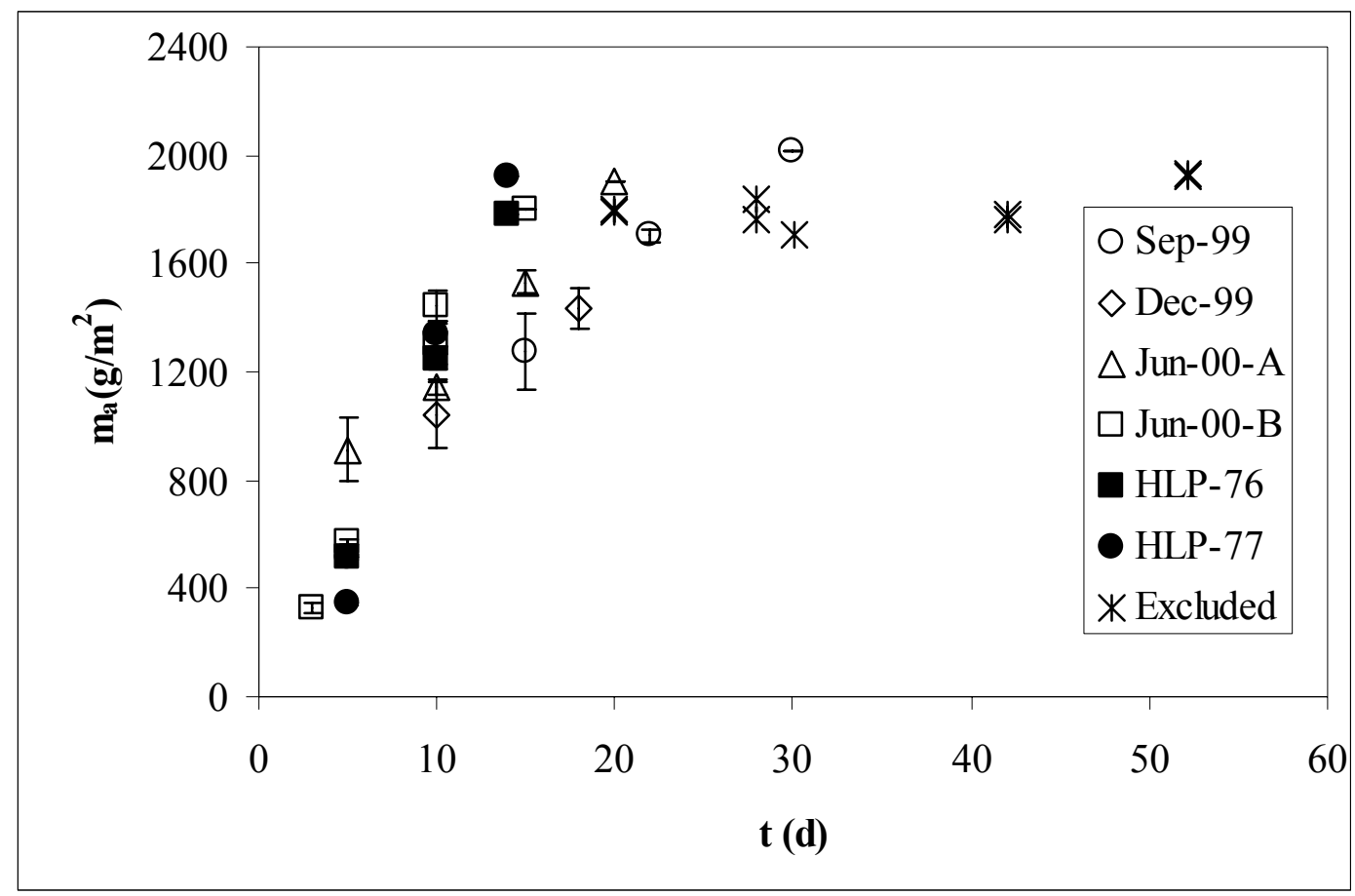

Figure 3.81. Comparison of VHT Responses for HLP-47, -76, and -77 Glasses

\subsection{Product Consistency Test}

Studies are underway to investigate the impact of chemical composition on the long-term behavior of Hanford LAW glasses. The PCT was conducted on two matrices of HLP glasses. For Phase I of this testing, 55 glasses were fabricated, heat treated, and characterized using both PCT-A and PCT-B methods. At the time of issuance of the second data package (Schulz et al. 2000), PCT-A testing on the Phase I glasses was complete along with PCT-B testing at 10, 100, 1000, and $5000 \mathrm{~h}$. The 10000 -h PCT had yet to be complete. Since then, all PCT testing of the Phase I glasses has been completed, and the results of the 10 000-h tests are listed in Section 3.6.1. In Phase II testing, 20 additional glasses were fabricated to help determine the influence on the test responses of key glass components that were not varied systematically in Phase I. As in Phase I, the 20 glasses comprising Phase II were subject to both methods of PCT. The results of Phase II PCT (PCT-A and up to 5000-h PCT-B) are shown in Section 3.6.2.

\subsubsection{000-h Testing of Phase I Glasses}

The measured concentrations of all Phase I PCTs up to $5000 \mathrm{~h}$ are listed in Schulz et al. (2000), but all of the release-rate data are summarized in Tables B-3 and B-4 of this report. This section reports only the results of the $10000-h$ testing. The glasses with the five largest and smallest release rates, $r$, from the boron and sodium PCT-B data are presented in Table 3.40 for $10000 \mathrm{~h}$. 
Table 3.40. Ordering of Release Rates for the Phase I HLP Glasses Based Upon 10000 h PCT-B Data

\begin{tabular}{||c|c|c|c||}
\hline \multicolumn{3}{|c|}{ Release Rate Rank Ordering by HLP Glass Number } \\
\hline & & \multicolumn{2}{c||}{ Release Rate, $\boldsymbol{r}$} \\
\hline Time (h) & Cation & Highest Five & Lowest Five \\
\hline 10000 & $\mathrm{~B}$ & $02>29>46>27>53$ & $30<34<38<06<19$ \\
\hline 10000 & $\mathrm{Na}$ & $27>53>46>29>52^{(\mathrm{a})}$ & $30<06<34<22<38$ \\
\hline
\end{tabular}

In Schulz et al. (2000), the glasses HLP-02, -31, -33, and -39 were chosen for analysis because they represented some of the largest release rates for all time periods (up to $5000 \mathrm{~h}$ ) for sodium and boron. For consistency, that analysis is continued for the 10000 -h tests of Phase I glasses (see Figure 3.82). As seen in Table 3.40, the only one of these glasses that still has one of the top five highest release rates of sodium or boron is HLP-02 (boron). However, HLP-31, -33, and -39 are still some of the least durable glasses at $10000 \mathrm{~h}$, as indicated by the rankings of Table B-2a and B-2b. The glasses analyzed with some of the smallest release rates are HLP-06, -22, -28, and -30 (see Figure 3.83). As evidenced from Table 2.1, B$4 \mathrm{a}$, and B-4b, these glasses consistently remained some of the most durable (lower release rates) glasses at all time periods of testing.

Also mentioned in Schulz et al. (2000) was data reproducibility. For Phase I testing, four glasses (HLP-01, -25, -26, and -43) were batched to the same target composition. For the release rate of boron at $10000 \mathrm{~h}$, the values fall in the range of $\sim 2.00 \times 10^{-3}$ to $2.48 \times 10^{-3} \mathrm{~g} / \mathrm{m}^{2} / \mathrm{d}$ (see Table 3.41 ). In terms of sodium release rates, the values range from $\sim 1.52 \times 10^{-3}$ to $1.69 \times 10^{-3} \mathrm{~g} / \mathrm{m}^{2} / \mathrm{d}$, which is a slightly smaller range than that of boron. Also included as part of this report is the normalized sodium, boron, and silicon releases, provided in Tables B-3a and B-3b (targeted and measured, respectively). For these aforementioned glasses, the largest range of measured normalized release values occurred for boron $(0.83$ to $1.03 \mathrm{~g} / \mathrm{m}^{2}$ ), while the values for sodium and silicon range 0.63 to $0.70 \mathrm{~g} / \mathrm{m}^{2}$ and 0.24 to $0.28 \mathrm{~g} / \mathrm{m}^{2}$, respectively. It can be stated that at $10000 \mathrm{~h}$, these four glasses are behaving the same, and the slight variances can be attributed to experimental error.

Table 3.41. Sodium and Boron Release Rates for Four Glasses with the Same Composition

\begin{tabular}{|c|c|c|}
\hline Glass ID & B Release Rate $\left(\mathbf{g} / \mathbf{m}^{2} / \mathbf{d a y}\right)$ & Na Release Rate $\left(\mathbf{g} / \mathbf{m}^{2} / \mathbf{d a y}\right)$ \\
\hline HLP-01 & $2.48 \times 10^{-3}$ & $1.65 \times 10^{-3}$ \\
\hline HLP-25 & $2.00 \times 10^{-3}$ & $1.52 \times 10^{-3}$ \\
\hline HLP-26 & $2.27 \times 10^{-3}$ & $1.69 \times 10^{-3}$ \\
\hline HLP-43 & $2.15 \times 10^{-3}$ & $1.66 \times 10^{-3}$ \\
\hline
\end{tabular}




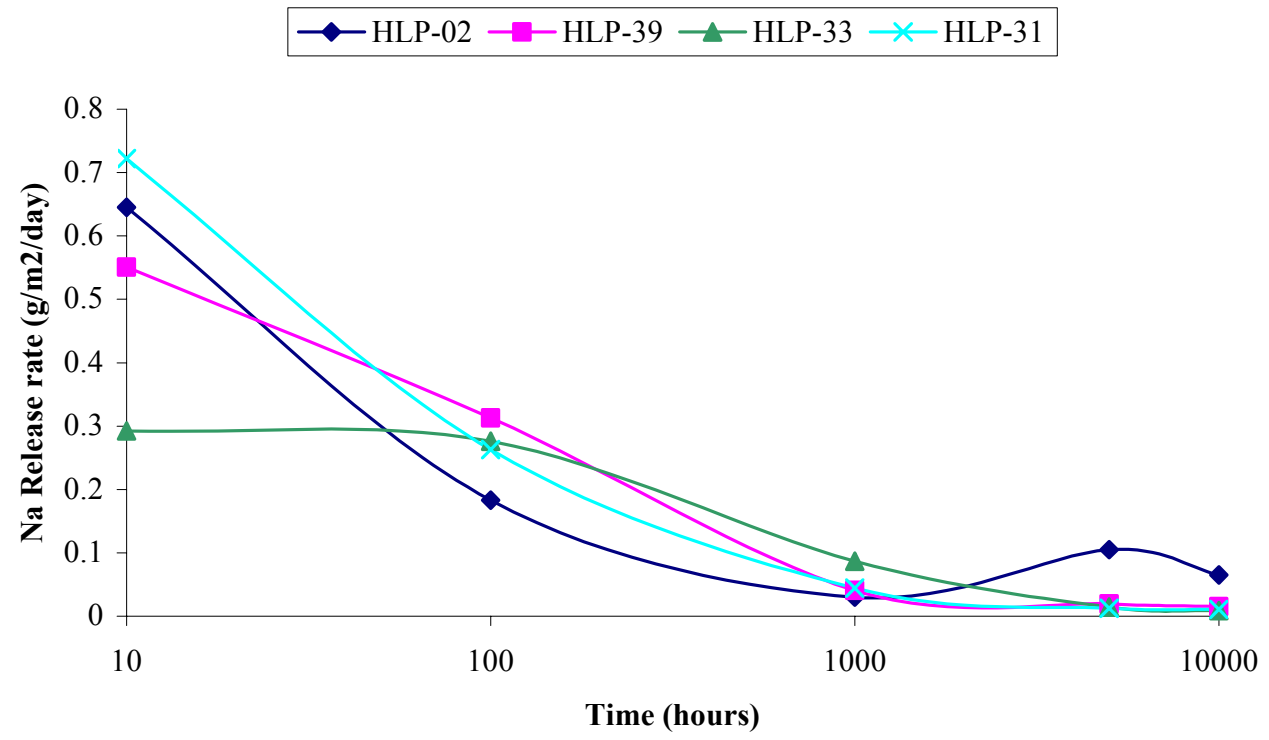

(A)

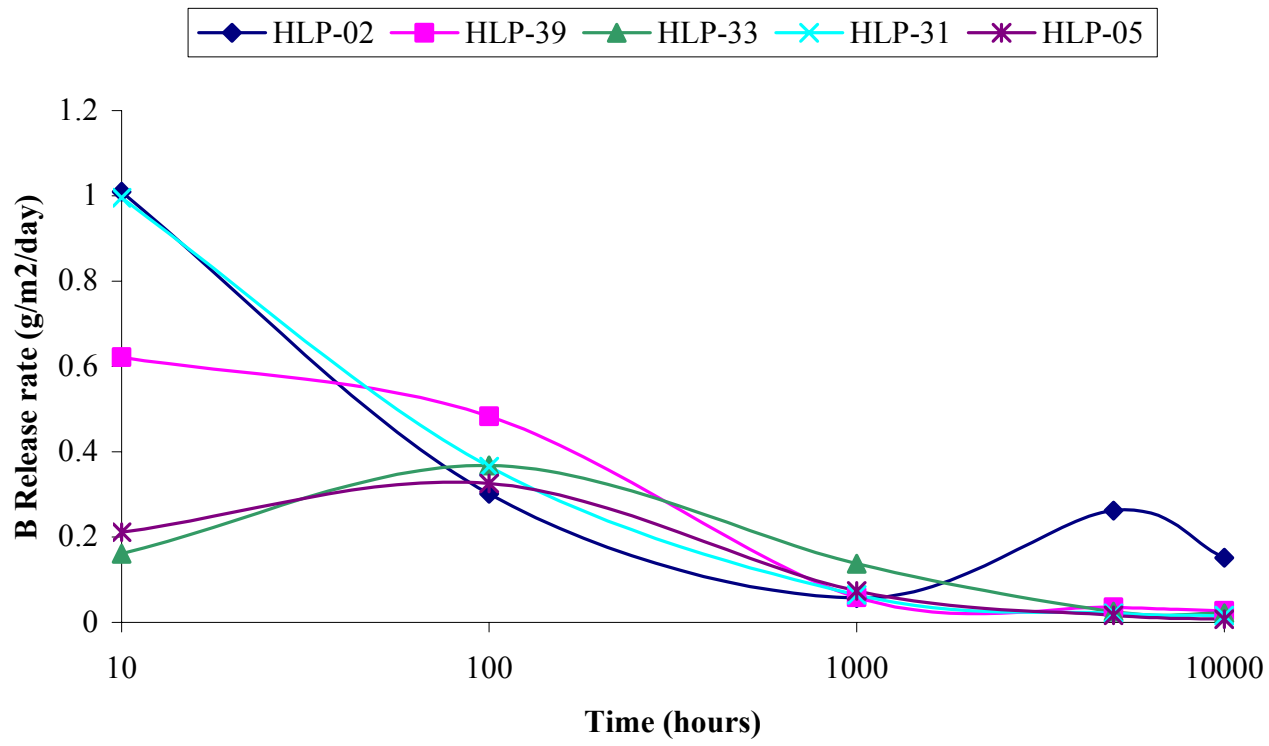

(B)

Figure 3.82. A) Release Rate Versus Time for Selected Glasses Representing the Largest Release Rates of Sodium. B) Release Rate Versus Time for Selected Glasses Representing the Largest Release Rates for Boron. With the exception of HLP-05, the same glasses represent both elements with similar trends. 

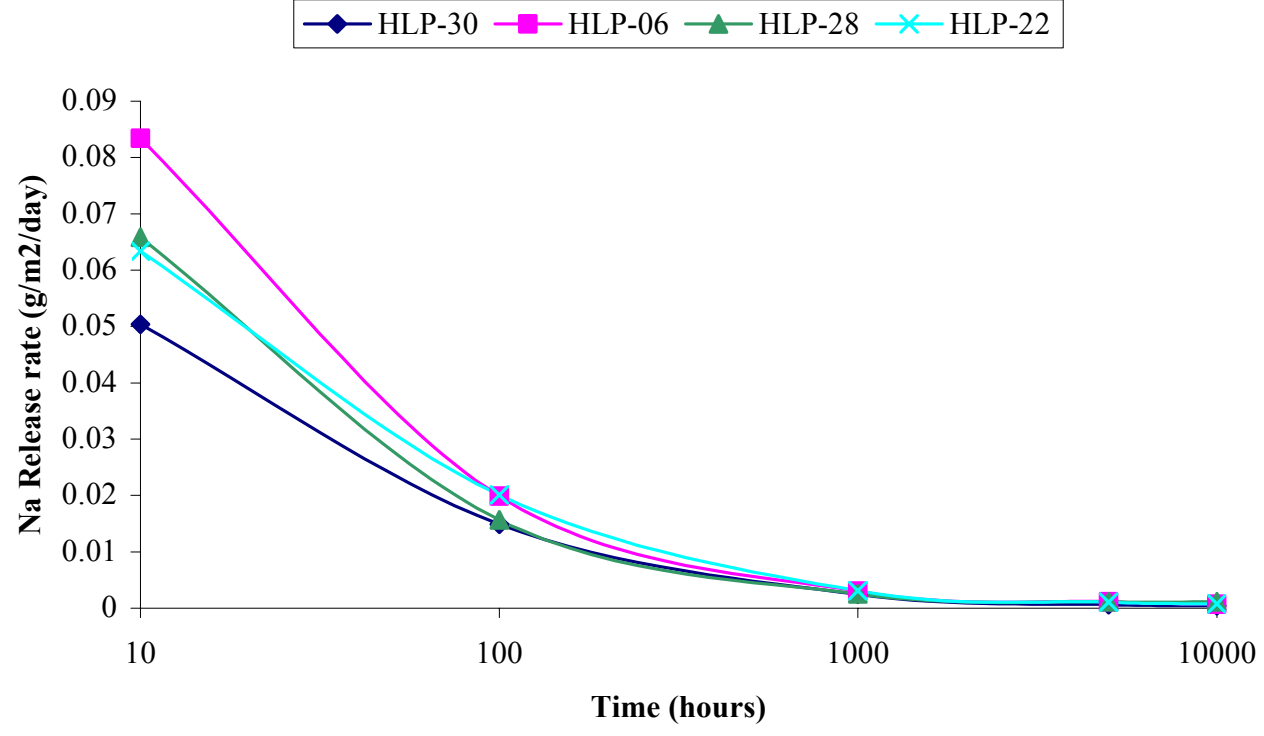

(A)

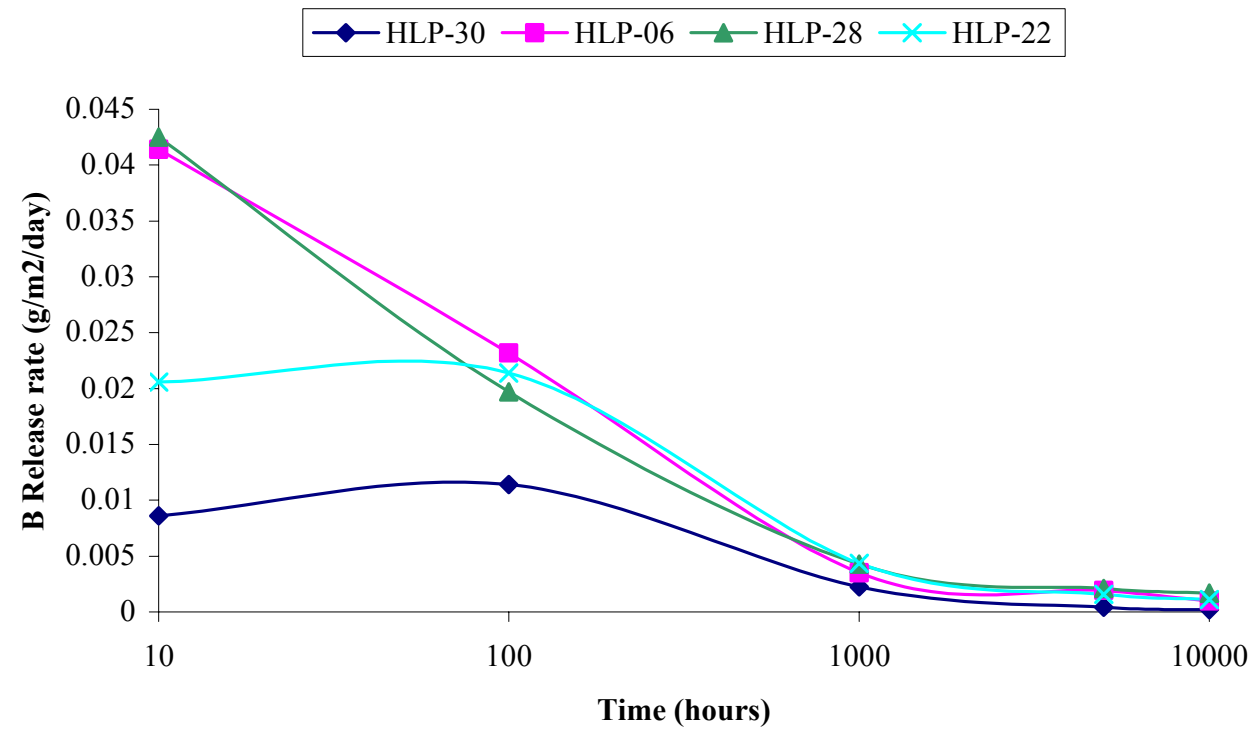

(B)

Figure 3.83. A) Release Rate Versus Time for Selected Glasses Representing the Smallest Release Rates for Sodium. B) Release Rate Versus Time for Selected Glasses Representing the Smallest Release Rates for Boron. Note that the same glasses are represented for both elements with similar trends. 


\subsubsection{Phase II Glasses}

The glasses of Phase II were subject to the same testing series as the glasses of Phase I. In addition to these 20 Phase II glasses, a few standard glasses were included in the testing for comparison purposes. These include the DWPF-EA (Environmental Assessment) glass (Jantzen et al. 1993), the approved reference material (ARM) (Mellinger and Daniel 1984), the low-level reference material (LRM) (Peeler et al. 1999), 165-TDS, and natural analog glasses (basalt and obsidian). The PCT-A (PCT-A is performed in triplicate) data for the Phase II glasses are listed in Table B.5. The only glasses included with the Phase II matrix glasses in this standard 7-day (168 h) test were the EA and ARM glasses, both of which were consistent between all three samples (see Table B.5 for these data as well). The largest incongruence in the PCT-A tests was for HLP-70, where the third solution had all elemental concentrations below the detection limits while the first two did not (see Table B.5).

All the PCT-B data are listed in Tables B.6 through B.13. Only single (no replicates) tests were performed for PCT-B. Thus, the random variations in the PCT-B results for a glass are likely higher than those reported for PCT-A for the same glass. The glasses with the five largest and smallest release rates, $r$, from the boron and sodium PCT-B data are presented in Table 3.42 for the Phase II glasses. The standards and natural-analog glasses are not included in this table, but will be analyzed in the Section 4.6.

Table 3.42. Ordering of Release Rates for the Phase II HLP Glasses Based Upon PCT-B Data

\begin{tabular}{|c|c|c|c|}
\hline \multicolumn{4}{|c|}{ Release Rate Rank Ordering by HLP Glass Number } \\
\hline & & \multicolumn{2}{c|}{ Release Rate, $\boldsymbol{r}$} \\
\hline Time (h) & Cation & Highest Five & Lowest Five \\
\hline 10 & $\mathrm{~B}$ & $71>67>70>66>63$ & $69<72<68<59<64$ \\
\hline & $\mathrm{Na}$ & $71>67>70>63>66$ & $69<72<58<62<59$ \\
\hline 100 & $\mathrm{~B}$ & $72>71>69>73>66$ & $59<62<74<60<65$ \\
\hline & $\mathrm{Na}$ & $72>73>71>66>58$ & $77<59<70<62<60$ \\
\hline $1000^{\text {(a) }}$ & $\mathrm{B}$ & $71>66>73>63>64$ & $69<62<68<59<65$ \\
\hline & $\mathrm{Na}$ & $71>63>66>73>67$ & $69<62<60<59<58$ \\
\hline $5000^{\text {(a) }}$ & $\mathrm{B}$ & $70>66>73>67>64$ & $69<68<60<62<59$ \\
\hline & $\mathrm{Na}$ & $70>66>67>64>73$ & $69<60<59<65<58$ \\
\hline & \multicolumn{3}{|c|}{ (a) No data available for HLP-70 at $1000 \mathrm{~h}$, and none for HLP-63 and $\mathrm{HL} \mathrm{P}-71$ at $5000 \mathrm{~h}$} \\
\hline
\end{tabular}

The targeted and measured concentrations for the Phase II glasses are listed in Table A.1. For data reproducibility purposes, the target compositions of HLP-76 and HLP-77 are the same. These two glasses target the LRM glass composition - they contain the same constituents as the other HLP glasses but also contain the following: $\mathrm{BaO}(0.005), \mathrm{CdO}(0.20), \mathrm{I}(0.002), \mathrm{Li}_{2} \mathrm{O}(0.10), \mathrm{MnO}(0.10), \mathrm{NiO}(0.10)$, and $\mathrm{PbO}(0.10)$ in mass percent (see Table A.1). In Figure 3.84, a comparison in the normalized release rates for boron, sodium, and silicon is made for these two glasses. As shown in Figure 3.84, the largest discrepancies occur in the release of silicon at $5000 \mathrm{~h}$ and in the release of boron and sodium at $100 \mathrm{~h}$. Though some statistical variations were calculated between the two glasses that were not attributable to compositional variances, there were insufficient data to determine the reason(s) for the inconsistencies. These normalized release values were not calculated for the LRM glass, though. However, the measured concentrations of each glass are shown in Tables B-6 through B-9 for the PCT-B solutions. These data show that the concentrations of B, Na, and Si in solution of the LRM glass at each time $(10,100,1000$, 
and $5000 \mathrm{~h}$ ) are much higher than those of HLP-76 and HLP-77. Further testing of the LRM standard and HLP-76 and -77 is necessary in order to resolve these discrepancies.
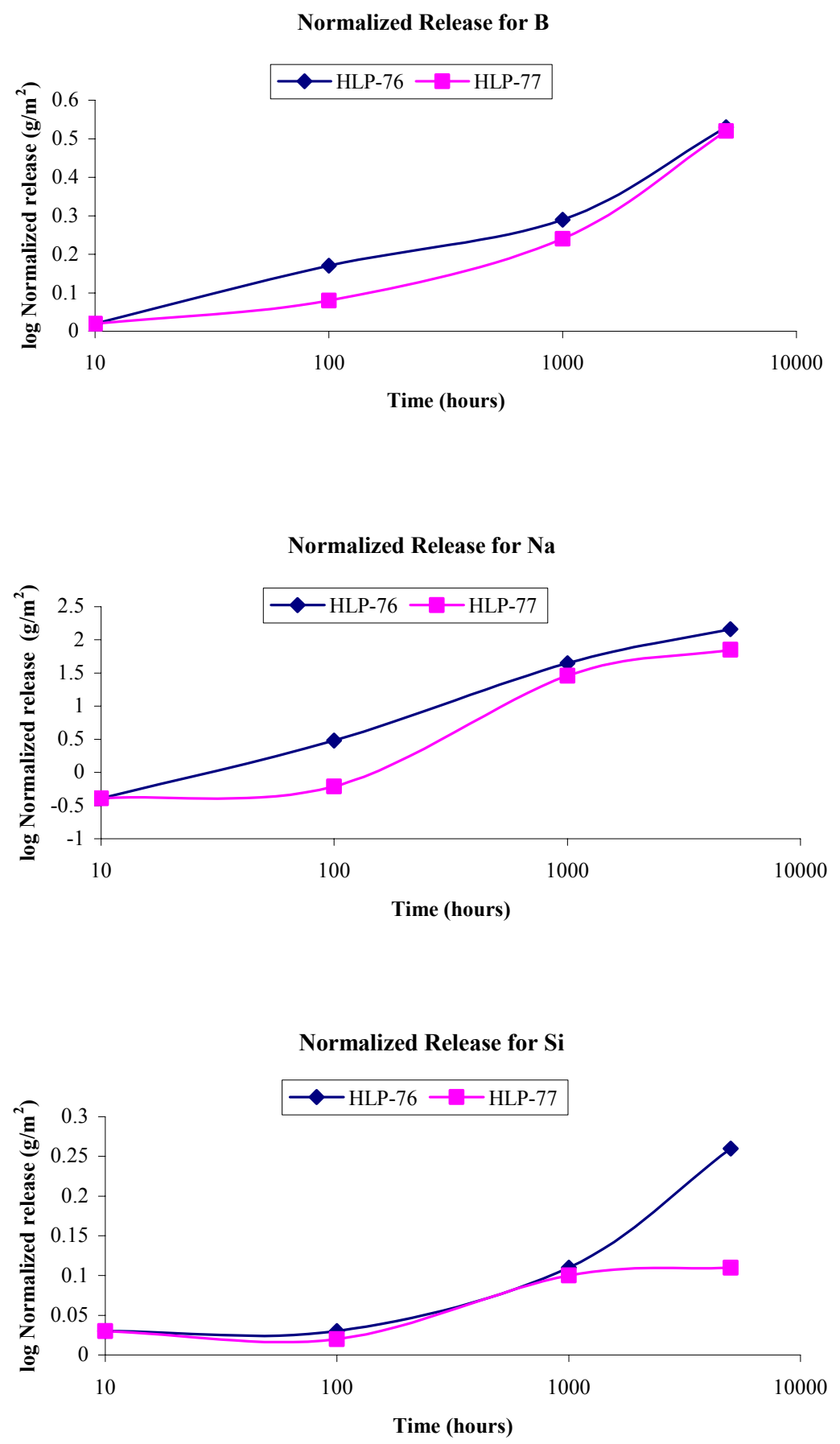

Figure 3.84. Normalized Releases Versus Time for Boron, Sodium, and Silicon for Glasses HLP-76 and HLP-77 


\subsubsection{Alteration Products on PCT Samples}

Samples of reacted glass from 21 PCTs (all from the Phase I 5000-h set) were examined with SEM/EDS at Argonne National Laboratory (Ebert et al. 2001). According to this report, most of the samples had a minor distribution of alteration products that had similar morphologies. For example, the composition of the alteration phase on HLP-02 was $\mathrm{Na}_{2.3} \mathrm{Zn}_{0.2} \mathrm{Al}_{1.6} \mathrm{Fe}_{0.9} \mathrm{Ti}_{0.5} \mathrm{Si}_{4} \mathrm{O}_{14.5}$ (Ebert et al. 2001). Glass HLP-29 exhibited another phase, where the composition was $\mathrm{Na}_{1.6} \mathrm{Al}_{2.1} \mathrm{Si}_{4} \mathrm{O}_{12.0}$. Also, varying degrees of alteration occurred on the glass surfaces, where some surfaces appeared smooth and unreacted while others appeared rough.

Evidence of alteration appeared on all but four PCT glass samples of the 21 examined (Ebert et al. 2001). Table 3.43 summarizes the data stated in Ebert et al. (2001) for the glass samples submitted. Distributions of the alteration phases were widely spaced, but were similar in composition and morphology. According to Ebert et al. (2001), it is likely that these materials would evolve into clays. All data on the analyses of the alteration phases of the PCT samples are listed in Ebert et al. (2001).

Table 3.43. Summary of Glass Surface Alteration on PCT Samples (from Ebert et al. 2001)

\begin{tabular}{||l|l||}
\hline Glass ID & \multicolumn{1}{c|}{ Evidence of Surface Alteration } \\
\hline HLP-02 & Alteration phases formed \\
\hline HLP-04 & Surface roughened \\
\hline HLP-06 & Some small features formed in some regions \\
\hline HLP-09 & Large number of small particles formed on surface \\
\hline HLP-14 & Formation of another phase \\
\hline HLP-27 & Formation of another phase \\
\hline HLP-28 & Surface roughened \\
\hline HLP-29 & Pitted surface and covered with another phase \\
\hline HLP-30 & Unreacted \\
\hline HLP-31 & Unreacted \\
\hline HLP-33 & Surface reacted, but no precipitated phases \\
\hline HLP-34 & Some surface regions of alteration \\
\hline HLP-35 & Parts of surface overlain with rod-like features \\
\hline HLP-39 & Some regions overlain with blocky features \\
\hline HLP-41 & Some regions overlain with blocky features \\
\hline HLP-43 & Some regions overlain by strings of beady features \\
\hline HLP-46 & Formation of another phase \\
\hline HLP-49 & Unreacted \\
\hline HLP-51 & Some regions overlain by strings of beady features \\
\hline HLP-52 & Formation of two other phases \\
\hline HLP-56 & Unreacted \\
\hline
\end{tabular}




\subsection{Data Analyses and Discussion}

\subsection{General LAW Glass Alteration Behavior}

Figure 4.1 schematically displays the general alteration curve for LAW glasses reacting with water in a closed system. The alteration process in a closed system can be divided into four distinguishable stages.

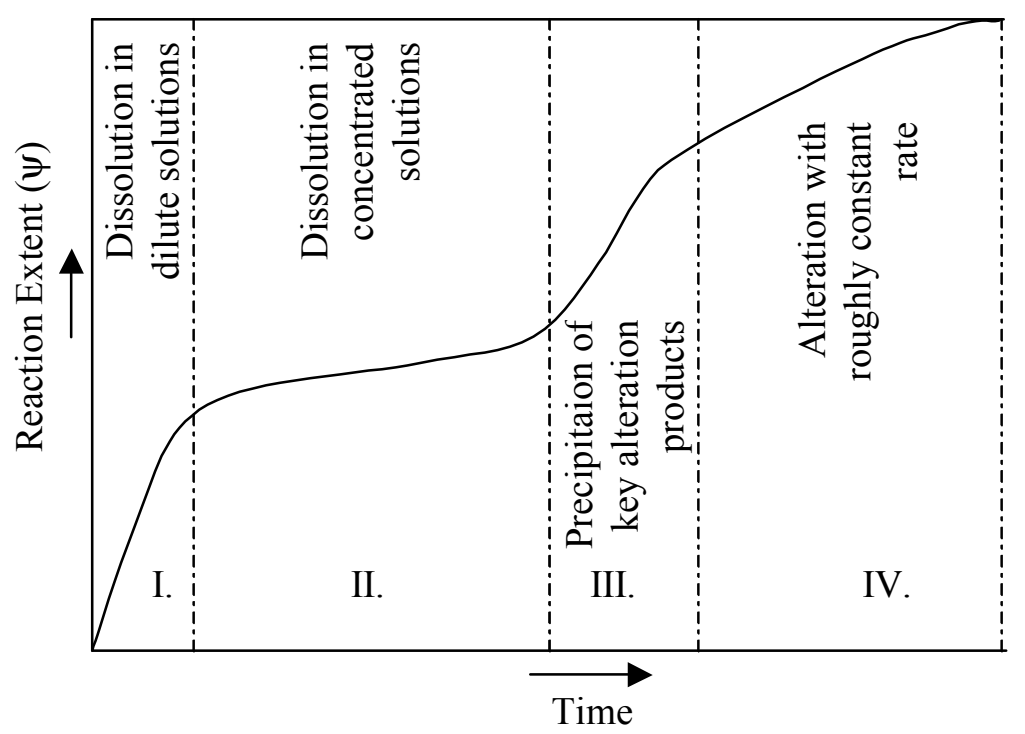

Figure 4.1. General Alteration Curve (after Jiricka et al. 2001)

In the first stage, glass reacts with the dilute solution at a roughly constant rate. This initial rate, also called the forward rate of dissolution, is a function of temperature, solution chemistry (primarily $\mathrm{pH}$ ), and glass composition.

In a closed system, the concentration of key corrosion products increases in the solution as the corrosion progresses. The second stage of corrosion occurs when the concentrations of solution species that affect corrosion rate become high enough to significantly lower the corrosion rate. The solution species most often credited for affecting the alteration rate is orthosilicic acid (see Advocate et al. 1990 and Grambow 1987 for examples). However, other solution species were observed to influence the alteration rate (Advocat et al. 1998; Abraitis et al. 1998).

As the corrosion progresses through the second stage of alteration, the concentrations of solution species become saturated to supersaturated with respect to a number of solid phases. At some point, one or more of these solid phases nucleate and precipitate. As components are incorporated into solid alteration products, their solution concentrations are controlled by the balance between the dissolution of the glass (source) and the precipitation of the solid (sink). This change of the corrosion mechanism proceeds abruptly, analogous to a sudden precipitation of ice in super-cooled water. In glasses containing $\mathrm{Al}, \mathrm{Na}$, and $\mathrm{Si}$, certain alteration products form that cause the concentration of the rate-affecting species to decrease. According to Van Iseghem and Grambow (1988) and Strachan and Croak (2000), the dissolution of the glass enters Stage III when these solid phases (mainly zeolites) are produced with 
sufficient rate to adversely affect dissolution. However, the sudden increase in glass alteration rate that exceeds the initial dissolution rate of the glass in a solution of identical $\mathrm{pH}$ indicates that a portion of glass that has been penetrated by water during the previous period of slow dissolution is rapidly converted to gel with a massive release of corrosion tracers, such as B. The mechanism of this transition has neither been sufficiently studied nor properly understood. Stage III processes are influenced by a number of parameters that cannot be precisely controlled. As a result, significant uncertainties are associated with the transition from Stage II to Stage III.

The first three stages of glass alteration have been observed in experiments conducted under static conditions with water in contact with the glass (Cunnane 1994, Van Iseghem and Grambow 1988, Harvey et al. 1991). Based on a study in which glass coupons were subjected to VHT, Jiricka et al. (2001) determined the existence and characteristics of Stage IV.

The reactions between glass and water and the precipitation of alteration products have been modeled in several studies. Modeling with geochemical codes has been used for rationalizing data from static dissolution tests at low ionic strengths. For application to waste glass corrosion under VHT and to some extent PCT-B conditions, these codes require a great deal of thermodynamic data for species in highionic-strength solutions and for a vast number of solids that are generally not end members but broad solid solutions. As glass corrosion progresses in a closed system, extremely high-ionic-strength solutions are produced that affect the kinetics of alteration-phase precipitation and the equilibrium solubilities of alteration phases. In addition, the response of glass to the VHT conditions would require knowledge of the amount of water available for reaction, which is difficult to determine. Moreover, the primary glass alteration product in Stages I and II is an amorphous gel and not well-defined minerals. The minerals that occur in Stages III and IV precipitate from the solution on the outer surface of the gel layer rather than being the products of gel-layer aging. Abrajano and Bates (1990) and Gin et al. (2001) studied the evolution of gel layers.

In previous reports, the PCT release as a function of time was focused on the first two stages and was described by a power-law function (Vienna et al. 2000; Schulz et al. 2000); a linear model was used to describe the Stage IV results from the VHT. Abrajano et al. (1989) described the beginning portion of the VHT response using a power-law equation. Gan and Pegg (2001) described the VHT $m_{a}-t$ curve with a modified Avrami model in an attempt to account for the complete reaction.

Generalizing these previous attempts, we propose below the use of an empirical relationship describing the time evolution of glass corrosion in experiments conducted in a closed vessel under isothermal conditions. From this, we proceed to formulate a rate equation that could possibly be applied to more general conditions. An important objective is to describe the effect of glass composition on the glass-corrosion behavior. For this ambitious goal, it is important that the number of parameters in the rate equation is as small as possible, and these parameters have a clear physical interpretation. The shape of the glass-corrosion curve shown in Figure 4.1 suggests that seven parameters are required to describe the full relationship between time and the extent of corrosion in a closed system. This can be achieved with a number of possible equations, for example: 


$$
\begin{aligned}
& m_{a}=r_{0} \frac{t_{1}}{n}\left[\left(1+\frac{t}{t_{1}}\right)^{n}-1\right]+r_{\infty}\left(\frac{1}{2}+\frac{1}{\pi} \arctan \frac{t-t_{2}}{t_{3}}\right)\left(t+t_{4}\right)-m_{0} \\
& m_{0}=r_{\infty}\left(\frac{1}{2}-\frac{1}{\pi} \arctan \frac{t_{2}}{t_{3}}\right) t_{4}
\end{aligned}
$$

where $m_{a}$ is the altered glass mass per unit surface area, $t$ is the corrosion time, and $n, r_{0}, r_{\infty}, t_{1}, t_{2}, t_{3}$, and $t_{4}$ are empirical coefficients.

The first two stages of corrosion are described by the first term of Equation (2). This term involves three empirical coefficients: $t_{1}$ represent the time for the transition from Stages I to Stage II, exponent $n$ accounts for the decrease in the rate of corrosion during Stage II (it is subjected to the condition $0<n<1$ ), and $r_{0}$ is the initial rate of corrosion. That Stages I and II are represented by a single term in Equation (2) reflects the fact that these two stages correspond to a continuous transition from the initial diffusion-dominated control to the reaction-dominated control. These controlling mechanisms, however, operate simultaneously from the very beginning of corrosion (dividing the corrosion process into Stages I and II is conventional).

The second term in Equation (2) stands for Stages III and IV and involves four coefficients. The rate of corrosion peaks during Stage III. The peculiar feature of Stage III is its probabilistic character. Stage III cannot be exactly described by a deterministic formula, but can be averaged or approximated as such. In Equation (2), this approximation is represented by the arctan function. Stage III evolves around $t=t_{2}$. Generally, $t_{2} \gg t_{1}$, i.e., Stage III sets in when Stage II has been fully established for some time and the solution is saturated or oversaturated with respect to the minerals that precipitate in Stage III. Coefficient $t_{3}$ represents its duration. Since the duration of Stage III is short, $t_{3}<<t_{2}$. Again, Stages III and VI are represented by a single term because both are related to nucleation and growth of the aluminosilicate crystalline phases.

In Stage I, $t<<t_{1}$. Since the second term in Equation (2) can be disregarded for $t<<t_{1}$, Equation (2) reduces to $m_{a}=r_{0} t$. During most of Stage II, $t_{1}<<t<<t_{2}$; thus, $m_{a}=\left(m_{1} / t_{1}\right) t^{n}$; accordingly, a power-law model describes Stage II corrosion. At $t \gg t_{2}$, the second term reduces to $m_{a}=m_{I V}+r_{\infty} t$ where $r_{\infty}$ is the final rate of corrosion and $m_{\mathrm{IV}}=r_{\infty} t_{4}$ is the extrapolated Stage IV intercept. This intercept is a measure for the increase of the corrosion extent in Stage III. The maximum rate of corrosion in Stage III is $r_{\max }=$ $\mathrm{d} m_{a} / \mathrm{d} t$ at $t=t_{2}$, i.e., $r_{\max }=\pi^{-1} r_{\infty}\left(t_{2}+t_{4}\right) / t_{3}$. Thus, all coefficients in Equation (2) have a clear physical meaning.

The outcome of this analytical description is highlighted in Figure 4.2. In this figure, two data sets were fitted to the equation to give examples of the different phases. In Figure 4.2, (a) HLP-55 PCT-B data from literature (see Vienna et al. 2000) were used to fit Stages I through III, while in (b), HLP-46 $175^{\circ} \mathrm{C}$ VHT data were used to fit Stages II through IV. Note that the PCT-B and VHT were not performed at the same temperature and $\mathrm{S} / \mathrm{V}$. Work is underway to develop a single data set to which Equation (2) can be fit for Stages I through IV. The fitted and estimated parameters are listed in Table 4.1. 


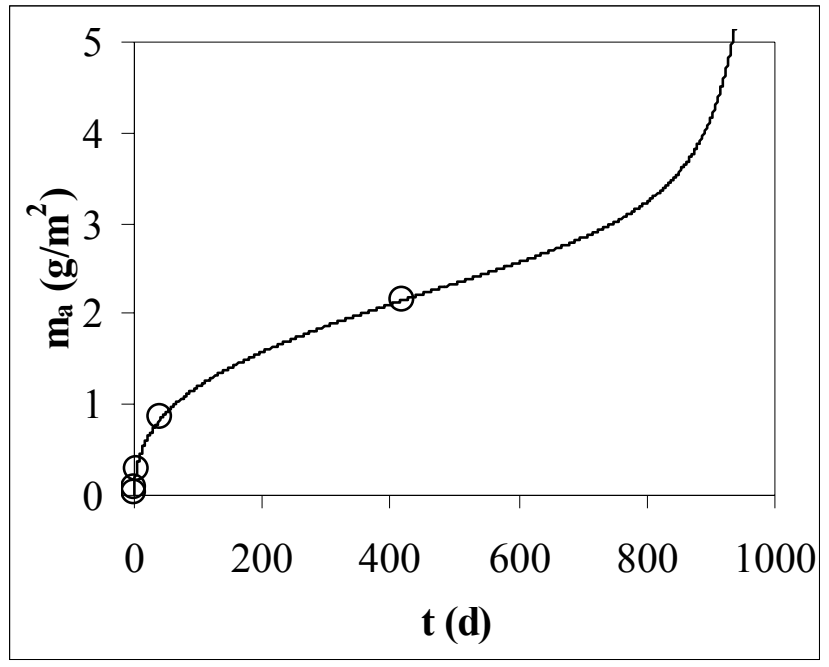

(a)

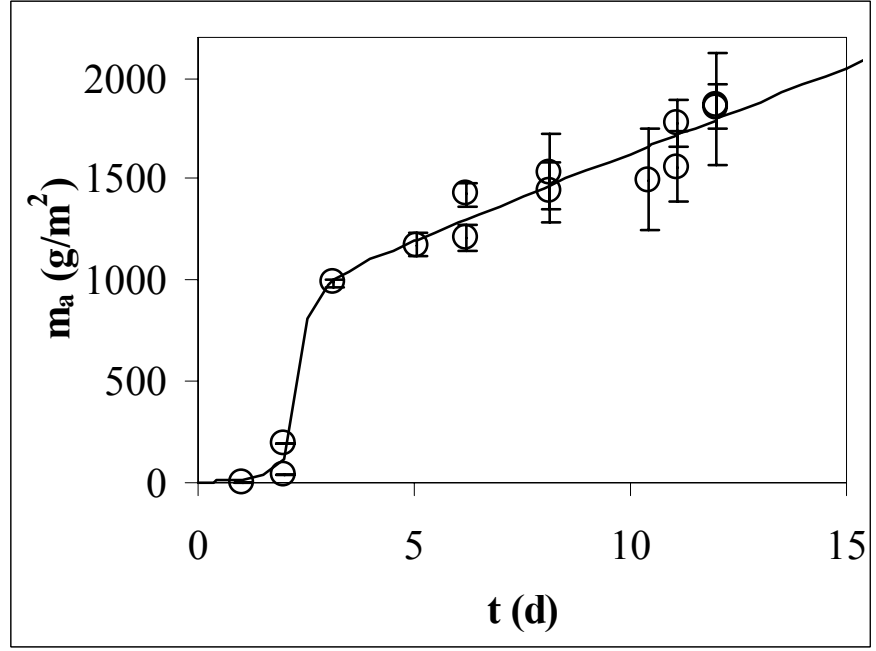

(b)

Figure 4.2. Typical Glass Alteration Curve Generated from Equation (2) with (a) HLP-55 PCT-B data and (b) HLP-46 $175^{\circ} \mathrm{C}$ VHT data

The empirical relationship represented by Equation (2) may be a useful data reduction tool when the number of parameters is required to be small. For applications under a broad range of conditions, the rate equation is needed. Such an equation must be frame-indifferent, which means that the rate cannot be an explicate function of time. Equation (2) is an example of a solution of an appropriate rate equation for the corrosion process that occurs in an isothermal closed system. A rate equation corresponding to Equation (2) is

$$
r=r_{0}\left(1+\frac{t}{t_{1}}\right)^{n-1}+r_{\infty}\left\{\frac{1}{2}+\frac{1}{\pi}\left[\arctan \frac{t-t_{2}}{t_{3}}+\frac{t_{3}\left(t+t_{4}\right)}{t_{3}^{2}+\left(t-t_{2}\right)^{2}}\right]\right\}
$$




\section{Table 4.1. Corrosion Parameters used to Generate Figure 4.2 (those parameters in bold were critical in obtaining a fit of the experimental data)}

\begin{tabular}{|c|c|c|c|}
\hline Parameter & Value (a) & Value (b) & Unit \\
\hline $\mathrm{n}$ & $\mathbf{0 . 3 5}$ & 0.5 & \\
\hline $\mathrm{t}_{1}$ & $\mathbf{0 . 1 4}$ & 0.001 & $\mathrm{~d}$ \\
\hline $\mathrm{t}_{2}$ & 1000 & $\mathbf{2 . 3}$ & $\mathrm{d}$ \\
\hline $\mathrm{t}_{3}$ & 1 & $\mathbf{0 . 1}$ & $\mathrm{d}$ \\
\hline $\mathrm{t}_{4}$ & 20 & $\mathbf{9 . 6}$ & $\mathrm{d}$ \\
\hline $\mathrm{r}_{0}$ & $\mathbf{0 . 3 2 9}$ & 75 & $\mathrm{~g} / \mathrm{m}^{2} \mathrm{~d}$ \\
\hline $\mathrm{r}_{\infty}$ & 0.5 & $\mathbf{8 3 . 6}$ & $\mathrm{g} / \mathrm{m}^{2} \mathrm{~d}$ \\
\hline
\end{tabular}

Equation (3) is rather awkward and is not frame-indifferent. Simpler rate equations can be constructed for individual stages:

Stages I and II

Stage III

$$
r_{I, I I}=r_{0}\left(1+b m_{a}\right)^{q}
$$

$$
r_{I I I}=\frac{r_{\max }}{1+\left(\frac{t-t_{2}}{t_{3}}\right)^{2}}
$$

Stage IV

where $b$ and $q$ are material coefficients $(q<0)$. A comparison with Equation (2) shows that $n=1 /(1-q)$ and $t_{1}=n / b r_{0}$. Equation (4) is the power-law function for Stages I and II. Equation (5) approximates the transition from Stage II to Stage IV. Equation (6) corresponds to the final corrosion rate proposed by Grambow (1987). Assuming that $r_{\infty}<<r_{0}$, which is indeed the case, Equation (3) approaches asymptotically Equation (4) when $t<<t_{2}$. Equation (5) approximates Equation (4) within the interval of $t_{2}$ $-t_{3}<t<t_{2}+t_{3}$. When $t>>t_{2}$, Equation (6) approaches asymptotically Equation (4). An integration of Equation (3) results in the first term of Equation (2).

Equation (4) is still not satisfactory because it has the corrosion progress as a variable, whereas the corrosion rate in Stages I and II responds to the solution composition, which depends on the boundary conditions (closed boundaries or flow through). Fortunately, Equation (4) can be easily modified to include open systems.

Equation (5) is a bridging formula for the transition to Stage IV. Its coefficients are fitting parameters whose physical meaning is clear for a closed system, but any generalization to other circumstances must be based on better information about this transition process, which probably involves more than just the nucleation of crystalline phases. For example, the glass previously weakened by water penetration during slow corrosion at the end of Stage II, can crack or rapidly convert to gel during Stage III. Moreover, it is possible that Stage III consists of not one but several spikes as the nucleation and associated phenomena 
occur at different positions on the gel surface at slightly different time intervals. At the temperatures of interest in our experiments, the rapid mobility and thermal mixing eventually over ride the local variances in Stage IV.

Coefficients in Equations (4) and (6) can be considered as material parameters that are functions of state variables, such as temperature and glass composition. If these functions are known, the independent variables that can be controlled by the waste product manufacturing and storage, such as glass composition and waste package makeup, can be optimized.

\subsection{VHT Response as a Function of Temperature}

Section 3.5.4 presents the effect of temperature on VHT response of selected glasses. These data are evaluated in terms of the influence of temperature on $r=r_{\infty}$ (the rate of alteration in Stage IV; the subscript $\infty$ is dropped in the following discussions). Table 4.2 lists the $r$ for those glasses for which VHT was performed at three or more temperatures. Also listed are the values of $\mathrm{E}_{\mathrm{a}}$, assuming the validity of a linear relationship $\ln [r]=\mathrm{E}_{\mathrm{a}} / \mathrm{RT}+$ constant for those glasses with $r$ values measured precisely (e.g., those values not marked by "a," "b," "c," "d," or "e"; see Section 3.5.2) for at least three temperatures.

The term $E_{a}$ cannot be considered an activation energy in the sense this term is used in the transition state theory because the dissolution of even a simple mineral consists of several reaction steps (five steps in case of quartz) (Lasaga 1995); during VHT, there is changing solution chemistry with reaction extent, dissolution processes, and precipitation processes that must be considered. It should be noted that the validity of the Arrhenius empirical relationship does not automatically imply that the mechanism is the same over the temperature interval in question and that the same alteration products are formed at high and low temperatures.

It should also be noted that the stability of water decreases with temperature, which means the concentration of both hydroxide and protons increases with temperature. It isn't clear how this affects the alteration of glass or how it influences the temperature effect on alteration kinetics.

The $\mathrm{E}_{\mathrm{a}}$ values range from 80 to $102 \mathrm{~kJ} / \mathrm{mol}$. Figure 4.3 shows the effect of inverse temperature on $\ln [r]$ of tested HLP glasses. The data set contains only glasses where the rate was accurately measured for at least three temperatures. Interestingly, a single $E_{a}$ value, $92.5 \mathrm{~kJ} / \mathrm{mol}$, suitably describes the impact of inverse temperature on $r$ of all the glasses.

These $E_{a}$ values are at the high end of the range commonly reported for glass corrosion by other test methods, which generally range from $32 \mathrm{~kJ} / \mathrm{mol}$ (for soda-lime and low $\mathrm{SiO}_{2}$ glasses) to $100 \mathrm{~kJ} / \mathrm{mol}$ (Lutze and Ewing 1988, Jercinovic and Ewing 1992, Westsik and Peters 1981, Abraitis et al. 1998, Jiricka and Helebrant 2000). It is uncertain if our measured $E_{a}$ values will remain constant with decreasing temperature. Mazer (1991) suggests caution in the use of temperature as an accelerating parameter until more is understood about the rate-determining mechanism at test and disposal-site temperatures.

Leturcq et al. (1998) summarized corrosion rate data for R7T7 glass within the temperature interval from $25^{\circ} \mathrm{C}$ to $300^{\circ} \mathrm{C}$ and confirmed the validity of Arrhenius behavior with a constant $\mathrm{E}_{\mathrm{a}}=60 \pm 5 \mathrm{~kJ} / \mathrm{mol}$. Likewise, Westsik and Peters (1981) showed that $\mathrm{E}_{\mathrm{a}}$ for PNL 76-68 glass corrosion remained constant at $53 \mathrm{~kJ} / \mathrm{mol}$ over the temperature range from $50^{\circ} \mathrm{C}$ to $150^{\circ} \mathrm{C}$; however, the $E_{a}$ was found to change below 
$50^{\circ} \mathrm{C}$ and above $150^{\circ} \mathrm{C}$. A possible explanation for the change in corrosion behavior at temperatures above $150^{\circ} \mathrm{C}$ was a change in the stage of corrosion. In the initial stage of corrosion (Stage I), ion

Table 4.2. VHT Rate as a Function of Temperature for HLP Glasses

\begin{tabular}{|c|c|c|c|c|c|c|c|c|c|}
\hline \multirow{2}{*}{\begin{tabular}{|c|} 
Glass \\
ID \\
\end{tabular}} & \multicolumn{8}{|c|}{$R\left(\mathrm{~g} / \mathrm{m}^{2} / \mathrm{d}\right)$} & \multirow{2}{*}{$\begin{array}{c}\mathrm{E}_{\mathrm{a}} \\
(\mathrm{kJ} / \mathrm{mol})\end{array}$} \\
\hline & $90^{\circ} \mathrm{C}$ & $125^{\circ} \mathrm{C}$ & $150^{\circ} \mathrm{C}$ & $175^{\circ} \mathrm{C}$ & $200^{\circ} \mathrm{C}$ & $250^{\circ} \mathrm{C}$ & $275^{\circ} \mathrm{C}$ & $300^{\circ} \mathrm{C}$ & \\
\hline HLP-01 & - & - & - & - & $4.3^{(\mathrm{b})}$ & 264 & - & 929 & - \\
\hline HLP-02 & - & 2.4 & 5.1 & - & 265 & - & - & - & 102 \\
\hline HLP-03 & - & - & - & - & $0.9^{(\mathrm{b})}$ & 56 & - & $510^{(\mathrm{d})}$ & - \\
\hline HLP-05 & - & - & - & - & $2.7^{(\mathrm{b})}$ & 595 & - & $703^{(\mathrm{d})}$ & - \\
\hline HLP-06 & - & - & - & - & $2.1^{(\mathrm{a})}$ & - & 220 & $523^{(\mathrm{d})}$ & - \\
\hline HLP-09 & - & - & - & - & $1.2^{(\mathrm{b})}$ & 60 & 344 & 409 & 97 \\
\hline HLP-10 & - & - & - & - & 11.7 & 299 & - & $542^{(\mathrm{e})}$ & - \\
\hline HLP-12 & - & - & - & - & 13.6 & 259 & - & 1126 & 100 \\
\hline HLP-13 & - & - & - & - & 2.1 & - & $213^{(a)}$ & $640^{(\mathrm{d})}$ & - \\
\hline HLP-15 & - & - & - & - & $1.4^{(\mathrm{b})}$ & - & 133 & $517^{(\mathrm{d})}$ & - \\
\hline HLP-16 & - & - & - & - & $7.6^{(\mathrm{b})}$ & 286 & $604^{(\mathrm{d})}$ & $670^{(\mathrm{d})}$ & - \\
\hline HLP-20 & - & - & - & - & $1.5^{(\mathrm{b})}$ & $104^{(\mathrm{a})}$ & - & $227^{(\mathrm{d})}$ & - \\
\hline HLP-22 & - & - & - & - & $0.3^{(\mathrm{b})}$ & - & 58.4 & $309^{(\mathrm{d})}$ & - \\
\hline HLP-24 & - & - & - & - & $1.7^{(\mathrm{b})}$ & - & $204^{(\mathrm{a})}$ & $324^{(\mathrm{d})}$ & - \\
\hline HLP-25 & - & - & - & - & $4.2^{(\mathrm{b})}$ & 292 & - & 737 & - \\
\hline HLP-26 & - & - & - & - & $1.2^{(\mathrm{b})}$ & 224 & - & 761 & - \\
\hline HLP-28 & - & - & - & - & 6.7 & - & 89.9 & 248 & 80 \\
\hline HLP-32 & - & - & - & - & $0.2^{(\mathrm{b})}$ & - & 65.0 & $478^{(\mathrm{d})}$ & - \\
\hline HLP-33 & - & - & - & - & 22.3 & $1930^{\text {(d) }}$ & - & $2050^{\text {(d) }}$ & - \\
\hline HLP-39 & - & - & - & - & $8.4^{(\mathrm{c})}$ & 709 & - & $2220^{(\mathrm{d})}$ & - \\
\hline HLP-40 & - & - & - & - & 1.5 & - & $204^{(c)}$ & $709^{(\mathrm{d})}$ & - \\
\hline HLP-41 & - & - & - & - & 9.9 & $729^{(\mathrm{d})}$ & - & $2126^{(\mathrm{d})}$ & - \\
\hline HLP-42 & - & - & - & - & $0.0^{(\mathrm{c})}$ & $47^{(\mathrm{c})}$ & - & $701^{(\mathrm{d})}$ & - \\
\hline HLP-43 & - & - & - & - & $4.6^{(\mathrm{b})}$ & 234 & - & 832 & - \\
\hline HLP-46 & $0.0^{(\mathrm{a})}$ & $0.2^{(\mathrm{a})}$ & 18.6 & 87.2 & 255 & - & - & - & 87 \\
\hline HLP-48 & - & - & 3.4 & 13.7 & 50.5 & 522 & - & - & 93 \\
\hline HLP-49 & - & - & - & - & $2.4^{(\mathrm{b})}$ & $120^{(\mathrm{e})}$ & $996^{\text {(d) }}$ & $709^{(\mathrm{d})}$ & - \\
\hline HLP-51 & - & - & $3.0^{(\mathrm{b})}$ & - & $4.0^{(\mathrm{b})}$ & 44 & 129 & 336 & 101 \\
\hline HLP-52 & - & 15.5 & 196 & - & 1219 & - & - & - & 88 \\
\hline HLP-56 & - & - & - & - & $1.9^{(\mathrm{b})}$ & 76 & - & 603 & - \\
\hline \multicolumn{10}{|c|}{ (a) Insufficient data to accurately determine the alteration rate } \\
\hline \multirow{2}{*}{\multicolumn{10}{|c|}{$\begin{array}{l}\text { (b) Sufficient alteration was not achieved before significant water loss. } \\
\text { (c) Specimen analyses difficulties }\end{array}$}} \\
\hline & & & & & & & & & \\
\hline \multicolumn{10}{|c|}{ (d) Rate is based on a single data poir } \\
\hline \multicolumn{10}{|c|}{ (e) Rate is based on only two data points. } \\
\hline
\end{tabular}

exchange is rate-controlling and $\mathrm{pH}$ increases rapidly; Westsik and Peters (1981) found that the normalized Na release was significantly higher than the normalized boron release for samples tested at 
temperatures below $50^{\circ} \mathrm{C}$. In Stage II, corrosion is roughly congruent, as was found by Westsik and Peters (1981) between $50^{\circ} \mathrm{C}$ and $150^{\circ} \mathrm{C}$, and the rate of corrosion drops as the concentration of aqueous species increases, decreasing the driving force for dissolution. In Stages III and IV, key mineral phases precipitate from solution, allowing the driving force for dissolution to increase and the dissolution rate to accelerate; it is believed that this stage was achieved in the Westsik and Peters (1981) tests at temperatures above $150^{\circ} \mathrm{C}$.

Insufficient data are available to determine if the mechanisms that determine the alteration rate of these glasses at $200^{\circ} \mathrm{C}$ are similar to those that would determine the alteration rate at $15^{\circ} \mathrm{C}$. The average $\mathrm{E}_{\mathrm{a}}$, for tested LAW glasses subjected to VHT at temperatures from $125^{\circ} \mathrm{C}$ to $300^{\circ} \mathrm{C}$, is roughly $92.5 \mathrm{~kJ} / \mathrm{mol}$.

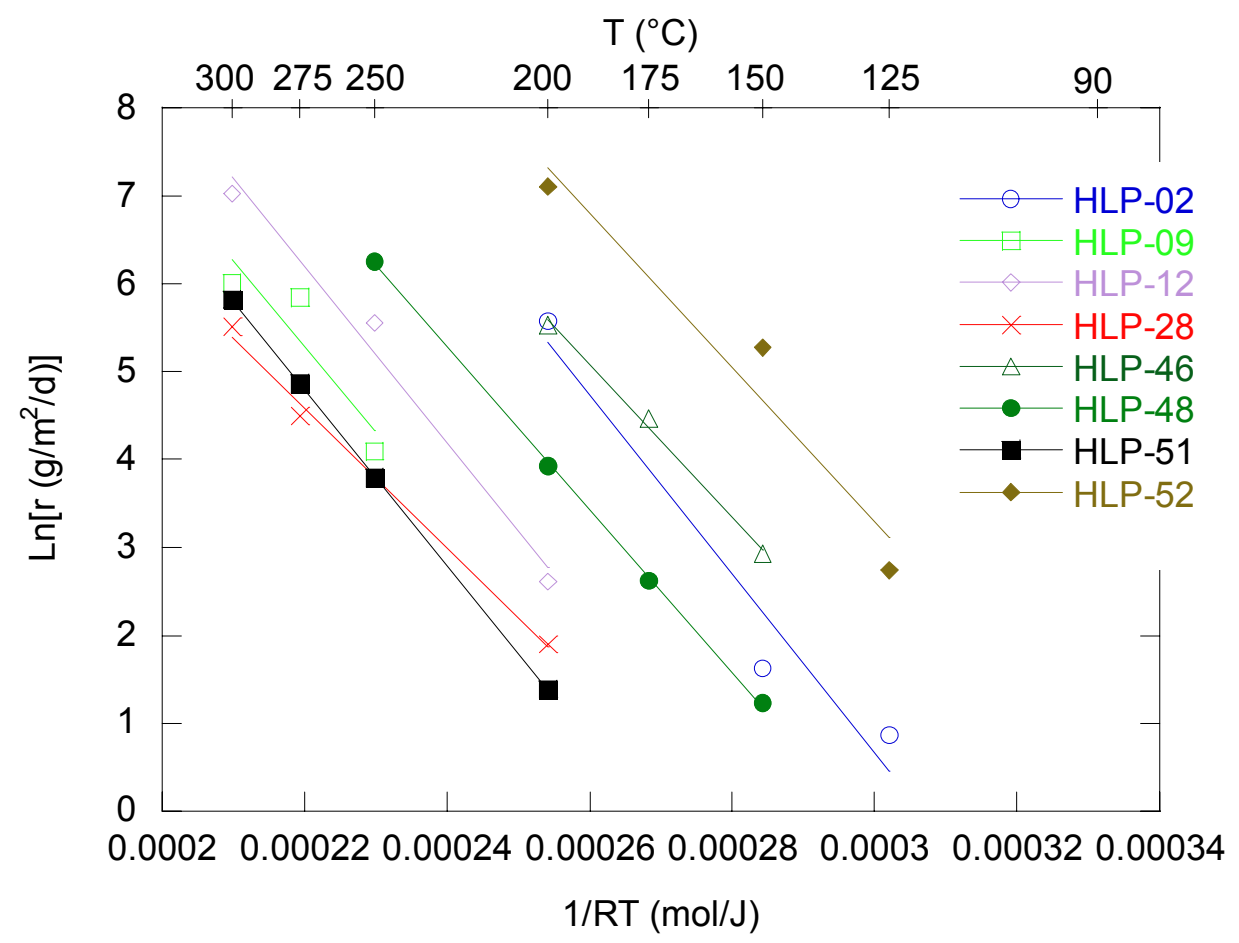

Figure 4.3. Effect of Temperature on the Alteration Rate of LAW Glasses

\subsection{VHT Response as a Function of Glass Composition}

It would be useful to describe the response of glass to VHT as a function of glass composition as is commonly done for PCT (see Jantzen 1991 and Hrma et al. 2001, for example). This would allow for the formulation qualification of Hanford LAW glasses. In an earlier report (Schulz et al. 2000), we found little correlation between $\ln [r]$ and a linear function of glass composition. Gan and Pegg (2001) attempted to model $m_{a}$ in Stage III as a function of both time and composition using a modified Avrami model with the Avrami parameters expanded as polynomial functions of composition. Although this model gave a reasonable description of the corrosion data in Stage III (but not in Stages I, II, and IV), it contained 41 empirically fit parameters and required second- and third-order component interaction terms. We attempt to revisit the composition effects on VHT here, focusing on Stage IV (Stage III has 
low reproducibility because it represents an abrupt transition from a highly unstable state to a steady state controlled by crystal formation).

To develop a consistent data set, only tests performed at $200^{\circ} \mathrm{C}$ were used. Since a majority of the response of interest was in Stage IV of the alteration curve, the focus was on $r$ (equivalent to $r_{\infty}$ in Equation (2), discussed above). All rates that were determined by one or two data points alone (notes $d$ and e in Table 3.17 and Appendix C), and all grossly crystallized glasses (note "g" in Table 3.17 and Appendix C) were excluded.

The obvious first step in assessing composition effects on the VHT rate of Hanford LAW glasses was to examine the effect of alkali oxide concentrations $\left(\mathrm{Na}_{2} \mathrm{O}, \mathrm{K}_{2} \mathrm{O}\right.$, and $\left.\mathrm{Li}_{2} \mathrm{O}\right)$. Since alkali ions break up the glass network, they make hydration and glass dissolution easier, and, when leached into solution, they increase the $\mathrm{pH}$. Figure 4.4 shows the effect of alkali oxides on $\ln [r]$ of HLP glasses from the VHT at $200^{\circ} \mathrm{C}$. The effect of alkali oxides concentration alone describes nearly $43 \%$ of the variation in $\ln [r]$ for these glasses. However, additional components influence VHT response.

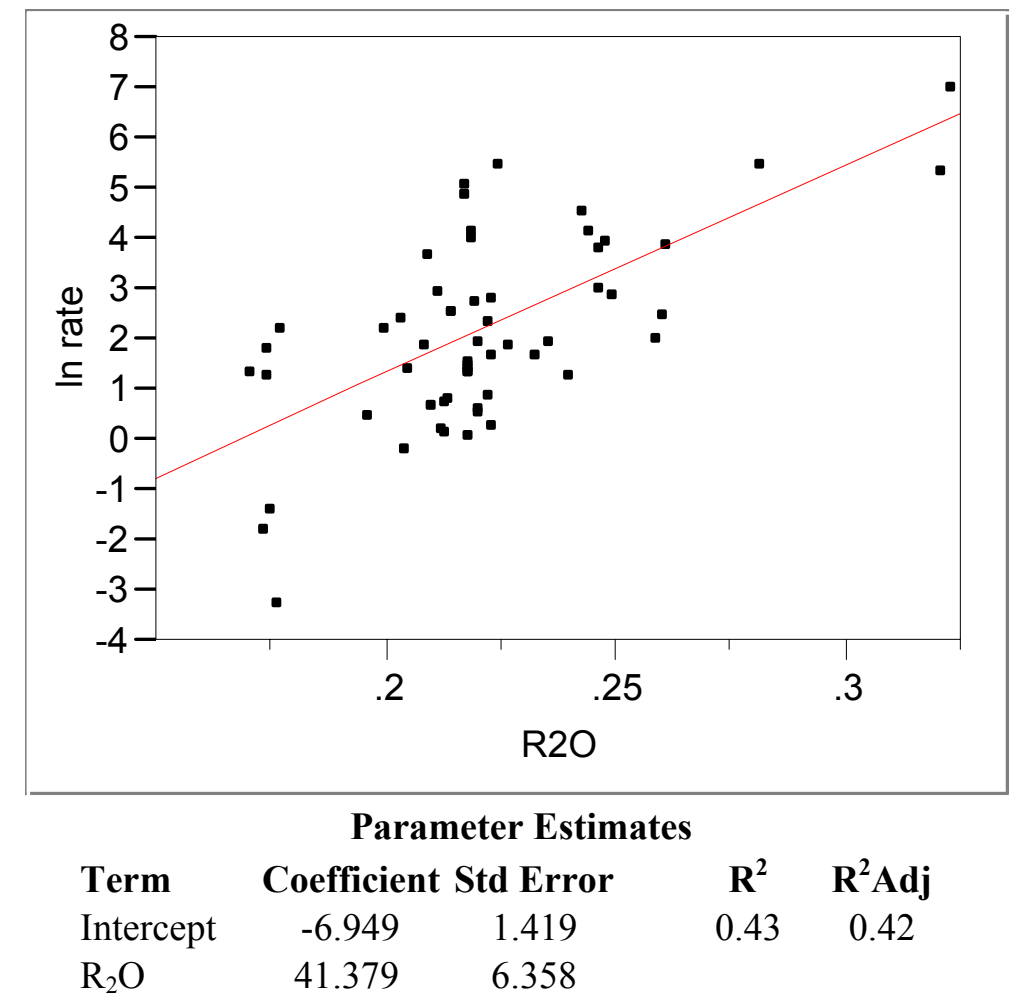

Figure 4.4. Effect of Alkali Oxide Mole Fraction $(\mathrm{R} \equiv \mathrm{Li}, \mathrm{Na}, \mathrm{K})$ on $\ln [r]$ for $\mathrm{VHT}$ at $200^{\circ} \mathrm{C}$

The second attempt to describe VHT response is by a simple first order expansion of $\ln [r]$ in glass composition according to:

$$
\ln [r]=\sum_{i=1}^{N} v_{i} x_{i}
$$


where $N$ is the number of glass components and $v_{i}$ and $x_{i}$ are the $\mathrm{i}^{\text {th }}$ component coefficient and mole fraction, respectively. For simplicity, the glass components were grouped into sets: $\mathrm{Na}_{2} \mathrm{O}, \mathrm{K}_{2} \mathrm{O}$, and $\mathrm{Li}_{2} \mathrm{O}$ were grouped into " $\mathrm{R}_{2} \mathrm{O}$ "; $\mathrm{CaO}, \mathrm{MgO}$, and $\mathrm{ZnO}$ were grouped into " $\mathrm{AO}$ "; $\mathrm{SiO}_{2}, \mathrm{Al}_{2} \mathrm{O}_{3}, \mathrm{~B}_{2} \mathrm{O}_{3}, \mathrm{Fe}_{2} \mathrm{O}_{3}$, $\mathrm{TiO}_{2}$, and $\mathrm{ZrO}_{2}$ were left as single components; and all other components were grouped into "Others." The pair-wise component correlations for those available glasses are listed in Table 4.3. Only two pairs have absolute correlations greater than 0.5: $\mathrm{SiO}_{2}-\mathrm{ZrO}_{2}$ and $\mathrm{SiO}_{2}-\mathrm{R}_{2} \mathrm{O}$ (both listed in bold). Figure 4.5 shows the distribution of data on a scatter-plot matrix graph of component concentrations. This graph shows a broad and even distribution of data. Those points in red are the glasses with rates higher than $50 \mathrm{~g} / \mathrm{m}^{2} / \mathrm{d}$, and those points in green are glasses with rates lower than $50 \mathrm{~g} / \mathrm{m}^{2} / \mathrm{d}$. Not surprisingly, the red points tend toward the high $\mathrm{R}_{2} \mathrm{O}$ range.

Table 4.3. Pair-wise Correlations Between Components in Glasses Used for VHTComposition Calculations

\begin{tabular}{||l|c|c|c|c|c|c|c|c||}
\hline & $\mathbf{S i O}_{\mathbf{2}}$ & $\mathbf{A l}_{\mathbf{2}} \mathbf{O}_{\mathbf{3}}$ & $\mathbf{B}_{\mathbf{2}} \mathbf{O}_{\mathbf{3}}$ & $\mathbf{F e}_{\mathbf{2}} \mathbf{O}_{\mathbf{3}}$ & $\mathbf{T i O}_{\mathbf{2}}$ & $\mathbf{\mathbf { Z r O } _ { 2 }}$ & $\mathbf{R}_{\mathbf{2}} \mathbf{O}$ & $\mathbf{A O}$ \\
\hline $\mathrm{SiO}_{2}$ & 1.0000 & 0.0545 & -0.3888 & -0.4241 & -0.3164 & $\mathbf{- 0 . 5 0 5 0}$ & $\mathbf{- 0 . 5 8 8 2}$ & -0.4843 \\
\hline $\mathrm{Al}_{2} \mathrm{O}_{3}$ & & 1.0000 & -0.2194 & -0.2318 & -0.2207 & -0.1093 & 0.0782 & -0.4140 \\
\hline $\mathrm{B}_{2} \mathrm{O}_{3}$ & & & 1.0000 & 0.1228 & 0.2804 & -0.1209 & 0.0338 & -0.0424 \\
\hline $\mathrm{Fe}_{2} \mathrm{O}_{3}$ & & & & 1.0000 & 0.1570 & 0.3658 & 0.0301 & 0.2902 \\
\hline $\mathrm{TiO}_{2}$ & & & & & 1.0000 & -0.1763 & -0.2124 & 0.3337 \\
\hline $\mathrm{ZrO}_{2}$ & & & & & & 1.0000 & 0.4587 & 0.2360 \\
\hline $\mathrm{R}_{2} \mathrm{O}$ & & & & & & & 1.0000 & -0.1149 \\
\hline $\mathrm{AO}$ & & & & & & & & 1.0000 \\
\hline
\end{tabular}

Table 4.4 summarizes the results of a first-order expansion of $\ln [r]$ in mole fraction of selected components. Figure 4.6 compares measured and calculated values of $\ln [r]$ for fitted glasses. With an $\mathrm{R}^{2}$ value of 0.805 , the simple composition expansion can explain roughly $80 \%$ of the variation in $\ln [r]$ for this data set. This level of correlation is consistent with composition-PCT models recently developed (Hrma et al. 2001; Gan and Pegg 2001 [when $\mathrm{R}^{2}$ is calculated for normalized release rather than the reported unnormalized release]). The $\mathrm{R}^{2}$ value is lower than that reported by Gan and Pegg (2001) for VHT release, but the model uses only nine first-order coefficients rather than 41 coefficients with first-, second-, and third-order terms used by Gan and Pegg. It also describes the steady-state corrosion in Stage IV whereas Gan and Pegg attempt to fit the $m_{a}-t$ behavior for glass corrosion in Stages II and III observed in VHT. Unfortunately, the modified Avrami model chosen by Gan and Pegg (2001) yields $r_{\infty}=0$ and therefore cannot describe the Stage IV corrosion data. Model validation for our model has not yet been performed, but is planned in the near future.

The value of the coefficients can be taken as a component effect on $\ln [r]$ where those components with coefficients higher than the maximum value (7.1) increase $\ln [r]$, and those components with coefficients lower than the minimum value (-3.2) lower $\ln [r]$. Not surprisingly, $\mathrm{SiO}_{2}, \mathrm{TiO}_{2}$, and $\mathrm{ZrO}_{2}$ decrease the alteration rate while $\mathrm{R}_{2} \mathrm{O}$ and $\mathrm{AO}$ increase the alteration rate. The effects of $\mathrm{B}_{2} \mathrm{O}_{3}, \mathrm{Fe}_{2} \mathrm{O}_{3}$, $\mathrm{Al}_{2} \mathrm{O}_{3}$, and Others could not be predicted from similar models for PCT release. $\mathrm{Al}_{2} \mathrm{O}_{3}$ strongly increases $\ln [r]$, likely because of its influence on the precipitation of aluminosilicates from solution as hypothesized by Strachan and Croak (2000). $\mathrm{B}_{2} \mathrm{O}_{3}$ and $\mathrm{Fe}_{2} \mathrm{O}_{3}$ strongly decrease $\ln [r]$ (more than $\mathrm{SiO}_{2}$ but less than $\mathrm{TiO}_{2}$ and $\mathrm{ZrO}_{2}$ ), likely because of their role in tying up alkali ions and cross-linking the glass network. Others include variable concentrations of $\mathrm{Cl}, \mathrm{Cr}_{2} \mathrm{O}_{3}, \mathrm{~F}, \mathrm{La}_{2} \mathrm{O}_{3}, \mathrm{MoO}_{3}, \mathrm{P}_{2} \mathrm{O}_{5}, \mathrm{ReO}_{2}$, and $\mathrm{SO}_{3}$ (along with 
additional components for some glasses). Others would be expected to decrease rate since $\mathrm{Cl}, \mathrm{F}$, $\mathrm{P}$, and $\mathrm{S}$ decrease solution $\mathrm{pH}$ or buffer the solution, and $\mathrm{La}_{2} \mathrm{O}_{3}$ was found to increase glass resistance to aqueous attack by stabilizing alkali, similar to $\mathrm{Al}_{2} \mathrm{O}_{3}$ (Volf 1984). It is not clear why Others so strongly increases $\ln [r]$.

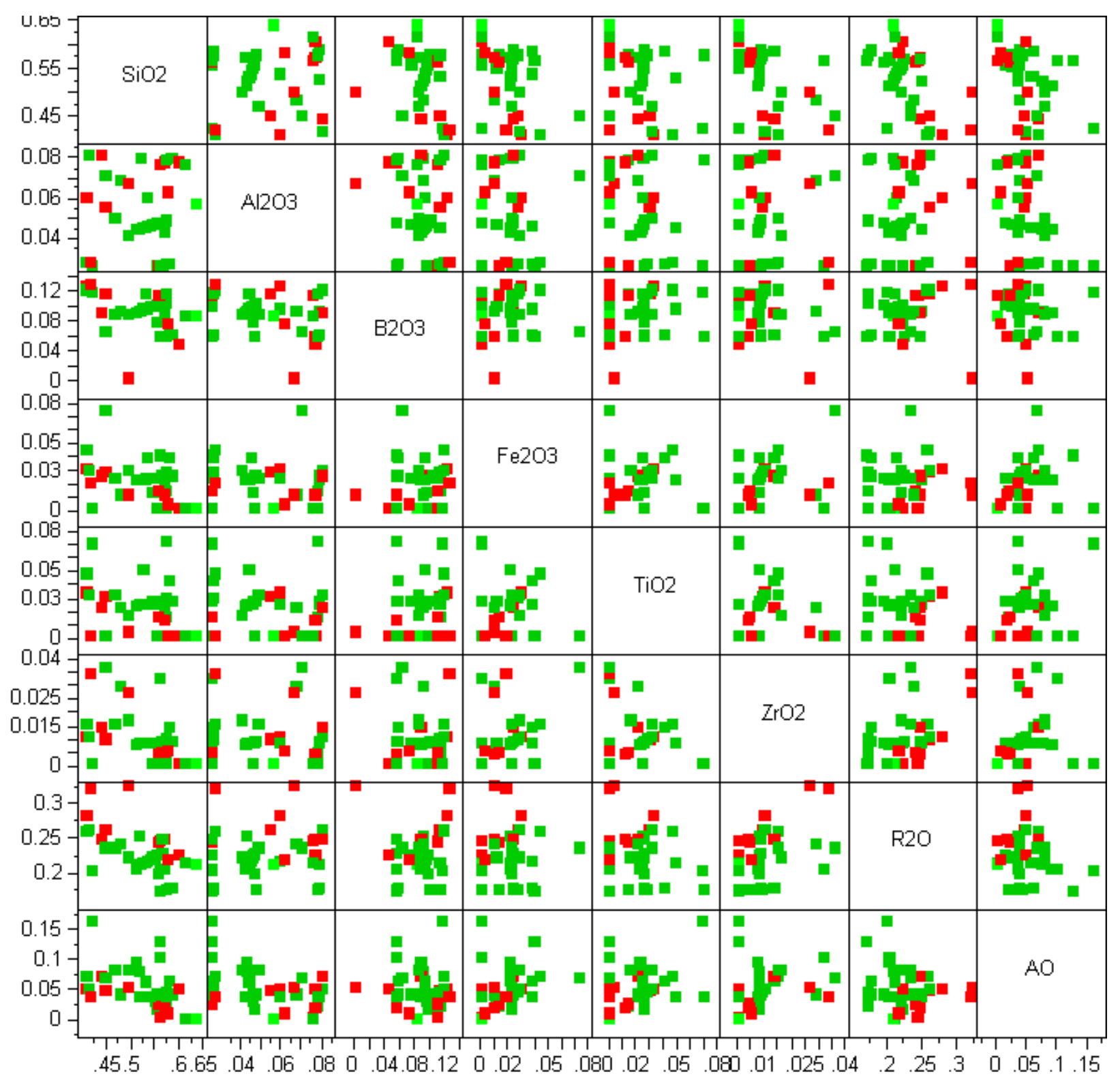

Figure 4.5. Scatter-Plot Matrix of Component Concentrations Used for VHT-Composition Calculations (red squares represent those glasses with $r>50 \mathrm{~g} / \mathrm{m}^{2} / \mathrm{d}$ at $200{ }^{\circ} \mathrm{C}$; green squares represent those glasses with $r<50 \mathrm{~g} / \mathrm{m}^{2} / \mathrm{d}$ at $200^{\circ} \mathrm{C}$ )

This model should not be considered a final tool for predicting VHT response, but a starting point to guide future model-development efforts. Considering model error only, a predicted VHT rate of 32 $\mathrm{g} / \mathrm{m}^{2} / \mathrm{d}$ or lower would be required to fall within the $95 \%$ confidence interval of the limit at $50 \mathrm{~g} / \mathrm{m}^{2} / \mathrm{d}$. This prediction would exclude glasses HLP-55 and HLP-35 from acceptability with measured VHT rates 
of 42.1 and $13.0 \mathrm{~g} / \mathrm{m}^{2} / \mathrm{d}$, respectively. The addition of four second-order terms $-\mathrm{B}_{2} \mathrm{O}_{3} \times \mathrm{B}_{2} \mathrm{O}_{3}, \mathrm{Al}_{2} \mathrm{O}_{3} \times$ $\mathrm{Fe}_{2} \mathrm{O}_{3}, \mathrm{Al}_{2} \mathrm{O}_{3} \times \mathrm{R}_{2} \mathrm{O}$, and $\mathrm{Fe}_{2} \mathrm{O}_{3} \times \mathrm{R}_{2} \mathrm{O}$ - substantially increases the $\mathrm{R}^{2}$ values $(0.882,0.850$, and 0.764 , for normal, adjusted, and prediction as compared to $0.805,0.773$, and 0.679 for the linear model) and lowers the width of the $95 \%$ confidence interval. However, second-order terms may subject the

Table 4.4. Summary of First-order Expansion Results

\begin{tabular}{|c|c|c|c|}
\hline Comp. & $v_{i}$ & Statistic & "Value \\
\hline $\mathrm{SiO}_{2}$ & -8.082 & Mean & 2.205 \\
\hline $\mathrm{Al}_{2} \mathrm{O}_{3}$ & 15.222 & Min & -3.189 \\
\hline $\mathrm{B}_{2} \mathrm{O}_{3}$ & -13.908 & Max & 7.106 \\
\hline $\mathrm{Fe}_{2} \mathrm{O}_{3}$ & -31.806 & & \\
\hline $\mathrm{TiO}_{2}$ & -40.331 & $\mathrm{R}^{2}$ & 0.805 \\
\hline $\mathrm{ZrO}_{2}$ & -90.213 & $\mathrm{R}^{2}$ adjusted & 0.773 \\
\hline $\mathrm{R}_{2} \mathrm{O}$ & 39.338 & $\mathrm{R}^{2}$ prediction & 0.679 \\
\hline $\mathrm{AO}$ & 7.246 & RMSE & 0.900 \\
\hline Others & 24.452 & Observations & 58 \\
\hline
\end{tabular}

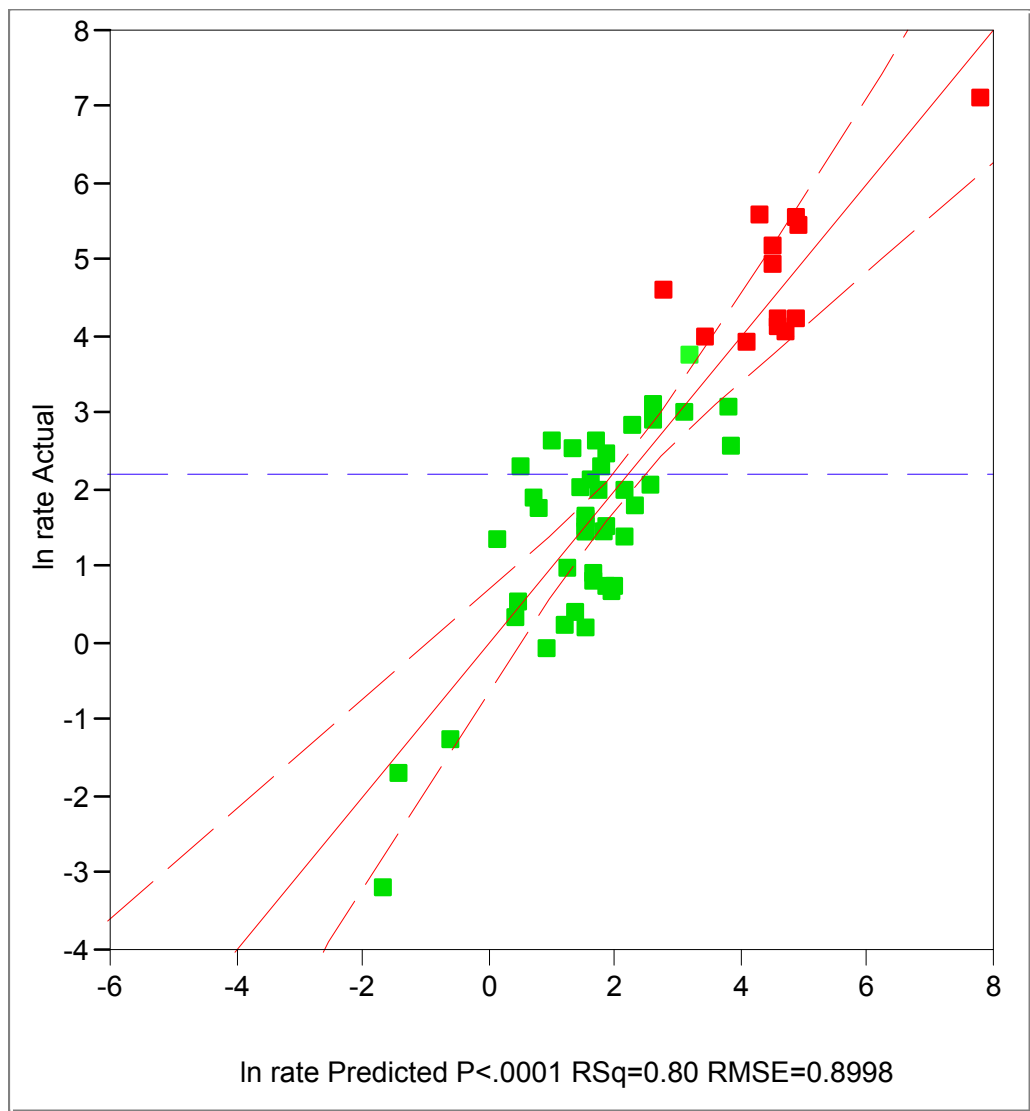

Figure 4.6. Predicted vs. Measured $\ln [r]$ for $200^{\circ} \mathrm{C}$ VHT (with predicted equals measured and $95 \%$ confidence lines shown, red squares represent those glasses with $r>50 \mathrm{~g} / \mathrm{m}^{2} / \mathrm{d}$ at $200{ }^{\circ} \mathrm{C}$, green squares represent those glasses with $\mathrm{r}<50 \mathrm{~g} / \mathrm{m}^{2} / \mathrm{d}$ at $200^{\circ} \mathrm{C}$ ) 
predictions of $\ln [r]$ for glasses not used in model fitting to unusually high uncertainty as often happens when second order terms are added to a model (Gan and Pegg 2001). The second order terms may serve to guide further model-development work in that they point to sources of non-linearity. $\mathrm{Al}_{2} \mathrm{O}_{3}$ and $\mathrm{Fe}_{2} \mathrm{O}_{3}$ interactions with $\mathrm{R}_{2} \mathrm{O}$ are frequently seen in glass durability-composition relationships and may stem from the need for charge compensation of the tetrahedrally coordinated species in the glass or due to the formation of alkali-containing minerals from the solution. Strachan and Croak (2000) suggest a significant difference in the effect of alumina on the time required for glass corrosion to accelerate at $\mathrm{Si} /(\mathrm{Si}+\mathrm{Al})<0.7$. The $\mathrm{B}_{2} \mathrm{O}_{3}$ squared term may stem from differences in boron coordination in glasses with different concentrations and has been widely known to have non-linear impacts on glass durability as measured by PCT and MCC-1 tests (Hrma et al. 1994). Finally, the $\mathrm{Fe}_{2} \mathrm{O}_{3}-\mathrm{Al}_{2} \mathrm{O}_{3}$ interaction may be due to competition for charge-compensating alkali ions, competition for network-forming sites in the glass, or due to influences on secondary phase precipitation.

\subsection{Comparison of VHT Response with Literature VHT Data}

As described in Section 3.5.1, three general procedures were used to measure the VHT response of nuclear waste glasses. In this section, we compare the VHT response of like glasses measured with the three methods. The literature results measured according to the Methods $\mathrm{A}$ and $\mathrm{C}$ were recalculated to yield the mass of glass converted to alteration products per unit surface area $\left(m_{a}\right.$ in $\left.\mathrm{g} / \mathrm{m}^{2}\right)$ to be directly compared to the results reported in this study. By Method A, the thickness of the sample before the test is $0.1 \mathrm{~cm}$, and the maximum amount of glass to be dissolved is $1300 \mathrm{~g} / \mathrm{m}^{2}$; we can assume that a zero thickness alteration layer $\left(d_{a}\right)$ corresponds to $0 \mathrm{~g} / \mathrm{m}^{2}$ of dissolved glass and a $1000-\mu \mathrm{m}$ thick alteration layer corresponds to $1300 \mathrm{~g} / \mathrm{m}^{2}$ of dissolved glass. This approximation enables direct comparison of the results by

$$
m_{a}=d_{a} \rho
$$

Assuming that $\rho=2.6 \mathrm{~g} / \mathrm{cm}^{3}$, then for $d_{a}$ in $\mu \mathrm{m}$, and $m_{a}$ in $\mathrm{g} / \mathrm{m}^{2}$, we have $m_{a}=1.30 d_{a}$. Likewise for method C with a $0.2-\mathrm{cm}$ initial sample thickness and $2600 \mathrm{~g} / \mathrm{m}^{2}$ corresponding to full dissolution, we use $m_{a}=2.60 d_{a}$. The literature VHT data are given in Appendix D along with the $m_{a}$ values estimated by the above process.

VHT response data for glasses tested in this study were found in three additional data sources: Muller et al. 2001, McGrail et al. 1999, and Feng et al. 1996. These data were obtained at different laboratories with different procedures (procedure C was used by Muller et al. 2001 and procedure A by McGrail et al. 1999 and Feng et al. 1996). Figure 4.7 shows a comparison of the measured results from literature with those obtained in this study. Keeping in mind the high relative uncertainty generally seen in VHT responses below $400 \mathrm{~g} / \mathrm{m}^{2}$, all these data appear to qualitatively match each other. The furthest deviation in data exists between studies for HLP-56 in Figure 4.7(i) where the data show different trends. It is not clear if this difference is from the aforementioned high uncertainty for responses below $400 \mathrm{~g} / \mathrm{m}^{2}$, or if there is a true mismatch in the data. No analyses were performed to determine if there are any statistically significant differences between data using different methods shown in this section. 


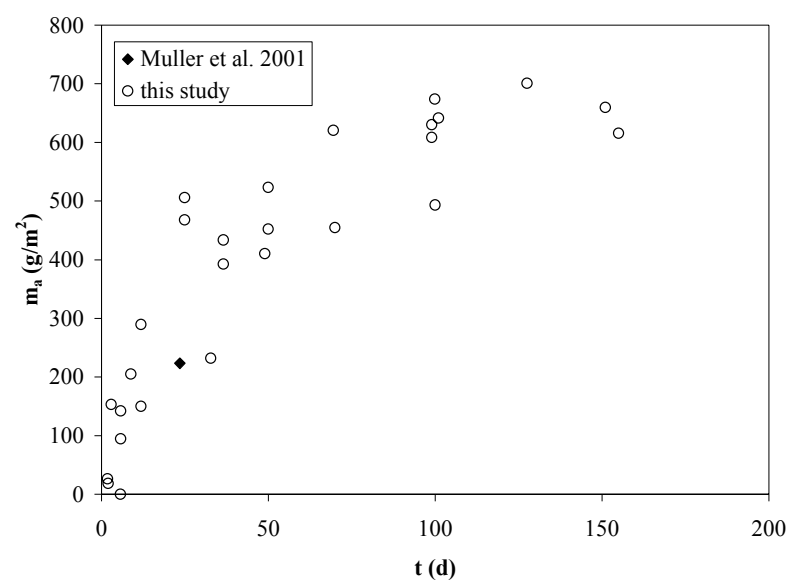

(a) HLP-01, $-25,-26$, and -43 at $200^{\circ} \mathrm{C}$

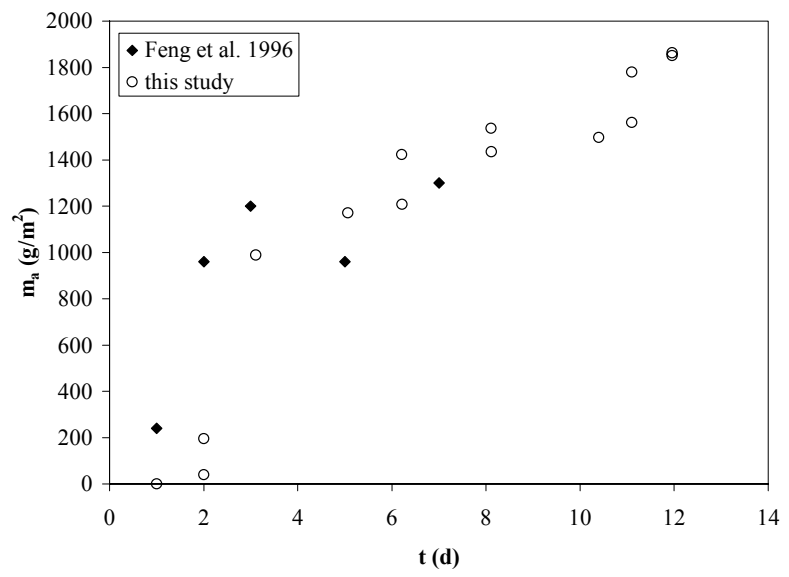

(c) HLP-46 at $175^{\circ} \mathrm{C}$

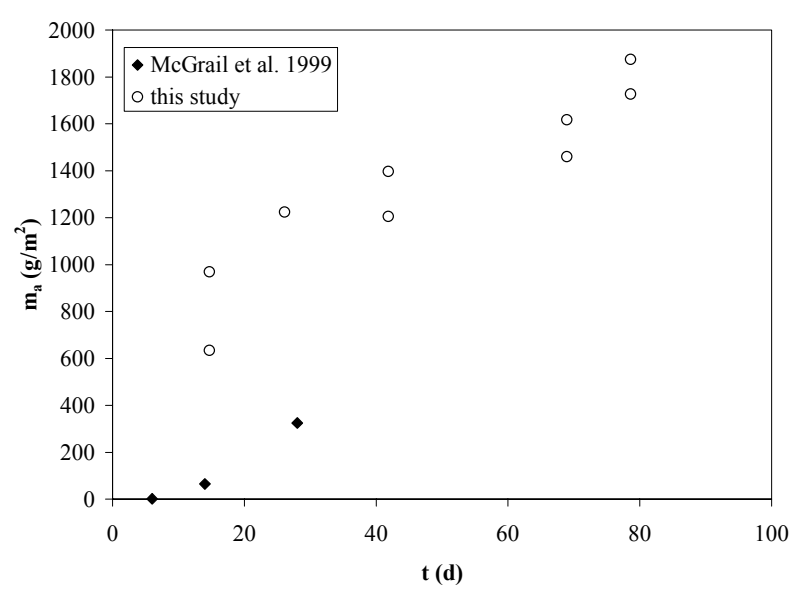

(e) HLP-48 at $175^{\circ} \mathrm{C}$

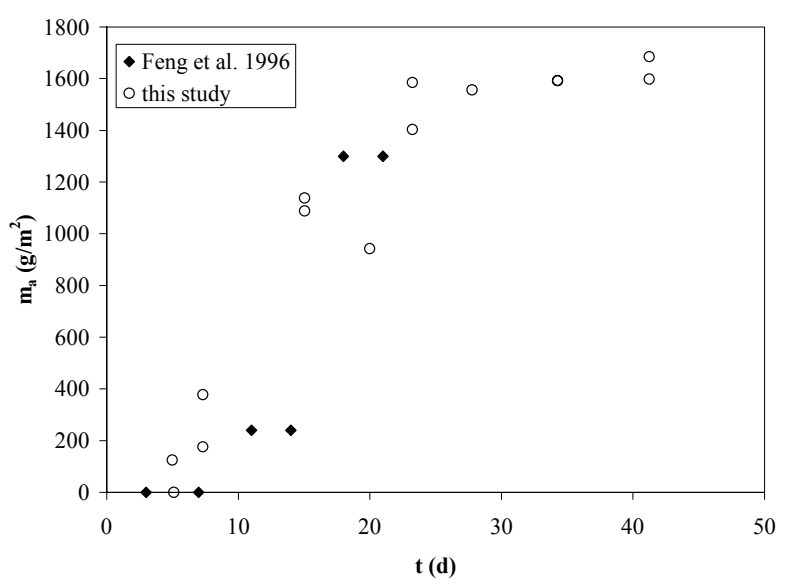

(b) $\mathrm{HLP}-46$ at $150^{\circ} \mathrm{C}$

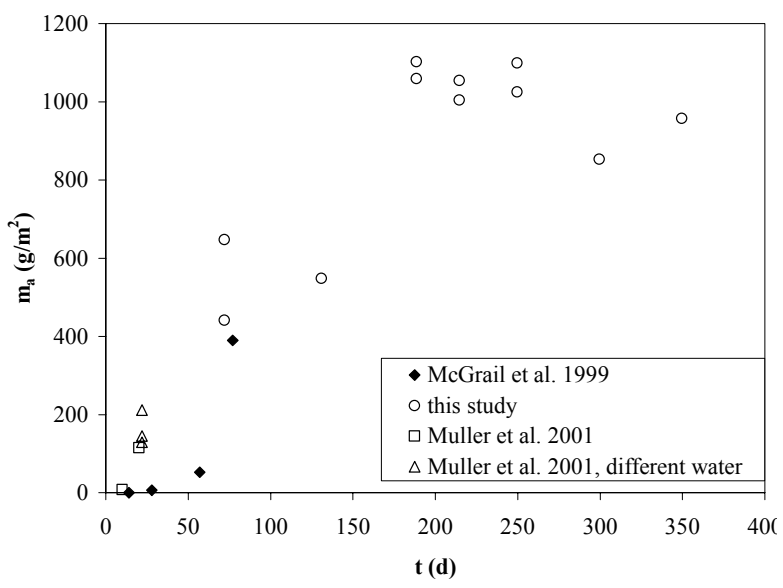

(d) HLP-48 at $150^{\circ} \mathrm{C}$

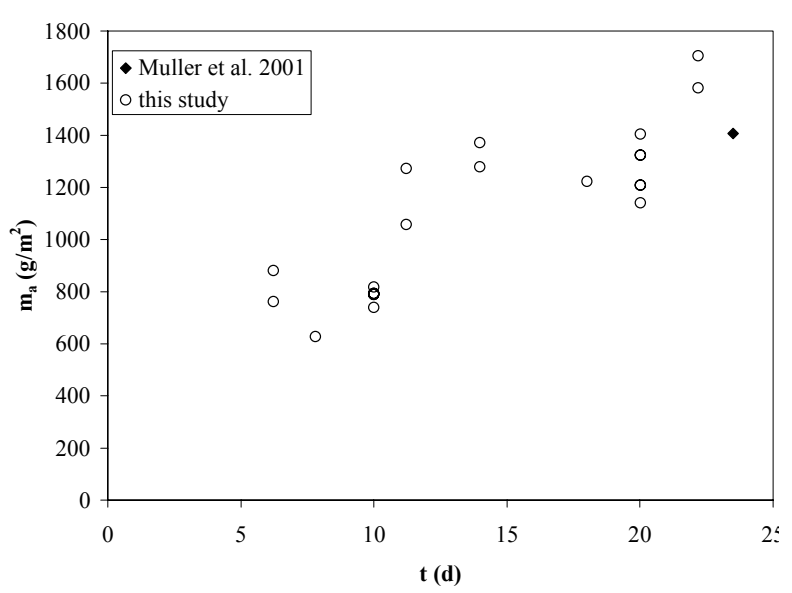

(f) HLP-48 at $200^{\circ} \mathrm{C}$

Figure 4.7. Comparison of VHT Results Reported in this Study with Those Reported in Literature for Glasses with the Same Target Compositions 


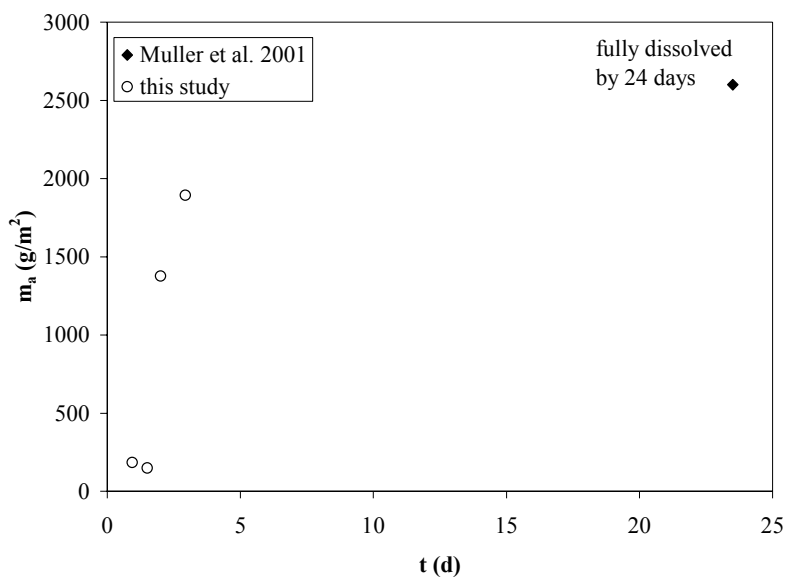

(g) HLP-51 at $200^{\circ} \mathrm{C}$

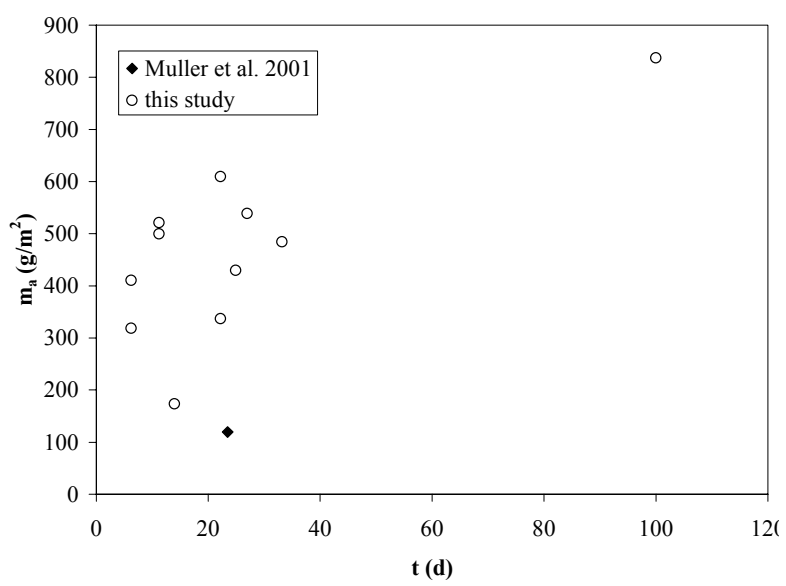

(h) HLP-53 at $200^{\circ} \mathrm{C}$

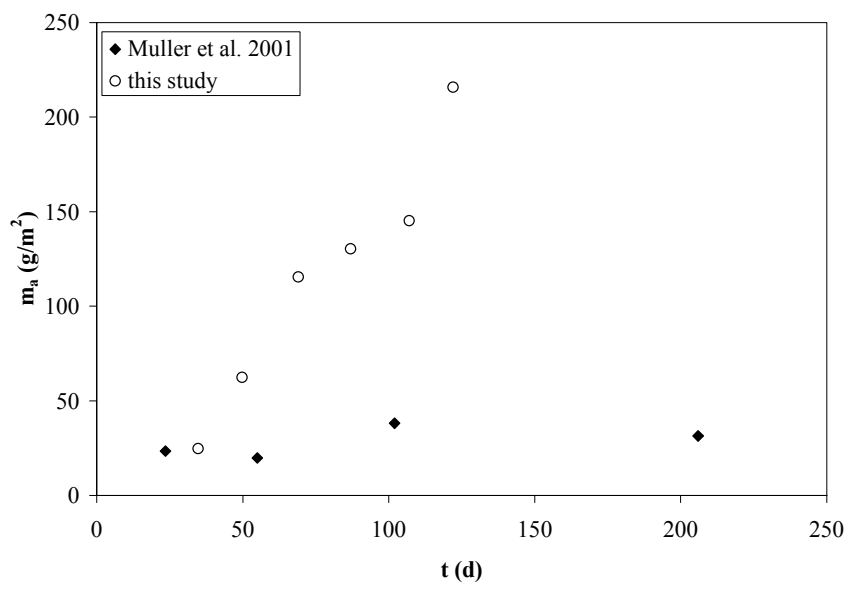

(i) HLP-56 at $200^{\circ} \mathrm{C}$

Figure 4.7 (Contd)

\subsection{Comparison of VHT and Other Test Methods}

As a relatively new method in evaluating the corrosion of waste glasses, it is beneficial to compare the response of glasses to VHT with their responses to other, more established, test methods. As described in Section 4.1, the alteration of glass in a closed or slowly replenished system may exhibit an acceleration of alteration marked by Stage III. This is often seen at the end of long-term PCTs and at the beginning of VHTs. Table 4.5 shows the comparison of VHT and PCT acceleration times. The PCTs were conducted with deionized water at $99^{\circ} \mathrm{C}$ with $\mathrm{S} / \mathrm{V}=20000 \mathrm{~m}^{-1}$ by McGrail et al. (1999).

The time to accelerate $\left(t_{a}\right)$, i.e., the time it takes to reach the third stage of alteration, plotted in Figure 4.8, was obtained from VHT as the time when the first solid alteration products were observed. In PCT, $\mathrm{t}_{\mathrm{a}}$ is the time where the normalized mass loss (calculated from boron release) increases rapidly on a logscale plot. The $t_{\mathrm{a}} \mathrm{s}$ are only estimated because neither of the tests is designed to precisely determine them. In PCT, some glasses may take a long time to accelerate or possibly not accelerate at all. Thus, $t_{a}$ cannot be determined exactly for these tests because of insufficient experimental results. Only those glasses where $t_{a}$ can be estimated for both PCT and VHT were included. Although the data show a limited 
amount of correlation, it is too soon to tell if a true relationship exists. If so, this may provide a tool that could be used in comparing results from these two tests.

Table 4.5. Estimated Time to Acceleration $\left(t_{a}\right)$

\begin{tabular}{|c|c|c|}
\hline Glass ID & $\begin{array}{c}\text { PCT (d) } \\
\left(99^{\circ} \mathrm{C}, 20000 \mathrm{~m}^{-1}\right)\end{array}$ & $\begin{array}{l}\text { VHT (d) } \\
\left(200^{\circ} \mathrm{C}\right)\end{array}$ \\
\hline HLP-10 & $\geq 12$ & $\leq 3$ \\
\hline HLP-46 & $\geq 10.5$ & $\leq 1$ \\
\hline HLP-47 & $\geq 41$ & $\leq 5$ \\
\hline HLP-52 & $\geq 7$ & $\leq 0.5$ \\
\hline
\end{tabular}

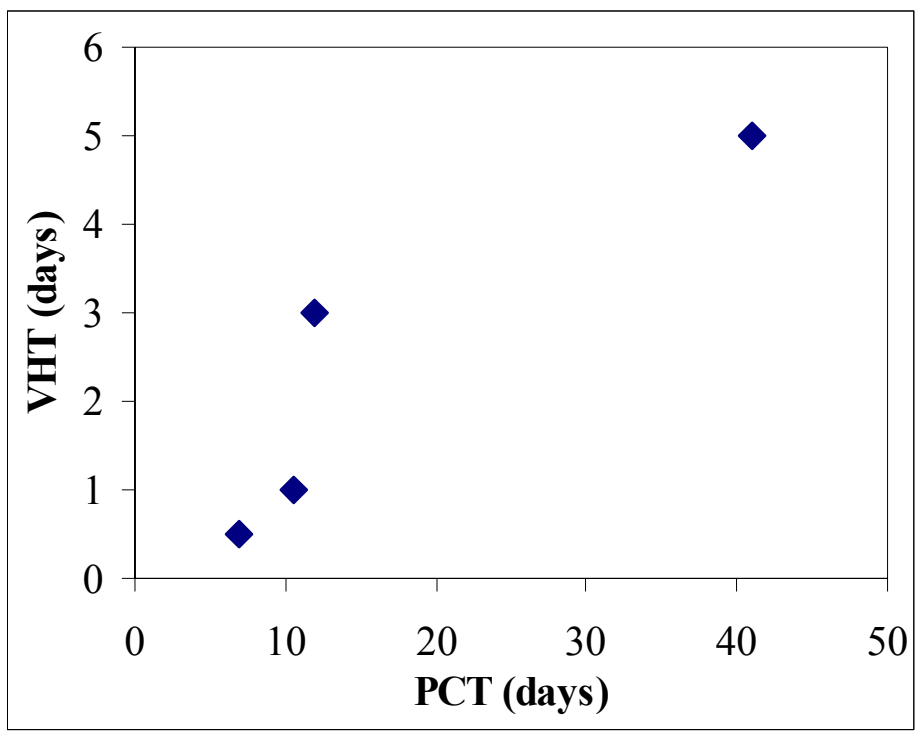

Figure 4.8. Time to Acceleration Comparison

The purpose of including VHT in the suite of tests to evaluate Hanford LAW glasses is to use it as a screening tool to determine if extremely high long-term corrosion rates are likely for the glasses tested. A sophisticated test to estimate the release and transport of glass components in an unsaturated environment such as the near-surface immobilized low-activity waste (ILAW) burial facility at Hanford- the Pressurized Unsaturated Flow-Through (PUF) test-was developed by McGrail et al. (1997b). This test more closely simulates the burial conditions expected for Hanford LAW than any other performed in the laboratory and accelerates the reaction by use of a relatively slow refresh rate $(2 \mathrm{~mL} / \mathrm{d})$, high surface area (-40/+60 mesh glass grains [roughly $250 \mu \mathrm{m}$ to $420 \mu \mathrm{m}$ diameter particles]) and high temperature $\left(99^{\circ} \mathrm{C}\right)$. Figure 4.9 shows the comparison between rates from VHT (at $200^{\circ} \mathrm{C}$ ) and PUF for all glasses that were tested by both methods (McGrail et al. 2001). A reasonable comparison between the results is evident (e.g., $95 \%$ confidence intervals are lower than an order of magnitude from the best-fit line over the region with experimental data). 


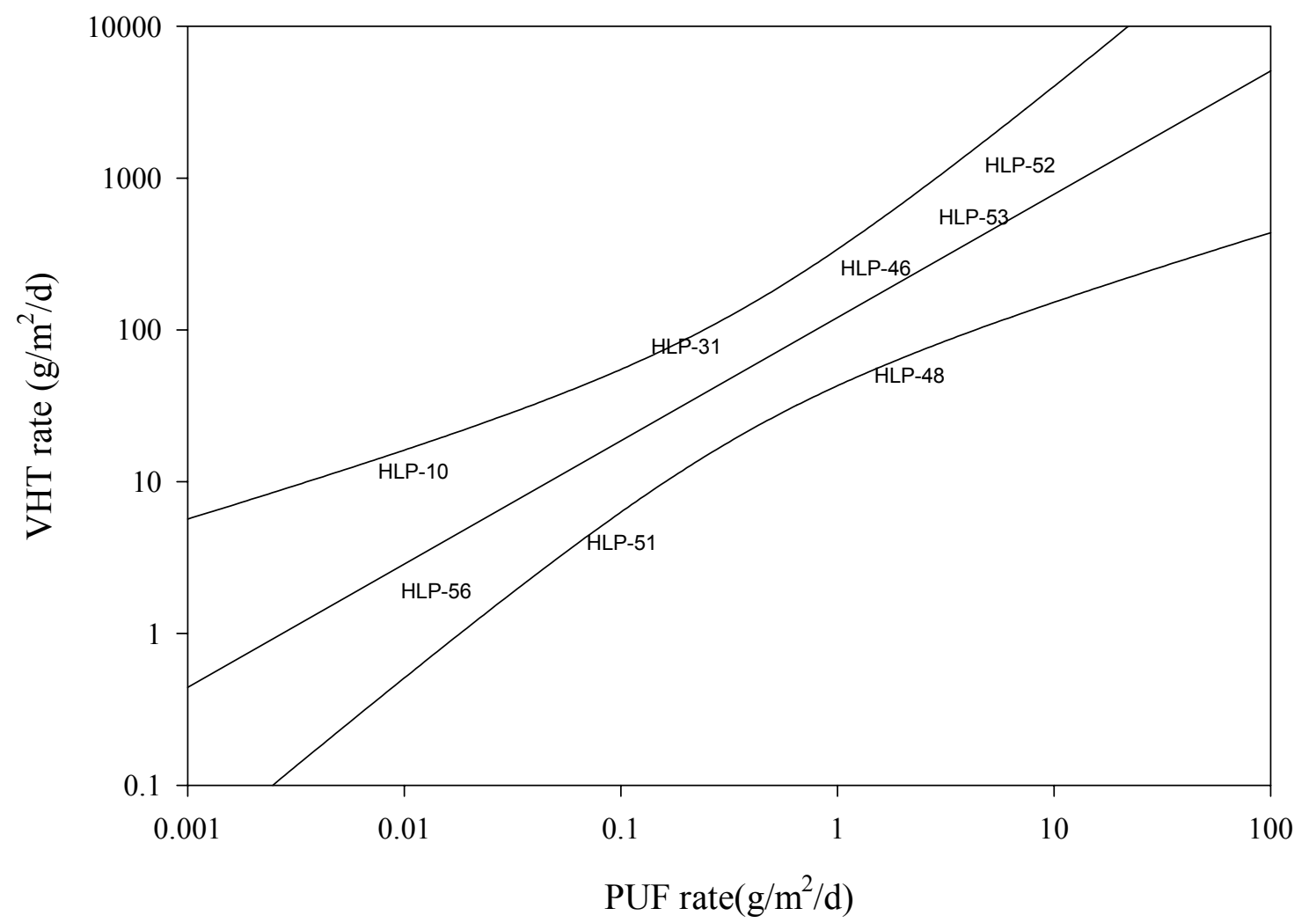

Figure 4.9. Comparison of VHT and PUF Alteration Rates for Selected Glasses (with linear regression and $95 \%$ confidence intervals lines)

\subsection{PCT Response as a Function of Time}

In the use of PCT, all Phase I testing has been completed, and Phase II testing is complete through $5000 \mathrm{~h}$. This analysis will first examine each Phase separately and then try to compare the two Phases to each other. The rates mentioned in this section are measured rates for the release of sodium and boron. The target release-rate values, which showed excellent correlation, were calculated using two linear functions with the boron or sodium concentrations of each glass, the surface area, and the duration of the test.

In Phase I testing, the HLP-02, $-31,-33,-39$, and -53 have some of the largest release rates for sodium and boron for all time periods of testing (PCT for these purposes was designed with a maximum test time of $10000 \mathrm{~h}$ ). This was initially stated in Schulz et al. (2000). As was also the case in the previous data package, the glasses that represent some of the smallest release rates for sodium and boron for all time periods are HLP-06, -22, -28, and -30. For all glasses of Phase I, the data show that release rates are highest at the initial onset of corrosion (at 10,100, and $168 \mathrm{~h}$ ), and then begin to lessen and settle with longer test times. Some possible explanations for this nonlinear behavior include solution saturation and the accumulation of alteration layers (see Figure 4.1) that act to prevent or slow the release of cations (Clark and Zoitos 1991; Clark et al. 1994; Schulz et al. 2000). The lone exception to this behavior is HLP-02 where its release rates of both sodium and boron had increased at $5000 \mathrm{~h}$, but were decreased 
again after $10000 \mathrm{~h}$. Also, glasses HLP-05 and -33 showed an increase in the release rate for boron after $100 \mathrm{~h}$ from $10 \mathrm{~h}$, but their release rates decreased like all the others after that (see Figure 3.82).

As expected, all of the glasses of Phase II followed the same behavioral trends as the glasses of Phase I. In Phase II testing, the glasses that had some of the largest release rates for sodium and boron for all time periods up to $5000 \mathrm{~h}$ are HLP-64, $-66,-70$, and -71 (note: No data were available for HLP-70 at $1000 \mathrm{~h}$ and none for HLP-71 at $5000 \mathrm{~h}$ ). Some of the glasses that had some of the smallest release rates at all time periods up to $5000 \mathrm{~h}$ are HLP-59, $-60,-62$, and -69. As stated earlier, some standard (ARM and EA), natural analog (basalt and obsidian), and other waste (165-TDS) glasses were included in the Phase II testing. Of these glasses, it appears from the data (Tables B-5 through B-9) that the most durable are basalt and obsidian according to the concentrations $(\mathrm{mg} / \mathrm{L})$ of sodium, boron, and silicon in the test solutions relative to the other added glasses. It appears that of these glasses, the ones that had the greatest release are the EA and 165-TDS glasses. These two glasses have high test-solution concentrations of boron and sodium at each time period (up to $5000 \mathrm{~h}$ ). At each time period, several HLP glasses have higher solution concentrations than the EA and 165-TDS glasses. Further testing, as well as test coupling (comparing PCT with VHT, etc.), will be required to determine release-rate acceptance limits.

The two phases of glass were also compared to determine which ones of the 77 HLP glasses might be some of the most or least durable according to PCT results. Table 4.6 lists the glasses with the ten largest and smallest release rates, $r$, from the boron and sodium PCT-B data. Each list was expanded to ten glasses (rather than five as in Table 3.40 and Table 3.42) since the number of glasses being compared was much larger. Also, since no data exist for the 10000 -h test of Phase II glasses, the comparison only goes up to $5000 \mathrm{~h}$. This table was constructed to mainly show that both Phases have some of the most durable glasses as well as some of the least durable glasses.

Table 4.6. Ordering of Release Rates for All HLP Glasses Based Upon PCT-B Data

\begin{tabular}{||c|c|c|c||}
\hline \multicolumn{4}{|c|}{ Release Rate Rank Ordering by HLP Glass Number } \\
\hline & & Highest Ten & Release Rate, $\boldsymbol{r}$ \\
\hline Time (h) & Cation & Lowest Ten \\
\hline 10 & $\mathrm{~B}$ & $71>67>70>66>02>31>39>63>73>52$ & $30<22<69<34<29<46<19<06<10<37$ \\
\hline & $\mathrm{Na}$ & $71>67>70>63>66>31>02>41>39>73$ & $46<04<69<30<72<52<22<58<62<28$ \\
\hline 100 & $\mathrm{~B}$ & $72>52>41>71>39>33>31>05>02>69$ & $44<45<599<62<51<74<30<60<65<28$ \\
\hline & $\mathrm{Na}$ & $72>52>41>73>39>33>31>05>71>02$ & $77<59<70<62<30<60<28<74<76<61$ \\
\hline 1000 & $\mathrm{~B}$ & $71>33>66>73>42 \mathrm{Q}>41>42>52>63>05$ & $69<30<62<68<59<49<06<65<58<08$ \\
\hline & $\mathrm{Na}$ & $71>52>63>66>33>73>41>42>42 \mathrm{Q}>67$ & $69<62<30<28<06<22<60<59<58<49$ \\
\hline 5000 & $\mathrm{~B}$ & $02>53>70>66>04>39>42>73>33>67$ & $69<30<68<60<62<59<45<65<49<34$ \\
\hline & $\mathrm{Na}$ & $53>02>70>66>04>40 \mathrm{Q}>39>42 \mathrm{Q}>33>67$ & $69<30<45<60<59<65<49<22<58<06$ \\
\hline
\end{tabular}

Some glasses show the same trends for the release of sodium as for boron. For instance, glasses HLP-30, -49, -59, -62, and -69 represent some of the smallest release rates of both sodium and boron for all time-periods up to $5000 \mathrm{~h}$. Those glasses representing some of the largest release rates of sodium and boron are HLP-02, $-33,39,-70$, and -71 . Based on these rankings, these listed glasses may be good examples of what might be acceptable (lowest release rates) versus unacceptable (highest release rates) glasses. The point of emphasis here is that there appear to be glasses from both Phases of testing that could be deemed compositionally acceptable (according to PCT data). Because the glasses of Phase II 
were designed before all of the data for Phase I were obtained, no glasses from one Phase were significantly better (in terms of durability as defined by the PCT) than the glasses from the other Phase.

\subsection{PCT Response as a Function of Glass Composition}

The main goal of this testing of Hanford LAW is to determine an acceptable glass-composition region for waste disposal. Though an exact determination of that compositional region cannot be concluded as of yet, the testing of the Phase I and Phase II glasses has helped greatly in that task. The components that were thought to have the most influence on the glass's behavior and most closely monitored during testing were $\mathrm{Al}_{2} \mathrm{O}_{3}, \mathrm{~B}_{2} \mathrm{O}_{3}, \mathrm{Na}_{2} \mathrm{O}$, and $\mathrm{SiO}_{2}$. There appears to be a strong correlation between the contents of aluminum and silicon and the release rates of sodium and boron. Judging by the data (Table 4.6, A.1, and A-1 from Schulz et al. 2000), the higher the target compositions of $\mathrm{SiO}_{2}$ and $\mathrm{Al}_{2} \mathrm{O}_{3}$, the lesser the release of sodium and boron. This is not the same trend as seen in the VHT response-composition relationship. This is especially true for aluminum content. For the realm of all HLP glasses, target compositions of $\mathrm{Al}_{2} \mathrm{O}_{3}$ ranged from 4.00 to $12.17 \%$ (mass) and $\mathrm{SiO}_{2}$ ranged from 36.00 to $59.78 \%$ (mass). It also seems that there is a general trend following $\mathrm{Na}_{2} \mathrm{O}$ concentration. Glasses with high target concentrations of sodium have some of greatest release of sodium. Certain trends are not clear enough to make such a determination for boron concentration. It is also difficult to correlate release with other component concentrations as well from the data. For instance, HLP-58 (low Ca content) and HLP-59 (high Ca content) both show up several times in the rankings for smallest release rates of sodium and boron (see Table 4.6). It appears that the concentration of $\mathrm{CaO}$ does not really matter, so no final statement about the relation of $\mathrm{CaO}$ concentration and release rates of sodium or boron can be made. Also, the target concentration of $\mathrm{ZrO}_{2}$ varies widely in the glasses in the rankings. The influence of some of the lesser variables may hinge on the concentrations of the more dominant ones $\left(\mathrm{Al}_{2} \mathrm{O}_{3}, \mathrm{~B}_{2} \mathrm{O}_{3}, \mathrm{Na}_{2} \mathrm{O}\right.$, and $\mathrm{SiO}_{2}$ ). Basically, there are too many variables to be able to make final determinations on all of them.

\subsection{Effect of Iron Redox on PCT and VHT Responses}

Jantzen (1984) stated that experiments have shown that ferrous iron can scavenge silica from a solution, thus causing an undersaturation of silica in the leachant. This enhances the dissolution of the glass. Jantzen (1984) also noted that leach rates for B and $\mathrm{Na}$ under oxic and anoxic conditions are similar, but anoxic conditions enhance the leach rates of Si. As discussed in Section 3.3, the baseline glass compositions (HLP-01, -25, -26, and -43) were prepared with different iron-oxidation states or redox $\left(\mathrm{Fe}^{\mathrm{II}} / \mathrm{Fe}\right)$. The fraction of iron in the divalent state in glasses HLP-44 and -45 are $20 \%$ and 59\%, respectively, compared to 1\% for HLP-26 (See Table 3.13). This section discusses the PCT and VHT results for these glasses in an attempt to highlight the influences of redox on glass corrosion.

\subsubsection{VHT Response}

The VHT responses of the reduced glasses (HLP-44 and HLP-45) are compared to those of the nonreduced baseline glass (HLP-01, $-25,-26$, and -43) in Figure 4.10 . At $200^{\circ} \mathrm{C}$, the data are highly scattered as discussed in Section 3.5.5, and reduced data appear to match the oxidized very well. The rates are compared in Table 4.7. The $r$ values of reduced glasses are well within the 50\% RSD of the non-reduced glasses. At $250^{\circ} \mathrm{C}$, the $r$ values of reduced glasses also fall within the expected uncertainty of the baseline glass. However, at $250^{\circ} \mathrm{C}$, there is a clear difference in the intercept of the reduced glasses. There 
appears to be a higher total mass of glass altered for the same amount of time in the most reduced glass. This is also the case for the measured $m_{a}$ values of HLP-44 up to roughly 4 days. The appearance of the most reduced glass during alteration is clearly different from that of the baseline glass as shown in Figure 4.11. With the reduced glass, there is a clear tinting of the glass at the altered-unaltered glass interface due to oxidation of iron in that region. The reduced glass also shows a great deal more cracking than the oxidized version. This behavior is consistent in other samples of these two glasses. The color change at the interface and cracking (seen in HLP-45) is seen to a lesser extent in some samples of HLP-44 and not seen in other samples.

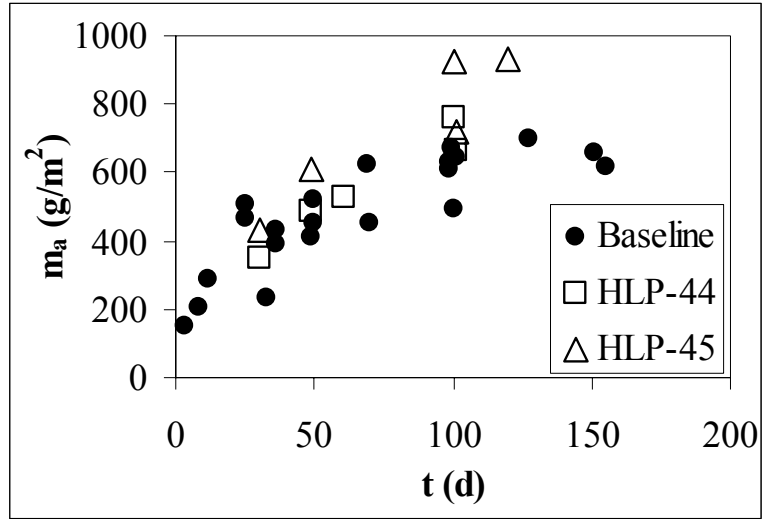

(a) $200^{\circ} \mathrm{C}$

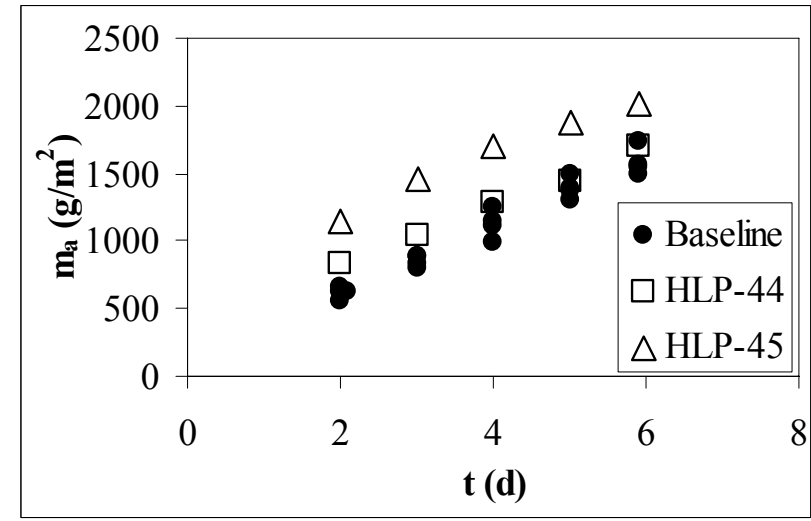

(b) $250^{\circ} \mathrm{C}$

Figure 4.10. VHT Response of Reduced and Oxidized Baseline Glasses

Table 4.7. Comparison of VHT Alteration Rates for Reduced and Oxidized Baseline Glasses

\begin{tabular}{||l|c|c||}
\hline \hline Glass & $\mathbf{2 0 0}{ }^{\circ} \mathbf{C} \boldsymbol{r}\left(\mathbf{g} / \mathbf{m}^{\mathbf{2}} / \mathbf{d}\right)$ & $\mathbf{2 5 0}^{\circ} \mathbf{C} \boldsymbol{r}\left(\mathbf{g} / \mathbf{m}^{\mathbf{2}} / \mathbf{d}\right)$ \\
\hline HLP-01 & 4.26 & 264 \\
\hline HLP-25 & 4.20 & 292 \\
\hline HLP-26 & 1.19 & 224 \\
\hline HLP-43 & 4.56 & 234 \\
\hline Combined & 2.92 & 253 \\
\hline HLP-44 & 4.92 & 218 \\
\hline HLP-45 & 5.15 & 220 \\
\hline
\end{tabular}




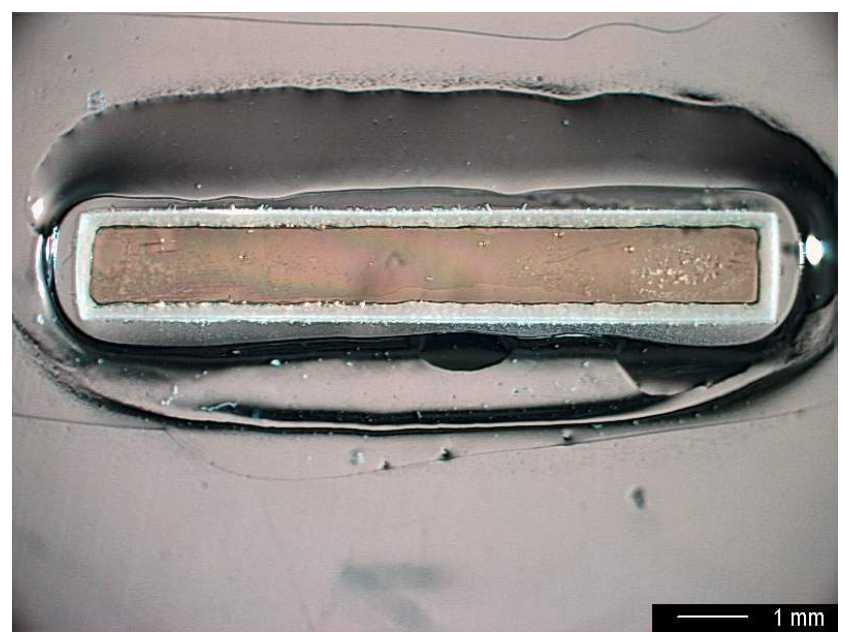

(a) HLP-01 at $200^{\circ} \mathrm{C}$ for $160 \mathrm{~d}$

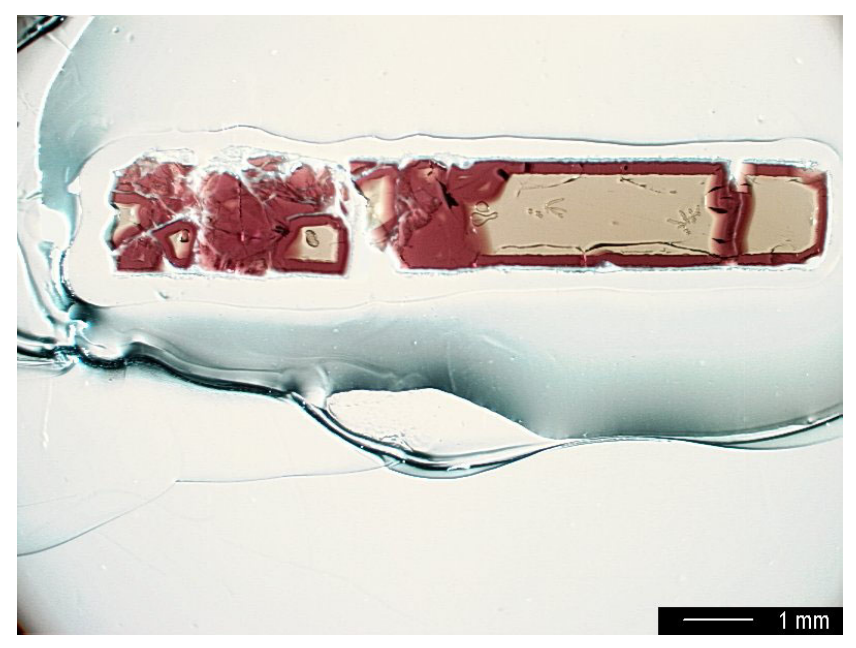

(b) $\mathrm{HLP}-45$ at $200^{\circ} \mathrm{C}$ for $100 \mathrm{~d}$

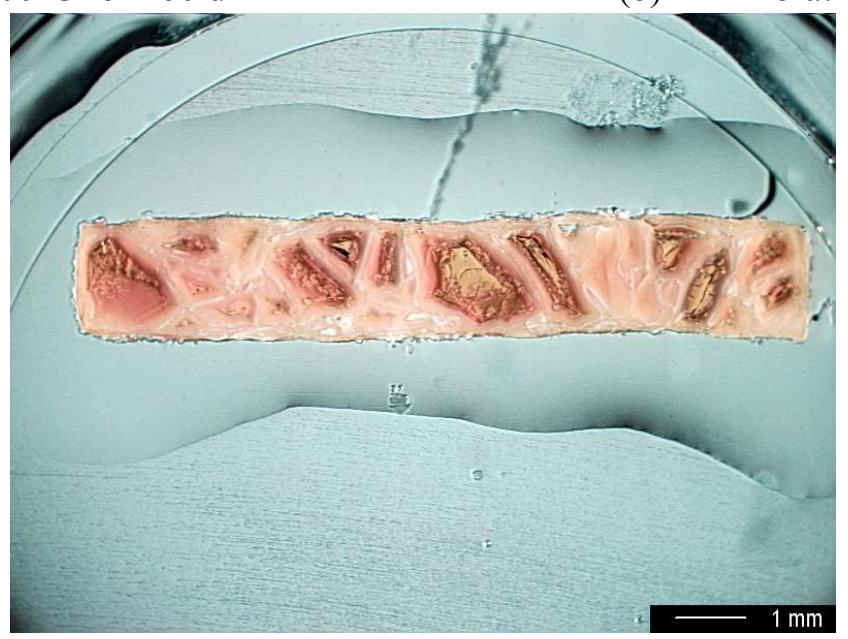

(c) HLP-45 at $200^{\circ} \mathrm{C}$ for $150 \mathrm{~d}$

Figure 4.11. Optical Light Micrographs of HLP-01 and HLP-45 Sample Cross-sections after VHT

\subsubsection{PCT Response}

Figure 4.12 shows the $\mathrm{NL}_{\mathrm{B}}$ and $\mathrm{NL}_{\mathrm{Na}}$ values for the reduced and oxidized baseline glasses by PCT-A. The $\mathrm{NL}_{\mathrm{i}}$ values of the reduced glasses fall within the range of those measured in the oxidized glasses. Figure 4.13 compares the $\mathrm{NL}_{\mathrm{B}}$ values for the reduced and oxidized baseline glasses by PCT-B. The $\mathrm{NL}_{\mathrm{B}}$ values of the reduced glasses are slightly higher than those of the oxidized glasses at $10 \mathrm{~h}$ and slightly lower than them at $1000 \mathrm{~h}$ and longer. The $100-\mathrm{h} \mathrm{NL} \mathrm{B}_{\mathrm{B}}$ values of the reduced glasses are significantly lower than those of the oxidized glasses and the 10-h and 1000-h samples. It is likely that this outlying data (HLP-44 and -45 at $100 \mathrm{~h}$ and HLP-45 at $5000 \mathrm{~h}$ ) was caused by an experimental error. These were the only glasses where such a drop-normalized-release occurred, and efforts to retest will be made. 


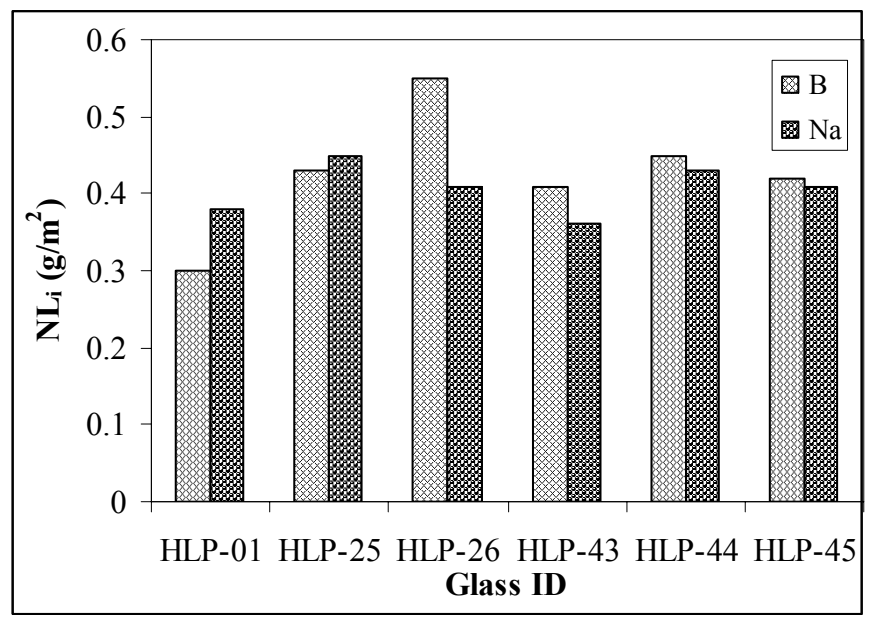

Figure 4.12. Normalized Loss of Na and B from Reduced and Oxidized Baseline Glasses from PCT-A

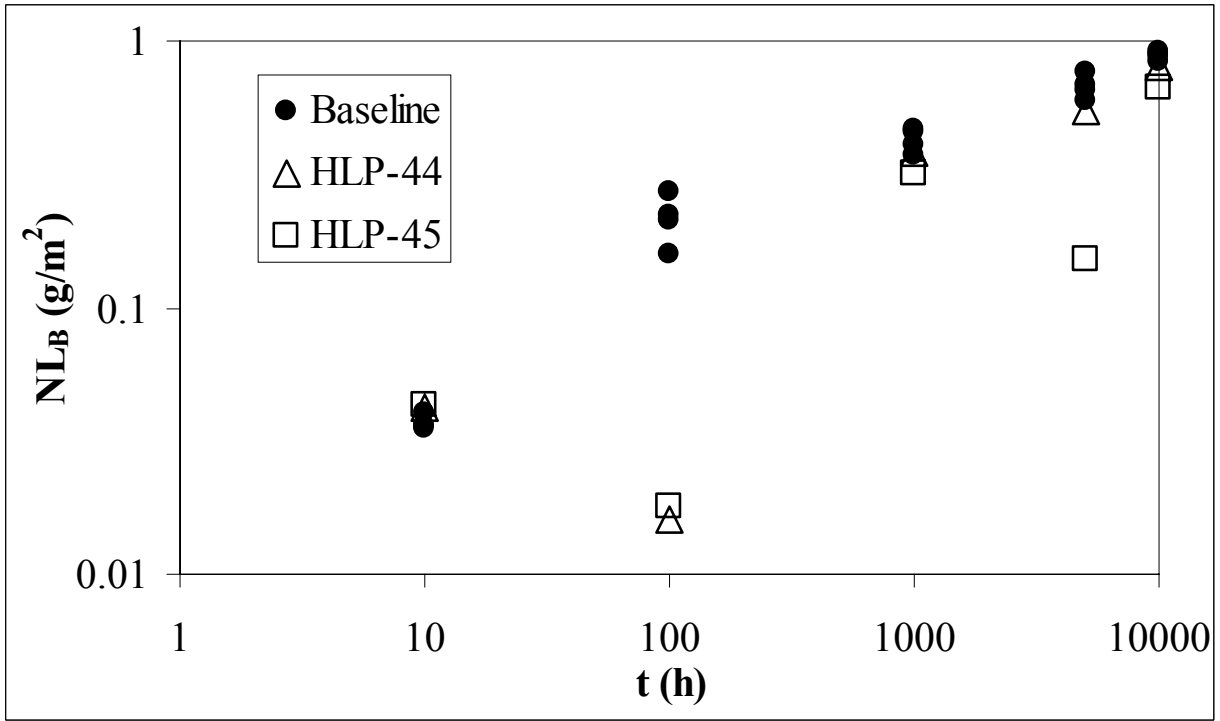

Figure 4.13. Normalized Loss of B from Reduced and Oxidized Baseline Glasses from PCT-B

Generally, there is little difference in the response of the oxidized and reduced glasses to the tests performed in this study. Those differences, including

- the tendency toward crack formation in VHT samples of HLP-45

- the difference in intercept of the linear portion of the $m_{a}-t$ relationship in $250^{\circ} \mathrm{C}$ VHT

- the relatively small release from the $100 \mathrm{~h}$ PCT-B of the reduced glasses

will be further considered in future testing. 


\subsection{Comparison of Test Responses to Hanford Contract Specifications and Glass "Acceptability"}

To be considered as "acceptable," each HLP glass must pass certain specifications set forth by Hanford Contract Section C (DOE 2000). If any glass fails the criteria of either the PCT or VHT, or both, then its composition cannot be considered for burial purposes according to contract guidelines.

For the Product Consistency Test (Specification 2.2.2.17.2), the contract reads as follows:

The normalized mass loss of sodium, silicon, and boron shall be measured using a seven-day product consistency test run at $90^{\circ} \mathrm{C}$ as defined in ASTM C1285-97. The test shall be conducted with a glass to water ratio of $1 \mathrm{~g}$ of glass $(-100+200$ mesh $)$ per 10 milliliters of water. The normalized mass loss shall be less than $2.0 \mathrm{~g} / \mathrm{m}^{2}$. Qualification testing shall include glass samples subjected to representative waste form cooling curves. The product consistency test shall be conducted on waste form samples that are statistically representative of the production glass.

That means the release of boron, sodium, and silicon must each be less than $2.0 \mathrm{~g} / \mathrm{m}^{2}$ for any heattreated HLP glass in order to be acceptable. Thus, the PCT-A data indicate that of all the HLP glasses tested, only 13 would not meet these specifications. Those glasses are HLP-02, -27, -31, -33, -39, -41, $52,-63,-64,-66,-67,-71$, and -73 .

Even if a glass passes the criteria of the PCT, it must still pass the contract specifications of the VHT. The limits stated by the referenced contract for the VHT read as follows:

The glass corrosion rate shall be measured using a seven-day vapor hydration test run at $200^{\circ} \mathrm{C}$ as defined in the DOE concurred upon Product and Secondary Waste Plan. The measured glass alteration rate shall be less than $50 \mathrm{~g} /\left(\mathrm{m}^{2}\right.$ day). Qualification testing shall include glass samples subjected to representative waste form cooling curves. The vapor hydration test shall be conducted on waste form samples that are statistically representative of the production glass.

However, there is a problem with this specification in that a rate cannot really be determined from a single point in time. It is assumed that to meet the specification, the value of $r$ or $r_{\infty}$ must be less than $50 \mathrm{~g} /\left(\mathrm{m}^{2} \cdot \mathrm{d}\right)$ at $200^{\circ} \mathrm{C}$. With that being the case, the glasses that fail are HLP-02, $-04,-27,-29,-31,-46,-$ $47,-48,-52,-63,-66,-67,-76$, and -77 .

Figure 4.14 shows all results for single-point $200^{\circ} \mathrm{C}-\mathrm{VHT}$ measurements for HLP glasses (653 in total). The open squares are data points for glasses with $r$ values higher than the $50-\mathrm{g} / \mathrm{m}^{2} / \mathrm{d}$ limit while the closed circles are those with $r<50 \mathrm{~g} / \mathrm{m}^{2} / \mathrm{d}$. It is clear from the figure that no instance of a glass with $r>$ $50 \mathrm{~g} / \mathrm{m}^{2} / \mathrm{d}$ showed a VHT response below the line marking an average rate of $50 \mathrm{~g} / \mathrm{m}^{2} / \mathrm{d}$. This suggests that "single-point measurements" is a conservative approach to ensuring compliance with the imposed VHT limit. Further examination shows that if the single-point measurement is taken at longer times, the possible conservatism in a single-point measurement becomes lower. If a singe-point measurement were taken at say $10 \mathrm{~d}$ (a short time) and showed an $m_{a}$ value of $>500 \mathrm{~g} / \mathrm{m}^{2}$, the chances of 


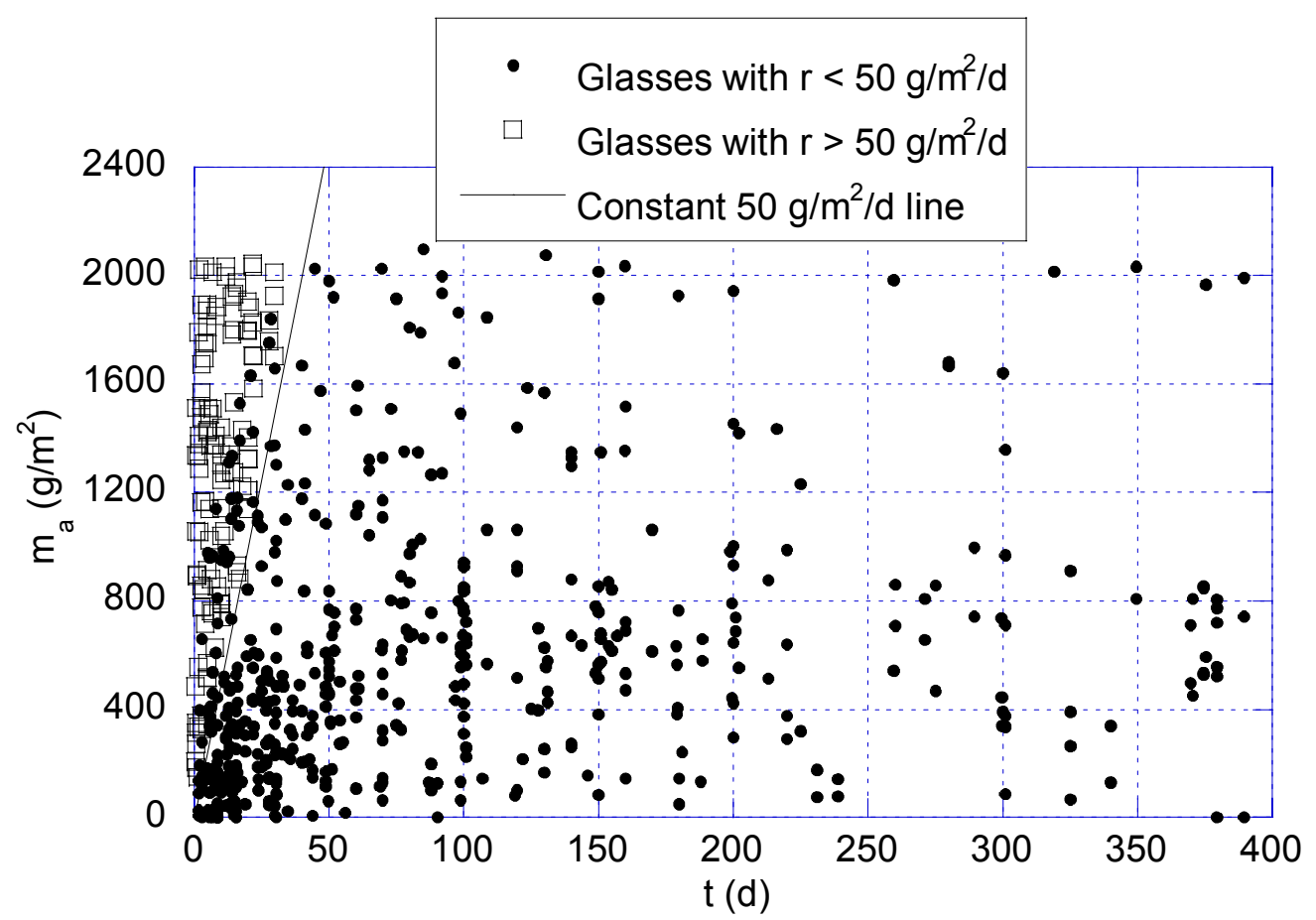

(a)

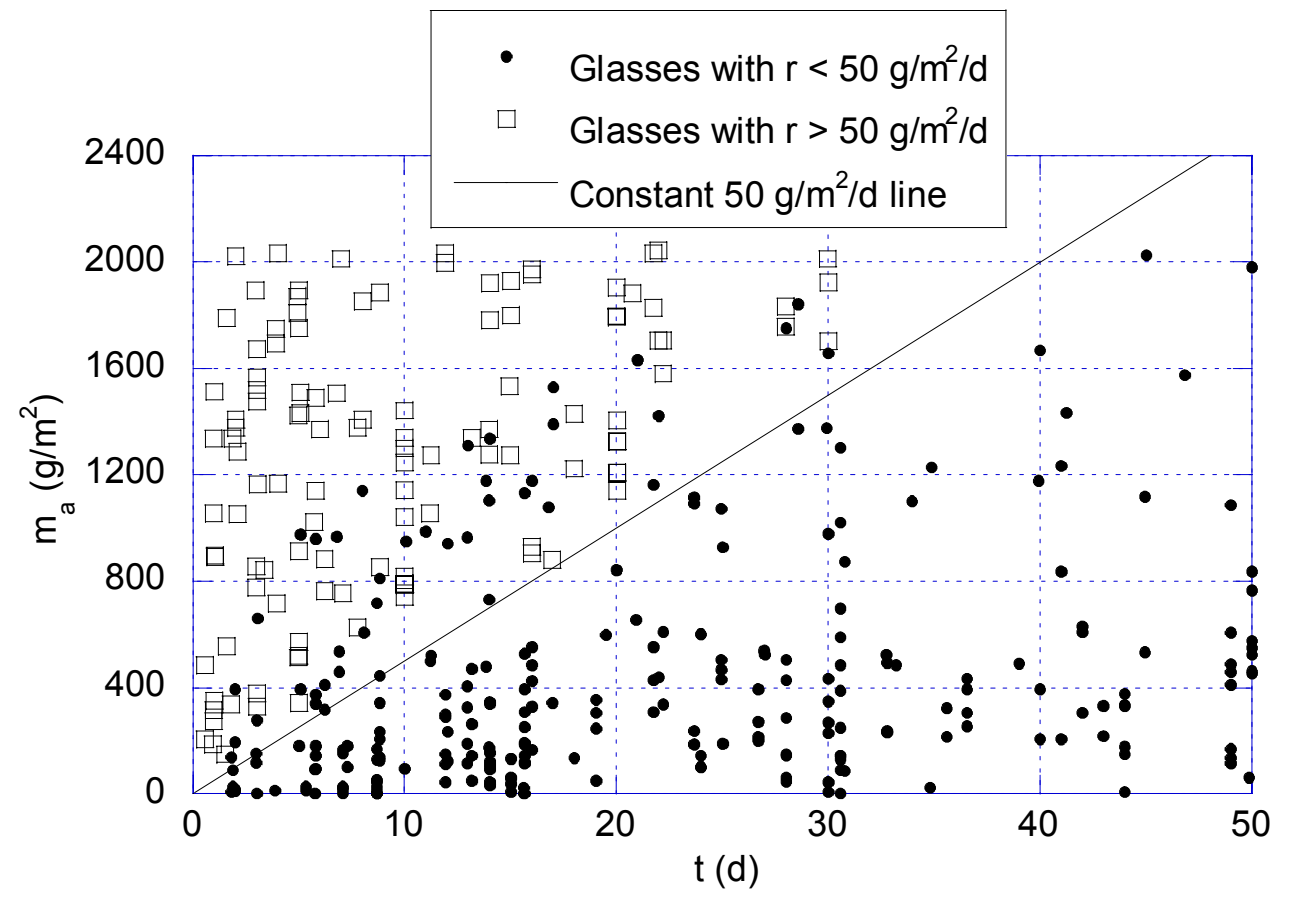

(b)

Figure 4.14. VHT Results for HLP Glasses Measured at $200^{\circ} \mathrm{C}$ with (a) Complete Time Scale and (b) 50-Day Time Scale 
that glass having a rate lower than $50 \mathrm{~g} / \mathrm{m}^{2} / \mathrm{d}$ would be significantly higher than a measurement taken at $30 \mathrm{~d}$ (a relatively long time) that showed an $m_{a}$ value of $1500 \mathrm{~g} / \mathrm{m}^{2}$. Therefore, these results support the use of a single-point measurement for meeting the contract requirements if the contract could be modified to require the associated $m_{a}$ value rather than rate.

The common glasses eliminated by both PCT and VHT, according to the stated contract specifications, are HLP-02, -27, -31, -52, -63, -66, and -67. A total of 20 glasses could be considered inadequate for disposal by one test or another. This indicates that no one test is good enough to eliminate all "unacceptable" glasses - the test(s) need work or the specifications may need to be rewritten. Both tests must be used for correct determinations.

If 20 glasses have an improper composition to meet contract specifications, then 53 of the 73 HLP glasses tested have a composition worthy of meeting the contract specifications of the PCT and VHT. Figure 4.15 shows a scatter-plot matrix of HLP glass-component concentrations (in mole fraction of oxides) with different colors for glasses that meet both contract specifications and those that do not meet at least one of the specifications. It is clear that high- $\mathrm{R}_{2} \mathrm{O}$ glasses are prone to failing one or both of the contract specifications. Additionally, the pairs of components that appear to best separate those glasses that pass contract specifications from those that do not are $\mathrm{R}_{2} \mathrm{O}-\mathrm{TiO}_{2}$ and $\mathrm{R}_{2} \mathrm{O}-\mathrm{ZrO}_{2}$.

These visual tools give only a preliminary glimpse at the compositionally defined "acceptability region" or AGCR. To fully develop such an AGCR, composition-response functions for PCT and VHT must be developed and validated and then applied to numerically define the AGCR with the desired confidence intervals. This work has begun, and Gan and Pegg (2001) and Hrma et al. (2001) have reported PCT-composition models for glasses with similar composition (high $\mathrm{R}_{2} \mathrm{O}$ glasses), and VHT response models have recently been proposed by Gan and Pegg (2001) and in this work. A method to empirically describe the entire glass alteration/time relationship was presented and may be useful in AGCR definition as would models based on geochemical tenets (such as Strachan and Croak 2000). For now, the AGCR definition remains scope for future studies. 


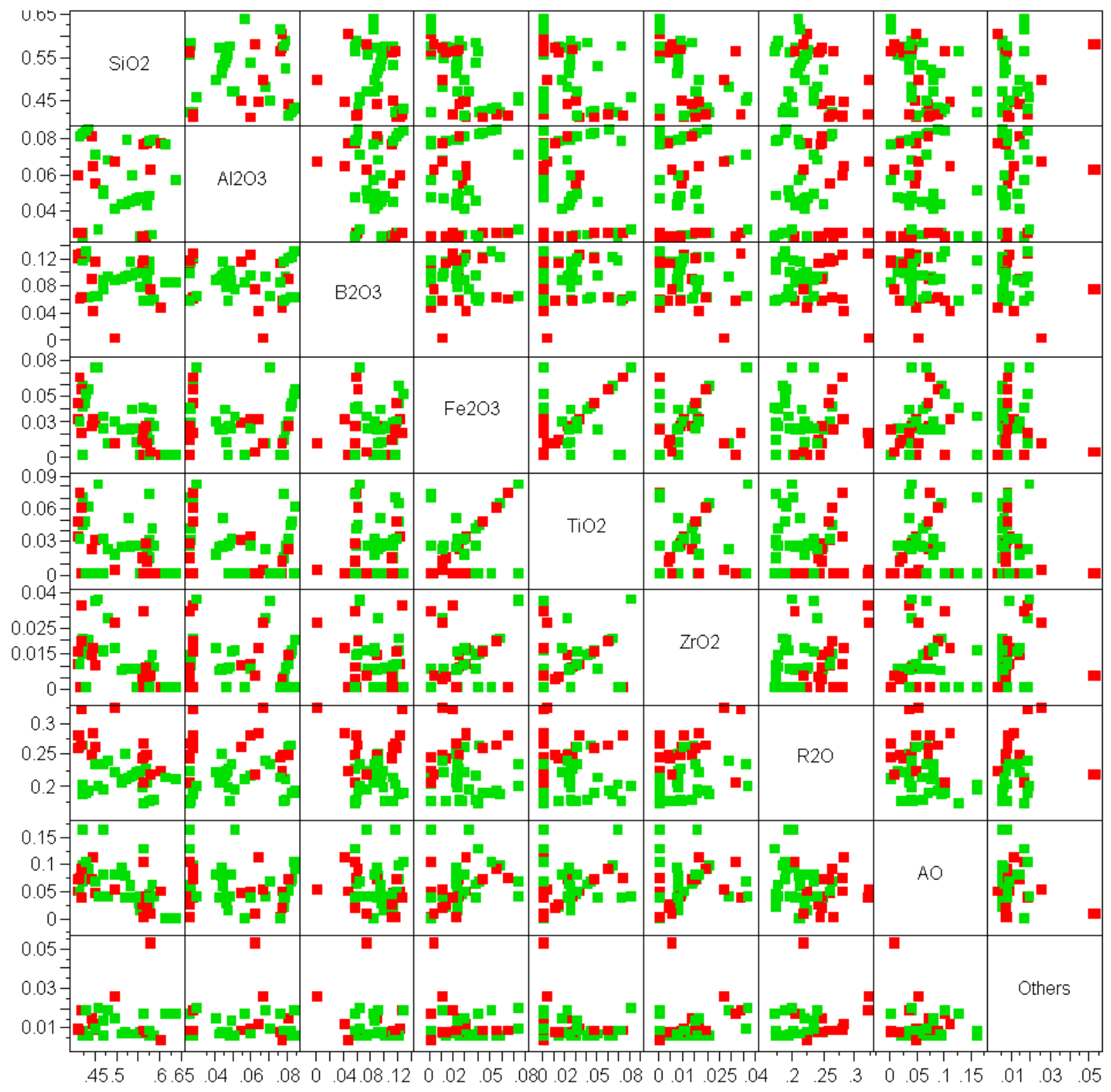

Figure 4.15. Scatter-Plot Matrix of HLP Glass with Red Symbols for Glasses that do not Meet one or both Contract Specifications and Green Symbols for Glasses that meet both Contract Specifications 


\subsection{Conclusions and Recommendations}

The goal of this ongoing study is to help determine the composition region of LAW glasses that will meet performance expectations and to develop a glass-corrosion property database covering a vast composition space of high-alkali glasses. To accomplish this goal, the corrosion characteristics of glasses covering a broad range of compositions applicable to the LAW immobilization project at Hanford are being studied. The tests used to characterize these glasses-PCT-A, PCT-B, and VHT-are intended to determine relative behaviors of glasses in late stages of the alteration process in high $\mathrm{S} / \mathrm{V}$ conditions. Criteria for acceptable response to these tests will be developed by the Hanford site Performance Assessment (PA) Program by linking test responses to bounding estimates of radionuclide releases. To date, a vast and growing database of corrosion characteristics has been developed on a systematically designed matrix of simulated LAW glasses. The conclusions drawn from the current database are described in the following paragraphs. Additional data will be developed as the study continues. Studies will be performed, in cooperation with the PA program, to help link test responses to behavior in the burial scenario. Once acceptability constraints are defined, tools will be developed to determine the acceptability of glass based on composition. Recommendations on specific studies to be performed to complete this study are listed at the end of this section.

\subsection{Product Consistency Test}

All PCTs on Phase I glasses are complete (through $10000 \mathrm{~h}$ ), and Phase II testing is complete up to $5000 \mathrm{~h}$. In Phase I testing, the HLP-02, -31, -33, -39, and -53 have some of the largest release rates for sodium and boron for all time periods of testing (PCT for these purposes was designed with a maximum test time of $10000 \mathrm{~h}$ ). Some of the glasses that represent some of the smallest release rates for sodium and boron for all time periods are HLP-06, $-22,-28$, and -30 . For all glasses of Phase I, the data show that release rates are highest at the initial onset of corrosion (at 10, 100, and $168 \mathrm{~h}$ ), and then begin to lessen and settle with longer test times. All of the glasses of Phase II followed the same behavioral trends as the glasses of Phase I. In Phase II testing, the glasses that had some of the largest release rates for sodium and boron for all time periods up to $5000 \mathrm{~h}$ are HLP-64, -66, -70, and -71. Some of the glasses that had some of the smallest release rates at all time periods up to $5000 \mathrm{~h}$ are HLP-59, $-60,-62$, and -69 . Some standard and natural analog glasses were included in the Phase II testing. At each time period, several HLP glasses had higher solution concentrations than the EA and 165-TDS standard glasses. The glasses of both Phases were compared to each other as well. It was discovered that glasses HLP-30, -49, -59, -62, and -69 represent some of the smallest release rates of both sodium and boron for all time periods up to $5000 \mathrm{~h}$. Those glasses representing some of the largest release rates of sodium and boron are HLP-02, $-33,-39,-70$, and -71 . Based on these rankings, these listed glasses may be good examples of what might be acceptable (smallest release rates) versus unacceptable (largest release rates) glasses.

\subsection{Vapor Hydration Test}

The VHT was performed on test-matrix glasses at $200^{\circ} \mathrm{C}$. Selected glasses were also tested as a function of temperature in the range from $90^{\circ} \mathrm{C}$ to $300^{\circ} \mathrm{C}$. The VHT results give evidence for a fourth stage of waste-glass dissolution behavior in a closed or slowly replenished system. A great deal of evidence has accumulated to define three distinct phases of corrosion in closed systems: 1) initial stage 
characterized by a high dissolution rate into a dilute solution, 2) the second stage characterized by a nearly constant rate into a concentrated solution (the rate is reduced due to high concentrations of key components in solution, lowering the driving force of dissolution), and 3) the third stage is marked by an abrupt increase in dissolution rate, which is caused by the precipitation of solid phases from key solution components (this increases the driving forces for dissolution). In typical closed-system dissolution tests, such as PCT, shortly after entry into the third stage of dissolution, the glass can be completely consumed. However, in VHT, there is ample glass available to continue to a new stage in the dissolution process, the fourth stage, in which the rate of conversion of the glass to solid alteration products in nearly constant. The rate of dissolution is assumed to be equal to the rate of precipitation of the key alteration products that first form in stage three.

The alteration rate from the fourth stage of dissolution was determined for most test matrix glasses at $200^{\circ} \mathrm{C}$. For some glasses, insufficient data or specimen analyses difficulties have caused the rate at $200^{\circ} \mathrm{C}$ (or other temperatures) to be imprecise. The rates were determined for most test-matrix glasses at $200^{\circ} \mathrm{C}$; they range from 0.00 to $1708 \mathrm{~g} / \mathrm{m}^{2} / \mathrm{d}$ (covering five orders of magnitude). The glasses with the five highest rates at $200^{\circ} \mathrm{C}$ are (with rate in $\mathrm{g} / \mathrm{m}^{2} / \mathrm{d}$ ) HLP-63 (1708), HLP-66 (1337), HLP-52 (1219), HLP53Q (553), and HLP-02 (265). The glasses with the lowest rates at $200^{\circ} \mathrm{C}$ are HLP-42 (0.00), HLP-19 (0.01), HLP-34 (0.04), and HLP-32 (0.18).

The time required for glasses to reach the third stage of dissolution was estimated from the VHT results. A trend was found between the time to reach the third stage of dissolution in VHT at $200^{\circ} \mathrm{C}$ with that in the PCT at $20000 \mathrm{~m}^{-1}$ tested at $99^{\circ} \mathrm{C}$ from McGrail et al. (1999). However, no correlation was found between the rates measured with the VHT at $200^{\circ} \mathrm{C}$ and the normalized releases measured with the PCT-B at either $1000 \mathrm{~h}$ or $5000 \mathrm{~h}$. More data are required to conclusively link long-term PCT and VHT data.

The major crystalline alteration products formed during the VHT of test-matrix glasses were identified. The most common crystalline phases include analcime, sodium aluminum-silicate-hydrate (or sodium aluminum silicate boron hydroxide hydrate with a similar crystal structure), and clinopyroxene. A combination of XRD and SEM/EDS analyses revealed that most of the crystalline phases appear on the surface of the specimen, while a majority of the alteration products are amorphous materials with compositions similar to those of the unreacted glass. A change in VHT temperature was found to change the proportion of crystalline alteration products observed, but not the type.

The effect of inverse temperature on the logarithm of the VHT rate was found to be nearly linear. The slope of $\ln r$ as a function of $1 / \mathrm{RT}, \mathrm{E}_{\mathrm{a}}$, of the VHT rate was found to range from $80 \mathrm{~kJ} / \mathrm{mol}$ to $102 \mathrm{~kJ} / \mathrm{mol}$ with an average of $92.5 \mathrm{~kJ} / \mathrm{mol}$. Interestingly, it was possible to use a single $\mathrm{E}_{\mathrm{a}}$ value, $92.5 \mathrm{~kJ} / \mathrm{mol}$, to describe the effect of temperature on all glasses within the error of rate determination. It is not yet clear what processes determine either the rate or the $\mathrm{E}_{\mathrm{a}}$. However, future testing will focus on obtaining a better understanding of these processes, which most likely include formation rates of key alteration products.

A preliminary glance at the effect of composition on the VHT rate at $200^{\circ} \mathrm{C}$ suggests that models with a linear relationship between logarithm rate and component concentrations may adequately describe the measured relationship. The addition of four second-order terms seems to greatly improve the fit over 
current data. The influence of glass redox was not found to be significant. Further study of these effects will be the focus of future study.

Single-point VHT measurements were compared to the Hanford contract specification for VHT of ILAW glasses. The contract specification calls for an alteration rate at $200^{\circ} \mathrm{C}$ of less than $50 \mathrm{~g} / \mathrm{m}^{2} / \mathrm{d}$. Single-point measurements of the mass of glass converted to alteration products $\left(m_{a} \mathrm{in} \mathrm{g} / \mathrm{m}^{2}\right)$ that falls below the $50 \mathrm{~g} / \mathrm{m}^{2} / \mathrm{d}$ line were not seen for glasses with actual rates of $50 \mathrm{~g} / \mathrm{m}^{2} / \mathrm{d}$ or higher. This leads to a possible method for achieving the VHT contract specification by VHT measurement at a single time. However, the shorter the time, the more conservatism that is added to the determination.

\subsection{Glass Composition}

The purpose of the PCT and VHT is to determine if a glass with a certain composition would be acceptable to Hanford contract specifications. If a glass were to fail one or both criteria of these tests, then its composition would be considered "unacceptable." For instance, glasses HLP-02, -27, -31, -33, $-39,-41,-52,-63,-64,-66,-67,-71$, and -73 failed the PCT criteria set forth by Hanford Contract DE-AC27-01RV14136 (DOE 2000). Glasses HLP-02, -04, -27, -29, -31, -46, -47, -48, -52, -63, -66, -67, -76 , and -77 failed the VHT criteria. That means that a total of 20 glasses could be considered inadequate for disposal. Investigations into the compositions indicate a general trend that the glass has a good chance of failing if at least one of the main glass component $\left(\mathrm{SiO}_{2}, \mathrm{Al}_{2} \mathrm{O}_{3}, \mathrm{~B}_{2} \mathrm{O}_{3}\right.$, and $\left.\mathrm{Na}_{2} \mathrm{O}\right)$ concentrations is "low." For instance, glasses HLP-02, -04, -39, -41, -48, -63, -67, -71, and -73 have a low or intermediate content of $\mathrm{SiO}_{2}$ (36 to 40\% mass). Glasses that have a low content of $\mathrm{Al}_{2} \mathrm{O}_{3}$ are HLP-31, -33, -39, -41, $63,-64,-66$, and -67 . Boron is low in HLP-29, $-33,-41,-46,-52(0 \%$ mass $),-64$, and -71 , and sodium is low in HLP-63, -64, and -73. One exception to this rule, though, is HLP-27. This glass has "high" contents of all four main components, but it has $0 \%$ target compositions of other minor components, such as $\mathrm{Fe}_{2} \mathrm{O}_{3}, \mathrm{TiO}_{2}, \mathrm{ZnO}, \mathrm{ZrO}_{2}, \mathrm{MgO}$, and $\mathrm{Li}_{2} \mathrm{O}$. These minor components are obviously necessary for good durability.

\subsection{Recommendations for Future Studies}

Additional studies are required to meet the main goals of this project and contract specifications. The following specific activities are recommended:

1. Continue long-term, low-temperature VHTs and attempt to understand the extrapolability of VHT to burial environment-like scenarios.

2. Standardize the VHT procedure so that data generated at different laboratories can be compared, and contract specifications can be met by use of a consensus standard procedure.

3. Data collection should continue for the testing of Phase II glasses. The PCT for Phase II glasses will be complete with the 10000 -h data. The VHT rates should be determined as precisely as possible for all matrix glasses at $200^{\circ} \mathrm{C}$.

4. Develop and validate composition-PCT-A and composition-VHT models for use in development of an acceptable glass-composition region. 
5. Based on composition-PCT and composition-VHT relationships, determine the key mechanisms related to differences in glass responses to these different tests.

6. More comparisons of results between tests (PCT, VHT, PUF, etc.) should be made to determine if any correlations can be made. 


\subsection{References}

Abraitis, P. K., D. J. Vaugham, F. R. Livens, J. Monteith, D. P. Tivedi, and J. S. Small. 1998.

"Dissolution of a Complex Borosilicate Glass at $60^{\circ} \mathrm{C}$ : The Influence of $\mathrm{pH}$ and Proton Adsorption on the Congruence of Short-term Leaching." In Material Research Society Symposium Proceedings. 506, p 4754.

Abrajano, T. A., and J. K. Bates. 1990. "Analytical Electron Microscopy of Leached Nuclear Waste Glasses," Ceram. Trans. 9, p 211-228.

Abrajano, T. A., J. K. Bates, and C. D. Byers. 1986. "Aqueous Corrosion of Natural Waste Glasses I. Comparative Rates of Hydration in Liquid and Vapor Environments at Elevated Temperatures. " J. NonCryst. Solids 84, p 251-257.

Abrajano, T. A., J. K. Bates, and J. J. Mazer. 1989. "Aqueous Corrosion of Natural and Nuclear Waste Glasses: II. Mechanism of Vapor Hydration of Nuclear Waste Glasses," J. Non-Cryst. Solids, 108, p 269288.

Advocat, T., J.,L. Crovisier, B. Fritz, and E. Vernaz. 1990. "Thermokinetic Model of Borosilicate Glass Dissolution: Contextural Affinity,” Mat. Res. Soc. Symp. Proc. 176, 241-248.

Advocat, T., J. L. Chouchan, J. L. Crovisier, C. Guy, V. Daux, C. Jegou, S. Gin and E. Vernaz. 1998. "Borosilicate Nuclear Waste Glass Alteration Kinetics: Chemical Inhibition and Affinity Control," Matl. Res. Soc. Symp. 506, p 63-70.

American Society for Testing and Materials (ASTM). 1998. "Standard Test Methods for Determining Chemical Durability of Nuclear, Hazardous, and Mixed Waste Glasses: The Product Consistency Test (PCT)," C 1285-97 in 1998 Annual Book of ASTM Standards Vol. 12.01, ASTM, West Conshohocken, Pennsylvania.

Bates, J. K., M. G. Seitz, and M. J. Steindler. 1984. "The Relevance of Vapor Phase Hydration Aging to Nuclear Waste Isolation," Nuclear and Chemical Waste Management, 5, p 63-73.

Brown, K. G., D. K. Peeler, J. C. Marra, J. D. Vienna, and A. Jiricka. 2000. Evaluation of the Testing Project in Support of Hanford Low-Activity Waste (LAW) Glass Product Acceptance, WSR-RP-200000280, Rev. 1, Westinghouse Savannah River Company, Aiken, South Carolina.

Clark, D.E. and B.K. Zoitos. 1991. Corrosion of Glass, Ceramics and Ceramic Superconductors, Noyes Publications, Park Ridge, New Jersey.

Clark, D.E., R.L. Schulz, G.G. Wicks, and A.R. Lodding. 1994. "Waste Glass Corrosion Processes and Rate Limiting Steps," In: Scientific Basis for Nuclear Waste Management XVII, (A. Barkatt and R.A. von Konynenburg, eds.), Materials Research Society Proceedings, Vol. 333, 107-122.

Cunnane, J. C. (ed.). 1994. High-Level Waste Borosilicate Glass: A Compendium of Corrosion Characteristics. DOE-EM-0177, U.S. Department of Energy, Washington, D.C.

Cullity, B. D. 1978. Elements of X-Ray Diffraction, Addison-Wesley Pub., New York. 
Ebert, W. L. and J.K. Bates. 1990. "The Reaction of Synthetic Nuclear Waste Glass in Steam and Hydrothermal Solution," Mat. Res. Soc. Symp. Proc., 176, p 339-346.

Ebert, W. L. and S. F. Wolf. 1999. Round-Robin Testing of a Reference Glass for Low-Activity Waste Forms, ANL-99/22, Argonne National Laboratory, Argonne, Illinois.

Ebert, W. L., and J. K. Bates. 1991. “The Importance of Secondary Phases in Glass Corrosion,” Mat. Res. Soc. Symp. Proc., 212, p 89-97.

Ebert, W. L., N. L. Dietz, M. A. Lewis, P. L. Johnson, and B. S. Tani. 2001. Long-term and Accelerated Testing of Hanford Low-Activity Waste Glasses: Data Report for Fiscal Year 2001, Argonne National Laboratory, Argonne, Illinois.

Feng, X., P.R. Hrma, J.H. Westsik, M.J. Schweiger, H. Li, J.D. Vienna, G. Chen, G.F. Piepel, D.K. Peeler, D.E. Smith, B.P. McGrail, S.E. Palmer, D. Kim, Y. Peng, W.K. Hahn, A.J. Bakel, and W.L. Ebert. 1996. Glass Optimization for Vitrification of Hanford Site Low-Level Tank Waste. PNNL-10918, Pacific Northwest National Laboratory, Richland, Washington.

Ferrara, D. M., C. L. Crawford, B. C. Ha, and N. E. Bibler. 1998. "Vitrification of Three Low-Activity Radioactive Waste Streams From Hanford," Proceedings of the International Conference on Decommissioning and Decontamination and on Nuclear and Hazardous Waste Management, p. 706-713, ANS, La Grange, Illinois.

Friedman, I., and W. Long. 1976. "Hydration of Obsidian.” Science 191:347-352.

Gan, H. and I. L. Pegg. 2001. Development of Property-Composition Models for RPP-WTP LAW Glasses, VSL-01R6600-1, Vitreous State Laboratory, The Catholic University of America Washington, D.C.

Gin, S., I. Ribet, and M. Couillard. 2001. "Role and Properties of the Gel Formed during Nuclear Glass Alteration: Importance of Gel Formation Conditions," J. Nucl. Matl. 298, p. 1-10.

Grambow, B. 1987. Nuclear Waste Glass Dissolution: Mechanism, Model, and Application, JSS Project Report 87-02, Swedish Nuclear Fuel and Waste Management Co., Stockholm.

Harvey, K. B., C. A. B. Larocque, S. Watson, and D. C. Doern. 1991. "The Dissolution of a Simple Specimen of a Glass," Ceram. Trans. 23, p 123-133.

Hrma, P. R., G. F. Piepel, M. J. Schweiger, D. E. Smith, D. S. Kim, P. E. Redgate, J. D. Vienna, C. A. LoPresti, D. B. Simpson, D. K. Peeler, and M. H. Langowski. 1994. Property/Composition Relationships for Hanford High-Level Waste Glasses Melting at $1150^{\circ} \mathrm{C}$, Volumes 1 and 2. PNL-10359, Pacific Northwest Laboratory, Richland, Washington.

Hrma, P., G. F. Piepel, J. D. Vienna, S. K. Cooley, D. S. Kim, R. L. Russell. 2001. Database and Interim Glass Property Models for Hanford HLW Glasses, PNNL-13573, Pacific Northwest National Laboratory, Richland, Washington. 
Jantzen, C. M. 1984. "Methods of Simulating Low Redox Potential (Eh) for a Basalt Repository." Materials Research Society Symposia Proceedings 26, ed. G.L. McVay, 613-621, Elsevier Science Publishing Co., New York.

Jantzen, C. M. 1991. "Relationship of Glass Composition to Glass Viscosity, Resistivity, Liquidus Temperature, and Durability: First-Principle Process Product Models for Vitrification of Nuclear Waste." Ceram. Trans. 23, 37-51, American Ceramic Society, Westerville, OH.

Jantzen, C. M., N. E. Bibler, D. C. Beam, C. L. Crawford, and M. A. Pickett. 1993. Characterization of the Defense Waste Processing Facility (DWPF) Environmental Assessment (EA) Glass Standard Reference Material (U), WSRC-TR-92-346, Revision 1, Westinghouse Savannah River Company, Aiken, South Carolina.

Jercinovic, M.J., and R.C. Ewing. 1992. "Corrosion of Geological and Archeological Glasses.” In Corrosion of Glass, Ceramics, and Ceramic Superconductors, eds. D.E. Clark and B. K. Zoitos. Noyes Publishing, Park Ridge, New Jersey.

Jiricka, A., and A. Helebrant. 2000. "Dissolution of Soda-Lime, Silica, and High-Level Waste Glass by Static and Single-Pass Flow-Through Tests," Ceram. Trans. 107, p 309-316, American Ceramic Society, Westerville, Ohio.

Jiricka, A., J. D. Vienna, P. Hrma, and D. M. Strachan. 2001. "The Effect of Experimental Conditions and Evaluation Techniques on the Alteration of Low-Activity Waste Glasses by Vapor Hydration," $J$. Non-cryst. Sol., 292, p 25-43.

Kim, D. S., P. Hrma, S. E. Palmer, D. E. Smith, and M. J. Schweiger. 1995. "Effect of $\mathrm{B}_{2} \mathrm{O}_{3}, \mathrm{CaO}$, and $\mathrm{Al}_{2} \mathrm{O}_{3}$ on the Chemical Durability of Silicate Glasses for Hanford Low-Level Waste Glass Immobilization," Ceram. Trans., 61, p 531-538, American Ceramic Society, Westerville, Ohio.

Lasaga, A. C. 1995. "Fundamental Approaches in Describing Mineral Dissolution and Precipitation Rates." In Chemical Weathering Rates of Silicate Minerals,31, eds. A.F. White and S.L. Bratley. Mineralogical Society of America p. 22-86.

Leturcq G., G. Berger, T. Advocat, C. Fillet, O. Halgand, and E. Vernaz. 1998. "Chemical Durability of Aluminosilicate Glasses Containing Low Solubility Chemical Elements.” Mat. Res. Soc. Symp. Proc., 506, p 199-214, Pittsburgh, Pennsylvania.

Luo, J. S., W. L. Ebert, J. J. Mazer, and J. K. Bates. 1997. "Simulation of Natural Corrosion by Vapor Hydration Test: Seven-year Results,” Mat. Res. Soc. Symp. Proc. 465, p157-163.

Lutze, W. and R. C. Ewing. 1988. Radioactive Waste Forms for the Future. North Holland, Amsterdam.

Mann, F. M., K. C. Burgard, W. R. root, R. J. Puigh, S. H. Finfrock, R. Khaleel, S. H. Bacon, E. J. Freeman, B. P. McGrail, S. K. Wurstner, and P. E. Lamont. 2001. Hanford Immobilized Low-Activity Waste Performance Assessment: 2001 Version, DOE/ORP-2000-24, Rev. 0, U. S. Department of Energy, Office of River Protection, Richland, Washington.

Mazer, J. J. 1991. Temperature Effects on Waste Glass Performance, ANL-91/17. Argonne National Laboratory, Argonne, Illinois. 
McGrail, B. P., C. W. Lindenmeier, P. F. Martin, and G. W. Gee. 1997b. "The Pressurized Unsaturated Flow (PUF) Test: A New Method for Engineered-Barrier Materials Evaluation," Ceramic Transactions, 72, p 317-329.

McGrail, B. P., W. L. Ebert, A. J. Bakel, and D. K. Peeler. 1997a. "Measurement of Kinetic Rate Law Parameters on a Na-Ca-Al Borosilicate Glass for Low-Activity Waste," Journal of Nuclear Materials, 249, p 175-189.

McGrail, B. P., D. H. Bacon, W. L. Ebert, and K. P. Saripalli. 2000. A Strategy to Conduct an Analysis of the Long-Term Performance of Low-Activity Waste Glass in a Shallow Subsurface Disposal System at Hanford. PNNL-11834 Rev. 1, Pacific Northwest National Laboratory, Richland, Washington.

McGrail, B. P., J. P. Icenhower, D. H. Bacon, J. D. Vienna, A. Jiricka, W. L. Ebert, P. F. Martin, H. T. Schaef, M. J. O'Hara, and E. A. Rodriguez. 1999. Waste Form Release Data Package for the 2001 Immobilized Low-Activity Waste Performance Assessment, PNNL-13043, Rev. 1, Pacific Northwest National Laboratory, Richland, Washington.

McGrail, B. P., J. P. Icenhower, D. H. Bacon, H. T. Schaef, P. F. Martin, E. A. Rodriguez, and J. L. Steele. 2001. Low-Activity Waste Glass Studies: FY2001 Summary Report. PNNL-13761, Pacific Northwest National Laboratory, Richland, Washington.

McVay, G. L., and C. Q. Buckwalter. 1983. "Effect of Iron on Waste-Glass Leaching," J. Am. Ceram. Soc. 66, 170-174.

Mellinger, G.B. and J.L. Daniel. 1984. "Approved Reference and tEsting Materials for Use in Nublear Waste Management Research and Development Programs," Pacific Northwest Laboratory, PNL-4955-2, Richland, Washington.

Muller I. S., A. C. Buechele, and I. L. Pegg. 2001. Glass Formulation and Testing with RPP-WTP LAW Simulants: Final Report, VSL-00R3560-2, Rev.0, Vitreous State Laboratory, The Catholic University of America Washington, DC.

Nesse, W. D. 1991. Introduction to Optical Minerology, $2^{\text {nd }}$ Ed., Oxford University Press, New York.

Peeler, D.K., A.D. Cozzi, D.R. Best, C.J. Coleman, and I.A. Reamer. 1999. "Characterization of the Low-Level Waste Reference Glass (LRM)," Westinghouse Savannah River Company, WSRC-TR-9900095, Aiken, South Carolina.

Schulz, R.L., T.H. Lorier, D.K. Peeler, K.G. Brown, I.A. Reamer, J.D. Vienna, A Jiricka, B.M. Jorgenson, and D.E. Smith. 2000. Hanford Immobilized LAW Product Acceptance: Tanks Focus Area Testing Data Package II, PNNL-13344, Pacific Northwest National Laboratory, Richland, Washington.

Strachan, D. M., T. L. Croak. 2000. "Compositional effects on long-term dissolution of borosilicate glass," J. Non-cryst. Sol., 272, p 22-33.

U.S. Department of Energy (DOE). 2000. Design, Construction, and Commissioning of the Hanford Tank Waste Treatment and Immobilization Plant, DOE Office of River Protection, Richland, Washington 99352; Contract with Bechtel National, Inc., San Francisco, California 94105, Contract No.: DE-AC2701RV14136, Issued August 31, 2000. 
Van Iseghem, P., and B. Grambow. 1988. "The Long-Term Corrosion and Modeling of Two Simulated Belgian Reference High-Level Waste Glasses," Matl. Res. Soc. Symp. 112, p 631-639.

Vienna, J. D., D. K. Peeler, and B. P. McGrail. 1999. Hanford Immobilized Low-Activity Waste Product Acceptance Test Plan (U), SRTC-RP-99-00288, Westinghouse Savannah River Company, Aiken, South Carolina.

Vienna, J. D., A. Jiricka, B. P. McGrail, B. M. Jorgensen, D. E. Smith, B. R. Allen, J. C. Marra, D. K. Peeler, K. G. Brown, I. A. Reamer, and W. L. Ebert. 2000. Hanford Immobilized LAW Product Acceptance: Initial Tank Focus Area Testing Data Package, PNNL-13101, Pacific Northwest National Laboratory, Richland, Washington.

Volf, M. B. 1984. Chemical Approach to Glass, Elsevier, NY.

Westsik, J. H., Jr. and R. D. Peters. 1981. "Time and Temperature Dependence of the Leaching of a Simulated High-Level Waste Glass," in Scientific Basis for Nuclear Waste Management, 3, Plenum Press, New York.

Wolf, S. F., W. L. Ebert, J. S. Luo, and D. M. Strachan. 1998. A Data Base and Standard Material for Use in Acceptance Testing of Low-Activity Waste Products, ANL-98/9, Argonne National Laboratory, Argonne, Illinois. 


\section{Appendix A}

Target and Measured Compositions of the HLP Glasses 


\section{Appendix A: Target and Measured Compositions of the HLP Glasses}

Table A-1. Target and measured compositions (in mass \% of oxides) for Phase I and II glasses.

\begin{tabular}{|c|c|c|c|c|c|c|c|c|c|}
\hline Glass ID & $\begin{array}{l}\text { Oxide/ } \\
\text { Anion }\end{array}$ & $\begin{array}{c}\text { Targeted } \\
\text { Comp. }\end{array}$ & $\begin{array}{l}\text { Meas. } \\
\text { Comp. }\end{array}$ & $\begin{array}{c}\% \\
\text { Diff. }\end{array}$ & Glass ID & $\begin{array}{l}\text { Oxide/ } \\
\text { Anion }\end{array}$ & $\begin{array}{c}\text { Targeted } \\
\text { Comp. }\end{array}$ & $\begin{array}{l}\text { Meas. } \\
\text { Comp. }\end{array}$ & $\begin{array}{c}\% \\
\text { Diff. }\end{array}$ \\
\hline "HLP-01 & $\overline{\mathrm{A \textrm {Al } _ { 2 } \mathrm { O } _ { 3 }}}$ & 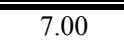 & $\overline{77.04}$ & 0.57 & 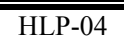 & $\overline{\mathrm{A \textrm {Al } _ { 2 } \mathrm { O } _ { 3 }}}$ & 8.24 & 8.74 & 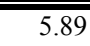 \\
\hline HLP-01 & $\mathrm{B}_{2} \mathrm{O}_{3}$ & 10.00 & 8.92 & 11.42 & HLP-04 & $\mathrm{B}_{2} \mathrm{O}_{3}$ & 11.78 & 12.40 & 5.13 \\
\hline HLP-01 & $\mathrm{CaO}$ & 0.01 & 0.01 & 0.00 & HLP-04 & $\mathrm{CaO}$ & 0.01 & BD & \\
\hline HLP-01 & $\mathrm{Cr}_{2} \mathrm{O}_{3}$ & 0.08 & 0.25 & 103.03 & HLP-04 & $\mathrm{Cr}_{2} \mathrm{O}_{3}$ & 0.09 & 0.24 & 90.91 \\
\hline HLP-01 & $\mathrm{Fe}_{2} \mathrm{O}_{3}$ & 5.50 & 6.52 & 16.97 & HLP-04 & $\mathrm{Fe}_{2} \mathrm{O}_{3}$ & 6.48 & 7.72 & 17.46 \\
\hline HLP-01 & $\mathrm{K}_{2} \mathrm{O}$ & 0.41 & 0.40 & 2.47 & HLP-04 & $\mathrm{K}_{2} \mathrm{O}$ & 0.49 & 0.52 & 5.94 \\
\hline HLP-01 & $\mathrm{La}_{2} \mathrm{O}_{3}$ & 0.00 & 0.02 & 200.00 & HLP-04 & $\mathrm{La}_{2} \mathrm{O}_{3}$ & 0.00 & $\mathrm{BD}$ & \\
\hline HLP-01 & $\mathrm{Li}_{2} \mathrm{O}$ & 0.00 & BD & & HLP-04 & $\mathrm{Li}_{2} \mathrm{O}$ & 0.00 & BD & \\
\hline HLP-01 & $\mathrm{MgO}$ & 1.50 & 1.41 & 6.19 & HLP-04 & $\mathrm{MgO}$ & 1.77 & 1.68 & 5.22 \\
\hline HLP-01 & $\mathrm{MoO}_{3}$ & 0.00 & & & HLP-04 & $\mathrm{MoO}_{3}$ & 0.00 & & \\
\hline HLP-01 & $\mathrm{Na}_{2} \mathrm{O}$ & 20.00 & 18.40 & 8.33 & HLP-04 & $\mathrm{Na}_{2} \mathrm{O}$ & 23.57 & 22.20 & 5.99 \\
\hline HLP-01 & $\mathrm{P}_{2} \mathrm{O}_{5}$ & 0.06 & & & HLP-04 & $\mathrm{P}_{2} \mathrm{O}_{5}$ & 0.07 & & \\
\hline HLP-01 & $\mathrm{SiO}_{2}$ & 49.07 & 48.80 & 0.55 & HLP-04 & $\mathrm{SiO}_{2}$ & 40.00 & 40.40 & 1.00 \\
\hline HLP-01 & $\mathrm{TiO}_{2}$ & 3.00 & 3.00 & 0.00 & HLP-04 & $\mathrm{TiO}_{2}$ & 3.53 & 3.56 & 0.85 \\
\hline HLP-01 & $\mathrm{ZnO}$ & 1.50 & 1.46 & 2.70 & HLP-04 & $\mathrm{ZnO}$ & 1.77 & 1.74 & 1.71 \\
\hline HLP-01 & $\mathrm{ZrO}_{2}$ & 1.50 & 1.54 & 2.63 & HLP-04 & $\mathrm{ZrO}_{2}$ & 1.77 & 1.74 & 1.71 \\
\hline HLP-01 & $\mathrm{Cl}$ & 0.28 & & & HLP-04 & $\mathrm{Cl}$ & 0.33 & & \\
\hline HLP-01 & $\mathrm{F}$ & 0.01 & & & HLP-04 & $\mathrm{F}$ & 0.01 & & \\
\hline HLP-01 & $\mathrm{SO}_{3}$ & 0.07 & & & HLP-04 & $\mathrm{SO}_{3}$ & 0.09 & & \\
\hline HLP-01 & TOTAL & 100.00 & 97.77 & 2.26 & HLP-04 & TOTAL & 100.01 & 100.94 & 0.93 \\
\hline HLP-02 & $\mathrm{Al}_{2} \mathrm{O}_{3}$ & 8.79 & 8.95 & 1.80 & HLP-05 & $\mathrm{Al}_{2} \mathrm{O}_{3}$ & 4.00 & 4.24 & 5.83 \\
\hline HLP-02 & $\mathrm{B}_{2} \mathrm{O}_{3}$ & 12.57 & 11.40 & 9.76 & HLP-05 & $\mathrm{B}_{2} \mathrm{O}_{3}$ & 10.32 & 10.30 & 0.19 \\
\hline HLP-02 & $\mathrm{CaO}$ & 0.02 & BD & & HLP-05 & $\mathrm{CaO}$ & 0.01 & BD & \\
\hline HLP-02 & $\mathrm{Cr}_{2} \mathrm{O}_{3}$ & 0.09 & 0.22 & 83.87 & HLP-05 & $\mathrm{Cr}_{2} \mathrm{O}_{3}$ & 0.08 & 0.27 & 108.57 \\
\hline HLP-02 & $\mathrm{Fe}_{2} \mathrm{O}_{3}$ & 6.92 & 7.63 & 9.76 & HLP-05 & $\mathrm{Fe}_{2} \mathrm{O}_{3}$ & 5.68 & 6.80 & 17.95 \\
\hline HLP-02 & $\mathrm{K}_{2} \mathrm{O}$ & 0.52 & 0.59 & 12.61 & HLP-05 & $\mathrm{K}_{2} \mathrm{O}$ & 0.43 & 0.50 & 15.05 \\
\hline HLP-02 & $\mathrm{La}_{2} \mathrm{O}_{3}$ & 0.00 & $\mathrm{BD}$ & & HLP-05 & $\mathrm{La}_{2} \mathrm{O}_{3}$ & 0.00 & $\mathrm{BD}$ & \\
\hline HLP-02 & $\mathrm{Li}_{2} \mathrm{O}$ & 0.00 & $\mathrm{BD}$ & & HLP-05 & $\mathrm{Li}_{2} \mathrm{O}$ & 0.00 & $\mathrm{BD}$ & \\
\hline HLP-02 & $\mathrm{MgO}$ & 1.88 & 1.81 & 3.79 & HLP-05 & $\mathrm{MgO}$ & 1.55 & 1.45 & 6.67 \\
\hline HLP-02 & $\mathrm{MoO}_{3}$ & 0.00 & & & HLP-05 & $\mathrm{MoO}_{3}$ & 0.00 & & \\
\hline HLP-02 & $\mathrm{Na}_{2} \mathrm{O}$ & 25.14 & 25.80 & 2.59 & HLP-05 & $\mathrm{Na}_{2} \mathrm{O}$ & 20.65 & 20.30 & 1.71 \\
\hline HLP-02 & $\mathrm{P}_{2} \mathrm{O}_{5}$ & 0.07 & & & HLP-05 & $\mathrm{P}_{2} \mathrm{O}_{5}$ & 0.06 & & \\
\hline HLP-02 & $\mathrm{SiO}_{2}$ & 36.00 & 35.20 & 2.25 & HLP-05 & $\mathrm{SiO}_{2}$ & 50.65 & 47.30 & 6.84 \\
\hline HLP-02 & $\mathrm{TiO}_{2}$ & 3.77 & 3.86 & 2.36 & HLP-05 & $\mathrm{TiO}_{2}$ & 3.09 & 3.17 & 2.56 \\
\hline HLP-02 & $\mathrm{ZnO}$ & 1.88 & 1.88 & 0.00 & HLP-05 & $\mathrm{ZnO}$ & 1.55 & 1.56 & 0.64 \\
\hline HLP-02 & $\mathrm{ZrO}_{2}$ & 1.88 & 1.88 & 0.00 & HLP-05 & $\mathrm{ZrO}_{2}$ & 1.55 & 1.45 & 6.67 \\
\hline HLP-02 & $\mathrm{Cl}$ & 0.35 & & & HLP-05 & $\mathrm{Cl}$ & 0.29 & & \\
\hline HLP-02 & $\mathrm{F}$ & 0.01 & & & HLP-05 & $\mathrm{F}$ & 0.01 & & \\
\hline HLP-02 & $\mathrm{SO}_{3}$ & 0.09 & & & HLP-05 & $\mathrm{SO}_{3}$ & 0.08 & & \\
\hline HLP-02 & TOTAL & 99.99 & 99.22 & 0.77 & HLP-05 & TOTAL & 100.01 & 97.34 & 2.71 \\
\hline HLP-03 & $\mathrm{Al}_{2} \mathrm{O}_{3}$ & 6.60 & 7.08 & 7.02 & HLP-06 & $\mathrm{Al}_{2} \mathrm{O}_{3}$ & 11.94 & 12.30 & 2.97 \\
\hline HLP-03 & $\mathrm{B}_{2} \mathrm{O}_{3}$ & 9.43 & 9.09 & 3.67 & HLP-06 & $\mathrm{B}_{2} \mathrm{O}_{3}$ & 9.47 & 8.89 & 6.32 \\
\hline HLP-03 & $\mathrm{CaO}$ & 0.01 & BD & & HLP-06 & $\mathrm{CaO}$ & 0.01 & BD & \\
\hline HLP-03 & $\mathrm{Cr}_{2} \mathrm{O}_{3}$ & 0.07 & 0.19 & 92.31 & HLP-06 & $\mathrm{Cr}_{2} \mathrm{O}_{3}$ & 0.07 & 0.14 & 66.67 \\
\hline HLP-03 & $\mathrm{Fe}_{2} \mathrm{O}_{3}$ & 5.19 & 6.06 & 15.47 & HLP-06 & $\mathrm{Fe}_{2} \mathrm{O}_{3}$ & 5.21 & 5.96 & 13.43 \\
\hline HLP-03 & $\mathrm{K}_{2} \mathrm{O}$ & 0.39 & 0.41 & 5.00 & HLP-06 & $\mathrm{K}_{2} \mathrm{O}$ & 0.39 & 0.42 & 7.41 \\
\hline HLP-03 & $\mathrm{La}_{2} \mathrm{O}_{3}$ & 0.00 & $\mathrm{BD}$ & & HLP-06 & $\mathrm{La}_{2} \mathrm{O}_{3}$ & 0.00 & $\mathrm{BD}$ & \\
\hline HLP-03 & $\mathrm{Li}_{2} \mathrm{O}$ & 0.00 & $\mathrm{BD}$ & & HLP-06 & $\mathrm{Li}_{2} \mathrm{O}$ & 0.00 & $\mathrm{BD}$ & \\
\hline HLP-03 & $\mathrm{MgO}$ & 1.41 & 1.36 & 3.61 & HLP-06 & $\mathrm{MgO}$ & 1.42 & 1.34 & 5.80 \\
\hline HLP-03 & $\mathrm{MoO}_{3}$ & 0.00 & & & HLP-06 & $\mathrm{MoO}_{3}$ & 0.00 & & \\
\hline HLP-03 & $\mathrm{Na}_{2} \mathrm{O}$ & 18.85 & 17.90 & 5.17 & HLP-06 & $\mathrm{Na}_{2} \mathrm{O}$ & 18.94 & 19.10 & 0.84 \\
\hline HLP-03 & $\mathrm{P}_{2} \mathrm{O}_{5}$ & 0.05 & & & HLP-06 & $\mathrm{P}_{2} \mathrm{O}_{5}$ & 0.05 & & \\
\hline HLP-03 & $\mathrm{SiO}_{2}$ & 52.00 & 51.50 & 0.97 & HLP-06 & $\mathrm{SiO}_{2}$ & 46.46 & 44.60 & 4.09 \\
\hline HLP-03 & $\mathrm{TiO}_{2}$ & 2.82 & 2.89 & 2.45 & HLP-06 & $\mathrm{TiO}_{2}$ & 2.84 & 2.94 & 3.46 \\
\hline HLP-03 & $\mathrm{ZnO}$ & 1.41 & 1.43 & 1.41 & HLP-06 & $\mathrm{ZnO}$ & 1.42 & 1.42 & 0.00 \\
\hline HLP-03 & $\mathrm{ZrO}_{2}$ & 1.41 & 1.36 & 3.61 & HLP-06 & $\mathrm{ZrO}_{2}$ & 1.42 & 1.35 & 5.05 \\
\hline HLP-03 & $\mathrm{Cl}$ & 0.26 & & & HLP-06 & $\mathrm{Cl}$ & 0.26 & & \\
\hline HLP-03 & $\mathrm{F}$ & 0.01 & & & HLP-06 & $\mathrm{F}$ & 0.01 & & \\
\hline HLP-03 & $\mathrm{SO}_{3}$ & 0.07 & & & HLP-06 & $\mathrm{SO}_{3}$ & 0.07 & & \\
\hline HLP-03 & TOTAL & 99.99 & 99.27 & 0.72 & HLP-06 & TOTAL & 99.99 & 98.46 & 1.54 \\
\hline
\end{tabular}




\begin{tabular}{|c|c|c|c|c|c|c|c|c|c|}
\hline Glass ID & $\begin{array}{l}\text { Oxide/ } \\
\text { Anion } \\
\end{array}$ & $\begin{array}{c}\text { Targeted } \\
\text { Comp. } \\
\end{array}$ & $\begin{array}{l}\text { Meas. } \\
\text { Comp. }\end{array}$ & $\begin{array}{c}\% \\
\text { Diff. }\end{array}$ & Glass ID & $\begin{array}{c}\text { Oxide/ } \\
\text { Anion } \\
\end{array}$ & $\begin{array}{c}\text { Targeted } \\
\text { Comp. } \\
\end{array}$ & $\begin{array}{l}\text { Meas. } \\
\text { Comp. }\end{array}$ & $\begin{array}{c}\% \\
\text { Diff. }\end{array}$ \\
\hline HLP-07 & $\mathrm{Al}_{2} \mathrm{O}_{3}$ & 9.00 & 9.79 & 8.41 & HLP-10 & $\mathrm{Al}_{2} \mathrm{O}_{3}$ & 7.15 & 7.04 & 1.55 \\
\hline HLP-07 & $\mathrm{B}_{2} \mathrm{O}_{3}$ & 9.79 & 9.45 & 3.53 & HLP-10 & $\mathrm{B}_{2} \mathrm{O}_{3}$ & 8.00 & 8.92 & 10.87 \\
\hline HLP-07 & $\mathrm{CaO}$ & 0.01 & $\mathrm{BD}$ & & HLP-10 & $\mathrm{CaO}$ & 0.01 & $\mathrm{BD}$ & \\
\hline HLP-07 & $\mathrm{Cr}_{2} \mathrm{O}_{3}$ & 0.07 & 0.20 & 96.30 & HLP-10 & $\mathrm{Cr}_{2} \mathrm{O}_{3}$ & 0.08 & 0.22 & 93.33 \\
\hline HLP-07 & $\mathrm{Fe}_{2} \mathrm{O}_{3}$ & 5.38 & 6.32 & 16.07 & HLP-10 & $\mathrm{Fe}_{2} \mathrm{O}_{3}$ & 5.63 & 6.33 & 11.71 \\
\hline HLP-07 & $\mathrm{K}_{2} \mathrm{O}$ & 0.40 & 0.43 & 7.23 & HLP-10 & $\mathrm{K}_{2} \mathrm{O}$ & 0.42 & 0.48 & 13.33 \\
\hline HLP-07 & $\mathrm{La}_{2} \mathrm{O}_{3}$ & 0.00 & $\mathrm{BD}$ & & HLP-10 & $\mathrm{La}_{2} \mathrm{O}_{3}$ & 0.00 & 0.01 & 200.00 \\
\hline HLP-07 & $\mathrm{Li}_{2} \mathrm{O}$ & 0.00 & $\mathrm{BD}$ & & HLP-10 & $\mathrm{Li}_{2} \mathrm{O}$ & 0.00 & $\mathrm{BD}$ & \\
\hline HLP-07 & $\mathrm{MgO}$ & 1.47 & 1.46 & 0.68 & HLP-10 & $\mathrm{MgO}$ & 1.53 & 1.36 & 11.76 \\
\hline HLP-07 & $\mathrm{MoO}_{3}$ & 0.00 & & & HLP-10 & $\mathrm{MoO}_{3}$ & 0.00 & & \\
\hline HLP-07 & $\mathrm{Na}_{2} \mathrm{O}$ & 19.57 & 19.30 & 1.39 & HLP-10 & $\mathrm{Na}_{2} \mathrm{O}$ & 20.45 & 18.40 & 10.55 \\
\hline HLP-07 & $\mathrm{P}_{2} \mathrm{O}_{5}$ & 0.05 & & & HLP-10 & $\mathrm{P}_{2} \mathrm{O}_{5}$ & 0.06 & & \\
\hline HLP-07 & $\mathrm{SiO}_{2}$ & 48.01 & 50.30 & 4.66 & HLP-10 & $\mathrm{SiO}_{2}$ & 50.16 & 47.90 & 4.61 \\
\hline HLP-07 & $\mathrm{TiO}_{2}$ & 2.93 & 3.15 & 7.24 & HLP-10 & $\mathrm{TiO}_{2}$ & 3.06 & 3.09 & 0.98 \\
\hline HLP-07 & $\mathrm{ZnO}$ & 1.47 & 1.56 & 5.94 & HLP-10 & $\mathrm{ZnO}$ & 1.53 & 1.49 & 2.65 \\
\hline HLP-07 & $\mathrm{ZrO}_{2}$ & 1.47 & 1.55 & 5.30 & HLP-10 & $\mathrm{ZrO}_{2}$ & 1.53 & 1.55 & 1.30 \\
\hline HLP-07 & $\mathrm{Cl}$ & 0.27 & & & HLP-10 & $\mathrm{Cl}$ & 0.28 & & \\
\hline HLP-07 & $\mathrm{F}$ & 0.01 & & & HLP-10 & $\mathrm{F}$ & 0.01 & & \\
\hline HLP-07 & $\mathrm{SO}_{3}$ & 0.07 & & & HLP-10 & $\mathrm{SO}_{3}$ & 0.07 & & \\
\hline HLP-07 & TOTAL & 99.98 & 103.51 & 3.47 & HLP-10 & TOTAL & 99.98 & 96.79 & 3.24 \\
\hline HLP-08 & $\mathrm{Al}_{2} \mathrm{O}_{3}$ & 7.31 & 7.06 & 3.48 & HLP-11 & $\mathrm{Al}_{2} \mathrm{O}_{3}$ & 7.41 & 6.91 & 6.98 \\
\hline HLP-08 & $\mathrm{B}_{2} \mathrm{O}_{3}$ & 6.00 & 5.94 & 1.01 & HLP-11 & $\mathrm{B}_{2} \mathrm{O}_{3}$ & 10.58 & 10.60 & 0.19 \\
\hline HLP-08 & $\mathrm{CaO}$ & 0.01 & $\mathrm{BD}$ & & HLP-11 & $\mathrm{CaO}$ & 0.01 & $\mathrm{BD}$ & \\
\hline HLP-08 & $\mathrm{Cr}_{2} \mathrm{O}_{3}$ & 0.08 & 0.09 & 11.76 & HLP-11 & $\mathrm{Cr}_{2} \mathrm{O}_{3}$ & 0.08 & 0.21 & 89.66 \\
\hline HLP-08 & $\mathrm{Fe}_{2} \mathrm{O}_{3}$ & 5.75 & 5.84 & 1.55 & HLP-11 & $\mathrm{Fe}_{2} \mathrm{O}_{3}$ & 0.00 & 0.55 & 200.00 \\
\hline HLP-08 & $\mathrm{K}_{2} \mathrm{O}$ & 0.43 & 0.56 & 26.26 & HLP-11 & $\mathrm{K}_{2} \mathrm{O}$ & 0.44 & 0.40 & 9.52 \\
\hline HLP-08 & $\mathrm{La}_{2} \mathrm{O}_{3}$ & 0.00 & $\mathrm{BD}$ & & HLP-11 & $\mathrm{La}_{2} \mathrm{O}_{3}$ & 0.00 & $\mathrm{BD}$ & \\
\hline HLP-08 & $\mathrm{Li}_{2} \mathrm{O}$ & 0.00 & $\mathrm{BD}$ & & HLP-11 & $\mathrm{Li}_{2} \mathrm{O}$ & 0.00 & $\mathrm{BD}$ & \\
\hline HLP-08 & $\mathrm{MgO}$ & 1.57 & 1.31 & 18.06 & HLP-11 & $\mathrm{MgO}$ & 1.59 & 1.23 & 25.53 \\
\hline HLP-08 & $\mathrm{MoO}_{3}$ & 0.00 & & & HLP-11 & $\mathrm{MoO}_{3}$ & 0.00 & & \\
\hline HLP-08 & $\mathrm{Na}_{2} \mathrm{O}$ & 20.89 & 19.50 & 6.88 & HLP-11 & $\mathrm{Na}_{2} \mathrm{O}$ & 21.17 & 18.20 & 15.09 \\
\hline HLP-08 & $\mathrm{P}_{2} \mathrm{O}_{5}$ & 0.06 & & & HLP-11 & $\mathrm{P}_{2} \mathrm{O}_{5}$ & 0.06 & & \\
\hline HLP-08 & $\mathrm{SiO}_{2}$ & 51.25 & 48.90 & 4.69 & HLP-11 & $\mathrm{SiO}_{2}$ & 51.93 & 50.80 & 2.20 \\
\hline HLP-08 & $\mathrm{TiO}_{2}$ & 3.13 & 3.04 & 2.92 & HLP-11 & $\mathrm{TiO}_{2}$ & 3.17 & 2.83 & 11.33 \\
\hline HLP-08 & $\mathrm{ZnO}$ & 1.57 & 1.46 & 7.26 & HLP-11 & $\mathrm{ZnO}$ & 1.59 & 1.48 & 7.17 \\
\hline HLP-08 & $\mathrm{ZrO}_{2}$ & 1.57 & 1.44 & 8.64 & HLP-11 & $\mathrm{ZrO}_{2}$ & 1.59 & 1.38 & 14.14 \\
\hline HLP-08 & $\mathrm{Cl}$ & 0.29 & & & HLP-11 & $\mathrm{Cl}$ & 0.29 & & \\
\hline HLP-08 & $\mathrm{F}$ & 0.01 & & & HLP-11 & $\mathrm{F}$ & 0.01 & & \\
\hline HLP-08 & $\mathrm{SO}_{3}$ & 0.08 & & & HLP-11 & $\mathrm{SO}_{3}$ & 0.08 & & \\
\hline HLP-08 & TOTAL & 100.01 & 95.24 & 4.89 & HLP-11 & TOTAL & 100.01 & 94.59 & 5.57 \\
\hline HLP-09 & $\mathrm{Al}_{2} \mathrm{O}_{3}$ & 6.84 & 7.12 & 4.01 & HLP-12 & $\mathrm{Al}_{2} \mathrm{O}_{3}$ & 6.74 & 6.44 & 4.55 \\
\hline HLP-09 & $\mathrm{B}_{2} \mathrm{O}_{3}$ & 12.00 & 11.80 & 1.68 & HLP-12 & $\mathrm{B}_{2} \mathrm{O}_{3}$ & 9.63 & 10.20 & 5.75 \\
\hline HLP-09 & $\mathrm{CaO}$ & 0.01 & $\mathrm{BD}$ & & HLP-12 & $\mathrm{CaO}$ & 0.01 & 0.05 & 133.33 \\
\hline HLP-09 & $\mathrm{Cr}_{2} \mathrm{O}_{3}$ & 0.07 & 0.21 & 100.00 & HLP-12 & $\mathrm{Cr}_{2} \mathrm{O}_{3}$ & 0.07 & 0.23 & 106.67 \\
\hline HLP-09 & $\mathrm{Fe}_{2} \mathrm{O}_{3}$ & 5.38 & 6.40 & 17.32 & HLP-12 & $\mathrm{Fe}_{2} \mathrm{O}_{3}$ & 9.00 & 9.20 & 2.20 \\
\hline HLP-09 & $\mathrm{K}_{2} \mathrm{O}$ & 0.40 & 0.41 & 2.47 & HLP-12 & $\mathrm{K}_{2} \mathrm{O}$ & 0.40 & 0.46 & 13.95 \\
\hline HLP-09 & $\mathrm{La}_{2} \mathrm{O}_{3}$ & 0.00 & $\mathrm{BD}$ & & HLP-12 & $\mathrm{La}_{2} \mathrm{O}_{3}$ & 0.00 & $\mathrm{BD}$ & \\
\hline HLP-09 & $\mathrm{Li}_{2} \mathrm{O}$ & 0.00 & $\mathrm{BD}$ & & HLP-12 & $\mathrm{Li}_{2} \mathrm{O}$ & 0.00 & $\mathrm{BD}$ & \\
\hline HLP-09 & $\mathrm{MgO}$ & 1.47 & 1.29 & 13.04 & HLP-12 & $\mathrm{MgO}$ & 1.44 & 1.23 & 15.73 \\
\hline HLP-09 & $\mathrm{MoO}_{3}$ & 0.00 & & & HLP-12 & $\mathrm{MoO}_{3}$ & 0.00 & & \\
\hline HLP-09 & $\mathrm{Na}_{2} \mathrm{O}$ & 19.56 & 18.60 & 5.03 & HLP-12 & $\mathrm{Na}_{2} \mathrm{O}$ & 19.26 & 18.00 & 6.76 \\
\hline HLP-09 & $\mathrm{P}_{2} \mathrm{O}_{5}$ & 0.05 & & & HLP-12 & $\mathrm{P}_{2} \mathrm{O}_{5}$ & 0.05 & & \\
\hline HLP-09 & $\mathrm{SiO}_{2}$ & 47.98 & 43.30 & 10.25 & HLP-12 & $\mathrm{SiO}_{2}$ & 47.25 & 44.80 & 5.32 \\
\hline HLP-09 & $\mathrm{TiO}_{2}$ & 2.93 & 2.87 & 2.07 & HLP-12 & $\mathrm{TiO}_{2}$ & 2.89 & 2.75 & 4.96 \\
\hline HLP-09 & $\mathrm{ZnO}$ & 1.47 & 1.51 & 2.68 & HLP-12 & $\mathrm{ZnO}$ & 1.44 & 1.45 & 0.69 \\
\hline HLP-09 & $\mathrm{ZrO}_{2}$ & 1.47 & 1.22 & 18.59 & HLP-12 & $\mathrm{ZrO}_{2}$ & 1.44 & 1.34 & 7.19 \\
\hline HLP-09 & $\mathrm{Cl}$ & 0.27 & & & HLP-12 & $\mathrm{Cl}$ & 0.27 & & \\
\hline HLP-09 & $\mathrm{F}$ & 0.01 & & & HLP-12 & $\mathrm{F}$ & 0.01 & & \\
\hline HLP-09 & $\mathrm{SO}_{3}$ & 0.07 & & & HLP-12 & $\mathrm{SO}_{3}$ & 0.07 & & \\
\hline HLP-09 & TOTAL & 99.99 & 94.73 & 5.40 & HLP-12 & TOTAL & 99.98 & 96.15 & 3.91 \\
\hline
\end{tabular}




\begin{tabular}{|c|c|c|c|c|c|c|c|c|c|}
\hline Glass ID & $\begin{array}{c}\text { Oxide/ } \\
\text { Anion } \\
\end{array}$ & $\begin{array}{c}\text { Targeted } \\
\text { Comp. }\end{array}$ & $\begin{array}{l}\text { Meas. } \\
\text { Comp. }\end{array}$ & $\begin{array}{c}\% \% \\
\text { Diff. } \\
\end{array}$ & Glass ID & $\begin{array}{c}\text { Oxide/ } \\
\text { Anion } \\
\end{array}$ & $\begin{array}{c}\text { Targeted } \\
\text { Comp. } \\
\end{array}$ & $\begin{array}{l}\text { Meas. } \\
\text { Comp. } \\
\end{array}$ & $\begin{array}{c}\% \% \\
\text { Diff. } \\
\end{array}$ \\
\hline HLP-13 & $\mathrm{Al}_{2} \mathrm{O}_{3}$ & 7.18 & 6.44 & 10.87 & HLP-16 & $\mathrm{Al}_{2} \mathrm{O}_{3}$ & 7.10 & 6.79 & 4.46 \\
\hline HLP-13 & $\mathrm{B}_{2} \mathrm{O}_{3}$ & 10.27 & 10.20 & 0.68 & HLP-16 & $\mathrm{B}_{2} \mathrm{O}_{3}$ & 10.15 & 10.00 & 1.49 \\
\hline HLP-13 & $\mathrm{CaO}$ & 0.01 & 0.06 & 142.86 & HLP-16 & $\mathrm{CaO}$ & 0.01 & 0.08 & 155.56 \\
\hline HLP-13 & $\mathrm{Cr}_{2} \mathrm{O}_{3}$ & 0.08 & 0.24 & 100.00 & HLP-16 & $\mathrm{Cr}_{2} \mathrm{O}_{3}$ & 0.08 & 0.26 & 105.88 \\
\hline HLP-13 & $\mathrm{Fe}_{2} \mathrm{O}_{3}$ & 3.00 & 3.80 & 23.53 & HLP-16 & $\mathrm{Fe}_{2} \mathrm{O}_{3}$ & 5.59 & 6.84 & 20.11 \\
\hline HLP-13 & $\mathrm{K}_{2} \mathrm{O}$ & 0.42 & 0.41 & 2.41 & HLP-16 & $\mathrm{K}_{2} \mathrm{O}$ & 0.42 & 0.41 & 2.41 \\
\hline HLP-13 & $\mathrm{La}_{2} \mathrm{O}_{3}$ & 0.00 & $\mathrm{BD}$ & & HLP-16 & $\mathrm{La}_{2} \mathrm{O}_{3}$ & 0.00 & $\mathrm{BD}$ & \\
\hline HLP-13 & $\mathrm{Li}_{2} \mathrm{O}$ & 0.00 & $\mathrm{BD}$ & & HLP-16 & $\mathrm{Li}_{2} \mathrm{O}$ & 0.00 & $\mathrm{BD}$ & \\
\hline HLP-13 & $\mathrm{MgO}$ & 1.54 & 1.51 & 1.97 & HLP-16 & $\mathrm{MgO}$ & 1.52 & 1.61 & 5.75 \\
\hline HLP-13 & $\mathrm{MoO}_{3}$ & 0.00 & & & HLP-16 & $\mathrm{MoO}_{3}$ & 0.00 & & \\
\hline HLP-13 & $\mathrm{Na}_{2} \mathrm{O}$ & 20.53 & 18.50 & 10.40 & HLP-16 & $\mathrm{Na}_{2} \mathrm{O}$ & 20.31 & 19.00 & 6.66 \\
\hline HLP-13 & $\mathrm{P}_{2} \mathrm{O}_{5}$ & 0.06 & & & HLP-16 & $\mathrm{P}_{2} \mathrm{O}_{5}$ & 0.06 & & \\
\hline HLP-13 & $\mathrm{SiO}_{2}$ & 50.37 & 49.90 & 0.94 & HLP-16 & $\mathrm{SiO}_{2}$ & 49.82 & 53.40 & 6.94 \\
\hline HLP-13 & $\mathrm{TiO}_{2}$ & 3.08 & 2.95 & 4.31 & HLP-16 & $\mathrm{TiO}_{2}$ & 3.04 & 3.18 & 4.50 \\
\hline HLP-13 & $\mathrm{ZnO}$ & 1.54 & 1.53 & 0.65 & HLP-16 & $\mathrm{ZnO}$ & 0.00 & $\mathrm{BD}$ & \\
\hline HLP-13 & $\mathrm{ZrO}_{2}$ & 1.54 & 1.34 & 13.89 & HLP-16 & $\mathrm{ZrO}_{2}$ & 1.52 & 1.30 & 15.60 \\
\hline HLP-13 & $\mathrm{Cl}$ & 0.28 & & & HLP-16 & $\mathrm{Cl}$ & 0.28 & & \\
\hline HLP-13 & $\mathrm{F}$ & 0.01 & & & HLP-16 & $\mathrm{F}$ & 0.01 & & \\
\hline HLP-13 & $\mathrm{SO}_{3}$ & 0.08 & & & HLP-16 & $\mathrm{SO}_{3}$ & 0.07 & & \\
\hline HLP-13 & TOTAL & 100.00 & 96.88 & 3.17 & HLP-16 & TOTAL & 99.99 & 102.87 & 2.84 \\
\hline HLP-14 & $\mathrm{Al}_{2} \mathrm{O}_{3}$ & 7.21 & 7.23 & 0.28 & HLP-17 & $\mathrm{Al}_{2} \mathrm{O}_{3}$ & 6.82 & 6.84 & 0.29 \\
\hline HLP-14 & $\mathrm{B}_{2} \mathrm{O}_{3}$ & 10.31 & 10.10 & 2.06 & HLP-17 & $\mathrm{B}_{2} \mathrm{O}_{3}$ & 9.75 & 9.86 & 1.12 \\
\hline HLP-14 & $\mathrm{CaO}$ & 0.01 & 0.06 & 142.86 & HLP-17 & $\mathrm{CaO}$ & 0.01 & BD & \\
\hline HLP-14 & $\mathrm{Cr}_{2} \mathrm{O}_{3}$ & 0.08 & 0.24 & 100.00 & HLP-17 & $\mathrm{Cr}_{2} \mathrm{O}_{3}$ & 0.07 & 0.23 & 106.67 \\
\hline HLP-14 & $\mathrm{Fe}_{2} \mathrm{O}_{3}$ & 5.67 & 6.31 & 10.68 & HLP-17 & $\mathrm{Fe}_{2} \mathrm{O}_{3}$ & 5.36 & 6.36 & 17.06 \\
\hline HLP-14 & $\mathrm{K}_{2} \mathrm{O}$ & 0.43 & 0.45 & 4.55 & HLP-17 & $\mathrm{K}_{2} \mathrm{O}$ & 0.40 & 0.36 & 10.53 \\
\hline HLP-14 & $\mathrm{La}_{2} \mathrm{O}_{3}$ & 0.00 & $\mathrm{BD}$ & & HLP-17 & $\mathrm{La}_{2} \mathrm{O}_{3}$ & 0.00 & 0.05 & 200.00 \\
\hline HLP-14 & $\mathrm{Li}_{2} \mathrm{O}$ & 0.00 & $\mathrm{BD}$ & & HLP-17 & $\mathrm{Li}_{2} \mathrm{O}$ & 0.00 & $\mathrm{BD}$ & \\
\hline HLP-14 & $\mathrm{MgO}$ & 1.55 & 1.53 & 1.30 & HLP-17 & $\mathrm{MgO}$ & 1.46 & 1.53 & 4.68 \\
\hline HLP-14 & $\mathrm{MoO}_{3}$ & 0.00 & & & HLP-17 & $\mathrm{MoO}_{3}$ & 0.00 & & \\
\hline HLP-14 & $\mathrm{Na}_{2} \mathrm{O}$ & 20.62 & 19.40 & 6.10 & HLP-17 & $\mathrm{Na}_{2} \mathrm{O}$ & 19.50 & 18.40 & 5.80 \\
\hline HLP-14 & $\mathrm{P}_{2} \mathrm{O}_{5}$ & 0.06 & & & HLP-17 & $\mathrm{P}_{2} \mathrm{O}_{5}$ & 0.05 & & \\
\hline HLP-14 & $\mathrm{SiO}_{2}$ & 50.59 & 47.30 & 6.72 & HLP-17 & $\mathrm{SiO}_{2}$ & 47.82 & 48.30 & 1.00 \\
\hline HLP-14 & $\mathrm{TiO}_{2}$ & 0.00 & $\mathrm{BD}$ & & HLP-17 & $\mathrm{TiO}_{2}$ & 2.92 & 3.00 & 2.70 \\
\hline HLP-14 & $\mathrm{ZnO}$ & 1.55 & 1.55 & 0.00 & HLP-17 & $\mathrm{ZnO}$ & 4.00 & 3.96 & 1.01 \\
\hline HLP-14 & $\mathrm{ZrO}_{2}$ & 1.55 & 1.43 & 8.05 & HLP-17 & $\mathrm{ZrO}_{2}$ & 1.46 & 1.30 & 11.59 \\
\hline HLP-14 & $\mathrm{Cl}$ & 0.29 & & & HLP-17 & $\mathrm{Cl}$ & 0.27 & & \\
\hline HLP-14 & $\mathrm{F}$ & 0.01 & & & HLP-17 & $\mathrm{F}$ & 0.01 & & \\
\hline HLP-14 & $\mathrm{SO}_{3}$ & 0.08 & & & HLP-17 & $\mathrm{SO}_{3}$ & 0.07 & & \\
\hline HLP-14 & TOTAL & 100.02 & 95.60 & 4.52 & HLP-17 & TOTAL & 99.98 & 100.19 & 0.21 \\
\hline HLP-15 & $\mathrm{Al}_{2} \mathrm{O}_{3}$ & 6.78 & 6.52 & 3.91 & HLP-18 & $\mathrm{Al}_{2} \mathrm{O}_{3}$ & 7.10 & 7.45 & 4.81 \\
\hline HLP-15 & $\mathrm{B}_{2} \mathrm{O}_{3}$ & 9.69 & 9.72 & 0.31 & HLP-18 & $\mathrm{B}_{2} \mathrm{O}_{3}$ & 10.15 & 10.20 & 0.49 \\
\hline HLP-15 & $\mathrm{CaO}$ & 0.01 & 0.07 & 150.00 & HLP-18 & $\mathrm{CaO}$ & 0.01 & $\mathrm{BD}$ & \\
\hline HLP-15 & $\mathrm{Cr}_{2} \mathrm{O}_{3}$ & 0.07 & 0.26 & 115.15 & HLP-18 & $\mathrm{Cr}_{2} \mathrm{O}_{3}$ & 0.08 & 0.26 & 105.88 \\
\hline HLP-15 & $\mathrm{Fe}_{2} \mathrm{O}_{3}$ & 5.33 & 6.69 & 22.63 & HLP-18 & $\mathrm{Fe}_{2} \mathrm{O}_{3}$ & 5.59 & 6.22 & 10.67 \\
\hline HLP-15 & $\mathrm{K}_{2} \mathrm{O}$ & 0.40 & 0.38 & 5.13 & HLP-18 & $\mathrm{K}_{2} \mathrm{O}$ & 0.42 & 0.43 & 2.35 \\
\hline HLP-15 & $\mathrm{La}_{2} \mathrm{O}_{3}$ & 0.00 & $\mathrm{BD}$ & & HLP-18 & $\mathrm{La}_{2} \mathrm{O}_{3}$ & 0.00 & $\mathrm{BD}$ & \\
\hline HLP-15 & $\mathrm{Li}_{2} \mathrm{O}$ & 0.00 & $\mathrm{BD}$ & & HLP-18 & $\mathrm{Li}_{2} \mathrm{O}$ & 0.00 & $\mathrm{BD}$ & \\
\hline HLP-15 & $\mathrm{MgO}$ & 1.45 & 1.54 & 6.02 & HLP-18 & $\mathrm{MgO}$ & 1.52 & 1.54 & 1.31 \\
\hline HLP-15 & $\mathrm{MoO}_{3}$ & 0.00 & & & HLP-18 & $\mathrm{MoO}_{3}$ & 0.00 & & \\
\hline HLP-15 & $\mathrm{Na}_{2} \mathrm{O}$ & 19.39 & 18.60 & 4.16 & HLP-18 & $\mathrm{Na}_{2} \mathrm{O}$ & 20.31 & 19.20 & 5.62 \\
\hline HLP-15 & $\mathrm{P}_{2} \mathrm{O}_{5}$ & 0.05 & & & HLP-18 & $\mathrm{P}_{2} \mathrm{O}_{5}$ & 0.06 & & \\
\hline HLP-15 & $\mathrm{SiO}_{2}$ & 47.55 & 47.80 & 0.52 & HLP-18 & $\mathrm{SiO}_{2}$ & 49.82 & 46.20 & 7.54 \\
\hline HLP-15 & $\mathrm{TiO}_{2}$ & 6.00 & 5.91 & 1.51 & HLP-18 & $\mathrm{TiO}_{2}$ & 3.04 & 3.18 & 4.50 \\
\hline HLP-15 & $\mathrm{ZnO}$ & 1.45 & 1.51 & 4.05 & HLP-18 & $\mathrm{ZnO}$ & 1.52 & 1.54 & 1.31 \\
\hline HLP-15 & $\mathrm{ZrO}_{2}$ & 1.45 & 1.06 & 31.08 & HLP-18 & $\mathrm{ZrO}_{2}$ & 0.00 & $\mathrm{BD}$ & \\
\hline HLP-15 & $\mathrm{Cl}$ & 0.27 & & & HLP-18 & $\mathrm{Cl}$ & 0.28 & & \\
\hline HLP-15 & $\mathrm{F}$ & 0.01 & & & HLP-18 & $\mathrm{F}$ & 0.01 & & \\
\hline HLP-15 & $\mathrm{SO}_{3}$ & 0.07 & & & HLP-18 & $\mathrm{SO}_{3}$ & 0.07 & & \\
\hline HLP-15 & TOTAL & 99.98 & 100.06 & 0.08 & HLP-18 & TOTAL & 99.99 & 96.22 & 3.84 \\
\hline
\end{tabular}




\begin{tabular}{|c|c|c|c|c|c|c|c|c|c|}
\hline Glass ID & $\begin{array}{c}\text { Oxide/ } \\
\text { Anion } \\
\end{array}$ & $\begin{array}{c}\text { Targeted } \\
\text { Comp. }\end{array}$ & $\begin{array}{l}\text { Meas. } \\
\text { Comp. }\end{array}$ & $\begin{array}{c}\% \% \\
\text { Diff. } \\
\end{array}$ & Glass ID & $\begin{array}{c}\text { Oxide/ } \\
\text { Anion } \\
\end{array}$ & $\begin{array}{c}\text { Targeted } \\
\text { Comp. } \\
\end{array}$ & $\begin{array}{l}\text { Meas. } \\
\text { Comp. } \\
\end{array}$ & $\begin{array}{c}\% \\
\text { Diff. }\end{array}$ \\
\hline HLP-19 & $\mathrm{Al}_{2} \mathrm{O}_{3}$ & 6.68 & 6.94 & 3.82 & HLP-22 & $\mathrm{Al}_{2} \mathrm{O}_{3}$ & 7.37 & 7.67 & 3.99 \\
\hline HLP-19 & $\mathrm{B}_{2} \mathrm{O}_{3}$ & 9.55 & 9.63 & 0.83 & HLP-22 & $\mathrm{B}_{2} \mathrm{O}_{3}$ & 10.53 & 11.00 & 4.37 \\
\hline HLP-19 & $\mathrm{CaO}$ & 0.01 & $\mathrm{BD}$ & & HLP-22 & $\mathrm{CaO}$ & 0.01 & $\mathrm{BD}$ & \\
\hline HLP-19 & $\mathrm{Cr}_{2} \mathrm{O}_{3}$ & 0.07 & 0.25 & 112.50 & HLP-22 & $\mathrm{Cr}_{2} \mathrm{O}_{3}$ & 0.06 & 0.27 & 127.27 \\
\hline HLP-19 & $\mathrm{Fe}_{2} \mathrm{O}_{3}$ & 5.25 & 6.40 & 19.74 & HLP-22 & $\mathrm{Fe}_{2} \mathrm{O}_{3}$ & 5.79 & 7.02 & 19.20 \\
\hline HLP-19 & $\mathrm{K}_{2} \mathrm{O}$ & 0.39 & 0.43 & 9.76 & HLP-22 & $\mathrm{K}_{2} \mathrm{O}$ & 0.33 & 0.30 & 9.52 \\
\hline HLP-19 & $\mathrm{La}_{2} \mathrm{O}_{3}$ & 0.00 & $\mathrm{BD}$ & & HLP-22 & $\mathrm{La}_{2} \mathrm{O}_{3}$ & 0.00 & $\mathrm{BD}$ & \\
\hline HLP-19 & $\mathrm{Li}_{2} \mathrm{O}$ & 0.00 & $\mathrm{BD}$ & & HLP-22 & $\mathrm{Li}_{2} \mathrm{O}$ & 0.00 & $\mathrm{BD}$ & \\
\hline HLP-19 & $\mathrm{MgO}$ & 1.43 & 1.47 & 2.76 & HLP-22 & $\mathrm{MgO}$ & 1.58 & 1.66 & 4.94 \\
\hline HLP-19 & $\mathrm{MoO}_{3}$ & 0.00 & & & HLP-22 & $\mathrm{MoO}_{3}$ & 0.00 & & \\
\hline HLP-19 & $\mathrm{Na}_{2} \mathrm{O}$ & 19.09 & 17.80 & 6.99 & HLP-22 & $\mathrm{Na}_{2} \mathrm{O}$ & 16.00 & 15.40 & 3.82 \\
\hline HLP-19 & $\mathrm{P}_{2} \mathrm{O}_{5}$ & 0.05 & & & HLP-22 & $\mathrm{P}_{2} \mathrm{O}_{5}$ & 0.04 & & \\
\hline HLP-19 & $\mathrm{SiO}_{2}$ & 46.83 & 48.20 & 2.88 & HLP-22 & $\mathrm{SiO}_{2}$ & 51.67 & 53.30 & 3.11 \\
\hline HLP-19 & $\mathrm{TiO}_{2}$ & 2.86 & 2.98 & 4.11 & HLP-22 & $\mathrm{TiO}_{2}$ & 3.16 & 3.27 & 3.42 \\
\hline HLP-19 & $\mathrm{ZnO}$ & 1.43 & 1.50 & 4.78 & HLP-22 & $\mathrm{ZnO}$ & 1.58 & 1.65 & 4.33 \\
\hline HLP-19 & $\mathrm{ZrO}_{2}$ & 6.00 & 5.64 & 6.19 & HLP-22 & $\mathrm{ZrO}_{2}$ & 1.58 & 1.26 & 22.54 \\
\hline HLP-19 & $\mathrm{Cl}$ & 0.26 & & & HLP-22 & $\mathrm{Cl}$ & 0.22 & & \\
\hline HLP-19 & $\mathrm{F}$ & 0.01 & & & HLP-22 & $\mathrm{F}$ & 0.01 & & \\
\hline HLP-19 & $\mathrm{SO}_{3}$ & 0.07 & & & HLP-22 & $\mathrm{SO}_{3}$ & 0.06 & & \\
\hline HLP-19 & TOTAL & 99.99 & 101.24 & 1.24 & HLP-22 & TOTAL & 100.00 & 102.80 & 2.76 \\
\hline HLP-20 & $\mathrm{Al}_{2} \mathrm{O}_{3}$ & 7.10 & 7.19 & 1.26 & HLP-23 & $\mathrm{Al}_{2} \mathrm{O}_{3}$ & 6.72 & 6.92 & 2.93 \\
\hline HLP-20 & $\mathrm{B}_{2} \mathrm{O}_{3}$ & 10.15 & 10.10 & 0.49 & HLP-23 & $\mathrm{B}_{2} \mathrm{O}_{3}$ & 9.61 & 9.65 & 0.42 \\
\hline HLP-20 & $\mathrm{CaO}$ & 0.01 & BD & & HLP-23 & $\mathrm{CaO}$ & 0.01 & BD & \\
\hline HLP-20 & $\mathrm{Cr}_{2} \mathrm{O}_{3}$ & 0.08 & 0.26 & 105.88 & HLP-23 & $\mathrm{Cr}_{2} \mathrm{O}_{3}$ & 0.09 & 0.27 & 100.00 \\
\hline HLP-20 & $\mathrm{Fe}_{2} \mathrm{O}_{3}$ & 5.59 & 6.26 & 11.31 & HLP-23 & $\mathrm{Fe}_{2} \mathrm{O}_{3}$ & 5.29 & 5.91 & 11.07 \\
\hline HLP-20 & $\mathrm{K}_{2} \mathrm{O}$ & 0.42 & 0.40 & 4.88 & HLP-23 & $\mathrm{K}_{2} \mathrm{O}$ & 0.47 & 0.42 & 11.24 \\
\hline HLP-20 & $\mathrm{La}_{2} \mathrm{O}_{3}$ & 0.00 & $\mathrm{BD}$ & & HLP-23 & $\mathrm{La}_{2} \mathrm{O}_{3}$ & 0.00 & $\mathrm{BD}$ & \\
\hline HLP-20 & $\mathrm{Li}_{2} \mathrm{O}$ & 0.00 & $\mathrm{BD}$ & & HLP-23 & $\mathrm{Li}_{2} \mathrm{O}$ & 0.00 & $\mathrm{BD}$ & \\
\hline HLP-20 & $\mathrm{MgO}$ & 0.00 & $\mathrm{BD}$ & & HLP-23 & $\mathrm{MgO}$ & 1.44 & 1.47 & 2.06 \\
\hline HLP-20 & $\mathrm{MoO}_{3}$ & 0.00 & & & HLP-23 & $\mathrm{MoO}_{3}$ & 0.00 & & \\
\hline HLP-20 & $\mathrm{Na}_{2} \mathrm{O}$ & 20.31 & 19.30 & 5.10 & HLP-23 & $\mathrm{Na}_{2} \mathrm{O}$ & 23.00 & 21.50 & 6.74 \\
\hline HLP-20 & $\mathrm{P}_{2} \mathrm{O}_{5}$ & 0.06 & & & HLP-23 & $\mathrm{P}_{2} \mathrm{O}_{5}$ & 0.06 & & \\
\hline HLP-20 & $\mathrm{SiO}_{2}$ & 49.82 & 49.30 & 1.05 & HLP-23 & $\mathrm{SiO}_{2}$ & 47.13 & 44.10 & 6.64 \\
\hline HLP-20 & $\mathrm{TiO}_{2}$ & 3.04 & 3.20 & 5.13 & HLP-23 & $\mathrm{TiO}_{2}$ & 2.88 & 2.90 & 0.69 \\
\hline HLP-20 & $\mathrm{ZnO}$ & 1.52 & 1.60 & 5.13 & HLP-23 & $\mathrm{ZnO}$ & 1.44 & 1.47 & 2.06 \\
\hline HLP-20 & $\mathrm{ZrO}_{2}$ & 1.52 & 1.51 & 0.66 & HLP-23 & $\mathrm{ZrO}_{2}$ & 1.44 & 1.38 & 4.26 \\
\hline HLP-20 & $\mathrm{Cl}$ & 0.28 & & & HLP-23 & $\mathrm{Cl}$ & 0.32 & & \\
\hline HLP-20 & $\mathrm{F}$ & 0.01 & & & HLP-23 & $\mathrm{F}$ & 0.01 & & \\
\hline HLP-20 & $\mathrm{SO}_{3}$ & 0.07 & & & HLP-23 & $\mathrm{SO}_{3}$ & 0.08 & & \\
\hline HLP-20 & TOTAL & 99.99 & 99.12 & 0.87 & HLP-23 & TOTAL & 100.00 & 95.99 & 4.09 \\
\hline HLP-21 & $\mathrm{Al}_{2} \mathrm{O}_{3}$ & 6.82 & 6.89 & 1.02 & HLP-24 & $\mathrm{Al}_{2} \mathrm{O}_{3}$ & 7.18 & 7.44 & 3.56 \\
\hline HLP-21 & $\mathrm{B}_{2} \mathrm{O}_{3}$ & 9.75 & 10.20 & 4.51 & HLP-24 & $\mathrm{B}_{2} \mathrm{O}_{3}$ & 10.27 & 10.00 & 2.66 \\
\hline HLP-21 & $\mathrm{CaO}$ & 0.01 & $\mathrm{BD}$ & & HLP-24 & $\mathrm{CaO}$ & 0.01 & $\mathrm{BD}$ & \\
\hline HLP-21 & $\mathrm{Cr}_{2} \mathrm{O}_{3}$ & 0.07 & 0.25 & 112.50 & HLP-24 & $\mathrm{Cr}_{2} \mathrm{O}_{3}$ & 0.07 & 0.24 & 109.68 \\
\hline HLP-21 & $\mathrm{Fe}_{2} \mathrm{O}_{3}$ & 5.36 & 6.71 & 22.37 & HLP-24 & $\mathrm{Fe}_{2} \mathrm{O}_{3}$ & 5.65 & 6.59 & 15.36 \\
\hline HLP-21 & $\mathrm{K}_{2} \mathrm{O}$ & 0.40 & 0.37 & 7.79 & HLP-24 & $\mathrm{K}_{2} \mathrm{O}$ & 0.37 & 0.40 & 7.79 \\
\hline HLP-21 & $\mathrm{La}_{2} \mathrm{O}_{3}$ & 0.00 & $\mathrm{BD}$ & & HLP-24 & $\mathrm{La}_{2} \mathrm{O}_{3}$ & 0.00 & $\mathrm{BD}$ & \\
\hline HLP-21 & $\mathrm{Li}_{2} \mathrm{O}$ & 0.00 & $\mathrm{BD}$ & & HLP-24 & $\mathrm{Li}_{2} \mathrm{O}$ & 0.00 & $\mathrm{BD}$ & \\
\hline HLP-21 & $\mathrm{MgO}$ & 4.00 & 3.93 & 1.77 & HLP-24 & $\mathrm{MgO}$ & 1.54 & 1.63 & 5.68 \\
\hline HLP-21 & $\mathrm{MoO}_{3}$ & 0.00 & & & HLP-24 & $\mathrm{MoO}_{3}$ & 0.00 & & \\
\hline HLP-21 & $\mathrm{Na}_{2} \mathrm{O}$ & 19.50 & 18.30 & 6.35 & HLP-24 & $\mathrm{Na}_{2} \mathrm{O}$ & 18.00 & 17.20 & 4.55 \\
\hline HLP-21 & $\mathrm{P}_{2} \mathrm{O}_{5}$ & 0.05 & & & HLP-24 & $\mathrm{P}_{2} \mathrm{O}_{5}$ & 0.05 & & \\
\hline HLP-21 & $\mathrm{SiO}_{2}$ & 47.82 & 45.90 & 4.10 & HLP-24 & $\mathrm{SiO}_{2}$ & 50.37 & 48.90 & 2.96 \\
\hline HLP-21 & $\mathrm{TiO}_{2}$ & 2.92 & 3.03 & 3.70 & HLP-24 & $\mathrm{TiO}_{2}$ & 3.08 & 3.24 & 5.06 \\
\hline HLP-21 & $\mathrm{ZnO}$ & 1.46 & 1.68 & 14.01 & HLP-24 & $\mathrm{ZnO}$ & 1.54 & 1.60 & 3.82 \\
\hline HLP-21 & $\mathrm{ZrO}_{2}$ & 1.46 & 1.34 & 8.57 & HLP-24 & $\mathrm{ZrO}_{2}$ & 1.54 & 1.51 & 1.97 \\
\hline HLP-21 & $\mathrm{Cl}$ & 0.27 & & & HLP-24 & $\mathrm{Cl}$ & 0.25 & & \\
\hline HLP-21 & $\mathrm{F}$ & 0.01 & & & HLP-24 & $\mathrm{F}$ & 0.01 & & \\
\hline HLP-21 & $\mathrm{SO}_{3}$ & 0.07 & & & HLP-24 & $\mathrm{SO}_{3}$ & 0.07 & & \\
\hline HLP-21 & TOTAL & 99.98 & 98.60 & 1.39 & HLP-24 & TOTAL & 100.01 & 98.75 & 1.27 \\
\hline
\end{tabular}




\begin{tabular}{|c|c|c|c|c|c|c|c|c|c|}
\hline Glass ID & $\begin{array}{c}\text { Oxide/ } \\
\text { Anion } \\
\end{array}$ & $\begin{array}{c}\text { Targeted } \\
\text { Comp. }\end{array}$ & $\begin{array}{l}\text { Meas. } \\
\text { Comp. }\end{array}$ & $\begin{array}{c}\% \\
\text { Diff. } \\
\end{array}$ & Glass ID & $\begin{array}{c}\text { Oxide/ } \\
\text { Anion } \\
\end{array}$ & $\begin{array}{c}\text { Targeted } \\
\text { Comp. }\end{array}$ & $\begin{array}{l}\text { Meas. } \\
\text { Comp. } \\
\end{array}$ & $\begin{array}{c}\% \\
\text { Diff. }\end{array}$ \\
\hline HLP-25 & $\mathrm{Al}_{2} \mathrm{O}_{3}$ & 7.00 & 6.76 & 3.49 & HLP-28 & $\mathrm{Al}_{2} \mathrm{O}_{3}$ & 11.94 & 12.10 & 1.33 \\
\hline HLP-25 & $\mathrm{B}_{2} \mathrm{O}_{3}$ & 10.00 & 10.10 & 1.00 & HLP-28 & $\mathrm{B}_{2} \mathrm{O}_{3}$ & 12.00 & 13.00 & 8.00 \\
\hline HLP-25 & $\mathrm{CaO}$ & 0.01 & 0.01 & 0.00 & HLP-28 & $\mathrm{CaO}$ & 0.01 & $\mathrm{BD}$ & \\
\hline HLP-25 & $\mathrm{Cr}_{2} \mathrm{O}_{3}$ & 0.08 & 0.21 & 89.66 & HLP-28 & $\mathrm{Cr}_{2} \mathrm{O}_{3}$ & 0.06 & 0.22 & 114.29 \\
\hline HLP-25 & $\mathrm{Fe}_{2} \mathrm{O}_{3}$ & 5.50 & 6.27 & 13.08 & HLP-28 & $\mathrm{Fe}_{2} \mathrm{O}_{3}$ & 3.10 & 3.82 & 20.81 \\
\hline HLP-25 & $\mathrm{K}_{2} \mathrm{O}$ & 0.41 & 0.41 & 0.00 & HLP-28 & $\mathrm{K}_{2} \mathrm{O}$ & 0.33 & & \\
\hline HLP-25 & $\mathrm{La}_{2} \mathrm{O}_{3}$ & 0.00 & 0.02 & 200.00 & HLP-28 & $\mathrm{La}_{2} \mathrm{O}_{3}$ & 0.00 & $\mathrm{BD}$ & \\
\hline HLP-25 & $\mathrm{Li}_{2} \mathrm{O}$ & 0.00 & $\mathrm{BD}$ & & HLP-28 & $\mathrm{Li}_{2} \mathrm{O}$ & 0.00 & $\mathrm{BD}$ & \\
\hline HLP-25 & $\mathrm{MgO}$ & 1.50 & 1.54 & 2.63 & HLP-28 & $\mathrm{MgO}$ & 0.84 & 0.80 & 4.88 \\
\hline HLP-25 & $\mathrm{MoO}_{3}$ & 0.00 & & & HLP-28 & $\mathrm{MoO}_{3}$ & 0.00 & & \\
\hline HLP-25 & $\mathrm{Na}_{2} \mathrm{O}$ & 20.00 & 18.50 & 7.79 & HLP-28 & $\mathrm{Na}_{2} \mathrm{O}$ & 16.00 & 15.10 & 5.79 \\
\hline HLP-25 & $\mathrm{P}_{2} \mathrm{O}_{5}$ & 0.06 & & & HLP-28 & $\mathrm{P}_{2} \mathrm{O}_{5}$ & 0.04 & & \\
\hline HLP-25 & $\mathrm{SiO}_{2}$ & 49.07 & 47.20 & 3.88 & HLP-28 & $\mathrm{SiO}_{2}$ & 52.00 & 51.80 & 0.39 \\
\hline HLP-25 & $\mathrm{TiO}_{2}$ & 3.00 & 2.66 & 12.01 & HLP-28 & $\mathrm{TiO}_{2}$ & 1.69 & 1.74 & 2.92 \\
\hline HLP-25 & $\mathrm{ZnO}$ & 1.50 & 1.49 & 0.67 & HLP-28 & $\mathrm{ZnO}$ & 0.84 & 0.92 & 9.09 \\
\hline HLP-25 & $\mathrm{ZrO}_{2}$ & 1.50 & 1.48 & 1.34 & HLP-28 & $\mathrm{ZrO}_{2}$ & 0.84 & 0.75 & 11.32 \\
\hline HLP-25 & $\mathrm{Cl}$ & 0.28 & & & HLP-28 & $\mathrm{Cl}$ & 0.22 & & \\
\hline HLP-25 & $\mathrm{F}$ & 0.01 & & & HLP-28 & $\mathrm{F}$ & 0.01 & & \\
\hline HLP-25 & $\mathrm{SO}_{3}$ & 0.07 & & & HLP-28 & $\mathrm{SO}_{3}$ & 0.06 & & \\
\hline HLP-25 & TOTAL & 100.00 & 96.65 & 3.41 & HLP-28 & TOTAL & 99.99 & 100.25 & 0.26 \\
\hline HLP-26 & $\mathrm{Al}_{2} \mathrm{O}_{3}$ & 7.00 & 6.68 & 4.68 & HLP-29 & $\mathrm{Al}_{2} \mathrm{O}_{3}$ & 11.94 & 11.80 & 1.18 \\
\hline HLP-26 & $\mathrm{B}_{2} \mathrm{O}_{3}$ & 10.00 & 9.43 & 5.87 & HLP-29 & $\mathrm{B}_{2} \mathrm{O}_{3}$ & 6.00 & 6.51 & 8.15 \\
\hline HLP-26 & $\mathrm{CaO}$ & 0.01 & $\mathrm{BD}$ & & HLP-29 & $\mathrm{CaO}$ & 0.01 & BD & \\
\hline HLP-26 & $\mathrm{Cr}_{2} \mathrm{O}_{3}$ & 0.08 & 0.21 & 89.66 & HLP-29 & $\mathrm{Cr}_{2} \mathrm{O}_{3}$ & 0.09 & 0.25 & 94.12 \\
\hline HLP-26 & $\mathrm{Fe}_{2} \mathrm{O}_{3}$ & 5.50 & 5.97 & 8.20 & HLP-29 & $\mathrm{Fe}_{2} \mathrm{O}_{3}$ & 2.54 & 3.12 & 20.49 \\
\hline HLP-26 & $\mathrm{K}_{2} \mathrm{O}$ & 0.41 & 0.43 & 4.76 & HLP-29 & $\mathrm{K}_{2} \mathrm{O}$ & 0.47 & 0.42 & 11.24 \\
\hline HLP-26 & $\mathrm{La}_{2} \mathrm{O}_{3}$ & 0.00 & $\mathrm{BD}$ & & HLP-29 & $\mathrm{La}_{2} \mathrm{O}_{3}$ & 0.00 & $\mathrm{BD}$ & \\
\hline HLP-26 & $\mathrm{Li}_{2} \mathrm{O}$ & 0.00 & $\mathrm{BD}$ & & HLP-29 & $\mathrm{Li}_{2} \mathrm{O}$ & 0.00 & $\mathrm{BD}$ & \\
\hline HLP-26 & $\mathrm{MgO}$ & 1.50 & 1.45 & 3.39 & HLP-29 & $\mathrm{MgO}$ & 0.69 & 0.69 & 0.00 \\
\hline HLP-26 & $\mathrm{MoO}_{3}$ & 0.00 & & & HLP-29 & $\mathrm{MoO}_{3}$ & 0.00 & & \\
\hline HLP-26 & $\mathrm{Na}_{2} \mathrm{O}$ & 20.00 & 18.20 & 9.42 & HLP-29 & $\mathrm{Na}_{2} \mathrm{O}$ & 23.00 & 21.50 & 6.74 \\
\hline HLP-26 & $\mathrm{P}_{2} \mathrm{O}_{5}$ & 0.06 & & & HLP-29 & $\mathrm{P}_{2} \mathrm{O}_{5}$ & 0.06 & & \\
\hline HLP-26 & $\mathrm{SiO}_{2}$ & 49.07 & 46.80 & 4.74 & HLP-29 & $\mathrm{SiO}_{2}$ & 52.00 & 49.50 & 4.93 \\
\hline HLP-26 & $\mathrm{TiO}_{2}$ & 3.00 & 2.86 & 4.78 & HLP-29 & $\mathrm{TiO}_{2}$ & 1.38 & 1.41 & 2.15 \\
\hline HLP-26 & $\mathrm{ZnO}$ & 1.50 & 1.40 & 6.90 & HLP-29 & $\mathrm{ZnO}$ & 0.69 & 0.73 & 5.63 \\
\hline HLP-26 & $\mathrm{ZrO}_{2}$ & 1.50 & 1.50 & 0.00 & HLP-29 & $\mathrm{ZrO}_{2}$ & 0.69 & 0.64 & 7.52 \\
\hline HLP-26 & $\mathrm{Cl}$ & 0.28 & & & HLP-29 & $\mathrm{Cl}$ & 0.32 & & \\
\hline HLP-26 & $\mathrm{F}$ & 0.01 & & & HLP-29 & $\mathrm{F}$ & 0.01 & & \\
\hline HLP-26 & $\mathrm{SO}_{3}$ & 0.07 & & & HLP-29 & $\mathrm{SO}_{3}$ & 0.08 & & \\
\hline HLP-26 & TOTAL & 100.00 & 94.93 & 5.20 & HLP-29 & TOTAL & 99.98 & 96.57 & 3.47 \\
\hline HLP-27 & $\mathrm{Al}_{2} \mathrm{O}_{3}$ & 11.94 & 12.00 & 0.50 & HLP-30 & $\mathrm{Al}_{2} \mathrm{O}_{3}$ & 11.94 & 12.20 & 2.15 \\
\hline HLP-27 & $\mathrm{B}_{2} \mathrm{O}_{3}$ & 12.00 & 12.30 & 2.47 & HLP-30 & $\mathrm{B}_{2} \mathrm{O}_{3}$ & 6.00 & 6.56 & 8.92 \\
\hline HLP-27 & $\mathrm{CaO}$ & 0.01 & $\mathrm{BD}$ & & HLP-30 & $\mathrm{CaO}$ & 0.01 & $\mathrm{BD}$ & \\
\hline HLP-27 & $\mathrm{Cr}_{2} \mathrm{O}_{3}$ & 0.09 & 0.26 & 97.14 & HLP-30 & $\mathrm{Cr}_{2} \mathrm{O}_{3}$ & 0.06 & 0.23 & 117.24 \\
\hline HLP-27 & $\mathrm{Fe}_{2} \mathrm{O}_{3}$ & 0.00 & 0.60 & 200.00 & HLP-30 & $\mathrm{Fe}_{2} \mathrm{O}_{3}$ & 5.64 & 6.38 & 12.31 \\
\hline HLP-27 & $\mathrm{K}_{2} \mathrm{O}$ & 0.47 & 0.44 & 6.59 & HLP-30 & $\mathrm{K}_{2} \mathrm{O}$ & 0.33 & 0.29 & 12.90 \\
\hline HLP-27 & $\mathrm{La}_{2} \mathrm{O}_{3}$ & 0.00 & $\mathrm{BD}$ & & HLP-30 & $\mathrm{La}_{2} \mathrm{O}_{3}$ & 0.00 & $\mathrm{BD}$ & \\
\hline HLP-27 & $\mathrm{Li}_{2} \mathrm{O}$ & 0.00 & $\mathrm{BD}$ & & HLP-30 & $\mathrm{Li}_{2} \mathrm{O}$ & 0.00 & $\mathrm{BD}$ & \\
\hline HLP-27 & $\mathrm{MgO}$ & 0.00 & $\mathrm{BD}$ & & HLP-30 & $\mathrm{MgO}$ & 1.54 & 1.50 & 2.63 \\
\hline HLP-27 & $\mathrm{MoO}_{3}$ & 0.00 & & & HLP-30 & $\mathrm{MoO}_{3}$ & 0.00 & & \\
\hline HLP-27 & $\mathrm{Na}_{2} \mathrm{O}$ & 23.00 & 21.70 & 5.82 & HLP-30 & $\mathrm{Na}_{2} \mathrm{O}$ & 16.00 & 15.40 & 3.82 \\
\hline HLP-27 & $\mathrm{P}_{2} \mathrm{O}_{5}$ & 0.06 & & & HLP-30 & $\mathrm{P}_{2} \mathrm{O}_{5}$ & 0.04 & & \\
\hline HLP-27 & $\mathrm{SiO}_{2}$ & 52.00 & 50.40 & 3.13 & HLP-30 & $\mathrm{SiO}_{2}$ & 52.00 & 47.30 & 9.47 \\
\hline HLP-27 & $\mathrm{TiO}_{2}$ & 0.00 & $\mathrm{BD}$ & & HLP-30 & $\mathrm{TiO}_{2}$ & 3.07 & 3.20 & 4.15 \\
\hline HLP-27 & $\mathrm{ZnO}$ & 0.00 & $\mathrm{BD}$ & & HLP-30 & $\mathrm{ZnO}$ & 1.54 & 1.55 & 0.65 \\
\hline HLP-27 & $\mathrm{ZrO}_{2}$ & 0.00 & $\mathrm{BD}$ & & HLP-30 & $\mathrm{ZrO}_{2}$ & 1.54 & 1.43 & 7.41 \\
\hline HLP-27 & $\mathrm{Cl}$ & 0.32 & & & HLP-30 & $\mathrm{Cl}$ & 0.22 & & \\
\hline HLP-27 & $\mathrm{F}$ & 0.01 & & & HLP-30 & $\mathrm{F}$ & 0.01 & & \\
\hline HLP-27 & $\mathrm{SO}_{3}$ & 0.08 & & & HLP-30 & $\mathrm{SO}_{3}$ & 0.06 & & \\
\hline HLP-27 & TOTAL & 99.99 & 97.70 & 2.32 & HLP-30 & TOTAL & 100.01 & 96.04 & 4.05 \\
\hline
\end{tabular}




\begin{tabular}{|c|c|c|c|c|c|c|c|c|c|}
\hline Glass ID & $\begin{array}{c}\text { Oxide/ } \\
\text { Anion } \\
\end{array}$ & $\begin{array}{c}\text { Targeted } \\
\text { Comp. }\end{array}$ & $\begin{array}{l}\text { Meas. } \\
\text { Comp. }\end{array}$ & $\begin{array}{c}\% \% \\
\text { Diff. } \\
\end{array}$ & Glass ID & $\begin{array}{c}\text { Oxide/ } \\
\text { Anion } \\
\end{array}$ & $\begin{array}{c}\text { Targeted } \\
\text { Comp. }\end{array}$ & $\begin{array}{l}\text { Meas. } \\
\text { Comp. }\end{array}$ & $\begin{array}{c}\% \\
\text { Diff. }\end{array}$ \\
\hline HLP-31 & $\mathrm{Al}_{2} \mathrm{O}_{3}$ & 4.00 & 4.20 & 4.88 & HLP-34 & $\mathrm{Al}_{2} \mathrm{O}_{3}$ & 4.00 & 3.97 & 0.75 \\
\hline HLP-31 & $\mathrm{B}_{2} \mathrm{O}_{3}$ & 12.00 & 12.30 & 2.47 & HLP-34 & $\mathrm{B}_{2} \mathrm{O}_{3}$ & 6.00 & 6.24 & 3.92 \\
\hline HLP-31 & $\mathrm{CaO}$ & 0.01 & BD & & HLP-34 & $\mathrm{CaO}$ & 0.01 & $\mathrm{BD}$ & \\
\hline HLP-31 & $\mathrm{Cr}_{2} \mathrm{O}_{3}$ & 0.09 & 0.24 & 90.91 & HLP-34 & $\mathrm{Cr}_{2} \mathrm{O}_{3}$ & 0.06 & 0.20 & 107.69 \\
\hline HLP-31 & $\mathrm{Fe}_{2} \mathrm{O}_{3}$ & 3.36 & 4.30 & 24.54 & HLP-34 & $\mathrm{Fe}_{2} \mathrm{O}_{3}$ & 9.00 & 10.20 & 12.50 \\
\hline HLP-31 & $\mathrm{K}_{2} \mathrm{O}$ & 0.47 & 0.40 & 16.09 & HLP-34 & $\mathrm{K}_{2} \mathrm{O}$ & 0.33 & 0.30 & 9.52 \\
\hline HLP-31 & $\mathrm{La}_{2} \mathrm{O}_{3}$ & 0.00 & $\mathrm{BD}$ & & HLP-34 & $\mathrm{La}_{2} \mathrm{O}_{3}$ & 0.00 & $\mathrm{BD}$ & \\
\hline HLP-31 & $\mathrm{Li}_{2} \mathrm{O}$ & 0.00 & $\mathrm{BD}$ & & HLP-34 & $\mathrm{Li}_{2} \mathrm{O}$ & 0.00 & $\mathrm{BD}$ & \\
\hline HLP-31 & $\mathrm{MgO}$ & 0.92 & 0.84 & 9.09 & HLP-34 & $\mathrm{MgO}$ & 2.45 & 2.10 & 15.38 \\
\hline HLP-31 & $\mathrm{MoO}_{3}$ & 0.00 & & & HLP-34 & $\mathrm{MoO}_{3}$ & 0.00 & & \\
\hline HLP-31 & $\mathrm{Na}_{2} \mathrm{O}$ & 23.00 & 22.00 & 4.44 & HLP-34 & $\mathrm{Na}_{2} \mathrm{O}$ & 16.00 & 14.30 & 11.22 \\
\hline HLP-31 & $\mathrm{P}_{2} \mathrm{O}_{5}$ & 0.06 & & & HLP-34 & $\mathrm{P}_{2} \mathrm{O}_{5}$ & 0.04 & & \\
\hline HLP-31 & $\mathrm{SiO}_{2}$ & 52.00 & 48.90 & 6.14 & HLP-34 & $\mathrm{SiO}_{2}$ & 52.00 & 51.00 & 1.94 \\
\hline HLP-31 & $\mathrm{TiO}_{2}$ & 1.83 & 1.78 & 2.77 & HLP-34 & $\mathrm{TiO}_{2}$ & 4.90 & 4.70 & 4.17 \\
\hline HLP-31 & $\mathrm{ZnO}$ & 0.92 & 0.94 & 2.15 & HLP-34 & $\mathrm{ZnO}$ & 2.45 & 2.32 & 5.45 \\
\hline HLP-31 & $\mathrm{ZrO}_{2}$ & 0.92 & 0.70 & 27.16 & HLP-34 & $\mathrm{ZrO}_{2}$ & 2.45 & 2.00 & 20.22 \\
\hline HLP-31 & $\mathrm{Cl}$ & 0.32 & & & HLP-34 & $\mathrm{Cl}$ & 0.22 & & \\
\hline HLP-31 & $\mathrm{F}$ & 0.01 & & & HLP-34 & $\mathrm{F}$ & 0.01 & & \\
\hline HLP-31 & $\mathrm{SO}_{3}$ & 0.08 & & & HLP-34 & $\mathrm{SO}_{3}$ & 0.06 & & \\
\hline HLP-31 & TOTAL & 100.00 & 96.60 & 3.46 & HLP-34 & TOTAL & 99.99 & 97.33 & 2.70 \\
\hline HLP-32 & $\mathrm{Al}_{2} \mathrm{O}_{3}$ & 4.00 & 4.21 & 5.12 & HLP-35 & $\mathrm{Al}_{2} \mathrm{O}_{3}$ & 11.94 & 11.50 & 3.75 \\
\hline HLP-32 & $\mathrm{B}_{2} \mathrm{O}_{3}$ & 12.00 & 12.90 & 7.23 & HLP-35 & $\mathrm{B}_{2} \mathrm{O}_{3}$ & 12.00 & 12.10 & 0.83 \\
\hline HLP-32 & $\mathrm{CaO}$ & 0.01 & BD & & HLP-35 & $\mathrm{CaO}$ & 0.01 & $\mathrm{BD}$ & \\
\hline HLP-32 & $\mathrm{Cr}_{2} \mathrm{O}_{3}$ & 0.06 & 0.25 & 122.58 & HLP-35 & $\mathrm{Cr}_{2} \mathrm{O}_{3}$ & 0.09 & 0.22 & 83.87 \\
\hline HLP-32 & $\mathrm{Fe}_{2} \mathrm{O}_{3}$ & 6.46 & 7.05 & 8.73 & HLP-35 & $\mathrm{Fe}_{2} \mathrm{O}_{3}$ & 6.77 & 7.47 & 9.83 \\
\hline HLP-32 & $\mathrm{K}_{2} \mathrm{O}$ & 0.33 & 0.31 & 6.25 & HLP-35 & $\mathrm{K}_{2} \mathrm{O}$ & 0.47 & 0.50 & 6.19 \\
\hline HLP-32 & $\mathrm{La}_{2} \mathrm{O}_{3}$ & 0.00 & $\mathrm{BD}$ & & HLP-35 & $\mathrm{La}_{2} \mathrm{O}_{3}$ & 0.00 & $\mathrm{BD}$ & \\
\hline HLP-32 & $\mathrm{Li}_{2} \mathrm{O}$ & 0.00 & $\mathrm{BD}$ & & HLP-35 & $\mathrm{Li}_{2} \mathrm{O}$ & 0.00 & $\mathrm{BD}$ & \\
\hline HLP-32 & $\mathrm{MgO}$ & 1.76 & 1.66 & 5.85 & HLP-35 & $\mathrm{MgO}$ & 1.85 & 1.68 & 9.63 \\
\hline HLP-32 & $\mathrm{MoO}_{3}$ & 0.00 & & & HLP-35 & $\mathrm{MoO}_{3}$ & 0.00 & & \\
\hline HLP-32 & $\mathrm{Na}_{2} \mathrm{O}$ & 16.00 & 15.70 & 1.89 & HLP-35 & $\mathrm{Na}_{2} \mathrm{O}$ & 23.00 & 21.60 & 6.28 \\
\hline HLP-32 & $\mathrm{P}_{2} \mathrm{O}_{5}$ & 0.04 & & & HLP-35 & $\mathrm{P}_{2} \mathrm{O}_{5}$ & 0.06 & & \\
\hline HLP-32 & $\mathrm{SiO}_{2}$ & 52.00 & 46.00 & 12.24 & HLP-35 & $\mathrm{SiO}_{2}$ & 36.00 & 36.00 & 0.00 \\
\hline HLP-32 & $\mathrm{TiO}_{2}$ & 3.52 & 3.57 & 1.41 & HLP-35 & $\mathrm{TiO}_{2}$ & 3.69 & 3.61 & 2.19 \\
\hline HLP-32 & $\mathrm{ZnO}$ & 1.76 & 1.86 & 5.52 & HLP-35 & $\mathrm{ZnO}$ & 1.85 & 1.83 & 1.09 \\
\hline HLP-32 & $\mathrm{ZrO}_{2}$ & 1.76 & 1.60 & 9.52 & HLP-35 & $\mathrm{ZrO}_{2}$ & 1.85 & 1.73 & 6.70 \\
\hline HLP-32 & $\mathrm{Cl}$ & 0.22 & & & HLP-35 & $\mathrm{Cl}$ & 0.32 & & \\
\hline HLP-32 & $\mathrm{F}$ & 0.01 & & & HLP-35 & $\mathrm{F}$ & 0.01 & & \\
\hline HLP-32 & $\mathrm{SO}_{3}$ & 0.06 & & & HLP-35 & $\mathrm{SO}_{3}$ & 0.08 & & \\
\hline HLP-32 & TOTAL & 100.00 & 95.11 & 5.01 & HLP-35 & TOTAL & 100.00 & 98.24 & 1.78 \\
\hline HLP-33 & $\mathrm{Al}_{2} \mathrm{O}_{3}$ & 4.00 & 4.16 & 3.92 & HLP-36 & $\mathrm{Al}_{2} \mathrm{O}_{3}$ & 11.94 & 12.00 & 0.50 \\
\hline HLP-33 & $\mathrm{B}_{2} \mathrm{O}_{3}$ & 6.00 & 6.44 & 7.07 & HLP-36 & $\mathrm{B}_{2} \mathrm{O}_{3}$ & 12.00 & 12.60 & 4.88 \\
\hline HLP-33 & $\mathrm{CaO}$ & 0.01 & $\mathrm{BD}$ & & HLP-36 & $\mathrm{CaO}$ & 0.01 & $\mathrm{BD}$ & \\
\hline HLP-33 & $\mathrm{Cr}_{2} \mathrm{O}_{3}$ & 0.09 & 0.30 & 107.69 & HLP-36 & $\mathrm{Cr}_{2} \mathrm{O}_{3}$ & 0.06 & 0.17 & 95.65 \\
\hline HLP-33 & $\mathrm{Fe}_{2} \mathrm{O}_{3}$ & 5.90 & 6.92 & 15.91 & HLP-36 & $\mathrm{Fe}_{2} \mathrm{O}_{3}$ & 9.87 & 10.30 & 4.26 \\
\hline HLP-33 & $\mathrm{K}_{2} \mathrm{O}$ & 0.47 & 0.45 & 4.35 & HLP-36 & $\mathrm{K}_{2} \mathrm{O}$ & 0.33 & 0.27 & 20.00 \\
\hline HLP-33 & $\mathrm{La}_{2} \mathrm{O}_{3}$ & 0.00 & $\mathrm{BD}$ & & HLP-36 & $\mathrm{La}_{2} \mathrm{O}_{3}$ & 0.00 & $\mathrm{BD}$ & \\
\hline HLP-33 & $\mathrm{Li}_{2} \mathrm{O}$ & 0.00 & $\mathrm{BD}$ & & HLP-36 & $\mathrm{Li}_{2} \mathrm{O}$ & 0.00 & $\mathrm{BD}$ & \\
\hline HLP-33 & $\mathrm{MgO}$ & 1.61 & 1.57 & 2.52 & HLP-36 & $\mathrm{MgO}$ & 2.69 & 2.41 & 10.98 \\
\hline HLP-33 & $\mathrm{MoO}_{3}$ & 0.00 & & & HLP-36 & $\mathrm{MoO}_{3}$ & 0.00 & & \\
\hline HLP-33 & $\mathrm{Na}_{2} \mathrm{O}$ & 23.00 & 22.00 & 4.44 & HLP-36 & $\mathrm{Na}_{2} \mathrm{O}$ & 16.00 & 15.50 & 3.17 \\
\hline HLP-33 & $\mathrm{P}_{2} \mathrm{O}_{5}$ & 0.06 & & & HLP-36 & $\mathrm{P}_{2} \mathrm{O}_{5}$ & 0.04 & & \\
\hline HLP-33 & $\mathrm{SiO}_{2}$ & 52.00 & 52.30 & 0.58 & HLP-36 & $\mathrm{SiO}_{2}$ & 36.00 & 35.60 & 1.12 \\
\hline HLP-33 & $\mathrm{TiO}_{2}$ & 3.21 & 3.23 & 0.62 & HLP-36 & $\mathrm{TiO}_{2}$ & 5.38 & 5.49 & 2.02 \\
\hline HLP-33 & $\mathrm{ZnO}$ & 1.61 & 1.67 & 3.66 & HLP-36 & $\mathrm{ZnO}$ & 2.69 & 2.69 & 0.00 \\
\hline HLP-33 & $\mathrm{ZrO}_{2}$ & 1.61 & 1.31 & 20.55 & HLP-36 & $\mathrm{ZrO}_{2}$ & 2.69 & 2.44 & 9.75 \\
\hline HLP-33 & $\mathrm{Cl}$ & 0.32 & & & HLP-36 & $\mathrm{Cl}$ & 0.22 & & \\
\hline HLP-33 & $\mathrm{F}$ & 0.01 & & & HLP-36 & $\mathrm{F}$ & 0.01 & & \\
\hline HLP-33 & $\mathrm{SO}_{3}$ & 0.08 & & & HLP-36 & $\mathrm{SO}_{3}$ & 0.06 & & \\
\hline HLP-33 & TOTAL & 99.99 & 100.35 & 0.36 & HLP-36 & TOTAL & 100.00 & 99.47 & 0.53 \\
\hline
\end{tabular}




\begin{tabular}{|c|c|c|c|c|c|c|c|c|c|}
\hline Glass ID & $\begin{array}{c}\text { Oxide/ } \\
\text { Anion } \\
\end{array}$ & $\begin{array}{c}\text { Targeted } \\
\text { Comp. }\end{array}$ & $\begin{array}{l}\text { Meas. } \\
\text { Comp. }\end{array}$ & $\begin{array}{c}\% \\
\text { Diff. } \\
\end{array}$ & Glass ID & $\begin{array}{c}\text { Oxide/ } \\
\text { Anion } \\
\end{array}$ & $\begin{array}{c}\text { Targeted } \\
\text { Comp. }\end{array}$ & $\begin{array}{l}\text { Meas. } \\
\text { Comp. } \\
\end{array}$ & $\begin{array}{c}\% \\
\text { Diff. }\end{array}$ \\
\hline HLP-37 & $\mathrm{Al}_{2} \mathrm{O}_{3}$ & 11.94 & 11.60 & 2.89 & HLP-40 & $\mathrm{Al}_{2} \mathrm{O}_{3}$ & 4.00 & 4.26 & 6.30 \\
\hline HLP-37 & $\mathrm{B}_{2} \mathrm{O}_{3}$ & 6.00 & 6.78 & 12.21 & HLP-40 & $\mathrm{B}_{2} \mathrm{O}_{3}$ & 12.00 & 12.40 & 3.28 \\
\hline HLP-37 & $\mathrm{CaO}$ & 0.01 & $\mathrm{BD}$ & & HLP-40 & $\mathrm{CaO}$ & 0.01 & $\mathrm{BD}$ & \\
\hline HLP-37 & $\mathrm{Cr}_{2} \mathrm{O}_{3}$ & 0.09 & 0.19 & 71.43 & HLP-40 & $\mathrm{Cr}_{2} \mathrm{O}_{3}$ & 0.06 & 0.18 & 100.00 \\
\hline HLP-37 & $\mathrm{Fe}_{2} \mathrm{O}_{3}$ & 9.31 & 9.71 & 4.21 & HLP-40 & $\mathrm{Fe}_{2} \mathrm{O}_{3}$ & 13.23 & 13.40 & 1.28 \\
\hline HLP-37 & $\mathrm{K}_{2} \mathrm{O}$ & 0.47 & 0.40 & 16.09 & HLP-40 & $\mathrm{K}_{2} \mathrm{O}$ & 0.33 & 0.31 & 6.25 \\
\hline HLP-37 & $\mathrm{La}_{2} \mathrm{O}_{3}$ & 0.00 & $\mathrm{BD}$ & & HLP-40 & $\mathrm{La}_{2} \mathrm{O}_{3}$ & 0.00 & $\mathrm{BD}$ & \\
\hline HLP-37 & $\mathrm{Li}_{2} \mathrm{O}$ & 0.00 & $\mathrm{BD}$ & & HLP-40 & $\mathrm{Li}_{2} \mathrm{O}$ & 0.00 & $\mathrm{BD}$ & \\
\hline HLP-37 & $\mathrm{MgO}$ & 2.54 & 2.19 & 14.80 & HLP-40 & $\mathrm{MgO}$ & 3.61 & 3.65 & 1.10 \\
\hline HLP-37 & $\mathrm{MoO}_{3}$ & 0.00 & & & HLP-40 & $\mathrm{MoO}_{3}$ & 0.00 & & \\
\hline HLP-37 & $\mathrm{Na}_{2} \mathrm{O}$ & 23.00 & 21.80 & 5.36 & HLP-40 & $\mathrm{Na}_{2} \mathrm{O}$ & 16.00 & 16.30 & 1.86 \\
\hline HLP-37 & $\mathrm{P}_{2} \mathrm{O}_{5}$ & 0.06 & & & HLP-40 & $\mathrm{P}_{2} \mathrm{O}_{5}$ & 0.04 & & \\
\hline HLP-37 & $\mathrm{SiO}_{2}$ & 36.00 & 35.60 & 1.12 & HLP-40 & $\mathrm{SiO}_{2}$ & 36.00 & 35.10 & 2.53 \\
\hline HLP-37 & $\mathrm{TiO}_{2}$ & 5.07 & 5.04 & 0.59 & HLP-40 & $\mathrm{TiO}_{2}$ & 7.21 & 7.65 & 5.92 \\
\hline HLP-37 & $\mathrm{ZnO}$ & 2.54 & 2.46 & 3.20 & HLP-40 & $\mathrm{ZnO}$ & 3.61 & 3.73 & 3.27 \\
\hline HLP-37 & $\mathrm{ZrO}_{2}$ & 2.54 & 2.28 & 10.79 & HLP-40 & $\mathrm{ZrO}_{2}$ & 3.61 & 3.44 & 4.82 \\
\hline HLP-37 & $\mathrm{Cl}$ & 0.32 & & & HLP-40 & $\mathrm{Cl}$ & 0.22 & & \\
\hline HLP-37 & $\mathrm{F}$ & 0.01 & & & HLP-40 & $\mathrm{F}$ & 0.01 & & \\
\hline HLP-37 & $\mathrm{SO}_{3}$ & 0.08 & & & HLP-40 & $\mathrm{SO}_{3}$ & 0.06 & & \\
\hline HLP-37 & TOTAL & 99.99 & 98.05 & 1.96 & HLP-40 & TOTAL & 100.01 & 100.42 & 0.41 \\
\hline HLP-38 & $\mathrm{Al}_{2} \mathrm{O}_{3}$ & 11.94 & 12.00 & 0.50 & HLP-40Q & $\mathrm{Al}_{2} \mathrm{O}_{3}$ & 4.00 & 4.01 & 0.25 \\
\hline HLP-38 & $\mathrm{B}_{2} \mathrm{O}_{3}$ & 6.00 & 6.09 & 1.49 & HLP-40Q & $\mathrm{B}_{2} \mathrm{O}_{3}$ & 12.00 & 12.70 & 5.67 \\
\hline HLP-38 & $\mathrm{CaO}$ & 0.01 & $\mathrm{BD}$ & & HLP-40Q & $\mathrm{CaO}$ & 0.01 & $\mathrm{BD}$ & \\
\hline HLP-38 & $\mathrm{Cr}_{2} \mathrm{O}_{3}$ & 0.06 & 0.17 & 95.65 & HLP-40Q & $\mathrm{Cr}_{2} \mathrm{O}_{3}$ & 0.06 & 0.20 & 107.69 \\
\hline HLP-38 & $\mathrm{Fe}_{2} \mathrm{O}_{3}$ & 12.41 & 12.60 & 1.52 & HLP-40Q & $\mathrm{Fe}_{2} \mathrm{O}_{3}$ & 13.23 & 13.40 & 1.28 \\
\hline HLP-38 & $\mathrm{K}_{2} \mathrm{O}$ & 0.33 & 0.30 & 9.52 & HLP-40Q & $\mathrm{K}_{2} \mathrm{O}$ & 0.33 & 0.31 & 6.25 \\
\hline HLP-38 & $\mathrm{La}_{2} \mathrm{O}_{3}$ & 0.00 & $\mathrm{BD}$ & & HLP-40Q & $\mathrm{La}_{2} \mathrm{O}_{3}$ & 0.00 & $\mathrm{BD}$ & \\
\hline HLP-38 & $\mathrm{Li}_{2} \mathrm{O}$ & 0.00 & $\mathrm{BD}$ & & HLP-40Q & $\mathrm{Li}_{2} \mathrm{O}$ & 0.00 & $\mathrm{BD}$ & \\
\hline HLP-38 & $\mathrm{MgO}$ & 3.38 & 3.15 & 7.04 & HLP-40Q & $\mathrm{MgO}$ & 3.61 & 3.46 & 4.24 \\
\hline HLP-38 & $\mathrm{MoO}_{3}$ & 0.00 & & & HLP-40Q & $\mathrm{MoO}_{3}$ & 0.00 & & \\
\hline HLP-38 & $\mathrm{Na}_{2} \mathrm{O}$ & 16.00 & 15.30 & 4.47 & HLP-40Q & $\mathrm{Na}_{2} \mathrm{O}$ & 16.00 & 15.40 & 3.82 \\
\hline HLP-38 & $\mathrm{P}_{2} \mathrm{O}_{5}$ & 0.04 & & & HLP-40Q & $\mathrm{P}_{2} \mathrm{O}_{5}$ & 0.04 & & \\
\hline HLP-38 & $\mathrm{SiO}_{2}$ & 36.00 & 35.40 & 1.68 & HLP-40Q & $\mathrm{SiO}_{2}$ & 36.00 & 34.10 & 5.42 \\
\hline HLP-38 & $\mathrm{TiO}_{2}$ & 6.76 & 6.88 & 1.76 & HLP-40Q & $\mathrm{TiO}_{2}$ & 7.21 & 7.28 & 0.97 \\
\hline HLP-38 & $\mathrm{ZnO}$ & 3.38 & 3.33 & 1.49 & HLP-40Q & $\mathrm{ZnO}$ & 3.61 & 3.62 & 0.28 \\
\hline HLP-38 & $\mathrm{ZrO}_{2}$ & 3.38 & 3.38 & 0.00 & HLP-40Q & $\mathrm{ZrO}_{2}$ & 3.61 & 3.16 & 13.29 \\
\hline HLP-38 & $\mathrm{Cl}$ & 0.22 & & & HLP-40Q & $\mathrm{Cl}$ & 0.22 & & \\
\hline HLP-38 & $\mathrm{F}$ & 0.01 & & & HLP-40Q & $\mathrm{F}$ & 0.01 & & \\
\hline HLP-38 & $\mathrm{SO}_{3}$ & 0.06 & & & HLP-40Q & $\mathrm{SO}_{3}$ & 0.06 & & \\
\hline HLP-38 & TOTAL & 99.99 & 98.60 & 1.40 & HLP-40Q & TOTAL & 100.01 & 97.64 & 2.40 \\
\hline HLP-39 & $\mathrm{Al}_{2} \mathrm{O}_{3}$ & 4.00 & 3.99 & 0.25 & HLP-41 & $\mathrm{Al}_{2} \mathrm{O}_{3}$ & 4.00 & 3.91 & 2.28 \\
\hline HLP-39 & $\mathrm{B}_{2} \mathrm{O}_{3}$ & 12.00 & 12.60 & 4.88 & HLP-41 & $\mathrm{B}_{2} \mathrm{O}_{3}$ & 6.00 & 6.47 & 7.54 \\
\hline HLP-39 & $\mathrm{CaO}$ & 0.01 & $\mathrm{BD}$ & & HLP-41 & $\mathrm{CaO}$ & 0.01 & $\mathrm{BD}$ & \\
\hline HLP-39 & $\mathrm{Cr}_{2} \mathrm{O}_{3}$ & 0.09 & 0.23 & 87.50 & HLP-41 & $\mathrm{Cr}_{2} \mathrm{O}_{3}$ & 0.09 & 0.22 & 83.87 \\
\hline HLP-39 & $\mathrm{Fe}_{2} \mathrm{O}_{3}$ & 10.13 & 10.40 & 2.63 & HLP-41 & $\mathrm{Fe}_{2} \mathrm{O}_{3}$ & 12.67 & 13.00 & 2.57 \\
\hline HLP-39 & $\mathrm{K}_{2} \mathrm{O}$ & 0.47 & 0.45 & 4.35 & HLP-41 & $\mathrm{K}_{2} \mathrm{O}$ & 0.47 & 0.43 & 8.89 \\
\hline HLP-39 & $\mathrm{La}_{2} \mathrm{O}_{3}$ & 0.00 & $\mathrm{BD}$ & & HLP-41 & $\mathrm{La}_{2} \mathrm{O}_{3}$ & 0.00 & $\mathrm{BD}$ & \\
\hline HLP-39 & $\mathrm{Li}_{2} \mathrm{O}$ & 0.00 & $\mathrm{BD}$ & & HLP-41 & $\mathrm{Li}_{2} \mathrm{O}$ & 0.00 & $\mathrm{BD}$ & \\
\hline HLP-39 & $\mathrm{MgO}$ & 2.76 & 2.59 & 6.36 & HLP-41 & $\mathrm{MgO}$ & 3.45 & 3.20 & 7.52 \\
\hline HLP-39 & $\mathrm{MoO}_{3}$ & 0.00 & & & HLP-41 & $\mathrm{MoO}_{3}$ & 0.00 & & \\
\hline HLP-39 & $\mathrm{Na}_{2} \mathrm{O}$ & 23.00 & 21.50 & 6.74 & HLP-41 & $\mathrm{Na}_{2} \mathrm{O}$ & 23.00 & 21.60 & 6.28 \\
\hline HLP-39 & $\mathrm{P}_{2} \mathrm{O}_{5}$ & 0.06 & & & HLP-41 & $\mathrm{P}_{2} \mathrm{O}_{5}$ & 0.06 & & \\
\hline HLP-39 & $\mathrm{SiO}_{2}$ & 36.00 & 34.40 & 4.55 & HLP-41 & $\mathrm{SiO}_{2}$ & 36.00 & 35.00 & 2.82 \\
\hline HLP-39 & $\mathrm{TiO}_{2}$ & 5.52 & 5.50 & 0.36 & HLP-41 & $\mathrm{TiO}_{2}$ & 6.90 & 6.78 & 1.75 \\
\hline HLP-39 & $\mathrm{ZnO}$ & 2.76 & 2.72 & 1.46 & HLP-41 & $\mathrm{ZnO}$ & 3.45 & 3.48 & 0.87 \\
\hline HLP-39 & $\mathrm{ZrO}_{2}$ & 2.76 & 2.62 & 5.20 & HLP-41 & $\mathrm{ZrO}_{2}$ & 3.45 & 3.19 & 7.83 \\
\hline HLP-39 & $\mathrm{Cl}$ & 0.32 & & & HLP-41 & $\mathrm{Cl}$ & 0.32 & & \\
\hline HLP-39 & $\mathrm{F}$ & 0.01 & & & HLP-41 & $\mathrm{F}$ & 0.01 & & \\
\hline HLP-39 & $\mathrm{SO}_{3}$ & 0.08 & & & HLP-41 & $\mathrm{SO}_{3}$ & 0.08 & & \\
\hline HLP-39 & TOTAL & 99.98 & 97.00 & 3.03 & HLP-41 & TOTAL & 99.97 & 97.28 & 2.73 \\
\hline
\end{tabular}




\begin{tabular}{|c|c|c|c|c|c|c|c|c|c|}
\hline Glass ID & $\begin{array}{c}\text { Oxide/ } \\
\text { Anion } \\
\end{array}$ & $\begin{array}{c}\text { Targeted } \\
\text { Comp. }\end{array}$ & $\begin{array}{l}\text { Meas. } \\
\text { Comp. }\end{array}$ & $\begin{array}{c}\% \% \\
\text { Diff. } \\
\end{array}$ & Glass ID & $\begin{array}{c}\text { Oxide/ } \\
\text { Anion } \\
\end{array}$ & $\begin{array}{c}\text { Targeted } \\
\text { Comp. }\end{array}$ & $\begin{array}{l}\text { Meas. } \\
\text { Comp. }\end{array}$ & $\begin{array}{c}\% \\
\text { Diff. }\end{array}$ \\
\hline HLP-42 & $\mathrm{Al}_{2} \mathrm{O}_{3}$ & 4.00 & 4.13 & 3.20 & HLP-44 & $\mathrm{Al}_{2} \mathrm{O}_{3}$ & 7.00 & 6.93 & 1.01 \\
\hline HLP-42 & $\mathrm{B}_{2} \mathrm{O}_{3}$ & 6.00 & 6.46 & 7.38 & HLP-44 & $\mathrm{B}_{2} \mathrm{O}_{3}$ & 10.00 & 9.97 & 0.30 \\
\hline HLP-42 & $\mathrm{CaO}$ & 0.01 & $\mathrm{BD}$ & & HLP-44 & $\mathrm{CaO}$ & 0.01 & $\mathrm{BD}$ & \\
\hline HLP-42 & $\mathrm{Cr}_{2} \mathrm{O}_{3}$ & 0.06 & 0.17 & 95.65 & HLP-44 & $\mathrm{Cr}_{2} \mathrm{O}_{3}$ & 0.08 & 0.21 & 89.66 \\
\hline HLP-42 & $\mathrm{Fe}_{2} \mathrm{O}_{3}$ & 15.77 & 15.80 & 0.19 & HLP-44 & $\mathrm{Fe}_{2} \mathrm{O}_{3}$ & 5.50 & 6.07 & 9.85 \\
\hline HLP-42 & $\mathrm{K}_{2} \mathrm{O}$ & 0.33 & 0.42 & 24.00 & HLP-44 & $\mathrm{K}_{2} \mathrm{O}$ & 0.41 & 0.35 & 15.79 \\
\hline HLP-42 & $\mathrm{La}_{2} \mathrm{O}_{3}$ & 0.00 & $\mathrm{BD}$ & & HLP-44 & $\mathrm{La}_{2} \mathrm{O}_{3}$ & 0.00 & $\mathrm{BD}$ & \\
\hline HLP-42 & $\mathrm{Li}_{2} \mathrm{O}$ & 0.00 & $\mathrm{BD}$ & & HLP-44 & $\mathrm{Li}_{2} \mathrm{O}$ & 0.00 & $\mathrm{BD}$ & \\
\hline HLP-42 & $\mathrm{MgO}$ & 4.30 & 4.09 & 5.01 & HLP-44 & $\mathrm{MgO}$ & 1.50 & 1.46 & 2.70 \\
\hline HLP-42 & $\mathrm{MoO}_{3}$ & 0.00 & & & HLP-44 & $\mathrm{MoO}_{3}$ & 0.00 & & \\
\hline HLP-42 & $\mathrm{Na}_{2} \mathrm{O}$ & 16.00 & 15.60 & 2.53 & HLP-44 & $\mathrm{Na}_{2} \mathrm{O}$ & 20.00 & 18.60 & 7.25 \\
\hline HLP-42 & $\mathrm{P}_{2} \mathrm{O}_{5}$ & 0.04 & & & HLP-44 & $\mathrm{P}_{2} \mathrm{O}_{5}$ & 0.06 & & \\
\hline HLP-42 & $\mathrm{SiO}_{2}$ & 36.00 & 34.20 & 5.13 & HLP-44 & $\mathrm{SiO}_{2}$ & 49.07 & 48.30 & 1.58 \\
\hline HLP-42 & $\mathrm{TiO}_{2}$ & 8.59 & 8.66 & 0.81 & HLP-44 & $\mathrm{TiO}_{2}$ & 3.00 & 3.12 & 3.92 \\
\hline HLP-42 & $\mathrm{ZnO}$ & 4.30 & 4.17 & 3.07 & HLP-44 & $\mathrm{ZnO}$ & 1.50 & 1.51 & 0.66 \\
\hline HLP-42 & $\mathrm{ZrO}_{2}$ & 4.30 & 3.78 & 12.87 & HLP-44 & $\mathrm{ZrO}_{2}$ & 1.50 & 1.22 & 20.59 \\
\hline HLP-42 & $\mathrm{Cl}$ & 0.22 & & & HLP-44 & $\mathrm{Cl}$ & 0.28 & & \\
\hline HLP-42 & $\mathrm{F}$ & 0.01 & & & HLP-44 & $\mathrm{F}$ & 0.01 & & \\
\hline HLP-42 & $\mathrm{SO}_{3}$ & 0.06 & & & HLP-44 & $\mathrm{SO}_{3}$ & 0.07 & & \\
\hline HLP-42 & TOTAL & 100.00 & 97.48 & 2.55 & HLP-44 & TOTAL & 100.00 & 97.74 & 2.29 \\
\hline HLP-42Q & $\mathrm{Al}_{2} \mathrm{O}_{3}$ & 4.00 & 4.09 & 2.22 & HLP-45 & $\mathrm{Al}_{2} \mathrm{O}_{3}$ & 7.00 & 7.10 & 1.42 \\
\hline HLP-42Q & $\mathrm{B}_{2} \mathrm{O}_{3}$ & 6.00 & 6.32 & 5.19 & HLP-45 & $\mathrm{B}_{2} \mathrm{O}_{3}$ & 10.00 & 10.10 & 1.00 \\
\hline HLP-42Q & $\mathrm{CaO}$ & 0.01 & $\mathrm{BD}$ & & HLP-45 & $\mathrm{CaO}$ & 0.01 & $\mathrm{BD}$ & \\
\hline HLP-42Q & $\mathrm{Cr}_{2} \mathrm{O}_{3}$ & 0.06 & 0.19 & 104.00 & HLP-45 & $\mathrm{Cr}_{2} \mathrm{O}_{3}$ & 0.08 & 0.22 & 93.33 \\
\hline HLP-42Q & $\mathrm{Fe}_{2} \mathrm{O}_{3}$ & 15.77 & 16.80 & 6.32 & HLP-45 & $\mathrm{Fe}_{2} \mathrm{O}_{3}$ & 5.50 & 6.06 & 9.69 \\
\hline HLP-42Q & $\mathrm{K}_{2} \mathrm{O}$ & 0.33 & 0.37 & 11.43 & HLP-45 & $\mathrm{K}_{2} \mathrm{O}$ & 0.41 & 0.34 & 18.67 \\
\hline HLP-42Q & $\mathrm{La}_{2} \mathrm{O}_{3}$ & 0.00 & 0.10 & 200.00 & HLP-45 & $\mathrm{La}_{2} \mathrm{O}_{3}$ & 0.00 & $\mathrm{BD}$ & \\
\hline HLP-42Q & $\mathrm{Li}_{2} \mathrm{O}$ & 0.00 & $\mathrm{BD}$ & & HLP-45 & $\mathrm{Li}_{2} \mathrm{O}$ & 0.00 & $\mathrm{BD}$ & \\
\hline HLP-42Q & $\mathrm{MgO}$ & 4.30 & 4.05 & 5.99 & HLP-45 & $\mathrm{MgO}$ & 1.50 & 1.55 & 3.28 \\
\hline HLP-42Q & $\mathrm{MoO}_{3}$ & 0.00 & & & HLP-45 & $\mathrm{MoO}_{3}$ & 0.00 & & \\
\hline HLP-42Q & $\mathrm{Na}_{2} \mathrm{O}$ & 16.00 & 15.50 & 3.17 & HLP-45 & $\mathrm{Na}_{2} \mathrm{O}$ & 20.00 & 18.50 & 7.79 \\
\hline HLP-42Q & $\mathrm{P}_{2} \mathrm{O}_{5}$ & 0.04 & & & HLP-45 & $\mathrm{P}_{2} \mathrm{O}_{5}$ & 0.06 & & \\
\hline HLP-42Q & $\mathrm{SiO}_{2}$ & 36.00 & 35.10 & 2.53 & HLP-45 & $\mathrm{SiO}_{2}$ & 49.07 & 48.60 & 0.96 \\
\hline HLP-42Q & $\mathrm{TiO}_{2}$ & 8.59 & 8.31 & 3.31 & HLP-45 & $\mathrm{TiO}_{2}$ & 3.00 & 2.93 & 2.36 \\
\hline HLP-42Q & $\mathrm{ZnO}$ & 4.30 & 4.29 & 0.23 & HLP-45 & $\mathrm{ZnO}$ & 1.50 & 1.46 & 2.70 \\
\hline HLP-42Q & $\mathrm{ZrO}_{2}$ & 4.30 & 3.27 & 27.21 & HLP-45 & $\mathrm{ZrO}_{2}$ & 1.50 & 1.34 & 11.27 \\
\hline HLP-42Q & $\mathrm{Cl}$ & 0.22 & & & HLP-45 & $\mathrm{Cl}$ & 0.28 & & \\
\hline HLP-42Q & $\mathrm{F}$ & 0.01 & & & HLP-45 & $\mathrm{F}$ & 0.01 & & \\
\hline HLP-42Q & $\mathrm{SO}_{3}$ & 0.06 & & & HLP-45 & $\mathrm{SO}_{3}$ & 0.07 & & \\
\hline HLP-42Q & TOTAL & 100.00 & 98.39 & 1.62 & HLP-45 & TOTAL & 100.00 & 98.20 & 1.82 \\
\hline HLP-43 & $\mathrm{Al}_{2} \mathrm{O}_{3}$ & 7.00 & 6.69 & 4.53 & HLP-46 & $\mathrm{Al}_{2} \mathrm{O}_{3}$ & 12.00 & 11.70 & 3.94 \\
\hline HLP-43 & $\mathrm{B}_{2} \mathrm{O}_{3}$ & 10.00 & 9.85 & 1.51 & HLP-46 & $\mathrm{B}_{2} \mathrm{O}_{3}$ & 5.00 & 5.50 & 8.53 \\
\hline HLP-43 & $\mathrm{CaO}$ & 0.01 & 0.01 & 0.00 & HLP-46 & $\mathrm{CaO}$ & 4.00 & 3.92 & 4.98 \\
\hline HLP-43 & $\mathrm{Cr}_{2} \mathrm{O}_{3}$ & 0.08 & 0.23 & 96.77 & HLP-46 & $\mathrm{Cr}_{2} \mathrm{O}_{3}$ & 0.04 & 0.16 & 104.76 \\
\hline HLP-43 & $\mathrm{Fe}_{2} \mathrm{O}_{3}$ & 5.50 & 6.23 & 12.45 & HLP-46 & $\mathrm{Fe}_{2} \mathrm{O}_{3}$ & 0.00 & 0.49 & 126.67 \\
\hline HLP-43 & $\mathrm{K}_{2} \mathrm{O}$ & 0.41 & 0.47 & 13.64 & HLP-46 & $\mathrm{K}_{2} \mathrm{O}$ & 1.46 & 0.28 & 142.27 \\
\hline HLP-43 & $\mathrm{La}_{2} \mathrm{O}_{3}$ & 0.00 & $\mathrm{BD}$ & & HLP-46 & $\mathrm{La}_{2} \mathrm{O}_{3}$ & 0.00 & $\mathrm{BD}$ & \\
\hline HLP-43 & $\mathrm{Li}_{2} \mathrm{O}$ & 0.00 & $\mathrm{BD}$ & & HLP-46 & $\mathrm{Li}_{2} \mathrm{O}$ & 0.00 & $\mathrm{BD}$ & \\
\hline HLP-43 & $\mathrm{MgO}$ & 1.50 & 1.33 & 12.01 & HLP-46 & $\mathrm{MgO}$ & 0.00 & $\mathrm{BD}$ & \\
\hline HLP-43 & $\mathrm{MoO}_{3}$ & 0.00 & & & HLP-46 & $\mathrm{MoO}_{3}$ & 0.15 & & \\
\hline HLP-43 & $\mathrm{Na}_{2} \mathrm{O}$ & 20.00 & 18.50 & 7.79 & HLP-46 & $\mathrm{Na}_{2} \mathrm{O}$ & 20.00 & 18.00 & 12.55 \\
\hline HLP-43 & $\mathrm{P}_{2} \mathrm{O}_{5}$ & 0.06 & & & HLP-46 & $\mathrm{P}_{2} \mathrm{O}_{5}$ & 0.19 & & \\
\hline HLP-43 & $\mathrm{SiO}_{2}$ & 49.07 & 48.40 & 1.37 & HLP-46 & $\mathrm{SiO}_{2}$ & 55.91 & 57.70 & 3.15 \\
\hline HLP-43 & $\mathrm{TiO}_{2}$ & 3.00 & 2.86 & 4.78 & HLP-46 & $\mathrm{TiO}_{2}$ & 0.02 & $\mathrm{BD}$ & \\
\hline HLP-43 & $\mathrm{ZnO}$ & 1.50 & 1.40 & 6.90 & HLP-46 & $\mathrm{ZnO}$ & 0.14 & $\mathrm{BD}$ & \\
\hline HLP-43 & $\mathrm{ZrO}_{2}$ & 1.50 & 1.50 & 0.00 & HLP-46 & $\mathrm{ZrO}_{2}$ & 0.08 & $\mathrm{BD}$ & \\
\hline HLP-43 & $\mathrm{Cl}$ & 0.28 & & & HLP-46 & $\mathrm{Cl}$ & 0.35 & & \\
\hline HLP-43 & $\mathrm{F}$ & 0.01 & & & HLP-46 & $\mathrm{F}$ & 0.29 & & \\
\hline HLP-43 & $\mathrm{SO}_{3}$ & 0.07 & & & HLP-46 & $\mathrm{SO}_{3}$ & 0.22 & & \\
\hline HLP-43 & TOTAL & 100.00 & 97.47 & 2.56 & HLP-46 & TOTAL & 100.00 & 97.75 & 2.40 \\
\hline
\end{tabular}




\begin{tabular}{|c|c|c|c|c|c|c|c|c|c|}
\hline Glass ID & $\begin{array}{c}\text { Oxide/ } \\
\text { Anion } \\
\end{array}$ & $\begin{array}{c}\text { Targeted } \\
\text { Comp. }\end{array}$ & $\begin{array}{l}\text { Meas. } \\
\text { Comp. }\end{array}$ & $\begin{array}{c}\% \% \\
\text { Diff. } \\
\end{array}$ & Glass ID & $\begin{array}{c}\text { Oxide/ } \\
\text { Anion } \\
\end{array}$ & $\begin{array}{c}\text { Targeted } \\
\text { Comp. }\end{array}$ & $\begin{array}{l}\text { Meas. } \\
\text { Comp. }\end{array}$ & $\begin{array}{c}\% \% \\
\text { Diff. } \\
\end{array}$ \\
\hline HLP-47 & $\mathrm{Al}_{2} \mathrm{O}_{3}$ & 10.00 & 9.42 & 5.97 & HLP-51 & $\mathrm{Al}_{2} \mathrm{O}_{3}$ & 10.00 & 9.68 & 3.25 \\
\hline HLP-47 & $\mathrm{B}_{2} \mathrm{O}_{3}$ & 8.00 & 7.64 & 4.60 & HLP-51 & $\mathrm{B}_{2} \mathrm{O}_{3}$ & 9.25 & 9.26 & 0.11 \\
\hline HLP-47 & $\mathrm{CaO}$ & 0.50 & 0.52 & 3.92 & HLP-51 & $\mathrm{CaO}$ & 0.00 & $\mathrm{BD}$ & \\
\hline HLP-47 & $\mathrm{Cr}_{2} \mathrm{O}_{3}$ & 0.20 & 0.32 & 46.15 & HLP-51 & $\mathrm{Cr}_{2} \mathrm{O}_{3}$ & 0.02 & 0.14 & 150.00 \\
\hline HLP-47 & $\mathrm{Fe}_{2} \mathrm{O}_{3}$ & 1.00 & 2.04 & 68.42 & HLP-51 & $\mathrm{Fe}_{2} \mathrm{O}_{3}$ & 2.50 & 2.94 & 16.18 \\
\hline HLP-47 & $\mathrm{K}_{2} \mathrm{O}$ & 1.50 & 1.40 & 6.90 & HLP-51 & $\mathrm{K}_{2} \mathrm{O}$ & 2.20 & 2.07 & 6.09 \\
\hline HLP-47 & $\mathrm{La}_{2} \mathrm{O}_{3}$ & 0.01 & $\mathrm{BD}$ & & HLP-51 & $\mathrm{La}_{2} \mathrm{O}_{3}$ & 2.00 & 1.94 & 3.05 \\
\hline HLP-47 & $\mathrm{Li}_{2} \mathrm{O}$ & 0.10 & 0.12 & 18.18 & HLP-51 & $\mathrm{Li}_{2} \mathrm{O}$ & 0.00 & $\mathrm{BD}$ & \\
\hline HLP-47 & $\mathrm{MgO}$ & 0.10 & 0.11 & 9.52 & HLP-51 & $\mathrm{MgO}$ & 1.00 & 0.92 & 8.33 \\
\hline HLP-47 & $\mathrm{MoO}_{3}$ & 0.00 & & & HLP-51 & $\mathrm{MoO}_{3}$ & 0.00 & & \\
\hline HLP-47 & $\mathrm{Na}_{2} \mathrm{O}$ & 20.00 & 18.90 & 5.66 & HLP-51 & $\mathrm{Na}_{2} \mathrm{O}$ & 20.00 & 18.80 & 6.19 \\
\hline HLP-47 & $\mathrm{P}_{2} \mathrm{O}_{5}$ & 0.50 & & & HLP-51 & $\mathrm{P}_{2} \mathrm{O}_{5}$ & 0.08 & & \\
\hline HLP-47 & $\mathrm{SiO}_{2}$ & 54.37 & 55.10 & 1.33 & HLP-51 & $\mathrm{SiO}_{2}$ & 41.89 & 41.20 & 1.66 \\
\hline HLP-47 & $\mathrm{TiO}_{2}$ & 0.10 & 0.09 & 10.53 & HLP-51 & $\mathrm{TiO}_{2}$ & 2.49 & 2.37 & 4.94 \\
\hline HLP-47 & $\mathrm{ZnO}$ & 0.00 & $\mathrm{BD}$ & & HLP-51 & $\mathrm{ZnO}$ & 2.60 & 2.51 & 3.52 \\
\hline HLP-47 & $\mathrm{ZrO}_{2}$ & 1.00 & 0.94 & 6.19 & HLP-51 & $\mathrm{ZrO}_{2}$ & 5.25 & 3.90 & 29.51 \\
\hline HLP-47 & $\mathrm{Cl}$ & 0.80 & & & HLP-51 & $\mathrm{Cl}$ & 0.58 & & \\
\hline HLP-47 & $\mathrm{F}$ & 1.00 & & & HLP-51 & $\mathrm{F}$ & 0.04 & & \\
\hline HLP-47 & $\mathrm{SO}_{3}$ & 0.20 & & & HLP-51 & $\mathrm{SO}_{3}$ & 0.10 & & \\
\hline HLP-47 & TOTAL & 99.38 & 96.60 & 2.84 & HLP-51 & TOTAL & 100.00 & 95.73 & 4.36 \\
\hline HLP-48 & $\mathrm{Al}_{2} \mathrm{O}_{3}$ & 11.97 & 11.50 & 4.01 & HLP-52 & $\mathrm{Al}_{2} \mathrm{O}_{3}$ & 10.19 & 9.63 & 5.26 \\
\hline HLP-48 & $\mathrm{B}_{2} \mathrm{O}_{3}$ & 8.85 & 8.93 & 0.90 & HLP-52 & $\mathrm{B}_{2} \mathrm{O}_{3}$ & 0.00 & 0.10 & 200.00 \\
\hline HLP-48 & $\mathrm{CaO}$ & 0.00 & $\mathrm{BD}$ & & HLP-52 & $\mathrm{CaO}$ & 2.60 & 2.51 & 3.14 \\
\hline HLP-48 & $\mathrm{Cr}_{2} \mathrm{O}_{3}$ & 0.02 & 0.14 & 150.00 & HLP-52 & $\mathrm{Cr}_{2} \mathrm{O}_{3}$ & 0.08 & 0.21 & 89.66 \\
\hline HLP-48 & $\mathrm{Fe}_{2} \mathrm{O}_{3}$ & 5.77 & 6.37 & 9.88 & HLP-52 & $\mathrm{Fe}_{2} \mathrm{O}_{3}$ & 2.54 & 3.00 & 17.00 \\
\hline HLP-48 & $\mathrm{K}_{2} \mathrm{O}$ & 3.10 & 2.75 & 11.97 & HLP-52 & $\mathrm{K}_{2} \mathrm{O}$ & 1.97 & 1.80 & 8.51 \\
\hline HLP-48 & $\mathrm{La}_{2} \mathrm{O}_{3}$ & 0.00 & $\mathrm{BD}$ & & HLP-52 & $\mathrm{La}_{2} \mathrm{O}_{3}$ & 0.00 & $\mathrm{BD}$ & \\
\hline HLP-48 & $\mathrm{Li}_{2} \mathrm{O}$ & 0.00 & $\mathrm{BD}$ & & HLP-52 & $\mathrm{Li}_{2} \mathrm{O}$ & 0.00 & $\mathrm{BD}$ & \\
\hline HLP-48 & $\mathrm{MgO}$ & 1.99 & 1.83 & 8.38 & HLP-52 & $\mathrm{MgO}$ & 1.18 & 1.08 & 8.85 \\
\hline HLP-48 & $\mathrm{MoO}_{3}$ & 0.00 & & & HLP-52 & $\mathrm{MoO}_{3}$ & 0.00 & & \\
\hline HLP-48 & $\mathrm{Na}_{2} \mathrm{O}$ & 20.00 & 18.50 & 7.79 & HLP-52 & $\mathrm{Na}_{2} \mathrm{O}$ & 28.74 & 27.50 & 3.99 \\
\hline HLP-48 & $\mathrm{P}_{2} \mathrm{O}_{5}$ & 0.08 & & & HLP-52 & $\mathrm{P}_{2} \mathrm{O}_{5}$ & 1.91 & & \\
\hline HLP-48 & $\mathrm{SiO}_{2}$ & 38.25 & 36.40 & 4.96 & HLP-52 & $\mathrm{SiO}_{2}$ & 44.64 & 45.80 & 2.97 \\
\hline HLP-48 & $\mathrm{TiO}_{2}$ & 2.49 & 2.45 & 1.62 & HLP-52 & $\mathrm{TiO}_{2}$ & 0.38 & 0.37 & 2.67 \\
\hline HLP-48 & $\mathrm{ZnO}$ & 4.27 & 4.10 & 4.06 & HLP-52 & $\mathrm{ZnO}$ & 0.00 & $\mathrm{BD}$ & \\
\hline HLP-48 & $\mathrm{ZrO}_{2}$ & 2.49 & 2.04 & 19.87 & HLP-52 & $\mathrm{ZrO}_{2}$ & 5.02 & 2.54 & 65.25 \\
\hline HLP-48 & $\mathrm{Cl}$ & 0.58 & & & HLP-52 & $\mathrm{Cl}$ & 0.13 & & \\
\hline HLP-48 & $\mathrm{F}$ & 0.04 & & & HLP-52 & $\mathrm{F}$ & 0.31 & & \\
\hline HLP-48 & $\mathrm{SO}_{3}$ & 0.10 & & & HLP-52 & $\mathrm{SO}_{3}$ & 0.30 & & \\
\hline HLP-48 & TOTAL & 100.00 & 95.01 & 5.12 & HLP-52 & TOTAL & 99.99 & 94.54 & 5.45 \\
\hline HLP-49 & $\mathrm{Al}_{2} \mathrm{O}_{3}$ & 8.03 & 7.76 & 3.42 & HLP-53 & $\mathrm{Al}_{2} \mathrm{O}_{3}$ & 9.86 & 9.31 & 5.74 \\
\hline HLP-49 & $\mathrm{B}_{2} \mathrm{O}_{3}$ & 8.07 & 8.74 & 7.97 & HLP-53 & $\mathrm{B}_{2} \mathrm{O}_{3}$ & 4.23 & 5.46 & 25.39 \\
\hline HLP-49 & $\mathrm{CaO}$ & 7.03 & 6.96 & 1.00 & HLP-53 & $\mathrm{CaO}$ & 4.38 & 4.21 & 3.96 \\
\hline HLP-49 & $\mathrm{Cr}_{2} \mathrm{O}_{3}$ & 0.10 & 0.24 & 82.35 & HLP-53 & $\mathrm{Cr}_{2} \mathrm{O}_{3}$ & 0.01 & 0.14 & 173.33 \\
\hline HLP-49 & $\mathrm{Fe}_{2} \mathrm{O}_{3}$ & 8.03 & 8.71 & 8.12 & HLP-53 & $\mathrm{Fe}_{2} \mathrm{O}_{3}$ & 7.30 & 7.67 & 4.94 \\
\hline HLP-49 & $\mathrm{K}_{2} \mathrm{O}$ & 0.36 & 0.36 & 0.00 & HLP-53 & $\mathrm{K}_{2} \mathrm{O}$ & 3.10 & 2.75 & 11.97 \\
\hline HLP-49 & $\mathrm{La}_{2} \mathrm{O}_{3}$ & 0.00 & $\mathrm{BD}$ & & HLP-53 & $\mathrm{La}_{2} \mathrm{O}_{3}$ & 0.00 & $\mathrm{BD}$ & \\
\hline HLP-49 & $\mathrm{Li}_{2} \mathrm{O}$ & 4.08 & 4.11 & 0.73 & HLP-53 & $\mathrm{Li}_{2} \mathrm{O}$ & 2.04 & 2.29 & 11.55 \\
\hline HLP-49 & $\mathrm{MgO}$ & 3.00 & 2.81 & 6.54 & HLP-53 & $\mathrm{MgO}$ & 2.04 & 1.93 & 5.54 \\
\hline HLP-49 & $\mathrm{MoO}_{3}$ & 0.00 & & & HLP-53 & $\mathrm{MoO}_{3}$ & 0.00 & & \\
\hline HLP-49 & $\mathrm{Na}_{2} \mathrm{O}$ & 10.00 & 9.65 & 3.56 & HLP-53 & $\mathrm{Na}_{2} \mathrm{O}$ & 20.00 & 18.60 & 7.25 \\
\hline HLP-49 & $\mathrm{P}_{2} \mathrm{O}_{5}$ & 0.01 & & & HLP-53 & $\mathrm{P}_{2} \mathrm{O}_{5}$ & 0.08 & & \\
\hline HLP-49 & $\mathrm{SiO}_{2}$ & 43.93 & 41.10 & 6.66 & HLP-53 & $\mathrm{SiO}_{2}$ & 40.15 & 39.50 & 1.63 \\
\hline HLP-49 & $\mathrm{TiO}_{2}$ & 0.00 & $\mathrm{BD}$ & & HLP-53 & $\mathrm{TiO}_{2}$ & 0.00 & $\mathrm{BD}$ & \\
\hline HLP-49 & $\mathrm{ZnO}$ & 3.99 & 3.93 & 1.52 & HLP-53 & $\mathrm{ZnO}$ & 3.28 & 3.09 & 5.97 \\
\hline HLP-49 & $\mathrm{ZrO}_{2}$ & 3.04 & 2.73 & 10.75 & HLP-53 & $\mathrm{ZrO}_{2}$ & 2.99 & 2.76 & 8.00 \\
\hline HLP-49 & $\mathrm{Cl}$ & 0.29 & & & HLP-53 & $\mathrm{Cl}$ & 0.36 & & \\
\hline HLP-49 & $\mathrm{F}$ & 0.00 & & & HLP-53 & $\mathrm{F}$ & 0.12 & & \\
\hline HLP-49 & $\mathrm{SO}_{3}$ & 0.02 & & & HLP-53 & $\mathrm{SO}_{3}$ & 0.04 & & \\
\hline HLP-49 & TOTAL & 99.98 & 97.10 & 2.92 & HLP-53 & TOTAL & 99.98 & 97.71 & 2.30 \\
\hline
\end{tabular}




\begin{tabular}{|c|c|c|c|c|c|c|c|c|c|}
\hline Glass ID & $\begin{array}{c}\text { Oxide/ } \\
\text { Anion } \\
\end{array}$ & $\begin{array}{c}\text { Targeted } \\
\text { Comp. }\end{array}$ & $\begin{array}{l}\text { Meas. } \\
\text { Comp. }\end{array}$ & $\begin{array}{c}\% \% \\
\text { Diff. }\end{array}$ & Glass ID & $\begin{array}{c}\text { Oxide/ } \\
\text { Anion } \\
\end{array}$ & $\begin{array}{c}\text { Targeted } \\
\text { Comp. }\end{array}$ & $\begin{array}{l}\text { Meas. } \\
\text { Comp. }\end{array}$ & $\begin{array}{c}\% \\
\text { Diff. }\end{array}$ \\
\hline HLP-53Q & $\mathrm{Al}_{2} \mathrm{O}_{3}$ & 9.86 & 9.79 & 0.71 & HLP-56 & $\mathrm{Al}_{2} \mathrm{O}_{3}$ & 6.20 & 6.33 & 2.08 \\
\hline HLP-53Q & $\mathrm{B}_{2} \mathrm{O}_{3}$ & 4.23 & 4.54 & 7.07 & HLP-56 & $\mathrm{B}_{2} \mathrm{O}_{3}$ & 8.90 & 9.31 & 4.50 \\
\hline HLP-53Q & $\mathrm{CaO}$ & 4.38 & 4.33 & 1.15 & HLP-56 & $\mathrm{CaO}$ & 1.99 & 2.06 & 3.46 \\
\hline HLP-53Q & $\mathrm{Cr}_{2} \mathrm{O}_{3}$ & 0.01 & $\mathrm{BD}$ & & HLP-56 & $\mathrm{Cr}_{2} \mathrm{O}_{3}$ & 0.02 & 0.02 & 0.00 \\
\hline HLP-53Q & $\mathrm{Fe}_{2} \mathrm{O}_{3}$ & 7.30 & 7.52 & 2.97 & HLP-56 & $\mathrm{Fe}_{2} \mathrm{O}_{3}$ & 6.98 & 7.05 & 1.00 \\
\hline HLP-53Q & $\mathrm{K}_{2} \mathrm{O}$ & 3.10 & 3.08 & 0.65 & HLP-56 & $\mathrm{K}_{2} \mathrm{O}$ & 0.50 & 2.12 & 123.66 \\
\hline HLP-53Q & $\mathrm{La}_{2} \mathrm{O}_{3}$ & 0.00 & $\mathrm{BD}$ & & HLP-56 & $\mathrm{La}_{2} \mathrm{O}_{3}$ & 0.00 & $\mathrm{BD}$ & \\
\hline HLP-53Q & $\mathrm{Li}_{2} \mathrm{O}$ & 2.04 & 2.13 & 4.32 & HLP-56 & $\mathrm{Li}_{2} \mathrm{O}$ & 0.00 & $\mathrm{BD}$ & \\
\hline HLP-53Q & $\mathrm{MgO}$ & 2.04 & 1.84 & 10.31 & HLP-56 & $\mathrm{MgO}$ & 1.99 & 2.04 & 2.48 \\
\hline HLP-53Q & $\mathrm{MoO}_{3}$ & 0.00 & & & HLP-56 & $\mathrm{MoO}_{3}$ & 0.01 & & \\
\hline HLP-53Q & $\mathrm{Na}_{2} \mathrm{O}$ & 20.00 & 20.40 & 1.98 & HLP-56 & $\mathrm{Na}_{2} \mathrm{O}$ & 20.00 & 18.10 & 9.97 \\
\hline HLP-53Q & $\mathrm{P}_{2} \mathrm{O}_{5}$ & 0.08 & & & HLP-56 & $\mathrm{P}_{2} \mathrm{O}_{5}$ & 0.03 & & \\
\hline HLP-53Q & $\mathrm{SiO}_{2}$ & 40.15 & 40.80 & 1.61 & HLP-56 & $\mathrm{SiO}_{2}$ & 44.55 & 46.90 & 5.14 \\
\hline HLP-53Q & $\mathrm{TiO}_{2}$ & 0.00 & $\mathrm{BD}$ & & HLP-56 & $\mathrm{TiO}_{2}$ & 1.99 & & \\
\hline HLP-53Q & $\mathrm{ZnO}$ & 3.28 & 3.24 & 1.23 & HLP-56 & $\mathrm{ZnO}$ & 2.96 & 4.09 & 32.06 \\
\hline HLP-53Q & $\mathrm{ZrO}_{2}$ & 2.99 & 2.82 & 5.85 & HLP-56 & $\mathrm{ZrO}_{2}$ & 2.99 & 1.35 & 75.58 \\
\hline HLP-53Q & $\mathrm{Cl}$ & 0.36 & & & HLP-56 & $\mathrm{Cl}$ & 0.65 & & \\
\hline HLP-53Q & $\mathrm{F}$ & 0.12 & & & HLP-56 & $\mathrm{F}$ & 0.01 & & \\
\hline HLP-53Q & $\mathrm{SO}_{3}$ & 0.04 & & & HLP-56 & $\mathrm{SO}_{3}$ & 0.10 & & \\
\hline HLP-53Q & TOTAL & 99.98 & 100.49 & 0.51 & HLP-56 & TOTAL & 99.99 & 99.37 & 1.01 \\
\hline HLP-54 & $\mathrm{Al}_{2} \mathrm{O}_{3}$ & 12.00 & 11.70 & 2.53 & HLP-58 & $\mathrm{Al}_{2} \mathrm{O}_{3}$ & 6.86 & 6.63 & 3.41 \\
\hline HLP-54 & $\mathrm{B}_{2} \mathrm{O}_{3}$ & 9.00 & 8.76 & 2.70 & HLP-58 & $\mathrm{B}_{2} \mathrm{O}_{3}$ & 9.80 & 9.98 & 1.82 \\
\hline HLP-54 & $\mathrm{CaO}$ & 0.00 & $\mathrm{BD}$ & & HLP-58 & $\mathrm{CaO}$ & 2.00 & 2.02 & 1.00 \\
\hline HLP-54 & $\mathrm{Cr}_{2} \mathrm{O}_{3}$ & 0.04 & 0.16 & 120.00 & HLP-58 & $\mathrm{Cr}_{2} \mathrm{O}_{3}$ & 0.08 & 0.08 & 0.00 \\
\hline HLP-54 & $\mathrm{Fe}_{2} \mathrm{O}_{3}$ & 0.00 & 0.56 & 200.00 & HLP-58 & $\mathrm{Fe}_{2} \mathrm{O}_{3}$ & 5.39 & 5.45 & 1.11 \\
\hline HLP-54 & $\mathrm{K}_{2} \mathrm{O}$ & 0.33 & 0.28 & 16.39 & HLP-58 & $\mathrm{K}_{2} \mathrm{O}$ & 0.40 & 0.45 & 11.76 \\
\hline HLP-54 & $\mathrm{La}_{2} \mathrm{O}_{3}$ & 0.01 & $\mathrm{BD}$ & & HLP-58 & $\mathrm{La}_{2} \mathrm{O}_{3}$ & 0.00 & 0.01 & 200.00 \\
\hline HLP-54 & $\mathrm{Li}_{2} \mathrm{O}$ & 0.00 & $\mathrm{BD}$ & & HLP-58 & $\mathrm{Li}_{2} \mathrm{O}$ & 0.00 & 0.13 & 200.00 \\
\hline HLP-54 & $\mathrm{MgO}$ & 0.00 & $\mathrm{BD}$ & & HLP-58 & $\mathrm{MgO}$ & 1.47 & 1.43 & 2.76 \\
\hline HLP-54 & $\mathrm{MoO}_{3}$ & 0.00 & & & HLP-58 & $\mathrm{MoO}_{3}$ & 0.00 & 0.02 & 200.00 \\
\hline HLP-54 & $\mathrm{Na}_{2} \mathrm{O}$ & 20.00 & 17.80 & 11.64 & HLP-58 & $\mathrm{Na}_{2} \mathrm{O}$ & 19.60 & 19.03 & 2.95 \\
\hline HLP-54 & $\mathrm{P}_{2} \mathrm{O}_{5}$ & 1.19 & & & HLP-58 & $\mathrm{P}_{2} \mathrm{O}_{5}$ & 0.06 & 0.08 & 28.57 \\
\hline HLP-54 & $\mathrm{SiO}_{2}$ & 56.78 & 56.40 & 0.67 & HLP-58 & $\mathrm{SiO}_{2}$ & 48.09 & 48.22 & 0.27 \\
\hline HLP-54 & $\mathrm{TiO}_{2}$ & 0.00 & $\mathrm{BD}$ & & HLP-58 & $\mathrm{TiO}_{2}$ & 2.94 & 3.01 & 2.35 \\
\hline HLP-54 & $\mathrm{ZnO}$ & 0.00 & $\mathrm{BD}$ & & HLP-58 & $\mathrm{ZnO}$ & 1.47 & 1.43 & 2.76 \\
\hline HLP-54 & $\mathrm{ZrO}_{2}$ & 0.00 & 0.07 & 200.00 & HLP-58 & $\mathrm{ZrO}_{2}$ & 1.47 & 1.46 & 0.68 \\
\hline HLP-54 & $\mathrm{Cl}$ & 0.09 & & & HLP-58 & $\mathrm{Cl}$ & 0.27 & 0.27 & 0.00 \\
\hline HLP-54 & $\mathrm{F}$ & 0.21 & & & HLP-58 & $\mathrm{F}$ & 0.01 & 0.05 & 133.33 \\
\hline HLP-54 & $\mathrm{SO}_{3}$ & 0.32 & & & HLP-58 & $\mathrm{SO}_{3}$ & 0.07 & 0.09 & 25.00 \\
\hline HLP-54 & TOTAL & 99.97 & 95.73 & 4.33 & HLP-58 & TOTAL & 99.98 & 99.83 & 0.15 \\
\hline HLP-55 & $\mathrm{Al}_{2} \mathrm{O}_{3}$ & 9.00 & 8.87 & 1.45 & HLP-59 & $\mathrm{Al}_{2} \mathrm{O}_{3}$ & 6.65 & 6.59 & 0.91 \\
\hline HLP-55 & $\mathrm{B}_{2} \mathrm{O}_{3}$ & 9.00 & 8.92 & 0.89 & HLP-59 & $\mathrm{B}_{2} \mathrm{O}_{3}$ & 9.50 & 9.32 & 1.91 \\
\hline HLP-55 & $\mathrm{CaO}$ & 0.00 & $\mathrm{BD}$ & & HLP-59 & $\mathrm{CaO}$ & 5.00 & 4.68 & 6.61 \\
\hline HLP-55 & $\mathrm{Cr}_{2} \mathrm{O}_{3}$ & 0.04 & 0.17 & 123.81 & HLP-59 & $\mathrm{Cr}_{2} \mathrm{O}_{3}$ & 0.08 & 0.08 & 0.00 \\
\hline HLP-55 & $\mathrm{Fe}_{2} \mathrm{O}_{3}$ & 0.00 & 0.58 & 200.00 & HLP-59 & $\mathrm{Fe}_{2} \mathrm{O}_{3}$ & 5.23 & 5.40 & 3.20 \\
\hline HLP-55 & $\mathrm{K}_{2} \mathrm{O}$ & 0.33 & 0.32 & 3.08 & HLP-59 & $\mathrm{K}_{2} \mathrm{O}$ & 0.39 & 0.45 & 14.29 \\
\hline HLP-55 & $\mathrm{La}_{2} \mathrm{O}_{3}$ & 0.01 & $\mathrm{BD}$ & & HLP-59 & $\mathrm{La}_{2} \mathrm{O}_{3}$ & 0.00 & 0.01 & 200.00 \\
\hline HLP-55 & $\mathrm{Li}_{2} \mathrm{O}$ & 0.00 & $\mathrm{BD}$ & & HLP-59 & $\mathrm{Li}_{2} \mathrm{O}$ & 0.00 & 0.13 & 200.00 \\
\hline HLP-55 & $\mathrm{MgO}$ & 0.00 & $\mathrm{BD}$ & & HLP-59 & $\mathrm{MgO}$ & 1.43 & 1.38 & 3.56 \\
\hline HLP-55 & $\mathrm{MoO}_{3}$ & 0.00 & & & HLP-59 & $\mathrm{MoO}_{3}$ & 0.00 & 0.02 & 200.00 \\
\hline HLP-55 & $\mathrm{Na}_{2} \mathrm{O}$ & 20.00 & 17.70 & 12.20 & HLP-59 & $\mathrm{Na}_{2} \mathrm{O}$ & 19.00 & 18.37 & 3.37 \\
\hline HLP-55 & $\mathrm{P}_{2} \mathrm{O}_{5}$ & 1.19 & & & HLP-59 & $\mathrm{P}_{2} \mathrm{O}_{5}$ & 0.06 & 0.05 & 18.18 \\
\hline HLP-55 & $\mathrm{SiO}_{2}$ & 59.78 & 60.60 & 1.36 & HLP-59 & $\mathrm{SiO}_{2}$ & 46.62 & 44.82 & 3.94 \\
\hline HLP-55 & $\mathrm{TiO}_{2}$ & 0.00 & $\mathrm{BD}$ & & HLP-59 & $\mathrm{TiO}_{2}$ & 2.85 & 2.88 & 1.05 \\
\hline HLP-55 & $\mathrm{ZnO}$ & 0.00 & $\mathrm{BD}$ & & HLP-59 & $\mathrm{ZnO}$ & 1.43 & 1.43 & 0.00 \\
\hline HLP-55 & $\mathrm{ZrO}_{2}$ & 0.00 & $\mathrm{BD}$ & & HLP-59 & $\mathrm{ZrO}_{2}$ & 1.43 & 1.52 & 6.10 \\
\hline HLP-55 & $\mathrm{Cl}$ & 0.09 & & & HLP-59 & $\mathrm{Cl}$ & 0.27 & 0.31 & 13.79 \\
\hline HLP-55 & $\mathrm{F}$ & 0.21 & & & HLP-59 & $\mathrm{F}$ & 0.01 & 0.05 & 133.33 \\
\hline HLP-55 & $\mathrm{SO}_{3}$ & 0.32 & & & HLP-59 & $\mathrm{SO}_{3}$ & 0.07 & 0.09 & 25.00 \\
\hline HLP-55 & TOTAL & 99.97 & 97.16 & 2.85 & HLP-59 & TOTAL & 100.02 & 97.58 & 2.47 \\
\hline
\end{tabular}




\begin{tabular}{|c|c|c|c|c|c|c|c|c|c|}
\hline Glass ID & $\begin{array}{c}\text { Oxide/ } \\
\text { Anion } \\
\end{array}$ & $\begin{array}{c}\text { Targeted } \\
\text { Comp. }\end{array}$ & $\begin{array}{l}\text { Meas. } \\
\text { Comp. }\end{array}$ & $\begin{array}{c}\% \% \\
\text { Diff. } \\
\end{array}$ & Glass ID & $\begin{array}{c}\text { Oxide/ } \\
\text { Anion } \\
\end{array}$ & $\begin{array}{c}\text { Targeted } \\
\text { Comp. }\end{array}$ & $\begin{array}{l}\text { Meas. } \\
\text { Comp. }\end{array}$ & $\begin{array}{c}\% \% \\
\text { Diff. } \\
\end{array}$ \\
\hline HLP-60 & $\mathrm{Al}_{2} \mathrm{O}_{3}$ & 11.94 & 11.81 & 1.09 & HLP-63 & $\mathrm{Al}_{2} \mathrm{O}_{3}$ & 4.00 & 3.90 & 2.53 \\
\hline HLP-60 & $\mathrm{B}_{2} \mathrm{O}_{3}$ & 12.57 & 12.25 & 2.58 & HLP-63 & $\mathrm{B}_{2} \mathrm{O}_{3}$ & 6.00 & 6.00 & 0.00 \\
\hline HLP-60 & $\mathrm{CaO}$ & 0.01 & 0.02 & 66.67 & HLP-63 & $\mathrm{CaO}$ & 0.01 & 0.01 & 0.00 \\
\hline HLP-60 & $\mathrm{Cr}_{2} \mathrm{O}_{3}$ & 0.09 & 0.10 & 10.53 & HLP-63 & $\mathrm{Cr}_{2} \mathrm{O}_{3}$ & 0.09 & 0.08 & 11.76 \\
\hline HLP-60 & $\mathrm{Fe}_{2} \mathrm{O}_{3}$ & 1.71 & 1.85 & 7.87 & HLP-63 & $\mathrm{Fe}_{2} \mathrm{O}_{3}$ & 15.04 & 14.52 & 3.52 \\
\hline HLP-60 & $\mathrm{K}_{2} \mathrm{O}$ & 0.33 & 0.38 & 14.08 & HLP-63 & $\mathrm{K}_{2} \mathrm{O}$ & 0.33 & 0.38 & 14.08 \\
\hline HLP-60 & $\mathrm{La}_{2} \mathrm{O}_{3}$ & 0.00 & 0.01 & 200.00 & HLP-63 & $\mathrm{La}_{2} \mathrm{O}_{3}$ & 0.00 & 0.01 & 200.00 \\
\hline HLP-60 & $\mathrm{Li}_{2} \mathrm{O}$ & 0.00 & 0.13 & 200.00 & HLP-63 & $\mathrm{Li}_{2} \mathrm{O}$ & 0.00 & 0.11 & 200.00 \\
\hline HLP-60 & $\mathrm{MgO}$ & 4.30 & 3.90 & 9.76 & HLP-63 & $\mathrm{MgO}$ & 4.30 & 3.91 & 9.50 \\
\hline HLP-60 & $\mathrm{MoO}_{3}$ & 0.00 & 0.02 & 200.00 & HLP-63 & $\mathrm{MoO}_{3}$ & 0.00 & 0.02 & 200.00 \\
\hline HLP-60 & $\mathrm{Na}_{2} \mathrm{O}$ & 16.00 & 15.69 & 1.96 & HLP-63 & $\mathrm{Na}_{2} \mathrm{O}$ & 25.14 & 25.65 & 2.01 \\
\hline HLP-60 & $\mathrm{P}_{2} \mathrm{O}_{5}$ & 2.00 & 0.68 & 98.51 & HLP-63 & $\mathrm{P}_{2} \mathrm{O}_{5}$ & 0.04 & 0.08 & 66.67 \\
\hline HLP-60 & $\mathrm{SiO}_{2}$ & 36.00 & 35.31 & 1.94 & HLP-63 & $\mathrm{SiO}_{2}$ & 36.00 & 36.96 & 2.63 \\
\hline HLP-60 & $\mathrm{TiO}_{2}$ & 8.59 & 8.57 & 0.23 & HLP-63 & $\mathrm{TiO}_{2}$ & 8.59 & 8.83 & 2.76 \\
\hline HLP-60 & $\mathrm{ZnO}$ & 0.00 & 0.02 & 200.00 & HLP-63 & $\mathrm{ZnO}$ & 0.00 & 0.00 & \\
\hline HLP-60 & $\mathrm{ZrO}_{2}$ & 6.00 & 4.14 & 36.69 & HLP-63 & $\mathrm{ZrO}_{2}$ & 0.00 & 0.06 & 200.00 \\
\hline HLP-60 & $\mathrm{Cl}$ & 0.35 & 0.31 & 12.12 & HLP-63 & $\mathrm{Cl}$ & 0.35 & 0.36 & 2.82 \\
\hline HLP-60 & $\mathrm{F}$ & 0.01 & 0.11 & 166.67 & HLP-63 & $\mathrm{F}$ & 0.01 & 0.05 & 133.33 \\
\hline HLP-60 & $\mathrm{SO}_{3}$ & 0.09 & 0.09 & 0.00 & HLP-63 & $\mathrm{SO}_{3}$ & 0.09 & 0.14 & 43.48 \\
\hline HLP-60 & TOTAL & 100.00 & 95.38 & 4.73 & HLP-63 & TOTAL & 100.00 & 101.05 & 1.04 \\
\hline HLP-61 & $\mathrm{Al}_{2} \mathrm{O}_{3}$ & 4.00 & 4.08 & 1.98 & HLP-64 & $\mathrm{Al}_{2} \mathrm{O}_{3}$ & 4.00 & 4.04 & 1.00 \\
\hline HLP-61 & $\mathrm{B}_{2} \mathrm{O}_{3}$ & 12.57 & 12.52 & 0.40 & HLP-64 & $\mathrm{B}_{2} \mathrm{O}_{3}$ & 6.00 & 6.09 & 1.49 \\
\hline HLP-61 & $\mathrm{CaO}$ & 5.00 & 4.74 & 5.34 & HLP-64 & $\mathrm{CaO}$ & 0.01 & 0.00 & 200.00 \\
\hline HLP-61 & $\mathrm{Cr}_{2} \mathrm{O}_{3}$ & 0.09 & 0.10 & 10.53 & HLP-64 & $\mathrm{Cr}_{2} \mathrm{O}_{3}$ & 0.09 & 0.07 & 25.00 \\
\hline HLP-61 & $\mathrm{Fe}_{2} \mathrm{O}_{3}$ & 0.00 & 0.13 & 200.00 & HLP-64 & $\mathrm{Fe}_{2} \mathrm{O}_{3}$ & 0.00 & 0.16 & 200.00 \\
\hline HLP-61 & $\mathrm{K}_{2} \mathrm{O}$ & 5.00 & 4.78 & 4.50 & HLP-64 & $\mathrm{K}_{2} \mathrm{O}$ & 5.00 & 4.60 & 8.33 \\
\hline HLP-61 & $\mathrm{La}_{2} \mathrm{O}_{3}$ & 0.00 & 0.01 & 200.00 & HLP-64 & $\mathrm{La}_{2} \mathrm{O}_{3}$ & 0.00 & 0.01 & 200.00 \\
\hline HLP-61 & $\mathrm{Li}_{2} \mathrm{O}$ & 0.00 & 0.14 & 200.00 & HLP-64 & $\mathrm{Li}_{2} \mathrm{O}$ & 0.00 & 0.11 & 200.00 \\
\hline HLP-61 & $\mathrm{MgO}$ & 4.30 & 3.87 & 10.53 & HLP-64 & $\mathrm{MgO}$ & 4.30 & 3.92 & 9.25 \\
\hline HLP-61 & $\mathrm{MoO}_{3}$ & 0.00 & 0.02 & 200.00 & HLP-64 & $\mathrm{MoO}_{3}$ & 0.00 & 0.02 & 200.00 \\
\hline HLP-61 & $\mathrm{Na}_{2} \mathrm{O}$ & 16.00 & 15.92 & 0.50 & HLP-64 & $\mathrm{Na}_{2} \mathrm{O}$ & 16.00 & 15.99 & 0.06 \\
\hline HLP-61 & $\mathrm{P}_{2} \mathrm{O}_{5}$ & 0.04 & 0.07 & 54.55 & HLP-64 & $\mathrm{P}_{2} \mathrm{O}_{5}$ & 2.00 & 1.06 & 61.44 \\
\hline HLP-61 & $\mathrm{SiO}_{2}$ & 39.65 & 39.45 & 0.51 & HLP-64 & $\mathrm{SiO}_{2}$ & 52.00 & 52.96 & 1.83 \\
\hline HLP-61 & $\mathrm{TiO}_{2}$ & 8.59 & 8.46 & 1.52 & HLP-64 & $\mathrm{TiO}_{2}$ & 0.00 & 0.00 & \\
\hline HLP-61 & $\mathrm{ZnO}$ & 4.30 & 3.99 & 7.48 & HLP-64 & $\mathrm{ZnO}$ & 4.14 & 3.73 & 10.42 \\
\hline HLP-61 & $\mathrm{ZrO}_{2}$ & 0.00 & 0.07 & 200.00 & HLP-64 & $\mathrm{ZrO}_{2}$ & 6.00 & 4.24 & 34.38 \\
\hline HLP-61 & $\mathrm{Cl}$ & 0.35 & 0.32 & 8.96 & HLP-64 & $\mathrm{Cl}$ & 0.35 & 0.33 & 5.88 \\
\hline HLP-61 & $\mathrm{F}$ & 0.01 & 0.05 & 133.33 & HLP-64 & $\mathrm{F}$ & 0.01 & 0.05 & 133.33 \\
\hline HLP-61 & $\mathrm{SO}_{3}$ & 0.09 & 0.13 & 36.36 & HLP-64 & $\mathrm{SO}_{3}$ & 0.09 & 0.04 & 76.92 \\
\hline HLP-61 & TOTAL & 100.00 & 98.82 & 1.19 & HLP-64 & TOTAL & 99.99 & 97.40 & 2.62 \\
\hline HLP-62 & $\mathrm{Al}_{2} \mathrm{O}_{3}$ & 4.00 & 4.03 & 0.75 & HLP-65 & $\mathrm{Al}_{2} \mathrm{O}_{3}$ & 4.00 & 3.99 & 0.25 \\
\hline HLP-62 & $\mathrm{B}_{2} \mathrm{O}_{3}$ & 12.57 & 12.78 & 1.66 & HLP-65 & $\mathrm{B}_{2} \mathrm{O}_{3}$ & 6.00 & 6.02 & 0.33 \\
\hline HLP-62 & $\mathrm{CaO}$ & 5.00 & 4.67 & 6.83 & HLP-65 & $\mathrm{CaO}$ & 5.00 & 4.66 & 7.04 \\
\hline HLP-62 & $\mathrm{Cr}_{2} \mathrm{O}_{3}$ & 0.09 & 0.07 & 25.00 & HLP-65 & $\mathrm{Cr}_{2} \mathrm{O}_{3}$ & 0.09 & 0.08 & 11.76 \\
\hline HLP-62 & $\mathrm{Fe}_{2} \mathrm{O}_{3}$ & 0.00 & 0.19 & 200.00 & HLP-65 & $\mathrm{Fe}_{2} \mathrm{O}_{3}$ & 9.82 & 9.90 & 0.81 \\
\hline HLP-62 & $\mathrm{K}_{2} \mathrm{O}$ & 0.33 & 0.37 & 11.43 & HLP-65 & $\mathrm{K}_{2} \mathrm{O}$ & 0.33 & 0.37 & 11.43 \\
\hline HLP-62 & $\mathrm{La}_{2} \mathrm{O}_{3}$ & 0.00 & 0.01 & 200.00 & HLP-65 & $\mathrm{La}_{2} \mathrm{O}_{3}$ & 0.00 & 0.01 & 200.00 \\
\hline HLP-62 & $\mathrm{Li}_{2} \mathrm{O}$ & 0.00 & 0.12 & 200.00 & HLP-65 & $\mathrm{Li}_{2} \mathrm{O}$ & 0.00 & 0.11 & 200.00 \\
\hline HLP-62 & $\mathrm{MgO}$ & 0.00 & 0.00 & & HLP-65 & $\mathrm{MgO}$ & 4.30 & 3.98 & 7.73 \\
\hline HLP-62 & $\mathrm{MoO}_{3}$ & 0.00 & 0.02 & 200.00 & HLP-65 & $\mathrm{MoO}_{3}$ & 0.00 & 0.02 & 200.00 \\
\hline HLP-62 & $\mathrm{Na}_{2} \mathrm{O}$ & 16.00 & 16.41 & 2.53 & HLP-65 & $\mathrm{Na}_{2} \mathrm{O}$ & 16.00 & 16.88 & 5.35 \\
\hline HLP-62 & $\mathrm{P}_{2} \mathrm{O}_{5}$ & 0.04 & 0.07 & 54.55 & HLP-65 & $\mathrm{P}_{2} \mathrm{O}_{5}$ & 2.00 & 1.98 & 1.01 \\
\hline HLP-62 & $\mathrm{SiO}_{2}$ & 46.92 & 48.39 & 3.08 & HLP-65 & $\mathrm{SiO}_{2}$ & 52.00 & 53.40 & 2.66 \\
\hline HLP-62 & $\mathrm{TiO}_{2}$ & 8.59 & 8.56 & 0.35 & HLP-65 & $\mathrm{TiO}_{2}$ & 0.00 & 0.00 & \\
\hline HLP-62 & $\mathrm{ZnO}$ & 0.00 & 0.00 & & HLP-65 & $\mathrm{ZnO}$ & 0.00 & 0.00 & \\
\hline HLP-62 & $\mathrm{ZrO}_{2}$ & 6.00 & 5.52 & 8.33 & HLP-65 & $\mathrm{ZrO}_{2}$ & 0.00 & 0.04 & 200.00 \\
\hline HLP-62 & $\mathrm{Cl}$ & 0.35 & 0.32 & 8.96 & HLP-65 & $\mathrm{Cl}$ & 0.35 & 0.32 & 8.96 \\
\hline HLP-62 & $\mathrm{F}$ & 0.01 & 0.15 & 175.00 & HLP-65 & $\mathrm{F}$ & 0.01 & 0.05 & 133.33 \\
\hline HLP-62 & $\mathrm{SO}_{3}$ & 0.09 & 0.13 & 36.36 & HLP-65 & $\mathrm{SO}_{3}$ & 0.09 & 0.11 & 20.00 \\
\hline HLP-62 & TOTAL & 99.99 & 101.81 & 1.80 & HLP-65 & TOTAL & 99.99 & 101.91 & 1.90 \\
\hline
\end{tabular}




\begin{tabular}{|c|c|c|c|c|c|c|c|c|c|}
\hline Glass ID & $\begin{array}{c}\text { Oxide/ } \\
\text { Anion } \\
\end{array}$ & $\begin{array}{c}\text { Targeted } \\
\text { Comp. }\end{array}$ & $\begin{array}{l}\text { Meas. } \\
\text { Comp. }\end{array}$ & $\begin{array}{c}\% \\
\text { Diff. } \\
\end{array}$ & Glass ID & $\begin{array}{c}\text { Oxide/ } \\
\text { Anion } \\
\end{array}$ & $\begin{array}{c}\text { Targeted } \\
\text { Comp. }\end{array}$ & $\begin{array}{l}\text { Meas. } \\
\text { Comp. }\end{array}$ & $\begin{array}{c}\% \% \\
\text { Diff. } \\
\end{array}$ \\
\hline HLP-66 & $\mathrm{Al}_{2} \mathrm{O}_{3}$ & 4.00 & 4.18 & 4.40 & HLP-69 & $\mathrm{Al}_{2} \mathrm{O}_{3}$ & 11.94 & 11.31 & 5.42 \\
\hline HLP-66 & $\mathrm{B}_{2} \mathrm{O}_{3}$ & 12.57 & 12.57 & 0.00 & HLP-69 & $\mathrm{B}_{2} \mathrm{O}_{3}$ & 6.00 & 6.11 & 1.82 \\
\hline HLP-66 & $\mathrm{CaO}$ & 0.01 & 0.04 & 120.00 & HLP-69 & $\mathrm{CaO}$ & 0.01 & 0.00 & 200.00 \\
\hline HLP-66 & $\mathrm{Cr}_{2} \mathrm{O}_{3}$ & 0.09 & 0.09 & 0.00 & HLP-69 & $\mathrm{Cr}_{2} \mathrm{O}_{3}$ & 0.09 & 0.07 & 25.00 \\
\hline HLP-66 & $\mathrm{Fe}_{2} \mathrm{O}_{3}$ & 5.36 & 5.44 & 1.48 & HLP-69 & $\mathrm{Fe}_{2} \mathrm{O}_{3}$ & 0.24 & 0.38 & 45.16 \\
\hline HLP-66 & $\mathrm{K}_{2} \mathrm{O}$ & 0.33 & 0.41 & 21.62 & HLP-69 & $\mathrm{K}_{2} \mathrm{O}$ & 0.33 & 0.38 & 14.08 \\
\hline HLP-66 & $\mathrm{La}_{2} \mathrm{O}_{3}$ & 0.00 & 0.01 & 200.00 & HLP-69 & $\mathrm{La}_{2} \mathrm{O}_{3}$ & 0.00 & 0.01 & 200.00 \\
\hline HLP-66 & $\mathrm{Li}_{2} \mathrm{O}$ & 0.00 & 0.13 & 200.00 & HLP-69 & $\mathrm{Li}_{2} \mathrm{O}$ & 0.00 & 0.11 & 200.00 \\
\hline HLP-66 & $\mathrm{MgO}$ & 0.00 & 0.00 & & HLP-69 & $\mathrm{MgO}$ & 0.00 & 0.00 & \\
\hline HLP-66 & $\mathrm{MoO}_{3}$ & 0.00 & 0.02 & 200.00 & HLP-69 & $\mathrm{MoO}_{3}$ & 0.00 & 0.02 & 200.00 \\
\hline HLP-66 & $\mathrm{Na}_{2} \mathrm{O}$ & 25.14 & 23.49 & 6.79 & HLP-69 & $\mathrm{Na}_{2} \mathrm{O}$ & 16.00 & 16.94 & 5.71 \\
\hline HLP-66 & $\mathrm{P}_{2} \mathrm{O}_{5}$ & 0.04 & 0.04 & 0.00 & HLP-69 & $\mathrm{P}_{2} \mathrm{O}_{5}$ & 0.04 & 0.09 & 76.92 \\
\hline HLP-66 & $\mathrm{SiO}_{2}$ & 52.00 & 51.51 & 0.95 & HLP-69 & $\mathrm{SiO}_{2}$ & 52.00 & 53.89 & 3.57 \\
\hline HLP-66 & $\mathrm{TiO}_{2}$ & 0.00 & 0.04 & 200.00 & HLP-69 & $\mathrm{TiO}_{2}$ & 8.59 & 8.79 & 2.30 \\
\hline HLP-66 & $\mathrm{ZnO}$ & 0.00 & 0.01 & 200.00 & HLP-69 & $\mathrm{ZnO}$ & 4.30 & 3.94 & 8.74 \\
\hline HLP-66 & $\mathrm{ZrO}_{2}$ & 0.00 & 0.02 & 200.00 & HLP-69 & $\mathrm{ZrO}_{2}$ & 0.00 & 0.07 & 200.00 \\
\hline HLP-66 & $\mathrm{Cl}$ & 0.35 & 0.34 & 2.90 & HLP-69 & $\mathrm{Cl}$ & 0.35 & 0.30 & 15.38 \\
\hline HLP-66 & $\mathrm{F}$ & 0.01 & 0.05 & 133.33 & HLP-69 & $\mathrm{F}$ & 0.01 & 0.05 & 133.33 \\
\hline HLP-66 & $\mathrm{SO}_{3}$ & 0.09 & 0.11 & 20.00 & HLP-69 & $\mathrm{SO}_{3}$ & 0.09 & 0.04 & 76.92 \\
\hline HLP-66 & TOTAL & 99.99 & 98.49 & 1.51 & HLP-69 & TOTAL & 99.99 & 102.50 & 2.48 \\
\hline HLP-67 & $\mathrm{Al}_{2} \mathrm{O}_{3}$ & 4.00 & 4.10 & 2.47 & HLP-70 & $\mathrm{Al}_{2} \mathrm{O}_{3}$ & 11.94 & 11.79 & 1.26 \\
\hline HLP-67 & $\mathrm{B}_{2} \mathrm{O}_{3}$ & 12.57 & 12.32 & 2.01 & HLP-70 & $\mathrm{B}_{2} \mathrm{O}_{3}$ & 6.00 & 6.16 & 2.63 \\
\hline HLP-67 & $\mathrm{CaO}$ & 0.01 & 0.02 & 66.67 & HLP-70 & $\mathrm{CaO}$ & 4.78 & 4.56 & 4.71 \\
\hline HLP-67 & $\mathrm{Cr}_{2} \mathrm{O}_{3}$ & 0.09 & 0.09 & 0.00 & HLP-70 & $\mathrm{Cr}_{2} \mathrm{O}_{3}$ & 0.09 & 0.07 & 25.00 \\
\hline HLP-67 & $\mathrm{Fe}_{2} \mathrm{O}_{3}$ & 4.43 & 4.43 & 0.00 & HLP-70 & $\mathrm{Fe}_{2} \mathrm{O}_{3}$ & 0.00 & 0.23 & 200.00 \\
\hline HLP-67 & $\mathrm{K}_{2} \mathrm{O}$ & 5.00 & 4.73 & 5.55 & HLP-70 & $\mathrm{K}_{2} \mathrm{O}$ & 5.00 & 4.97 & 0.60 \\
\hline HLP-67 & $\mathrm{La}_{2} \mathrm{O}_{3}$ & 0.00 & 0.01 & 200.00 & HLP-70 & $\mathrm{La}_{2} \mathrm{O}_{3}$ & 0.00 & 0.01 & 200.00 \\
\hline HLP-67 & $\mathrm{Li}_{2} \mathrm{O}$ & 0.00 & 0.13 & 200.00 & HLP-70 & $\mathrm{Li}_{2} \mathrm{O}$ & 0.00 & 0.12 & 200.00 \\
\hline HLP-67 & $\mathrm{MgO}$ & 0.00 & 0.00 & & HLP-70 & $\mathrm{MgO}$ & 0.00 & 0.00 & \\
\hline HLP-67 & $\mathrm{MoO}_{3}$ & 0.00 & 0.02 & 200.00 & HLP-70 & $\mathrm{MoO}_{3}$ & 0.00 & 0.02 & 200.00 \\
\hline HLP-67 & $\mathrm{Na}_{2} \mathrm{O}$ & 25.14 & 23.72 & 5.81 & HLP-70 & $\mathrm{Na}_{2} \mathrm{O}$ & 25.14 & 24.31 & 3.36 \\
\hline HLP-67 & $\mathrm{P}_{2} \mathrm{O}_{5}$ & 2.00 & 0.55 & 113.73 & HLP-70 & $\mathrm{P}_{2} \mathrm{O}_{5}$ & 2.00 & 1.93 & 3.56 \\
\hline HLP-67 & $\mathrm{SiO}_{2}$ & 36.00 & 35.26 & 2.08 & HLP-70 & $\mathrm{SiO}_{2}$ & 36.00 & 37.99 & 5.38 \\
\hline HLP-67 & $\mathrm{TiO}_{2}$ & 0.00 & 0.01 & 200.00 & HLP-70 & $\mathrm{TiO}_{2}$ & 8.59 & 8.43 & 1.88 \\
\hline HLP-67 & $\mathrm{ZnO}$ & 4.30 & 3.95 & 8.48 & HLP-70 & $\mathrm{ZnO}$ & 0.00 & 0.00 & \\
\hline HLP-67 & $\mathrm{ZrO}_{2}$ & 6.00 & 3.79 & 45.15 & HLP-70 & $\mathrm{ZrO}_{2}$ & 0.00 & 0.05 & 200.00 \\
\hline HLP-67 & $\mathrm{Cl}$ & 0.35 & 0.35 & 0.00 & HLP-70 & $\mathrm{Cl}$ & 0.35 & 0.37 & 5.56 \\
\hline HLP-67 & $\mathrm{F}$ & 0.01 & 0.05 & 133.33 & HLP-70 & $\mathrm{F}$ & 0.01 & 0.05 & 133.33 \\
\hline HLP-67 & $\mathrm{SO}_{3}$ & 0.09 & 0.11 & 20.00 & HLP-70 & $\mathrm{SO}_{3}$ & 0.09 & 0.09 & 0.00 \\
\hline HLP-67 & TOTAL & 99.99 & 93.60 & 6.60 & HLP-70 & TOTAL & 99.99 & 101.15 & 1.15 \\
\hline HLP-68 & $\mathrm{Al}_{2} \mathrm{O}_{3}$ & 9.64 & 9.41 & 2.41 & HLP-71 & $\mathrm{Al}_{2} \mathrm{O}_{3}$ & 11.94 & 11.84 & 0.84 \\
\hline HLP-68 & $\mathrm{B}_{2} \mathrm{O}_{3}$ & 6.00 & 6.24 & 3.92 & HLP-71 & $\mathrm{B}_{2} \mathrm{O}_{3}$ & 6.00 & 5.90 & 1.68 \\
\hline HLP-68 & $\mathrm{CaO}$ & 5.00 & 4.70 & 6.19 & HLP-71 & $\mathrm{CaO}$ & 5.00 & 4.65 & 7.25 \\
\hline HLP-68 & $\mathrm{Cr}_{2} \mathrm{O}_{3}$ & 0.09 & 0.08 & 11.76 & HLP-71 & $\mathrm{Cr}_{2} \mathrm{O}_{3}$ & 0.09 & 0.09 & 0.00 \\
\hline HLP-68 & $\mathrm{Fe}_{2} \mathrm{O}_{3}$ & 15.77 & 15.90 & 0.82 & HLP-71 & $\mathrm{Fe}_{2} \mathrm{O}_{3}$ & 0.40 & 0.45 & 11.76 \\
\hline HLP-68 & $\mathrm{K}_{2} \mathrm{O}$ & 5.00 & 4.64 & 7.47 & HLP-71 & $\mathrm{K}_{2} \mathrm{O}$ & 0.33 & 0.37 & 11.43 \\
\hline HLP-68 & $\mathrm{La}_{2} \mathrm{O}_{3}$ & 0.00 & 0.01 & 200.00 & HLP-71 & $\mathrm{La}_{2} \mathrm{O}_{3}$ & 0.00 & 0.01 & 200.00 \\
\hline HLP-68 & $\mathrm{Li}_{2} \mathrm{O}$ & 0.00 & 0.12 & 200.00 & HLP-71 & $\mathrm{Li}_{2} \mathrm{O}$ & 0.00 & 0.13 & 200.00 \\
\hline HLP-68 & $\mathrm{MgO}$ & 0.00 & 0.00 & & HLP-71 & $\mathrm{MgO}$ & 4.30 & 3.91 & 9.50 \\
\hline HLP-68 & $\mathrm{MoO}_{3}$ & 0.00 & 0.02 & 200.00 & HLP-71 & $\mathrm{MoO}_{3}$ & 0.00 & 0.02 & 200.00 \\
\hline HLP-68 & $\mathrm{Na}_{2} \mathrm{O}$ & 16.00 & 16.31 & 1.92 & HLP-71 & $\mathrm{Na}_{2} \mathrm{O}$ & 25.14 & 24.47 & 2.70 \\
\hline HLP-68 & $\mathrm{P}_{2} \mathrm{O}_{5}$ & 0.04 & 0.06 & 40.00 & HLP-71 & $\mathrm{P}_{2} \mathrm{O}_{5}$ & 0.04 & 0.04 & 0.00 \\
\hline HLP-68 & $\mathrm{SiO}_{2}$ & 36.00 & 37.78 & 4.83 & HLP-71 & $\mathrm{SiO}_{2}$ & 36.00 & 35.79 & 0.59 \\
\hline HLP-68 & $\mathrm{TiO}_{2}$ & 0.00 & 0.00 & & HLP-71 & $\mathrm{TiO}_{2}$ & 0.00 & 0.01 & 200.00 \\
\hline HLP-68 & $\mathrm{ZnO}$ & 0.00 & 0.00 & & HLP-71 & $\mathrm{ZnO}$ & 4.30 & 3.93 & 8.99 \\
\hline HLP-68 & $\mathrm{ZrO}_{2}$ & 6.00 & 5.63 & 6.36 & HLP-71 & $\mathrm{ZrO}_{2}$ & 6.00 & 6.12 & 1.98 \\
\hline HLP-68 & $\mathrm{Cl}$ & 0.35 & 0.29 & 18.75 & HLP-71 & $\mathrm{Cl}$ & 0.35 & 0.36 & 2.82 \\
\hline HLP-68 & $\mathrm{F}$ & 0.01 & 0.05 & 133.33 & HLP-71 & $\mathrm{F}$ & 0.01 & 0.05 & 133.33 \\
\hline HLP-68 & $\mathrm{SO}_{3}$ & 0.09 & 0.14 & 43.48 & HLP-71 & $\mathrm{SO}_{3}$ & 0.09 & 0.12 & 28.57 \\
\hline HLP-68 & TOTAL & 99.99 & 101.35 & 1.35 & HLP-71 & TOTAL & 99.99 & 98.24 & 1.77 \\
\hline
\end{tabular}




\begin{tabular}{|c|c|c|c|c|c|c|c|c|c|}
\hline Glass ID & $\begin{array}{l}\text { Oxide/ } \\
\text { Anion } \\
\end{array}$ & $\begin{array}{c}\text { Targeted } \\
\text { Comp. } \\
\end{array}$ & $\begin{array}{l}\text { Meas. } \\
\text { Comp. }\end{array}$ & $\begin{array}{c}\% \\
\text { Diff. }\end{array}$ & Glass ID & $\begin{array}{l}\text { Oxide/ } \\
\text { Anion } \\
\end{array}$ & $\begin{array}{c}\text { Targeted } \\
\text { Comp. } \\
\end{array}$ & $\begin{array}{l}\text { Meas. } \\
\text { Comp. }\end{array}$ & $\begin{array}{c}\% \\
\text { Diff. }\end{array}$ \\
\hline HLP-72 & $\mathrm{Al}_{2} \mathrm{O}_{3}$ & 4.00 & 4.01 & 0.25 & HLP-75 & $\overline{\mathrm{Al}_{2} \mathrm{O}_{3}}$ & 7.43 & 7.62 & 2.52 \\
\hline HLP-72 & $\mathrm{B}_{2} \mathrm{O}_{3}$ & 6.00 & 6.15 & 2.47 & HLP-75 & $\mathrm{B}_{2} \mathrm{O}_{3}$ & 8.93 & 9.43 & 5.45 \\
\hline HLP-72 & $\mathrm{CaO}$ & 0.01 & 0.17 & 177.78 & HLP-75 & $\mathrm{CaO}$ & 2.31 & 2.38 & 2.99 \\
\hline HLP-72 & $\mathrm{Cr}_{2} \mathrm{O}_{3}$ & 0.09 & 0.08 & 11.76 & HLP-75 & $\mathrm{Cr}_{2} \mathrm{O}_{3}$ & 0.09 & 0.09 & 0.00 \\
\hline HLP-72 & $\mathrm{Fe}_{2} \mathrm{O}_{3}$ & 15.77 & 15.33 & 2.83 & HLP-75 & $\mathrm{Fe}_{2} \mathrm{O}_{3}$ & 5.54 & 5.85 & 5.44 \\
\hline HLP-72 & $\mathrm{K}_{2} \mathrm{O}$ & 0.33 & 0.37 & 11.43 & HLP-75 & $\mathrm{K}_{2} \mathrm{O}$ & 2.49 & 2.64 & 5.85 \\
\hline HLP-72 & $\mathrm{La}_{2} \mathrm{O}_{3}$ & 0.00 & 0.01 & 200.00 & HLP-75 & $\mathrm{La}_{2} \mathrm{O}_{3}$ & 0.00 & 0.01 & 200.00 \\
\hline HLP-72 & $\mathrm{Li}_{2} \mathrm{O}$ & 0.00 & 0.15 & 200.00 & HLP-75 & $\mathrm{Li}_{2} \mathrm{O}$ & 0.00 & 0.28 & 200.00 \\
\hline HLP-72 & $\mathrm{MgO}$ & 0.00 & 0.04 & 200.00 & HLP-75 & $\mathrm{MgO}$ & 2.00 & 1.95 & 2.53 \\
\hline HLP-72 & $\mathrm{MoO}_{3}$ & 0.00 & 0.02 & 200.00 & HLP-75 & $\mathrm{MoO}_{3}$ & 0.00 & 0.02 & 200.00 \\
\hline HLP-72 & $\mathrm{Na}_{2} \mathrm{O}$ & 16.00 & 16.42 & 2.59 & HLP-75 & $\mathrm{Na}_{2} \mathrm{O}$ & 19.84 & 19.25 & 3.02 \\
\hline HLP-72 & $\mathrm{P}_{2} \mathrm{O}_{5}$ & 2.00 & 0.87 & 78.75 & HLP-75 & $\mathrm{P}_{2} \mathrm{O}_{5}$ & 0.99 & 0.80 & 21.23 \\
\hline HLP-72 & $\mathrm{SiO}_{2}$ & 36.45 & 37.01 & 1.52 & HLP-75 & $\mathrm{SiO}_{2}$ & 41.55 & 42.25 & 1.67 \\
\hline HLP-72 & $\mathrm{TiO}_{2}$ & 8.59 & 8.56 & 0.35 & HLP-75 & $\mathrm{TiO}_{2}$ & 3.68 & 3.66 & 0.54 \\
\hline HLP-72 & $\mathrm{ZnO}$ & 4.30 & 3.86 & 10.78 & HLP-75 & $\mathrm{ZnO}$ & 2.00 & 1.97 & 1.51 \\
\hline HLP-72 & $\mathrm{ZrO}_{2}$ & 6.00 & 3.85 & 43.65 & HLP-75 & $\mathrm{ZrO}_{2}$ & 2.70 & 2.53 & 6.50 \\
\hline HLP-72 & $\mathrm{Cl}$ & 0.35 & 0.33 & 5.88 & HLP-75 & $\mathrm{Cl}$ & 0.35 & 0.28 & 22.22 \\
\hline HLP-72 & $\mathrm{F}$ & 0.01 & 0.05 & 133.33 & HLP-75 & $\mathrm{F}$ & 0.01 & 0.05 & 133.33 \\
\hline HLP-72 & $\mathrm{SO}_{3}$ & 0.09 & 0.14 & 43.48 & HLP-75 & $\mathrm{SO}_{3}$ & 0.09 & 0.10 & 10.53 \\
\hline HLP-72 & TOTAL & 100.00 & 97.42 & 2.61 & HLP-75 & TOTAL & 100.00 & 101.14 & 1.13 \\
\hline HLP-73 & $\mathrm{Al}_{2} \mathrm{O}_{3}$ & 11.94 & 11.81 & 1.09 & HLP-76 & $\mathrm{Al}_{2} \mathrm{O}_{3}$ & 10.00 & 9.97 & 0.30 \\
\hline HLP-73 & $\mathrm{B}_{2} \mathrm{O}_{3}$ & 12.57 & 12.20 & 2.99 & HLP-76 & $\mathrm{B}_{2} \mathrm{O}_{3}$ & 8.00 & 7.85 & 1.89 \\
\hline HLP-73 & $\mathrm{CaO}$ & 0.01 & 0.04 & 120.00 & HLP-76 & $\mathrm{CaO}$ & 0.50 & 0.54 & 7.69 \\
\hline HLP-73 & $\mathrm{Cr}_{2} \mathrm{O}_{3}$ & 0.09 & 0.09 & 0.00 & HLP-76 & $\mathrm{Cr}_{2} \mathrm{O}_{3}$ & 0.20 & 0.19 & 5.13 \\
\hline HLP-73 & $\mathrm{Fe}_{2} \mathrm{O}_{3}$ & 13.59 & 13.49 & 0.74 & HLP-76 & $\mathrm{Fe}_{2} \mathrm{O}_{3}$ & 1.00 & 1.57 & 44.36 \\
\hline HLP-73 & $\mathrm{K}_{2} \mathrm{O}$ & 5.00 & 4.78 & 4.50 & HLP-76 & $\mathrm{K}_{2} \mathrm{O}$ & 1.50 & 1.64 & 8.92 \\
\hline HLP-73 & $\mathrm{La}_{2} \mathrm{O}_{3}$ & 0.00 & 0.01 & 200.00 & HLP-76 & $\mathrm{La}_{2} \mathrm{O}_{3}$ & 0.01 & 0.01 & 0.00 \\
\hline HLP-73 & $\mathrm{Li}_{2} \mathrm{O}$ & 0.00 & 0.13 & 200.00 & HLP-76 & $\mathrm{Li}_{2} \mathrm{O}$ & 0.10 & 0.18 & 57.14 \\
\hline HLP-73 & $\mathrm{MgO}$ & 4.30 & 3.91 & 9.50 & HLP-76 & $\mathrm{MgO}$ & 0.10 & 0.09 & 10.53 \\
\hline HLP-73 & $\mathrm{MoO}_{3}$ & 0.00 & 0.02 & 200.00 & HLP-76 & $\mathrm{MoO}_{3}$ & 0.00 & 0.09 & 200.00 \\
\hline HLP-73 & $\mathrm{Na}_{2} \mathrm{O}$ & 16.00 & 15.56 & 2.79 & HLP-76 & $\mathrm{Na}_{2} \mathrm{O}$ & 20.00 & 19.38 & 3.15 \\
\hline HLP-73 & $\mathrm{P}_{2} \mathrm{O}_{5}$ & 0.04 & 0.05 & 22.22 & HLP-76 & $\mathrm{P}_{2} \mathrm{O}_{5}$ & 0.50 & 0.52 & 3.92 \\
\hline HLP-73 & $\mathrm{SiO}_{2}$ & 36.00 & 35.32 & 1.91 & HLP-76 & $\mathrm{SiO}_{2}$ & 54.37 & 55.46 & 0.83 \\
\hline HLP-73 & $\mathrm{TiO}_{2}$ & 0.00 & 0.02 & 200.00 & HLP-76 & $\mathrm{TiO}_{2}$ & 0.10 & 0.13 & 26.09 \\
\hline HLP-73 & $\mathrm{ZnO}$ & 0.00 & 0.01 & 200.00 & HLP-76 & $\mathrm{ZnO}$ & 0.00 & 0.01 & 200.00 \\
\hline HLP-73 & $\mathrm{ZrO}_{2}$ & 0.00 & 0.01 & 200.00 & HLP-76 & $\mathrm{ZrO}_{2}$ & 1.00 & 1.11 & 10.43 \\
\hline HLP-73 & $\mathrm{Cl}$ & 0.35 & 0.32 & 8.96 & HLP-76 & $\mathrm{Cl}$ & 0.80 & 0.11 & 151.65 \\
\hline HLP-73 & $\mathrm{F}$ & 0.01 & 0.05 & 133.33 & HLP-76 & $\mathrm{F}$ & 1.00 & 0.86 & 15.05 \\
\hline HLP-73 & $\mathrm{SO}_{3}$ & 0.09 & 0.14 & 43.48 & HLP-76 & $\mathrm{SO}_{3}$ & 0.20 & 0.20 & 0.00 \\
\hline HLP-73 & TOTAL & 99.99 & 97.96 & 2.05 & HLP-76 & TOTAL & 99.38 & 99.91 & 0.10 \\
\hline HLP-74 & $\mathrm{Al}_{2} \mathrm{O}_{3}$ & 11.94 & 11.93 & 0.08 & HLP-77 & $\mathrm{Al}_{2} \mathrm{O}_{3}$ & 10.00 & 9.58 & 4.29 \\
\hline HLP-74 & $\mathrm{B}_{2} \mathrm{O}_{3}$ & 12.57 & 12.45 & 0.96 & HLP-77 & $\mathrm{B}_{2} \mathrm{O}_{3}$ & 8.00 & 7.90 & 1.26 \\
\hline HLP-74 & $\mathrm{CaO}$ & 5.00 & 4.73 & 5.55 & HLP-77 & $\mathrm{CaO}$ & 0.50 & 0.49 & 2.02 \\
\hline HLP-74 & $\mathrm{Cr}_{2} \mathrm{O}_{3}$ & 0.09 & 0.08 & 11.76 & HLP-77 & $\mathrm{Cr}_{2} \mathrm{O}_{3}$ & 0.20 & 0.18 & 10.53 \\
\hline HLP-74 & $\mathrm{Fe}_{2} \mathrm{O}_{3}$ & 11.31 & 11.08 & 2.05 & HLP-77 & $\mathrm{Fe}_{2} \mathrm{O}_{3}$ & 1.00 & 1.67 & 50.19 \\
\hline HLP-74 & $\mathrm{K}_{2} \mathrm{O}$ & 0.33 & 0.42 & 24.00 & HLP-77 & $\mathrm{K}_{2} \mathrm{O}$ & 1.50 & 1.56 & 3.92 \\
\hline HLP-74 & $\mathrm{La}_{2} \mathrm{O}_{3}$ & 0.00 & 0.01 & 200.00 & HLP-77 & $\mathrm{La}_{2} \mathrm{O}_{3}$ & 0.01 & 0.01 & 0.00 \\
\hline HLP-74 & $\mathrm{Li}_{2} \mathrm{O}$ & 0.00 & 0.14 & 200.00 & HLP-77 & $\mathrm{Li}_{2} \mathrm{O}$ & 0.10 & 0.19 & 62.07 \\
\hline HLP-74 & $\mathrm{MgO}$ & 0.00 & 0.00 & & HLP-77 & $\mathrm{MgO}$ & 0.10 & 0.06 & 50.00 \\
\hline HLP-74 & $\mathrm{MoO}_{3}$ & 0.00 & 0.02 & 200.00 & HLP-77 & $\mathrm{MoO}_{3}$ & 0.00 & 0.08 & 200.00 \\
\hline HLP-74 & $\mathrm{Na}_{2} \mathrm{O}$ & 16.00 & 15.73 & 1.70 & HLP-77 & $\mathrm{Na}_{2} \mathrm{O}$ & 20.00 & 20.29 & 1.44 \\
\hline HLP-74 & $\mathrm{P}_{2} \mathrm{O}_{5}$ & 2.00 & 2.01 & 0.50 & HLP-77 & $\mathrm{P}_{2} \mathrm{O}_{5}$ & 0.50 & 0.52 & 3.92 \\
\hline HLP-74 & $\mathrm{SiO}_{2}$ & 36.00 & 35.84 & 0.45 & HLP-77 & $\mathrm{SiO}_{2}$ & 54.37 & 56.12 & 2.02 \\
\hline HLP-74 & $\mathrm{TiO}_{2}$ & 0.00 & 0.00 & & HLP-77 & $\mathrm{TiO}_{2}$ & 0.10 & 0.08 & 22.22 \\
\hline HLP-74 & $\mathrm{ZnO}$ & 4.30 & 4.01 & 6.98 & HLP-77 & $\mathrm{ZnO}$ & 0.00 & 0.00 & \\
\hline HLP-74 & $\mathrm{ZrO}_{2}$ & 0.00 & 0.00 & & HLP-77 & $\mathrm{ZrO}_{2}$ & 1.00 & 1.01 & 1.00 \\
\hline HLP-74 & $\mathrm{Cl}$ & 0.35 & 0.34 & 2.90 & HLP-77 & $\mathrm{Cl}$ & 0.80 & 0.10 & 155.56 \\
\hline HLP-74 & $\mathrm{F}$ & 0.01 & 0.05 & 133.33 & HLP-77 & $\mathrm{F}$ & 1.00 & 0.86 & 15.05 \\
\hline HLP-74 & $\mathrm{SO}_{3}$ & 0.09 & 0.10 & 10.53 & HLP-77 & $\mathrm{SO}_{3}$ & 0.20 & 0.19 & 5.13 \\
\hline HLP-74 & TOTAL & 99.99 & 98.93 & 1.07 & HLP-77 & TOTAL & 99.38 & 100.90 & 0.89 \\
\hline
\end{tabular}

NOTE: All glasses listed above had a target $\mathrm{ReO}_{2}$ composition of $0.01 \%$, with the exceptions of glasses HLP-46 through HLP-56, and HLP-76 and HLP-77. They had a target $\mathrm{ReO}_{2}$ composition of $0.00 \%$. However, $\mathrm{ReO}_{2}$ does not appear in this Table since it was not analyzed for (measured composition is unknown) 
Appendix B

\section{PCT-A and PCT-B Data for the HLP Glasses}




\section{Appendix B: PCT-A and PCT-B Data for the HLP Glasses}

\section{Measured Concentrations in 10,000-hour (Phase I) PCT-B Solutions}

Table B-1. Measured concentrations for the 10,000-h Hanford PCT-B series of Phase I glasses. Results reported on $12 / 7 / 2000$. Test temperature $=90^{\circ} \mathrm{C}$, test duration $=10,000-\mathrm{h},(\mathrm{S} / \mathrm{V}) \approx 20,000 / \mathrm{m}$, and dilution factor $=5 / 3$.

\begin{tabular}{|c|c|c|c|c|c|c|}
\hline \multicolumn{7}{|c|}{ Diluted Concentration. $b_{i}$ in Test Solution $(\mathrm{mg} / \mathrm{L})$} \\
\hline Sample ID & pH & B & $\mathbf{K}$ & $\mathbf{L i}$ & $\mathbf{N a}$ & Si \\
\hline STD & NA & 18.6 & 10.3 & 11.1 & 79.1 & 47.5 \\
\hline Blank 1 & 6.03 & 0.424 & $<0.290$ & $<0.040$ & $<0.100$ & $<0.790$ \\
\hline Blank 2 & --- & $<0.150$ & $<0.290$ & $<0.040$ & 0.133 & $<0.790$ \\
\hline Blank 3 & --- & 0.275 & $<0.290$ & $<0.040$ & 0.646 & 1.50 \\
\hline Blank 4 & 6.61 & 0.289 & 1.79 & $<0.040$ & 1.47 & 1.56 \\
\hline Blank 5 & 5.39 & $<0.150$ & $<0.290$ & $<0.040$ & 0.332 & $<0.790$ \\
\hline HLP-1 & 11.64 & 349 & $<2.90$ & $<0.400$ & 1140 & 191 \\
\hline HLP-2 & 11.00 & 26800 & 1064 & $<0.400$ & 62000 & 7720 \\
\hline HLP-3 & 11.25 & 216 & $<2.90$ & $<0.400$ & 734 & 158 \\
\hline HLP-4 & 11.00 & 18500 & 535 & $<0.400$ & 40400 & 3490 \\
\hline HLP-5 & 11.00 & 1280 & 14.4 & $<0.400$ & 3730 & 284 \\
\hline HLP-6 & 11.11 & 145 & $<2.90$ & $<0.400$ & 501 & 63.1 \\
\hline HLP-7 & 11.46 & 226 & $<2.90$ & $<0.400$ & 731 & 96.0 \\
\hline HLP-8 & 12.46 & 144 & $<2.90$ & $<0.400$ & 1210 & 1040 \\
\hline HLP-9 & 10.63 & 746 & $<2.90$ & $<0.400$ & 1600 & 79.0 \\
\hline HLP-10 & 11.00 & 143 & $<2.90$ & $<0.400$ & 822 & 193 \\
\hline STD & NA & 18.6 & 10.0 & 10.4 & 78.1 & 48.2 \\
\hline HLP-11 & 11.00 & 300 & $<2.90$ & $<0.400$ & 904 & 210 \\
\hline HLP-12 & 10.00 & 245 & $<2.90$ & $<0.400$ & 826 & 149 \\
\hline HLP-13 & 11.94 & 366 & $<2.90$ & $<0.400$ & 1300 & 207 \\
\hline HLP-14 & 11.74 & 444 & $<2.90$ & $<0.400$ & 1330 & 1670 \\
\hline HLP-15 & 11.59 & 207 & $<2.90$ & $<0.400$ & 772 & 150 \\
\hline HLP-16 & 11.89 & 325 & $<2.90$ & $<0.400$ & 1090 & 167 \\
\hline HLP-17 & 11.55 & 288 & $<2.90$ & $<0.400$ & 1090 & 164 \\
\hline HLP- 18 & 11.84 & 390 & $<2.90$ & $<0.400$ & 1330 & 207 \\
\hline HLP-19 & 11.62 & 151 & $<2.90$ & $<0.400$ & 605 & 101 \\
\hline HLP-20 & 11.78 & 261 & $<2.90$ & $<0.400$ & 904 & 149 \\
\hline STD & NA & 18.5 & 9.51 & 10.4 & 78.9 & 48 \\
\hline HLP-21 & 11.63 & 356 & $<2.90$ & $<0.400$ & 1160 & 194 \\
\hline HLP-22 & 10.00 & 196 & $<2.90$ & $<0.400$ & 469 & 75.6 \\
\hline HLP-23 & 12.54 & 2150 & 26.4 & $<0.400$ & 7170 & 179 \\
\hline HLP-24 & 10.48 & 244 & $<2.90$ & $<0.400$ & 691 & 112 \\
\hline HLP-25 & 11.77 & 320 & $<2.90$ & $<0.400$ & 1060 & 207 \\
\hline HLP-26 & 11.71 & 338 & $<2.90$ & $<0.400$ & 1160 & 173 \\
\hline HLP-27 & 12.04 & 24000 & 615 & 1.58 & 73900 & 45200 \\
\hline HLP-28 & 9.53 & 360 & $<2.90$ & 0.419 & 675 & 169 \\
\hline HLP-29 & 10.00 & 12700 & 517 & $<0.400$ & 57400 & 30800 \\
\hline HLP-30 & 10.89 & 22.5 & $<2.90$ & $<0.400$ & 256 & 97.7 \\
\hline STD & NA & 18.4 & 10.2 & 10.8 & 77.9 & 47.8 \\
\hline HLP-31 & 11.81 & 3130 & 47 & $<0.400$ & 8970 & 289 \\
\hline HLP-32 & 10.31 & 501 & $<2.90$ & $<0.400$ & 946 & 92.6 \\
\hline HLP-33 & 12.00 & 2170 & 83.3 & $<0.400$ & 7130 & 5410 \\
\hline HLP-34 & 11.22 & 52.1 & $<2.90$ & $<0.400$ & 417 & 169 \\
\hline
\end{tabular}

B. 1 


\begin{tabular}{ccccccc}
\hline Sample ID & $\mathbf{~ p H}$ & $\mathbf{B}$ & $\mathbf{K}$ & $\mathbf{L i}$ & $\mathbf{N a}$ & $\mathbf{S i}$ \\
\hline HLP-35 & 12.49 & 1690 & 45.6 & $<0.400$ & 4020 & 188 \\
HLP-36 & 9.75 & 912 & $<2.90$ & $<0.400$ & 1350 & 29.8 \\
HLP-37 & 13.23 & 8390 & 552 & $<0.400$ & 29100 & 2460 \\
HLP-38 & 11.72 & 75.3 & $<2.90$ & $<0.400$ & 455 & 63.7 \\
HLP-39 & 12.66 & 5200 & 139 & $<0.400$ & 11800 & 1030 \\
HLP-40Q & 10.51 & 3370 & 71.8 & $<0.400$ & 7460 & 144 \\
HLP-40 & 10.05 & 911 & $<2.90$ & $<0.400$ & 1720 & 61.1 \\
STD & NA & 18.1 & 10.2 & 10.9 & 75.5 & 46.4 \\
HLP-41 & 13.18 & 4640 & 265 & $<0.400$ & 18800 & 2740 \\
HLP-42Q & 12.42 & 1510 & 25.1 & $<0.400$ & 3950 & 357 \\
HLP-42 & 12.32 & 882 & 2.91 & $<0.400$ & 2560 & 500 \\
HLP-43 & 11.64 & 335 & $<2.90$ & $<0.400$ & 1160 & 210 \\
HLP-44 & 11.65 & 299 & $<2.90$ & $<0.400$ & 1000 & 179 \\
HLP-45 & 11.56 & 253 & $<2.90$ & $<0.400$ & 1010 & 184 \\
HLP-46 & 11.00 & 10700 & 1040 & 2.46 & 53400 & 39000 \\
HLP-47 & 11.72 & 12200 & 673 & 118 & 47000 & 30300 \\
HLP-48 & 12.20 & 397 & 103 & $<0.400$ & 1480 & 113 \\
HLP-49 & 12.01 & 458 & 6.07 & 199 & 797 & 1080 \\
STD & NA & 18.2 & 10.9 & 10.9 & 77.3 & 46.8 \\
HLP-51 & 12.17 & 257 & 34.7 & $<0.400$ & 1060 & 110 \\
HLP-52 & 11.00 & 5.54 & 4050 & $<0.400$ & 68200 & 33900 \\
HLP-53 & 11.00 & 8950 & 3920 & 108 & 53600 & 9040 \\
HLP-54 & 11.54 & 309 & $<2.90$ & $<0.400$ & 1120 & 127 \\
HLP-55 & 11.18 & 598 & $<2.90$ & $<0.400$ & 2200 & 1100 \\
Blank 6 & 5.12 & $<0.150$ & $<0.290$ & $<0.040$ & $<0.100$ & $<0.790$ \\
Blank 7 & 7.32 & 0.380 & $<0.290$ & $<0.040$ & 0.114 & $<0.790$ \\
Blank 8 & 5.32 & 0.513 & $<0.290$ & $<0.040$ & 0.335 & $<0.790$ \\
Blank 9 & 6.57 & 0.343 & $<0.290$ & $<0.040$ & 0.550 & 0.837 \\
Blank 10 & 6.08 & $<0.150$ & $<0.290$ & $<0.040$ & $<0.100$ & $<0.790$ \\
STD & NA & 18.3 & 10.0 & 10.9 & 75.8 & 46.8 \\
\hline
\end{tabular}


Table B-2a. Ranking of Glasses by Normalized Boron Release of Phase I Glasses (10 000-h) (Ascending Order)

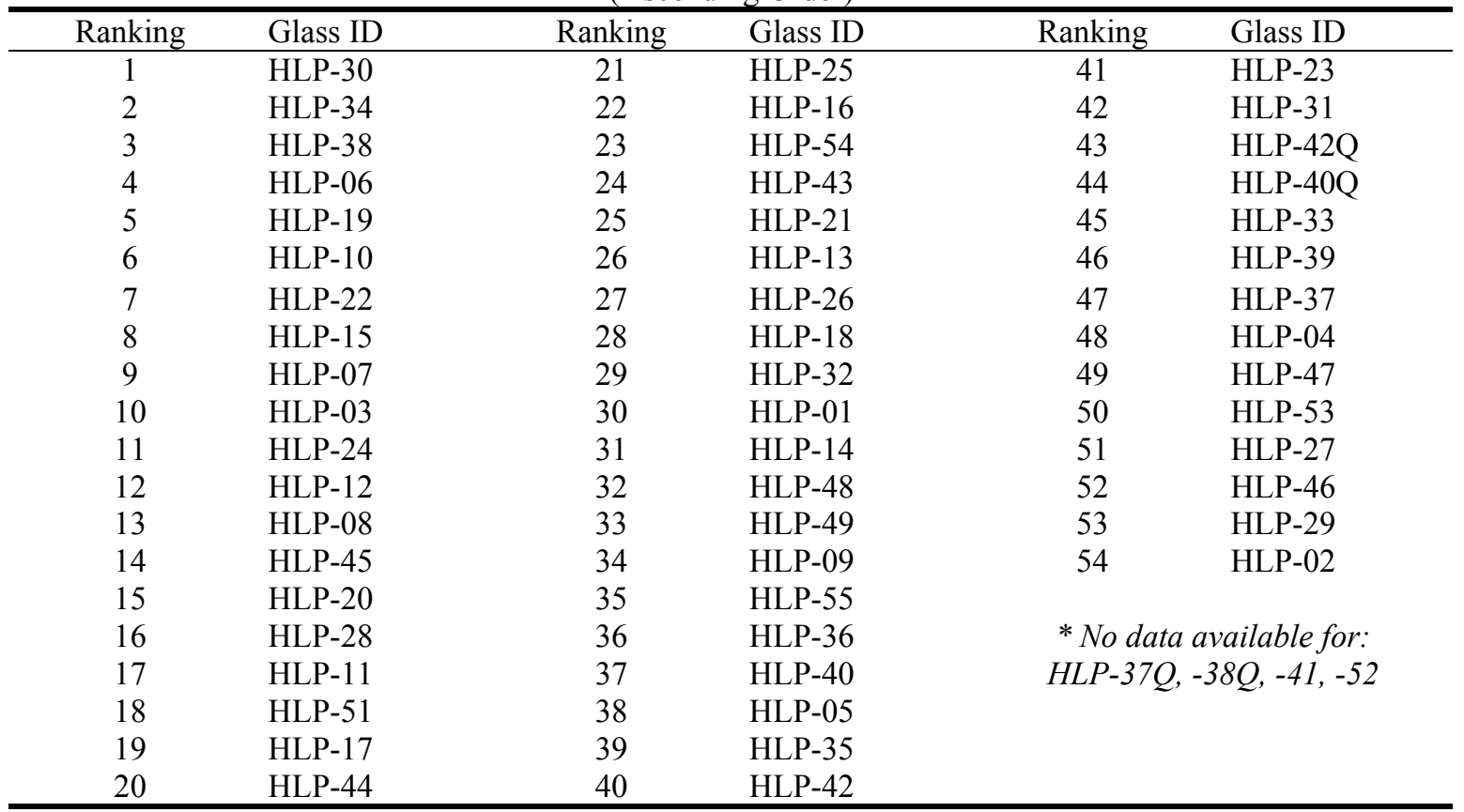

Table B-2b. Ranking of Glasses by Normalized Sodium Release of Phase I Glasses (10 000 hours) (Ascending Order)

\begin{tabular}{cccccc}
\hline Ranking & Glass ID & Ranking & Glass ID & Ranking & Glass ID \\
\hline 1 & HLP-30 & 21 & HLP-54 & 41 & HLP-42Q \\
2 & HLP-06 & 22 & HLP-17 & 42 & HLP-33 \\
3 & HLP-34 & 23 & HLP-32 & 43 & HLP-23 \\
4 & HLP-22 & 24 & HLP-01 & 44 & HLP-31 \\
5 & HLP-38 & 25 & HLP-43 & 45 & HLP-40Q \\
6 & HLP-19 & 26 & HLP-21 & 46 & HLP-39 \\
7 & HLP-07 & 27 & HLP-08 & 47 & HLP-41 \\
8 & HLP-24 & 28 & HLP-26 & 48 & HLP-37 \\
9 & HLP-03 & 29 & HLP-14 & 49 & HLP-04 \\
10 & HLP-15 & 30 & HLP-18 & 50 & HLP-47 \\
11 & HLP-28 & 31 & HLP-13 & 51 & HLP-02 \\
12 & HLP-10 & 32 & HLP-48 & 52 & HLP-52 \\
13 & HLP-12 & 33 & HLP-19 & 53 & HLP-29 \\
14 & HLP-20 & 34 & HLP-49 & 54 & HLP-46 \\
15 & HLP-11 & 35 & HLP-36 & 55 & HLP-53 \\
16 & HLP-44 & 36 & HLP-40 & 56 & HLP-27 \\
17 & HLP-45 & HLP-55 & & No data available for: \\
18 & HLP-16 & 37 & HLP-42 & HLP-37Q, -38Q \\
\hline
\end{tabular}




\section{PCT-B Normalized Release Information for Phase I Glasses}

Table B-3a. Targeted normalized release values for the PCT-B boron, sodium, and silicon results for the Hanford glasses $\left(\right.$ Phase I). Test temperature $=90^{\circ} \mathrm{C}$; test duration $=10,100,1000,5000$, and 10,000 hours; and $(\mathrm{S} / \mathrm{V}) \approx 20,000 / \mathrm{m}$.

\begin{tabular}{|c|c|c|c|c|c|c|c|c|}
\hline \multirow[b]{2}{*}{ SampleID } & \multirow{2}{*}{$\begin{array}{l}\text { Time, } t \\
\text { (hours) }\end{array}$} & \multirow{2}{*}{$\begin{array}{l}\text { (S/V)t } \\
(\mathbf{h} / \mathbf{m})\end{array}$} & \multicolumn{3}{|c|}{$N C_{i}(g / L)$} & \multicolumn{3}{|c|}{$N_{i}\left(g / m^{2}\right)$} \\
\hline & & & B & $\mathbf{N a}$ & $\mathbf{S i}$ & B & $\mathbf{N a}$ & $\mathbf{S i}$ \\
\hline HLP-01 & 10 & $2 \times 10^{5}$ & 0.71 & 1.05 & 0.34 & 0.036 & 0.053 & 0.02 \\
\hline HLP-01 & 100 & $2 \times 10^{6}$ & 3.26 & 2.90 & 0.67 & 0.16 & 0.14 & 0.03 \\
\hline HLP-01 & 1000 & $2 \times 10^{7}$ & 7.46 & 5.67 & 0.92 & 0.37 & 0.28 & 0.05 \\
\hline HLP-01 & 5000 & $1.02 \times 10^{8}$ & 12.14 & 7.82 & 0.49 & 0.60 & 0.38 & 0.02 \\
\hline HLP-01 & 10000 & $2 \times 10^{9}$ & 18.73 & 12.81 & 1.39 & 0.92 & 0.63 & 0.07 \\
\hline HLP-02 & 10 & $2 \times 10^{5}$ & 7.60 & 5.50 & 0.70 & 0.38 & 0.27 & 0.04 \\
\hline HLP-02 & 100 & $2 \times 10^{6}$ & 22.71 & 15.55 & 1.13 & 1.14 & 0.78 & 0.06 \\
\hline HLP-02 & 1000 & $2 \times 10^{7}$ & 42.99 & 25.47 & 1.60 & 2.15 & 1.27 & 0.08 \\
\hline HLP-02 & 5000 & $9.96 \times 10^{7}$ & 986.85 & 447.46 & 29.06 & 49.56 & 22.47 & 1.46 \\
\hline HLP-02 & 10000 & $2 \times 10^{9}$ & 1144.47 & 554.18 & 76.48 & 57.47 & 27.83 & 3.84 \\
\hline HLP-03 & 10 & $2 \times 10^{5}$ & 0.57 & 0.90 & 0.33 & 0.029 & 0.045 & 0.02 \\
\hline HLP-03 & 100 & $2 \times 10^{6}$ & 2.81 & 2.63 & 0.68 & 0.14 & 0.13 & 0.03 \\
\hline HLP-03 & 1000 & $2 \times 10^{7}$ & 6.26 & 4.42 & 0.91 & 0.31 & 0.22 & 0.04 \\
\hline HLP-03 & 5000 & $1.02 \times 10^{8}$ & 11.73 & 6.72 & 0.59 & 0.57 & 0.33 & 0.03 \\
\hline HLP-03 & 10000 & $2 \times 10^{9}$ & 12.30 & 8.75 & 1.08 & 0.60 & 0.43 & 0.05 \\
\hline HLP-04 & 10 & $2 \times 10^{5}$ & 2.73 & 0.26 & 0.52 & 0.14 & 0.01 & 0.03 \\
\hline HLP-04 & 100 & $2 \times 10^{6}$ & 15.40 & 9.72 & 0.98 & 0.77 & 0.49 & 0.05 \\
\hline HLP-04 & 1000 & $2 \times 10^{7}$ & 31.20 & 17.91 & 1.34 & 1.56 & 0.90 & 0.07 \\
\hline HLP-04 & 5000 & $1.00 \times 10^{8}$ & 179.54 & 91.93 & 6.47 & 8.95 & 4.58 & 0.32 \\
\hline HLP-04 & 10000 & $2 \times 10^{9}$ & 843.01 & 385.17 & 31.12 & 42.03 & 19.20 & 1.55 \\
\hline HLP-05 & 10 & $2 \times 10^{5}$ & 1.77 & 1.74 & 0.63 & 0.09 & 0.09 & 0.03 \\
\hline HLP-05 & 100 & $2 \times 10^{6}$ & 27.25 & 16.97 & 3.72 & 1.36 & 0.85 & 0.18 \\
\hline HLP-05 & 1000 & $2 \times 10^{7}$ & 61.89 & 34.78 & 6.65 & 3.09 & 1.74 & 0.33 \\
\hline HLP-05 & 5000 & $1.01 \times 10^{8}$ & 72.22 & 37.46 & 4.08 & 3.59 & 1.86 & 0.20 \\
\hline HLP-05 & 10000 & $2 \times 10^{9}$ & 66.58 & 40.59 & 2.00 & 3.31 & 2.02 & 0.10 \\
\hline HLP-06 & 10 & $2 \times 10^{5}$ & 0.34 & 0.74 & 0.29 & 0.017 & 0.037 & 0.01 \\
\hline HLP-06 & 100 & $2 \times 10^{6}$ & 1.91 & 1.76 & 0.42 & 0.10 & 0.09 & 0.02 \\
\hline HLP-06 & 1000 & $2 \times 10^{7}$ & 2.87 & 2.69 & 0.52 & 0.14 & 0.13 & 0.02 \\
\hline HLP-06 & 5000 & $1.05 \times 10^{8}$ & 7.88 & 4.94 & 0.34 & 0.38 & 0.24 & 0.02 \\
\hline HLP-06 & 10000 & $2 \times 10^{9}$ & 8.22 & 5.94 & 0.48 & 0.39 & 0.28 & 0.02 \\
\hline HLP-07 & 10 & $2 \times 10^{5}$ & 0.50 & 0.91 & 0.38 & 0.03 & 0.05 & 0.02 \\
\hline HLP-07 & 100 & $2 \times 10^{6}$ & 2.49 & 2.16 & 0.59 & 0.12 & 0.11 & 0.03 \\
\hline HLP-07 & 1000 & $2 \times 10^{7}$ & 4.91 & 4.05 & 0.69 & 0.25 & 0.20 & 0.03 \\
\hline HLP-07 & 5000 & $1.04 \times 10^{8}$ & 11.30 & 6.80 & 0.46 & 0.55 & 0.33 & 0.02 \\
\hline HLP-07 & 10000 & $2 \times 10^{9}$ & 12.39 & 8.39 & 0.71 & 0.60 & 0.41 & 0.03 \\
\hline HLP-08 & 10 & $2 \times 10^{5}$ & 0.37 & 1.24 & 0.44 & 0.018 & 0.062 & 0.02 \\
\hline HLP-08 & 100 & $2 \times 10^{6}$ & 2.36 & 2.96 & 0.87 & 0.12 & 0.15 & 0.04 \\
\hline HLP-08 & 1000 & $2 \times 10^{7}$ & 3.32 & 5.22 & 1.17 & 0.17 & 0.26 & 0.06 \\
\hline HLP-08 & 5000 & $9.99 \times 10^{7}$ & 6.57 & 7.83 & 0.86 & 0.33 & 0.39 & 0.04 \\
\hline HLP-08 & 10000 & $2 \times 10^{9}$ & 12.88 & 13.02 & 7.24 & 0.64 & 0.65 & 0.36 \\
\hline HLP-09 & 10 & $2 \times 10^{5}$ & 0.77 & 1.04 & 0.33 & 0.039 & 0.052 & 0.02 \\
\hline HLP-09 & 100 & $2 \times 10^{6}$ & 4.74 & 3.29 & 0.55 & 0.24 & 0.16 & 0.03 \\
\hline HLP-09 & 1000 & $2 \times 10^{7}$ & 16.15 & 8.97 & 0.60 & 0.81 & 0.45 & 0.03 \\
\hline HLP-09 & 5000 & $1.03 \times 10^{8}$ & 16.51 & 8.71 & 0.25 & 0.80 & 0.42 & 0.01 \\
\hline
\end{tabular}




\begin{tabular}{|c|c|c|c|c|c|c|c|c|}
\hline \multirow[b]{2}{*}{ SampleID } & \multirow{2}{*}{$\begin{array}{l}\text { Time, t } \\
\text { (hours) }\end{array}$} & \multirow{2}{*}{$\begin{array}{l}(\mathbf{S} / \mathbf{V}) \mathbf{t} \\
(\mathbf{h} / \mathbf{m})\end{array}$} & \multicolumn{3}{|c|}{$\mathrm{NC}_{\mathrm{i}}(\mathrm{g} / \mathrm{L})$} & \multicolumn{3}{|c|}{$\mathrm{NL}_{\mathrm{i}}\left(\mathrm{g} / \mathrm{m}^{2}\right)$} \\
\hline & & & B & $\mathrm{Na}$ & $\mathbf{S i}$ & B & $\mathrm{Na}$ & $\mathbf{S i}$ \\
\hline HLP-09 & 10000 & $2 \times 10^{9}$ & 33.37 & 18.38 & 0.59 & 1.61 & 0.89 & 0.03 \\
\hline HLP-10 & 10 & $2 \times 10^{5}$ & 0.40 & 1.03 & 0.38 & 0.020 & 0.052 & 0.02 \\
\hline HLP-10 & 100 & $2 \times 10^{6}$ & 2.60 & 2.75 & 0.77 & 0.13 & 0.14 & 0.04 \\
\hline HLP-10 & 1000 & $2 \times 10^{7}$ & 6.57 & 4.14 & 0.81 & 0.33 & 0.21 & 0.04 \\
\hline HLP-10 & 5000 & $1.03 \times 10^{8}$ & 8.73 & 7.43 & 0.77 & 0.43 & 0.36 & 0.04 \\
\hline HLP-10 & 10000 & $2 \times 10^{9}$ & 9.60 & 9.03 & 1.37 & 0.47 & 0.44 & 0.07 \\
\hline HLP-11 & 10 & $2 \times 10^{5}$ & 1.18 & 1.42 & 0.48 & 0.06 & 0.07 & 0.02 \\
\hline HLP-11 & 100 & $2 \times 10^{6}$ & 9.38 & 6.25 & 1.55 & 0.47 & 0.31 & 0.07 \\
\hline HLP-11 & 1000 & $2 \times 10^{7}$ & 16.69 & 10.46 & 1.70 & 0.83 & 0.52 & 0.08 \\
\hline HLP-11 & 5000 & $1.05 \times 10^{8}$ & 14.97 & 8.47 & 0.61 & 0.71 & 0.40 & 0.03 \\
\hline HLP-11 & 10000 & $2 \times 10^{9}$ & 15.22 & 9.60 & 1.44 & 0.73 & 0.46 & 0.07 \\
\hline HLP-12 & 10 & $2 \times 10^{5}$ & 0.53 & 0.94 & 0.38 & 0.027 & 0.047 & 0.02 \\
\hline HLP-12 & 100 & $2 \times 10^{6}$ & 2.83 & 2.50 & 0.66 & 0.14 & 0.12 & 0.03 \\
\hline HLP-12 & 1000 & $2 \times 10^{7}$ & 5.46 & 4.40 & 0.86 & 0.27 & 0.22 & 0.04 \\
\hline HLP-12 & 5000 & $1.00 \times 10^{8}$ & 11.03 & 7.08 & 0.55 & 0.55 & 0.35 & 0.03 \\
\hline HLP-12 & 10000 & $2 \times 10^{9}$ & 13.66 & 9.64 & 1.12 & 0.68 & 0.48 & 0.06 \\
\hline HLP-13 & 10 & $2 \times 10^{5}$ & 0.61 & 1.12 & 0.41 & 0.031 & 0.056 & 0.02 \\
\hline HLP-13 & 100 & $2 \times 10^{6}$ & 4.69 & 3.68 & 0.92 & 0.23 & 0.18 & 0.04 \\
\hline HLP-13 & 1000 & $2 \times 10^{7}$ & 9.93 & 6.69 & 1.13 & 0.50 & 0.33 & 0.05 \\
\hline HLP-13 & 5000 & $1.03 \times 10^{8}$ & 17.09 & 10.57 & 0.81 & 0.83 & 0.51 & 0.04 \\
\hline HLP-13 & 10000 & $2 \times 10^{9}$ & 19.13 & 14.23 & 1.47 & 0.93 & 0.69 & 0.07 \\
\hline HLP-14 & 10 & $2 \times 10^{5}$ & 1.02 & 1.36 & 0.43 & 0.051 & 0.068 & 0.02 \\
\hline HLP-14 & 100 & $2 \times 10^{6}$ & 7.76 & 5.31 & 1.06 & 0.39 & 0.27 & 0.05 \\
\hline HLP-14 & 1000 & $2 \times 10^{7}$ & 14.32 & 8.23 & 1.28 & 0.72 & 0.41 & 0.06 \\
\hline HLP-14 & 5000 & $1.04 \times 10^{8}$ & 21.60 & 12.54 & 0.84 & 1.04 & 0.60 & 0.04 \\
\hline HLP-14 & 10000 & $2 \times 10^{9}$ & 23.12 & 14.49 & 11.77 & 1.11 & 0.70 & 0.57 \\
\hline HLP-15 & 10 & $2 \times 10^{5}$ & 0.49 & 1.02 & 0.39 & 0.024 & 0.051 & 0.02 \\
\hline HLP-15 & 100 & $2 \times 10^{6}$ & 2.68 & 2.73 & 0.77 & 0.13 & 0.14 & 0.04 \\
\hline HLP-15 & 1000 & $2 \times 10^{7}$ & 5.36 & 4.25 & 0.87 & 0.27 & 0.21 & 0.04 \\
\hline HLP-15 & 5000 & $1.02 \times 10^{8}$ & 8.86 & 6.21 & 0.56 & 0.43 & 0.30 & 0.03 \\
\hline HLP-15 & 10000 & $2 \times 10^{9}$ & 11.47 & 8.95 & 1.12 & 0.56 & 0.44 & 0.05 \\
\hline HLP-16 & 10 & $2 \times 10^{5}$ & 0.71 & 1.18 & 0.42 & 0.036 & 0.059 & 0.02 \\
\hline HLP-16 & 100 & $2 \times 10^{6}$ & 3.98 & 3.22 & 0.79 & 0.20 & 0.16 & 0.04 \\
\hline HLP-16 & 1000 & $2 \times 10^{7}$ & 7.77 & 5.67 & 0.89 & 0.39 & 0.28 & 0.04 \\
\hline HLP-16 & 5000 & $1.04 \times 10^{8}$ & 14.07 & 8.81 & 0.65 & 0.68 & 0.42 & 0.03 \\
\hline HLP-16 & 10000 & $2 \times 10^{9}$ & 17.19 & 12.06 & 1.20 & 0.83 & 0.58 & 0.06 \\
\hline HLP-17 & 10 & $2 \times 10^{5}$ & 0.51 & 1.05 & 0.41 & 0.026 & 0.053 & 0.02 \\
\hline HLP-17 & 100 & $2 \times 10^{6}$ & 3.67 & 3.25 & 0.81 & 0.18 & 0.16 & 0.04 \\
\hline HLP-17 & 1000 & $2 \times 10^{7}$ & 7.71 & 5.05 & 0.97 & 0.39 & 0.25 & 0.05 \\
\hline HLP-17 & 5000 & $1.01 \times 10^{8}$ & 11.84 & 8.11 & 0.68 & 0.58 & 0.40 & 0.03 \\
\hline HLP-17 & 10000 & $2 \times 10^{9}$ & 15.86 & 12.56 & 1.22 & 0.78 & 0.62 & 0.06 \\
\hline HLP-18 & 10 & $2 \times 10^{5}$ & 0.70 & 1.18 & 0.47 & 0.035 & 0.059 & 0.02 \\
\hline HLP-18 & 100 & $2 \times 10^{6}$ & 4.87 & 3.71 & 1.05 & 0.24 & 0.19 & 0.05 \\
\hline HLP-18 & 1000 & $2 \times 10^{7}$ & 10.58 & 6.66 & 1.18 & 0.53 & 0.33 & 0.06 \\
\hline HLP-18 & 5000 & $1.04 \times 10^{8}$ & 8.09 & 5.14 & 0.40 & 0.39 & 0.25 & 0.02 \\
\hline HLP-18 & 10000 & $2 \times 10^{9}$ & 20.63 & 14.72 & 1.48 & 1.00 & 0.71 & 0.07 \\
\hline HLP-19 & 10 & $2 \times 10^{5}$ & 0.34 & 0.87 & 0.29 & 0.017 & 0.044 & 0.01 \\
\hline HLP-19 & 100 & $2 \times 10^{6}$ & 2.19 & 2.18 & 0.55 & 0.11 & 0.11 & 0.03 \\
\hline HLP-19 & 1000 & $2 \times 10^{7}$ & 4.01 & 3.32 & 0.64 & 0.20 & 0.17 & 0.03 \\
\hline HLP-19 & 5000 & $1.01 \times 10^{8}$ & 6.63 & 5.32 & 0.43 & 0.33 & 0.26 & 0.02 \\
\hline
\end{tabular}




\begin{tabular}{|c|c|c|c|c|c|c|c|c|}
\hline \multirow[b]{2}{*}{ SampleID } & \multirow{2}{*}{$\begin{array}{l}\text { Time, t } \\
\text { (hours) }\end{array}$} & \multirow{2}{*}{$\begin{array}{l}(\mathrm{S} / \mathrm{V}) \mathrm{t} \\
(\mathrm{h} / \mathrm{m})\end{array}$} & \multicolumn{3}{|c|}{$\mathrm{NC}_{\mathrm{i}}(\mathrm{g} / \mathrm{L})$} & \multicolumn{3}{|c|}{$N_{i}\left(g / m^{2}\right)$} \\
\hline & & & B & $\mathrm{Na}$ & $\mathbf{S i}$ & B & $\mathrm{Na}$ & $\mathbf{S i}$ \\
\hline HLP-19 & 10000 & $2 \times 10^{9}$ & 8.49 & 7.12 & 0.77 & 0.42 & 0.35 & 0.04 \\
\hline HLP-20 & 10 & $2 \times 10^{5}$ & 0.67 & 1.07 & 0.41 & 0.033 & 0.054 & 0.02 \\
\hline HLP-20 & 100 & $2 \times 10^{6}$ & 2.98 & 2.77 & 0.69 & 0.15 & 0.14 & 0.03 \\
\hline HLP-20 & 1000 & $2 \times 10^{7}$ & 5.66 & 4.17 & 0.83 & 0.28 & 0.21 & 0.04 \\
\hline HLP-20 & 5000 & $1.02 \times 10^{8}$ & 11.37 & 7.76 & 0.62 & 0.56 & 0.38 & 0.03 \\
\hline HLP-20 & 10000 & $2 \times 10^{9}$ & 13.80 & 10.00 & 1.07 & 0.67 & 0.49 & 0.05 \\
\hline HLP-21 & 10 & $2 \times 10^{5}$ & 0.94 & 1.23 & 0.44 & 0.047 & 0.062 & 0.02 \\
\hline HLP-21 & 100 & $2 \times 10^{6}$ & 6.05 & 4.30 & 0.90 & 0.30 & 0.21 & 0.04 \\
\hline HLP-21 & 1000 & $2 \times 10^{7}$ & 11.61 & 7.35 & 1.17 & 0.58 & 0.37 & 0.06 \\
\hline HLP-21 & 5000 & $1.03 \times 10^{8}$ & 15.08 & 9.50 & 0.71 & 0.73 & 0.46 & 0.03 \\
\hline HLP-21 & 10000 & $2 \times 10^{9}$ & 19.60 & 13.37 & 1.45 & 0.95 & 0.65 & 0.07 \\
\hline HLP-22 & 10 & $2 \times 10^{5}$ & 0.19 & 0.53 & 0.25 & 0.009 & 0.026 & 0.01 \\
\hline HLP-22 & 100 & $2 \times 10^{6}$ & 1.93 & 1.67 & 0.46 & 0.10 & 0.084 & 0.02 \\
\hline HLP-22 & 1000 & $2 \times 10^{7}$ & 3.92 & 2.57 & 0.49 & 0.20 & 0.13 & 0.02 \\
\hline HLP-22 & 5000 & $1.04 \times 10^{8}$ & 7.19 & 4.48 & 0.29 & 0.35 & 0.22 & 0.01 \\
\hline HLP-22 & 10000 & $2 \times 10^{9}$ & 9.99 & 6.59 & 0.52 & 0.48 & 0.32 & 0.03 \\
\hline HLP-23 & 10 & $2 \times 10^{5}$ & 1.63 & 2.21 & 0.67 & 0.082 & 0.11 & 0.03 \\
\hline HLP-23 & 100 & $2 \times 10^{6}$ & 8.49 & 7.09 & 1.41 & 0.42 & 0.35 & 0.07 \\
\hline HLP-23 & 1000 & $2 \times 10^{7}$ & 14.07 & 10.06 & 1.69 & 0.70 & 0.50 & 0.08 \\
\hline HLP-23 & 5000 & $1.02 \times 10^{8}$ & 15.75 & 10.20 & 1.02 & 0.77 & 0.50 & 0.05 \\
\hline HLP-23 & 10000 & $2 \times 10^{9}$ & 120.09 & 70.05 & 1.35 & 5.87 & 3.42 & 0.07 \\
\hline HLP-24 & 10 & $2 \times 10^{5}$ & 0.44 & 0.84 & 0.34 & 0.022 & 0.042 & 0.02 \\
\hline HLP-24 & 100 & $2 \times 10^{6}$ & 2.82 & 2.32 & 0.61 & 0.14 & 0.12 & 0.03 \\
\hline HLP-24 & 1000 & $2 \times 10^{7}$ & 6.06 & 3.97 & 0.07 & 0.30 & 0.20 & 0.00 \\
\hline HLP-24 & 5000 & $1.03 \times 10^{8}$ & 10.45 & 6.31 & 0.40 & 0.51 & 0.31 & 0.02 \\
\hline HLP-24 & 10000 & $2 \times 10^{9}$ & 12.75 & 8.63 & 0.79 & 0.62 & 0.42 & 0.04 \\
\hline HLP-25 & 10 & $2 \times 10^{5}$ & 0.71 & 1.26 & 0.42 & 0.035 & 0.063 & 0.02 \\
\hline HLP-25 & 100 & $2 \times 10^{6}$ & 4.32 & 3.47 & 0.82 & 0.22 & 0.17 & 0.04 \\
\hline HLP-25 & 1000 & $2 \times 10^{7}$ & 9.23 & 5.79 & 1.06 & 0.46 & 0.29 & 0.05 \\
\hline HLP-25 & 5000 & $1.02 \times 10^{8}$ & 14.06 & 8.93 & 0.66 & 0.69 & 0.44 & 0.03 \\
\hline HLP-25 & 10000 & $2 \times 10^{9}$ & 17.18 & 11.91 & 1.50 & 0.84 & 0.58 & 0.07 \\
\hline HLP-26 & 10 & $2 \times 10^{5}$ & 0.79 & 1.19 & 0.41 & 0.040 & 0.060 & 0.02 \\
\hline HLP-26 & 100 & $2 \times 10^{6}$ & 4.19 & 3.17 & 0.81 & 0.21 & 0.16 & 0.04 \\
\hline HLP-26 & 1000 & $2 \times 10^{7}$ & 8.16 & 5.82 & 1.03 & 0.41 & 0.29 & 0.05 \\
\hline HLP-26 & 5000 & $1.02 \times 10^{8}$ & 15.51 & 9.46 & 0.67 & 0.76 & 0.46 & 0.03 \\
\hline HLP-26 & 10000 & $2 \times 10^{9}$ & 18.14 & 13.03 & 1.26 & 0.89 & 0.64 & 0.06 \\
\hline HLP-27 & 10 & $2 \times 10^{5}$ & 3.31 & 2.59 & 0.46 & 0.166 & 0.129 & 0.02 \\
\hline HLP-27 & 100 & $2 \times 10^{6}$ & 17.17 & 10.84 & 0.95 & 0.86 & 0.54 & 0.04 \\
\hline HLP-27 & 1000 & $2 \times 10^{7}$ & 39.94 & 20.90 & 1.24 & 2.00 & 1.05 & 0.06 \\
\hline HLP-27 & 5000 & $1.07 \times 10^{8}$ & No result & or this $\mathrm{s}$ & & & & \\
\hline HLP-27 & 10000 & $2 \times 10^{9}$ & 1073.58 & 722.01 & 309.99 & 49.97 & 33.61 & 14.43 \\
\hline HLP-28 & 10 & $2 \times 10^{5}$ & 0.41 & 0.55 & 0.20 & 0.021 & 0.028 & 0.01 \\
\hline HLP-28 & 100 & $2 \times 10^{6}$ & 1.90 & 1.32 & 0.32 & 0.10 & 0.07 & 0.02 \\
\hline HLP-28 & 1000 & $2 \times 10^{7}$ & 4.14 & 2.12 & 0.27 & 0.21 & 0.11 & 0.01 \\
\hline HLP-28 & 5000 & $1.07 \times 10^{8}$ & 10.11 & 4.72 & 0.14 & 0.47 & 0.22 & 0.01 \\
\hline HLP-28 & 10000 & $2 \times 10^{9}$ & 16.10 & 9.48 & 1.16 & 0.75 & 0.44 & 0.05 \\
\hline HLP-29 & 10 & $2 \times 10^{5}$ & 0.33 & 1.47 & 0.42 & 0.017 & 0.073 & 0.02 \\
\hline HLP-29 & 100 & $2 \times 10^{6}$ & 2.42 & 3.32 & 0.86 & 0.12 & 0.17 & 0.04 \\
\hline HLP-29 & 1000 & $2 \times 10^{7}$ & 4.85 & 6.03 & 1.13 & 0.24 & 0.30 & 0.05 \\
\hline HLP-29 & 5000 & $1.05 \times 10^{8}$ & 8.41 & 10.45 & 1.08 & 0.40 & 0.50 & 0.05 \\
\hline
\end{tabular}




\begin{tabular}{|c|c|c|c|c|c|c|c|c|}
\hline \multirow[b]{2}{*}{ SampleID } & \multirow{2}{*}{$\begin{array}{l}\text { Time, } t \\
\text { (hours) }\end{array}$} & \multirow{2}{*}{$\begin{array}{l}(\mathrm{S} / \mathrm{V}) \mathrm{t} \\
(\mathbf{h} / \mathbf{m})\end{array}$} & \multicolumn{3}{|c|}{$N C_{i}(g / L)$} & \multicolumn{3}{|c|}{$\mathrm{NL}_{\mathrm{i}}\left(\mathrm{g} / \mathrm{m}^{2}\right)$} \\
\hline & & & B & $\mathrm{Na}$ & $\mathbf{S i}$ & B & $\mathrm{Na}$ & $\mathbf{S i}$ \\
\hline HLP-29 & 10000 & $2 \times 10^{9}$ & 1136.21 & 560.80 & 211.23 & 54.25 & 26.77 & 10.08 \\
\hline HLP-30 & 10 & $2 \times 10^{5}$ & 0.08 & 0.58 & 0.23 & 0.004 & 0.029 & 0.01 \\
\hline HLP-30 & 100 & $2 \times 10^{6}$ & 1.07 & 1.24 & 0.42 & 0.054 & 0.062 & 0.02 \\
\hline HLP-30 & 1000 & $2 \times 10^{7}$ & 2.12 & 2.03 & 0.48 & 0.11 & 0.10 & 0.02 \\
\hline HLP-30 & 5000 & $1.04 \times 10^{8}$ & 2.05 & 2.75 & 0.29 & 0.10 & 0.13 & 0.01 \\
\hline HLP-30 & 10000 & $2 \times 10^{9}$ & 2.01 & 3.60 & 0.67 & 0.10 & 0.17 & 0.03 \\
\hline HLP-31 & 10 & $2 \times 10^{5}$ & 8.72 & 5.90 & 2.03 & 0.436 & 0.295 & 0.10 \\
\hline HLP-31 & 100 & $2 \times 10^{6}$ & 31.93 & 21.49 & 5.51 & 1.60 & 1.07 & 0.27 \\
\hline HLP-31 & 1000 & $2 \times 10^{7}$ & 56.80 & 36.14 & 7.89 & 2.84 & 1.81 & 0.38 \\
\hline HLP-31 & 5000 & $1.03 \times 10^{8}$ & 93.03 & 50.83 & 0.58 & 4.54 & 2.48 & 0.03 \\
\hline HLP-31 & 10000 & $2 \times 10^{9}$ & 140.01 & 87.64 & 1.98 & 6.83 & 4.27 & 0.10 \\
\hline HLP-32 & 10 & $2 \times 10^{5}$ & 0.82 & 0.88 & 0.36 & 0.041 & 0.044 & 0.02 \\
\hline HLP-32 & 100 & $2 \times 10^{6}$ & 4.52 & 2.89 & 0.66 & 0.23 & 0.14 & 0.03 \\
\hline HLP-32 & 1000 & $2 \times 10^{7}$ & 12.30 & 5.69 & 0.84 & 0.61 & 0.28 & 0.04 \\
\hline HLP-32 & 5000 & $1.03 \times 10^{8}$ & 21.39 & 11.55 & 0.39 & 1.04 & 0.56 & 0.02 \\
\hline HLP-32 & 10000 & $2 \times 10^{9}$ & 22.41 & 13.29 & 0.64 & 1.09 & 0.65 & 0.03 \\
\hline HLP-33 & 10 & $2 \times 10^{5}$ & 1.47 & 2.37 & 0.95 & 0.073 & 0.119 & 0.05 \\
\hline HLP-33 & 100 & $2 \times 10^{6}$ & 33.63 & 22.47 & 8.71 & 1.68 & 1.12 & 0.43 \\
\hline HLP-33 & 1000 & $2 \times 10^{7}$ & 126.12 & 70.62 & 3.33 & 6.31 & 3.53 & 0.16 \\
\hline HLP-33 & 5000 & $1.02 \times 10^{8}$ & 115.02 & 58.01 & 1.30 & 5.63 & 2.84 & 0.06 \\
\hline HLP-33 & 10000 & $2 \times 10^{9}$ & 194.14 & 69.66 & 37.10 & 9.51 & 3.41 & 1.82 \\
\hline HLP-34 & 10 & $2 \times 10^{5}$ & 0.24 & 0.80 & 0.32 & 0.012 & 0.040 & 0.02 \\
\hline HLP-34 & 100 & $2 \times 10^{6}$ & 2.85 & 2.29 & 0.84 & 0.14 & 0.11 & 0.04 \\
\hline HLP-34 & 1000 & $2 \times 10^{7}$ & 5.81 & 3.43 & 1.29 & 0.29 & 0.17 & 0.06 \\
\hline HLP-34 & 5000 & $1.00 \times 10^{8}$ & 5.45 & 5.10 & 0.72 & 0.27 & 0.25 & 0.04 \\
\hline HLP-34 & 10000 & $2 \times 10^{9}$ & 4.66 & 5.86 & 1.16 & 0.23 & 0.29 & 0.06 \\
\hline HLP-35 & 10 & $2 \times 10^{5}$ & 1.66 & 1.65 & 0.44 & 0.083 & 0.083 & 0.02 \\
\hline HLP-35 & 100 & $2 \times 10^{6}$ & 12.08 & 7.22 & 0.65 & 0.60 & 0.36 & 0.03 \\
\hline HLP-35 & 1000 & $2 \times 10^{7}$ & 23.70 & 14.85 & 0.68 & 1.19 & 0.74 & 0.03 \\
\hline HLP-35 & 5000 & $1.02 \times 10^{8}$ & 30.57 & 18.39 & 0.43 & 1.50 & 0.90 & 0.02 \\
\hline HLP-35 & 10000 & $2 \times 10^{9}$ & 75.60 & 39.28 & 1.86 & 3.71 & 1.93 & 0.09 \\
\hline HLP-36 & 10 & $2 \times 10^{5}$ & 0.58 & 0.82 & 0.26 & 0.029 & 0.041 & 0.01 \\
\hline HLP-36 & 100 & $2 \times 10^{6}$ & 3.70 & 2.44 & 0.35 & 0.19 & 0.12 & 0.02 \\
\hline HLP-36 & 1000 & $2 \times 10^{7}$ & 14.67 & 7.74 & 0.30 & 0.73 & 0.39 & 0.02 \\
\hline HLP-36 & 5000 & $9.8 \times 10^{7}$ & 60.09 & 29.59 & 0.20 & 3.06 & 1.51 & 0.01 \\
\hline HLP-36 & 10000 & $2 \times 10^{9}$ & 40.80 & 18.96 & 0.30 & 2.08 & 0.97 & 0.02 \\
\hline HLP-37 & 10 & $2 \times 10^{5}$ & 0.40 & 1.56 & 0.47 & 0.020 & 0.078 & 0.02 \\
\hline HLP-37 & 100 & $2 \times 10^{6}$ & 7.96 & 5.67 & 0.96 & 0.40 & 0.28 & 0.05 \\
\hline HLP-37 & 1000 & $2 \times 10^{7}$ & 12.83 & 10.73 & 1.26 & 0.64 & 0.54 & 0.06 \\
\hline HLP-37 & 5000 & $9.94 \times 10^{7}$ & 26.10 & 13.28 & 0.55 & 1.31 & 0.67 & 0.03 \\
\hline HLP-37 & 10000 & $2 \times 10^{9}$ & 750.61 & 284.31 & 24.37 & 37.74 & 14.29 & 1.23 \\
\hline HLP-37Q & 10 & $2 \times 10^{5}$ & 0.64 & 1.77 & 0.44 & 0.032 & 0.088 & 0.02 \\
\hline HLP-37Q & 100 & $2 \times 10^{6}$ & 3.48 & 4.90 & 1.05 & 0.17 & 0.25 & 0.05 \\
\hline HLP-37Q & 1000 & $2 \times 10^{7}$ & 6.80 & 8.34 & 1.33 & 0.34 & 0.42 & 0.07 \\
\hline HLP-37Q & 5000 & $9.94 \times 10^{7}$ & 5.15 & 2.32 & 0.37 & 0.26 & 0.12 & 0.02 \\
\hline HLP-37Q & 10000 & $2 \times 10^{9}$ & 1136.21 & 400.57 & 41.61 & 57.13 & 20.14 & 2.09 \\
\hline HLP-38 & 10 & $2 \times 10^{5}$ & 0.37 & 0.93 & 0.29 & 0.019 & 0.046 & 0.02 \\
\hline HLP-38 & 100 & $2 \times 10^{6}$ & 2.35 & 2.01 & 0.52 & 0.12 & 0.10 & 0.03 \\
\hline HLP-38 & 1000 & $2 \times 10^{7}$ & 3.72 & 3.54 & 0.69 & 0.19 & 0.18 & 0.04 \\
\hline HLP-38 & 5000 & $9.67 \times 10^{7}$ & 8.59 & 5.56 & 2.41 & 0.44 & 0.29 & 0.12 \\
\hline
\end{tabular}




\begin{tabular}{|c|c|c|c|c|c|c|c|c|}
\hline \multirow[b]{2}{*}{ SampleID } & \multirow{2}{*}{$\begin{array}{l}\text { Time, t } \\
\text { (hours) }\end{array}$} & \multirow{2}{*}{$\begin{array}{l}(\mathbf{S} / \mathbf{V}) \mathbf{t} \\
(\mathbf{h} / \mathbf{m})\end{array}$} & \multicolumn{3}{|c|}{$\mathrm{NC}_{\mathrm{i}}(\mathrm{g} / \mathrm{L})$} & \multicolumn{3}{|c|}{$\mathrm{NL}_{\mathrm{i}}\left(\mathrm{g} / \mathrm{m}^{2}\right)$} \\
\hline & & & B & $\mathrm{Na}$ & $\mathbf{S i}$ & B & $\mathrm{Na}$ & $\mathbf{S i}$ \\
\hline HLP-38 & 10000 & $2 \times 10^{9}$ & 6.74 & 6.39 & 0.63 & 0.35 & 0.33 & 0.03 \\
\hline HLP-38Q & 10 & $2 \times 10^{5}$ & 0.081 & 0.74 & 0.26 & 0.0040 & 0.037 & 0.01 \\
\hline HLP-38Q & 100 & $2 \times 10^{6}$ & 1.78 & 2.02 & 0.54 & 0.089 & 0.10 & 0.03 \\
\hline HLP-38Q & 1000 & $2 \times 10^{7}$ & 3.88 & 3.48 & 0.72 & 0.19 & 0.17 & 0.04 \\
\hline HLP-38Q & 5000 & $9.67 \times 10^{7}$ & 66.01 & 17.36 & 0.32 & 3.41 & 0.90 & 0.02 \\
\hline HLP-38Q & 10000 & $2 \times 10^{9}$ & 3.71 & 5.93 & 1.04 & 0.19 & 0.31 & 0.05 \\
\hline HLP-39 & 10 & $2 \times 10^{5}$ & 5.37 & 4.23 & 0.72 & 0.27 & 0.21 & 0.04 \\
\hline HLP-39 & 100 & $2 \times 10^{6}$ & 41.64 & 24.03 & 3.09 & 2.08 & 1.20 & 0.16 \\
\hline HLP-39 & 1000 & $2 \times 10^{7}$ & 50.54 & 31.16 & 4.17 & 2.53 & 1.56 & 0.21 \\
\hline HLP-39 & 5000 & $9.85 \times 10^{7}$ & 155.39 & 73.89 & 1.35 & 7.88 & 3.75 & 0.07 \\
\hline HLP-39 & 10000 & $2 \times 10^{9}$ & 232.61 & 115.29 & 10.20 & 11.80 & 5.85 & 0.52 \\
\hline HLP-40 & 10 & $2 \times 10^{5}$ & 1.18 & 1.30 & 0.39 & 0.059 & 0.065 & 0.02 \\
\hline HLP-40 & 100 & $2 \times 10^{6}$ & 16.15 & 9.20 & 0.65 & 0.81 & 0.46 & 0.03 \\
\hline HLP-40 & 1000 & $2 \times 10^{7}$ & 31.57 & 18.54 & 0.54 & 1.58 & 0.93 & 0.03 \\
\hline HLP-40 & 5000 & $9.52 \times 10^{7}$ & 55.03 & 28.92 & 4.18 & 2.89 & 1.52 & 0.22 \\
\hline HLP-40 & 10000 & $2 \times 10^{9}$ & 40.75 & 24.16 & 0.61 & 2.14 & 1.27 & 0.03 \\
\hline HLP-40Q & 10 & $2 \times 10^{5}$ & 0.88 & 1.13 & 0.34 & 0.044 & 0.056 & 0.02 \\
\hline HLP-40Q & 100 & $2 \times 10^{6}$ & 16.91 & 9.27 & 0.46 & 0.85 & 0.46 & 0.02 \\
\hline HLP-40Q & 1000 & $2 \times 10^{7}$ & 32.60 & 19.71 & 0.57 & 1.63 & 0.986 & 0.03 \\
\hline HLP-40Q & 5000 & $9.52 \times 10^{7}$ & 63.43 & 84.56 & 0.87 & 3.33 & 4.44 & 0.05 \\
\hline HLP-40Q & 10000 & $2 \times 10^{9}$ & 150.75 & 104.77 & 1.43 & 7.91 & 5.51 & 0.07 \\
\hline HLP-41 & 10 & $2 \times 10^{5}$ & 4.28 & 4.25 & 0.93 & 0.21 & 0.21 & 0.05 \\
\hline HLP-41 & 100 & $2 \times 10^{6}$ & 62.08 & 31.84 & 0.55 & 3.104 & 1.59 & 0.03 \\
\hline HLP-41 & 1000 & $2 \times 10^{7}$ & 83.19 & 45.52 & 8.59 & 4.16 & 2.28 & 0.45 \\
\hline HLP-41 & 5000 & $9.56 \times 10^{7}$ & 13.20 & 4.34 & 0.79 & 0.69 & 0.23 & 0.04 \\
\hline HLP-41 & 10000 & $2 \times 10^{9}$ & --- & 183.68 & 27.14 & --- & 9.61 & 1.42 \\
\hline HLP-42 & 10 & $2 \times 10^{5}$ & 0.60 & 1.29 & 0.41 & 0.030 & 0.064 & 0.02 \\
\hline HLP-42 & 100 & $2 \times 10^{6}$ & 11.18 & 6.50 & 1.74 & 0.56 & 0.33 & 0.10 \\
\hline HLP-42 & 1000 & $2 \times 10^{7}$ & 74.69 & 42.13 & 5.04 & 3.73 & 2.11 & 0.28 \\
\hline HLP-42 & 5000 & $9.11 \times 10^{7}$ & 118.76 & 52.90 & 0.89 & 6.51 & 2.90 & 0.05 \\
\hline HLP-42 & 10000 & $2 \times 10^{9}$ & 78.91 & 35.95 & 4.95 & 4.33 & 1.97 & 0.27 \\
\hline HLP-42Q & 10 & $2 \times 10^{5}$ & 0.71 & 1.14 & 0.32 & 0.036 & 0.057 & 0.02 \\
\hline HLP-42Q & 100 & $2 \times 10^{6}$ & 10.73 & 5.55 & 1.26 & 0.54 & 0.28 & 0.07 \\
\hline HLP-42Q & 1000 & $2 \times 10^{7}$ & 78.71 & 34.26 & 2.67 & 3.94 & 1.71 & 0.15 \\
\hline HLP-42Q & 5000 & $9.11 \times 10^{7}$ & 24.14 & 10.76 & 0.43 & .32 & 0.59 & 0.02 \\
\hline HLP-42Q & 10000 & $2 \times 10^{9}$ & 135.09 & 55.48 & 3.54 & 7.41 & 3.04 & 0.19 \\
\hline HLP-43 & 10 & $2 \times 10^{5}$ & 0.71 & 1.00 & 0.33 & 0.036 & 0.050 & 0.02 \\
\hline HLP-43 & 100 & $2 \times 10^{6}$ & 5.34 & 3.93 & 0.90 & 0.27 & 0.20 & 0.04 \\
\hline HLP-43 & 1000 & $2 \times 10^{7}$ & 9.34 & 5.59 & 1.08 & 0.47 & 0.28 & 0.05 \\
\hline HLP-43 & 5000 & $1.02 \times 10^{8}$ & 13.20 & 8.32 & 0.14 & 0.65 & 0.41 & 0.01 \\
\hline HLP-43 & 10000 & $2 \times 10^{9}$ & 17.98 & 13.03 & 1.53 & 0.88 & 0.64 & 0.07 \\
\hline HLP-44 & 10 & $2 \times 10^{5}$ & 0.83 & 0.99 & 0.36 & 0.042 & 0.049 & 0.02 \\
\hline HLP-44 & 100 & $2 \times 10^{6}$ & 0.31 & 2.30 & 0.02 & 0.016 & 0.12 & 0.00 \\
\hline HLP-44 & 1000 & $2 \times 10^{7}$ & 7.62 & 6.10 & 0.96 & 0.38 & 0.31 & 0.05 \\
\hline HLP-44 & 5000 & $1.02 \times 10^{8}$ & 11.27 & 7.94 & 0.40 & 0.55 & 0.39 & 0.02 \\
\hline HLP-44 & 10000 & $2 \times 10^{9}$ & 16.05 & 11.24 & 1.30 & 0.79 & 0.55 & 0.06 \\
\hline HLP-45 & 10 & $2 \times 10^{5}$ & 0.86 & 1.07 & 0.37 & 0.043 & 0.054 & 0.02 \\
\hline HLP-45 & 100 & $2 \times 10^{6}$ & 0.35 & 2.67 & 0.02 & 0.018 & 0.13 & 0.00 \\
\hline HLP-45 & 1000 & $2 \times 10^{7}$ & 6.39 & 6.37 & 0.99 & 0.32 & 0.32 & 0.05 \\
\hline HLP-45 & 5000 & $1.01 \times 10^{8}$ & 3.09 & 2.67 & 0.27 & 0.15 & 0.13 & 0.01 \\
\hline
\end{tabular}




\begin{tabular}{|c|c|c|c|c|c|c|c|c|}
\hline \multirow[b]{2}{*}{ SampleID } & \multirow{2}{*}{$\begin{array}{l}\text { Time, } t \\
\text { (hours) }\end{array}$} & \multirow{2}{*}{$\begin{array}{l}(\mathrm{S} / \mathrm{V}) \mathrm{t} \\
(\mathbf{h} / \mathbf{m})\end{array}$} & \multicolumn{3}{|c|}{$N C_{i}(g / L)$} & \multicolumn{3}{|c|}{$N_{i}\left(g / m^{2}\right)$} \\
\hline & & & B & $\mathbf{N a}$ & Si & B & $\mathbf{N a}$ & Si \\
\hline HLP-45 & 10000 & $2 \times 10^{9}$ & 13.58 & 11.35 & 1.34 & 0.67 & 0.56 & 0.07 \\
\hline HLP-46 & 10 & $2 \times 10^{5}$ & 0.35 & $2.9 \times 10^{-3}$ & 0.35 & 0.018 & $1.0 \times 10^{-4}$ & 0.02 \\
\hline HLP-46 & 100 & $2 \times 10^{6}$ & 1.98 & 5.17 & 0.91 & 0.10 & 0.26 & 0.04 \\
\hline HLP-46 & 1000 & $2 \times 10^{7}$ & 5.92 & 8.56 & 1.61 & 0.30 & 0.43 & 0.08 \\
\hline HLP-46 & 5000 & $1.06 \times 10^{8}$ & \multicolumn{6}{|c|}{ No results for this sample } \\
\hline HLP-46 & 10000 & $2 \times 10^{9}$ & 1137.36 & 587.93 & 248.76 & 53.66 & 27.74 & 11.74 \\
\hline HLP-47 & 10 & $2 \times 10^{5}$ & 1.12 & 1.62 & 0.38 & 0.056 & 0.081 & 0.02 \\
\hline HLP-47 & 100 & $2 \times 10^{6}$ & 6.49 & 5.16 & 0.96 & 0.32 & 0.26 & 0.05 \\
\hline HLP-47 & 1000 & $2 \times 10^{7}$ & 18.31 & 12.13 & 1.41 & 0.92 & 0.61 & 0.07 \\
\hline HLP-47 & 5000 & $1.07 \times 10^{8}$ & 32.41 & 28.09 & 3.47 & 1.52 & 1.32 & 0.16 \\
\hline HLP-47 & 10000 & $2 \times 10^{9}$ & 818.61 & 528.07 & 198.74 & 38.39 & 24.76 & 9.32 \\
\hline HLP-48 & 10 & $2 \times 10^{5}$ & 1.20 & 1.26 & 0.40 & 0.060 & 0.063 & 0.02 \\
\hline HLP-48 & 100 & $2 \times 10^{6}$ & 5.92 & 4.06 & 0.66 & 0.30 & 0.20 & 0.03 \\
\hline HLP-48 & 1000 & $2 \times 10^{7}$ & 13.10 & 9.03 & 0.87 & 0.65 & 0.45 & 0.04 \\
\hline HLP-48 & 5000 & $1.00 \times 10^{8}$ & 16.87 & 10.24 & 0.49 & 0.84 & 0.51 & 0.02 \\
\hline HLP-48 & 10000 & $2 \times 10^{9}$ & 24.08 & 16.63 & 1.10 & 1.20 & 0.83 & 0.05 \\
\hline HLP-49 & 10 & $2 \times 10^{5}$ & 0.61 & 0.77 & 0.22 & 0.030 & 0.039 & 0.01 \\
\hline HLP-49 & 100 & $2 \times 10^{6}$ & 2.25 & 1.80 & 0.46 & 0.11 & 0.09 & 0.02 \\
\hline HLP-49 & 1000 & $2 \times 10^{7}$ & 3.05 & 3.08 & 0.64 & 0.15 & 0.15 & 0.03 \\
\hline HLP-49 & 5000 & $9.71 \times 10^{7}$ & 4.01 & 3.87 & 0.31 & 0.21 & 0.20 & 0.01 \\
\hline HLP-49 & 10000 & $2 \times 10^{9}$ & 30.46 & 17.91 & 8.77 & 1.57 & 0.92 & 0.45 \\
\hline HLP-51 & 10 & $2 \times 10^{5}$ & 0.77 & 1.12 & 0.29 & 0.038 & 0.056 & 0.01 \\
\hline HLP-51 & 100 & $2 \times 10^{6}$ & 0.80 & 2.61 & 0.01 & 0.04 & 0.13 & 0.00 \\
\hline HLP-51 & 1000 & $2 \times 10^{7}$ & 6.61 & 6.48 & 0.69 & 0.33 & 0.32 & 0.03 \\
\hline HLP-51 & 5000 & $9.89 \times 10^{7}$ & 10.68 & 7.97 & 0.42 & 0.54 & 0.40 & 0.02 \\
\hline HLP-51 & 10000 & $2 \times 10^{9}$ & 14.91 & 11.91 & 0.94 & 0.75 & 0.60 & 0.05 \\
\hline HLP-52 & 10 & $2 \times 10^{5}$ & $--^{(a)}$ & 0.46 & 0.93 & $--^{(a)}$ & 0.023 & 0.05 \\
\hline HLP-52 & 100 & $2 \times 10^{6}$ & $--^{\text {(a) }}$ & 44.74 & 2.94 & $--^{(a)}$ & 2.24 & 0.15 \\
\hline HLP-52 & 1000 & $2 \times 10^{7}$ & $--^{\text {(a) }}$ & 144.1 & 42.44 & $--^{(a)}$ & 7.21 & 2.09 \\
\hline HLP-52 & 5000 & $1.01 \times 10^{8}$ & \multicolumn{6}{|c|}{ No results for this sample } \\
\hline HLP-52 & 10000 & $2 \times 10^{9}$ & --- & 535.48 & 271.92 & --- & 26.41 & 13.41 \\
\hline HLP-53 & 10 & $2 \times 10^{5}$ & \multicolumn{6}{|c|}{ No results for this sample } \\
\hline HLP-53 & 100 & $2 \times 10^{6}$ & \multicolumn{6}{|c|}{ No results for this sample } \\
\hline HLP-53 & 1000 & $2 \times 10^{7}$ & \multicolumn{6}{|c|}{ No results for this sample } \\
\hline HLP-53 & 5000 & $9.87 \times 10^{7}$ & 776.48 & 361.94 & 50.09 & 39.33 & 18.33 & 2.54 \\
\hline HLP-53 & 10000 & $2 \times 10^{9}$ & 1135.76 & 602.23 & 80.30 & 57.53 & 30.51 & 4.07 \\
\hline HLP-54 & 10 & $2 \times 10^{5}$ & 0.44 & 1.51 & 0.21 & 0.022 & 0.075 & 0.01 \\
\hline HLP-54 & 100 & $2 \times 10^{6}$ & 2.43 & 2.40 & 0.49 & 0.12 & 0.12 & 0.02 \\
\hline HLP-54 & 1000 & $2 \times 10^{7}$ & 4.91 & 4.04 & 0.58 & 0.25 & 0.20 & 0.03 \\
\hline HLP-54 & 5000 & $1.08 \times 10^{8}$ & 1294.20 & 603.23 & --- & 65.56 & 30.56 & --- \\
\hline HLP-54 & 10000 & $2 \times 10^{9}$ & 18.43 & 12.58 & 0.80 & 0.85 & 0.58 & 0.04 \\
\hline HLP-55 & 10 & $2 \times 10^{5}$ & 1.50 & 1.83 & 0.44 & 0.075 & 0.092 & 0.02 \\
\hline HLP-55 & 100 & $2 \times 10^{6}$ & 6.08 & 4.13 & 1.17 & 0.30 & 0.21 & 0.05 \\
\hline HLP-55 & 1000 & $2 \times 10^{7}$ & 14.01 & 9.56 & 1.58 & 0.70 & 0.48 & 0.07 \\
\hline HLP-55 & 5000 & $1.10 \times 10^{8}$ & \multicolumn{6}{|c|}{ No results for this sample } \\
\hline HLP-55 & 10000 & $2 \times 10^{9}$ & 35.67 & 24.72 & 6.56 & 1.63 & 1.13 & 0.30 \\
\hline
\end{tabular}

a Glass HLP-52 contained no boron, so the test solution concentration cannot be normalized using the concentration in the glass. 


\section{PCT-B Normalized Release Information for Phase I Glasses}

Table B-3b. Measured Normalized Release Values for the PCT-B Boron, Sodium, and Silicon Results for the Hanford Glasses (Phase I). Test Temperature $=90^{\circ} \mathrm{C}$; Test Duration $=10,100,1000,5000$, and 10,000 hours; and $(\mathrm{S} / \mathrm{V}) \approx 20,000 / \mathrm{m}$.

\begin{tabular}{|c|c|c|c|c|c|c|c|c|}
\hline \multirow[b]{2}{*}{ SampleID } & \multirow{2}{*}{$\begin{array}{l}\text { Time, } t \\
\text { (hours) }\end{array}$} & \multirow{2}{*}{$\begin{array}{l}(\mathrm{S} / \mathrm{V}) \mathrm{t} \\
(\mathrm{h} / \mathbf{m})\end{array}$} & \multicolumn{3}{|c|}{$\mathrm{NC}_{\mathrm{i}}(\mathrm{g} / \mathrm{L})$} & \multicolumn{3}{|c|}{$N_{i}\left(g / m^{2}\right)$} \\
\hline & & & B & $\mathrm{Na}$ & Si & B & Na & $\mathbf{S i}$ \\
\hline HLP-01 & 10 & $2 \times 10^{5}$ & 0.80 & 1.14 & 0.34 & 0.04 & 0.06 & 0.02 \\
\hline HLP-01 & 100 & $2 \times 10^{6}$ & 3.66 & 3.15 & 0.68 & 0.18 & 0.16 & 0.03 \\
\hline HLP-01 & 1000 & $2 \times 10^{7}$ & 8.36 & 6.17 & 0.92 & 0.41 & 0.30 & 0.05 \\
\hline HLP-01 & 5000 & $1.02 \times 10^{8}$ & 13.61 & 8.50 & 0.49 & 0.67 & 0.42 & 0.02 \\
\hline HLP-01 & 10000 & $2 \times 10^{9}$ & 21.00 & 13.92 & 1.40 & 1.03 & 0.69 & 0.07 \\
\hline HLP-02 & 10 & $2 \times 10^{5}$ & 8.38 & 5.36 & 0.72 & 0.42 & 0.27 & 0.04 \\
\hline HLP-02 & 100 & $2 \times 10^{6}$ & 25.05 & 15.15 & 1.15 & 1.26 & 0.76 & 0.06 \\
\hline HLP-02 & 1000 & $2 \times 10^{7}$ & 47.41 & 24.82 & 1.64 & 2.38 & 1.25 & 0.08 \\
\hline HLP-02 & 5000 & $9.96 \times 10^{7}$ & 1088.1 & 436.01 & 29.72 & 54.64 & 21.89 & 1.49 \\
\hline HLP-02 & 10000 & $2 \times 10^{9}$ & 1261.9 & 540.01 & 78.21 & 63.37 & 27.12 & 3.93 \\
\hline HLP-03 & 10 & $2 \times 10^{5}$ & 0.60 & 0.95 & 0.34 & 0.03 & 0.05 & 0.02 \\
\hline HLP-03 & 100 & $2 \times 10^{6}$ & 2.91 & 2.77 & 0.69 & 0.14 & 0.14 & 0.03 \\
\hline HLP-03 & 1000 & $2 \times 10^{7}$ & 6.49 & 4.66 & 0.92 & 0.32 & 0.23 & 0.05 \\
\hline HLP-03 & 5000 & $1.02 \times 10^{8}$ & 12.17 & 7.08 & 0.60 & 0.60 & 0.35 & 0.03 \\
\hline HLP-03 & 10000 & $2 \times 10^{9}$ & 12.76 & 9.21 & 1.09 & 0.62 & 0.45 & 0.05 \\
\hline HLP-04 & 10 & $2 \times 10^{5}$ & 2.60 & 0.27 & 0.51 & 0.13 & 0.01 & 0.03 \\
\hline HLP-04 & 100 & $2 \times 10^{6}$ & 14.63 & 10.32 & 0.97 & 0.73 & 0.51 & 0.05 \\
\hline HLP-04 & 1000 & $2 \times 10^{7}$ & 29.64 & 19.02 & 1.32 & 1.48 & 0.95 & 0.07 \\
\hline HLP-04 & 5000 & $1.00 \times 10^{8}$ & 170.57 & 97.61 & 6.41 & 8.50 & 4.87 & 0.32 \\
\hline HLP-04 & 10000 & $2 \times 10^{9}$ & 800.86 & 408.93 & 30.81 & 39.93 & 20.39 & 1.54 \\
\hline HLP-05 & 10 & $2 \times 10^{5}$ & 1.78 & 1.77 & 0.68 & 0.09 & 0.09 & 0.03 \\
\hline HLP-05 & 100 & $2 \times 10^{6}$ & 27.30 & 17.27 & 3.98 & 1.36 & 0.86 & 0.20 \\
\hline HLP-05 & 1000 & $2 \times 10^{7}$ & 62.01 & 35.38 & 7.12 & 3.08 & 1.76 & 0.35 \\
\hline HLP-05 & 5000 & $1.01 \times 10^{8}$ & 72.36 & 38.11 & 4.37 & 3.60 & 1.89 & 0.22 \\
\hline HLP-05 & 10000 & $2 \times 10^{9}$ & 66.71 & 41.29 & 2.14 & 3.32 & 2.05 & 0.11 \\
\hline HLP-06 & 10 & $2 \times 10^{5}$ & 0.36 & 0.73 & 0.30 & 0.02 & 0.03 & 0.01 \\
\hline HLP-06 & 100 & $2 \times 10^{6}$ & 2.03 & 1.74 & 0.44 & 0.10 & 0.08 & 0.02 \\
\hline HLP-06 & 1000 & $2 \times 10^{7}$ & 3.06 & 2.67 & 0.54 & 0.15 & 0.13 & 0.03 \\
\hline HLP-06 & 5000 & $1.05 \times 10^{8}$ & 8.40 & 4.90 & 0.35 & 0.40 & 0.23 & 0.02 \\
\hline HLP-06 & 10000 & $2 \times 10^{9}$ & 8.76 & 5.89 & 0.50 & 0.42 & 0.28 & 0.02 \\
\hline HLP-07 & 10 & $2 \times 10^{5}$ & 0.52 & 0.92 & 0.36 & 0.03 & 0.04 & 0.02 \\
\hline HLP-07 & 100 & $2 \times 10^{6}$ & 2.58 & 2.19 & 0.56 & 0.12 & 0.11 & 0.03 \\
\hline HLP-07 & 1000 & $2 \times 10^{7}$ & 5.09 & 4.11 & 0.66 & 0.25 & 0.20 & 0.03 \\
\hline HLP-07 & 5000 & $1.04 \times 10^{8}$ & 11.70 & 6.90 & 0.44 & 0.57 & 0.33 & 0.02 \\
\hline HLP-07 & 10000 & $2 \times 10^{9}$ & 12.84 & 8.51 & 0.68 & 0.62 & 0.41 & 0.03 \\
\hline HLP-08 & 10 & $2 \times 10^{5}$ & 0.37 & 1.32 & 0.46 & 0.02 & 0.07 & 0.02 \\
\hline HLP-08 & 100 & $2 \times 10^{6}$ & 2.39 & 3.17 & 0.91 & 0.12 & 0.16 & 0.05 \\
\hline HLP-08 & 1000 & $2 \times 10^{7}$ & 3.35 & 5.59 & 1.22 & 0.17 & 0.28 & 0.06 \\
\hline HLP-08 & 5000 & $9.99 \times 10^{7}$ & 6.63 & 8.39 & 0.91 & 0.33 & 0.42 & 0.05 \\
\hline HLP-08 & 10000 & $2 \times 10^{9}$ & 13.01 & 13.94 & 7.58 & 0.65 & 0.70 & 0.38 \\
\hline HLP-09 & 10 & $2 \times 10^{5}$ & 0.79 & 1.09 & 0.37 & 0.04 & 0.05 & 0.02 \\
\hline HLP-09 & 100 & $2 \times 10^{6}$ & 4.82 & 3.45 & 0.61 & 0.23 & 0.17 & 0.03 \\
\hline HLP-09 & 1000 & $2 \times 10^{7}$ & 16.42 & 9.43 & 0.66 & 0.79 & 0.46 & 0.03 \\
\hline HLP-09 & 5000 & $1.03 \times 10^{8}$ & 16.79 & 9.16 & 0.27 & 0.81 & 0.44 & 0.01 \\
\hline HLP-09 & 10000 & $2 \times 10^{9}$ & 33.94 & 19.33 & 0.65 & 1.64 & 0.93 & 0.03 \\
\hline
\end{tabular}




\begin{tabular}{|c|c|c|c|c|c|c|c|c|}
\hline \multirow[b]{2}{*}{ SampleID } & \multirow{2}{*}{$\begin{array}{l}\text { Time, t } \\
\text { (hours) }\end{array}$} & \multirow{2}{*}{$\begin{array}{l}(\mathrm{S} / \mathrm{V}) \mathrm{t} \\
(\mathrm{h} / \mathrm{m})\end{array}$} & \multicolumn{3}{|c|}{$\mathrm{NC}_{\mathrm{i}}(\mathrm{g} / \mathrm{L})$} & \multicolumn{3}{|c|}{$\mathrm{NL}_{\mathrm{i}}\left(\mathrm{g} / \mathrm{m}^{2}\right)$} \\
\hline & & & B & $\mathrm{Na}$ & $\mathbf{S i}$ & B & $\mathrm{Na}$ & $\mathbf{S i}$ \\
\hline HLP-10 & 10 & $2 \times 10^{5}$ & 0.36 & 1.15 & 0.40 & 0.02 & 0.06 & 0.02 \\
\hline HLP-10 & 100 & $2 \times 10^{6}$ & 2.33 & 3.05 & 0.81 & 0.11 & 0.15 & 0.04 \\
\hline HLP-10 & 1000 & $2 \times 10^{7}$ & 5.90 & 4.60 & 0.85 & 0.29 & 0.22 & 0.04 \\
\hline HLP-10 & 5000 & $1.03 \times 10^{8}$ & 7.83 & 8.25 & 0.80 & 0.38 & 0.40 & 0.04 \\
\hline HLP-10 & 10000 & $2 \times 10^{9}$ & 8.61 & 10.04 & 1.44 & 0.42 & 0.49 & 0.07 \\
\hline HLP-11 & 10 & $2 \times 10^{5}$ & 1.17 & 1.65 & 0.49 & 0.06 & 0.08 & 0.02 \\
\hline HLP-11 & 100 & $2 \times 10^{6}$ & 9.37 & 7.27 & 1.59 & 0.45 & 0.35 & 0.08 \\
\hline HLP-11 & 1000 & $2 \times 10^{7}$ & 16.66 & 12.17 & 1.73 & 0.79 & 0.58 & 0.08 \\
\hline HLP-11 & 5000 & $1.05 \times 10^{8}$ & 14.94 & 9.85 & 0.62 & 0.71 & 0.47 & 0.03 \\
\hline HLP-11 & 10000 & $2 \times 10^{9}$ & 15.19 & 11.16 & 1.47 & 0.72 & 0.53 & 0.07 \\
\hline HLP-12 & 10 & $2 \times 10^{5}$ & 0.50 & 1.01 & 0.40 & 0.03 & 0.05 & 0.02 \\
\hline HLP-12 & 100 & $2 \times 10^{6}$ & 2.67 & 0.13 & 0.70 & 0.13 & 0.13 & 0.03 \\
\hline HLP-12 & 1000 & $2 \times 10^{7}$ & 5.16 & 0.23 & 0.91 & 0.26 & 0.23 & 0.05 \\
\hline HLP-12 & 5000 & $1.00 \times 10^{8}$ & 10.42 & 7.57 & 0.58 & 0.52 & 0.38 & 0.03 \\
\hline HLP-12 & 10000 & $2 \times 10^{9}$ & 12.89 & 10.31 & 1.19 & 0.64 & 0.51 & 0.06 \\
\hline HLP-13 & 10 & $2 \times 10^{5}$ & 0.62 & 0.06 & 0.41 & 0.03 & 0.06 & 0.02 \\
\hline HLP-13 & 100 & $2 \times 10^{6}$ & 4.72 & 0.20 & 0.93 & 0.23 & 0.20 & 0.05 \\
\hline HLP-13 & 1000 & $2 \times 10^{7}$ & 10.00 & 0.36 & 1.14 & 0.48 & 0.36 & 0.06 \\
\hline HLP-13 & 5000 & $1.03 \times 10^{8}$ & 17.21 & 11.73 & 0.81 & 0.83 & 0.57 & 0.04 \\
\hline HLP-13 & 10000 & $2 \times 10^{9}$ & 19.26 & 15.79 & 1.48 & 0.93 & 0.77 & 0.07 \\
\hline HLP-14 & 10 & $2 \times 10^{5}$ & 1.04 & 0.07 & 0.46 & 0.05 & 0.07 & 0.02 \\
\hline HLP-14 & 100 & $2 \times 10^{6}$ & 7.92 & 0.27 & 1.14 & 0.38 & 0.27 & 0.05 \\
\hline HLP-14 & 1000 & $2 \times 10^{7}$ & 14.61 & 0.42 & 1.37 & 0.70 & 0.42 & 0.07 \\
\hline HLP-14 & 5000 & $1.04 \times 10^{8}$ & 22.05 & 13.33 & 0.90 & 1.06 & 0.64 & 0.04 \\
\hline HLP-14 & 10000 & $2 \times 10^{9}$ & 23.60 & 15.41 & 12.59 & 1.13 & 0.74 & 0.61 \\
\hline HLP-15 & 10 & $2 \times 10^{5}$ & 0.49 & 0.05 & 0.39 & 0.02 & 0.05 & 0.02 \\
\hline HLP-15 & 100 & $2 \times 10^{6}$ & 2.67 & 0.14 & 0.77 & 0.13 & 0.14 & 0.04 \\
\hline HLP-15 & 1000 & $2 \times 10^{7}$ & 5.34 & 0.22 & 0.87 & 0.26 & 0.22 & 0.04 \\
\hline HLP-15 & 5000 & $1.02 \times 10^{8}$ & 8.83 & 6.47 & 0.56 & 0.43 & 0.32 & 0.03 \\
\hline HLP-15 & 10000 & $2 \times 10^{9}$ & 11.43 & 9.33 & 1.12 & 0.56 & 0.46 & 0.05 \\
\hline HLP-16 & 10 & $2 \times 10^{5}$ & 0.72 & 0.06 & 0.39 & 0.03 & 0.06 & 0.02 \\
\hline HLP-16 & 100 & $2 \times 10^{6}$ & 4.04 & 0.17 & 0.74 & 0.19 & 0.17 & 0.04 \\
\hline HLP-16 & 1000 & $2 \times 10^{7}$ & 7.89 & 0.29 & 0.83 & 0.38 & 0.29 & 0.04 \\
\hline HLP-16 & 5000 & $1.04 \times 10^{8}$ & 14.29 & 9.42 & 0.61 & 0.69 & 0.45 & 0.03 \\
\hline HLP-16 & 10000 & $2 \times 10^{9}$ & 17.45 & 12.89 & 1.12 & 0.84 & 0.62 & 0.05 \\
\hline HLP-17 & 10 & $2 \times 10^{5}$ & 0.51 & 0.06 & 0.41 & 0.03 & 0.06 & 0.02 \\
\hline HLP-17 & 100 & $2 \times 10^{6}$ & 3.63 & 0.17 & 0.80 & 0.18 & 0.17 & 0.04 \\
\hline HLP-17 & 1000 & $2 \times 10^{7}$ & 7.62 & 0.26 & 0.96 & 0.38 & 0.26 & 0.05 \\
\hline HLP-17 & 5000 & $1.01 \times 10^{8}$ & 11.71 & 8.59 & 0.68 & 0.58 & 0.42 & 0.03 \\
\hline HLP-17 & 10000 & $2 \times 10^{9}$ & 15.68 & 13.31 & 1.21 & 0.77 & 0.66 & 0.06 \\
\hline HLP-18 & 10 & $2 \times 10^{5}$ & 0.70 & 0.06 & 0.51 & 0.03 & 0.06 & 0.02 \\
\hline HLP-18 & 100 & $2 \times 10^{6}$ & 4.85 & 0.19 & 1.13 & 0.23 & 0.19 & 0.05 \\
\hline HLP-18 & 1000 & $2 \times 10^{7}$ & 10.52 & 0.34 & 1.27 & 0.51 & 0.34 & 0.06 \\
\hline HLP-18 & 5000 & $1.04 \times 10^{8}$ & 8.06 & 5.44 & 0.43 & 0.39 & 0.26 & 0.02 \\
\hline HLP-18 & 10000 & $2 \times 10^{9}$ & 20.52 & 15.57 & 1.60 & 0.99 & 0.75 & 0.08 \\
\hline HLP-19 & 10 & $2 \times 10^{5}$ & 0.34 & 0.05 & 0.28 & 0.02 & 0.05 & 0.01 \\
\hline HLP-19 & 100 & $2 \times 10^{6}$ & 2.17 & 0.12 & 0.53 & 0.11 & 0.12 & 0.03 \\
\hline HLP-19 & 1000 & $2 \times 10^{7}$ & 3.97 & 0.18 & 0.62 & 0.20 & 0.18 & 0.03 \\
\hline HLP-19 & 5000 & $1.01 \times 10^{8}$ & 6.58 & 5.70 & 0.42 & 0.33 & 0.28 & 0.02 \\
\hline HLP-19 & 10000 & $2 \times 10^{9}$ & 8.42 & 7.64 & 0.75 & 0.42 & 0.38 & 0.04 \\
\hline
\end{tabular}




\begin{tabular}{|c|c|c|c|c|c|c|c|c|}
\hline \multirow[b]{2}{*}{ SampleID } & \multirow{2}{*}{$\begin{array}{l}\text { Time, } t \\
\text { (hours) }\end{array}$} & \multirow{2}{*}{$\begin{array}{l}(\mathrm{S} / \mathrm{V}) \mathrm{t} \\
(\mathrm{h} / \mathrm{m})\end{array}$} & \multicolumn{3}{|c|}{$\mathrm{NC}_{\mathrm{i}}(\mathrm{g} / \mathrm{L})$} & \multicolumn{3}{|c|}{$\mathrm{NL}_{\mathrm{i}}\left(\mathrm{g} / \mathrm{m}^{2}\right)$} \\
\hline & & & B & $\mathrm{Na}$ & $\mathbf{S i}$ & B & $\mathrm{Na}$ & $\mathbf{S i}$ \\
\hline HLP-20 & 10 & $2 \times 10^{5}$ & 0.67 & 0.05 & 0.41 & 0.03 & 0.05 & 0.02 \\
\hline HLP-20 & 100 & $2 \times 10^{6}$ & 3.00 & 0.14 & 0.69 & 0.15 & 0.14 & 0.03 \\
\hline HLP-20 & 1000 & $2 \times 10^{7}$ & 5.69 & 0.21 & 0.84 & 0.28 & 0.21 & 0.04 \\
\hline HLP-20 & 5000 & $1.02 \times 10^{8}$ & 11.43 & 8.17 & 0.62 & 0.56 & 0.40 & 0.03 \\
\hline HLP-20 & 10000 & $2 \times 10^{9}$ & 13.87 & 10.53 & 1.08 & 0.68 & 0.51 & 0.05 \\
\hline HLP-21 & 10 & $2 \times 10^{5}$ & 0.90 & 0.06 & 0.46 & 0.04 & 0.06 & 0.02 \\
\hline HLP-21 & 100 & $2 \times 10^{6}$ & 5.79 & 0.22 & 0.94 & 0.28 & 0.22 & 0.05 \\
\hline HLP-21 & 1000 & $2 \times 10^{7}$ & 11.10 & 0.38 & 1.22 & 0.54 & 0.38 & 0.06 \\
\hline HLP-21 & 5000 & $1.03 \times 10^{8}$ & 14.42 & 10.13 & 0.74 & 0.70 & 0.49 & 0.04 \\
\hline HLP-21 & 10000 & $2 \times 10^{9}$ & 18.74 & 14.24 & 1.51 & 0.91 & 0.69 & 0.07 \\
\hline HLP-22 & 10 & $2 \times 10^{5}$ & 0.18 & 0.03 & 0.25 & 0.01 & 0.03 & 0.01 \\
\hline HLP-22 & 100 & $2 \times 10^{6}$ & 1.85 & 0.08 & 0.44 & 0.09 & 0.08 & 0.02 \\
\hline HLP-22 & 1000 & $2 \times 10^{7}$ & 3.76 & 0.13 & 0.48 & 0.18 & 0.13 & 0.02 \\
\hline HLP-22 & 5000 & $1.04 \times 10^{8}$ & 6.88 & 4.65 & 0.28 & 0.33 & 0.22 & 0.01 \\
\hline HLP-22 & 10000 & $2 \times 10^{9}$ & 9.56 & 6.84 & 0.51 & 0.46 & 0.33 & 0.02 \\
\hline HLP-23 & 10 & $2 \times 10^{5}$ & 1.62 & 0.12 & 0.72 & 0.08 & 0.12 & 0.04 \\
\hline HLP-23 & 100 & $2 \times 10^{6}$ & 8.45 & 0.37 & 1.51 & 0.41 & 0.37 & 0.07 \\
\hline HLP-23 & 1000 & $2 \times 10^{7}$ & 14.01 & 0.53 & 1.80 & 0.68 & 0.53 & 0.09 \\
\hline HLP-23 & 5000 & $1.02 \times 10^{8}$ & 15.69 & 10.91 & 1.09 & 0.77 & 0.53 & 0.05 \\
\hline HLP-23 & 10000 & $2 \times 10^{9}$ & 119.60 & 74.94 & 1.45 & 5.84 & 3.66 & 0.07 \\
\hline HLP-24 & 10 & $2 \times 10^{5}$ & 0.46 & 0.04 & 0.35 & 0.02 & 0.04 & 0.02 \\
\hline HLP-24 & 100 & $2 \times 10^{6}$ & 2.90 & 0.12 & 0.63 & 0.14 & 0.12 & 0.03 \\
\hline HLP-24 & 1000 & $2 \times 10^{7}$ & 6.23 & 0.20 & 0.07 & 0.30 & 0.20 & 0.00 \\
\hline HLP-24 & 5000 & $1.03 \times 10^{8}$ & 10.73 & 6.60 & 0.41 & 0.52 & 0.32 & 0.02 \\
\hline HLP-24 & 10000 & $2 \times 10^{9}$ & 13.10 & 9.03 & 0.82 & 0.63 & 0.44 & 0.04 \\
\hline HLP-25 & 10 & $2 \times 10^{5}$ & 0.70 & 0.07 & 0.44 & 0.03 & 0.07 & 0.02 \\
\hline HLP-25 & 100 & $2 \times 10^{6}$ & 4.28 & 0.18 & 0.85 & 0.21 & 0.18 & 0.04 \\
\hline HLP-25 & 1000 & $2 \times 10^{7}$ & 9.14 & 0.31 & 1.10 & 0.45 & 0.31 & 0.05 \\
\hline HLP-25 & 5000 & $1.02 \times 10^{8}$ & 13.92 & 9.65 & 0.69 & 0.68 & 0.47 & 0.03 \\
\hline HLP-25 & 10000 & $2 \times 10^{9}$ & 17.01 & 12.88 & 1.56 & 0.83 & 0.63 & 0.08 \\
\hline HLP-26 & 10 & $2 \times 10^{5}$ & 0.84 & 1.31 & 0.43 & 0.04 & 0.06 & 0.02 \\
\hline HLP-26 & 100 & $2 \times 10^{6}$ & 4.44 & 3.48 & 0.85 & 0.22 & 0.17 & 0.04 \\
\hline HLP-26 & 1000 & $2 \times 10^{7}$ & 8.65 & 6.39 & 1.08 & 0.42 & 0.31 & 0.05 \\
\hline HLP-26 & 5000 & $1.02 \times 10^{8}$ & 16.44 & 10.40 & 0.70 & 0.81 & 0.51 & 0.03 \\
\hline HLP-26 & 10000 & $2 \times 10^{9}$ & 19.24 & 14.32 & 1.32 & 0.94 & 0.70 & 0.06 \\
\hline HLP-27 & 10 & $2 \times 10^{5}$ & 3.23 & 2.74 & & 0.15 & 0.13 & 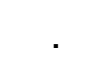 \\
\hline HLP-27 & 100 & $2 \times 10^{6}$ & 16.76 & 11.49 & & 0.78 & 0.53 & \\
\hline HLP-27 & 1000 & $2 \times 10^{7}$ & 38.96 & 22.16 & & 1.81 & 1.03 & \\
\hline HLP-27 & 5000 & $1.07 \times 10^{8}$ & No results & or this $\mathrm{s}$ & aple & & & \\
\hline HLP-27 & 10000 & $2 \times 10^{9}$ & 1047.4 & 765.26 & 1176.6 & 48.75 & 35.62 & 54.77 \\
\hline HLP-28 & 10 & $2 \times 10^{5}$ & 0.38 & 0.59 & 0.20 & 0.02 & 0.03 & 0.01 \\
\hline HLP- 28 & 100 & $2 \times 10^{6}$ & 1.75 & 1.40 & 0.32 & 0.08 & 0.07 & 0.02 \\
\hline HLP- 28 & 1000 & $2 \times 10^{7}$ & 3.82 & 2.25 & 0.27 & 0.18 & 0.11 & 0.01 \\
\hline HLP- 28 & 5000 & $1.07 \times 10^{8}$ & 9.34 & 5.00 & 0.14 & 0.44 & 0.23 & 0.01 \\
\hline HLP-28 & 10000 & $2 \times 10^{9}$ & 14.86 & 10.05 & 1.16 & 0.70 & 0.47 & 0.05 \\
\hline HLP-29 & 10 & $2 \times 10^{5}$ & 0.31 & 1.57 & 0.44 & 0.01 & 0.07 & 0.02 \\
\hline HLP-29 & 100 & $2 \times 10^{6}$ & 2.23 & 3.55 & 0.91 & 0.11 & 0.17 & 0.04 \\
\hline HLP-29 & 1000 & $2 \times 10^{7}$ & 4.47 & 6.46 & 1.18 & 0.21 & 0.31 & 0.06 \\
\hline HLP-29 & 5000 & $1.05 \times 10^{8}$ & 7.75 & 11.18 & 1.14 & 0.37 & 0.53 & 0.05 \\
\hline HLP-29 & 10000 & $2 \times 10^{9}$ & 1047.2 & 599.93 & 221.90 & 50.00 & 28.64 & 10.59 \\
\hline
\end{tabular}




\begin{tabular}{|c|c|c|c|c|c|c|c|c|}
\hline \multirow[b]{2}{*}{ SampleID } & \multirow{2}{*}{$\begin{array}{l}\text { Time, t } \\
\text { (hours) }\end{array}$} & \multirow{2}{*}{$\begin{array}{l}(\mathbf{S} / \mathbf{V}) \mathbf{t} \\
(\mathbf{h} / \mathbf{m})\end{array}$} & \multicolumn{3}{|c|}{$\mathrm{NC}_{\mathrm{i}}(\mathrm{g} / \mathrm{L})$} & \multicolumn{3}{|c|}{$\mathrm{NL}_{\mathrm{i}}\left(\mathrm{g} / \mathrm{m}^{2}\right)$} \\
\hline & & & B & $\mathrm{Na}$ & $\mathbf{S i}$ & B & $\mathrm{Na}$ & $\mathbf{S i}$ \\
\hline HLP-30 & 10 & $2 \times 10^{5}$ & 0.07 & 0.43 & 0.24 & 0.00 & 0.02 & 0.01 \\
\hline HLP-30 & 100 & $2 \times 10^{6}$ & 0.98 & 1.29 & 0.46 & 0.05 & 0.06 & 0.02 \\
\hline HLP-30 & 1000 & $2 \times 10^{7}$ & 1.94 & 2.11 & 0.52 & 0.09 & 0.10 & 0.03 \\
\hline HLP-30 & 5000 & $1.04 \times 10^{8}$ & 1.88 & 2.86 & 0.32 & 0.09 & 0.14 & 0.02 \\
\hline HLP-30 & 10000 & $2 \times 10^{9}$ & 1.84 & 3.74 & 0.74 & 0.09 & 0.18 & 0.04 \\
\hline HLP-31 & 10 & $2 \times 10^{5}$ & 8.51 & 6.17 & 2.16 & 0.41 & 0.30 & 0.11 \\
\hline HLP-31 & 100 & $2 \times 10^{6}$ & 31.15 & 22.47 & 5.86 & 1.52 & 1.10 & 0.29 \\
\hline HLP-31 & 1000 & $2 \times 10^{7}$ & 55.41 & 37.78 & 8.39 & 2.70 & 1.84 & 0.41 \\
\hline HLP-31 & 5000 & $1.03 \times 10^{8}$ & 90.76 & 53.14 & 0.62 & 4.43 & 2.59 & 0.03 \\
\hline HLP-31 & 10000 & $2 \times 10^{9}$ & 136.60 & 91.62 & 2.11 & 6.66 & 4.47 & 0.10 \\
\hline HLP-32 & 10 & $2 \times 10^{5}$ & 0.76 & 0.90 & 0.40 & 0.04 & 0.04 & 0.02 \\
\hline HLP-32 & 100 & $2 \times 10^{6}$ & 4.20 & 2.95 & 0.74 & 0.20 & 0.14 & 0.04 \\
\hline HLP-32 & 1000 & $2 \times 10^{7}$ & 11.44 & 5.80 & 0.95 & 0.56 & 0.28 & 0.05 \\
\hline HLP-32 & 5000 & $1.03 \times 10^{8}$ & 19.90 & 11.77 & 0.45 & 0.97 & 0.57 & 0.02 \\
\hline HLP-32 & 10000 & $2 \times 10^{9}$ & 20.85 & 13.54 & 0.72 & 1.02 & 0.66 & 0.04 \\
\hline HLP-33 & 10 & $2 \times 10^{5}$ & 1.37 & 2.48 & 0.94 & 0.07 & 0.12 & 0.05 \\
\hline HLP-33 & 100 & $2 \times 10^{6}$ & 31.33 & 23.49 & 8.66 & 1.53 & 1.15 & 0.42 \\
\hline HLP-33 & 1000 & $2 \times 10^{7}$ & 117.50 & 73.83 & 3.31 & 5.75 & 3.62 & 0.16 \\
\hline HLP-33 & 5000 & $1.02 \times 10^{8}$ & 107.16 & 60.64 & 1.29 & 5.25 & 2.97 & 0.06 \\
\hline HLP-33 & 10000 & $2 \times 10^{9}$ & 180.88 & 72.83 & 36.89 & 8.86 & 3.57 & 1.81 \\
\hline HLP-34 & 10 & $2 \times 10^{5}$ & 0.23 & 0.90 & 0.33 & 0.01 & 0.04 & 0.02 \\
\hline HLP-34 & 100 & $2 \times 10^{6}$ & 2.74 & 2.56 & 0.85 & 0.14 & 0.13 & 0.04 \\
\hline HLP-34 & 1000 & $2 \times 10^{7}$ & 5.58 & 3.83 & 1.31 & 0.28 & 0.19 & 0.07 \\
\hline HLP-34 & 5000 & $1.00 \times 10^{8}$ & 5.24 & 5.70 & 0.74 & 0.26 & 0.28 & 0.04 \\
\hline HLP-34 & 10000 & $2 \times 10^{9}$ & 4.48 & 6.55 & 1.18 & 0.22 & 0.33 & 0.06 \\
\hline HLP-35 & 10 & $2 \times 10^{5}$ & 1.65 & 1.76 & 0.44 & 0.08 & 0.09 & 0.02 \\
\hline HLP-35 & 100 & $2 \times 10^{6}$ & 11.98 & 7.69 & 0.65 & 0.59 & 0.38 & 0.03 \\
\hline HLP-35 & 1000 & $2 \times 10^{7}$ & 23.51 & 15.81 & 0.68 & 1.15 & 0.78 & 0.03 \\
\hline HLP-35 & 5000 & $1.02 \times 10^{8}$ & 30.31 & 19.58 & 0.43 & 1.49 & 0.96 & 0.02 \\
\hline HLP-35 & 10000 & $2 \times 10^{9}$ & 74.97 & 41.82 & 1.86 & 3.68 & 2.05 & 0.09 \\
\hline HLP-36 & 10 & $2 \times 10^{5}$ & 0.55 & 0.85 & 0.26 & 0.03 & 0.04 & 0.01 \\
\hline HLP-36 & 100 & $2 \times 10^{6}$ & 3.53 & 2.52 & 0.35 & 0.18 & 0.13 & 0.02 \\
\hline HLP-36 & 1000 & $2 \times 10^{7}$ & 13.97 & 7.99 & 0.30 & 0.71 & 0.41 & 0.02 \\
\hline HLP-36 & 5000 & $9.8 \times 10^{7}$ & 57.23 & 30.54 & 0.20 & 2.92 & 1.56 & 0.01 \\
\hline HLP-36 & 10000 & $2 \times 10^{9}$ & 38.85 & 19.57 & 0.30 & 1.98 & 1.00 & 0.02 \\
\hline HLP-37 & 10 & $2 \times 10^{5}$ & 0.35 & 1.65 & 0.48 & 0.02 & 0.08 & 0.02 \\
\hline HLP-37 & 100 & $2 \times 10^{6}$ & 7.04 & 5.98 & 0.97 & 0.35 & 0.30 & 0.05 \\
\hline HLP-37 & 1000 & $2 \times 10^{7}$ & 11.35 & 11.32 & 1.27 & 0.57 & 0.57 & 0.06 \\
\hline HLP-37 & 5000 & $9.94 \times 10^{7}$ & 23.10 & 14.01 & 0.55 & 1.16 & 0.70 & 0.03 \\
\hline HLP-37 & 10000 & $2 \times 10^{9}$ & 664.26 & 299.96 & 24.64 & 33.40 & 15.08 & 1.24 \\
\hline HLP-37Q & 10 & $2 \times 10^{5}$ & --- & --- & . & --- & --- & . \\
\hline HLP-37Q & 100 & $2 \times 10^{6}$ & --- & --- & . & --- & -- & . \\
\hline HLP-37Q & 1000 & $2 \times 10^{7}$ & --- & --- & . & --- & -- & . \\
\hline HLP-37Q & 5000 & $9.94 \times 10^{7}$ & --- & --- & 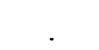 & --- & -- & . \\
\hline HLP-37Q & 10000 & $2 \times 10^{9}$ & --- & --- & . & --- & --- & 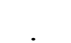 \\
\hline HLP-38 & 10 & $2 \times 10^{5}$ & 0.36 & 0.97 & 0.30 & 0.02 & 0.05 & 0.02 \\
\hline HLP-38 & 100 & $2 \times 10^{6}$ & 2.32 & 2.10 & 0.53 & 0.12 & 0.11 & 0.03 \\
\hline HLP-38 & 1000 & $2 \times 10^{7}$ & 3.67 & 3.70 & 0.71 & 0.19 & 0.19 & 0.04 \\
\hline HLP-38 & 5000 & $9.67 \times 10^{7}$ & 8.46 & 5.81 & 2.45 & 0.44 & 0.30 & 0.13 \\
\hline HLP-38 & 10000 & $2 \times 10^{9}$ & 6.64 & 6.68 & 0.64 & 0.34 & 0.35 & 0.03 \\
\hline
\end{tabular}




\begin{tabular}{|c|c|c|c|c|c|c|c|c|}
\hline \multirow[b]{2}{*}{ SampleID } & \multirow{2}{*}{$\begin{array}{l}\text { Time, t } \\
\text { (hours) }\end{array}$} & \multirow{2}{*}{$\begin{array}{l}(\mathrm{S} / \mathrm{V}) \mathrm{t} \\
(\mathrm{h} / \mathrm{m})\end{array}$} & \multicolumn{3}{|c|}{$\mathrm{NC}_{\mathrm{i}}(\mathrm{g} / \mathrm{L})$} & \multicolumn{3}{|c|}{$N_{i}\left(g / m^{2}\right)$} \\
\hline & & & B & $\mathrm{Na}$ & $\mathbf{S i}$ & B & $\mathrm{Na}$ & $\mathbf{S i}$ \\
\hline HLP-38Q & 10 & $2 \times 10^{5}$ & --- & --- & - & --- & --- & . \\
\hline HLP-38Q & 100 & $2 \times 10^{6}$ & --- & --- & . & --- & --- & 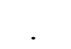 \\
\hline HLP-38Q & 1000 & $2 \times 10^{7}$ & --- & --- & . & --- & -- & . \\
\hline HLP-38Q & 5000 & $9.67 \times 10^{7}$ & --- & --- & . & --- & --- & 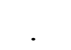 \\
\hline HLP-38Q & 10000 & $2 \times 10^{9}$ & --- & --- & . & --- & --- & \\
\hline HLP-39 & 10 & $2 \times 10^{5}$ & --- & --- & 0.76 & --- & --- & 0.04 \\
\hline HLP-39 & 100 & $2 \times 10^{6}$ & 5.11 & 4.52 & 3.23 & 0.26 & 0.23 & 0.16 \\
\hline HLP-39 & 1000 & $2 \times 10^{7}$ & 39.65 & 25.71 & 4.36 & 2.01 & 1.30 & 0.22 \\
\hline HLP-39 & 5000 & $9.85 \times 10^{7}$ & 147.99 & 79.04 & 1.41 & 7.51 & 4.01 & 0.07 \\
\hline HLP-39 & 10000 & $2 \times 10^{9}$ & 221.53 & 123.33 & 10.68 & 11.24 & 6.26 & 0.54 \\
\hline HLP-40 & 10 & $2 \times 10^{5}$ & 36.24 & 37.75 & 0.40 & 1.84 & 1.92 & 0.02 \\
\hline HLP-40 & 100 & $2 \times 10^{6}$ & 1.14 & 1.28 & 0.67 & 0.06 & 0.07 & 0.04 \\
\hline HLP-40 & 1000 & $2 \times 10^{7}$ & 15.62 & 9.03 & 0.55 & 0.82 & 0.47 & 0.03 \\
\hline HLP-40 & 5000 & $9.52 \times 10^{7}$ & 53.26 & 28.39 & 4.29 & 2.80 & 1.49 & 0.23 \\
\hline HLP-40 & 10000 & $2 \times 10^{9}$ & 39.44 & 23.71 & 0.62 & 2.07 & 1.24 & 0.03 \\
\hline HLP-40Q & 10 & $2 \times 10^{5}$ & 34.49 & 31.19 & 0.36 & 1.81 & 1.64 & 0.02 \\
\hline HLP-40Q & 100 & $2 \times 10^{6}$ & 0.83 & 1.17 & 0.48 & 0.04 & 0.06 & 0.03 \\
\hline HLP-40Q & 1000 & $2 \times 10^{7}$ & 15.97 & 9.63 & 0.60 & 0.84 & 0.51 & 0.03 \\
\hline HLP-40Q & 5000 & $9.52 \times 10^{7}$ & 59.93 & 87.85 & 0.92 & 3.15 & 4.61 & 0.05 \\
\hline HLP-40Q & 10000 & $2 \times 10^{9}$ & 142.44 & 108.85 & 1.51 & 7.48 & 5.71 & 0.08 \\
\hline HLP-41 & 10 & $2 \times 10^{5}$ & 6.85 & 6.70 & 0.96 & 0.36 & 0.35 & 0.05 \\
\hline HLP-41 & 100 & $2 \times 10^{6}$ & 3.97 & 4.52 & 0.56 & 0.21 & 0.24 & 0.03 \\
\hline HLP-41 & 1000 & $2 \times 10^{7}$ & 57.57 & 33.91 & 8.83 & 3.01 & 1.77 & 0.46 \\
\hline HLP-41 & 5000 & $9.56 \times 10^{7}$ & 12.24 & 4.62 & 0.81 & 0.64 & 0.24 & 0.04 \\
\hline HLP-41 & 10000 & $2 \times 10^{9}$ & --- & 195.58 & 27.92 & --- & 10.23 & 1.46 \\
\hline HLP-42 & 10 & $2 \times 10^{5}$ & 12.24 & 4.62 & 0.43 & 0.64 & 0.24 & 0.02 \\
\hline HLP-42 & 100 & $2 \times 10^{6}$ & 10.38 & 6.67 & 1.83 & 0.57 & 0.37 & 0.10 \\
\hline HLP-42 & 1000 & $2 \times 10^{7}$ & 69.37 & 43.21 & 5.31 & 3.81 & 2.37 & 0.29 \\
\hline HLP-42 & 5000 & $9.11 \times 10^{7}$ & 110.30 & 54.26 & 0.94 & 6.05 & 2.98 & 0.05 \\
\hline HLP-42 & 10000 & $2 \times 10^{9}$ & 73.29 & 36.88 & 5.21 & 4.02 & 2.02 & 0.29 \\
\hline HLP-42Q & 10 & $2 \times 10^{5}$ & 0.68 & 1.18 & 0.33 & 0.04 & 0.06 & 0.02 \\
\hline HLP-42Q & 100 & $2 \times 10^{6}$ & 10.19 & 5.73 & 1.29 & 0.56 & 0.31 & 0.07 \\
\hline HLP-42Q & 1000 & $2 \times 10^{7}$ & 74.73 & 35.37 & 2.74 & 4.10 & 1.94 & 0.15 \\
\hline HLP-42Q & 5000 & $9.11 \times 10^{7}$ & 22.92 & 11.10 & 0.44 & 1.26 & 0.61 & 0.02 \\
\hline HLP-42Q & 10000 & $2 \times 10^{9}$ & 128.25 & 57.27 & 3.63 & 7.04 & 3.14 & 0.20 \\
\hline HLP-43 & 10 & $2 \times 10^{5}$ & 0.72 & 1.08 & 0.34 & 0.04 & 0.05 & 0.02 \\
\hline HLP-43 & 100 & $2 \times 10^{6}$ & 5.42 & 4.25 & 0.91 & 0.27 & 0.21 & 0.04 \\
\hline HLP-43 & 1000 & $2 \times 10^{7}$ & 9.48 & 6.05 & 1.09 & 0.46 & 0.30 & 0.05 \\
\hline HLP-43 & 5000 & $1.02 \times 10^{8}$ & 13.40 & 8.99 & 0.15 & 0.66 & 0.44 & 0.01 \\
\hline HLP-43 & 10000 & $2 \times 10^{9}$ & 18.26 & 14.09 & 1.55 & 0.89 & 0.69 & 0.08 \\
\hline HLP-44 & 10 & $2 \times 10^{5}$ & 0.83 & 1.06 & 0.37 & 0.04 & 0.05 & 0.02 \\
\hline HLP-44 & 100 & $2 \times 10^{6}$ & 0.31 & 2.48 & 0.02 & 0.02 & 0.12 & 0.00 \\
\hline HLP-44 & 1000 & $2 \times 10^{7}$ & 7.64 & 6.56 & 0.97 & 0.37 & 0.32 & 0.05 \\
\hline HLP-44 & 5000 & $1.02 \times 10^{8}$ & 11.31 & 8.54 & 0.41 & 0.55 & 0.42 & 0.02 \\
\hline HLP-44 & 10000 & $2 \times 10^{9}$ & 16.10 & 12.08 & 1.32 & 0.79 & 0.59 & 0.06 \\
\hline HLP-45 & 10 & $2 \times 10^{5}$ & 0.86 & 1.16 & 0.37 & 0.04 & 0.06 & 0.02 \\
\hline HLP-45 & 100 & $2 \times 10^{6}$ & 0.35 & 2.89 & 0.02 & 0.02 & 0.14 & 0.00 \\
\hline HLP-45 & 1000 & $2 \times 10^{7}$ & 6.32 & 6.89 & 1.00 & 0.31 & 0.34 & 0.05 \\
\hline HLP-45 & 5000 & $1.01 \times 10^{8}$ & 3.06 & 2.89 & 0.27 & 0.15 & 0.14 & 0.01 \\
\hline HLP-45 & 10000 & $2 \times 10^{9}$ & 13.45 & 12.27 & 1.35 & 0.66 & 0.61 & 0.07 \\
\hline
\end{tabular}




\begin{tabular}{|c|c|c|c|c|c|c|c|c|}
\hline \multirow[b]{2}{*}{ SampleID } & \multirow{2}{*}{$\begin{array}{l}\text { Time, } t \\
\text { (hours) }\end{array}$} & \multirow{2}{*}{$\begin{array}{l}(\mathbf{S} / \mathbf{V}) \mathbf{t} \\
(\mathbf{h} / \mathbf{m})\end{array}$} & \multicolumn{3}{|c|}{$\mathrm{NC}_{\mathrm{i}}(\mathrm{g} / \mathrm{L})$} & \multicolumn{3}{|c|}{$\mathrm{NL}_{\mathrm{i}}\left(\mathrm{g} / \mathrm{m}^{2}\right)$} \\
\hline & & & B & $\mathbf{N a}$ & $\mathbf{S i}$ & B & $\mathbf{N a}$ & $\mathbf{S i}$ \\
\hline HLP-46 & 10 & $2 \times 10^{5}$ & 0.32 & 0.00 & 0.33 & 0.02 & 0.00 & 0.02 \\
\hline HLP-46 & 100 & $2 \times 10^{6}$ & 1.81 & 5.87 & 0.88 & 0.09 & 0.28 & 0.04 \\
\hline HLP-46 & 1000 & $2 \times 10^{7}$ & 5.44 & 9.71 & 1.56 & 0.26 & 0.46 & 0.07 \\
\hline HLP-46 & 5000 & $1.06 \times 10^{8}$ & \multicolumn{6}{|c|}{ No results for this sample } \\
\hline HLP-46 & 10000 & $2 \times 10^{9}$ & 1044.3 & 666.64 & 241.04 & 49.27 & 31.45 & 11.37 \\
\hline HLP-47 & 10 & $2 \times 10^{5}$ & 1.17 & 1.71 & 0.37 & 0.06 & 0.08 & 0.02 \\
\hline HLP-47 & 100 & $2 \times 10^{6}$ & 6.80 & 5.46 & 0.95 & 0.32 & 0.26 & 0.04 \\
\hline HLP-47 & 1000 & $2 \times 10^{7}$ & 19.18 & 12.84 & 1.39 & 0.90 & 0.60 & 0.07 \\
\hline HLP-47 & 5000 & $1.07 \times 10^{8}$ & 33.93 & 29.72 & 3.42 & 1.59 & 1.39 & 0.16 \\
\hline HLP-47 & 10000 & $2 \times 10^{9}$ & 857.18 & 558.81 & 196.11 & 40.19 & 26.20 & 9.20 \\
\hline HLP-48 & 10 & $2 \times 10^{5}$ & 1.19 & 1.36 & 0.42 & 0.06 & 0.07 & 0.02 \\
\hline HLP-48 & 100 & $2 \times 10^{6}$ & 5.87 & 4.38 & 0.69 & 0.29 & 0.22 & 0.03 \\
\hline HLP-48 & 1000 & $2 \times 10^{7}$ & 12.98 & 9.76 & 0.92 & 0.65 & 0.49 & 0.05 \\
\hline HLP-48 & 5000 & $1.00 \times 10^{8}$ & 16.72 & 11.07 & 0.52 & 0.83 & 0.55 & 0.03 \\
\hline HLP-48 & 10000 & $2 \times 10^{9}$ & 23.86 & 17.98 & 1.16 & 1.19 & 0.90 & 0.06 \\
\hline HLP-49 & 10 & $2 \times 10^{5}$ & 0.56 & 0.80 & 0.23 & 0.03 & 0.04 & 0.01 \\
\hline HLP-49 & 100 & $2 \times 10^{6}$ & 2.08 & 1.87 & 0.49 & 0.11 & 0.10 & 0.03 \\
\hline HLP-49 & 1000 & $2 \times 10^{7}$ & 2.81 & 3.19 & 0.68 & 0.14 & 0.16 & 0.04 \\
\hline HLP-49 & 5000 & $9.71 \times 10^{7}$ & 3.70 & 4.01 & 0.34 & 0.19 & 0.21 & 0.02 \\
\hline HLP-49 & 10000 & $2 \times 10^{9}$ & 28.13 & 18.56 & 9.37 & 1.45 & 0.96 & 0.48 \\
\hline HLP-51 & 10 & $2 \times 10^{5}$ & 0.77 & 1.19 & 0.30 & 0.04 & 0.06 & 0.01 \\
\hline HLP-51 & 100 & $2 \times 10^{6}$ & 0.80 & 2.77 & 0.01 & 0.04 & 0.14 & 0.00 \\
\hline HLP-51 & 1000 & $2 \times 10^{7}$ & 6.61 & 6.90 & 0.70 & 0.33 & 0.35 & 0.04 \\
\hline HLP-51 & 5000 & $9.89 \times 10^{7}$ & 10.67 & 8.48 & 0.43 & 0.54 & 0.43 & 0.02 \\
\hline HLP-51 & 10000 & $2 \times 10^{9}$ & 14.90 & 12.67 & 0.95 & 0.75 & 0.64 & 0.05 \\
\hline HLP-52 & 10 & $2 \times 10^{5}$ & --(a) & 0.48 & 0.90 & $--^{(a)}$ & 0.02 & 0.04 \\
\hline HLP-52 & 100 & $2 \times 10^{6}$ & --(a) & 46.57 & 2.86 & ---(a) & 2.30 & 0.14 \\
\hline HLP-52 & 1000 & $2 \times 10^{7}$ & --(a) & 150.00 & 41.19 & $--^{(a)}$ & 7.40 & 2.03 \\
\hline HLP-52 & 5000 & $1.01 \times 10^{8}$ & \multicolumn{6}{|c|}{ No results for this sample } \\
\hline HLP-52 & 10000 & $2 \times 10^{9}$ & $--^{\text {(a) }}$ & 557.29 & 263.96 & $--^{(a)}$ & 27.48 & 13.02 \\
\hline HLP-53 & 10 & $2 \times 10^{5}$ & \multicolumn{6}{|c|}{ No results for this sample } \\
\hline HLP-53 & 100 & $2 \times 10^{6}$ & \multicolumn{6}{|c|}{ No results for this sample } \\
\hline HLP-53 & 1000 & $2 \times 10^{7}$ & --- & 12.61 & 3.04 & --- & 0.64 & 0.15 \\
\hline HLP-53 & 5000 & $9.87 \times 10^{7}$ & 1002.6 & 648.64 & 50.91 & 50.79 & 32.86 & 2.58 \\
\hline HLP-53 & 10000 & $2 \times 10^{9}$ & 879.90 & 647.56 & 81.62 & 44.57 & 32.80 & 4.13 \\
\hline HLP-54 & 10 & $2 \times 10^{5}$ & 0.45 & 1.69 & 0.22 & 0.02 & 0.08 & 0.01 \\
\hline HLP-54 & 100 & $2 \times 10^{6}$ & 2.49 & 2.70 & 0.49 & 0.12 & 0.12 & 0.02 \\
\hline HLP-54 & 1000 & $2 \times 10^{7}$ & 5.05 & 4.54 & 0.59 & 0.23 & 0.21 & 0.03 \\
\hline HLP-54 & 5000 & $1.08 \times 10^{8}$ & \multicolumn{6}{|c|}{ No results for this sample } \\
\hline HLP-54 & 10000 & $2 \times 10^{9}$ & 18.93 & 14.14 & 0.80 & 0.88 & 0.65 & 0.04 \\
\hline HLP-55 & 10 & $2 \times 10^{5}$ & 1.51 & 2.07 & 0.44 & 0.07 & 0.09 & 0.02 \\
\hline HLP-55 & 100 & $2 \times 10^{6}$ & 6.14 & 4.67 & 1.15 & 0.28 & 0.21 & 0.05 \\
\hline HLP-55 & 1000 & $2 \times 10^{7}$ & 14.14 & 10.80 & 1.56 & 0.64 & 0.49 & 0.07 \\
\hline HLP-55 & 5000 & $1.10 \times 10^{8}$ & \multicolumn{6}{|c|}{ No results for this sample } \\
\hline HLP-55 & 10000 & $2 \times 10^{9}$ & 35.99 & 27.93 & 6.47 & 1.64 & 1.27 & 0.30 \\
\hline
\end{tabular}

Glass HLP-52 contained no boron, so the test solution concentration cannot be normalized using the concentration in the glass. 
Short-term Release Rates Based Upon PCT-B Results of Phase I Glasses.

Table B-4a. Short-term boron release rates (g/m²/day) of Phase I glasses based upon measured $\mathrm{NL}_{\mathrm{B}}$.

\begin{tabular}{|c|c|c|c|}
\hline Sample ID & Time (hours) & $\begin{array}{c}\text { Release Rate, } \\
\text { r } \\
\end{array}$ & $\begin{array}{c}\text { Differential Release Rate, } \\
\mathbf{r}_{\Delta}{ }^{*}\end{array}$ \\
\hline HLP-01 & 10 & $9.46 \mathrm{E}-02$ & $9.46 \mathrm{E}-02$ \\
\hline HLP-01 & 100 & 4.32E-02 & $3.75 \mathrm{E}-02$ \\
\hline HLP-01 & 1000 & 9.88E-03 & $6.18 \mathrm{E}-03$ \\
\hline HLP-01 & 5000 & $3.22 \mathrm{E}-03$ & $1.55 \mathrm{E}-03$ \\
\hline HLP-01 & 10000 & 2.48E-03 & $1.73 \mathrm{E}-03$ \\
\hline HLP-02 & 10 & $1.01 \mathrm{E}+00$ & $1.01 \mathrm{E}+00$ \\
\hline HLP-02 & 100 & 3.02E-01 & 2.23E-01 \\
\hline HLP-02 & 1000 & $5.71 \mathrm{E}-02$ & 2.99E-02 \\
\hline HLP-02 & 5000 & $2.62 \mathrm{E}-01$ & $3.14 \mathrm{E}-01$ \\
\hline HLP-02 & 10000 & $1.52 \mathrm{E}-01$ & 4.19E-02 \\
\hline HLP-03 & 10 & 7.01E-02 & 7.01E-02 \\
\hline HLP-03 & 100 & $3.42 \mathrm{E}-02$ & 3.02E-02 \\
\hline HLP-03 & 1000 & 7.64E-03 & 4.68E-03 \\
\hline HLP-03 & 5000 & $2.86 \mathrm{E}-03$ & 1.67E-03 \\
\hline HLP-03 & 10000 & $1.50 \mathrm{E}-03$ & $1.15 \mathrm{E}-04$ \\
\hline HLP-04 & 10 & $3.11 \mathrm{E}-01$ & $3.11 \mathrm{E}-01$ \\
\hline HLP-04 & 100 & $1.75 \mathrm{E}-01$ & $1.60 \mathrm{E}-01$ \\
\hline HLP-04 & 1000 & $3.55 \mathrm{E}-02$ & $2.00 \mathrm{E}-02$ \\
\hline HLP-04 & 5000 & 4.08E-02 & $4.22 \mathrm{E}-02$ \\
\hline HLP-04 & 10000 & $9.58 \mathrm{E}-02$ & $1.51 \mathrm{E}-01$ \\
\hline HLP-05 & 10 & $2.12 \mathrm{E}-01$ & $2.12 \mathrm{E}-01$ \\
\hline HLP-05 & 100 & $3.26 \mathrm{E}-01$ & $3.38 \mathrm{E}-01$ \\
\hline HLP-05 & 1000 & 7.40E-02 & 4.60E-02 \\
\hline HLP-05 & 5000 & 1.73E-02 & 3.09E-03 \\
\hline HLP-05 & 10000 & 7.96E-03 & 1.33E-03 \\
\hline HLP-06 & 10 & 4.14E-02 & 4.14E-02 \\
\hline HLP-06 & 100 & 2.32E-02 & 2.12E-02 \\
\hline HLP-06 & 1000 & $3.50 \mathrm{E}-03$ & $1.30 \mathrm{E}-03$ \\
\hline HLP-06 & 5000 & $1.92 \mathrm{E}-03$ & $1.52 \mathrm{E}-03$ \\
\hline HLP-06 & 10000 & $1.00 \mathrm{E}-03$ & $9.78 \mathrm{E}-05$ \\
\hline HLP-07 & 10 & $6.03 \mathrm{E}-02$ & $6.03 \mathrm{E}-02$ \\
\hline HLP-07 & 100 & $3.00 \mathrm{E}-02$ & $2.66 \mathrm{E}-02$ \\
\hline HLP-07 & 1000 & $5.91 \mathrm{E}-03$ & $3.23 \mathrm{E}-03$ \\
\hline HLP-07 & 5000 & 2.72E-03 & $1.92 \mathrm{E}-03$ \\
\hline HLP-07 & 10000 & 1.49E-03 & $2.59 \mathrm{E}-04$ \\
\hline HLP-08 & 10 & 4.47E-02 & 4.47E-02 \\
\hline HLP-08 & 100 & $2.86 \mathrm{E}-02$ & $2.68 \mathrm{E}-02$ \\
\hline HLP-08 & 1000 & 4.02E-03 & 1.29E-03 \\
\hline HLP-08 & 5000 & $1.59 \mathrm{E}-03$ & $9.85 \mathrm{E}-04$ \\
\hline HLP-08 & 10000 & $1.56 \mathrm{E}-03$ & $1.53 \mathrm{E}-03$ \\
\hline HLP-09 & 10 & $9.13 \mathrm{E}-02$ & $9.13 \mathrm{E}-02$ \\
\hline HLP-09 & 100 & $5.59 \mathrm{E}-02$ & $5.20 \mathrm{E}-02$ \\
\hline HLP-09 & 1000 & $1.91 \mathrm{E}-02$ & $1.50 \mathrm{E}-02$ \\
\hline HLP-09 & 5000 & $3.90 \mathrm{E}-03$ & $1.07 \mathrm{E}-04$ \\
\hline HLP-09 & 10000 & $3.94 \mathrm{E}-03$ & $3.98 \mathrm{E}-03$ \\
\hline HLP-10 & 10 & 4.22E-02 & 4.22E-02 \\
\hline HLP-10 & 100 & 2.72E-02 & $2.56 \mathrm{E}-02$ \\
\hline HLP-10 & 1000 & $6.90 \mathrm{E}-03$ & 4.64E-03 \\
\hline HLP-10 & 5000 & $1.83 \mathrm{E}-03$ & $5.65 \mathrm{E}-04$ \\
\hline HLP-10 & 10000 & $1.01 \mathrm{E}-03$ & $1.85 \mathrm{E}-04$ \\
\hline HLP-11 & 10 & $1.34 \mathrm{E}-01$ & $1.34 \mathrm{E}-01$ \\
\hline
\end{tabular}

B. 16 


\begin{tabular}{|c|c|c|c|}
\hline Sample ID & Time (hours) & $\begin{array}{c}\text { Release Rate, } \\
\text { r } \\
\end{array}$ & Differential Release Rate, \\
\hline HLP-11 & 100 & $1.07 \mathrm{E}-01$ & $1.04 \mathrm{E}-01$ \\
\hline HLP-11 & 1000 & $1.90 \mathrm{E}-02$ & $9.26 \mathrm{E}-03$ \\
\hline HLP-11 & 5000 & $3.42 \mathrm{E}-03$ & $4.91 \mathrm{E}-04$ \\
\hline HLP-11 & 10000 & $1.74 \mathrm{E}-03$ & $4.07 \mathrm{E}-05$ \\
\hline HLP-12 & 10 & $6.02 \mathrm{E}-02$ & $6.02 \mathrm{E}-02$ \\
\hline HLP-12 & 100 & $3.19 \mathrm{E}-02$ & $2.88 \mathrm{E}-02$ \\
\hline HLP-12 & 1000 & $6.17 \mathrm{E}-03$ & $3.31 \mathrm{E}-03$ \\
\hline HLP-12 & 5000 & $2.49 \mathrm{E}-03$ & $1.57 \mathrm{E}-03$ \\
\hline HLP-12 & 10000 & $1.54 \mathrm{E}-03$ & $5.80 \mathrm{E}-04$ \\
\hline HLP-13 & 10 & $7.16 \mathrm{E}-02$ & $7.16 \mathrm{E}-02$ \\
\hline HLP-13 & 100 & $5.49 \mathrm{E}-02$ & $5.30 \mathrm{E}-02$ \\
\hline HLP-13 & 1000 & $1.16 \mathrm{E}-02$ & $6.82 \mathrm{E}-03$ \\
\hline HLP-13 & 5000 & $4.00 \mathrm{E}-03$ & $2.10 \mathrm{E}-03$ \\
\hline HLP-13 & 10000 & $2.24 \mathrm{E}-03$ & $4.62 \mathrm{E}-04$ \\
\hline HLP-14 & 10 & $1.20 \mathrm{E}-01$ & $1.20 \mathrm{E}-01$ \\
\hline HLP-14 & 100 & $9.14 \mathrm{E}-02$ & $8.83 \mathrm{E}-02$ \\
\hline HLP-14 & 1000 & $1.69 \mathrm{E}-02$ & $8.59 \mathrm{E}-03$ \\
\hline HLP-14 & 5000 & $5.09 \mathrm{E}-03$ & $2.15 \mathrm{E}-03$ \\
\hline HLP-14 & 10000 & $2.72 \mathrm{E}-03$ & $3.34 \mathrm{E}-04$ \\
\hline HLP-15 & 10 & $5.69 \mathrm{E}-02$ & $5.69 \mathrm{E}-02$ \\
\hline HLP-15 & 100 & $3.13 \mathrm{E}-02$ & $2.84 \mathrm{E}-02$ \\
\hline HLP-15 & 1000 & $6.26 \mathrm{E}-03$ & $3.48 \mathrm{E}-03$ \\
\hline HLP-15 & 5000 & $2.07 \mathrm{E}-03$ & $1.02 \mathrm{E}-03$ \\
\hline HLP-15 & 10000 & $1.34 \mathrm{E}-03$ & $6.17 \mathrm{E}-04$ \\
\hline HLP-16 & 10 & 8.38E-02 & 8.38E-02 \\
\hline HLP-16 & 100 & $4.67 \mathrm{E}-02$ & $4.26 \mathrm{E}-02$ \\
\hline HLP-16 & 1000 & $9.12 \mathrm{E}-03$ & 4.94E-03 \\
\hline HLP-16 & 5000 & $3.30 \mathrm{E}-03$ & $1.85 \mathrm{E}-03$ \\
\hline HLP-16 & 10000 & $2.02 \mathrm{E}-03$ & 7.29E-04 \\
\hline HLP-17 & 10 & $6.03 \mathrm{E}-02$ & $6.03 \mathrm{E}-02$ \\
\hline HLP-17 & 100 & $4.30 \mathrm{E}-02$ & $4.11 \mathrm{E}-02$ \\
\hline HLP-17 & 1000 & $9.03 \mathrm{E}-03$ & $5.25 \mathrm{E}-03$ \\
\hline HLP-17 & 5000 & $2.78 \mathrm{E}-03$ & $1.21 \mathrm{E}-03$ \\
\hline HLP-17 & 10000 & $1.86 \mathrm{E}-03$ & $9.21 \mathrm{E}-04$ \\
\hline HLP-18 & 10 & $8.11 \mathrm{E}-02$ & $8.11 \mathrm{E}-02$ \\
\hline HLP-18 & 100 & $5.62 \mathrm{E}-02$ & $5.34 \mathrm{E}-02$ \\
\hline HLP-18 & 1000 & $1.22 \mathrm{E}-02$ & 7.31E-03 \\
\hline HLP-18 & 5000 & $1.87 \mathrm{E}-03$ & $7.15 \mathrm{E}-04$ \\
\hline HLP-18 & 10000 & $2.38 \mathrm{E}-03$ & $2.88 \mathrm{E}-03$ \\
\hline HLP-19 & 10 & $4.03 \mathrm{E}-02$ & $4.03 \mathrm{E}-02$ \\
\hline HLP-19 & 100 & $2.58 \mathrm{E}-02$ & $2.42 \mathrm{E}-02$ \\
\hline HLP-19 & 1000 & $4.73 \mathrm{E}-03$ & 2.39E-03 \\
\hline HLP-19 & 5000 & $1.57 \mathrm{E}-03$ & $7.76 \mathrm{E}-04$ \\
\hline HLP-19 & 10000 & $1.00 \mathrm{E}-03$ & $4.49 \mathrm{E}-04$ \\
\hline HLP-20 & 10 & $7.84 \mathrm{E}-02$ & 7.84E-02 \\
\hline HLP-20 & 100 & $3.51 \mathrm{E}-02$ & $3.03 \mathrm{E}-02$ \\
\hline HLP-20 & 1000 & $6.66 \mathrm{E}-03$ & $3.50 \mathrm{E}-03$ \\
\hline HLP-20 & 5000 & $2.68 \mathrm{E}-03$ & $1.68 \mathrm{E}-03$ \\
\hline HLP-20 & 10000 & $1.63 \mathrm{E}-03$ & $5.87 \mathrm{E}-04$ \\
\hline HLP-21 & 10 & $1.05 \mathrm{E}-01$ & $1.05 \mathrm{E}-01$ \\
\hline HLP-21 & 100 & $6.75 \mathrm{E}-02$ & $6.33 \mathrm{E}-02$ \\
\hline HLP-21 & 1000 & $1.29 \mathrm{E}-02$ & $6.89 \mathrm{E}-03$ \\
\hline HLP-21 & 5000 & $3.36 \mathrm{E}-03$ & $9.67 \mathrm{E}-04$ \\
\hline HLP-21 & 10000 & $2.19 \mathrm{E}-03$ & $1.01 \mathrm{E}-03$ \\
\hline
\end{tabular}




\begin{tabular}{|c|c|c|c|}
\hline Sample ID & Time (hours) & $\begin{array}{c}\text { Release Rate, } \\
\text { r }\end{array}$ & Differential Release Rate, \\
\hline HLP-22 & 10 & $2.06 \mathrm{E}-02$ & $3.33 \mathrm{E}-03$ \\
\hline HLP-22 & 100 & $2.14 \mathrm{E}-02$ & $2.14 \mathrm{E}-02$ \\
\hline HLP-22 & 1000 & $4.34 \mathrm{E}-03$ & $2.45 \mathrm{E}-03$ \\
\hline HLP-22 & 5000 & $1.59 \mathrm{E}-03$ & $9.03 \mathrm{E}-04$ \\
\hline HLP-22 & 10000 & $1.11 \mathrm{E}-03$ & $6.18 \mathrm{E}-04$ \\
\hline HLP-23 & 10 & $1.90 \mathrm{E}-01$ & $1.90 \mathrm{E}-01$ \\
\hline HLP-23 & 100 & 9.91E-02 & 8.90E-02 \\
\hline HLP-23 & 1000 & $1.64 \mathrm{E}-02$ & 7.24E-03 \\
\hline HLP-23 & 5000 & $3.68 \mathrm{E}-03$ & 4.90E-04 \\
\hline HLP-23 & 10000 & $1.40 \mathrm{E}-02$ & $2.44 \mathrm{E}-02$ \\
\hline HLP-24 & 10 & $5.30 \mathrm{E}-02$ & $3.58 \mathrm{E}-03$ \\
\hline HLP-24 & 100 & $3.37 \mathrm{E}-02$ & $3.16 \mathrm{E}-02$ \\
\hline HLP-24 & 1000 & 7.24E-03 & 4.30E-03 \\
\hline HLP-24 & 5000 & $2.50 \mathrm{E}-03$ & $1.31 \mathrm{E}-03$ \\
\hline HLP-24 & 10000 & $1.52 \mathrm{E}-03$ & $5.27 \mathrm{E}-04$ \\
\hline HLP-25 & 10 & $8.26 \mathrm{E}-02$ & $8.26 \mathrm{E}-02$ \\
\hline HLP-25 & 100 & $5.04 \mathrm{E}-02$ & $4.68 \mathrm{E}-02$ \\
\hline HLP-25 & 1000 & $1.08 \mathrm{E}-02$ & $6.36 \mathrm{E}-03$ \\
\hline HLP-25 & 5000 & $3.28 \mathrm{E}-03$ & $1.41 \mathrm{E}-03$ \\
\hline HLP-25 & 10000 & 2.00E-03 & 7.05E-04 \\
\hline HLP-26 & 10 & 9.92E-02 & 3.09E-03 \\
\hline HLP-26 & 100 & $5.23 \mathrm{E}-02$ & 4.71E-02 \\
\hline HLP-26 & 1000 & $1.02 \mathrm{E}-02$ & $5.51 \mathrm{E}-03$ \\
\hline HLP-26 & 5000 & $3.88 \mathrm{E}-03$ & 2.30E-03 \\
\hline HLP-26 & 10000 & 2.27E-03 & $6.37 \mathrm{E}-04$ \\
\hline HLP-27 & 10 & $3.61 \mathrm{E}-01$ & $3.16 \mathrm{E}-03$ \\
\hline HLP-27 & 100 & $1.87 \mathrm{E}-01$ & $1.68 \mathrm{E}-01$ \\
\hline HLP-27 & 1000 & 4.35E-02 & $2.76 \mathrm{E}-02$ \\
\hline HLP-27 & 5000 & --- & --- \\
\hline HLP-27 & 10000 & $1.17 \mathrm{E}-01$ & --- \\
\hline HLP-28 & 10 & $4.25 \mathrm{E}-02$ & $4.25 \mathrm{E}-02$ \\
\hline HLP-28 & 100 & $1.97 \mathrm{E}-02$ & $1.72 \mathrm{E}-02$ \\
\hline HLP-28 & 1000 & 4.29E-03 & $2.58 \mathrm{E}-03$ \\
\hline HLP-28 & 5000 & 2.10E-03 & $1.55 \mathrm{E}-03$ \\
\hline HLP-28 & 10000 & $1.67 \mathrm{E}-03$ & $1.26 \mathrm{E}-03$ \\
\hline HLP-29 & 10 & $3.53 \mathrm{E}-02$ & $3.53 \mathrm{E}-02$ \\
\hline HLP-29 & 100 & $2.55 \mathrm{E}-02$ & $2.44 \mathrm{E}-02$ \\
\hline HLP-29 & 1000 & $5.12 \mathrm{E}-03$ & $2.86 \mathrm{E}-03$ \\
\hline HLP-29 & 5000 & $1.78 \mathrm{E}-03$ & 9.39E-04 \\
\hline HLP-29 & 10000 & $1.20 \mathrm{E}-01$ & $2.38 \mathrm{E}-01$ \\
\hline HLP-30 & 10 & 8.60E-03 & 8.60E-03 \\
\hline HLP-30 & 100 & $1.14 \mathrm{E}-02$ & $1.17 \mathrm{E}-02$ \\
\hline HLP-30 & 1000 & 2.24E-03 & $1.23 \mathrm{E}-03$ \\
\hline HLP-30 & 5000 & $4.36 \mathrm{E}-04$ & $1.62 \mathrm{E}-05$ \\
\hline HLP-30 & 10000 & $2.13 \mathrm{E}-04$ & $3.65 \mathrm{E}-06$ \\
\hline HLP-31 & 10 & $9.96 \mathrm{E}-01$ & $9.96 \mathrm{E}-01$ \\
\hline HLP-31 & 100 & $3.65 \mathrm{E}-01$ & $2.95 \mathrm{E}-01$ \\
\hline HLP-31 & 1000 & $6.49 \mathrm{E}-02$ & $3.16 \mathrm{E}-02$ \\
\hline HLP-31 & 5000 & 2.12E-02 & $1.03 \mathrm{E}-02$ \\
\hline HLP-31 & 10000 & $1.60 \mathrm{E}-02$ & $1.07 \mathrm{E}-02$ \\
\hline HLP-32 & 10 & 8.91E-02 & 8.91E-02 \\
\hline HLP-32 & 100 & 4.92E-02 & $4.48 \mathrm{E}-02$ \\
\hline HLP-32 & 1000 & $1.34 \mathrm{E}-02$ & $9.42 \mathrm{E}-03$ \\
\hline HLP-32 & 5000 & $4.66 \mathrm{E}-03$ & $2.48 \mathrm{E}-03$ \\
\hline
\end{tabular}




\begin{tabular}{|c|c|c|c|}
\hline Sample ID & Time (hours) & $\begin{array}{c}\text { Release Rate, } \\
\text { r } \\
\end{array}$ & $\begin{array}{c}\text { Differential Release Rate, } \\
\mathbf{r}_{\Delta}{ }^{*}\end{array}$ \\
\hline HLP-32 & 10000 & $2.44 \mathrm{E}-03$ & $2.37 \mathrm{E}-04$ \\
\hline HLP-33 & 10 & $1.61 \mathrm{E}-01$ & $1.61 \mathrm{E}-01$ \\
\hline HLP-33 & 100 & $3.68 \mathrm{E}-01$ & $3.91 \mathrm{E}-01$ \\
\hline HLP-33 & 1000 & $1.38 \mathrm{E}-01$ & $1.13 \mathrm{E}-01$ \\
\hline HLP-33 & 5000 & $2.52 \mathrm{E}-02$ & $3.04 \mathrm{E}-03$ \\
\hline HLP-33 & 10000 & $2.13 \mathrm{E}-02$ & $1.73 \mathrm{E}-02$ \\
\hline HLP-34 & 10 & $2.74 \mathrm{E}-02$ & $2.74 \mathrm{E}-02$ \\
\hline HLP-34 & 100 & $3.27 \mathrm{E}-02$ & $3.33 \mathrm{E}-02$ \\
\hline HLP-34 & 1000 & $6.65 \mathrm{E}-03$ & $3.76 \mathrm{E}-03$ \\
\hline HLP-34 & 5000 & $1.25 \mathrm{E}-03$ & $1.01 \mathrm{E}-04$ \\
\hline HLP-34 & 10000 & $5.34 \mathrm{E}-04$ & $1.94 \mathrm{E}-04$ \\
\hline HLP-35 & 10 & $1.95 \mathrm{E}-01$ & $1.95 \mathrm{E}-01$ \\
\hline HLP-35 & 100 & $1.41 \mathrm{E}-01$ & $1.35 \mathrm{E}-01$ \\
\hline HLP-35 & 1000 & $2.77 \mathrm{E}-02$ & $1.51 \mathrm{E}-02$ \\
\hline HLP-35 & 5000 & $7.15 \mathrm{E}-03$ & $2.01 \mathrm{E}-03$ \\
\hline HLP-35 & 10000 & $8.84 \mathrm{E}-03$ & $1.05 \mathrm{E}-02$ \\
\hline HLP-36 & 10 & $6.72 \mathrm{E}-02$ & $6.72 \mathrm{E}-02$ \\
\hline HLP-36 & 100 & $4.32 \mathrm{E}-02$ & $4.05 \mathrm{E}-02$ \\
\hline HLP-36 & 1000 & $1.71 \mathrm{E}-02$ & $1.42 \mathrm{E}-02$ \\
\hline HLP-36 & 5000 & $1.40 \mathrm{E}-02$ & $1.32 \mathrm{E}-02$ \\
\hline HLP-36 & 10000 & $4.75 \mathrm{E}-03$ & $4.50 \mathrm{E}-03$ \\
\hline HLP-37 & 10 & $4.24 \mathrm{E}-02$ & $4.24 \mathrm{E}-02$ \\
\hline HLP-37 & 100 & $8.50 \mathrm{E}-02$ & $8.97 \mathrm{E}-02$ \\
\hline HLP-37 & 1000 & $1.37 \mathrm{E}-02$ & $5.77 \mathrm{E}-03$ \\
\hline HLP-37 & 5000 & $5.58 \mathrm{E}-03$ & $3.54 \mathrm{E}-03$ \\
\hline HLP-37 & 10000 & $8.02 \mathrm{E}-02$ & $1.55 \mathrm{E}-01$ \\
\hline HLP-38 & 10 & $4.53 \mathrm{E}-02$ & $4.53 \mathrm{E}-02$ \\
\hline HLP-38 & 100 & $2.88 \mathrm{E}-02$ & $2.69 \mathrm{E}-02$ \\
\hline HLP-38 & 1000 & $4.55 \mathrm{E}-03$ & $1.86 \mathrm{E}-03$ \\
\hline HLP-38 & 5000 & $2.10 \mathrm{E}-03$ & $1.49 \mathrm{E}-03$ \\
\hline HLP-38 & 10000 & $8.24 \mathrm{E}-04$ & $4.68 \mathrm{E}-04$ \\
\hline HLP-39 & 10 & $6.22 \mathrm{E}-01$ & $6.22 \mathrm{E}-01$ \\
\hline HLP-39 & 100 & $4.83 \mathrm{E}-01$ & $4.67 \mathrm{E}-01$ \\
\hline HLP-39 & 1000 & $5.86 \mathrm{E}-02$ & $1.15 \mathrm{E}-02$ \\
\hline HLP-39 & 5000 & $3.60 \mathrm{E}-02$ & $3.04 \mathrm{E}-02$ \\
\hline HLP-39 & 10000 & $2.70 \mathrm{E}-02$ & $1.79 \mathrm{E}-02$ \\
\hline HLP-40 (ht) & 10 & $1.43 \mathrm{E}-01$ & $1.43 \mathrm{E}-01$ \\
\hline HLP-40 (ht) & 100 & $1.97 \mathrm{E}-01$ & $2.03 \mathrm{E}-01$ \\
\hline HLP-40 (ht) & 1000 & $3.85 \mathrm{E}-02$ & $2.09 \mathrm{E}-02$ \\
\hline HLP-40 (ht) & 5000 & $1.34 \mathrm{E}-02$ & $7.15 \mathrm{E}-03$ \\
\hline HLP-40 (ht) & 10000 & $4.97 \mathrm{E}-03$ & $3.48 \mathrm{E}-03$ \\
\hline HLP-40 (q) & 10 & $1.04 \mathrm{E}-01$ & $1.04 \mathrm{E}-01$ \\
\hline HLP-40 (q) & 100 & $2.01 \mathrm{E}-01$ & $2.12 \mathrm{E}-01$ \\
\hline HLP-40 (q) & 1000 & $3.88 \mathrm{E}-02$ & $2.08 \mathrm{E}-02$ \\
\hline $\operatorname{HLP}-40$ (q) & 5000 & $1.51 \mathrm{E}-02$ & $9.17 \mathrm{E}-03$ \\
\hline HLP-40 (q) & 10000 & $1.79 \mathrm{E}-02$ & $2.08 \mathrm{E}-02$ \\
\hline HLP-41 & 10 & $4.98 \mathrm{E}-01$ & $4.98 \mathrm{E}-01$ \\
\hline HLP-41 & 100 & $7.22 \mathrm{E}-01$ & $7.47 \mathrm{E}-01$ \\
\hline HLP-41 & 1000 & $9.68 \mathrm{E}-02$ & $2.73 \mathrm{E}-02$ \\
\hline HLP-41 & 5000 & $3.07 \mathrm{E}-03$ & $2.04 \mathrm{E}-02$ \\
\hline HLP-41 & 10000 & --- & --- \\
\hline HLP-42 (ht) & 10 & 7.38E-02 & 7.38E-02 \\
\hline HLP-42 (ht) & 100 & $1.37 \mathrm{E}-01$ & $1.44 \mathrm{E}-01$ \\
\hline HLP-42 (ht) & 1000 & $9.13 \mathrm{E}-02$ & $8.63 \mathrm{E}-02$ \\
\hline
\end{tabular}

B.19 


\begin{tabular}{|c|c|c|c|}
\hline Sample ID & Time (hours) & $\begin{array}{c}\text { Release Rate, } \\
\text { r } \\
\end{array}$ & Differential Release Rate, \\
\hline HLP-42 (ht) & 5000 & $2.90 \mathrm{E}-02$ & $1.35 \mathrm{E}-02$ \\
\hline HLP-42 (ht) & 10000 & $9.65 \mathrm{E}-03$ & $9.75 \mathrm{E}-03$ \\
\hline HLP-42 (q) & 10 & $8.90 \mathrm{E}-02$ & $8.90 \mathrm{E}-02$ \\
\hline HLP-42 (q) & 100 & $1.34 \mathrm{E}-01$ & $1.39 \mathrm{E}-01$ \\
\hline HLP-42 (q) & 1000 & $9.84 \mathrm{E}-02$ & $9.44 \mathrm{E}-02$ \\
\hline HLP-42 (q) & 5000 & $6.04 \mathrm{E}-03$ & $1.71 \mathrm{E}-02$ \\
\hline HLP-42 (q) & 10000 & $1.69 \mathrm{E}-02$ & $2.78 \mathrm{E}-02$ \\
\hline HLP-43 & 10 & $8.52 \mathrm{E}-02$ & $8.52 \mathrm{E}-02$ \\
\hline HLP-43 & 100 & $6.37 \mathrm{E}-02$ & $6.13 \mathrm{E}-02$ \\
\hline HLP-43 & 1000 & $1.11 \mathrm{E}-02$ & $5.30 \mathrm{E}-03$ \\
\hline HLP-43 & 5000 & $3.15 \mathrm{E}-03$ & $1.15 \mathrm{E}-03$ \\
\hline HLP-43 & 10000 & $2.15 \mathrm{E}-03$ & $1.12 \mathrm{E}-03$ \\
\hline HLP-44 & 10 & $9.82 \mathrm{E}-02$ & $9.82 \mathrm{E}-02$ \\
\hline HLP-44 & 100 & $3.68 \mathrm{E}-03$ & $6.83 \mathrm{E}-03$ \\
\hline HLP-44 & 1000 & $9.00 \mathrm{E}-03$ & $9.59 \mathrm{E}-03$ \\
\hline HLP-44 & 5000 & $2.66 \mathrm{E}-03$ & $1.08 \mathrm{E}-03$ \\
\hline HLP-44 & 10000 & $1.90 \mathrm{E}-03$ & $1.13 \mathrm{E}-03$ \\
\hline HLP-45 & 10 & $1.01 \mathrm{E}-01$ & $1.01 \mathrm{E}-01$ \\
\hline HLP-45 & 100 & $4.14 \mathrm{E}-03$ & $6.67 \mathrm{E}-03$ \\
\hline HLP-45 & 1000 & $7.49 \mathrm{E}-03$ & $7.87 \mathrm{E}-03$ \\
\hline HLP-45 & 5000 & $7.25 \mathrm{E}-04$ & $9.67 \mathrm{E}-04$ \\
\hline HLP-45 & 10000 & $1.59 \mathrm{E}-03$ & $2.44 \mathrm{E}-03$ \\
\hline HLP-46 & 10 & $3.67 \mathrm{E}-02$ & $3.67 \mathrm{E}-02$ \\
\hline HLP-46 & 100 & $2.06 \mathrm{E}-02$ & $1.88 \mathrm{E}-02$ \\
\hline HLP-46 & 1000 & $6.15 \mathrm{E}-03$ & $4.55 \mathrm{E}-03$ \\
\hline HLP-46 & 5000 & --- & --- \\
\hline HLP-46 & 10000 & $1.18 \mathrm{E}-01$ & --- \\
\hline HLP-47 & 10 & $1.32 \mathrm{E}-01$ & $1.32 \mathrm{E}-01$ \\
\hline HLP-47 & 100 & $7.65 \mathrm{E}-02$ & 7.04E-02 \\
\hline HLP-47 & 1000 & $2.16 \mathrm{E}-02$ & $1.55 \mathrm{E}-02$ \\
\hline HLP-47 & 5000 & $7.64 \mathrm{E}-03$ & $4.15 \mathrm{E}-03$ \\
\hline HLP-47 & 10000 & $9.65 \mathrm{E}-02$ & $1.85 \mathrm{E}-01$ \\
\hline HLP-48 & 10 & $1.43 \mathrm{E}-01$ & $1.43 \mathrm{E}-01$ \\
\hline HLP-48 & 100 & $7.03 \mathrm{E}-02$ & $6.23 \mathrm{E}-02$ \\
\hline HLP-48 & 1000 & $1.56 \mathrm{E}-02$ & $9.48 \mathrm{E}-03$ \\
\hline HLP-48 & 5000 & $4.01 \mathrm{E}-03$ & $1.12 \mathrm{E}-03$ \\
\hline HLP-48 & 10000 & $2.86 \mathrm{E}-03$ & $1.71 \mathrm{E}-03$ \\
\hline HLP-49 & 10 & $6.93 \mathrm{E}-02$ & $6.93 \mathrm{E}-02$ \\
\hline HLP-49 & 100 & $2.57 \mathrm{E}-02$ & $2.08 \mathrm{E}-02$ \\
\hline HLP-49 & 1000 & $3.48 \mathrm{E}-03$ & $1.01 \mathrm{E}-03$ \\
\hline HLP-49 & 5000 & $9.15 \mathrm{E}-04$ & $2.75 \mathrm{E}-04$ \\
\hline HLP-49 & 10000 & $3.48 \mathrm{E}-03$ & $6.04 \mathrm{E}-03$ \\
\hline HLP-51 & 10 & $9.29 \mathrm{E}-02$ & $9.29 \mathrm{E}-02$ \\
\hline HLP-51 & 100 & $9.71 \mathrm{E}-03$ & $4.69 \mathrm{E}-04$ \\
\hline HLP-51 & 1000 & $8.02 \mathrm{E}-03$ & $7.83 \mathrm{E}-03$ \\
\hline HLP-51 & 5000 & $2.59 \mathrm{E}-03$ & $1.23 \mathrm{E}-03$ \\
\hline HLP-51 & 10000 & $1.81 \mathrm{E}-03$ & $1.01 \mathrm{E}-03$ \\
\hline HLP-52 & 10 & $5.72 \mathrm{E}-01$ & $5.72 \mathrm{E}-01$ \\
\hline HLP-52 & 100 & $9.66 \mathrm{E}-01$ & $1.01 \mathrm{E}+00$ \\
\hline HLP-52 & 1000 & $8.51 \mathrm{E}-02$ & $1.28 \mathrm{E}-02$ \\
\hline HLP-52 & 5000 & --- & --- \\
\hline HLP-52 & 10000 & --- & --- \\
\hline HLP-53 & 5000 & $2.44 \mathrm{E}-01$ & $2.44 \mathrm{E}-01$ \\
\hline HLP-53 & 10000 & $1.07 \mathrm{E}-01$ & $2.44 \mathrm{E}-01$ \\
\hline
\end{tabular}




\begin{tabular}{cccc}
\hline Sample ID & Time (hours) & $\begin{array}{c}\text { Release Rate, } \\
\mathbf{r}\end{array}$ & $\begin{array}{c}\text { Differential Release Rate, } \\
\mathbf{r}_{\Delta}{ }^{*}\end{array}$ \\
\hline HLP-54 & & $5.03 \mathrm{E}-02$ & $5.03 \mathrm{E}-02$ \\
HLP-54 & 10 & $2.77 \mathrm{E}-02$ & $2.52 \mathrm{E}-02$ \\
HLP-54 & 1000 & $5.61 \mathrm{E}-03$ & $3.15 \mathrm{E}-03$ \\
HLP-54 & 5000 & --- & --- \\
HLP-54 & 10000 & $2.10 \mathrm{E}-03$ & --- \\
HLP-55 & 10 & $1.65 \mathrm{E}-01$ & $1.65 \mathrm{E}-01$ \\
HLP-55 & 100 & $6.72 \mathrm{E}-02$ & $5.63 \mathrm{E}-02$ \\
HLP-55 & 1000 & $1.55 \mathrm{E}-02$ & $9.73 \mathrm{E}-03$ \\
HLP-55 & 5000 & --- & --- \\
HLP-55 & 10000 & $3.94 \mathrm{E}-03$ & --- \\
\hline
\end{tabular}

* Release rate and differential release rate are the same at 10 hours. 
Short-term Release Rates Based Upon PCT-B Results of Phase I Glasses.

Table B-4b. Short-term sodium release rates $\left(\mathrm{g} / \mathrm{m}^{2} /\right.$ day) based upon measured $\mathrm{NL}_{\mathrm{Na}}$

\begin{tabular}{|c|c|c|c|}
\hline Sample ID & Time (hours) & $\begin{array}{c}\text { Release Rate, } \\
\text { r }\end{array}$ & $\begin{array}{c}\text { Differential Release Rate, } \\
\mathbf{r}_{\Delta}{ }^{*}\end{array}$ \\
\hline HLP-01 & 10 & $1.35 \mathrm{E}-01$ & $1.35 \mathrm{E}-01$ \\
\hline HLP-01 & 100 & $3.72 \mathrm{E}-02$ & $2.64 \mathrm{E}-02$ \\
\hline HLP-01 & 1000 & $7.29 \mathrm{E}-03$ & $3.96 \mathrm{E}-03$ \\
\hline HLP-01 & 5000 & $2.01 \mathrm{E}-03$ & $6.88 \mathrm{E}-04$ \\
\hline HLP-01 & 10000 & $1.65 \mathrm{E}-03$ & $1.30 \mathrm{E}-03$ \\
\hline HLP-02 & 10 & $6.45 \mathrm{E}-01$ & $6.45 \mathrm{E}-01$ \\
\hline HLP-02 & 100 & $1.83 \mathrm{E}-01$ & $1.31 \mathrm{E}-01$ \\
\hline HLP-02 & 1000 & $2.99 \mathrm{E}-02$ & $1.29 \mathrm{E}-02$ \\
\hline HLP-02 & 5000 & $1.05 \mathrm{E}-01$ & $1.24 \mathrm{E}-01$ \\
\hline HLP-02 & 10000 & $6.51 \mathrm{E}-02$ & $2.51 \mathrm{E}-02$ \\
\hline HLP-03 & 10 & $1.12 \mathrm{E}-01$ & $1.12 \mathrm{E}-01$ \\
\hline HLP-03 & 100 & $3.26 \mathrm{E}-02$ & $2.38 \mathrm{E}-02$ \\
\hline HLP-03 & 1000 & $5.48 \mathrm{E}-03$ & $2.46 \mathrm{E}-03$ \\
\hline HLP-03 & 5000 & $1.67 \mathrm{E}-03$ & 7.12E-04 \\
\hline HLP-03 & 10000 & $1.08 \mathrm{E}-03$ & $4.95 \mathrm{E}-04$ \\
\hline HLP-04 & 10 & $3.26 \mathrm{E}-02$ & $3.26 \mathrm{E}-02$ \\
\hline HLP-04 & 100 & $1.24 \mathrm{E}-01$ & $1.34 \mathrm{E}-01$ \\
\hline HLP-04 & 1000 & $2.28 \mathrm{E}-02$ & $1.16 \mathrm{E}-02$ \\
\hline HLP-04 & 5000 & $2.34 \mathrm{E}-02$ & $2.35 \mathrm{E}-02$ \\
\hline HLP-04 & 10000 & $4.89 \mathrm{E}-02$ & 7.45E-02 \\
\hline HLP-05 & 10 & $2.11 \mathrm{E}-01$ & $2.11 \mathrm{E}-01$ \\
\hline HLP-05 & 100 & $2.06 \mathrm{E}-01$ & $2.05 \mathrm{E}-01$ \\
\hline HLP-05 & 1000 & $4.22 \mathrm{E}-02$ & $2.40 \mathrm{E}-02$ \\
\hline HLP-05 & 5000 & $9.10 \mathrm{E}-03$ & $8.14 \mathrm{E}-04$ \\
\hline HLP-05 & 10000 & 4.93E-03 & $7.45 \mathrm{E}-04$ \\
\hline HLP-06 & 10 & 8.34E-02 & 8.34E-02 \\
\hline HLP-06 & 100 & $1.99 \mathrm{E}-02$ & $1.28 \mathrm{E}-02$ \\
\hline HLP-06 & 1000 & $3.05 \mathrm{E}-03$ & $1.18 \mathrm{E}-03$ \\
\hline HLP-06 & 5000 & $1.12 \mathrm{E}-03$ & $6.35 \mathrm{E}-04$ \\
\hline HLP-06 & 10000 & $6.73 \mathrm{E}-04$ & $2.26 \mathrm{E}-04$ \\
\hline HLP-07 & 10 & $1.07 \mathrm{E}-01$ & $1.07 \mathrm{E}-01$ \\
\hline HLP-07 & 100 & $2.54 \mathrm{E}-02$ & $1.63 \mathrm{E}-02$ \\
\hline HLP-07 & 1000 & $4.77 \mathrm{E}-03$ & $2.48 \mathrm{E}-03$ \\
\hline HLP-07 & 5000 & $1.60 \mathrm{E}-03$ & 8.09E-04 \\
\hline HLP-07 & 10000 & $9.88 \mathrm{E}-04$ & $3.67 \mathrm{E}-04$ \\
\hline HLP-08 & 10 & $1.59 \mathrm{E}-01$ & $1.59 \mathrm{E}-01$ \\
\hline HLP-08 & 100 & $3.80 \mathrm{E}-02$ & $2.46 \mathrm{E}-02$ \\
\hline HLP-08 & 1000 & $6.71 \mathrm{E}-03$ & $3.23 \mathrm{E}-03$ \\
\hline HLP-08 & 5000 & $2.01 \mathrm{E}-03$ & $8.40 \mathrm{E}-04$ \\
\hline HLP-08 & 10000 & $1.67 \mathrm{E}-03$ & $1.35 \mathrm{E}-03$ \\
\hline HLP-09 & 10 & $1.27 \mathrm{E}-01$ & $1.27 \mathrm{E}-01$ \\
\hline HLP-09 & 100 & $4.01 \mathrm{E}-02$ & $3.04 \mathrm{E}-02$ \\
\hline HLP-09 & 1000 & $1.09 \mathrm{E}-02$ & 7.71E-03 \\
\hline HLP-09 & 5000 & $2.13 \mathrm{E}-03$ & 7.93E-05 \\
\hline HLP-09 & 10000 & $2.24 \mathrm{E}-03$ & 2.34E-03 \\
\hline HLP-10 & 10 & $1.34 \mathrm{E}-01$ & $1.34 \mathrm{E}-01$ \\
\hline HLP-10 & 100 & $3.57 \mathrm{E}-02$ & $2.47 \mathrm{E}-02$ \\
\hline HLP-10 & 1000 & 5.39E-03 & 2.02E-03 \\
\hline HLP-10 & 5000 & $1.93 \mathrm{E}-03$ & $1.07 \mathrm{E}-03$ \\
\hline HLP-10 & 10000 & $1.17 \mathrm{E}-03$ & $4.21 \mathrm{E}-04$ \\
\hline HLP-11 & 10 & $1.89 \mathrm{E}-01$ & $1.89 \mathrm{E}-01$ \\
\hline
\end{tabular}




\begin{tabular}{|c|c|c|c|}
\hline Sample ID & Time (hours) & $\begin{array}{c}\text { Release Rate, } \\
\text { r }\end{array}$ & $\begin{array}{c}\text { Differential Release Rate, } \\
\mathbf{r}_{\Delta}{ }^{*}\end{array}$ \\
\hline HLP-11 & 100 & $8.31 \mathrm{E}-02$ & $7.13 \mathrm{E}-02$ \\
\hline HLP-11 & 1000 & 1.39E-02 & $6.22 \mathrm{E}-03$ \\
\hline HLP-11 & 5000 & $2.25 \mathrm{E}-03$ & $6.63 \mathrm{E}-04$ \\
\hline HLP-11 & 10000 & $1.28 \mathrm{E}-03$ & 2.92E-04 \\
\hline HLP-12 & 10 & $1.21 \mathrm{E}-01$ & $1.21 \mathrm{E}-01$ \\
\hline HLP-12 & 100 & $3.19 \mathrm{E}-02$ & $2.21 \mathrm{E}-02$ \\
\hline HLP-12 & 1000 & $5.63 \mathrm{E}-03$ & $2.70 \mathrm{E}-03$ \\
\hline HLP-12 & 5000 & $1.81 \mathrm{E}-03$ & $8.58 \mathrm{E}-04$ \\
\hline HLP-12 & 10000 & $1.23 \mathrm{E}-03$ & $6.36 \mathrm{E}-04$ \\
\hline HLP-13 & 10 & $1.44 \mathrm{E}-01$ & $1.44 \mathrm{E}-01$ \\
\hline HLP-13 & 100 & 4.75E-02 & $3.67 \mathrm{E}-02$ \\
\hline HLP-13 & 1000 & 8.63E-03 & 4.32E-03 \\
\hline HLP-13 & 5000 & 2.73E-03 & $1.25 \mathrm{E}-03$ \\
\hline HLP-13 & 10000 & $1.84 \mathrm{E}-03$ & $9.68 \mathrm{E}-04$ \\
\hline HLP-14 & 10 & $1.67 \mathrm{E}-01$ & $1.67 \mathrm{E}-01$ \\
\hline HLP-14 & 100 & $6.51 \mathrm{E}-02$ & $5.38 \mathrm{E}-02$ \\
\hline HLP-14 & 1000 & $1.01 \mathrm{E}-02$ & $3.98 \mathrm{E}-03$ \\
\hline HLP-14 & 5000 & 3.08E-03 & $1.32 \mathrm{E}-03$ \\
\hline HLP-14 & 10000 & $1.78 \mathrm{E}-03$ & 4.76E-04 \\
\hline HLP-15 & 10 & $1.25 \mathrm{E}-01$ & $1.25 \mathrm{E}-01$ \\
\hline HLP-15 & 100 & 3.34E-02 & 2.32E-02 \\
\hline HLP-15 & 1000 & $5.20 \mathrm{E}-03$ & $2.06 \mathrm{E}-03$ \\
\hline HLP-15 & 5000 & $1.52 \mathrm{E}-03$ & $5.98 \mathrm{E}-04$ \\
\hline HLP-15 & 10000 & 1.09E-03 & $6.91 \mathrm{E}-04$ \\
\hline HLP-16 & 10 & $1.46 \mathrm{E}-01$ & $1.46 \mathrm{E}-01$ \\
\hline HLP-16 & 100 & $3.98 \mathrm{E}-02$ & 2.79E-02 \\
\hline HLP-16 & 1000 & 7.01E-03 & 3.37E-03 \\
\hline HLP-16 & 5000 & $2.18 \mathrm{E}-03$ & $9.69 \mathrm{E}-04$ \\
\hline HLP-16 & 10000 & $1.49 \mathrm{E}-03$ & 7.99E-04 \\
\hline HLP-17 & 10 & $1.32 \mathrm{E}-01$ & $1.32 \mathrm{E}-01$ \\
\hline HLP-17 & 100 & 4.08E-02 & $3.06 \mathrm{E}-02$ \\
\hline HLP-17 & 1000 & $6.34 \mathrm{E}-03$ & $2.51 \mathrm{E}-03$ \\
\hline HLP-17 & 5000 & 2.04E-03 & $9.61 \mathrm{E}-04$ \\
\hline HLP-17 & 10000 & $1.58 \mathrm{E}-03$ & $1.13 \mathrm{E}-03$ \\
\hline HLP-18 & 10 & $1.45 \mathrm{E}-01$ & $1.45 \mathrm{E}-01$ \\
\hline HLP-18 & 100 & $4.55 \mathrm{E}-02$ & $3.44 \mathrm{E}-02$ \\
\hline HLP-18 & 1000 & $8.17 \mathrm{E}-03$ & 4.02E-03 \\
\hline HLP-18 & 5000 & $1.26 \mathrm{E}-03$ & 4.64E-04 \\
\hline HLP-18 & 10000 & $1.81 \mathrm{E}-03$ & 2.34E-03 \\
\hline HLP-19 & 10 & $1.11 \mathrm{E}-01$ & $1.11 \mathrm{E}-01$ \\
\hline HLP-19 & 100 & 2.78E-02 & $1.85 \mathrm{E}-02$ \\
\hline HLP-19 & 1000 & 4.24E-03 & $1.62 \mathrm{E}-03$ \\
\hline HLP-19 & 5000 & $1.36 \mathrm{E}-03$ & $6.38 \mathrm{E}-04$ \\
\hline HLP-19 & 10000 & 9.09E-04 & $4.66 \mathrm{E}-04$ \\
\hline HLP-20 & 10 & $1.32 \mathrm{E}-01$ & $1.32 \mathrm{E}-01$ \\
\hline HLP-20 & 100 & $3.41 \mathrm{E}-02$ & 2.32E-02 \\
\hline HLP-20 & 1000 & $5.14 \mathrm{E}-03$ & $1.92 \mathrm{E}-03$ \\
\hline HLP-20 & 5000 & $1.91 \mathrm{E}-03$ & $1.11 \mathrm{E}-03$ \\
\hline HLP-20 & 10000 & $1.23 \mathrm{E}-03$ & $5.35 \mathrm{E}-04$ \\
\hline HLP-21 & 10 & $1.53 \mathrm{E}-01$ & $1.53 \mathrm{E}-01$ \\
\hline HLP-21 & 100 & 5.34E-02 & $4.23 \mathrm{E}-02$ \\
\hline HLP-21 & 1000 & $9.13 \mathrm{E}-03$ & $4.22 \mathrm{E}-03$ \\
\hline HLP-21 & 5000 & $2.36 \mathrm{E}-03$ & $6.69 \mathrm{E}-04$ \\
\hline HLP-21 & 10000 & $1.66 \mathrm{E}-03$ & $9.50 \mathrm{E}-04$ \\
\hline
\end{tabular}




\begin{tabular}{|c|c|c|c|}
\hline Sample ID & Time (hours) & $\begin{array}{c}\text { Release Rate, } \\
\text { r } \\
\end{array}$ & Differential Release Rate, \\
\hline HLP-22 & 10 & $6.34 \mathrm{E}-02$ & $6.34 \mathrm{E}-02$ \\
\hline HLP-22 & 100 & $2.01 \mathrm{E}-02$ & $1.52 \mathrm{E}-02$ \\
\hline HLP-22 & 1000 & $3.08 \mathrm{E}-03$ & $1.20 \mathrm{E}-03$ \\
\hline HLP-22 & 5000 & $1.08 \mathrm{E}-03$ & $5.73 \mathrm{E}-04$ \\
\hline HLP-22 & 10000 & $7.91 \mathrm{E}-04$ & $5.09 \mathrm{E}-04$ \\
\hline HLP-23 & 10 & $2.77 \mathrm{E}-01$ & $2.77 \mathrm{E}-01$ \\
\hline HLP-23 & 100 & $8.89 \mathrm{E}-02$ & $6.81 \mathrm{E}-02$ \\
\hline HLP-23 & 1000 & $1.26 \mathrm{E}-02$ & $4.14 \mathrm{E}-03$ \\
\hline HLP-23 & 5000 & $2.56 \mathrm{E}-03$ & $4.40 \mathrm{E}-05$ \\
\hline HLP-23 & 10000 & 8.79E-03 & $1.50 \mathrm{E}-02$ \\
\hline HLP-24 & 10 & $1.02 \mathrm{E}-01$ & $1.02 \mathrm{E}-01$ \\
\hline HLP-24 & 100 & $2.83 \mathrm{E}-02$ & $2.00 \mathrm{E}-02$ \\
\hline HLP-24 & 1000 & $4.83 \mathrm{E}-03$ & $2.23 \mathrm{E}-03$ \\
\hline HLP-24 & 5000 & $1.54 \mathrm{E}-03$ & $7.12 \mathrm{E}-04$ \\
\hline HLP-24 & 10000 & $1.05 \mathrm{E}-03$ & $5.76 \mathrm{E}-04$ \\
\hline HLP-25 & 10 & $1.60 \mathrm{E}-01$ & $1.60 \mathrm{E}-01$ \\
\hline HLP-25 & 100 & $4.42 \mathrm{E}-02$ & $3.13 \mathrm{E}-02$ \\
\hline HLP-25 & 1000 & $7.37 \mathrm{E}-03$ & $3.27 \mathrm{E}-03$ \\
\hline HLP-25 & 5000 & $2.27 \mathrm{E}-03$ & $1.00 \mathrm{E}-03$ \\
\hline HLP-25 & 10000 & $1.52 \mathrm{E}-03$ & $7.50 \mathrm{E}-04$ \\
\hline HLP-26 & 10 & $1.54 \mathrm{E}-01$ & $1.54 \mathrm{E}-01$ \\
\hline HLP-26 & 100 & 4.10E-02 & $2.84 \mathrm{E}-02$ \\
\hline HLP-26 & 1000 & $7.53 \mathrm{E}-03$ & $3.81 \mathrm{E}-03$ \\
\hline HLP-26 & 5000 & $2.45 \mathrm{E}-03$ & $1.18 \mathrm{E}-03$ \\
\hline HLP-26 & 10000 & $1.69 \mathrm{E}-03$ & $9.10 \mathrm{E}-04$ \\
\hline HLP-27 & 10 & $3.07 \mathrm{E}-01$ & $3.07 \mathrm{E}-01$ \\
\hline HLP-27 & 100 & $1.28 \mathrm{E}-01$ & $1.09 \mathrm{E}-01$ \\
\hline HLP-27 & 1000 & $2.48 \mathrm{E}-02$ & $1.32 \mathrm{E}-02$ \\
\hline HLP-27 & 5000 & --- & --- \\
\hline HLP-27 & 10000 & $8.55 \mathrm{E}-02$ & --- \\
\hline HLP-28 & 10 & $6.58 \mathrm{E}-02$ & $6.58 \mathrm{E}-02$ \\
\hline HLP-28 & 100 & $1.57 \mathrm{E}-02$ & $1.02 \mathrm{E}-02$ \\
\hline HLP-28 & 1000 & $2.52 \mathrm{E}-03$ & $1.05 \mathrm{E}-03$ \\
\hline HLP-28 & 5000 & $1.12 \mathrm{E}-03$ & $7.72 \mathrm{E}-04$ \\
\hline HLP-28 & 10000 & $1.13 \mathrm{E}-03$ & $1.13 \mathrm{E}-03$ \\
\hline HLP-29 & 10 & $1.80 \mathrm{E}-01$ & $1.80 \mathrm{E}-01$ \\
\hline HLP-29 & 100 & $4.07 \mathrm{E}-02$ & $2.53 \mathrm{E}-02$ \\
\hline HLP-29 & 1000 & $7.40 \mathrm{E}-03$ & $3.70 \mathrm{E}-03$ \\
\hline HLP-29 & 5000 & $2.56 \mathrm{E}-03$ & $1.35 \mathrm{E}-03$ \\
\hline HLP-29 & 10000 & $6.87 \mathrm{E}-02$ & $1.35 \mathrm{E}-01$ \\
\hline HLP-30 & 10 & $5.04 \mathrm{E}-02$ & $5.04 \mathrm{E}-02$ \\
\hline HLP-30 & 100 & $1.49 \mathrm{E}-02$ & $1.10 \mathrm{E}-02$ \\
\hline HLP-30 & 1000 & $2.45 \mathrm{E}-03$ & $1.06 \mathrm{E}-03$ \\
\hline HLP-30 & 5000 & $6.63 \mathrm{E}-04$ & $2.17 \mathrm{E}-04$ \\
\hline HLP-30 & 10000 & $4.33 \mathrm{E}-04$ & $2.01 \mathrm{E}-04$ \\
\hline HLP-31 & 10 & $7.22 \mathrm{E}-01$ & $7.22 \mathrm{E}-01$ \\
\hline HLP-31 & 100 & $2.63 \mathrm{E}-01$ & $2.12 \mathrm{E}-01$ \\
\hline HLP-31 & 1000 & $4.42 \mathrm{E}-02$ & $1.99 \mathrm{E}-02$ \\
\hline HLP-31 & 5000 & $1.24 \mathrm{E}-02$ & 4.49E-03 \\
\hline HLP-31 & 10000 & $1.07 \mathrm{E}-02$ & $9.02 \mathrm{E}-03$ \\
\hline HLP-32 & 10 & $1.05 \mathrm{E}-01$ & $1.05 \mathrm{E}-01$ \\
\hline HLP-32 & 100 & $3.45 \mathrm{E}-02$ & $2.67 \mathrm{E}-02$ \\
\hline HLP-32 & 1000 & $6.79 \mathrm{E}-03$ & $3.70 \mathrm{E}-03$ \\
\hline HLP-32 & 5000 & $2.76 \mathrm{E}-03$ & $1.75 \mathrm{E}-03$ \\
\hline
\end{tabular}




\begin{tabular}{|c|c|c|c|}
\hline Sample ID & Time (hours) & $\begin{array}{c}\text { Release Rate, } \\
\text { r }\end{array}$ & $\begin{array}{c}\text { Differential Release Rate, } \\
\mathbf{r}_{\Delta}{ }^{*}\end{array}$ \\
\hline HLP-32 & 10000 & $1.59 \mathrm{E}-03$ & $4.13 \mathrm{E}-04$ \\
\hline HLP-33 & 10 & $2.92 \mathrm{E}-01$ & $2.92 \mathrm{E}-01$ \\
\hline HLP-33 & 100 & $2.76 \mathrm{E}-01$ & $2.74 \mathrm{E}-01$ \\
\hline HLP-33 & 1000 & 8.68E-02 & $6.57 \mathrm{E}-02$ \\
\hline HLP-33 & 5000 & $1.43 \mathrm{E}-02$ & $3.88 \mathrm{E}-03$ \\
\hline HLP-33 & 10000 & $8.56 \mathrm{E}-03$ & $2.88 \mathrm{E}-03$ \\
\hline HLP-34 & 10 & $1.07 \mathrm{E}-01$ & $1.07 \mathrm{E}-01$ \\
\hline HLP-34 & 100 & $3.05 \mathrm{E}-02$ & $2.20 \mathrm{E}-02$ \\
\hline HLP-34 & 1000 & 4.57E-03 & $1.69 \mathrm{E}-03$ \\
\hline HLP-34 & 5000 & $1.36 \mathrm{E}-03$ & $5.57 \mathrm{E}-04$ \\
\hline HLP-34 & 10000 & $7.81 \mathrm{E}-04$ & $2.25 \mathrm{E}-04$ \\
\hline HLP-35 & 10 & $2.07 \mathrm{E}-01$ & $2.07 \mathrm{E}-01$ \\
\hline HLP-35 & 100 & $9.06 \mathrm{E}-02$ & 7.77E-02 \\
\hline HLP-35 & 1000 & $1.86 \mathrm{E}-02$ & $1.06 \mathrm{E}-02$ \\
\hline HLP-35 & 5000 & 4.62E-03 & $1.11 \mathrm{E}-03$ \\
\hline HLP-35 & 10000 & 4.93E-03 & $5.22 \mathrm{E}-03$ \\
\hline HLP-36 & 10 & $1.04 \mathrm{E}-01$ & 1.04E-01 \\
\hline HLP-36 & 100 & 3.09E-02 & $2.28 \mathrm{E}-02$ \\
\hline HLP-36 & 1000 & $9.77 \mathrm{E}-03$ & 7.43E-03 \\
\hline HLP-36 & 5000 & 7.48E-03 & $6.90 \mathrm{E}-03$ \\
\hline HLP-36 & 10000 & $2.40 \mathrm{E}-03$ & $2.68 \mathrm{E}-03$ \\
\hline HLP-37 & 10 & $1.99 \mathrm{E}-01$ & $1.99 \mathrm{E}-01$ \\
\hline HLP-37 & 100 & $7.21 \mathrm{E}-02$ & $5.80 \mathrm{E}-02$ \\
\hline HLP-37 & 1000 & $1.37 \mathrm{E}-02$ & $7.16 \mathrm{E}-03$ \\
\hline HLP-37 & 5000 & $3.38 \mathrm{E}-03$ & $8.14 \mathrm{E}-04$ \\
\hline HLP-37 & 10000 & $3.62 \mathrm{E}-02$ & $6.90 \mathrm{E}-02$ \\
\hline HLP-38 & 10 & $1.20 \mathrm{E}-01$ & $1.20 \mathrm{E}-01$ \\
\hline HLP-38 & 100 & $2.61 \mathrm{E}-02$ & $1.56 \mathrm{E}-02$ \\
\hline HLP-38 & 1000 & $4.59 \mathrm{E}-03$ & $2.21 \mathrm{E}-03$ \\
\hline HLP-38 & 5000 & $1.44 \mathrm{E}-03$ & $6.56 \mathrm{E}-04$ \\
\hline HLP-38 & 10000 & 8.29E-04 & $2.37 \mathrm{E}-04$ \\
\hline HLP-39 & 10 & $5.51 \mathrm{E}-01$ & $5.51 \mathrm{E}-01$ \\
\hline HLP-39 & 100 & $3.13 \mathrm{E}-01$ & $2.87 \mathrm{E}-01$ \\
\hline HLP-39 & 1000 & $4.06 \mathrm{E}-02$ & $1.03 \mathrm{E}-02$ \\
\hline HLP-39 & 5000 & $1.93 \mathrm{E}-02$ & $1.39 \mathrm{E}-02$ \\
\hline HLP-39 & 10000 & $1.50 \mathrm{E}-02$ & $1.08 \mathrm{E}-02$ \\
\hline HLP-40 (ht) & 10 & $1.61 \mathrm{E}-01$ & $1.61 \mathrm{E}-01$ \\
\hline HLP-40 (ht) & 100 & $1.14 \mathrm{E}-01$ & $1.09 \mathrm{E}-01$ \\
\hline HLP-40 (ht) & 1000 & 2.29E-02 & $1.28 \mathrm{E}-02$ \\
\hline HLP-40 (ht) & 5000 & $7.15 \mathrm{E}-03$ & $3.21 \mathrm{E}-03$ \\
\hline HLP-40 (ht) & 10000 & 2.99E-03 & $1.20 \mathrm{E}-03$ \\
\hline HLP-40 (q) & 10 & $1.48 \mathrm{E}-01$ & $1.48 \mathrm{E}-01$ \\
\hline HLP-40 (q) & 100 & $1.21 \mathrm{E}-01$ & $1.18 \mathrm{E}-01$ \\
\hline HLP-40 (q) & 1000 & $2.58 \mathrm{E}-02$ & $1.52 \mathrm{E}-02$ \\
\hline HLP-40 (q) & 5000 & $2.21 \mathrm{E}-02$ & $2.12 \mathrm{E}-02$ \\
\hline HLP-40 (q) & 10000 & $1.37 \mathrm{E}-02$ & $5.27 \mathrm{E}-03$ \\
\hline HLP-41 & 10 & $5.68 \mathrm{E}-01$ & $5.68 \mathrm{E}-01$ \\
\hline HLP-41 & 100 & $4.26 \mathrm{E}-01$ & $4.10 \mathrm{E}-01$ \\
\hline HLP-41 & 1000 & $6.08 \mathrm{E}-02$ & $2.03 \mathrm{E}-02$ \\
\hline HLP-41 & 5000 & $1.16 \mathrm{E}-03$ & $1.38 \mathrm{E}-02$ \\
\hline HLP-41 & 10000 & $2.45 \mathrm{E}-02$ & 4.79E-02 \\
\hline HLP-42 (ht) & 10 & $1.74 \mathrm{E}-01$ & $1.74 \mathrm{E}-01$ \\
\hline HLP-42 (ht) & 100 & $8.78 \mathrm{E}-02$ & $7.82 \mathrm{E}-02$ \\
\hline HLP-42 (ht) & 1000 & 5.69E-02 & 5.34E-02 \\
\hline
\end{tabular}




\begin{tabular}{|c|c|c|c|}
\hline Sample ID & Time (hours) & $\begin{array}{c}\text { Release Rate, } \\
\text { r } \\
\end{array}$ & Differential Release Rate, \\
\hline HLP-42 (ht) & 5000 & $1.43 \mathrm{E}-02$ & $3.64 \mathrm{E}-03$ \\
\hline HLP-42 (ht) & 10000 & $4.86 \mathrm{E}-03$ & $4.59 \mathrm{E}-03$ \\
\hline HLP-42 (q) & 10 & $1.55 \mathrm{E}-01$ & $1.55 \mathrm{E}-01$ \\
\hline HLP-42 (q) & 100 & 7.54E-02 & $6.65 \mathrm{E}-02$ \\
\hline HLP-42 (q) & 1000 & 4.66E-02 & 4.34E-02 \\
\hline HLP-42 (q) & 5000 & $2.92 \mathrm{E}-03$ & 7.99E-03 \\
\hline HLP-42 (q) & 10000 & 7.54E-03 & $1.21 \mathrm{E}-02$ \\
\hline HLP-43 & 10 & $1.26 \mathrm{E}-01$ & $1.26 \mathrm{E}-01$ \\
\hline HLP-43 & 100 & $5.00 \mathrm{E}-02$ & 4.15E-02 \\
\hline HLP-43 & 1000 & $7.11 \mathrm{E}-03$ & $2.35 \mathrm{E}-03$ \\
\hline HLP-43 & 5000 & $2.11 \mathrm{E}-03$ & $8.65 \mathrm{E}-04$ \\
\hline HLP-43 & 10000 & $1.66 \mathrm{E}-03$ & $1.20 \mathrm{E}-03$ \\
\hline HLP-44 & 10 & $1.25 \mathrm{E}-01$ & $1.25 \mathrm{E}-01$ \\
\hline HLP-44 & 100 & $2.91 \mathrm{E}-02$ & $1.85 \mathrm{E}-02$ \\
\hline HLP-44 & 1000 & 7.72E-03 & $5.34 \mathrm{E}-03$ \\
\hline HLP-44 & 5000 & $2.01 \mathrm{E}-03$ & 5.83E-04 \\
\hline HLP-44 & 10000 & $1.42 \mathrm{E}-03$ & $8.21 \mathrm{E}-04$ \\
\hline HLP-45 & 10 & $1.38 \mathrm{E}-01$ & $1.38 \mathrm{E}-01$ \\
\hline HLP-45 & 100 & $3.43 \mathrm{E}-02$ & $2.28 \mathrm{E}-02$ \\
\hline HLP-45 & 1000 & $8.16 \mathrm{E}-03$ & $5.26 \mathrm{E}-03$ \\
\hline HLP-45 & 5000 & 6.84E-04 & $1.19 \mathrm{E}-03$ \\
\hline HLP-45 & 10000 & $1.45 \mathrm{E}-03$ & $2.24 \mathrm{E}-03$ \\
\hline HLP-46 & 10 & $3.75 \mathrm{E}-04$ & $3.75 \mathrm{E}-04$ \\
\hline HLP-46 & 100 & 6.64E-02 & 7.38E-02 \\
\hline HLP-46 & 1000 & $1.10 \mathrm{E}-02$ & 4.84E-03 \\
\hline HLP-46 & 5000 & --- & --- \\
\hline HLP-46 & 10000 & 7.55E-02 & --- \\
\hline HLP-47 & 10 & $1.93 \mathrm{E}-01$ & $1.93 \mathrm{E}-01$ \\
\hline HLP-47 & 100 & $6.14 \mathrm{E}-02$ & 4.68E-02 \\
\hline HLP-47 & 1000 & $1.44 \mathrm{E}-02$ & $9.23 \mathrm{E}-03$ \\
\hline HLP-47 & 5000 & $6.69 \mathrm{E}-03$ & $4.75 \mathrm{E}-03$ \\
\hline HLP-47 & 10000 & $6.29 \mathrm{E}-02$ & $1.19 \mathrm{E}-01$ \\
\hline HLP-48 & 10 & $1.63 \mathrm{E}-01$ & $1.63 \mathrm{E}-01$ \\
\hline HLP-48 & 100 & $5.25 \mathrm{E}-02$ & 4.03E-02 \\
\hline HLP-48 & 1000 & $1.17 \mathrm{E}-02$ & $7.16 \mathrm{E}-03$ \\
\hline HLP-48 & 5000 & $2.65 \mathrm{E}-03$ & $3.93 \mathrm{E}-04$ \\
\hline HLP-48 & 10000 & $2.16 \mathrm{E}-03$ & $1.67 \mathrm{E}-03$ \\
\hline HLP-49 & 10 & 9.90E-02 & 9.90E-02 \\
\hline HLP-49 & 100 & $2.31 \mathrm{E}-02$ & $1.47 \mathrm{E}-02$ \\
\hline HLP-49 & 1000 & $3.94 \mathrm{E}-03$ & $1.81 \mathrm{E}-03$ \\
\hline HLP-49 & 5000 & 9.91E-04 & $2.53 \mathrm{E}-04$ \\
\hline HLP-49 & 10000 & 2.29E-03 & $3.62 \mathrm{E}-03$ \\
\hline HLP-51 & 10 & $1.45 \mathrm{E}-01$ & $1.45 \mathrm{E}-01$ \\
\hline HLP-51 & 100 & $3.37 \mathrm{E}-02$ & $2.13 \mathrm{E}-02$ \\
\hline HLP-51 & 1000 & $8.37 \mathrm{E}-03$ & $5.56 \mathrm{E}-03$ \\
\hline HLP-51 & 5000 & $2.06 \mathrm{E}-03$ & $4.80 \mathrm{E}-04$ \\
\hline HLP-51 & 10000 & $1.54 \mathrm{E}-03$ & $1.01 \mathrm{E}-03$ \\
\hline HLP-52 & 10 & $5.71 \mathrm{E}-02$ & $5.71 \mathrm{E}-02$ \\
\hline HLP-52 & 100 & $5.51 \mathrm{E}-01$ & $6.06 \mathrm{E}-01$ \\
\hline HLP-52 & 1000 & $1.78 \mathrm{E}-01$ & $1.36 \mathrm{E}-01$ \\
\hline HLP-52 & 5000 & --- & --- \\
\hline HLP-52 & 10000 & $6.60 \mathrm{E}-02$ & --- \\
\hline HLP-53 & 5000 & $1.58 \mathrm{E}-01$ & $1.58 \mathrm{E}-01$ \\
\hline HLP-53 & 10000 & 7.87E-02 & $1.58 \mathrm{E}-01$ \\
\hline
\end{tabular}




\begin{tabular}{cccc}
\hline Sample ID & Time (hours) & $\begin{array}{c}\text { Release Rate, } \\
\mathbf{r}\end{array}$ & $\begin{array}{c}\text { Differential Release Rate, } \\
\mathbf{r}_{\Delta}{ }^{*}\end{array}$ \\
\hline HLP-54 & 10 & $1.88 \mathrm{E}-01$ & $1.88 \mathrm{E}-01$ \\
HLP-54 & 100 & $3.00 \mathrm{E}-02$ & $1.25 \mathrm{E}-02$ \\
HLP-54 & 1000 & $5.05 \mathrm{E}-03$ & $2.27 \mathrm{E}-03$ \\
HLP-54 & 5000 & --- & --- \\
HLP-54 & 10000 & $1.57 \mathrm{E}-03$ & --- \\
HLP-55 & 10 & $2.26 \mathrm{E}-01$ & $3.17 \mathrm{E}-01$ \\
HLP-55 & 100 & $5.11 \mathrm{E}-02$ & $7.46 \mathrm{E}-03$ \\
HLP-55 & 1000 & $1.18 \mathrm{E}-02$ & --- \\
HLP-55 & 5000 & --- & --- \\
HLP-55 & 10000 & $3.06 \mathrm{E}-03$ &
\end{tabular}

* Release rate and differential release rate are the same at 10 hours. 


\section{Measured Concentrations in PCT-A (Phase II) Solutions}

Table B-5. $\quad$ Measured concentrations for the Hanford PCT-A Series of Phase II glasses. Results reported on $3 / 9 / 2001$. Test temperature $=90^{\circ} \mathrm{C}$; test duration $=168$ hours; $(\mathrm{S} / \mathrm{V}) \approx 2000 \mathrm{~m}^{-1}$; and dilution factor $=5 / 3$.

\begin{tabular}{|c|c|c|c|c|c|c|c|c|c|c|}
\hline \multicolumn{11}{|c|}{ Diluted Concentration, $p_{i}$, in Test Solution $(\mathrm{mg} / \mathrm{L})$} \\
\hline SampleID & pH & Al & B & $\mathbf{F e}$ & Mg & $\mathbf{N a}$ & $\mathbf{S i}$ & $\mathbf{T i}$ & Zn & $\mathbf{Z r}$ \\
\hline HLP-58-1 & 10.46 & 4.60 & 9.57 & 0.141 & $<0.04$ & 55.2 & 41.0 & $<0.07$ & $<0.01$ & $<0.01$ \\
\hline HLP-58-2 & 10.47 & 3.06 & 9.62 & $<0.04$ & $<0.04$ & 51.7 & 35.7 & $<0.07$ & $<0.01$ & $<0.01$ \\
\hline HLP-58-3 & 10.46 & 4.57 & 10.5 & 0.115 & $<0.04$ & 58.2 & 42.4 & $<0.07$ & $<0.01$ & $<0.01$ \\
\hline HLP-59-1 & 10.73 & 2.49 & 10.2 & $<0.04$ & $<0.04$ & 63.8 & 39.4 & $<0.07$ & $<0.01$ & $<0.01$ \\
\hline HLP-59-2 & 10.75 & 2.30 & 11.0 & $<0.04$ & $<0.04$ & 60.4 & 38.5 & $<0.07$ & $<0.01$ & $<0.01$ \\
\hline HLP-59-3 & 10.73 & 2.41 & 10.3 & $<0.04$ & $<0.04$ & 64.0 & 38.2 & $<0.07$ & $<0.01$ & $<0.01$ \\
\hline HLP-60-1 & --- & 4.47 & 7.39 & $<0.04$ & $<0.04$ & 54.7 & 36.3 & $<0.07$ & $<0.01$ & $<0.01$ \\
\hline HLP-60-2 & --- & 4.32 & 6.52 & $<0.04$ & $<0.04$ & 51.7 & 35.7 & $<0.07$ & $<0.01$ & $<0.01$ \\
\hline HLP-60-3 & --- & 4.20 & 5.88 & 0.124 & $<0.04$ & 53.0 & 34.4 & $<0.07$ & $<0.01$ & $<0.01$ \\
\hline HLP-61-1 & 10.57 & 0.504 & 21.5 & $<0.04$ & $<0.04$ & 74.2 & 48.5 & $<0.07$ & $<0.01$ & $<0.01$ \\
\hline HLP-61-2 & 10.57 & 0.492 & 21.3 & $<0.04$ & $<0.04$ & 71.4 & 48.1 & $<0.07$ & $<0.01$ & $<0.01$ \\
\hline HLP-61-3 & 10.58 & 0.354 & 21.6 & $<0.04$ & $<0.04$ & 74.6 & 48.9 & $<0.07$ & $<0.01$ & $<0.01$ \\
\hline HLP-62-1 & 9.97 & 0.612 & 11.7 & $<0.04$ & $<0.04$ & 39.0 & 30.1 & $<0.07$ & $<0.01$ & $<0.01$ \\
\hline HLP-62-2 & 9.96 & 0.709 & 11.5 & $<0.04$ & $<0.04$ & 37.3 & 30.6 & $<0.07$ & $<0.01$ & $<0.01$ \\
\hline HLP-62-3 & 9.98 & 0.726 & 11.7 & $<0.04$ & $<0.04$ & 37.8 & 30.3 & $<0.07$ & $<0.01$ & $<0.01$ \\
\hline HLP-63-1 & 11.86 & 6.19 & 57.8 & 5.13 & 2.54 & 518 & 205 & 0.179 & $<0.01$ & $<0.01$ \\
\hline HLP-63-2 & 11.86 & 7.18 & 59.6 & 9.02 & 6.05 & 518 & 222 & 0.672 & $<0.01$ & $<0.01$ \\
\hline HLP-63-3 & 11.86 & 5.97 & 57.8 & 4.34 & 1.94 & 530 & 222 & 0.183 & $<0.01$ & $<0.01$ \\
\hline HLP-64-1 & 11.18 & $<0.10$ & 71.6 & $<0.04$ & $<0.04$ & 354 & 178 & $<0.07$ & $<0.01$ & $<0.01$ \\
\hline HLP-64-2 & 11.21 & $<0.10$ & 71.9 & $<0.04$ & $<0.04$ & 350 & 175 & $<0.07$ & $<0.01$ & $<0.01$ \\
\hline HLP-64-3 & 11.19 & $<0.10$ & 76.5 & $<0.04$ & $<0.04$ & 347 & 167 & $<0.07$ & $<0.01$ & $<0.01$ \\
\hline HLP-65-1 & 10.55 & 0.98 & 10.2 & $<0.04$ & $<0.04$ & 71.9 & 69.1 & $<0.07$ & $<0.01$ & $<0.01$ \\
\hline HLP-65-2 & 10.60 & 0.954 & 10.7 & $<0.04$ & $<0.04$ & 73.7 & 69.4 & $<0.07$ & $<0.01$ & $<0.01$ \\
\hline HLP-65-3 & 10.56 & 0.96 & 10.4 & $<0.04$ & $<0.04$ & 70.5 & 70.1 & $<0.07$ & $<0.01$ & $<0.01$ \\
\hline HLP-66-1 & 11.55 & 0.319 & 441 & 0.522 & $<0.04$ & 1470 & 721 & $<0.07$ & $<0.01$ & $<0.01$ \\
\hline HLP-66-2 & 11.53 & 0.402 & 437 & 0.371 & $<0.04$ & 1460 & 711 & $<0.07$ & $<0.01$ & $<0.01$ \\
\hline HLP-66-3 & 11.54 & 0.349 & 435 & 0.918 & $<0.04$ & 1460 & 710 & $<0.07$ & $<0.01$ & $<0.01$ \\
\hline HLP-67-1 & 12.18 & 1.77 & 355 & 0.241 & $<0.04$ & 1240 & 175 & $<0.07$ & $<0.01$ & $<0.01$ \\
\hline HLP-67-2 & 12.22 & 1.63 & 358 & 0.21 & $<0.04$ & 1250 & 184 & $<0.07$ & $<0.01$ & $<0.01$ \\
\hline HLP-67-3 & 12.19 & 1.78 & 360 & 0.165 & $<0.04$ & 1270 & 190 & $<0.07$ & $<0.01$ & $<0.01$ \\
\hline HLP-68-1 & 11.19 & 8.63 & 7.45 & $<0.04$ & $<0.04$ & 59.1 & 23.2 & $<0.07$ & $<0.01$ & $<0.01$ \\
\hline HLP-68-2 & 11.20 & 8.08 & 6.23 & $<0.04$ & $<0.04$ & 57.0 & 20.6 & $<0.07$ & $<0.01$ & $<0.01$ \\
\hline HLP-68-3 & 11.17 & 8.39 & 7.03 & $<0.04$ & $<0.04$ & 60.9 & 23.0 & $<0.07$ & $<0.01$ & $<0.01$ \\
\hline HLP-69-1 & 10.30 & 8.38 & 3.53 & $<0.04$ & $<0.04$ & 28.9 & 40.5 & 0.436 & $<0.01$ & $<0.01$ \\
\hline HLP-69-2 & 10.28 & 8.86 & 6.03 & $<0.04$ & $<0.04$ & 31.6 & 42.4 & 0.271 & $<0.01$ & $<0.01$ \\
\hline HLP-69-3 & 10.31 & 9.26 & 5.08 & $<0.04$ & $<0.04$ & 31.9 & 42.1 & 0.299 & $<0.01$ & $<0.01$ \\
\hline HLP-70-1 & 12.27 & 16.3 & 69.2 & $<0.04$ & $<0.04$ & 839 & 234 & $<0.07$ & $<0.01$ & $<0.01$ \\
\hline HLP-70-2 & 12.27 & 17.2 & 68.8 & $<0.04$ & $<0.04$ & 841 & 230 & $<0.07$ & $<0.01$ & $<0.01$ \\
\hline HLP-70-3 & 12.29 & $<0.10$ & $<0.15$ & $<0.04$ & $<0.04$ & $<0.10$ & $<0.79$ & $<0.07$ & $<0.01$ & $<0.01$ \\
\hline HLP-71-1 & 12.45 & 46.5 & 950 & $<0.04$ & $<0.04$ & 2460 & 92.4 & $<0.07$ & $<0.01$ & $<0.01$ \\
\hline HLP-71-2 & 12.49 & 48.0 & 940 & $<0.04$ & $<0.04$ & 2440 & 92.5 & $<0.07$ & $<0.01$ & $<0.01$ \\
\hline HLP-71-3 & 12.46 & 63.6 & 969 & $<0.04$ & $<0.04$ & 2480 & 75.0 & $<0.07$ & $<0.01$ & $<0.01$ \\
\hline HLP-72-1 & 9.90 & 9.87 & 13.5 & $<0.04$ & $<0.04$ & 41.9 & 25.4 & $<0.07$ & $<0.01$ & $<0.01$ \\
\hline HLP-72-2 & 9.87 & 10.1 & 14.0 & $<0.04$ & $<0.04$ & 43.7 & 24.9 & $<0.07$ & $<0.01$ & $<0.01$ \\
\hline HLP-72-3 & 9.91 & 9.91 & 13.9 & $<0.04$ & $<0.04$ & 44.3 & 25.9 & $<0.07$ & $<0.01$ & $<0.01$ \\
\hline HLP-73-1 & 10.26 & 5.90 & 97.3 & 0.642 & $<0.04$ & 180 & 27.9 & $<0.07$ & $<0.01$ & $<0.01$ \\
\hline HLP-73-2 & 10.25 & 6.22 & 103 & 0.555 & 40.5 & 185 & 29.5 & $<0.07$ & $<0.01$ & $<0.01$ \\
\hline
\end{tabular}




\begin{tabular}{|c|c|c|c|c|c|c|c|c|c|c|}
\hline \multicolumn{11}{|c|}{ Diluted Concentration, $p_{i}$, in Test Solution $(\mathrm{mg} / \mathrm{L})$} \\
\hline SampleID & pH & Al & B & $\mathrm{Fe}$ & Mg & $\mathbf{N a}$ & $\mathbf{S i}$ & $\mathbf{T i}$ & $\mathbf{Z n}$ & $\mathbf{Z r}$ \\
\hline HLP-73-3 & 10.29 & 6.08 & 99.1 & 0.579 & $<0.04$ & 185 & 27.9 & $<0.07$ & $<0.01$ & $<0.01$ \\
\hline HLP-74-1 & 10.18 & 7.78 & 11.7 & $<0.04$ & $<0.04$ & 40.9 & 19.9 & $<0.07$ & 0.01 & $<0.01$ \\
\hline HLP-74-2 & 10.20 & 7.21 & 11.0 & $<0.04$ & $<0.04$ & 40.6 & 18.6 & $<0.07$ & $<0.01$ & $<0.01$ \\
\hline HLP-74-3 & 10.17 & 7.73 & 12.0 & $<0.04$ & $<0.04$ & 43.0 & 20.1 & $<0.07$ & $<0.01$ & $<0.01$ \\
\hline HLP-75-1 & 10.98 & 6.31 & 10.7 & 0.08 & $<0.04$ & 74.4 & 38.3 & $<0.07$ & $<0.01$ & $<0.01$ \\
\hline HLP. & 10.97 & 6.69 & 11.3 & $<0.04$ & $<0.04$ & 77.1 & 40.3 & $<0.07$ & $<0.01$ & $<0.01$ \\
\hline HLP & 10.95 & 6.55 & 11.5 & $<0.04$ & $<0.04$ & 76.5 & 40.6 & 0.072 & $<0.01$ & $<0.01$ \\
\hline $\mathrm{HLI}$ & 10.78 & 7.06 & 6. & 1.02 & $<0.04$ & 54.6 & 40.0 & 0.078 & 0.01 & 0.554 \\
\hline $\mathrm{HL}$ & 10. & 7.32 & 7. & 1.11 & $<0.04$ & 58.9 & 42.3 & $<0$. & 0.01 & 0.485 \\
\hline HLP-76-3 & 10.81 & 7.69 & 7.10 & 1.21 & $<0.04$ & 58.3 & 41.7 & $<0.07$ & $<0.01$ & 0.470 \\
\hline HLP-77-1 & 10.75 & 7.58 & 7.04 & 1.17 & $<0.04$ & 57.3 & 41.3 & $<0.07$ & $<0.01$ & 0.463 \\
\hline HLF & 10.75 & 7.51 & 7.12 & 1.08 & $<0.04$ & 57.1 & 42.2 & 0.085 & $<0.01$ & 0.612 \\
\hline HLF & 10.78 & 7.35 & 6.76 & 1.24 & $<0.04$ & 56.7 & 42.0 & $<0.07$ & $<0.01$ & 0.484 \\
\hline & 11.85 & $<0.10$ & 38.8 & $<0.04$ & $<0.04$ & 103 & 55.7 & $<0.07$ & $<0.01$ & $<0.01$ \\
\hline & & .10 & 37.8 & $<$ & $<0.04$ & 99.3 & & $<0.0$ & $<0.01$ & $<0.01$ \\
\hline & 1 & $<0.1$ & 3 & $<0.04$ & $<0.04$ & 5.0 & 50.2 & $<0.07$ & $<0.01$ & $<0.01$ \\
\hline ARM-1 & 10.2 & 24 & 10.1 & $<0.04$ & $<0.04$ & 21.0 & 34.8 & $<0.07$ & $<0.01$ & $<0.01$ \\
\hline ARM-2 & 10.2 & 2.4 & 10.4 & $<0.04$ & $<0.04$ & 20.4 & 35.0 & $<0.07$ & $<0.01$ & $<0.01$ \\
\hline ARM-3 & 10.27 & 2. & 11.4 & $<0.0$ & $<0.04$ & 21.9 & 35.4 & $<0.07$ & $<0.01$ & $<0.01$ \\
\hline Blank 1 & --- & $<0.10$ & $<0.15$ & $<0.04$ & $<0.04$ & $<0.10$ & $<0.79$ & $<0.07$ & $<0.01$ & $<0.01$ \\
\hline Blank 2 & --- & $<0.10$ & 0.211 & $<0.04$ & $<0.04$ & $<0.10$ & $<0.79$ & $<0.07$ & $<0.01$ & $<0.01$ \\
\hline & --- & & 20.2 & 3.64 & $<0.04$ & & 48.1 & $<0.07$ & $<0.01$ & $<0.01$ \\
\hline & --- & & 20.1 & 37 & $<0.04$ & 78.5 & & & & $<0.01$ \\
\hline & --- & & 21.2 & 28 & $<0.04$ & 70 & 49.4 & $<0.07$ & $<0.01$ & $<0.01$ \\
\hline & --- & 3. & 20.2 & 3.81 & $<0.04$ & 810 & 48.5 & $<0.07$ & $<0.01$ & $<0.01$ \\
\hline & --- & 3.8 & 19. & 37 & $<0.04$ & 80 & 48.3 & $<0.07$ & $<0.01$ & $<0.01$ \\
\hline & --- & 3.8 & 19.7 & 3.78 & $<0.04$ & 82 & 48.3 & $<0.07$ & $<0.01$ & $<0.01$ \\
\hline & --- & 3.8 & 19.9 & 3.77 & $<0.04$ & 79.9 & 48.2 & $<0.07$ & $<0.01$ & $<0.01$ \\
\hline & --- & 3.85 & 21.1 & 3.77 & $<0.04$ & 80.3 & 48.3 & $<0.07$ & $<0.01$ & $<0.01$ \\
\hline STD & --- & 3.95 & 20.0 & 3.75 & $<0.04$ & 81.8 & 48.6 & $<0.07$ & $<0.01$ & $<0.01$ \\
\hline
\end{tabular}




\section{Measured Concentrations in 10-hour (Phase II) PCT-B Solutions}

Table B-6. $\quad$ Measured concentrations for the 10-hour Hanford PCT-B series of Phase II glasses. Results reported on $4 / 17 / 2001$. Test temperature $=90^{\circ} \mathrm{C}$; test duration $=10 \mathrm{~h} ;(\mathrm{S} / \mathrm{V}) \approx 20,000 \mathrm{~m}^{-1}$; and dilution factor $=5 / 3$.

\begin{tabular}{|c|c|c|c|c|c|c|c|c|c|c|}
\hline \multicolumn{11}{|c|}{ Diluted Concentration, $p_{i}$, in Test Solution (mg/L) } \\
\hline SampleID & pH & Al & B & $\mathrm{Fe}$ & Mg & $\mathbf{N a}$ & Si & $\mathbf{T i}$ & Zn & $\mathbf{Z r}$ \\
\hline HLP-58 & 10.71 & 3.88 & 13.12 & $<0.04$ & $<0.01$ & 77.51 & 41.23 & $<0.07$ & $<0.01$ & $<0.01$ \\
\hline HLP-59 & 10.81 & 2.83 & 11.88 & $<0.04$ & $<0.01$ & 85.85 & 40.70 & $<0.07$ & $<0.01$ & $<0.01$ \\
\hline HLP-60 & 10.75 & 2.97 & 9.33 & $<0.04$ & $<0.01$ & 72.90 & 33.35 & $<0.07$ & $<0.01$ & $<0.01$ \\
\hline HLP-61 & 10.84 & 0.71 & 44.89 & $<0.04$ & $<0.01$ & 149.5 & 67.24 & $<0.07$ & $<0.01$ & $<0.01$ \\
\hline HLP-62 & 9.91 & 0.21 & 22.83 & $<0.04$ & $<0.01$ & 65.74 & 37.24 & $<0.07$ & $<0.01$ & $<0.01$ \\
\hline HLP-63 & 12.24 & 5.51 & 184.01 & 1.22 & $<0.01$ & 1169.5 & 231.83 & $<0.07$ & $<0.01$ & $<0.01$ \\
\hline HLP-64 & 10.97 & 0.57 & 7.93 & $<0.04$ & $<0.01$ & 76.69 & 40.95 & $<0.07$ & $<0.01$ & $<0.01$ \\
\hline HLP-65 & 10.56 & 0.71 & 14.79 & 0.38 & $<0.01$ & 94.84 & 65.50 & $<0.07$ & $<0.01$ & $<0.01$ \\
\hline HLP-66 & 11.53 & $<0.09$ & 475.49 & 0.32 & $<0.01$ & 1649.9 & 658.91 & $<0.07$ & $<0.01$ & $<0.01$ \\
\hline HLP-67 & 12.23 & 1.32 & 574.99 & 0.87 & $<0.01$ & 2064.8 & 195.42 & $<0.07$ & 1.24 & $<0.01$ \\
\hline HLP-68 & 11.19 & 8.30 & 6.81 & $<0.04$ & $<0.01$ & 83.61 & 23.54 & $<0.07$ & $<0.01$ & $<0.01$ \\
\hline HLP-69 & 10.26 & 6.29 & 3.94 & $<0.04$ & $<0.01$ & 36.25 & 31.45 & $<0.07$ & $<0.01$ & $<0.01$ \\
\hline HLP-70 & 12.34 & 9.57 & 229.47 & $<0.04$ & $<0.01$ & 2119.4 & 460.42 & $<0.07$ & $<0.01$ & $<0.01$ \\
\hline HLP-71 & 12.34 & 30.39 & 4504.0 & $<0.04$ & $<0.01$ & 11298 & 82.21 & $<0.07$ & $<0.01$ & $<0.01$ \\
\hline HLP-72 & 10.02 & 6.74 & 13.84 & 0.37 & $<0.01$ & 50.00 & 19.55 & $<0.07$ & $<0.01$ & $<0.01$ \\
\hline HLP-73 & 9.90 & 3.57 & 187.49 & $<0.04$ & $<0.01$ & 324.00 & 18.80 & $<0.07$ & $<0.01$ & $<0.01$ \\
\hline HLP-74 & 9.73 & 5.29 & 34.16 & $<0.04$ & $<0.01$ & 78.79 & 20.44 & $<0.07$ & $<0.01$ & $<0.01$ \\
\hline HLP-75 & 11.01 & 5.71 & 14.75 & 0.14 & $<0.01$ & 109.50 & 41.64 & $<0.07$ & $<0.01$ & $<0.01$ \\
\hline HLP-76 & 10.86 & 5.13 & 11.10 & 0.90 & $<0.01$ & 97.44 & 43.65 & $<0.07$ & $<0.01$ & $<0.01$ \\
\hline HLP-77 & 10.82 & 4.58 & 12.80 & 0.53 & $<0.01$ & 101.50 & 43.41 & $<0.07$ & $<0.01$ & $<0.01$ \\
\hline EA & 11.84 & $<0.09$ & 45.88 & $<0.04$ & $<0.01$ & 118.79 & 49.53 & $<0.07$ & $<0.01$ & $<0.01$ \\
\hline ARM & 10.27 & 1.64 & 22.54 & $<0.04$ & $<0.01$ & 43.85 & 49.64 & $<0.07$ & $<0.01$ & $<0.01$ \\
\hline LRM & 11.02 & 5.10 & 19.74 & 1.30 & $<0.01$ & 146.00 & 56.04 & $<0.07$ & $<0.01$ & $<0.01$ \\
\hline Basalt & 7.70 & 0.10 & $<0.15$ & $<0.04$ & $<0.01$ & 9.12 & 30.20 & $<0.07$ & $<0.01$ & $<0.01$ \\
\hline Obsidian & 8.66 & 1.73 & $<0.15$ & $<0.04$ & $<0.01$ & 3.85 & 10.09 & $<0.07$ & $<0.01$ & $<0.01$ \\
\hline 165-TDS & 10.53 & 1.08 & 14.60 & 0.81 & $<0.01$ & 49.20 & 77.00 & $<0.07$ & $<0.01$ & $<0.01$ \\
\hline Blank 1 & 6.93 & $<0.09$ & $<0.15$ & $<0.04$ & $<0.01$ & 0.446 & $<0.79$ & $<0.07$ & $<0.01$ & $<0.01$ \\
\hline Blank 2 & 6.81 & $<0.09$ & $<0.15$ & $<0.04$ & $<0.01$ & 0.339 & $<0.79$ & $<0.07$ & $<0.01$ & $<0.01$ \\
\hline STD & --- & 3.98 & 20.6 & 3.98 & $<0.01$ & 87.5 & 51.5 & $<0.07$ & $<0.01$ & $<0.01$ \\
\hline STD & --- & 4.04 & 20.8 & 4.20 & $<0.01$ & 84.3 & 51.4 & $<0.07$ & $<0.01$ & $<0.01$ \\
\hline STD & --- & 4.14 & 21.5 & 4.03 & $<0.01$ & 84.2 & 51.6 & $<0.07$ & $<0.01$ & $<0.01$ \\
\hline STD & --- & 4.02 & 20.1 & 4.07 & $<0.01$ & 83.6 & 49.6 & $<0.07$ & $<0.01$ & $<0.01$ \\
\hline STD & --- & 4.05 & 21.1 & 4.22 & $<0.01$ & 83.4 & 50.9 & $<0.07$ & $<0.01$ & $<0.01$ \\
\hline STD & --- & 3.94 & 20.5 & 4.18 & $<0.01$ & 79.7 & 50.4 & $<0.07$ & $<0.01$ & $<0.01$ \\
\hline STD & --- & 3.98 & 19.9 & 4.30 & $<0.01$ & 80.0 & 50.8 & $<0.07$ & $<0.01$ & $<0.01$ \\
\hline STD & --- & 3.98 & 20.5 & 4.27 & $<0.01$ & 80.4 & 50.4 & $<0.07$ & $<0.01$ & $<0.01$ \\
\hline STD & --- & 3.94 & 20.4 & 3.95 & $<0.01$ & 81.0 & 50.6 & $<0.07$ & $<0.01$ & $<0.01$ \\
\hline
\end{tabular}




\section{Measured Concentrations in 100-hour (Phase II) PCT-B Solutions}

Table B-7. Measured concentrations for the 100-hour Hanford PCT-B series of Phase II glasses. Results reported on $4 / 17 / 2001$. Test temperature $=90^{\circ} \mathrm{C}$; test duration $=100 \mathrm{~h} ;(\mathrm{S} / \mathrm{V}) \approx 20,000 \mathrm{~m}^{-1}$; and dilution factor $=5 / 3$.

\begin{tabular}{|c|c|c|c|c|c|c|c|c|c|c|}
\hline \multicolumn{11}{|c|}{ Diluted Concentration, $\mathrm{p}_{\mathrm{i}}$, in Test Solution (mg/L) } \\
\hline SampleID & pH & Al & B & $\mathrm{Fe}$ & Mg & $\mathbf{N a}$ & $\mathbf{S i}$ & Ti & $\mathbf{Z n}$ & $\mathrm{Zr}$ \\
\hline HLP-58 & 11.12 & 6.36 & 50.72 & 3.27 & 0.33 & 242.47 & 91.77 & 0.11 & $<0.01$ & $<0.01$ \\
\hline HLP-59 & 11.24 & 4.88 & 40.67 & $<0.04$ & $<0.01$ & 261.70 & 96.08 & $<0.07$ & $<0.01$ & $<0.01$ \\
\hline HLP-60 & 11.13 & 5.38 & 20.47 & 1.03 & $<0.01$ & 181.00 & 66.49 & $<0.07$ & 0.34 & $<0.01$ \\
\hline HLP-61 & 11.25 & 1.60 & 159.50 & $<0.04$ & $<0.01$ & 467.00 & 131.62 & $<0.07$ & $<0.01$ & $<0.01$ \\
\hline HLP-62 & 10.14 & 1.05 & 45.83 & $<0.04$ & $<0.01$ & 146.99 & 62.32 & $<0.07$ & $<0.01$ & $<0.01$ \\
\hline HLP-63 & 12.53 & 13.15 & 691.95 & $<0.04$ & $<0.01$ & 4545.0 & 753.80 & $<0.07$ & $<0.01$ & $<0.01$ \\
\hline HLP-64 & 11.68 & 0.47 & 546.63 & $<0.04$ & $<0.01$ & 2323.1 & 618.99 & $<0.07$ & $<0.01$ & $<0.01$ \\
\hline HLP-65 & 11.03 & 2.57 & 36.73 & 5.20 & 1.15 & 274.12 & 160.20 & $<0.07$ & $<0.01$ & $<0.01$ \\
\hline HLP-66 & 11.89 & 1.36 & 1569.9 & 0.44 & $<0.01$ & 5049.0 & 237.94 & $<0.07$ & $<0.01$ & $<0.01$ \\
\hline HLP-67 & 12.44 & 4.32 & 1149.8 & 1.35 & $<0.01$ & 4039.6 & 237.37 & $<0.07$ & 4.30 & $<0.01$ \\
\hline HLP-68 & 11.57 & 16.70 & 18.75 & 0.44 & $<0.01$ & 207.50 & 46.93 & $<0.07$ & $<0.01$ & $<0.01$ \\
\hline HLP-69 & 10.68 & 11.55 & 11.92 & $<0.04$ & $<0.01$ & 85.92 & 59.40 & 0.41 & $<0.01$ & $<0.01$ \\
\hline HLP-70 & 12.62 & 23.35 & 684.47 & $<0.04$ & $<0.01$ & 5425.5 & 953.39 & $<0.07$ & $<0.01$ & $<0.01$ \\
\hline HLP-71 & 12.70 & 85.06 & 8844.4 & $<0.04$ & $<0.01$ & 21800 & 117.73 & $<0.07$ & 0.64 & $<0.01$ \\
\hline HLP-72 & 9.89 & 9.88 & 89.54 & 0.26 & 2.15 & 180.49 & 27.58 & $<0.07$ & $<0.01$ & $<0.01$ \\
\hline HLP-73 & 10.00 & 2.83 & 957.64 & $<0.04$ & $<0.01$ & 1603.3 & 26.65 & $<0.07$ & $<0.01$ & $<0.01$ \\
\hline HLP-74 & 9.92 & 6.57 & 163.89 & 0.04 & $<0.01$ & 341.47 & 30.28 & $<0.07$ & $<0.01$ & $<0.01$ \\
\hline HLP-75 & 11.47 & 9.98 & 53.82 & 0.68 & $<0.01$ & 319.99 & 86.23 & $<0.07$ & $<0.01$ & $<0.01$ \\
\hline HLP-76 & 11.38 & 9.49 & 47.08 & 1.40 & $<0.01$ & 339.09 & 99.56 & $<0.07$ & $<0.01$ & 0.09 \\
\hline HLP-77 & 11.34 & 8.91 & 47.92 & 0.85 & $<0.01$ & 300.96 & 98.13 & $<0.07$ & $<0.01$ & 0.08 \\
\hline EA & 12.13 & 4.89 & 2199.9 & $<0.04$ & $<0.01$ & 5429.9 & 478.47 & $<0.07$ & $<0.01$ & $<0.01$ \\
\hline ARM & 10.61 & 2.14 & 61.19 & $<0.04$ & $<0.01$ & 101.34 & 100.15 & $<0.07$ & $<0.01$ & $<0.01$ \\
\hline LRM & 11.43 & 5.25 & 83.79 & $<0.04$ & $<0.01$ & 425.00 & 127.98 & $<0.07$ & $<0.01$ & $<0.01$ \\
\hline Basalt & 7.56 & 0.43 & $<0.15$ & $<0.04$ & 2.86 & 14.60 & 39.40 & $<0.07$ & $<0.01$ & $<0.01$ \\
\hline Obsidian & 8.96 & 5.55 & $<0.15$ & $<0.04$ & $<0.01$ & 9.52 & 31.95 & $<0.07$ & $<0.01$ & $<0.01$ \\
\hline 165-TDS & 11.61 & 0.67 & 979.00 & $<0.04$ & $<0.01$ & 2010.0 & 799.00 & $<0.07$ & $<0.01$ & $<0.01$ \\
\hline Blank 1 & 6.64 & 0.411 & 0.176 & $<0.04$ & $<0.01$ & 0.324 & $<0.790$ & $<0.07$ & $<0.01$ & $<0.01$ \\
\hline Blank 2 & 6.58 & 0.316 & $<0.150$ & $<0.04$ & $<0.01$ & 0.275 & $<0.790$ & $<0.07$ & $<0.01$ & $<0.01$ \\
\hline STD & --- & 3.99 & 20.5 & 3.87 & $<0.01$ & 83 & 50.6 & $<0.07$ & $<0.01$ & $<0.01$ \\
\hline STD & --- & 4.08 & 21.3 & 4.03 & $<0.01$ & 82.3 & 51.4 & $<0.07$ & $<0.01$ & $<0.01$ \\
\hline STD & --- & 4.03 & 20.7 & 3.70 & $<0.01$ & 75.9 & 49.9 & $<0.07$ & $<0.01$ & $<0.01$ \\
\hline STD & --- & 4.08 & 19.6 & 4.23 & $<0.01$ & 75.5 & 48.2 & $<0.07$ & $<0.01$ & $<0.01$ \\
\hline STD & --- & 4.07 & 20.0 & 3.86 & $<0.01$ & 76.2 & 48.0 & $<0.07$ & $<0.01$ & $<0.01$ \\
\hline STD & --- & 4.11 & 20.2 & 4.17 & $<0.01$ & 75 & 46.9 & $<0.07$ & $<0.01$ & $<0.01$ \\
\hline STD & --- & 4.01 & 20.5 & 3.98 & $<0.01$ & 77.9 & 48.3 & $<0.07$ & $<0.01$ & $<0.01$ \\
\hline STD & --- & 4.03 & 20.6 & 4.33 & $<0.01$ & 77.7 & 48.8 & $<0.07$ & $<0.01$ & $<0.01$ \\
\hline STD & --- & 4.03 & 20.5 & 4.31 & $<0.01$ & 79.4 & 48.6 & $<0.07$ & $<0.01$ & $<0.01$ \\
\hline
\end{tabular}




\section{Measured Concentrations in 1000-hour (Phase II) PCT-B Solutions}

Table B-8. $\quad$ Measured concentrations for the 1000-hour Hanford PCT-B series of Phase II glasses. Results reported on $3 / 9 / 2001$. Test temperature $=90^{\circ} \mathrm{C}$; test duration $=1000 \mathrm{~h} ;(\mathrm{S} / \mathrm{V}) \approx$ $20,000 \mathrm{~m}^{-1}$; and dilution factor $=5 / 3$.

\begin{tabular}{|c|c|c|c|c|c|c|c|c|c|c|}
\hline \multicolumn{11}{|c|}{ Diluted Concentration, $p_{i}$, in Test Solution $(\mathrm{mg} / \mathrm{L})$} \\
\hline SampleID & pH & Al & B & $\mathbf{F e}$ & $\mathrm{Mg}$ & $\mathbf{N a}$ & $\mathbf{S i}$ & $\mathbf{T i}$ & Zn & $\mathbf{Z r}$ \\
\hline HLP-58 & 11.47 & 4.67 & 106.49 & 1.24 & 0.29 & 466.86 & 132.76 & $<0.07$ & 0.32 & $<0.01$ \\
\hline HLP-59 & 11.63 & 5.84 & 82.41 & $<0.04$ & $<0.04$ & 415.99 & 142.48 & $<0.07$ & $<0.01$ & $<0.01$ \\
\hline HLP-60 & 11.56 & 5.91 & 119.49 & 4.93 & $<0.04$ & 324.99 & 105.44 & 0.25 & 5.57 & 0.30 \\
\hline HLP-61 & 11.54 & 0.74 & 300.92 & $<0.04$ & $<0.04$ & 852.66 & 196.42 & $<0.07$ & $<0.01$ & $<0.01$ \\
\hline HLP-62 & 10.40 & $<0.09$ & 83.86 & $<0.04$ & $<0.04$ & 237.39 & 84.38 & $<0.07$ & $<0.01$ & $<0.01$ \\
\hline HLP-63 & 12.84 & 17.12 & 2425.0 & 5.68 & $<0.04$ & 13700 & 3040.0 & 0.23 & $<0.01$ & $<0.01$ \\
\hline HLP-64 & 11.80 & $<0.09$ & 1009.3 & $<0.04$ & $<0.04$ & 3993.3 & 251.67 & $<0.07$ & $<0.01$ & $<0.01$ \\
\hline HLP-65 & 11.47 & 1.36 & 61.47 & $<0.04$ & $<0.04$ & 450.68 & 252.39 & $<0.07$ & $<0.01$ & $<0.01$ \\
\hline HLP-66 & 11.63 & 12.71 & 4582.7 & 2.24 & $<0.04$ & 14879 & 1998.9 & $<0.07$ & $<0.01$ & $<0.01$ \\
\hline HLP-67 & 12.65 & 10.20 & 1833.0 & 0.64 & $<0.04$ & 6613.2 & 246.38 & $<0.07$ & 8.44 & $<0.01$ \\
\hline HLP-68 & 11.98 & 23.55 & 50.42 & 0.23 & $<0.04$ & 449.51 & 76.60 & $<0.07$ & $<0.01$ & $<0.01$ \\
\hline HLP-69 & 11.15 & 13.10 & 19.49 & $<0.04$ & $<0.04$ & 155.54 & 78.17 & 0.53 & 0.81 & $<0.01$ \\
\hline HLP-70 & 13.29 & --- & --- & --- & --- & --- & --- & --- & --- & --- \\
\hline HLP-71 & 12.83 & 65.40 & 9959.0 & $<0.04$ & $<0.04$ & 31462 & 589.09 & $<0.07$ & 113.5 & $<0.01$ \\
\hline HLP-72 & 9.58 & 5.23 & 482.00 & $<0.04$ & 3.09 & 808.29 & 19.98 & $<0.07$ & $<0.01$ & $<0.01$ \\
\hline HLP-73 & 10.26 & $<0.09$ & 4037.6 & $<0.04$ & $<0.04$ & 6568.6 & 40.40 & $<0.07$ & $<0.01$ & $<0.01$ \\
\hline HLP-74 & 9.77 & 1.76 & 576.00 & $<0.04$ & $<0.04$ & 1010.0 & 32.20 & $<0.07$ & $<0.01$ & $<0.01$ \\
\hline HLP-75 & 11.88 & 10.23 & 141.57 & $<0.04$ & $<0.04$ & 617.77 & 124.00 & $<0.07$ & $<0.01$ & $<0.01$ \\
\hline HLP-76 & 11.80 & 10.03 & 152.00 & $<0.04$ & $<0.04$ & 751.00 & 162.50 & $<0.07$ & $<0.01$ & $<0.01$ \\
\hline HLP-77 & 11.79 & 10.80 & 122.85 & $<0.04$ & $<0.04$ & 649.36 & 146.99 & $<0.07$ & $<0.01$ & $<0.01$ \\
\hline EA & 12.42 & 2.52 & 6265.0 & $<0.04$ & $<0.04$ & 15200 & 2629.8 & $<0.07$ & $<0.01$ & $<0.01$ \\
\hline ARM & 10.96 & 2.09 & 116.83 & $<0.04$ & $<0.04$ & 155.40 & 153.88 & $<0.07$ & 0.93 & $<0.01$ \\
\hline LRM & 11.92 & 9.36 & 240.44 & $<0.04$ & $<0.04$ & 1160.0 & 185.96 & $<0.07$ & $<0.01$ & $<0.01$ \\
\hline Basalt & 8.34 & $<0.09$ & $<0.15$ & $<0.04$ & 10.12 & 31.12 & 40.12 & $<0.07$ & $<0.01$ & $<0.01$ \\
\hline Obsidian & 9.54 & 5.06 & $<0.15$ & $<0.04$ & $<0.04$ & 15.25 & 41.19 & $<0.07$ & $<0.01$ & $<0.01$ \\
\hline 165-TDS & 11.32 & $<0.09$ & 1239.0 & $<0.04$ & $<0.04$ & 2494.9 & 691.50 & $<0.07$ & $<0.01$ & $<0.01$ \\
\hline Blank 1 & 6.84 & $<0.09$ & $<0.15$ & $<0.04$ & $<0.04$ & $<0.10$ & $<0.79$ & $<0.07$ & $<0.01$ & $<0.01$ \\
\hline Blank 2 & 5.23 & $<0.09$ & $<0.15$ & $<0.04$ & $<0.04$ & $<0.10$ & $<0.79$ & $<0.07$ & $<0.01$ & $<0.01$ \\
\hline STD & --- & 3.90 & 20.9 & 4.04 & $<0.04$ & 83.6 & 50.6 & $<0.07$ & $<0.01$ & $<0.01$ \\
\hline STD & --- & 3.79 & 20.5 & 4.18 & $<0.04$ & 80.1 & 49.5 & $<0.07$ & $<0.01$ & $<0.01$ \\
\hline STD & --- & 3.83 & 22.3 & 4.24 & $<0.04$ & 81.2 & 49.3 & $<0.07$ & $<0.01$ & $<0.01$ \\
\hline STD & --- & 4.02 & 20 & 4.24 & $<0.04$ & 82.1 & 50.2 & $<0.07$ & $<0.01$ & $<0.01$ \\
\hline STD & --- & 4.19 & 20.4 & 4.25 & $<0.04$ & 83.5 & 51.1 & $<0.07$ & $<0.01$ & $<0.01$ \\
\hline STD & --- & 3.86 & 20.8 & 4.26 & $<0.04$ & 82.6 & 49.6 & $<0.07$ & $<0.01$ & $<0.01$ \\
\hline STD & --- & 4.17 & 19.6 & 4.23 & $<0.04$ & 87.0 & 51.9 & $<0.07$ & $<0.01$ & $<0.01$ \\
\hline STD & --- & 3.97 & 19.7 & 4.08 & $<0.04$ & 85.4 & 51.3 & $<0.07$ & $<0.01$ & $<0.01$ \\
\hline STD & --- & 4.12 & 21.5 & 4.12 & $<0.04$ & 83.7 & 50.8 & $<0.07$ & $<0.01$ & $<0.01$ \\
\hline
\end{tabular}




\section{Measured Concentrations in 5000-hour (Phase II) PCT-B Solutions}

Table B-9. $\quad$ Measured concentrations for the 5000-hour Hanford PCT-B series of Phase II glasses. Results reported on $6 / 20 / 2001$. Test temperature $=90^{\circ} \mathrm{C}$; test duration $=5000 \mathrm{~h} ;(\mathrm{S} / \mathrm{V}) \approx$ $20,000 \mathrm{~m}^{-1}$; and dilution factor $=5 / 3$.

\begin{tabular}{|c|c|c|c|c|c|c|c|c|c|c|}
\hline \multicolumn{11}{|c|}{ Diluted Concentration, $p_{i}$, in Test Solution $(\mathrm{mg} / \mathrm{L})$} \\
\hline SampleID & $\mathbf{p H}$ & Al & B & $\mathbf{F e}$ & Mg & $\mathbf{N a}$ & $\mathbf{S i}$ & $\mathbf{T i}$ & $\mathbf{Z n}$ & $\mathbf{Z r}$ \\
\hline HLP-58 & 11.62 & 6.34 & 167.85 & $<0.40$ & $<0.40$ & 674.47 & 156.00 & $<0.70$ & $<0.10$ & $<0.10$ \\
\hline HLP-59 & 11.77 & 8.95 & 76.25 & $<0.40$ & $<0.40$ & 534.97 & 178.50 & $<0.70$ & $<0.10$ & $<0.10$ \\
\hline HLP-60 & 11.51 & 8.16 & 38.69 & $<0.40$ & $<0.40$ & 352.51 & 106.16 & $<0.70$ & $<0.10$ & $<0.10$ \\
\hline HLP-61 & 11.61 & 2.88 & 438.32 & $<0.40$ & $<0.40$ & 1239.6 & 235.90 & $<0.70$ & $<0.10$ & $<0.10$ \\
\hline HLP-62 & 10.32 & 2.18 & 101.14 & $<0.40$ & $<0.40$ & 1007.5 & 81.80 & $<0.70$ & $<0.10$ & $<0.10$ \\
\hline HLP-63 & 12.98 & 37.8 & 7610 & $<0.40$ & $<0.40$ & 34200 & 7370 & $<0.70$ & $<0.10$ & $<0.10$ \\
\hline HLP-64 & 11.93 & 2.10 & 1161.2 & $<0.40$ & $<0.40$ & 3890.6 & 727.69 & $<0.70$ & $<0.10$ & $<0.10$ \\
\hline HLP-65 & 11.75 & 3.68 & 62.21 & $<0.40$ & $<0.40$ & 521.81 & 289.97 & $<0.70$ & $<0.10$ & $<0.10$ \\
\hline HLP-66 & 11.71 & 62.80 & 8460.0 & $<0.40$ & $<0.40$ & 20000 & 13600 & $<0.70$ & $<0.10$ & $<0.10$ \\
\hline HLP-67 & 12.66 & 10.56 & 3831.3 & $<0.40$ & $<0.40$ & 10368 & 1341.1 & $<0.70$ & 3.83 & $<0.10$ \\
\hline HLP-68 & 12.11 & 25.22 & 40.76 & $<0.40$ & $<0.40$ & 611.50 & 82.45 & $<0.70$ & $<0.10$ & $<0.10$ \\
\hline HLP-69 & 11.20 & 14.50 & 21.96 & $<0.40$ & $<0.40$ & 204.00 & 80.75 & $<0.70$ & $<0.10$ & $<0.10$ \\
\hline HLP-70 & 13.20 & 124.0 & 12300 & $<0.40$ & $<0.40$ & 66400 & 19000 & $<0.70$ & $<0.10$ & $<0.10$ \\
\hline HLP-71 & --- & --- & --- & --- & --- & --- & --- & --- & --- & --- \\
\hline HLP-72 & 9.71 & 6.08 & 950.87 & $<0.40$ & $<0.40$ & 1440.0 & 11.43 & $<0.70$ & $<0.10$ & $<0.10$ \\
\hline HLP-73 & 10.33 & 2.21 & 4664.6 & $<0.40$ & $<0.40$ & 1925.4 & 70.46 & $<0.70$ & $<0.10$ & $<0.10$ \\
\hline HLP-74 & 9.82 & 3.48 & 537.46 & $<0.40$ & $<0.40$ & 1185.0 & 26.95 & $<0.70$ & $<0.10$ & $<0.10$ \\
\hline HLP-75 & 12.02 & 8.77 & 195.81 & $<0.40$ & $<0.40$ & 942.83 & 170.95 & $<0.70$ & $<0.10$ & $<0.10$ \\
\hline HLP-76 & 11.81 & 2.98 & 273.42 & $<0.40$ & $<0.40$ & 1245.0 & 389.78 & $<0.70$ & $<0.10$ & $<0.10$ \\
\hline HLP-77 & 11.90 & 12.48 & 269.65 & $<0.40$ & $<0.40$ & 952.63 & 161.17 & $<0.70$ & $<0.10$ & $<0.10$ \\
\hline EA & 12.49 & 4.47 & 1750 & $<0.40$ & $<0.40$ & 3610 & 812 & $<0.70$ & $<0.10$ & $<0.10$ \\
\hline ARM & 10.98 & 4.82 & 132.48 & $<0.40$ & $<0.40$ & 201.64 & 177.64 & $<0.70$ & $<0.10$ & $<0.10$ \\
\hline LRM & 11.76 & 9.33 & 2687.0 & $<0.40$ & $<0.40$ & 6391.4 & 6510.0 & $<0.70$ & $<0.10$ & $<0.10$ \\
\hline Basalt & --- & --- & --- & --- & --- & --- & --- & --- & --- & --- \\
\hline Obsidian & 9.34 & 9.73 & $<1.50$ & $<0.40$ & $<0.40$ & 15.27 & 47.58 & $<0.70$ & $<0.10$ & $<0.10$ \\
\hline 165-TDS & 11.35 & 3.57 & 3090.0 & $<0.40$ & $<0.40$ & 4469.9 & 821.35 & $<0.70$ & $<0.10$ & $<0.10$ \\
\hline Blank 1 & 6.40 & 3.25 & $<1.50$ & $<0.40$ & $<0.40$ & 5.18 & $<8.00$ & $<0.70$ & $<0.10$ & $<0.10$ \\
\hline Blank 2 & 4.83 & 3.22 & 2.11 & $<0.40$ & $<0.40$ & 4.50 & $<8.00$ & $<0.70$ & $<0.10$ & $<0.10$ \\
\hline Blank 3 & 4.70 & 3.16 & $<1.50$ & $<0.40$ & $<0.40$ & 4.89 & $<8.00$ & $<0.70$ & $<0.10$ & $<0.10$ \\
\hline Blank 4 & 4.68 & 3.20 & $<1.50$ & $<0.40$ & $<0.40$ & 4.77 & $<8.00$ & $<0.70$ & $<0.10$ & $<0.10$ \\
\hline STD & --- & 3.98 & 20.4 & 3.78 & $<0.40$ & 82.8 & 49.9 & $<0.70$ & $<0.10$ & $<0.10$ \\
\hline STD & --- & 3.98 & 20.6 & 3.78 & $<0.40$ & 80.8 & 50.0 & $<0.70$ & $<0.10$ & $<0.10$ \\
\hline STD & --- & 4.02 & 20.9 & 3.81 & $<0.40$ & 82.2 & 50.5 & $<0.70$ & $<0.10$ & $<0.10$ \\
\hline STD & --- & 3.98 & 19.9 & 3.78 & $<0.40$ & 80.1 & 49.7 & $<0.70$ & $<0.10$ & $<0.10$ \\
\hline STD & --- & 4.00 & 20.4 & 3.79 & $<0.40$ & 80.3 & 50.1 & $<0.70$ & $<0.10$ & $<0.10$ \\
\hline STD & --- & 4.10 & 20.8 & 3.82 & $<0.40$ & 81.7 & 51.2 & $<0.70$ & $<0.10$ & $<0.10$ \\
\hline STD & --- & 4.05 & 20.6 & 3.81 & $<0.40$ & 83.5 & 49.9 & $<0.70$ & $<0.10$ & $<0.10$ \\
\hline STD & --- & 4.07 & 21.0 & 3.87 & $<0.40$ & 79.2 & 51.1 & $<0.70$ & $<0.10$ & $<0.10$ \\
\hline STD & --- & 4.13 & 21.3 & 4.06 & $<0.40$ & 82.3 & 52.0 & $<0.70$ & $<0.10$ & $<0.10$ \\
\hline
\end{tabular}




\section{PCT-B Normalized Release Information for Phase II Glasses}

Table B-10a. Targeted normalized release values for the PCT-B boron, sodium, and silicon results for the Hanford glasses (Phase II). Test temperature $=90^{\circ} \mathrm{C}$; test duration $=10,100,1000$, and 5000 hours; and $(\mathrm{S} / \mathrm{V}) \approx 20,000 / \mathrm{m}$.

\begin{tabular}{|c|c|c|c|c|c|c|c|c|}
\hline \multirow[b]{2}{*}{ SampleID } & \multirow{2}{*}{$\begin{array}{l}\text { Time, } t \\
\text { (hours) }\end{array}$} & \multirow{2}{*}{$\begin{array}{c}(\mathrm{S} / \mathrm{V}) \mathrm{t} \\
(\mathbf{h} / \mathbf{m})\end{array}$} & \multicolumn{3}{|c|}{$\mathrm{NC}_{\mathrm{i}}(\mathrm{g} / \mathrm{L})$} & \multicolumn{3}{|c|}{$N_{i}\left(g / m^{2}\right)$} \\
\hline & & & B & $\mathbf{N a}$ & Si & B & $\mathbf{N a}$ & Si \\
\hline HLP-58 & 10 & $2.05 \times 10^{5}$ & 0.43 & 0.53 & 0.18 & 0.02 & 0.03 & 0.01 \\
\hline HLP-58 & 100 & $2.05 \times 10^{6}$ & 10.55 & 10.75 & 1.58 & 0.51 & 0.52 & 0.08 \\
\hline HLP-58 & 1000 & $2.05 \times 10^{7}$ & 3.50 & 3.21 & 0.59 & 0.17 & 0.16 & 0.03 \\
\hline HLP-58 & 5000 & $1.03 \times 10^{8}$ & 5.52 & 4.64 & 0.69 & 0.27 & 0.23 & 0.03 \\
\hline HLP-59 & 10 & $2.03 \times 10^{5}$ & 0.40 & 0.61 & 0.19 & 0.02 & 0.03 & 0.01 \\
\hline HLP-59 & 100 & $2.03 \times 10^{6}$ & 0.65 & 0.89 & 0.22 & 0.03 & 0.04 & 0.01 \\
\hline HLP-59 & 1000 & $2.03 \times 10^{7}$ & 2.79 & 2.95 & 0.65 & 0.14 & 0.15 & 0.03 \\
\hline HLP-59 & 5000 & $1.02 \times 10^{8}$ & 2.58 & 3.80 & 0.82 & 0.13 & 0.19 & 0.04 \\
\hline HLP-60 & 10 & $1.83 \times 10^{5}$ & 0.50 & 0.61 & 0.20 & 0.03 & 0.03 & 0.01 \\
\hline HLP-60 & 100 & $1.83 \times 10^{6}$ & 1.33 & 1.18 & 0.42 & 0.07 & 0.06 & 0.02 \\
\hline HLP-60 & 1000 & $1.83 \times 10^{7}$ & 6.41 & --- & 0.62 & 0.35 & --- & 0.03 \\
\hline HLP-60 & 5000 & $9.17 \times 10^{7}$ & 2.08 & 2.97 & 0.62 & 0.11 & 0.16 & 0.03 \\
\hline HLP-61 & 10 & $2.01 \times 10^{5}$ & 2.41 & 0.80 & 0.40 & 0.12 & 0.04 & 0.02 \\
\hline HLP-61 & 100 & $2.01 \times 10^{6}$ & 2.73 & 1.66 & 0.55 & 0.14 & 0.08 & 0.03 \\
\hline HLP-61 & 1000 & $2.01 \times 10^{7}$ & 16.15 & 4.57 & 1.17 & 0.80 & 0.23 & 0.06 \\
\hline HLP-61 & 5000 & $1.00 \times 10^{8}$ & 23.53 & 6.65 & 1.40 & 1.17 & 0.33 & 0.07 \\
\hline HLP-62 & 10 & $2.01 \times 10^{5}$ & 0.58 & 0.55 & 0.17 & 0.03 & 0.03 & 0.01 \\
\hline HLP-62 & 100 & $2.01 \times 10^{6}$ & 0.68 & 1.24 & 0.39 & 0.03 & 0.06 & 0.02 \\
\hline HLP-62 & 1000 & $2.01 \times 10^{7}$ & 2.15 & 2.00 & 0.38 & 0.11 & 0.10 & 0.02 \\
\hline HLP-62 & 5000 & $1.00 \times 10^{8}$ & 2.59 & 8.49 & 0.37 & 0.13 & 0.42 & 0.02 \\
\hline HLP-63 & 10 & $1.96 \times 10^{5}$ & 4.71 & 9.85 & 1.25 & 0.24 & 0.50 & 0.06 \\
\hline HLP-63 & 100 & $1.96 \times 10^{6}$ & 6.42 & 8.46 & 0.74 & 0.33 & 0.43 & 0.04 \\
\hline HLP-63 & 1000 & $1.96 \times 10^{7}$ & 62.12 & 115.42 & 16.40 & 3.16 & 5.87 & 0.83 \\
\hline HLP-63 & 5000 & $9.82 \times 10^{7}$ & --- & --- & --- & --- & --- & --- \\
\hline HLP-64 & 10 & $2.05 \times 10^{5}$ & 0.43 & 0.65 & 0.17 & 0.02 & 0.03 & 0.01 \\
\hline HLP-64 & 100 & $2.05 \times 10^{6}$ & 9.10 & 10.77 & 1.62 & 0.44 & 0.53 & 0.08 \\
\hline HLP-64 & 1000 & $2.05 \times 10^{7}$ & 54.16 & 33.64 & 1.04 & 2.64 & 1.64 & 0.05 \\
\hline HLP-64 & 5000 & $1.02 \times 10^{8}$ & 62.32 & 32.78 & 2.99 & 3.04 & 1.60 & 0.15 \\
\hline HLP-65 & 10 & $2.05 \times 10^{5}$ & 0.79 & 0.80 & 0.27 & 0.04 & 0.04 & 0.01 \\
\hline HLP-65 & 100 & $2.05 \times 10^{6}$ & 1.60 & 2.36 & 0.28 & 0.08 & 0.12 & 0.01 \\
\hline HLP-65 & 1000 & $2.05 \times 10^{7}$ & 3.30 & 3.80 & 1.04 & 0.16 & 0.19 & 0.05 \\
\hline HLP-65 & 5000 & $1.02 \times 10^{8}$ & 3.34 & 4.40 & 1.19 & 0.16 & 0.21 & 0.06 \\
\hline HLP-66 & 10 & $2.09 \times 10^{5}$ & 12.18 & 9.21 & 2.71 & 0.58 & 0.44 & 0.13 \\
\hline HLP-66 & 100 & $2.09 \times 10^{6}$ & 16.01 & 13.84 & 0.46 & 0.76 & 0.66 & 0.02 \\
\hline HLP-66 & 1000 & $2.09 \times 10^{7}$ & 117.39 & 83.09 & 8.22 & 5.60 & 3.97 & 0.39 \\
\hline HLP-66 & 5000 & $1.05 \times 10^{8}$ & 216.72 & 111.67 & 55.95 & 10.35 & 5.33 & 2.67 \\
\hline HLP-67 & 10 & $1.99 \times 10^{5}$ & 14.73 & 11.07 & 1.16 & 0.74 & 0.56 & 0.06 \\
\hline HLP-67 & 100 & $1.99 \times 10^{6}$ & 6.87 & 6.73 & 1.05 & 0.34 & 0.34 & 0.05 \\
\hline HLP-67 & 1000 & $1.99 \times 10^{7}$ & 46.96 & 35.46 & 1.46 & 2.35 & 1.78 & 0.07 \\
\hline HLP-67 & 5000 & $9.97 \times 10^{7}$ & 98.15 & 55.59 & 7.97 & 4.92 & 2.79 & 0.40 \\
\hline HLP-68 & 10 & $1.95 \times 10^{5}$ & 0.37 & 0.70 & 0.14 & 0.02 & 0.04 & 0.01 \\
\hline HLP-68 & 100 & $1.95 \times 10^{6}$ & 4.68 & 5.38 & 1.28 & 0.24 & 0.28 & 0.07 \\
\hline HLP-68 & 1000 & $1.95 \times 10^{7}$ & 2.71 & 3.79 & 0.46 & 0.14 & 0.19 & 0.02 \\
\hline HLP-68 & 5000 & $9.73 \times 10^{7}$ & 2.19 & 5.15 & 0.49 & 0.11 & 0.26 & 0.03 \\
\hline HLP-69 & 10 & $2.09 \times 10^{5}$ & 0.21 & 0.31 & 0.13 & 0.01 & 0.01 & 0.01 \\
\hline
\end{tabular}




\begin{tabular}{|c|c|c|c|c|c|c|c|c|}
\hline \multirow[b]{2}{*}{ SampleID } & \multirow{2}{*}{$\begin{array}{l}\text { Time, } t \\
\text { (hours) }\end{array}$} & \multirow{2}{*}{$\begin{array}{l}(\mathrm{S} / \mathrm{V}) \mathrm{t} \\
(\mathbf{h} / \mathbf{m})\end{array}$} & \multicolumn{3}{|c|}{$\mathrm{NC}_{\mathrm{i}}(\mathrm{g} / \mathrm{L})$} & \multicolumn{3}{|c|}{$\mathrm{NL}_{\mathrm{i}}\left(\mathrm{g} / \mathrm{m}^{2}\right)$} \\
\hline & & & B & $\mathrm{Na}$ & $\mathbf{S i}$ & B & $\mathbf{N a}$ & $\mathbf{S i}$ \\
\hline HLP-69 & 100 & $2.09 \times 10^{6}$ & 21.44 & 6.14 & 0.11 & 1.03 & 0.29 & 0.01 \\
\hline HLP-69 & 1000 & $2.09 \times 10^{7}$ & 1.05 & 1.31 & 0.32 & 0.05 & 0.06 & 0.02 \\
\hline HLP-69 & 5000 & $1.04 \times 10^{8}$ & 1.18 & 1.72 & 0.33 & 0.06 & 0.08 & 0.02 \\
\hline HLP-70 & 10 & $2.05 \times 10^{5}$ & 12.32 & 11.36 & 2.74 & 0.60 & 0.55 & 0.13 \\
\hline HLP-70 & 100 & $2.05 \times 10^{6}$ & 2.25 & 1.02 & 0.46 & 0.11 & 0.05 & 0.02 \\
\hline HLP-70 & 1000 & $2.05 \times 10^{7}$ & --- & --- & --- & --- & --- & --- \\
\hline HLP-70 & 5000 & $1.03 \times 10^{8}$ & 660.15 & 356.05 & 112.91 & 32.19 & 17.36 & 5.51 \\
\hline HLP-71 & 10 & $2.00 \times 10^{5}$ & 241.72 & 60.58 & 0.49 & 12.10 & 3.03 & 0.02 \\
\hline HLP-71 & 100 & $2.00 \times 10^{6}$ & 42.96 & 16.64 & 2.55 & 2.15 & 0.83 & 0.13 \\
\hline HLP-71 & 1000 & $2.00 \times 10^{7}$ & 534.47 & 168.71 & 3.50 & 26.76 & 8.45 & 0.18 \\
\hline HLP-71 & 5000 & $9.99 \times 10^{7}$ & --- & --- & --- & --- & --- & --- \\
\hline HLP-72 & 10 & $2.04 \times 10^{5}$ & 0.35 & 0.42 & 0.12 & 0.02 & 0.02 & 0.01 \\
\hline HLP-72 & 100 & $2.04 \times 10^{6}$ & 96.63 & 87.72 & 0.81 & 4.74 & 4.30 & 0.04 \\
\hline HLP-72 & 1000 & $2.04 \times 10^{7}$ & 12.35 & 6.81 & 0.12 & 0.61 & 0.33 & 0.01 \\
\hline HLP-72 & 5000 & $1.02 \times 10^{8}$ & 24.36 & 12.13 & 0.07 & 1.19 & 0.60 & 0.00 \\
\hline HLP-73 & 10 & $2.07 \times 10^{5}$ & 4.80 & 2.73 & 0.11 & 0.23 & 0.13 & 0.01 \\
\hline HLP-73 & 100 & $2.07 \times 10^{6}$ & 15.56 & 26.81 & 3.96 & 0.75 & 1.29 & 0.19 \\
\hline HLP-73 & 1000 & $2.07 \times 10^{7}$ & 103.43 & 55.34 & 0.24 & 4.99 & 2.67 & 0.01 \\
\hline HLP-73 & 5000 & $1.04 \times 10^{8}$ & 119.49 & 16.22 & 0.42 & 5.76 & 0.78 & 0.02 \\
\hline HLP-74 & 10 & $2.01 \times 10^{5}$ & 0.88 & 0.66 & 0.12 & 0.04 & 0.03 & 0.01 \\
\hline HLP-74 & 100 & $2.01 \times 10^{6}$ & 0.85 & 1.31 & 0.39 & 0.04 & 0.07 & 0.02 \\
\hline HLP-74 & 1000 & $2.01 \times 10^{7}$ & 14.76 & 8.51 & 0.19 & 0.73 & 0.42 & 0.01 \\
\hline HLP-74 & 5000 & $1.01 \times 10^{8}$ & 13.77 & 9.98 & 0.16 & 0.68 & 0.50 & 0.01 \\
\hline HLP-75 & 10 & $2.02 \times 10^{5}$ & 0.53 & 0.74 & 0.21 & 0.03 & 0.04 & 0.01 \\
\hline HLP-75 & 100 & $2.02 \times 10^{6}$ & 3.09 & 2.56 & 0.60 & 0.15 & 0.13 & 0.03 \\
\hline HLP-75 & 1000 & $2.02 \times 10^{7}$ & 5.11 & 4.20 & 0.64 & 0.25 & 0.21 & 0.03 \\
\hline HLP-75 & 5000 & $1.01 \times 10^{8}$ & 7.06 & 6.41 & 0.88 & 0.35 & 0.32 & 0.04 \\
\hline HLP-76 & 10 & $2.12 \times 10^{5}$ & 0.45 & 0.66 & 0.17 & 0.02 & 0.03 & 0.01 \\
\hline HLP-76 & 100 & $2.12 \times 10^{6}$ & 3.50 & 1.56 & 0.17 & 0.17 & 0.07 & 0.01 \\
\hline HLP-76 & 1000 & $2.12 \times 10^{7}$ & 6.12 & 5.06 & 0.63 & 0.29 & 0.24 & 0.03 \\
\hline HLP-76 & 5000 & $1.06 \times 10^{8}$ & 11.01 & 8.39 & 1.52 & 0.52 & 0.40 & 0.07 \\
\hline HLP-77 & 10 & $2.11 \times 10^{5}$ & 0.52 & 0.68 & 0.17 & 0.02 & 0.03 & 0.01 \\
\hline HLP-77 & 100 & $2.11 \times 10^{6}$ & 1.71 & 0.82 & 0.14 & 0.08 & 0.04 & 0.01 \\
\hline HLP-77 & 1000 & $2.11 \times 10^{7}$ & 4.95 & 4.38 & 0.57 & 0.23 & 0.21 & 0.03 \\
\hline HLP-77 & 5000 & $1.06 \times 10^{8}$ & 10.85 & 6.42 & 0.63 & 0.51 & 0.30 & 0.03 \\
\hline
\end{tabular}




\section{PCT-B Normalized Release Information for Phase II Glasses}

Table B-10b. Measured normalized release values for the PCT-B boron, sodium, and silicon results for the Hanford glasses (Phase II). Test temperature $=90^{\circ} \mathrm{C}$; test duration $=10,100,1000$, and 5000 hours; and $(\mathrm{S} / \mathrm{V}) \approx 20,000 / \mathrm{m}$.

\begin{tabular}{|c|c|c|c|c|c|c|c|c|}
\hline \multirow[b]{2}{*}{ SampleID } & \multirow{2}{*}{$\begin{array}{l}\text { Time, } t \\
\text { (hours) }\end{array}$} & \multirow{2}{*}{$\begin{array}{c}(\mathrm{S} / \mathrm{V}) \mathrm{t} \\
(\mathbf{h} / \mathbf{m})\end{array}$} & \multicolumn{3}{|c|}{$\mathrm{NC}_{\mathrm{i}}(\mathrm{g} / \mathrm{L})$} & \multicolumn{3}{|c|}{$\mathrm{NL}_{\mathrm{i}}\left(\mathrm{g} / \mathrm{m}^{2}\right)$} \\
\hline & & & B & $\mathbf{N a}$ & Si & B & $\mathbf{N a}$ & Si \\
\hline HLP-58 & 10 & $2.05 \times 10^{5}$ & 0.42 & 0.55 & 0.18 & 0.02 & -0.60 & 0.01 \\
\hline HLP-58 & 100 & $2.05 \times 10^{6}$ & 10.36 & 11.08 & 1.58 & 0.50 & 2.40 & 0.08 \\
\hline HLP-58 & 1000 & $2.05 \times 10^{7}$ & 3.44 & 3.31 & 0.59 & 0.17 & 1.20 & 0.03 \\
\hline HLP-58 & 5000 & $1.03 \times 10^{8}$ & 5.42 & 4.78 & 0.69 & 0.26 & 1.56 & 0.03 \\
\hline HLP-59 & 10 & $2.03 \times 10^{5}$ & 0.41 & 0.63 & 0.19 & 0.02 & -0.46 & 0.01 \\
\hline HLP-59 & 100 & $2.03 \times 10^{6}$ & 0.67 & 0.92 & 0.23 & 0.03 & -0.09 & 0.01 \\
\hline HLP-59 & 1000 & $2.03 \times 10^{7}$ & 2.85 & 3.05 & 0.68 & 0.14 & 1.12 & 0.03 \\
\hline HLP-59 & 5000 & $1.02 \times 10^{8}$ & 2.63 & 3.93 & 0.85 & 0.13 & 1.37 & 0.04 \\
\hline HLP-60 & 10 & $1.83 \times 10^{5}$ & 0.49 & 0.60 & 0.19 & 0.03 & -0.51 & 0.01 \\
\hline HLP-60 & 100 & $1.83 \times 10^{6}$ & 1.30 & 1.15 & 0.41 & 0.07 & 0.14 & 0.02 \\
\hline HLP-60 & 1000 & $1.83 \times 10^{7}$ & 6.25 & 2.67 & 0.61 & 0.34 & 0.98 & 0.03 \\
\hline HLP-60 & 5000 & $9.17 \times 10^{7}$ & 2.02 & 2.89 & 0.61 & 0.11 & 1.06 & 0.03 \\
\hline HLP-61 & 10 & $2.01 \times 10^{5}$ & 2.41 & 0.79 & 0.39 & 0.12 & -0.24 & 0.02 \\
\hline HLP-61 & 100 & $2.01 \times 10^{6}$ & 2.73 & 1.62 & 0.54 & 0.14 & 0.48 & 0.03 \\
\hline HLP-61 & 1000 & $2.01 \times 10^{7}$ & 16.15 & 4.48 & 1.14 & 0.80 & 1.50 & 0.06 \\
\hline HLP-61 & 5000 & $1.00 \times 10^{8}$ & 23.53 & 6.52 & 1.37 & 1.17 & 1.87 & 0.07 \\
\hline HLP-62 & 10 & $2.01 \times 10^{5}$ & 0.58 & 0.54 & 0.16 & 0.03 & -0.62 & 0.01 \\
\hline HLP-62 & 100 & $2.01 \times 10^{6}$ & 0.66 & 1.21 & 0.38 & 0.03 & 0.19 & 0.02 \\
\hline HLP-62 & 1000 & $2.01 \times 10^{7}$ & 2.11 & 1.95 & 0.37 & 0.11 & 0.67 & 0.02 \\
\hline HLP-62 & 5000 & $1.00 \times 10^{8}$ & 2.55 & 8.28 & 0.36 & 0.13 & 2.11 & 0.02 \\
\hline HLP-63 & 10 & $1.96 \times 10^{5}$ & 4.73 & 9.90 & 1.26 & 0.24 & 2.29 & 0.06 \\
\hline HLP-63 & 100 & $1.96 \times 10^{6}$ & 6.45 & 8.50 & 0.75 & 0.33 & 2.14 & 0.04 \\
\hline HLP-63 & 1000 & $1.96 \times 10^{7}$ & 62.40 & 116.00 & 16.48 & 3.18 & 4.75 & 0.84 \\
\hline HLP-63 & 5000 & $9.82 \times 10^{7}$ & --- & --- & --- & --- & --- & --- \\
\hline HLP-64 & 10 & $2.05 \times 10^{5}$ & 0.42 & 0.65 & 0.17 & 0.02 & -0.44 & 0.01 \\
\hline HLP-64 & 100 & $2.05 \times 10^{6}$ & 8.97 & 10.78 & 1.59 & 0.44 & 2.38 & 0.08 \\
\hline HLP-64 & 1000 & $2.05 \times 10^{7}$ & 53.37 & 33.68 & 1.02 & 2.61 & 3.52 & 0.05 \\
\hline HLP-64 & 5000 & $1.02 \times 10^{8}$ & 61.41 & 32.81 & 2.94 & 3.00 & 3.49 & 0.14 \\
\hline HLP-65 & 10 & $2.05 \times 10^{5}$ & 0.79 & 0.76 & 0.26 & 0.04 & -0.28 & 0.01 \\
\hline HLP-65 & 100 & $2.05 \times 10^{6}$ & 1.60 & 2.24 & 0.27 & 0.08 & 0.80 & 0.01 \\
\hline HLP-65 & 1000 & $2.05 \times 10^{7}$ & 3.29 & 3.60 & 1.01 & 0.16 & 1.28 & 0.05 \\
\hline HLP-65 & 5000 & $1.02 \times 10^{8}$ & 3.33 & 4.17 & 1.16 & 0.16 & 1.43 & 0.06 \\
\hline HLP-66 & 10 & $2.09 \times 10^{5}$ & 12.18 & 9.47 & 2.74 & 0.58 & 2.25 & 0.13 \\
\hline HLP-66 & 100 & $2.09 \times 10^{6}$ & 16.01 & 14.22 & 0.47 & 0.76 & 2.65 & 0.02 \\
\hline HLP-66 & 1000 & $2.09 \times 10^{7}$ & 117.37 & 85.40 & 8.30 & 5.60 & 4.45 & 0.40 \\
\hline HLP-66 & 5000 & $1.05 \times 10^{8}$ & 216.69 & 114.78 & 56.48 & 10.34 & 4.74 & 2.70 \\
\hline HLP-67 & 10 & $1.99 \times 10^{5}$ & 15.04 & 11.74 & 1.19 & 0.75 & 2.46 & 0.06 \\
\hline HLP-67 & 100 & $1.99 \times 10^{6}$ & 7.01 & 7.14 & 1.07 & 0.35 & 1.97 & 0.05 \\
\hline HLP-67 & 1000 & $1.99 \times 10^{7}$ & 47.93 & 37.59 & 1.49 & 2.40 & 3.63 & 0.07 \\
\hline HLP-67 & 5000 & $9.97 \times 10^{7}$ & 100.18 & 58.93 & 8.14 & 5.02 & 4.08 & 0.41 \\
\hline HLP-68 & 10 & $1.95 \times 10^{5}$ & 0.35 & 0.69 & 0.13 & 0.02 & -0.37 & 0.01 \\
\hline HLP-68 & 100 & $1.95 \times 10^{6}$ & 4.50 & 5.28 & 1.22 & 0.23 & 1.66 & 0.06 \\
\hline HLP-68 & 1000 & $1.95 \times 10^{7}$ & 2.60 & 3.72 & 0.43 & 0.13 & 1.31 & 0.02 \\
\hline HLP-68 & 5000 & $9.73 \times 10^{7}$ & 2.11 & 5.06 & 0.47 & 0.11 & 1.62 & 0.02 \\
\hline HLP-69 & 10 & $2.09 \times 10^{5}$ & 0.21 & 0.29 & 0.12 & 0.01 & -1.24 & 0.01 \\
\hline
\end{tabular}




\begin{tabular}{|c|c|c|c|c|c|c|c|c|}
\hline \multirow[b]{2}{*}{ SampleID } & \multirow{2}{*}{$\begin{array}{l}\text { Time, } t \\
\text { (hours) }\end{array}$} & \multirow{2}{*}{$\begin{array}{l}(\mathrm{S} / \mathrm{V}) \mathrm{t} \\
(\mathbf{h} / \mathbf{m})\end{array}$} & \multicolumn{3}{|c|}{$\mathrm{NC}_{\mathrm{i}}(\mathrm{g} / \mathrm{L})$} & \multicolumn{3}{|c|}{$\mathrm{NL}_{\mathrm{i}}\left(\mathrm{g} / \mathrm{m}^{2}\right)$} \\
\hline & & & B & $\mathrm{Na}$ & $\mathbf{S i}$ & B & $\mathbf{N a}$ & $\mathbf{S i}$ \\
\hline HLP-69 & 100 & $2.09 \times 10^{6}$ & 21.07 & 5.80 & 0.11 & 1.01 & 1.76 & 0.01 \\
\hline HLP-69 & 1000 & $2.09 \times 10^{7}$ & 1.03 & 1.24 & 0.31 & 0.05 & 0.21 & 0.01 \\
\hline HLP-69 & 5000 & $1.04 \times 10^{8}$ & 1.16 & 1.62 & 0.32 & 0.06 & 0.48 & 0.02 \\
\hline HLP-70 & 10 & $2.05 \times 10^{5}$ & 11.99 & 11.75 & 2.59 & 0.58 & 2.46 & 0.13 \\
\hline HLP-70 & 100 & $2.05 \times 10^{6}$ & 2.19 & 1.05 & 0.44 & 0.11 & 0.05 & 0.02 \\
\hline HLP-70 & 1000 & $2.05 \times 10^{7}$ & --- & --- & --- & --- & --- & --- \\
\hline HLP-70 & 5000 & $1.03 \times 10^{8}$ & 642.80 & 368.28 & 106.98 & 31.34 & 5.91 & 5.22 \\
\hline HLP-71 & 10 & $2.00 \times 10^{5}$ & 245.77 & 62.25 & 0.49 & 12.30 & 4.13 & 0.02 \\
\hline HLP-71 & 100 & $2.00 \times 10^{6}$ & 43.68 & 17.10 & 2.56 & 2.19 & 2.84 & 0.13 \\
\hline HLP-71 & 1000 & $2.00 \times 10^{7}$ & 543.43 & 173.36 & 3.52 & 27.21 & 5.16 & 0.18 \\
\hline HLP-71 & 5000 & $9.99 \times 10^{7}$ & --- & --- & --- & --- & --- & --- \\
\hline HLP-72 & 10 & $2.04 \times 10^{5}$ & 0.36 & 0.43 & 0.12 & 0.02 & -0.85 & 0.01 \\
\hline HLP-72 & 100 & $2.04 \times 10^{6}$ & 99.15 & 89.45 & 0.83 & 4.86 & 4.49 & 0.04 \\
\hline HLP-72 & 1000 & $2.04 \times 10^{7}$ & 12.67 & 6.94 & 0.12 & 0.62 & 1.94 & 0.01 \\
\hline HLP-72 & 5000 & $1.02 \times 10^{8}$ & 24.99 & 12.37 & 0.07 & 1.23 & 2.52 & 0.00 \\
\hline HLP-73 & 10 & $2.07 \times 10^{5}$ & 4.95 & 2.81 & 0.11 & 0.24 & 1.03 & 0.01 \\
\hline HLP-73 & 100 & $2.07 \times 10^{6}$ & 16.04 & 27.56 & 4.04 & 0.77 & 3.32 & 0.19 \\
\hline HLP-73 & 1000 & $2.07 \times 10^{7}$ & 106.61 & 56.90 & 0.24 & 5.14 & 4.04 & 0.01 \\
\hline HLP-73 & 5000 & $1.04 \times 10^{8}$ & 123.16 & 16.68 & 0.43 & 5.94 & 2.81 & 0.02 \\
\hline HLP-74 & 10 & $2.01 \times 10^{5}$ & 0.88 & 0.68 & 0.12 & 0.04 & -0.39 & 0.01 \\
\hline HLP-74 & 100 & $2.01 \times 10^{6}$ & 0.86 & 1.33 & 0.39 & 0.04 & 0.29 & 0.02 \\
\hline HLP-74 & 1000 & $2.01 \times 10^{7}$ & 14.90 & 8.66 & 0.19 & 0.74 & 2.16 & 0.01 \\
\hline HLP-74 & 5000 & $1.01 \times 10^{8}$ & 13.90 & 10.16 & 0.16 & 0.69 & 2.32 & 0.01 \\
\hline HLP-75 & 10 & $2.02 \times 10^{5}$ & 0.50 & 0.77 & 0.21 & 0.02 & -0.27 & 0.01 \\
\hline HLP-75 & 100 & $2.02 \times 10^{6}$ & 2.93 & 2.64 & 0.59 & 0.15 & 0.97 & 0.03 \\
\hline HLP-75 & 1000 & $2.02 \times 10^{7}$ & 4.83 & 4.33 & 0.63 & 0.24 & 1.46 & 0.03 \\
\hline HLP-75 & 5000 & $1.01 \times 10^{8}$ & 6.69 & 6.60 & 0.87 & 0.33 & 1.89 & 0.04 \\
\hline HLP-76 & 10 & $2.12 \times 10^{5}$ & 0.46 & 0.68 & 0.17 & 0.02 & -0.39 & 0.01 \\
\hline HLP-76 & 100 & $2.12 \times 10^{6}$ & 3.56 & 1.61 & 0.17 & 0.17 & 0.48 & 0.01 \\
\hline HLP-76 & 1000 & $2.12 \times 10^{7}$ & 6.24 & 5.22 & 0.63 & 0.29 & 1.65 & 0.03 \\
\hline HLP-76 & 5000 & $1.06 \times 10^{8}$ & 11.22 & 8.66 & 1.50 & 0.53 & 2.16 & 0.07 \\
\hline HLP-77 & 10 & $2.11 \times 10^{5}$ & 0.52 & 0.67 & 0.17 & 0.02 & -0.39 & 0.01 \\
\hline HLP-77 & 100 & $2.11 \times 10^{6}$ & 1.74 & 0.81 & 0.14 & 0.08 & -0.21 & 0.01 \\
\hline HLP-77 & 1000 & $2.11 \times 10^{7}$ & 5.01 & 4.31 & 0.56 & 0.24 & 1.46 & 0.03 \\
\hline HLP-77 & 5000 & $1.06 \times 10^{8}$ & 10.99 & 6.33 & 0.61 & 0.52 & 1.85 & 0.03 \\
\hline
\end{tabular}


Short-term Release Rates Based Upon PCT-B Results of Phase II Glasses.

Table B-11a. Short-term boron release rates (g/m²/day) of Phase II glasses based upon measured $\mathrm{NL}_{\mathrm{B}}$.

\begin{tabular}{|c|c|c|c|}
\hline Sample ID & Time (hours) & $\begin{array}{c}\text { Release Rate, } \\
\text { r }\end{array}$ & $\begin{array}{c}\text { Differential Release Rate, } \\
\mathbf{r}_{\Delta}{ }^{*}\end{array}$ \\
\hline HLP-58 & 10 & $4.95 \mathrm{E}-02$ & $4.95 \mathrm{E}-02$ \\
\hline HLP-58 & 100 & $1.21 \mathrm{E}-01$ & $1.29 \mathrm{E}-01$ \\
\hline HLP-58 & 1000 & $4.02 \mathrm{E}-03$ & $-8.99 \mathrm{E}-03$ \\
\hline HLP-58 & 5000 & $1.27 \mathrm{E}-03$ & 5.79E-04 \\
\hline HLP-59 & 10 & $4.85 \mathrm{E}-02$ & $4.85 \mathrm{E}-02$ \\
\hline HLP-59 & 100 & $7.87 \mathrm{E}-03$ & $3.36 \mathrm{E}-03$ \\
\hline HLP-59 & 1000 & $3.36 \mathrm{E}-03$ & $2.86 \mathrm{E}-03$ \\
\hline HLP-59 & 5000 & $6.22 \mathrm{E}-04$ & $-6.29 \mathrm{E}-05$ \\
\hline HLP-60 & 10 & $6.39 \mathrm{E}-02$ & $6.39 \mathrm{E}-02$ \\
\hline HLP-60 & 100 & $1.69 \mathrm{E}-02$ & $1.17 \mathrm{E}-02$ \\
\hline HLP-60 & 1000 & $8.18 \mathrm{E}-03$ & $7.20 \mathrm{E}-03$ \\
\hline HLP-60 & 5000 & $5.30 \mathrm{E}-04$ & $-1.38 \mathrm{E}-03$ \\
\hline HLP-61 & 10 & $2.88 \mathrm{E}-01$ & $2.88 \mathrm{E}-01$ \\
\hline HLP-61 & 100 & $3.26 \mathrm{E}-02$ & $4.20 \mathrm{E}-03$ \\
\hline HLP-61 & 1000 & $1.93 \mathrm{E}-02$ & $1.78 \mathrm{E}-02$ \\
\hline HLP-61 & 5000 & $5.62 \mathrm{E}-03$ & $2.20 \mathrm{E}-03$ \\
\hline HLP-62 & 10 & $6.88 \mathrm{E}-02$ & $6.88 \mathrm{E}-02$ \\
\hline HLP-62 & 100 & 7.95E-03 & $1.18 \mathrm{E}-03$ \\
\hline HLP-62 & 1000 & $2.53 \mathrm{E}-03$ & $1.93 \mathrm{E}-03$ \\
\hline HLP-62 & 5000 & $6.10 \mathrm{E}-04$ & $1.30 \mathrm{E}-04$ \\
\hline HLP-63 & 10 & $5.78 \mathrm{E}-01$ & $5.78 \mathrm{E}-01$ \\
\hline HLP-63 & 100 & 7.88E-02 & 2.33E-02 \\
\hline HLP-63 & 1000 & 7.62E-02 & $7.59 \mathrm{E}-02$ \\
\hline HLP-63 & 5000 & --- & --- \\
\hline HLP-64 & 10 & $4.92 \mathrm{E}-02$ & $4.92 \mathrm{E}-02$ \\
\hline HLP-64 & 100 & $1.05 \mathrm{E}-01$ & $1.11 \mathrm{E}-01$ \\
\hline HLP-64 & 1000 & $6.25 \mathrm{E}-02$ & $5.78 \mathrm{E}-02$ \\
\hline HLP-64 & 5000 & $1.44 \mathrm{E}-02$ & $2.35 \mathrm{E}-03$ \\
\hline HLP-65 & 10 & 9.29E-02 & 9.29E-02 \\
\hline HLP-65 & 100 & $1.88 \mathrm{E}-02$ & $1.05 \mathrm{E}-02$ \\
\hline HLP-65 & 1000 & $3.86 \mathrm{E}-03$ & $2.20 \mathrm{E}-03$ \\
\hline HLP-65 & 5000 & $7.81 \mathrm{E}-04$ & $1.17 \mathrm{E}-05$ \\
\hline HLP-66 & 10 & $1.40 \mathrm{E}+00$ & $1.40 \mathrm{E}+00$ \\
\hline HLP-66 & 100 & $1.83 \mathrm{E}-01$ & $4.88 \mathrm{E}-02$ \\
\hline HLP-66 & 1000 & $1.34 \mathrm{E}-01$ & $1.29 \mathrm{E}-01$ \\
\hline HLP-66 & 5000 & $4.97 \mathrm{E}-02$ & $2.84 \mathrm{E}-02$ \\
\hline HLP-67 & 10 & $1.81 \mathrm{E}+00$ & $1.81 \mathrm{E}+00$ \\
\hline HLP-67 & 100 & $8.44 \mathrm{E}-02$ & $-1.07 \mathrm{E}-01$ \\
\hline HLP-67 & 1000 & $5.77 \mathrm{E}-02$ & $5.47 \mathrm{E}-02$ \\
\hline HLP-67 & 5000 & $2.41 \mathrm{E}-02$ & $1.57 \mathrm{E}-02$ \\
\hline HLP-68 & 10 & 4.33E-02 & 4.33E-02 \\
\hline HLP-68 & 100 & $5.55 \mathrm{E}-02$ & $5.68 \mathrm{E}-02$ \\
\hline HLP-68 & 1000 & $3.21 \mathrm{E}-03$ & $-2.60 \mathrm{E}-03$ \\
\hline HLP-68 & 5000 & $5.19 \mathrm{E}-04$ & $-1.54 \mathrm{E}-04$ \\
\hline HLP-69 & 10 & 2.39E-02 & 2.39E-02 \\
\hline HLP-69 & 100 & $2.42 \mathrm{E}-01$ & $2.66 \mathrm{E}-01$ \\
\hline HLP-69 & 1000 & $1.18 \mathrm{E}-03$ & $-2.56 \mathrm{E}-02$ \\
\hline HLP-69 & 5000 & $2.66 \mathrm{E}-04$ & $3.74 \mathrm{E}-05$ \\
\hline HLP-70 & 10 & $1.40 \mathrm{E}+00$ & $1.40 \mathrm{E}+00$ \\
\hline HLP-70 & 100 & $2.56 \mathrm{E}-02$ & $-1.28 \mathrm{E}-01$ \\
\hline HLP-70 & 1000 & --- & --- \\
\hline
\end{tabular}




\begin{tabular}{lrcc}
\hline Sample ID & Time (hours) & $\begin{array}{c}\text { Release Rate, } \\
\mathbf{r}\end{array}$ & $\begin{array}{c}\text { Differential Release Rate, } \\
\mathbf{r}_{\Delta}{ }^{*}\end{array}$ \\
\hline HLP-70 & & $1.50 \mathrm{E}-01$ & --- \\
HLP-71 & 1000 & $2.95 \mathrm{E}+01$ & $2.95 \mathrm{E}+01$ \\
HLP-71 & 100 & $5.25 \mathrm{E}-01$ & $-2.70 \mathrm{E}+00$ \\
HLP-71 & 1000 & $6.53 \mathrm{E}-01$ & $6.67 \mathrm{E}-01$ \\
HLP-71 & 5000 & --- & $-1.63 \mathrm{E}-01$ \\
HLP-72 & 10 & $4.28 \mathrm{E}-02$ & $4.28 \mathrm{E}-02$ \\
HLP-72 & 100 & $1.17 \mathrm{E}+00$ & $1.29 \mathrm{E}+00$ \\
HLP-72 & 1000 & $1.49 \mathrm{E}-02$ & $-1.13 \mathrm{E}-01$ \\
HLP-72 & 5000 & $5.88 \mathrm{E}-03$ & $3.63 \mathrm{E}-03$ \\
HLP-73 & 10 & $5.73 \mathrm{E}-01$ & $5.73 \mathrm{E}-01$ \\
HLP-73 & 100 & $1.86 \mathrm{E}-01$ & $1.43 \mathrm{E}-01$ \\
HLP-73 & 1000 & $1.23 \mathrm{E}-01$ & $1.17 \mathrm{E}-01$ \\
HLP-73 & 5000 & $2.85 \mathrm{E}-02$ & $4.79 \mathrm{E}-03$ \\
HLP-74 & 10 & $1.05 \mathrm{E}-01$ & $1.05 \mathrm{E}-01$ \\
HLP-74 & 100 & $1.03 \mathrm{E}-02$ & $-2.79 \mathrm{E}-04$ \\
HLP-74 & 1000 & $1.78 \mathrm{E}-02$ & $1.86 \mathrm{E}-02$ \\
HLP-74 & 5000 & $3.32 \mathrm{E}-03$ & $-2.97 \mathrm{E}-04$ \\
HLP-75 & 10 & $5.99 \mathrm{E}-02$ & $5.99 \mathrm{E}-02$ \\
HLP-75 & 100 & $3.48 \mathrm{E}-02$ & $3.20 \mathrm{E}-02$ \\
HLP-75 & 1000 & $5.75 \mathrm{E}-03$ & $2.52 \mathrm{E}-03$ \\
HLP-75 & 5000 & $1.59 \mathrm{E}-03$ & $5.51 \mathrm{E}-04$ \\
HLP-76 & 10 & $5.17 \mathrm{E}-02$ & $5.17 \mathrm{E}-02$ \\
HLP-76 & 100 & $4.04 \mathrm{E}-02$ & $3.92 \mathrm{E}-02$ \\
HLP-76 & 1000 & $7.08 \mathrm{E}-03$ & $3.37 \mathrm{E}-03$ \\
HLP-76 & 5000 & $2.55 \mathrm{E}-03$ & $1.41 \mathrm{E}-03$ \\
HLP-77 & 10 & $5.92 \mathrm{E}-02$ & $5.92 \mathrm{E}-02$ \\
HLP-77 & 100 & $1.97 \mathrm{E}-02$ & $1.53 \mathrm{E}-02$ \\
HLP-77 & 1000 & $5.68 \mathrm{E}-03$ & $4.12 \mathrm{E}-03$ \\
HLP-77 & 5000 & $2.49 \mathrm{E}-03$ & $1.70 \mathrm{E}-03$ \\
\hline
\end{tabular}

* Release rate and differential release rate are the same at 10 hours. 
Short-term Release Rates Based Upon PCT-B Results of Phase II Glasses.

Table B-11b. Short-term sodium release rates $\left(\mathrm{g} / \mathrm{m}^{2} /\right.$ day) of Phase II glasses based upon measured $\mathrm{NL}_{\mathrm{Na}}$.

\begin{tabular}{|c|c|c|c|}
\hline Sample ID & Time (hours) & $\begin{array}{c}\text { Release Rate, } \\
\text { r }\end{array}$ & $\begin{array}{c}\text { Differential Release Rate, } \\
\mathbf{r}_{\Delta}{ }^{*}\end{array}$ \\
\hline HLP-58 & 10 & $6.42 \mathrm{E}-02$ & $6.42 \mathrm{E}-02$ \\
\hline HLP-58 & 100 & $1.29 \mathrm{E}-01$ & $8.01 \mathrm{E}-01$ \\
\hline HLP-58 & 1000 & $3.87 \mathrm{E}-03$ & $-3.22 \mathrm{E}-02$ \\
\hline HLP-58 & 5000 & $1.12 \mathrm{E}-03$ & $2.21 \mathrm{E}-03$ \\
\hline HLP-59 & 10 & 7.44E-02 & 7.44E-02 \\
\hline HLP-59 & 100 & $1.08 \mathrm{E}-02$ & $1.00 \mathrm{E}-01$ \\
\hline HLP-59 & 1000 & 3.61E-03 & $3.21 \mathrm{E}-02$ \\
\hline HLP-59 & 5000 & $9.27 \mathrm{E}-04$ & $1.51 \mathrm{E}-03$ \\
\hline HLP-60 & 10 & 7.83E-02 & $7.83 \mathrm{E}-02$ \\
\hline HLP-60 & 100 & $1.51 \mathrm{E}-02$ & $1.75 \mathrm{E}-01$ \\
\hline HLP-60 & 1000 & $3.49 \mathrm{E}-03$ & $2.24 \mathrm{E}-02$ \\
\hline HLP-60 & 5000 & $7.57 \mathrm{E}-04$ & 4.88E-04 \\
\hline HLP-61 & 10 & 9.39E-02 & 9.39E-02 \\
\hline HLP-61 & 100 & $1.94 \mathrm{E}-02$ & $1.93 \mathrm{E}-01$ \\
\hline HLP-61 & 1000 & $5.35 \mathrm{E}-03$ & $2.71 \mathrm{E}-02$ \\
\hline HLP-61 & 5000 & $1.56 \mathrm{E}-03$ & $2.25 \mathrm{E}-03$ \\
\hline HLP-62 & 10 & $6.46 \mathrm{E}-02$ & $6.46 \mathrm{E}-02$ \\
\hline HLP-62 & 100 & $1.44 \mathrm{E}-02$ & $2.14 \mathrm{E}-01$ \\
\hline HLP-62 & 1000 & 2.33E-03 & $1.28 \mathrm{E}-02$ \\
\hline HLP-62 & 5000 & $1.98 \mathrm{E}-03$ & 8.67E-03 \\
\hline HLP-63 & 10 & $1.21 \mathrm{E}+00$ & $1.21 \mathrm{E}+00$ \\
\hline HLP-63 & 100 & $1.04 \mathrm{E}-01$ & $-4.06 \mathrm{E}-02$ \\
\hline HLP-63 & 1000 & $1.42 \mathrm{E}-01$ & $6.97 \mathrm{E}-02$ \\
\hline HLP-63 & 5000 & --- & --- \\
\hline HLP-64 & 10 & 7.58E-02 & $7.58 \mathrm{E}-02$ \\
\hline HLP-64 & 100 & $1.26 \mathrm{E}-01$ & $7.50 \mathrm{E}-01$ \\
\hline HLP-64 & 1000 & $3.95 \mathrm{E}-02$ & $3.04 \mathrm{E}-02$ \\
\hline HLP-64 & 5000 & 7.69E-03 & $-1.57 \mathrm{E}-04$ \\
\hline HLP-65 & 10 & 8.89E-02 & 8.89E-02 \\
\hline HLP-65 & 100 & $2.62 \mathrm{E}-02$ & 2.89E-01 \\
\hline HLP-65 & 1000 & $4.22 \mathrm{E}-03$ & $1.27 \mathrm{E}-02$ \\
\hline HLP-65 & 5000 & $9.78 \mathrm{E}-04$ & 8.79E-04 \\
\hline HLP-66 & 10 & $1.09 \mathrm{E}+00$ & $1.09 \mathrm{E}+00$ \\
\hline HLP-66 & 100 & $1.63 \mathrm{E}-01$ & $1.08 \mathrm{E}-01$ \\
\hline HLP-66 & 1000 & $9.78 \mathrm{E}-02$ & 4.78E-02 \\
\hline HLP-66 & 5000 & 2.63E-02 & $1.77 \mathrm{E}-03$ \\
\hline HLP-67 & 10 & $1.41 \mathrm{E}+00$ & $1.41 \mathrm{E}+00$ \\
\hline HLP-67 & 100 & 8.59E-02 & $-1.33 \mathrm{E}-01$ \\
\hline HLP-67 & 1000 & $4.52 \mathrm{E}-02$ & $4.43 \mathrm{E}-02$ \\
\hline HLP-67 & 5000 & $1.42 \mathrm{E}-02$ & $2.70 \mathrm{E}-03$ \\
\hline HLP-68 & 10 & $8.52 \mathrm{E}-02$ & $8.52 \mathrm{E}-02$ \\
\hline HLP-68 & 100 & $6.51 \mathrm{E}-02$ & $5.42 \mathrm{E}-01$ \\
\hline HLP-68 & 1000 & $4.58 \mathrm{E}-03$ & $-9.36 \mathrm{E}-03$ \\
\hline HLP-68 & 5000 & $1.25 \mathrm{E}-03$ & $1.85 \mathrm{E}-03$ \\
\hline HLP-69 & 10 & $3.31 \mathrm{E}-02$ & $3.31 \mathrm{E}-02$ \\
\hline HLP-69 & 100 & $6.66 \mathrm{E}-02$ & $8.00 \mathrm{E}-01$ \\
\hline HLP-69 & 1000 & $1.42 \mathrm{E}-03$ & $-4.12 \mathrm{E}-02$ \\
\hline HLP-69 & 5000 & $3.73 \mathrm{E}-04$ & $1.63 \mathrm{E}-03$ \\
\hline HLP-70 & 10 & $1.38 \mathrm{E}+00$ & $1.38 \mathrm{E}+00$ \\
\hline HLP-70 & 100 & $1.23 \mathrm{E}-02$ & $-6.43 E-01$ \\
\hline
\end{tabular}


HLP-70 1000

\begin{tabular}{|c|c|c|c|}
\hline Sample ID & Time (hours) & $\begin{array}{c}\text { Release Rate, } \\
\mathbf{r} \\
\end{array}$ & $\begin{array}{c}\text { Differential Release Rate, } \\
\mathbf{r}_{\Delta}{ }^{*}\end{array}$ \\
\hline HLP-70 & 5000 & $8.62 \mathrm{E}-02$ & --- \\
\hline HLP-71 & 10 & $7.48 \mathrm{E}+00$ & $7.48 \mathrm{E}+00$ \\
\hline HLP-71 & 100 & $2.05 \mathrm{E}-01$ & $-3.45 \mathrm{E}-01$ \\
\hline HLP-71 & 1000 & $2.08 \mathrm{E}-01$ & $6.18 \mathrm{E}-02$ \\
\hline HLP-71 & 5000 & --- & --- \\
\hline HLP-72 & 10 & $5.06 \mathrm{E}-02$ & $5.06 \mathrm{E}-02$ \\
\hline HLP-72 & 100 & $1.05 \mathrm{E}+00$ & $1.42 \mathrm{E}+00$ \\
\hline HLP-72 & 1000 & $8.17 \mathrm{E}-03$ & $-6.82 \mathrm{E}-02$ \\
\hline HLP-72 & 5000 & $2.91 \mathrm{E}-03$ & $3.47 \mathrm{E}-03$ \\
\hline HLP-73 & 10 & $3.25 \mathrm{E}-01$ & $3.25 \mathrm{E}-01$ \\
\hline HLP-73 & 100 & $3.19 \mathrm{E}-01$ & $6.09 \mathrm{E}-01$ \\
\hline HLP-73 & 1000 & $6.59 \mathrm{E}-02$ & $1.93 \mathrm{E}-02$ \\
\hline HLP-73 & 5000 & $3.86 \mathrm{E}-03$ & $-7.36 \mathrm{E}-03$ \\
\hline HLP-74 & 10 & $8.05 \mathrm{E}-02$ & $8.05 \mathrm{E}-02$ \\
\hline HLP-74 & 100 & $1.59 \mathrm{E}-02$ & $1.82 \mathrm{E}-01$ \\
\hline HLP-74 & 1000 & $1.03 \mathrm{E}-02$ & $4.99 \mathrm{E}-02$ \\
\hline HLP-74 & 5000 & $2.42 \mathrm{E}-03$ & $9.59 \mathrm{E}-04$ \\
\hline HLP-75 & 10 & $9.12 \mathrm{E}-02$ & $9.12 \mathrm{E}-02$ \\
\hline HLP-75 & 100 & $3.14 \mathrm{E}-02$ & $3.29 \mathrm{E}-01$ \\
\hline HLP-75 & 1000 & $5.15 \mathrm{E}-03$ & $1.32 \mathrm{E}-02$ \\
\hline HLP-75 & 5000 & $1.57 \mathrm{E}-03$ & $2.54 \mathrm{E}-03$ \\
\hline HLP-76 & 10 & 7.69E-02 & 7.69E-02 \\
\hline HLP-76 & 100 & $1.83 \mathrm{E}-02$ & $2.31 \mathrm{E}-01$ \\
\hline HLP-76 & 1000 & 5.93E-03 & $3.14 \mathrm{E}-02$ \\
\hline HLP-76 & 5000 & $1.97 \mathrm{E}-03$ & $3.03 \mathrm{E}-03$ \\
\hline HLP-77 & 10 & $7.65 \mathrm{E}-02$ & $7.65 \mathrm{E}-02$ \\
\hline HLP-77 & 100 & $9.23 \mathrm{E}-03$ & 4.99E-02 \\
\hline HLP-77 & 1000 & 4.90E-03 & $4.45 \mathrm{E}-02$ \\
\hline HLP-77 & 5000 & $1.44 \mathrm{E}-03$ & $2.30 \mathrm{E}-03$ \\
\hline
\end{tabular}

* Release rate and differential release rate are the same at 10 hours. 
Table B-12. Ranking of Glasses by Normalized Boron Release of Phase II Glasses (Ascending Order)

\begin{tabular}{ccccc}
\hline Ranking & $\begin{array}{c}\text { 10 hours } \\
\text { Glass ID }\end{array}$ & $\begin{array}{c}\text { 100 hours } \\
\text { Glass ID }\end{array}$ & $\begin{array}{c}\text { 1000 hours } \\
\text { Glass ID }\end{array}$ & $\begin{array}{c}\text { 5000 hours } \\
\text { Glass ID }\end{array}$ \\
\hline 1 & HLP-69 & HLP-59 & HLP-69 & HLP-69 \\
2 & HLP-72 & HLP-62 & HLP-62 & HLP-68 \\
3 & HLP-68 & HLP-74 & HLP-68 & HLP-60 \\
4 & HLP-59 & HLP-60 & HLP-59 & HLP-62 \\
5 & HLP-64 & HLP-65 & HLP-65 & HLP-59 \\
6 & HLP-58 & HLP-77 & HLP-58 & HLP-65 \\
7 & HLP-76 & HLP-70 & HLP-77 & HLP-58 \\
8 & HLP-77 & HLP-61 & HLP-75 & HLP-75 \\
9 & HLP-75 & HLP-75 & HLP-76 & HLP-77 \\
10 & HLP-60 & HLP-76 & HLP-60 & HLP-76 \\
11 & HLP-62 & HLP-68 & HLP-72 & HLP-74 \\
12 & HLP-65 & HLP-63 & HLP-74 & HLP-61 \\
13 & HLP-74 & HLP-67 & HLP-61 & HLP-72 \\
14 & HLP-61 & HLP-64 & HLP-67 & HLP-64 \\
15 & HLP-73 & HLP-58 & HLP-64 & HLP-67 \\
16 & HLP-63 & HLP-66 & HLP-63 & HLP-73 \\
17 & HLP-66 & HLP-73 & HLP-73 & HLP-66 \\
18 & HLP-70 & HLP-69 & HLP-66 & HLP-70 \\
19 & HLP-67 & HLP-71 & HLP-71 & $* *$ \\
20 & HLP-71 & HLP-72 & $*$ & \\
\hline
\end{tabular}

* No data available for HLP-70.

** No data available for HLP-63 and HLP-71.

Table B-13. Ranking of Glasses by Normalized Sodium Release of Phase II Glasses

\begin{tabular}{ccccc}
\hline (Ascending Order) & & \\
\hline Ranking & 10 hours & $\begin{array}{c}\mathbf{1 0 0} \text { hours } \\
\text { Glass ID }\end{array}$ & $\begin{array}{c}\text { 1000 hours } \\
\text { Glass ID }\end{array}$ & $\begin{array}{c}\text { 5000 hours } \\
\text { Glass ID }\end{array}$ \\
\hline 1 & HLP-69 & HLP-77 & HLP-69 & HLP-69 \\
2 & HLP-72 & HLP-59 & HLP-62 & HLP-60 \\
3 & HLP-58 & HLP-70 & HLP-60 & HLP-59 \\
4 & HLP-62 & HLP-62 & HLP-59 & HLP-65 \\
5 & HLP-59 & HLP-60 & HLP-58 & HLP-58 \\
6 & HLP-64 & HLP-74 & HLP-65 & HLP-68 \\
7 & HLP-77 & HLP-76 & HLP-68 & HLP-77 \\
8 & HLP-76 & HLP-61 & HLP-77 & HLP-61 \\
9 & HLP-60 & HLP-65 & HLP-75 & HLP-75 \\
10 & HLP-74 & HLP-75 & HLP-61 & HLP-76 \\
11 & HLP-68 & HLP-68 & HLP-76 & HLP-62 \\
12 & HLP-65 & HLP-69 & HLP-72 & HLP-74 \\
13 & HLP-75 & HLP-67 & HLP-74 & HLP-72 \\
14 & HLP-61 & HLP-63 & HLP-64 & HLP-73 \\
15 & HLP-73 & HLP-64 & HLP-67 & HLP-64 \\
16 & HLP-66 & HLP-58 & HLP-73 & HLP-67 \\
17 & HLP-63 & HLP-66 & HLP-66 & HLP-66 \\
18 & HLP-70 & HLP-71 & HLP-63 & HLP-70 \\
19 & HLP-67 & HLP-73 & HLP-71 & $* *$ \\
20 & HLP-71 & HLP-72 & $*$ & \\
\hline
\end{tabular}

* No data available for HLP-70.

** No data available for HLP-63 and HLP-71. 


\section{PCT-A Normalized Release Information for Phase I and II Glasses}

Table B-14a. Targeted normalized release values for the PCT-A boron, sodium, and silicon results for the Hanford glasses (Phase I and II). Test temperature $=90^{\circ} \mathrm{C}$; test duration $=168$ hours (7 days); and $(\mathrm{S} / \mathrm{V}) \approx 2000 / \mathrm{m}$.

\begin{tabular}{|c|c|c|c|c|c|c|c|c|}
\hline \multirow[b]{2}{*}{ SampleID } & \multirow{2}{*}{$\begin{array}{l}\text { Time, } t \\
\text { (hours) }\end{array}$} & \multirow{2}{*}{$\begin{array}{l}(\mathrm{S} / \mathrm{V}) \mathrm{t} \\
(\mathrm{h} / \mathrm{m})\end{array}$} & \multicolumn{3}{|c|}{$\mathrm{NC}_{\mathrm{i}}(\mathrm{g} / \mathrm{L})$} & \multicolumn{3}{|c|}{$\mathrm{NL}_{\mathrm{i}}\left(\mathrm{g} / \mathrm{m}^{2}\right)$} \\
\hline & & & B & $\mathbf{N a}$ & $\mathbf{S i}$ & B & $\mathbf{N a}$ & Si \\
\hline HLP-01 & 168 & $3.36 \times 10^{5}$ & 0.54 & 0.71 & 0.34 & 0.27 & 0.35 & 0.17 \\
\hline HLP-02 & 168 & $3.36 \times 10^{5}$ & 5.77 & 4.60 & 0.67 & 2.90 & 2.31 & 0.33 \\
\hline HLP-03 & 168 & $3.36 \times 10^{5}$ & 0.58 & 0.65 & 0.36 & 0.28 & 0.32 & 0.18 \\
\hline HLP-04 & 168 & $3.36 \times 10^{5}$ & 3.90 & 2.35 & 0.61 & 1.94 & 1.17 & 0.31 \\
\hline HLP-05 & 168 & $3.36 \times 10^{5}$ & 2.57 & 1.70 & 0.84 & 1.28 & 0.84 & 0.42 \\
\hline HLP-06 & 168 & $3.36 \times 10^{5}$ & 0.62 & 0.60 & 0.37 & 0.30 & 0.28 & 0.18 \\
\hline HLP-07 & 168 & $3.36 \times 10^{5}$ & 0.63 & 0.64 & 0.36 & 0.30 & 0.31 & 0.18 \\
\hline HLP-08 & 168 & $3.36 \times 10^{5}$ & 0.65 & 0.87 & 0.43 & 0.33 & 0.44 & 0.22 \\
\hline HLP-09 & 168 & $3.36 \times 10^{5}$ & 1.03 & 0.94 & 0.34 & 0.50 & 0.45 & 0.16 \\
\hline HLP-10 & 168 & $3.36 \times 10^{5}$ & 0.70 & 0.76 & 0.40 & 0.34 & 0.37 & 0.20 \\
\hline HLP-11 & 168 & $3.36 \times 10^{5}$ & 0.93 & 0.86 & 0.41 & 0.44 & 0.41 & 0.20 \\
\hline HLP-12 & 168 & $3.36 \times 10^{5}$ & 0.81 & 0.68 & 0.45 & 0.41 & 0.34 & 0.22 \\
\hline HLP-13 & 168 & $3.36 \times 10^{5}$ & 0.93 & 0.89 & 0.41 & 0.45 & 0.43 & 0.20 \\
\hline HLP-14 & 168 & $3.36 \times 10^{5}$ & 1.44 & 1.12 & 0.40 & 0.69 & 0.54 & 0.19 \\
\hline HLP-15 & 168 & $3.36 \times 10^{5}$ & 0.70 & 0.71 & 0.45 & 0.34 & 0.35 & 0.22 \\
\hline HLP-16 & 168 & $3.36 \times 10^{5}$ & 0.74 & 0.75 & 0.42 & 0.36 & 0.36 & 0.20 \\
\hline HLP-17 & 168 & $3.36 \times 10^{5}$ & 0.89 & 0.85 & 0.40 & 0.44 & 0.42 & 0.20 \\
\hline HLP-18 & 168 & $3.36 \times 10^{5}$ & 1.05 & 0.94 & 0.50 & 0.51 & 0.45 & 0.24 \\
\hline HLP-19 & 168 & $3.36 \times 10^{5}$ & 0.55 & 0.60 & 0.33 & 0.27 & 0.30 & 0.16 \\
\hline HLP-20 & 168 & $3.36 \times 10^{5}$ & 0.75 & 0.68 & 0.41 & 0.37 & 0.33 & 0.20 \\
\hline HLP-21 & 168 & $3.36 \times 10^{5}$ & 1.20 & 0.96 & 0.47 & 0.58 & 0.46 & 0.23 \\
\hline HLP-22 & 168 & $3.36 \times 10^{5}$ & 0.49 & 0.47 & 0.35 & 0.24 & 0.23 & 0.17 \\
\hline HLP-23 & 168 & $3.36 \times 10^{5}$ & 1.96 & 1.56 & 0.61 & 0.96 & 0.76 & 0.30 \\
\hline HLP-24 & 168 & $3.36 \times 10^{5}$ & 0.68 & 0.72 & 0.39 & 0.33 & 0.35 & 0.19 \\
\hline HLP-25 & 168 & $3.36 \times 10^{5}$ & 0.88 & 0.85 & 0.41 & 0.43 & 0.42 & 0.20 \\
\hline HLP-26 & 168 & $3.36 \times 10^{5}$ & 1.06 & 0.77 & 0.46 & 0.52 & 0.38 & 0.22 \\
\hline HLP-27 & 168 & $3.36 \times 10^{5}$ & 4.66 & 3.26 & 0.49 & 2.17 & 1.52 & 0.23 \\
\hline HLP-28 & 168 & $3.36 \times 10^{5}$ & 0.53 & 0.41 & 0.38 & 0.25 & 0.19 & 0.18 \\
\hline HLP-29 & 168 & $3.36 \times 10^{5}$ & 0.80 & 1.12 & 0.54 & 0.38 & 0.53 & 0.26 \\
\hline HLP-30 & 168 & $3.36 \times 10^{5}$ & 0.31 & 0.49 & 0.31 & 0.15 & 0.24 & 0.15 \\
\hline HLP-31 & 168 & $3.36 \times 10^{5}$ & 13.42 & 9.58 & 3.04 & 6.54 & 4.67 & 1.48 \\
\hline HLP-32 & 168 & $3.36 \times 10^{5}$ & 0.95 & 0.70 & 0.37 & 0.46 & 0.34 & 0.18 \\
\hline HLP-33 & 168 & $3.36 \times 10^{5}$ & 3.93 & 3.30 & 1.64 & 1.92 & 1.61 & 0.81 \\
\hline HLP-34 & 168 & $3.36 \times 10^{5}$ & 0.76 & 0.72 & 0.38 & 0.38 & 0.36 & 0.19 \\
\hline HLP-35 & 168 & $3.36 \times 10^{5}$ & 2.70 & 2.04 & 0.44 & 1.32 & 1.00 & 0.21 \\
\hline HLP-36 & 168 & $3.36 \times 10^{5}$ & 0.85 & 0.69 & 0.31 & 0.43 & 0.35 & 0.16 \\
\hline HLP-37 & 168 & $3.36 \times 10^{5}$ & 2.59 & 2.29 & 0.80 & 1.30 & 1.15 & 0.40 \\
\hline HLP-37Q & 168 & $3.36 \times 10^{5}$ & 1.26 & 1.48 & 0.60 & 0.63 & 0.75 & 0.30 \\
\hline HLP-38 & 168 & $3.36 \times 10^{5}$ & 0.79 & 0.72 & 0.37 & 0.41 & 0.37 & 0.19 \\
\hline HLP-38Q & 168 & $3.36 \times 10^{5}$ & 0.77 & 0.71 & 0.34 & 0.40 & 0.37 & 0.18 \\
\hline HLP-39 & 168 & $3.36 \times 10^{5}$ & 4.56 & 2.93 & 0.78 & 2.31 & 1.49 & 0.40 \\
\hline HLP-40 & 168 & $3.36 \times 10^{5}$ & 1.80 & 1.39 & 0.39 & 0.94 & 0.73 & 0.21 \\
\hline HLP-40Q & 168 & $3.36 \times 10^{5}$ & 1.54 & 1.21 & 0.39 & 0.81 & 0.64 & 0.21 \\
\hline HLP-41 & 168 & $3.36 \times 10^{5}$ & 13.27 & 8.92 & 2.13 & 6.94 & 4.66 & 1.11 \\
\hline
\end{tabular}




\begin{tabular}{|c|c|c|c|c|c|c|c|c|}
\hline \multirow[b]{2}{*}{ SampleID } & \multirow{2}{*}{$\begin{array}{l}\text { Time, } t \\
\text { (hours) }\end{array}$} & \multirow{2}{*}{$\begin{array}{l}(\mathrm{S} / \mathrm{V}) \mathrm{t} \\
(\mathrm{h} / \mathrm{m})\end{array}$} & \multicolumn{3}{|c|}{$\mathrm{NC}_{\mathrm{i}}(\mathrm{g} / \mathrm{L})$} & \multicolumn{3}{|c|}{$\mathrm{NL}_{\mathrm{i}}\left(\mathrm{g} / \mathrm{m}^{2}\right)$} \\
\hline & & & B & $\mathbf{N a}$ & Si & B & $\mathrm{Na}$ & Si \\
\hline HLP-42 & 168 & $3.36 \times 10^{5}$ & 1.36 & 1.08 & 0.47 & 0.74 & 0.59 & 0.26 \\
\hline HLP-42Q & 168 & $3.36 \times 10^{5}$ & 1.77 & 1.30 & 0.48 & 0.97 & 0.71 & 0.27 \\
\hline HLP-43 & 168 & $3.36 \times 10^{5}$ & 0.82 & 0.68 & 0.37 & 0.40 & 0.33 & 0.18 \\
\hline HLP-44 & 168 & $3.36 \times 10^{5}$ & 0.92 & 0.82 & 0.35 & 0.45 & 0.40 & 0.17 \\
\hline HLP-45 & 168 & $3.36 \times 10^{5}$ & 0.85 & 0.76 & 0.35 & 0.42 & 0.38 & 0.17 \\
\hline HLP-46 & 168 & $3.36 \times 10^{5}$ & 0.10 & 1.00 & 0.24 & 0.05 & 0.47 & 0.11 \\
\hline HLP-47 & 168 & $3.36 \times 10^{5}$ & 1.05 & 1.05 & 0.30 & 0.49 & 0.49 & 0.14 \\
\hline HLP-48 & 168 & $3.36 \times 10^{5}$ & 1.23 & 1.04 & 0.34 & 0.61 & 0.52 & 0.17 \\
\hline HLP-49 & 168 & $3.36 \times 10^{5}$ & 0.60 & 0.56 & 0.18 & 0.31 & 0.29 & 0.09 \\
\hline HLP-51 & 168 & $3.36 \times 10^{5}$ & 0.67 & 0.75 & 0.29 & 0.34 & 0.38 & 0.15 \\
\hline HLP-52 & 168 & $3.36 \times 10^{5}$ & --- & 11.30 & 1.32 & --- & 5.57 & 0.65 \\
\hline HLP-53 & 168 & $3.36 \times 10^{5}$ & --- & --- & --- & --- & --- & --- \\
\hline HLP-54 & 168 & $3.36 \times 10^{5}$ & 0.93 & 0.97 & 0.41 & 0.43 & 0.45 & 0.19 \\
\hline HLP-55 & 168 & $3.36 \times 10^{5}$ & 0.31 & 0.55 & 0.25 & 0.14 & 0.25 & 0.11 \\
\hline HLP-58 & 168 & $3.36 \times 10^{5}$ & 0.54 & 0.63 & 0.29 & 0.26 & 0.31 & 0.14 \\
\hline HLP-59 & 168 & $3.36 \times 10^{5}$ & 0.59 & 0.74 & 0.30 & 0.29 & 0.37 & 0.15 \\
\hline HLP-60 & 168 & $3.36 \times 10^{5}$ & 0.59 & 0.75 & 0.35 & 0.03 & 0.04 & 0.02 \\
\hline HLP-61 & 168 & $3.36 \times 10^{5}$ & 1.92 & 0.66 & 0.48 & 0.96 & 0.33 & 0.24 \\
\hline HLP-62 & 168 & $3.36 \times 10^{5}$ & 0.50 & 0.53 & 0.23 & 0.25 & 0.27 & 0.12 \\
\hline HLP-63 & 168 & $3.36 \times 10^{5}$ & 2.49 & 7.33 & 1.95 & 1.27 & 3.73 & 0.99 \\
\hline HLP-64 & 168 & $3.36 \times 10^{5}$ & 6.56 & 4.92 & 1.19 & 3.20 & 2.40 & 0.58 \\
\hline HLP-65 & 168 & $3.36 \times 10^{5}$ & 0.93 & 1.01 & 0.48 & 0.46 & 0.49 & 0.23 \\
\hline HLP-66 & 168 & $3.36 \times 10^{5}$ & 18.69 & 13.62 & 4.91 & 8.92 & 6.50 & 2.34 \\
\hline HLP-67 & 168 & $3.36 \times 10^{5}$ & 15.27 & 11.20 & 1.82 & 7.66 & 5.62 & 0.91 \\
\hline HLP-68 & 168 & $3.36 \times 10^{5}$ & 0.62 & 0.83 & 0.22 & 0.32 & 0.43 & 0.11 \\
\hline HLP-69 & 168 & $3.36 \times 10^{5}$ & 0.43 & 0.43 & 0.29 & 0.20 & 0.21 & 0.14 \\
\hline HLP-70 & 168 & $3.36 \times 10^{5}$ & 0.63 & 0.29 & 0.27 & 0.31 & 0.14 & 0.13 \\
\hline HLP-71 & 168 & $3.36 \times 10^{5}$ & 85.25 & 21.99 & 0.86 & 42.68 & 11.01 & 0.43 \\
\hline HLP-72 & 168 & $3.36 \times 10^{5}$ & 0.59 & 0.61 & 0.25 & 0.29 & 0.30 & 0.12 \\
\hline HLP-73 & 168 & $3.36 \times 10^{5}$ & 4.26 & 2.57 & 0.28 & 2.06 & 1.24 & 0.14 \\
\hline HLP-74 & 168 & $3.36 \times 10^{5}$ & 0.49 & 0.58 & 0.19 & 0.25 & 0.29 & 0.10 \\
\hline HLP-75 & 168 & $3.36 \times 10^{5}$ & 0.67 & 0.86 & 0.34 & 0.33 & 0.43 & 0.17 \\
\hline HLP-76 & 168 & $3.36 \times 10^{5}$ & 0.48 & 0.64 & 0.27 & 0.23 & 0.30 & 0.13 \\
\hline HLP-77 & 168 & $3.36 \times 10^{5}$ & 0.47 & 0.64 & 0.27 & 0.22 & 0.30 & 0.13 \\
\hline
\end{tabular}




\section{PCT-A Normalized Release Information for Phase I and II Glasses}

Table B-14b. Measured normalized release values for the PCT-A boron, sodium, and silicon results for the Hanford glasses (Phase I and II). Test temperature $=90^{\circ} \mathrm{C}$; test duration $=168$ hours ( 7 days); and $(\mathrm{S} / \mathrm{V}) \approx 2000 / \mathrm{m}$.

\begin{tabular}{|c|c|c|c|c|c|c|c|c|}
\hline \multirow[b]{2}{*}{ SampleID } & \multirow{2}{*}{$\begin{array}{l}\text { Time, } t \\
\text { (hours) }\end{array}$} & \multirow{2}{*}{$\begin{array}{l}(\mathbf{S} / \mathbf{V}) \mathbf{t} \\
(\mathbf{h} / \mathbf{m})\end{array}$} & \multicolumn{3}{|c|}{$\mathrm{NC}_{\mathrm{i}}(\mathrm{g} / \mathrm{L})$} & \multicolumn{3}{|c|}{$\mathrm{NL}_{\mathrm{i}}\left(\mathrm{g} / \mathrm{m}^{2}\right)$} \\
\hline & & & B & $\mathbf{N a}$ & $\mathbf{S i}$ & B & Na & $\mathbf{S i}$ \\
\hline HLP-01 & 168 & $3.36 \times 10^{5}$ & 0.61 & 0.77 & 0.35 & 0.30 & 0.38 & 0.17 \\
\hline HLP-02 & 168 & $3.36 \times 10^{5}$ & 6.36 & 4.48 & 0.68 & 3.20 & 2.25 & 0.34 \\
\hline HLP-03 & 168 & $3.36 \times 10^{5}$ & 0.60 & 0.68 & 0.36 & 0.29 & 0.33 & 0.18 \\
\hline HLP-04 & 168 & $3.36 \times 10^{5}$ & 3.70 & 2.50 & 0.61 & 1.85 & 1.25 & 0.30 \\
\hline HLP-05 & 168 & $3.36 \times 10^{5}$ & 2.57 & 1.73 & 0.90 & 1.28 & 0.86 & 0.45 \\
\hline HLP-06 & 168 & $3.36 \times 10^{5}$ & 0.67 & 0.59 & 0.39 & 0.32 & 0.28 & 0.19 \\
\hline HLP-07 & 168 & $3.36 \times 10^{5}$ & 0.65 & 0.64 & 0.35 & 0.31 & 0.31 & 0.17 \\
\hline HLP-08 & 168 & $3.36 \times 10^{5}$ & 0.66 & 0.93 & 0.45 & 0.33 & 0.47 & 0.23 \\
\hline HLP-09 & 168 & $3.36 \times 10^{5}$ & 1.04 & 0.99 & 0.37 & 0.50 & 0.48 & 0.18 \\
\hline HLP-10 & 168 & $3.36 \times 10^{5}$ & 0.63 & 0.85 & 0.42 & 0.31 & 0.41 & 0.21 \\
\hline HLP-11 & 168 & $3.36 \times 10^{5}$ & 0.93 & 1.00 & 0.42 & 0.44 & 0.48 & 0.20 \\
\hline HLP-12 & 168 & $3.36 \times 10^{5}$ & 0.77 & 0.73 & 0.47 & 0.38 & 0.36 & 0.23 \\
\hline HLP-13 & 168 & $3.36 \times 10^{5}$ & 0.93 & 0.99 & 0.41 & 0.45 & 0.48 & 0.20 \\
\hline HLP-14 & 168 & $3.36 \times 10^{5}$ & 1.47 & 1.19 & 0.43 & 0.71 & 0.57 & 0.20 \\
\hline HLP-15 & 168 & $3.36 \times 10^{5}$ & 0.70 & 0.74 & 0.45 & 0.34 & 0.36 & 0.22 \\
\hline HLP-16 & 168 & $3.36 \times 10^{5}$ & 0.75 & 0.80 & 0.39 & 0.36 & 0.38 & 0.19 \\
\hline HLP-17 & 168 & $3.36 \times 10^{5}$ & 0.88 & 0.90 & 0.39 & 0.44 & 0.44 & 0.19 \\
\hline HLP-18 & 168 & $3.36 \times 10^{5}$ & 1.04 & 0.99 & 0.54 & 0.50 & 0.48 & 0.26 \\
\hline HLP-19 & 168 & $3.36 \times 10^{5}$ & 0.55 & 0.64 & 0.32 & 0.27 & 0.32 & 0.16 \\
\hline HLP-20 & 168 & $3.36 \times 10^{5}$ & 0.76 & 0.72 & 0.41 & 0.37 & 0.35 & 0.20 \\
\hline HLP-21 & 168 & $3.36 \times 10^{5}$ & 1.15 & 1.02 & 0.49 & 0.56 & 0.50 & 0.24 \\
\hline HLP-22 & 168 & $3.36 \times 10^{5}$ & 0.47 & 0.49 & 0.34 & 0.23 & 0.24 & 0.16 \\
\hline HLP-23 & 168 & $3.36 \times 10^{5}$ & 1.95 & 1.67 & 0.65 & 0.95 & 0.82 & 0.32 \\
\hline HLP-24 & 168 & $3.36 \times 10^{5}$ & 0.70 & 0.75 & 0.40 & 0.34 & 0.36 & 0.19 \\
\hline HLP-25 & 168 & $3.36 \times 10^{5}$ & 0.87 & 0.92 & 0.43 & 0.43 & 0.45 & 0.21 \\
\hline HLP-26 & 168 & $3.36 \times 10^{5}$ & 1.13 & 0.84 & 0.48 & 0.55 & 0.41 & 0.23 \\
\hline HLP-27 & 168 & $3.36 \times 10^{5}$ & 4.55 & 3.45 & 0.51 & 2.12 & 1.61 & 0.24 \\
\hline HLP-28 & 168 & $3.36 \times 10^{5}$ & 0.49 & 0.44 & 0.38 & 0.23 & 0.21 & 0.18 \\
\hline HLP-29 & 168 & $3.36 \times 10^{5}$ & 0.74 & 1.20 & 0.56 & 0.35 & 0.57 & 0.27 \\
\hline HLP-30 & 168 & $3.36 \times 10^{5}$ & 0.29 & 0.51 & 0.35 & 0.14 & 0.25 & 0.17 \\
\hline HLP-31 & 168 & $3.36 \times 10^{5}$ & 13.09 & 10.02 & 3.23 & 6.38 & 4.89 & 1.58 \\
\hline HLP-32 & 168 & $3.36 \times 10^{5}$ & 0.89 & 0.71 & 0.42 & 0.43 & 0.35 & 0.20 \\
\hline HLP-33 & 168 & $3.36 \times 10^{5}$ & 3.66 & 3.45 & 1.64 & 1.79 & 1.69 & 0.80 \\
\hline HLP-34 & 168 & $3.36 \times 10^{5}$ & 0.73 & 0.81 & 0.39 & 0.36 & 0.40 & 0.19 \\
\hline HLP-35 & 168 & $3.36 \times 10^{5}$ & 2.67 & 2.17 & 0.44 & 1.31 & 1.07 & 0.21 \\
\hline HLP-36 & 168 & $3.36 \times 10^{5}$ & 0.81 & 0.71 & 0.32 & 0.41 & 0.36 & 0.16 \\
\hline HLP-37 & 168 & $3.36 \times 10^{5}$ & 2.29 & 2.42 & 0.81 & 1.15 & 1.22 & 0.41 \\
\hline HLP-37Q & 168 & $3.36 \times 10^{5}$ & --- & --- & --- & --- & --- & --- \\
\hline HLP-38 & 168 & $3.36 \times 10^{5}$ & 0.78 & 0.75 & 0.37 & 0.40 & 0.39 & 0.19 \\
\hline HLP-38Q & 168 & $3.36 \times 10^{5}$ & --- & --- & --- & --- & --- & --- \\
\hline HLP-39 & 168 & $3.36 \times 10^{5}$ & 4.34 & 3.14 & 0.82 & 2.20 & 1.59 & 0.41 \\
\hline HLP-40 & 168 & $3.36 \times 10^{5}$ & 1.74 & 1.36 & 0.40 & 0.91 & 0.71 & 0.21 \\
\hline HLP-40Q & 168 & $3.36 \times 10^{5}$ & 1.45 & 1.26 & 0.42 & 0.76 & 0.66 & 0.22 \\
\hline HLP-41 & 168 & $3.36 \times 10^{5}$ & 12.30 & 9.50 & 2.19 & 6.43 & 4.97 & 1.14 \\
\hline
\end{tabular}




\begin{tabular}{|c|c|c|c|c|c|c|c|c|}
\hline \multirow[b]{2}{*}{ SampleID } & \multirow{2}{*}{$\begin{array}{l}\text { Time, } t \\
\text { (hours) }\end{array}$} & \multirow{2}{*}{$\begin{array}{l}(\mathrm{S} / \mathrm{V}) \mathrm{t} \\
(\mathrm{h} / \mathrm{m})\end{array}$} & \multicolumn{3}{|c|}{$\mathrm{NC}_{\mathrm{i}}(\mathrm{g} / \mathrm{L})$} & \multicolumn{3}{|c|}{$\mathrm{NL}_{\mathrm{i}}\left(\mathrm{g} / \mathrm{m}^{2}\right)$} \\
\hline & & & B & $\mathbf{N a}$ & Si & B & $\mathrm{Na}$ & $\mathbf{S i}$ \\
\hline HLP-42 & 168 & $3.36 \times 10^{5}$ & 1.26 & 1.11 & 0.50 & 0.69 & 0.61 & 0.27 \\
\hline HLP-42Q & 168 & $3.36 \times 10^{5}$ & 1.68 & 1.34 & 0.50 & 0.92 & 0.74 & 0.27 \\
\hline HLP-43 & 168 & $3.36 \times 10^{5}$ & 0.83 & 0.74 & 0.38 & 0.41 & 0.36 & 0.19 \\
\hline HLP-44 & 168 & $3.36 \times 10^{5}$ & 0.93 & 0.88 & 0.36 & 0.45 & 0.43 & 0.18 \\
\hline HLP-45 & 168 & $3.36 \times 10^{5}$ & 0.84 & 0.83 & 0.35 & 0.42 & 0.41 & 0.18 \\
\hline HLP-46 & 168 & $3.36 \times 10^{5}$ & 0.09 & 1.13 & 0.23 & 0.04 & 0.54 & 0.11 \\
\hline HLP-47 & 168 & $3.36 \times 10^{5}$ & 1.10 & 1.11 & 0.30 & 0.52 & 0.52 & 0.14 \\
\hline HLP-48 & 168 & $3.36 \times 10^{5}$ & 1.22 & 1.12 & 0.36 & 0.61 & 0.56 & 0.18 \\
\hline HLP-49 & 168 & $3.36 \times 10^{5}$ & 0.55 & 0.58 & 0.19 & 0.28 & 0.30 & 0.10 \\
\hline HLP-51 & 168 & $3.36 \times 10^{5}$ & 0.67 & 0.80 & 0.30 & 0.34 & 0.41 & 0.15 \\
\hline HLP-52 & 168 & $3.36 \times 10^{5}$ & 4.83 & 11.76 & 1.28 & 2.38 & 5.80 & 0.63 \\
\hline HLP-53 & 168 & $3.36 \times 10^{5}$ & --- & --- & --- & --- & --- & --- \\
\hline HLP-54 & 168 & $3.36 \times 10^{5}$ & 0.95 & 1.08 & 0.41 & 0.44 & 0.50 & 0.19 \\
\hline HLP-55 & 168 & $3.36 \times 10^{5}$ & 0.31 & 0.63 & 0.25 & 0.14 & 0.29 & 0.11 \\
\hline HLP-58 & 168 & $3.36 \times 10^{5}$ & 0.53 & 0.65 & 0.29 & 0.26 & 0.32 & 0.14 \\
\hline HLP-59 & 168 & $3.36 \times 10^{5}$ & 0.60 & 0.77 & 0.31 & 0.30 & 0.38 & 0.15 \\
\hline HLP-60 & 168 & $3.36 \times 10^{5}$ & 0.57 & 0.73 & 0.34 & 0.03 & 0.04 & 0.02 \\
\hline HLP-61 & 168 & $3.36 \times 10^{5}$ & 1.92 & 0.64 & 0.47 & 0.96 & 0.32 & 0.23 \\
\hline HLP-62 & 168 & $3.36 \times 10^{5}$ & 0.49 & 0.52 & 0.22 & 0.24 & 0.26 & 0.11 \\
\hline HLP-63 & 168 & $3.36 \times 10^{5}$ & 2.50 & 7.37 & 1.96 & 1.27 & 3.75 & 1.00 \\
\hline HLP-64 & 168 & $3.36 \times 10^{5}$ & 6.46 & 4.92 & 1.17 & 3.15 & 2.40 & 0.57 \\
\hline HLP-65 & 168 & $3.36 \times 10^{5}$ & 0.93 & 0.96 & 0.47 & 0.46 & 0.47 & 0.23 \\
\hline HLP-66 & 168 & $3.36 \times 10^{5}$ & 18.69 & 14.00 & 4.95 & 8.92 & 6.68 & 2.36 \\
\hline HLP-67 & 168 & $3.36 \times 10^{5}$ & 15.59 & 11.87 & 1.85 & 7.82 & 5.95 & 0.93 \\
\hline HLP-68 & 168 & $3.36 \times 10^{5}$ & 0.59 & 0.81 & 0.21 & 0.30 & 0.42 & 0.11 \\
\hline HLP-69 & 168 & $3.36 \times 10^{5}$ & 0.42 & 0.41 & 0.28 & 0.20 & 0.20 & 0.13 \\
\hline HLP-70 & 168 & $3.36 \times 10^{5}$ & 0.62 & 0.30 & 0.26 & 0.30 & 0.15 & 0.13 \\
\hline HLP-71 & 168 & $3.36 \times 10^{5}$ & 86.68 & 22.59 & 0.86 & 43.40 & 11.31 & 0.43 \\
\hline HLP-72 & 168 & $3.36 \times 10^{5}$ & 0.60 & 0.62 & 0.26 & 0.30 & 0.30 & 0.13 \\
\hline HLP-73 & 168 & $3.36 \times 10^{5}$ & 4.39 & 2.65 & 0.29 & 2.12 & 1.28 & 0.14 \\
\hline HLP-74 & 168 & $3.36 \times 10^{5}$ & 0.50 & 0.59 & 0.19 & 0.25 & 0.29 & 0.10 \\
\hline HLP-75 & 168 & $3.36 \times 10^{5}$ & 0.64 & 0.89 & 0.34 & 0.31 & 0.44 & 0.17 \\
\hline HLP-76 & 168 & $3.36 \times 10^{5}$ & 0.49 & 0.66 & 0.27 & 0.23 & 0.31 & 0.13 \\
\hline HLP-77 & 168 & $3.36 \times 10^{5}$ & 0.47 & 0.63 & 0.27 & 0.22 & 0.30 & 0.13 \\
\hline
\end{tabular}


Appendix C

\section{VHT Data for the HLP Glasses}




\section{Appendix C: VHT Data for the HLP Glasses}

Table C-1. VHT rates for HLP Glasses

\begin{tabular}{|c|c|c|c|c|c|c|}
\hline Glass ID & $\begin{array}{l}\text { Temp } \\
{\left[{ }^{\circ} \mathrm{C}\right]}\end{array}$ & $\begin{array}{c}\text { Rate } \\
{\left[\mathrm{g} / \mathrm{m}^{2} / \text { day }\right]}\end{array}$ & Note & $\begin{array}{c}\text { Intercept } \\
{\left[\mathrm{g} / \mathrm{m}^{2}\right]}\end{array}$ & qualifier & $\begin{array}{l}\text { Time to } \\
\text { acceleration } \\
\text { [days] }\end{array}$ \\
\hline HLP-01 & 200 & 4.3 & $\mathrm{~b}$ & 178.6 & Between 9 and 33 & 33.0 \\
\hline HLP-01 & 250 & 263.7 & & 12.7 & Less than & 2.0 \\
\hline HLP-01 & 300 & 928.6 & & 401.3 & Less than & 0.5 \\
\hline HLP-02 & 125 & 2.4 & & -276.1 & Roughly & 150.0 \\
\hline HLP-02 & 150 & 5.1 & & 337.7 & Less than & 28.0 \\
\hline \begin{tabular}{|l|} 
HLP-02 \\
\end{tabular} & 200 & 264.7 & & 76.0 & Less than & 0.5 \\
\hline HLP-03 & 200 & 0.9 & $\mathrm{~b}$ & 263.4 & Less than & 8.8 \\
\hline HLP-03 & 250 & 56.4 & & 635.3 & Less than & 6.0 \\
\hline HLP-03 & 300 & 509.7 & $\mathrm{~d}$ & - & Less than & 3.0 \\
\hline HLP-04 & 200 & 53.0 & & 177.1 & Less than & 3.0 \\
\hline \begin{tabular}{|l|} 
HLP-05 \\
\end{tabular} & 200 & 2.7 & $\mathrm{~b}, \mathrm{f}$ & 117.2 & Less than & 8.8 \\
\hline HLP-05 & 250 & 595.5 & & 105.0 & Less than & 1.0 \\
\hline HLP-05 & 300 & 703.2 & $\mathrm{~d}$ & - & Less than & 3.0 \\
\hline HLP-06 & 200 & 2.1 & $\mathrm{a}, \mathrm{f}$ & $409.36 *$ & Less than & 5.0 \\
\hline HLP-06 & 275 & 219.8 & & 456.9 & Less than & 2.0 \\
\hline \begin{tabular}{|l|} 
HLP-06 \\
\end{tabular} & 300 & 523.3 & $\mathrm{~d}$ & - & Less than & 3.0 \\
\hline HLP-07 & 200 & 13.8 & & 341.4 & Less than & 13.0 \\
\hline HLP-08 & 200 & 7.2 & & 231.4 & Less than & 16.0 \\
\hline \begin{tabular}{|l|} 
HLP-09 \\
\end{tabular} & 200 & 1.2 & $\mathrm{~b}$ & 414.4 & Roughly & 19.0 \\
\hline \begin{tabular}{|l|} 
HLP-09 \\
\end{tabular} & 250 & 60.1 & & 914.0 & Less than & 5.0 \\
\hline \begin{tabular}{|l|} 
HLP-09 \\
\end{tabular} & 275 & 343.9 & & 413.7 & Less than & 1.0 \\
\hline \begin{tabular}{|l|} 
HLP-09 \\
\end{tabular} & 300 & 409.3 & & 421.3 & Less than & 1.0 \\
\hline HLP-10 & 200 & 11.7 & & 17.7 & Less than & 3.0 \\
\hline \begin{tabular}{|l|} 
HLP-10 \\
\end{tabular} & 250 & 298.6 & & 103.7 & Less than & 2.0 \\
\hline \begin{tabular}{|l|} 
HLP-10 \\
\end{tabular} & 300 & 541.8 & $\mathrm{e}$ & 874.3 & Less than & 1.0 \\
\hline HLP-11 & 200 & 6.0 & & 739.5 & Roughly & 13 \\
\hline HLP-11 & 300 & 643.5 & $\mathrm{e}$ & - & Less than & 3 \\
\hline HLP-12 & 200 & 13.6 & & 263.2 & Less than & 7 \\
\hline \begin{tabular}{|l|} 
HLP-12 \\
\end{tabular} & 250 & 258.9 & & -10.0 & Less than & 2 \\
\hline HLP-12 & 300 & 1126.3 & & -141.1 & Less than & 0.5 \\
\hline HLP-13 & 200 & 2.1 & & 459.6 & Between 16 and 31 & 16 \\
\hline HLP-13 & 275 & 212.7 & $\mathrm{a}$ & 825.2 & Less than & 2 \\
\hline HLP-13 & 300 & 640.0 & $\mathrm{~d}$ & - & Less than & 3 \\
\hline \begin{tabular}{|l|} 
HLP-14 \\
\end{tabular} & 200 & 18.4 & & 382.1 & Between 9 and 16 & 9 \\
\hline HLP-15 & 200 & 1.4 & $\mathrm{~b}$ & 125.1 & Less than & 16 \\
\hline HLP-15 & 275 & 132.9 & & 510.7 & Less than & 2 \\
\hline HLP-15 & 300 & 517.3 & $\mathrm{~d}$ & - & Less than & 3 \\
\hline HLP-16 & 200 & 7.6 & $\mathrm{~b}$ & 217.5 & Less than & 16 \\
\hline HLP-16 & 250 & 286.1 & & 95.4 & Less than & 2 \\
\hline HLP-16 & 275 & 604.2 & $\mathrm{~d}$ & - & Less than & 3 \\
\hline HLP-16 & 300 & 670.1 & $\mathrm{~d}$ & - & Less than & 3 \\
\hline HLP-17 & 200 & 2.4 & & 81.2 & Less than & 16 \\
\hline
\end{tabular}

C.1 


\begin{tabular}{|c|c|c|c|c|c|c|}
\hline Glass ID & $\begin{array}{l}\text { Temp } \\
{\left[{ }^{\circ} \mathrm{C}\right]}\end{array}$ & $\begin{array}{c}\text { Rate } \\
{\left[\mathrm{g} / \mathrm{m}^{2} / \text { day }\right]}\end{array}$ & Note & $\begin{array}{c}\text { Intercept } \\
{\left[\mathrm{g} / \mathrm{m}^{2}\right]}\end{array}$ & qualifier & $\begin{array}{l}\text { Time to } \\
\text { acceleration } \\
\text { [days] }\end{array}$ \\
\hline HLP-17 & 250 & 103.7 & & 625.8 & Less than & 5 \\
\hline HLP-18 & 200 & 16.7 & & 347.0 & Very close & 8 \\
\hline HLP-19 & 200 & 0.0 & $\mathrm{~b}$ & & More than & 90 \\
\hline HLP-19 & 300 & 170.9 & & 275.6 & Less than & 2 \\
\hline HLP-20 & 200 & 1.5 & $\mathrm{~b}$ & 420.7 & Between 30 and 50 & 30 \\
\hline HLP-20 & 250 & 104.3 & $\mathrm{a}$ & 554.6 & Less than & 5 \\
\hline HLP-20 & 300 & 226.8 & $\mathrm{~d}$ & & Less than & 3 \\
\hline HLP-21 & 200 & 7.2 & & 36.0 & Between 16 and 30 & 16 \\
\hline HLP-21 & 250 & 370.7 & & -111.7 & Less than & 2 \\
\hline HLP-22 & 200 & 0.3 & $\mathrm{~b}$ & 84.4 & Less than & 16 \\
\hline HLP-22 & 275 & 58.4 & & 413.0 & Less than & 4 \\
\hline HLP-22 & 300 & 308.5 & $\mathrm{~d}$ & - & Less than & 3 \\
\hline HLP-23 & 200 & 19.9 & & 738.3 & Roughly & 6 \\
\hline HLP-24 & 200 & 1.7 & $\mathrm{~b}$ & 209.5 & Roughly & 9 \\
\hline HLP-24 & 275 & 204.3 & $\mathrm{a}$ & - & Between 3 and 5 & 3 \\
\hline HLP-24 & 300 & 323.9 & $\mathrm{~d}$ & - & Less than & 3 \\
\hline HLP-25 & 200 & 4.2 & $\mathrm{~b}$ & 256.0 & Between 6 and 12 & 6 \\
\hline HLP-25 & 250 & 291.9 & & 23.6 & Less than & 2 \\
\hline HLP-25 & 300 & 736.9 & & 518.0 & Less than & 1 \\
\hline HLP-26 & 200 & 1.2 & $\mathrm{~b}$ & 463.6 & Between 6 and 24 & 6 \\
\hline HLP-26 & 250 & 224.2 & & 210.0 & Less than & 2 \\
\hline HLP-26 & 300 & 760.6 & & 426.1 & Less than & 0.5 \\
\hline HLP-27 & 200 & 67.4 & & 1167.9 & Roughly & 1 \\
\hline HLP-28 & 200 & 6.7 & & 208.5 & Roughly & 2 \\
\hline HLP-28 & 275 & 89.9 & & 225.8 & Less than & 4 \\
\hline HLP-28 & 300 & 247.6 & & 184.0 & Less than & 2 \\
\hline HLP-29 & 200 & 56.6 & & 747.8 & Less than & 3 \\
\hline HLP-30 & 200 & 10.0 & $\mathrm{f}$ & 842.4 & between 2 and 12 & 2 \\
\hline HLP-30 & 250 & 83.2 & & -0.8 & less than & 3 \\
\hline HLP-31 & 175 & 4.3 & $\mathrm{c}$ & 874.8 & less than & 24.0 \\
\hline HLP-31 & 200 & 100.5 & $\mathrm{c}$ & 799.6 & roughly & 2.0 \\
\hline HLP-32 & 200 & 0.2 & $\mathrm{~b}$ & 53.7 & between 7 and 13 & 7.0 \\
\hline HLP-32 & 275 & 65.0 & & 476.4 & less than & 2.0 \\
\hline HLP-32 & 300 & 477.7 & $\mathrm{~d}$ & - & less than & 3.0 \\
\hline HLP-33 & 200 & 22.3 & & 1013.1 & roughly & 6.0 \\
\hline HLP-33 & 250 & 1930.0 & $\mathrm{~d}$ & - & less than & 1.0 \\
\hline HLP-33 & 300 & 2050.0 & $\mathrm{~d}$ & - & Less than & 1.0 \\
\hline HLP-34 & 200 & 0.0 & $\mathrm{~b}$ & 131.3 & & \\
\hline HLP-34 & 300 & 86.5 & & 258.1 & less than & 2.0 \\
\hline HLP-35 & 200 & 13.0 & & 914.3 & roughly & 2.0 \\
\hline HLP-36 & 200 & 13.8 & $\mathrm{~g}$ & 162.7 & between 9 and 16 & 9.0 \\
\hline HLP-36 & 250 & 227.9 & $\mathrm{~g}$ & 614.7 & less than & 1.0 \\
\hline HLP-37 & 200 & 2.0 & $\mathrm{~g}$ & 373.1 & roughly & 24.0 \\
\hline HLP-37 & 250 & 817.0 & $\mathrm{a}, \mathrm{g}$ & 440.7 & less than & 1.0 \\
\hline HLP-37Q & 250 & 1907.0 & $\mathrm{a}$ & - & less than & 0.5 \\
\hline
\end{tabular}




\begin{tabular}{|c|c|c|c|c|c|c|}
\hline Glass ID & $\begin{array}{l}\text { Temp } \\
{\left[{ }^{\circ} \mathrm{C}\right]}\end{array}$ & $\begin{array}{c}\text { Rate } \\
{\left[\mathrm{g} / \mathrm{m}^{2} / \text { day }\right]}\end{array}$ & Note & $\begin{array}{c}\text { Intercept } \\
{\left[\mathrm{g} / \mathrm{m}^{2}\right]}\end{array}$ & qualifier & $\begin{array}{l}\text { Time to } \\
\text { acceleration } \\
\text { [days] }\end{array}$ \\
\hline HLP-38 & 200 & 8.4 & $\mathrm{~g}$ & 356.0 & between 7 and 13 & 7.0 \\
\hline HLP-38 & 250 & 96.0 & $\mathrm{a}, \mathrm{g}$ & 995.4 & less than & 5.0 \\
\hline HLP-38H & 250 & 261.2 & $a, g$ & 183.3 & Less than & 2.0 \\
\hline HLP-39 & 200 & 8.4 & $\mathrm{c}, \mathrm{f}$ & -16.6 & between 5 and 10 & 5.0 \\
\hline HLP-39 & 250 & 709.4 & & 610.0 & less than & 0.5 \\
\hline HLP-39 & 300 & 2219.9 & $\mathrm{~d}$ & - & less than & 1.0 \\
\hline HLP-40 & 200 & 1.5 & $\mathrm{~g}$ & 80.2 & less than & 50.0 \\
\hline HLP-40 & 275 & 204.4 & $c, g$ & -1190.7 & between 5 and 10 & 5.0 \\
\hline HLP-40 & 300 & 708.6 & $\mathrm{~d}, \mathrm{~g}$ & - & less than & 3.0 \\
\hline HLP-40Q & 275 & 111.6 & & -144.0 & less than & 5.0 \\
\hline HLP-41 & 200 & 9.9 & $\mathrm{~g}$ & -96.2 & between 12 and 36 & 12.0 \\
\hline HLP-41 & 250 & 729.5 & $\mathrm{~d}, \mathrm{~g}$ & - & Less than & 3.0 \\
\hline HLP-41 & 300 & 2125.9 & $\mathrm{~d}, \mathrm{~g}$ & - & Less than & 1.0 \\
\hline HLP-41Q & 250 & 669.1 & $\mathrm{~d}$ & - & Less than & 3.0 \\
\hline HLP-42 & 200 & 0.0 & $\mathrm{c,g}$ & 0.0 & Between 7 and 13 & 7.0 \\
\hline HLP-42 & 250 & 47.2 & $\mathrm{c}, \mathrm{g}$ & -84.7 & Between 3 and 5 & 3.0 \\
\hline HLP-42 & 300 & 701.4 & $\mathrm{c}, \mathrm{d}, \mathrm{g}$ & - & Less than & 3.0 \\
\hline HLP-43 & 200 & 4.6 & $\mathrm{~b}$ & 167.5 & between 2 and 6 & 5.0 \\
\hline HLP-43 & 250 & 233.5 & & 157.2 & Less than & 2.0 \\
\hline HLP-43 & 300 & 832.2 & & 352.6 & Less than & 0.5 \\
\hline HLP-44 & 200 & 4.9 & & 221.2 & Less than & 30.0 \\
\hline HLP-44 & 250 & 218.2 & & 390.1 & Less than & 2.0 \\
\hline HLP-45 & 200 & 5.2 & $\mathrm{c}$ & 311.1 & More than & 30.0 \\
\hline HLP-45 & 250 & 219.8 & & 763.0 & Less than & 2.0 \\
\hline HLP-46 & 90 & $0.0126^{*}$ & $\mathrm{a}$ & - & less than & 500.0 \\
\hline HLP-46 & 125 & 0.2 & $\mathrm{a}$ & -6.2 & less than & 91.0 \\
\hline HLP-46 & 150 & 18.6 & $\mathrm{f}$ & 942.5 & roughly & 5.0 \\
\hline HLP-46 & 175 & 87.2 & & 743.3 & Less than & 2.0 \\
\hline HLP-46 & 200 & 254.6 & & 663.9 & Less than & 1.0 \\
\hline HLP-47 & 200 & 60.7 & $\mathrm{c}$ & 285.8 & Less than & 5.0 \\
\hline HLP-47S & 200 & 67.2 & $\mathrm{c}$ & 533.5 & Less than & 5.0 \\
\hline \begin{tabular}{|l|} 
HLP-48 \\
\end{tabular} & 150 & 3.4 & & 291.3 & Less than & 70.0 \\
\hline HLP-48 & 175 & 13.7 & & 686.1 & Less than & 15.0 \\
\hline HLP-48 & 200 & 50.5 & & 561.0 & Less than & 7.0 \\
\hline HLP-48 & 250 & 522.2 & & 454.0 & Less than & 1.0 \\
\hline HLP-49 & 200 & 2.4 & $b, g$ & 544.1 & Less than & 7.0 \\
\hline HLP-49 & 250 & 119.9 & $\mathrm{e}, \mathrm{g}$ & - & Less than & 8.0 \\
\hline HLP-49 & 275 & 996.3 & $\mathrm{~d}, \mathrm{~g}$ & - & Less than & 2.0 \\
\hline HLP-49 & 300 & 708.6 & $\mathrm{~d}, \mathrm{~g}$ & - & Less than & 3.0 \\
\hline HLP-49Q & 250 & 100.7 & $\mathrm{a}$ & 303.1 & Roughly & 2.0 \\
\hline \begin{tabular}{|l|} 
HLP-51 \\
\end{tabular} & 150 & 3.0 & $\mathrm{~b}$ & -19.9 & Less than & 75.0 \\
\hline HLP-51 & 200 & 4.0 & $\mathrm{~b}$ & 424.5 & Less than & 6.0 \\
\hline HLP-51 & 250 & 44.3 & & 799.2 & Less than & 5.0 \\
\hline HLP-51 & 275 & 129.3 & & 626.2 & Less than & 2.0 \\
\hline HLP-51 & 300 & 336.4 & & 331.5 & Less than & 1.0 \\
\hline
\end{tabular}




\begin{tabular}{|l|c|c|c|c|c|c|}
\hline Glass ID & $\begin{array}{c}\text { Temp } \\
{\left[{ }^{\circ} \mathrm{C}\right]}\end{array}$ & $\begin{array}{c}\text { Rate } \\
{\left[\mathrm{g} / \mathrm{m}^{2} / \mathrm{day}\right]}\end{array}$ & Note & $\begin{array}{c}\text { Intercept } \\
{\left[\mathrm{g} / \mathrm{m}^{2}\right]}\end{array}$ & qualifier & $\begin{array}{c}\text { Time to } \\
\text { acceleration } \\
\text { [days }]\end{array}$ \\
\hline HLP-52 & 125 & 15.5 & & 643.5 & roughly & 20.0 \\
\hline HLP-52 & 150 & 196.5 & & -498.6 & Less than & 7.0 \\
\hline HLP-52 & 200 & 1219.4 & & -15.9 & Less than & 0.5 \\
\hline HLP-53Q & 175 & 177.7 & & 624.4 & Between 2 and 4 & 2.0 \\
\hline HLP-53Q & 200 & 552.6 & $\mathrm{e}$ & 267.2 & Roughly & 1.5 \\
\hline HLP-54 & 200 & 21.4 & & 775.2 & Less than & 7.0 \\
\hline HLP-55 & 200 & 42.1 & & 653.3 & Less than & 7.0 \\
\hline HLP-56 & 200 & 1.9 & $\mathrm{~b}$ & -35.7 & More than & 122.0 \\
\hline HLP-56 & 250 & 76.5 & & 500.5 & Less than & 3.0 \\
\hline HLP-56 & 300 & 603.0 & & 369.3 & Less than & 1.0 \\
\hline HLP-58 & 200 & 2.2 & $\mathrm{~b}$ & 11.426 & Less than & 15 \\
\hline HLP-59 & 200 & 4.5 & $\mathrm{a}$ & -34.301 & Less than & 12 \\
\hline HLP-60 & 200 & 5.6 & $\mathrm{c}, \mathrm{g}$ & - & Between 28 and 44 & 36 \\
\hline HLP-61 & 200 & 10.0 & $\mathrm{f}$ & -72.404 & Between 15 and 30 & 15 \\
\hline HLP-62 & 200 & 1.7 & $\mathrm{c}$ & -31.051 & More than & 56 \\
\hline HLP-63 & 200 & 1707.6 & $\mathrm{e}$ & -1394.1 & Less than & 1 \\
\hline HLP-64 & 200 & 12.4 & $\mathrm{a}$ & -127.75 & Between 15 and 30 & 15 \\
\hline HLP-65 & 200 & 4.3 & & 36.996 & More than & 55 \\
\hline HLP-66 & 200 & 136.9 & $\mathrm{~d}$ & - & Less than & 1 \\
\hline HLP-67 & 200 & 230.5 & & 866.15 & Less than & 1 \\
\hline HLP-68 & 200 & 5.7 & & 77.036 & Between 14 and 28 & 21 \\
\hline HLP-69 & 200 & 3.8 & & 88.088 & More than & 54 \\
\hline HLP-70 & 200 & & $\mathrm{c}, \mathrm{g}$ & & & \\
\hline HLP-71 & 200 & & $\mathrm{c}, \mathrm{g}$ & & & \\
\hline HLP-72 & 200 & 9.6 & $\mathrm{a}, \mathrm{g}$ & 246.61 & Between 15 and 22 & 15 \\
\hline HLP-73 & 200 & & $\mathrm{~g}$ & & & 14 \\
\hline HLP-74 & 200 & 8.0 & $\mathrm{~g}$ & 273.16 & Less than & 14 \\
\hline HLP-75 & 200 & 7.9 & & 230.91 & Less than & 14 \\
\hline HLP-76 & 200 & 140.9 & $\mathrm{a}, \mathrm{c}$ & -179.41 & Less than & 5 \\
\hline HLP-77 & 200 & 176.4 & $\mathrm{a}, \mathrm{c}$ & -503.49 & Less than & 5 \\
\hline & & & & & & \\
\hline
\end{tabular}

Notes

Not enough data to accurately determine the alteration rate

Sufficient alteration was not achieved before significant water loss

Sample analyses difficulties

Rate based on single value

Rate based on two values

Outlying data point(s) were removed from fit

Grossly crystallized glass 
Table C-2. VHT Responses for HLP Glasses

\begin{tabular}{|c|c|c|c|c|c|c|c|c|}
\hline Glass ID & $\mathrm{T}\left({ }^{\circ} \mathrm{C}\right)$ & $t(d)$ & $\mathrm{vH}_{2} \mathrm{O}(\mathrm{mL})$ & $\mathrm{H}_{2} \mathrm{O}$ loss $(\mathrm{mL})$ & $\mathrm{pH}$ Out & $m_{a}\left(g / m^{2}\right)$ & $2 \sigma\left(\mathrm{g} / \mathrm{m}^{2}\right)$ & notes \\
\hline HLP-01 & 200 & 3.0 & 0.26 & -0.03 & 10.0 & 153.1 & 1.5 & \\
\hline HLP-01 & 200 & 8.8 & 0.26 & -0.04 & 10.0 & 204.8 & 1.1 & \\
\hline HLP-01 & 200 & 32.8 & 0.26 & -0.07 & 6.0 & 231.9 & 8.1 & \\
\hline HLP-01 & 200 & 36.5 & 0.25 & -0.06 & 10.0 & 433.6 & 9.8 & \\
\hline HLP-01 & 200 & 36.6 & 0.27 & -0.06 & 8.0 & 392.1 & 9.5 & \\
\hline HLP-01 & 200 & 60.0 & 0.20 & -0.06 & 7.5 & 730.6 & 9.5 & 7 \\
\hline HLP-01 & 200 & 76.0 & 0.20 & -0.12 & 7.0 & 421.7 & 5.1 & 7 \\
\hline HLP-01 & 200 & 81.0 & 0.20 & -0.08 & 6.0 & 676.2 & 10.4 & 7 \\
\hline HLP-01 & 200 & 127.5 & 0.25 & -0.18 & 5.0 & 700.9 & 29.4 & \\
\hline HLP-01 & 200 & 160.0 & 0.20 & -0.15 & 7.0 & 534.5 & 5.0 & 3 \\
\hline HLP-01 & 200 & 199.6 & 0.25 & -0.21 & 7.0 & 790.9 & 36.7 & 3 \\
\hline HLP-01 & 200 & 299.5 & 0.26 & -0.25 & - & 735.4 & 36.0 & 3 \\
\hline HLP-01 & 200 & 369.5 & 0.26 & -0.26 & - & 710.5 & 24.8 & 3 \\
\hline HLP-01 & 200 & 374.5 & 0.25 & -0.26 & - & 534.0 & 6.7 & 3 \\
\hline HLP-01 & 200 & 374.5 & 0.25 & -0.26 & - & 534.0 & 6.7 & 3 \\
\hline HLP-01 & 200 & 379.5 & 0.25 & -0.27 & - & 557.6 & 7.2 & 3 \\
\hline HLP-01 & 250 & 2.0 & 0.45 & -0.03 & 5.5 & 547.4 & 7.0 & \\
\hline HLP-01 & 250 & 3.0 & 0.45 & -0.04 & 7.0 & 830.5 & 13.6 & \\
\hline HLP-01 & 250 & 4.0 & 0.45 & -0.08 & 7.0 & 987.5 & 18.5 & \\
\hline HLP-01 & 250 & 5.0 & 0.45 & -0.05 & 7.5 & 1384.2 & 55.4 & \\
\hline HLP-01 & 250 & 5.9 & 0.45 & -0.06 & 10.0 & 1561.4 & 146.6 & \\
\hline HLP-01 & 250 & 10.0 & 0.45 & -0.09 & 8.0 & 1796.2 & 129.3 & 1 \\
\hline HLP-01 & 250 & 14.0 & 0.45 & -0.10 & 8.5 & 1955.6 & - & 1 \\
\hline HLP-01 & 300 & 0.5 & 0.80 & -0.03 & 5.5 & 865.5 & 6.0 & \\
\hline HLP-01 & 300 & 1.0 & 0.85 & -0.03 & 8.0 & 1330.0 & 32.0 & \\
\hline HLP-01 & 300 & 1.5 & 0.85 & -0.04 & 9.0 & 1794.1 & 190.6 & \\
\hline HLP-01 & 300 & 2.0 & 0.85 & -0.04 & 9.0 & 1894.7 & - & 1 \\
\hline HLP-01 & 300 & 2.5 & 0.85 & -0.04 & 8.5 & 1915.4 & - & 1 \\
\hline HLP-01 & 300 & 3.1 & 0.85 & -0.27 & 10.0 & 1785.3 & - & 1 \\
\hline HLP-02 & 125 & 150.9 & 0.08 & -0.02 & 9.5 & 9.2 & 0.0 & \\
\hline HLP-02 & 125 & 189.9 & 0.08 & -0.02 & 9.5 & 70.4 & 0.3 & \\
\hline HLP-02 & 125 & 235.0 & 0.08 & -0.03 & 10.0 & 491.2 & 20.2 & \\
\hline HLP-02 & 125 & 277.0 & 0.08 & -0.02 & - & 415.8 & 11.7 & \\
\hline HLP-02 & 125 & 319.0 & 0.08 & -0.02 & - & 549.3 & 10.8 & \\
\hline HLP-02 & 125 & 362.0 & 0.08 & -0.03 & - & 438.0 & 9.2 & \\
\hline HLP-02 & 150 & 28.0 & 0.10 & -0.02 & 9.5 & 555.2 & 23.9 & \\
\hline HLP-02 & 150 & 38.0 & 0.10 & -0.02 & 9.0 & 537.1 & 17.8 & \\
\hline HLP-02 & 150 & 47.0 & 0.10 & -0.02 & 9.5 & 671.5 & 48.7 & \\
\hline HLP-02 & 150 & 53.0 & 0.10 & -0.02 & 10.0 & 566.7 & 26.2 & \\
\hline HLP-02 & 150 & 63.0 & 0.10 & -0.03 & 10.0 & 581.4 & 19.6 & \\
\hline HLP-02 & 150 & 70.0 & 0.10 & -0.02 & 10.0 & 612.5 & 34.9 & \\
\hline HLP-02 & 150 & 99.0 & 0.10 & -0.03 & 10.0 & 779.7 & 28.1 & \\
\hline HLP-02 & 150 & 151.0 & 0.10 & -0.03 & - & 1163.1 & 165.3 & \\
\hline HLP-02 & 150 & 200.0 & 0.10 & -0.02 & - & 1356.6 & 286.1 & \\
\hline HLP-02 & 200 & 0.5 & 0.25 & -0.02 & 10.0 & 207.1 & 2.1 & \\
\hline HLP-02 & 200 & 1.0 & 0.25 & -0.02 & - & 351.3 & 21.9 & \\
\hline HLP-02 & 200 & 1.6 & 0.25 & -0.01 & 10.0 & 556.9 & 49.2 & \\
\hline HLP-02 & 200 & 3.0 & 0.25 & -0.02 & 8.0 & 777.5 & 122.0 & \\
\hline HLP-02 & 200 & 3.0 & 0.25 & -0.02 & 8.0 & 856.5 & 70.1 & \\
\hline HLP-02 & 200 & 5.0 & 0.25 & -0.02 & 8.0 & 1423.1 & 227.7 & \\
\hline
\end{tabular}




\begin{tabular}{|c|c|c|c|c|c|c|c|c|}
\hline Glass ID & $\mathrm{T}\left({ }^{\circ} \mathrm{C}\right)$ & $t(d)$ & $\mathrm{vH}_{2} \mathrm{O}(\mathrm{mL})$ & $\mathrm{H}_{2} \mathrm{O}$ loss $(\mathrm{mL})$ & $\mathrm{pH}$ Out & $m_{a}\left(g / m^{2}\right)$ & $2 \sigma\left(\mathrm{g} / \mathrm{m}^{2}\right)$ & notes \\
\hline HLP-02 & 200 & 8.8 & 0.26 & -0.04 & 10.0 & 1883.8 & - & 1 \\
\hline HLP-03 & 200 & 8.8 & 0.25 & -0.03 & 10.0 & 234.9 & 3.9 & \\
\hline HLP-03 & 200 & 17.0 & 0.26 & -0.04 & 10.0 & 342.6 & 6.2 & \\
\hline HLP-03 & 200 & 36.5 & 0.25 & -0.06 & 10.0 & 305.9 & 1.7 & \\
\hline HLP-03 & 200 & 36.6 & 0.27 & -0.06 & 8.0 & 253.9 & 3.0 & \\
\hline HLP-03 & 200 & 127.5 & 0.25 & -0.18 & 5.0 & 396.1 & 4.4 & \\
\hline HLP-03 & 200 & 199.6 & 0.25 & -0.21 & 7.0 & 441.9 & 5.2 & \\
\hline HLP-03 & 200 & 299.5 & 0.26 & -0.25 & - & 445.3 & 22.7 & 3 \\
\hline HLP-03 & 200 & 369.5 & 0.26 & -0.26 & - & 495.5 & 9.0 & 3 \\
\hline HLP-03 & 200 & 374.5 & 0.25 & -0.26 & - & 848.1 & 65.7 & 3 \\
\hline HLP-03 & 200 & 379.5 & 0.25 & -0.27 & - & 806.2 & 26.7 & 3 \\
\hline HLP-03 & 250 & 6.0 & 0.45 & -0.06 & 5.5 & 912.2 & 7.5 & \\
\hline HLP-03 & 250 & 10.0 & 0.45 & -0.08 & 5.5 & 1260.1 & 46.9 & \\
\hline HLP-03 & 250 & 14.0 & 0.45 & -0.09 & 10.0 & 1488.2 & 100.5 & \\
\hline HLP-03 & 250 & 18.0 & 0.45 & -0.12 & 6.0 & 1588.3 & 157.7 & \\
\hline HLP-03 & 300 & 3.0 & 0.80 & -0.06 & 5.5 & 1530.9 & 87.0 & \\
\hline HLP-04 & 200 & 3.0 & 0.26 & -0.03 & 10.0 & 377.2 & 2.2 & \\
\hline HLP-04 & 200 & 8.8 & 0.25 & -0.03 & 10.0 & 853.7 & 47.3 & \\
\hline HLP-04 & 200 & 16.0 & 0.26 & -0.03 & 10.0 & 904.0 & 202.9 & \\
\hline HLP-04 & 200 & 16.0 & 0.25 & -0.02 & 6.0 & 930.6 & 204.9 & \\
\hline HLP-04 & 200 & 17.0 & 0.26 & -0.04 & 10.0 & 879.2 & 34.7 & \\
\hline HLP-04 & 200 & 30.0 & 0.20 & -0.04 & 8.5 & 1925.7 & - & 2 \\
\hline HLP-04 & 200 & 41.0 & 0.25 & -0.03 & 10.0 & 1775.2 & 319.5 & 1 \\
\hline HLP-04 & 200 & 65.0 & 0.25 & -0.05 & 8.5 & 1947.4 & - & 1 \\
\hline HLP-04 & 200 & 83.1 & 0.25 & -0.08 & 7.0 & 2033.0 & - & 1 \\
\hline HLP-05 & 200 & 3.0 & 0.26 & -0.02 & 8.0 & 0.0 & - & 4 \\
\hline HLP-05 & 200 & 8.8 & 0.25 & -0.03 & 5.8 & 443.6 & 4.5 & 5 \\
\hline HLP-05 & 200 & 8.8 & 0.30 & -0.08 & 6.0 & 126.6 & 1.2 & \\
\hline HLP-05 & 200 & 12.0 & 0.27 & -0.03 & 5.8 & 125.1 & 14.5 & \\
\hline HLP-05 & 200 & 12.9 & 0.26 & -0.03 & 6.0 & 190.2 & 1.9 & \\
\hline HLP-05 & 200 & 13.9 & 0.26 & -0.03 & 8.0 & 479.6 & 11.1 & 6 \\
\hline HLP-05 & 200 & 23.7 & 0.26 & -0.03 & 6.0 & 187.6 & 1.9 & \\
\hline HLP-05 & 200 & 23.7 & 0.26 & -0.05 & 6.0 & 236.6 & 2.4 & \\
\hline HLP-05 & 200 & 41.0 & 0.25 & -0.06 & 8.5 & 207.0 & 3.4 & \\
\hline HLP-05 & 200 & 70.0 & 0.25 & -0.10 & 9.5 & 283.7 & - & \\
\hline HLP-05 & 200 & 100.0 & 0.25 & -0.13 & 10.0 & 311.0 & - & \\
\hline HLP-05 & 200 & 169.8 & 0.25 & -0.12 & 9.0 & 612.9 & 17.5 & \\
\hline HLP-05 & 250 & 1.0 & 0.45 & -0.03 & 6.0 & 673.4 & 14.1 & \\
\hline HLP-05 & 250 & 2.0 & 0.45 & -0.04 & 7.5 & 1350.1 & 266.8 & \\
\hline HLP-05 & 250 & 3.0 & 0.45 & -0.04 & 6.0 & 1864.3 & 122.0 & \\
\hline HLP-05 & 250 & 5.0 & 0.45 & -0.05 & 6.0 & 1958.1 & - & 1 \\
\hline HLP-05 & 250 & 8.0 & 0.45 & -0.07 & 9.0 & 2011.2 & - & 1 \\
\hline HLP-05 & 250 & 13.0 & 0.45 & -0.11 & 9.0 & 2034.4 & - & 1 \\
\hline HLP-05 & 250 & 18.0 & 0.45 & -0.13 & 5.5 & 1882.0 & - & 1 \\
\hline HLP-05 & 250 & 23.0 & 0.45 & -0.18 & 6.0 & 1873.8 & - & 1 \\
\hline HLP-05 & 250 & 27.0 & 0.45 & -0.19 & 5.5 & 2041.6 & - & 1 \\
\hline HLP-05 & 300 & 3.0 & 0.80 & -0.06 & 8.0 & 2109.5 & - & 2 \\
\hline HLP-06 & 200 & 3.0 & 0.26 & -0.02 & 8.0 & 278.0 & 2.9 & 9 \\
\hline HLP-06 & 200 & 5.1 & 0.25 & -0.02 & 10.0 & 394.5 & 13.2 & 8 \\
\hline HLP-06 & 200 & 8.8 & 0.25 & -0.03 & 5.8 & 811.2 & 26.0 & 9 \\
\hline HLP-06 & 200 & 13.9 & 0.26 & -0.03 & 8.0 & 1177.7 & 62.4 & 9 \\
\hline
\end{tabular}




\begin{tabular}{|c|c|c|c|c|c|c|c|c|}
\hline Glass ID & $\mathrm{T}\left({ }^{\circ} \mathrm{C}\right)$ & $t(d)$ & $\mathrm{vH}_{2} \mathrm{O}(\mathrm{mL})$ & & pH Out & $m_{a}\left(g / m^{2}\right)$ & $2 \sigma\left(\mathrm{g} / \mathrm{m}^{2}\right)$ & notes \\
\hline HLP-06 & 200 & 16.0 & 0.25 & -0.03 & 10.0 & 424.5 & 12.2 & 8 \\
\hline HLP-06 & 200 & 21.7 & 0.25 & -0.04 & 10.0 & 427.0 & 7.7 & 8 \\
\hline HLP-06 & 200 & 30.0 & 0.20 & -0.06 & 9.5 & 979.2 & 34.8 & 8 \\
\hline HLP-06 & 200 & 32.8 & 0.25 & -0.04 & 8.0 & 524.8 & 13.5 & 8 \\
\hline HLP-06 & 200 & 60.0 & 0.20 & -0.06 & 6.0 & 1121.1 & 64.9 & 9 \\
\hline HLP-06 & 200 & 61.0 & 0.20 & -0.09 & 7.0 & 1149.6 & 52.7 & 8 \\
\hline HLP-06 & 200 & 81.0 & 0.20 & -0.09 & 6.0 & 1008.5 & 76.0 & 9 \\
\hline HLP-06 & 200 & 108.7 & 0.25 & -0.09 & 10.0 & 569.2 & 7.5 & 8 \\
\hline HLP-06 & 200 & 199.0 & 0.20 & -0.16 & 7.0 & 981.8 & 84.8 & 3 \\
\hline HLP-06 & 200 & 216.0 & 0.20 & -0.13 & 6.0 & 1435.1 & 288.4 & 8 \\
\hline HLP-06 & 200 & 220.0 & 0.20 & -0.17 & 6.0 & 987.5 & 711.0 & 3 \\
\hline HLP-06 & 200 & 225.0 & 0.20 & -0.16 & 6.0 & 1231.5 & 886.7 & 3 \\
\hline HLP-06 & 275 & 2.0 & 0.57 & -0.04 & 8.5 & 891.2 & 77.3 & \\
\hline HLP-06 & 275 & 3.0 & 0.62 & -0.06 & 9.0 & 1124.0 & 14.5 & \\
\hline HLP-06 & 275 & 5.0 & 0.62 & -0.08 & 6.5 & 1553.1 & 90.7 & \\
\hline HLP-06 & 275 & 9.0 & 0.62 & -0.18 & 9.5 & 1776.2 & 232.5 & 1 \\
\hline HLP-06 & 275 & 11.0 & 0.62 & -0.17 & 5.5 & 1912.7 & - & 1 \\
\hline HLP-06 & 300 & 3.0 & 0.80 & -0.05 & 5.5 & 1569.8 & 150.7 & \\
\hline HLP-07 & 200 & 12.9 & 0.26 & -0.03 & 5.8 & 326.3 & 3.6 & 5 \\
\hline HLP-07 & 200 & 16.0 & 0.25 & -0.03 & 6.0 & 329.1 & 3.7 & 5 \\
\hline HLP-07 & 200 & 21.7 & 0.26 & -0.03 & 10.0 & 552.1 & 10.2 & \\
\hline HLP-07 & 200 & 44.9 & 0.25 & -0.02 & 10.0 & 1117.6 & 80.5 & \\
\hline HLP-07 & 200 & 77.9 & 0.25 & 0.00 & 9.0 & 1350.2 & 155.5 & \\
\hline HLP-07 & 200 & 108.7 & 0.25 & -0.08 & 8.5 & 1846.8 & 398.9 & \\
\hline HLP-07 & 200 & 159.8 & 0.25 & -0.14 & 9.5 & 2034.6 & - & 1 \\
\hline HLP-08 & 200 & 16.0 & 0.25 & -0.03 & 6.0 & 167.6 & 2.4 & 5 \\
\hline HLP-08 & 200 & 21.7 & 0.26 & -0.03 & 10.0 & 307.6 & 8.4 & 5 \\
\hline HLP-08 & 200 & 44.9 & 0.25 & -0.02 & 10.0 & 532.2 & 10.3 & \\
\hline HLP-08 & 200 & 77.9 & 0.25 & 0.00 & 9.0 & 794.2 & 28.0 & \\
\hline HLP-08 & 200 & 108.7 & 0.25 & -0.08 & 8.5 & 1063.3 & 38.8 & \\
\hline HLP-08 & 200 & 159.8 & 0.25 & -0.14 & 9.5 & 1355.1 & 191.3 & \\
\hline HLP-09 & 200 & 8.8 & 0.26 & -0.04 & 6.0 & 343.1 & 3.8 & 5 \\
\hline HLP-09 & 200 & 19.0 & 0.25 & -0.04 & 6.0 & 49.3 & 0.2 & 5 \\
\hline HLP-09 & 200 & 19.0 & 0.24 & -0.04 & 6.0 & 304.5 & 3.2 & 5 \\
\hline HLP-09 & 200 & 26.7 & 0.26 & -0.06 & 6.0 & 200.6 & 4.2 & 5 \\
\hline HLP-09 & 200 & 26.7 & 0.25 & -0.06 & 6.0 & 213.9 & 1.1 & 5 \\
\hline HLP-09 & 200 & 32.8 & 0.26 & -0.07 & 6.0 & 493.7 & 6.1 & \\
\hline HLP-09 & 200 & 96.9 & 0.26 & -0.16 & 8.0 & 433.9 & 14.9 & \\
\hline HLP-09 & 200 & 150.9 & 0.25 & -0.69 & 8.5 & 679.5 & 19.4 & \\
\hline HLP-09 & 200 & 200.0 & 0.25 & 1.91 & 6.0 & 644.8 & 22.5 & \\
\hline HLP-09 & 200 & 299.7 & 0.25 & -0.25 & 6.0 & 339.9 & 1.9 & 3 \\
\hline HLP-09 & 250 & 5.0 & 0.45 & -0.05 & 9.0 & 1079.4 & 21.3 & \\
\hline HLP-09 & 250 & 6.0 & 0.45 & -0.06 & 6.5 & 1287.4 & 18.2 & \\
\hline HLP-09 & 250 & 7.0 & 0.45 & -0.07 & 5.5 & 1328.0 & 19.9 & \\
\hline HLP-09 & 250 & 10.0 & 0.45 & -0.08 & 5.5 & 1814.8 & 173.2 & \\
\hline HLP-09 & 250 & 13.0 & 0.45 & -0.08 & - & 1589.2 & 157.8 & \\
\hline HLP-09 & 250 & 15.0 & 0.45 & -0.15 & 6.0 & 1746.7 & 104.8 & \\
\hline HLP-09 & 250 & 17.0 & 0.45 & -0.13 & 8.0 & 1937.3 & - & 2 \\
\hline HLP-09 & 250 & 20.0 & 0.45 & -0.22 & 6.5 & 1653.8 & 132.3 & 3 \\
\hline HLP-09 & 275 & 1.0 & 0.62 & -0.03 & 8.0 & 646.6 & 7.1 & \\
\hline HLP-09 & 275 & 2.0 & 0.62 & -0.05 & 9.0 & 1213.6 & - & \\
\hline
\end{tabular}




\begin{tabular}{|c|c|c|c|c|c|c|c|c|}
\hline Glass ID & $\mathrm{T}\left({ }^{\circ} \mathrm{C}\right)$ & $t(d)$ & $\mathrm{vH}_{2} \mathrm{O}(\mathrm{mL})$ & & pH Out & $\mathrm{m}_{\mathrm{a}}\left(\mathrm{g} / \mathrm{m}^{2}\right)$ & $2 \sigma\left(\mathrm{g} / \mathrm{m}^{2}\right)$ & notes \\
\hline HLP-09 & 275 & 2.1 & 0.62 & -0.04 & 8.5 & 1197.9 & - & \\
\hline HLP-09 & 275 & 3.0 & 0.62 & -0.08 & 5.5 & 1403.9 & - & \\
\hline HLP-09 & 275 & 4.0 & 1.62 & -1.08 & 6.0 & 1752.4 & 105.1 & \\
\hline HLP-09 & 275 & 6.0 & 0.62 & -0.14 & 8.5 & 1925.3 & - & 1 \\
\hline HLP-09 & 275 & 7.0 & 0.62 & -0.12 & 8.5 & 1892.4 & - & 1 \\
\hline HLP-09 & 300 & 1.0 & 0.79 & -0.02 & 5.5 & 826.6 & 13.2 & \\
\hline HLP-09 & 300 & 2.0 & 0.80 & -0.05 & 5.5 & 1247.8 & 31.0 & \\
\hline HLP-09 & 300 & 3.0 & 0.80 & -0.04 & 5.0 & 1645.2 & 236.9 & \\
\hline HLP-09 & 300 & 3.0 & 0.80 & -0.06 & 8.0 & 1893.7 & - & 1 \\
\hline HLP-09 & 300 & 5.2 & 0.80 & -0.77 & 10.0 & 1083.6 & 33.0 & 1 \\
\hline HLP-10 & 200 & 3.0 & 0.27 & -0.03 & 5.8 & 117.4 & 0.6 & \\
\hline HLP-10 & 200 & 8.8 & 0.26 & -0.04 & 6.0 & 138.0 & 1.4 & \\
\hline HLP-10 & 200 & 32.8 & 0.26 & -0.07 & 6.0 & 238.0 & 2.4 & \\
\hline HLP-10 & 200 & 39.0 & 0.20 & -0.07 & 9.0 & 489.5 & 2.7 & \\
\hline HLP-10 & 200 & 60.0 & 0.20 & -0.08 & 7.0 & 770.9 & 6.0 & \\
\hline HLP-10 & 200 & 80.0 & 0.20 & -0.07 & 7.5 & 975.1 & 19.7 & \\
\hline HLP-10 & 200 & 130.5 & 0.25 & -0.15 & 10.0 & 555.8 & 3.4 & 3 \\
\hline HLP-10 & 200 & 179.7 & 0.25 & -0.18 & 5.5 & 765.4 & 11.6 & 3 \\
\hline HLP-10 & 200 & 259.5 & 0.26 & -0.21 & - & 542.1 & 13.7 & 3 \\
\hline HLP-10 & 200 & 349.6 & 0.26 & -0.23 & - & 809.5 & 36.8 & 3 \\
\hline HLP-10 & 200 & 375.5 & 0.25 & -0.25 & - & 592.7 & 7.5 & 3 \\
\hline HLP-10 & 200 & 379.5 & 0.25 & -0.25 & - & 521.1 & 9.3 & 3 \\
\hline HLP-10 & 200 & 389.5 & 0.26 & -0.25 & - & 742.1 & 23.7 & 3 \\
\hline HLP-10 & 200 & 389.5 & 0.20 & -0.20 & - & 1992.1 & - & 3 \\
\hline HLP-10 & 250 & 2.0 & 0.45 & -0.04 & 5.5 & 595.0 & 4.1 & \\
\hline HLP-10 & 250 & 3.0 & 0.45 & -0.03 & 8.5 & 1045.0 & 31.8 & \\
\hline HLP-10 & 250 & 4.0 & 1.46 & -0.05 & 8.0 & 1416.6 & 68.0 & \\
\hline HLP-10 & 250 & 5.0 & 0.45 & -0.05 & 5.5 & 1646.1 & 222.2 & \\
\hline HLP-10 & 250 & 6.0 & 0.45 & -0.06 & 8.0 & 1787.4 & 85.8 & \\
\hline HLP-10 & 250 & 10.0 & 0.45 & -0.07 & 5.5 & 1985.0 & - & 1 \\
\hline HLP-10 & 250 & 14.0 & 0.45 & -0.12 & 6.0 & 2033.3 & - & 1 \\
\hline HLP-10 & 250 & 21.0 & 0.45 & -0.18 & 5.5 & 1965.9 & - & 1 \\
\hline HLP-10 & 300 & 1.0 & 0.80 & -0.03 & 7.5 & 1416.1 & 70.3 & \\
\hline HLP-10 & 300 & 2.0 & 0.80 & -0.05 & 8.0 & 1958.0 & - & \\
\hline HLP-11 & 200 & 7.3 & 0.26 & -0.03 & 6.0 & 101.1 & 1.9 & 5 \\
\hline HLP-11 & 200 & 12.9 & 0.26 & 0.06 & 6.0 & 114.4 & 1.7 & 5 \\
\hline HLP-11 & 200 & 30.8 & 0.25 & -0.05 & 6.0 & 873.3 & - & \\
\hline HLP-11 & 200 & 49.0 & 0.25 & -0.09 & 7.5 & 1085.5 & 91.9 & \\
\hline HLP-11 & 200 & 70.0 & 0.25 & -0.09 & 8.0 & 1169.9 & 27.2 & \\
\hline HLP-11 & 200 & 88.0 & 0.25 & -0.10 & 6.5 & 1267.0 & 16.3 & \\
\hline HLP-11 & 200 & 120.0 & 0.25 & -0.13 & 5.5 & 1438.8 & 57.6 & \\
\hline HLP-11 & 200 & 301.0 & 0.25 & -0.20 & - & 1356.0 & 48.8 & 3 \\
\hline HLP-11 & 200 & 319.0 & 0.25 & -0.20 & 9.0 & 2016.0 & - & 3 \\
\hline HLP-11 & 300 & 3.0 & 0.80 & -0.04 & 6.0 & 1923.5 & - & \\
\hline HLP-11 & 300 & 3.1 & 0.85 & -0.45 & 10.0 & 2008.7 & - & 2 \\
\hline HLP-12 & 200 & 7.3 & 0.26 & -0.03 & 6.0 & 180.1 & 2.8 & 5 \\
\hline HLP-12 & 200 & 12.9 & 0.26 & -0.01 & 6.0 & 405.1 & 9.4 & \\
\hline HLP-12 & 200 & 16.0 & 0.26 & -0.03 & 10.0 & 483.5 & 8.1 & \\
\hline HLP-12 & 200 & 16.0 & 0.25 & -0.02 & 6.0 & 552.6 & 10.4 & \\
\hline HLP-12 & 200 & 41.0 & 0.25 & -0.03 & 10.0 & 837.4 & 13.5 & \\
\hline HLP-12 & 200 & 65.0 & 0.25 & -0.05 & 8.5 & 1043.0 & 42.3 & \\
\hline
\end{tabular}




\begin{tabular}{|c|c|c|c|c|c|c|c|c|}
\hline Glass ID & $\mathrm{T}\left({ }^{\circ} \mathrm{C}\right)$ & $t(d)$ & $\mathrm{vH}_{2} \mathrm{O}(\mathrm{mL})$ & & pH Out & $\mathrm{m}_{\mathrm{a}}\left(\mathrm{g} / \mathrm{m}^{2}\right)$ & $2 \sigma\left(\mathrm{g} / \mathrm{m}^{2}\right)$ & notes \\
\hline HLP-12 & 200 & 83.1 & 0.25 & -0.08 & 7.0 & 1347.6 & 82.6 & \\
\hline HLP-12 & 200 & 96.7 & 0.26 & -0.08 & 10.0 & 1677.2 & 155.8 & \\
\hline HLP-12 & 250 & 2.0 & 0.45 & -0.03 & 5.5 & 509.6 & 9.8 & \\
\hline HLP-12 & 250 & 4.0 & 0.45 & -0.05 & 6.0 & 1004.8 & 40.2 & \\
\hline HLP-12 & 250 & 5.0 & 0.45 & -0.06 & 5.5 & 1281.4 & 31.3 & \\
\hline HLP-12 & 250 & 6.0 & 0.45 & -0.06 & 5.5 & 1604.2 & 165.0 & \\
\hline HLP-12 & 250 & 7.0 & 0.45 & -0.05 & 5.0 & 1764.5 & 66.9 & \\
\hline HLP-12 & 300 & 0.5 & 0.80 & -0.03 & 6.0 & 508.0 & 15.8 & \\
\hline HLP-12 & 300 & 1.0 & 0.79 & -0.05 & 6.0 & 894.6 & 24.8 & \\
\hline HLP-12 & 300 & 1.5 & 0.80 & -0.06 & 6.0 & 1584.3 & 184.0 & \\
\hline HLP-12 & 300 & 2.1 & 0.82 & -0.14 & 6.0 & 1643.2 & 155.7 & 3 \\
\hline HLP-13 & 200 & 8.7 & 0.25 & -0.03 & 6.0 & 170.6 & 2.3 & 5 \\
\hline HLP-13 & 200 & 15.6 & 0.25 & -0.02 & 6.0 & 185.8 & 31.7 & 5 \\
\hline HLP-13 & 200 & 30.6 & 0.25 & -0.09 & 5.0 & 590.8 & 6.7 & \\
\hline HLP-13 & 200 & 60.0 & 0.20 & -0.08 & 5.5 & 476.6 & 3.0 & \\
\hline HLP-13 & 200 & 79.9 & 0.22 & -0.07 & 5.5 & 666.9 & 16.4 & \\
\hline HLP-13 & 200 & 97.9 & 0.25 & -0.07 & 8.0 & 801.0 & 7.3 & \\
\hline HLP-13 & 200 & 120.0 & 0.20 & -0.15 & 6.0 & 516.2 & 3.8 & \\
\hline HLP-13 & 200 & 150.0 & 0.24 & -0.11 & 6.0 & 758.8 & 11.4 & \\
\hline HLP-13 & 200 & 200.0 & 0.26 & -0.12 & 6.0 & 932.3 & 9.6 & \\
\hline HLP-13 & 200 & 300.0 & 0.25 & -0.21 & 8.5 & 391.3 & 21.8 & 3 \\
\hline HLP-13 & 275 & 2.0 & 0.62 & -0.04 & 6.5 & 1298.3 & 119.3 & \\
\hline HLP-13 & 275 & 4.0 & 0.62 & -0.13 & 8.0 & 1532.3 & 259.6 & \\
\hline HLP-13 & 275 & 5.0 & 0.62 & -0.07 & 8.0 & 1984.1 & - & 2 \\
\hline HLP-13 & 275 & 7.0 & 0.62 & -0.15 & 8.0 & 2005.9 & - & 1 \\
\hline HLP-13 & 275 & 9.0 & 0.62 & -0.22 & 5.5 & 1915.0 & - & 1 \\
\hline HLP-13 & 300 & 3.0 & 0.80 & -0.05 & 8.5 & 1920.1 & - & 2 \\
\hline HLP-14 & 200 & 8.7 & 0.25 & -0.03 & 6.0 & 13.1 & 0.1 & 5 \\
\hline HLP-14 & 200 & 15.6 & 0.25 & -0.02 & 6.0 & 392.4 & 28.0 & 5 \\
\hline HLP-14 & 200 & 19.5 & 0.20 & -0.07 & 7.5 & 597.8 & 39.1 & \\
\hline HLP-14 & 200 & 20.9 & 0.20 & -0.04 & 5.0 & 656.4 & 9.1 & \\
\hline HLP-14 & 200 & 24.9 & 0.21 & -0.04 & 9.5 & 1072.2 & 51.7 & \\
\hline HLP-14 & 200 & 30.6 & 0.25 & -0.09 & 5.0 & 1302.8 & 24.2 & 7 \\
\hline HLP-14 & 200 & 39.9 & 0.20 & -0.07 & 6.0 & 1177.3 & 63.3 & \\
\hline HLP-14 & 200 & 60.0 & 0.20 & -0.06 & 6.5 & 1502.0 & 127.2 & \\
\hline HLP-14 & 200 & 79.9 & 0.22 & -0.07 & 5.5 & 1810.1 & 130.3 & \\
\hline HLP-14 & 200 & 97.9 & 0.25 & -0.07 & 8.0 & 1864.4 & - & 1 \\
\hline HLP-14 & 200 & 150.0 & 0.24 & -0.11 & 6.0 & 1915.3 & - & 1 \\
\hline HLP-14 & 200 & 200.0 & 0.26 & -0.12 & 6.0 & 1942.8 & - & 1 \\
\hline HLP-14 & 200 & 300.0 & 0.25 & -0.21 & 8.5 & 1639.3 & 122.1 & 1 \\
\hline HLP-15 & 200 & 8.7 & 0.25 & -0.07 & 10.0 & 0.0 & - & 5 \\
\hline HLP-15 & 200 & 15.6 & 0.25 & -0.04 & 6.0 & 118.8 & 0.6 & \\
\hline HLP-15 & 200 & 30.6 & 0.25 & -0.07 & 6.0 & 143.7 & 1.5 & \\
\hline HLP-15 & 200 & 76.9 & 0.23 & -0.11 & 8.0 & 326.2 & 1.9 & \\
\hline HLP-15 & 200 & 139.9 & 0.25 & -0.17 & 6.0 & 273.0 & 3.0 & 3 \\
\hline HLP-15 & 200 & 200.0 & 0.27 & -0.22 & 8.5 & 297.5 & 5.2 & 3 \\
\hline HLP-15 & 200 & 300.9 & 0.26 & -0.24 & 6.5 & 336.0 & 11.0 & 3 \\
\hline HLP-15 & 200 & 325.0 & 0.29 & -0.29 & - & 390.0 & 6.8 & 3 \\
\hline HLP-15 & 275 & 2.0 & 0.62 & -0.09 & 6.0 & 657.0 & 4.7 & \\
\hline HLP-15 & 275 & 4.0 & 0.62 & -0.09 & 6.0 & 1096.6 & 35.4 & \\
\hline HLP-15 & 275 & 5.0 & 0.62 & -0.08 & 6.0 & 1316.1 & 40.3 & \\
\hline
\end{tabular}




\begin{tabular}{|c|c|c|c|c|c|c|c|c|}
\hline Glass ID & $\mathrm{T}\left({ }^{\circ} \mathrm{C}\right)$ & $t(d)$ & $\mathrm{vH}_{2} \mathrm{O}(\mathrm{mL})$ & & $\mathrm{pH}$ Out & $\mathrm{m}_{\mathrm{a}}\left(\mathrm{g} / \mathrm{m}^{2}\right)$ & $2 \sigma\left(\mathrm{g} / \mathrm{m}^{2}\right)$ & notes \\
\hline HLP-15 & 275 & 7.0 & 0.61 & -0.38 & 6.0 & - & - & 3 \\
\hline HLP-15 & 275 & 9.0 & 0.62 & -0.16 & 5.5 & 1630.6 & 81.0 & \\
\hline HLP-15 & 300 & 3.0 & 0.80 & -0.07 & 6.0 & 1553.6 & 134.2 & \\
\hline HLP-16 & 200 & 8.7 & 0.25 & -0.07 & 10.0 & 0.0 & - & 5 \\
\hline HLP-16 & 200 & 15.6 & 0.25 & -0.04 & 6.0 & 309.7 & 5.2 & \\
\hline HLP-16 & 200 & 30.6 & 0.25 & -0.07 & 5.0 & 484.2 & 13.3 & \\
\hline HLP-16 & 200 & 76.9 & 0.23 & -0.11 & 8.0 & 791.9 & 18.8 & \\
\hline HLP-16 & 200 & 139.9 & 0.25 & -0.17 & 6.0 & 879.1 & 54.7 & 3 \\
\hline HLP-16 & 200 & 200.0 & 0.27 & -0.22 & 8.5 & 1003.8 & 59.4 & 3 \\
\hline HLP-16 & 200 & 300.9 & 0.26 & -0.24 & 6.5 & 967.9 & 32.8 & 3 \\
\hline HLP-16 & 200 & 325.0 & 0.29 & -0.29 & - & 911.4 & 23.4 & 3 \\
\hline HLP-16 & 250 & 2.0 & 0.45 & -0.03 & 6.5 & 654.9 & 9.2 & \\
\hline HLP-16 & 250 & 3.0 & 0.45 & -0.04 & 8.0 & 972.8 & 18.0 & \\
\hline HLP-16 & 250 & 5.0 & 0.45 & -0.06 & 8.5 & 1519.5 & 59.1 & \\
\hline HLP-16 & 275 & 3.0 & 0.62 & -0.06 & 9.0 & 1812.7 & - & 2 \\
\hline HLP-16 & 275 & 4.0 & 0.62 & -0.06 & 8.5 & 1809.1 & - & 1 \\
\hline HLP-16 & 275 & 6.0 & 0.62 & -0.09 & 9.5 & 2075.5 & - & 1 \\
\hline HLP-16 & 275 & 8.0 & 0.62 & -0.18 & 9.0 & 1969.2 & - & 1 \\
\hline HLP-16 & 275 & 9.0 & 0.62 & -0.14 & 5.5 & 1940.6 & - & 1 \\
\hline HLP-16 & 300 & 3.0 & 0.80 & -0.05 & 5.5 & 2010.4 & - & 1 \\
\hline HLP-17 & 200 & 8.7 & 0.25 & -0.05 & 6.0 & 53.0 & 0.0 & 5 \\
\hline HLP-17 & 200 & 15.6 & 0.25 & -0.04 & 6.0 & 192.8 & 9.6 & \\
\hline HLP-17 & 200 & 30.6 & 0.25 & -0.06 & 5.0 & 388.9 & 5.1 & \\
\hline HLP-17 & 200 & 49.0 & 0.20 & -0.08 & 6.5 & 169.7 & 0.8 & \\
\hline HLP-17 & 200 & 75.0 & 0.20 & -0.09 & 6.0 & 340.5 & 5.4 & \\
\hline HLP-17 & 200 & 76.9 & 0.25 & -0.09 & 10.0 & 890.2 & 49.4 & \\
\hline HLP-17 & 200 & 101.0 & 0.20 & -0.11 & 6.5 & 260.2 & 2.7 & \\
\hline HLP-17 & 200 & 125.0 & 0.20 & -0.12 & 6.0 & 402.7 & 16.1 & \\
\hline HLP-17 & 200 & 153.9 & 0.27 & -0.18 & 6.0 & 870.1 & 51.6 & 3 \\
\hline HLP-17 & 200 & 275.0 & 0.25 & -0.22 & - & 856.4 & 72.5 & 3 \\
\hline HLP-17 & 250 & 5.0 & 0.45 & -0.05 & 6.0 & 1132.3 & 23.0 & \\
\hline HLP-17 & 250 & 10.0 & 0.45 & -0.07 & 6.0 & 1695.4 & 140.8 & \\
\hline HLP-17 & 250 & 13.0 & 0.45 & -0.08 & 6.0 & 1954.0 & - & 2 \\
\hline HLP-17 & 250 & 17.0 & 0.45 & -0.12 & 8.0 & 1937.4 & - & 1 \\
\hline HLP-17 & 250 & 20.0 & 0.45 & -0.12 & 5.5 & 2001.3 & - & 1 \\
\hline HLP-18 & 200 & 8.7 & 0.25 & -0.06 & 6.0 & 128.4 & 0.7 & 5 \\
\hline HLP-18 & 200 & 15.6 & 0.25 & -0.04 & 6.0 & 527.2 & 3.5 & \\
\hline HLP-18 & 200 & 30.6 & 0.25 & -0.06 & 5.0 & 1021.5 & 50.7 & \\
\hline HLP-18 & 200 & 64.9 & 0.26 & -0.12 & 10.0 & 1320.4 & 69.6 & \\
\hline HLP-18 & 200 & 73.0 & 0.26 & -0.07 & 10.0 & 1509.1 & 205.6 & \\
\hline HLP-18 & 200 & 84.1 & 0.25 & -0.10 & 10.0 & 1789.1 & 257.6 & \\
\hline HLP-18 & 200 & 92.0 & 0.26 & -0.10 & 8.0 & 1935.9 & - & 2 \\
\hline HLP-18 & 200 & 140.0 & 0.25 & -0.12 & 9.0 & 1349.4 & 58.3 & 3 \\
\hline HLP-19 & 200 & 8.7 & 0.25 & -0.64 & 6.0 & 0.0 & - & \\
\hline HLP-19 & 200 & 15.6 & 0.25 & -0.04 & 7.0 & 0.0 & - & \\
\hline HLP-19 & 200 & 30.6 & 0.31 & -0.07 & 4.0 & 0.0 & - & \\
\hline HLP-19 & 200 & 90.1 & 0.28 & -0.14 & 6.0 & 0.0 & - & 3 \\
\hline HLP-19 & 200 & 231.0 & 0.25 & -0.26 & 7.0 & 77.4 & 1.1 & 3 \\
\hline HLP-19 & 200 & 300.9 & 0.26 & -0.28 & 7.5 & 337.3 & 5.6 & 3 \\
\hline HLP-19 & 200 & 325.0 & 0.25 & -0.28 & - & 66.8 & 0.3 & 3 \\
\hline HLP-19 & 200 & 339.9 & 0.26 & -0.29 & - & 130.0 & 1.3 & 3 \\
\hline
\end{tabular}




\begin{tabular}{|c|c|c|c|c|c|c|c|c|}
\hline Glass ID & $\mathrm{T}\left({ }^{\circ} \mathrm{C}\right)$ & $t(d)$ & $\mathrm{vH}_{2} \mathrm{O}(\mathrm{mL})$ & & pH Out & $m_{a}\left(g / m^{2}\right)$ & $2 \sigma\left(\mathrm{g} / \mathrm{m}^{2}\right)$ & notes \\
\hline HLP-19 & 300 & 2.0 & 0.80 & -0.06 & 5.5 & 580.3 & 3.8 & \\
\hline HLP-19 & 300 & 3.0 & 0.80 & -0.04 & 5.0 & 852.5 & 6.9 & \\
\hline HLP-19 & 300 & 4.0 & 0.80 & -0.07 & 5.5 & 952.6 & 17.8 & \\
\hline HLP-19 & 300 & 5.0 & 0.80 & -0.07 & 6.0 & 1111.3 & 34.3 & \\
\hline HLP-19 & 300 & 6.0 & 0.80 & -0.09 & 6.5 & 1302.9 & - & \\
\hline HLP-19 & 300 & 7.0 & 0.85 & -0.87 & 10.0 & 2050.0 & - & 1 \\
\hline HLP-20 & 200 & 8.7 & 0.25 & -0.64 & 6.0 & 44.6 & 2.0 & 5 \\
\hline HLP-20 & 200 & 15.6 & 0.25 & -0.04 & 7.0 & 142.0 & 0.7 & 5 \\
\hline HLP-20 & 200 & 30.6 & 0.31 & -0.07 & 5.0 & 142.4 & 2.2 & 5 \\
\hline HLP-20 & 200 & 49.0 & 0.20 & -0.06 & 6.0 & 457.8 & 15.1 & \\
\hline HLP-20 & 200 & 76.9 & 0.25 & -0.09 & 10.0 & 581.5 & 18.4 & \\
\hline HLP-20 & 200 & 101.0 & 0.20 & -0.10 & 6.0 & 565.4 & 86.0 & \\
\hline HLP-20 & 200 & 153.9 & 0.27 & -0.18 & 6.0 & 633.5 & 14.7 & \\
\hline HLP-20 & 200 & 157.0 & 0.20 & -0.17 & 6.5 & 670.9 & 47.9 & 3 \\
\hline HLP-20 & 200 & 200.0 & 0.24 & -0.20 & 8.0 & 421.4 & 10.6 & 3 \\
\hline HLP-20 & 200 & 275.0 & 0.25 & -0.22 & - & 468.3 & 5.9 & 3 \\
\hline HLP-20 & 200 & 300.9 & 0.29 & -0.27 & 1.0 & 711.3 & 15.8 & 3 \\
\hline HLP-20 & 250 & 5.0 & 0.45 & -0.05 & 7.5 & 1132.8 & 23.0 & \\
\hline HLP-20 & 250 & 10.0 & 0.45 & -0.13 & 5.5 & 1446.9 & 21.7 & \\
\hline HLP-20 & 250 & 13.0 & 0.45 & -0.12 & 5.5 & 2005.1 & - & 2 \\
\hline HLP-20 & 250 & 17.0 & 0.45 & -0.24 & 5.5 & 1930.1 & - & 1 \\
\hline HLP-20 & 250 & 20.0 & 0.45 & -0.17 & 5.5 & 2012.3 & - & 1 \\
\hline HLP-20 & 300 & 3.1 & 0.87 & -0.14 & 6.0 & 703.0 & 68.3 & \\
\hline HLP-21 & 200 & 8.7 & 0.25 & -0.02 & 6.0 & 0.0 & - & 5 \\
\hline HLP-21 & 200 & 15.6 & 0.25 & -0.04 & 6.0 & 25.9 & 0.3 & 5 \\
\hline HLP-21 & 200 & 30.6 & 0.25 & -0.05 & 10.0 & 247.8 & 1.3 & \\
\hline HLP-21 & 200 & 40.0 & 0.20 & -0.06 & 7.5 & 394.0 & 2.1 & \\
\hline HLP-21 & 200 & 60.0 & 0.20 & -0.09 & 6.0 & 434.4 & 5.6 & \\
\hline HLP-21 & 200 & 77.0 & 0.25 & -0.10 & 8.0 & 615.6 & 10.2 & \\
\hline HLP-21 & 200 & 85.0 & 0.25 & -0.08 & 7.5 & 662.7 & 11.3 & \\
\hline HLP-21 & 200 & 92.0 & 0.25 & -0.10 & 5.5 & 664.9 & 9.9 & \\
\hline HLP-21 & 200 & 100.0 & 0.25 & -0.12 & 9.0 & 595.4 & 25.7 & 3 \\
\hline HLP-21 & 200 & 130.0 & 0.25 & -0.13 & 8.0 & 628.7 & 11.3 & 3 \\
\hline HLP-21 & 200 & 131.0 & 0.25 & -0.14 & 7.0 & 579.8 & 49.6 & 3 \\
\hline HLP-21 & 200 & 150.0 & 0.25 & -0.15 & 7.0 & 854.2 & 36.2 & 3 \\
\hline HLP-21 & 200 & 160.0 & 0.25 & -0.15 & 9.0 & 722.3 & 45.0 & 3 \\
\hline HLP-21 & 250 & 1.0 & 0.45 & -0.03 & 6.0 & 193.9 & 2.0 & \\
\hline HLP-21 & 250 & 3.0 & -6.96 & -0.03 & 6.0 & 1131.3 & 28.6 & \\
\hline HLP-21 & 250 & 5.0 & 0.45 & -0.05 & 7.0 & 1654.5 & 198.5 & \\
\hline HLP-21 & 250 & 5.1 & 0.45 & -0.05 & 7.0 & 1782.9 & 142.6 & \\
\hline HLP-21 & 250 & 7.0 & 0.45 & -0.06 & 7.0 & 1955.6 & - & 1 \\
\hline HLP-21 & 250 & 10.0 & 0.45 & -0.11 & 7.5 & 2002.0 & - & 1 \\
\hline HLP-21 & 250 & 13.0 & 0.45 & -0.09 & 7.0 & 2004.8 & - & 1 \\
\hline HLP-21 & 250 & 15.0 & 0.45 & -0.10 & 8.0 & 2014.0 & - & 1 \\
\hline HLP-22 & 200 & 8.7 & 0.25 & -0.02 & 6.0 & 0.0 & - & \\
\hline HLP-22 & 200 & 15.6 & 0.25 & -0.04 & 6.0 & 0.0 & - & \\
\hline HLP-22 & 200 & 30.6 & 0.25 & -0.05 & 10.0 & 90.0 & 1.0 & \\
\hline HLP-22 & 200 & 60.0 & 0.20 & -0.09 & 5.5 & 107.7 & 0.8 & \\
\hline HLP-22 & 200 & 90.1 & 0.28 & -0.14 & 6.0 & 126.5 & 1.2 & \\
\hline HLP-22 & 200 & 119.0 & 0.20 & -0.12 & 6.5 & 81.6 & 0.7 & \\
\hline HLP-22 & 200 & 160.0 & 0.20 & -0.14 & 6.0 & 144.2 & 1.5 & \\
\hline
\end{tabular}




\begin{tabular}{|c|c|c|c|c|c|c|c|c|}
\hline Glass ID & $\mathrm{T}\left({ }^{\circ} \mathrm{C}\right)$ & $\mathrm{t}(\mathrm{d})$ & $\mathrm{vH}_{2} \mathrm{O}(\mathrm{mL})$ & & $\mathrm{pH}$ Out & $m_{a}\left(g / m^{2}\right)$ & $2 \sigma\left(\mathrm{g} / \mathrm{m}^{2}\right)$ & notes \\
\hline HLP-22 & 200 & 231.0 & 0.25 & -0.26 & 7.0 & 176.3 & 0.9 & 3 \\
\hline HLP-22 & 200 & 300.9 & 0.26 & -0.28 & 7.5 & 375.3 & 8.8 & 3 \\
\hline HLP-22 & 200 & 325.0 & 0.25 & -0.28 & - & 264.2 & 10.2 & 3 \\
\hline HLP-22 & 200 & 339.9 & 0.26 & -0.29 & - & 338.3 & 7.4 & 3 \\
\hline HLP-22 & 275 & 4.0 & 0.62 & -0.07 & 5.5 & 588.2 & 12.2 & \\
\hline HLP-22 & 275 & 7.0 & 0.62 & 0.87 & 5.5 & 894.3 & 37.4 & \\
\hline HLP-22 & 275 & 9.0 & 0.62 & -0.14 & 5.5 & 942.8 & 9.2 & \\
\hline HLP-22 & 275 & 9.0 & 0.62 & -0.15 & 5.5 & 972.2 & 9.5 & \\
\hline HLP-22 & 275 & 11.9 & 0.62 & -0.23 & 5.5 & 1055.4 & 48.1 & \\
\hline HLP-22 & 275 & 14.9 & 0.62 & -0.48 & 5.5 & 753.6 & 31.5 & 3 \\
\hline HLP-22 & 300 & 3.0 & 0.80 & -0.05 & 5.5 & 925.6 & 8.2 & \\
\hline HLP-23 & 200 & 5.8 & 0.25 & -0.03 & 10.0 & 92.2 & 0.9 & 5 \\
\hline HLP-23 & 200 & 16.8 & 0.20 & -0.04 & 9.0 & 1076.7 & 92.6 & \\
\hline HLP-23 & 200 & 34.9 & 0.20 & -0.06 & 8.5 & 1229.5 & 42.8 & \\
\hline HLP-23 & 200 & 40.0 & 0.20 & -0.05 & 7.5 & 1668.1 & 144.1 & \\
\hline HLP-23 & 200 & 51.8 & 0.20 & -0.05 & 8.5 & 1920.0 & - & 2 \\
\hline HLP-23 & 200 & 69.6 & 0.25 & -0.10 & 6.0 & 2027.4 & - & 2 \\
\hline HLP-23 & 200 & 85.0 & 0.25 & -0.08 & 7.5 & 2098.8 & - & 1 \\
\hline HLP-23 & 200 & 92.0 & 0.25 & -0.10 & 5.5 & 1997.1 & - & 1 \\
\hline HLP-23 & 200 & 130.0 & 0.25 & -0.13 & 8.0 & 1569.5 & 196.5 & 3 \\
\hline HLP-23 & 200 & 150.0 & 0.25 & -0.15 & 7.0 & 2016.0 & - & 1 \\
\hline HLP-24 & 200 & 8.7 & 0.26 & -0.06 & 6.0 & 50.8 & - & 5 \\
\hline HLP-24 & 200 & 15.6 & 0.25 & -0.24 & 10.0 & 114.3 & 1.1 & 5 \\
\hline HLP-24 & 200 & 30.6 & 0.25 & -0.08 & 8.0 & 128.0 & 1.3 & 5 \\
\hline HLP-24 & 200 & 70.0 & 0.25 & -0.09 & 9.8 & 322.9 & 11.0 & \\
\hline HLP-24 & 200 & 131.0 & 0.25 & -0.12 & 9.0 & 425.9 & 17.9 & \\
\hline HLP-24 & 200 & 131.0 & 0.25 & -0.14 & 7.0 & 465.3 & 20.2 & \\
\hline HLP-24 & 200 & 160.0 & 0.25 & -0.15 & 9.0 & 470.0 & 15.9 & \\
\hline HLP-24 & 275 & 3.0 & 0.62 & -0.65 & - & 53.3 & 0.3 & 3 \\
\hline HLP-24 & 275 & 5.0 & 0.62 & -0.10 & 6.0 & 1233.1 & 30.4 & \\
\hline HLP-24 & 275 & 6.0 & 0.62 & -0.10 & 5.5 & 1413.8 & 91.9 & \\
\hline HLP-24 & 275 & 8.0 & 0.62 & -0.25 & 6.0 & 1365.3 & 39.1 & \\
\hline HLP-24 & 275 & 10.0 & 0.62 & -0.46 & 5.5 & 1153.8 & 17.1 & 3 \\
\hline HLP-24 & 300 & 3.0 & 0.80 & -0.04 & 8.0 & 971.7 & 12.1 & \\
\hline HLP-25 & 200 & 5.8 & 0.25 & -0.03 & 10.0 & 0.0 & - & 5 \\
\hline HLP-25 & 200 & 11.9 & 0.25 & -0.02 & 10.0 & 289.4 & 2.4 & \\
\hline HLP-25 & 200 & 50.0 & 0.20 & -0.07 & 6.0 & 452.3 & 4.9 & \\
\hline HLP-25 & 200 & 69.6 & 0.25 & -0.10 & 6.0 & 620.7 & 16.7 & \\
\hline HLP-25 & 200 & 99.0 & 0.20 & -0.11 & 7.0 & 630.2 & 6.7 & \\
\hline HLP-25 & 200 & 151.0 & 0.20 & -0.13 & 6.0 & 575.5 & 3.7 & 3 \\
\hline HLP-25 & 250 & 2.0 & 0.45 & -0.03 & 5.5 & 653.7 & 8.7 & \\
\hline HLP-25 & 250 & 3.0 & 0.45 & -0.34 & 8.0 & 799.7 & 20.8 & \\
\hline HLP-25 & 250 & 4.0 & 0.45 & -0.04 & 8.5 & 1245.3 & 32.0 & \\
\hline HLP-25 & 250 & 5.0 & 0.45 & -0.04 & 8.0 & 1489.2 & 97.5 & \\
\hline HLP-25 & 250 & 5.9 & 0.45 & -0.06 & 10.0 & 1738.2 & 170.7 & \\
\hline HLP-25 & 250 & 10.0 & 0.45 & -0.07 & 9.0 & 1870.4 & - & 1 \\
\hline HLP-25 & 250 & 14.0 & 0.45 & -0.16 & 8.0 & 1989.4 & - & 1 \\
\hline HLP-25 & 250 & 16.0 & 0.45 & -0.11 & 8.5 & 2018.6 & - & 1 \\
\hline HLP-25 & 250 & 21.0 & 0.45 & -0.20 & 9.0 & 1982.8 & - & 1 \\
\hline HLP-25 & 300 & 0.5 & 0.80 & -0.03 & 5.5 & 845.4 & 8.1 & \\
\hline HLP-25 & 300 & 1.0 & 0.85 & -0.03 & 8.0 & 1357.4 & 113.6 & \\
\hline HLP-25 & 300 & 1.5 & 0.85 & -0.04 & 9.0 & 1541.1 & 39.6 & \\
\hline
\end{tabular}




\begin{tabular}{|c|c|c|c|c|c|c|c|c|}
\hline Glass ID & $\mathrm{T}\left({ }^{\circ} \mathrm{C}\right)$ & $t(d)$ & $\mathrm{vH}_{2} \mathrm{O}(\mathrm{mL})$ & & $\mathrm{pH}$ Out & $\mathrm{m}_{\mathrm{a}}\left(\mathrm{g} / \mathrm{m}^{2}\right)$ & $2 \sigma\left(\mathrm{g} / \mathrm{m}^{2}\right)$ & notes \\
\hline HLP-25 & 300 & 2.0 & 0.85 & -0.04 & 9.0 & 2012.4 & - & 2 \\
\hline HLP-25 & 300 & 2.5 & 0.85 & -0.04 & 8.5 & 1955.9 & - & 1 \\
\hline HLP-25 & 300 & 3.1 & 0.85 & -0.27 & 10.0 & 1916.2 & 344.9 & 1 \\
\hline HLP-26 & 200 & 1.9 & 0.25 & -0.02 & 10.0 & 26.5 & 0.2 & 5 \\
\hline HLP-26 & 200 & 5.8 & 0.25 & -0.01 & 10.0 & 94.5 & 0.6 & 5 \\
\hline HLP-26 & 200 & 24.9 & 0.25 & -0.05 & 6.0 & 467.8 & 3.5 & 8 \\
\hline HLP-26 & 200 & 24.9 & 0.25 & -0.05 & 6.0 & 505.7 & 6.0 & 8 \\
\hline HLP-26 & 200 & 50.0 & 0.20 & -0.07 & 6.0 & 523.2 & 20.7 & 8 \\
\hline HLP-26 & 200 & 99.0 & 0.20 & -0.11 & 5.5 & 608.3 & 23.4 & 8 \\
\hline HLP-26 & 200 & 99.9 & 0.25 & -0.14 & 6.0 & 673.7 & 13.5 & 8 \\
\hline HLP-26 & 200 & 100.0 & 0.20 & -0.10 & 5.5 & 493.3 & 9.0 & 8 \\
\hline HLP-26 & 200 & 143.6 & 0.24 & -0.20 & - & 636.0 & 8.5 & 3 \\
\hline HLP-26 & 200 & 151.0 & 0.20 & -0.13 & 8.5 & 659.7 & 21.5 & 8 \\
\hline HLP-26 & 200 & 155.0 & 0.20 & -0.13 & 6.0 & 615.6 & 13.9 & 8 \\
\hline HLP-26 & 200 & 179.0 & 0.20 & -0.16 & 5.5 & 566.7 & 4.8 & 3 \\
\hline HLP-26 & 200 & 188.6 & 0.25 & -0.22 & 6.0 & 658.9 & 4.8 & 3 \\
\hline HLP-26 & 200 & 213.0 & 0.20 & -0.16 & 6.0 & 513.7 & 4.2 & 3 \\
\hline HLP-26 & 200 & 289.6 & 0.25 & -0.22 & - & 741.2 & 4.1 & 3 \\
\hline HLP-26 & 200 & 370.5 & 0.25 & -0.25 & - & 450.1 & 5.4 & 3 \\
\hline HLP-26 & 200 & 374.5 & 0.25 & -0.24 & - & 854.7 & 9.1 & 3 \\
\hline HLP-26 & 200 & 379.5 & 0.25 & -0.24 & 0.0 & 718.9 & 7.5 & 3 \\
\hline HLP-26 & 250 & 2.0 & 0.45 & -0.03 & 6.0 & 627.4 & 5.0 & \\
\hline HLP-26 & 250 & 3.0 & 0.45 & -0.04 & 6.5 & 892.6 & 22.2 & \\
\hline HLP-26 & 250 & 4.0 & 0.45 & -0.05 & 7.0 & 1138.0 & 39.0 & \\
\hline HLP-26 & 250 & 5.0 & 1.56 & -0.05 & 8.0 & 1367.0 & 41.0 & \\
\hline HLP-26 & 250 & 5.9 & 0.45 & -0.05 & 10.0 & 1486.0 & 36.9 & \\
\hline HLP-26 & 250 & 10.0 & 0.45 & -0.10 & 7.5 & 1857.1 & 133.7 & 1 \\
\hline HLP-26 & 250 & 14.0 & 0.45 & -0.11 & 8.0 & 1949.8 & - & 1 \\
\hline HLP-26 & 250 & 16.0 & 0.45 & -0.10 & 5.5 & 2005.9 & - & 1 \\
\hline HLP-26 & 250 & 21.0 & 0.45 & -0.19 & 7.5 & 1993.0 & - & 1 \\
\hline HLP-26 & 300 & 0.5 & 0.80 & -0.03 & 5.5 & 769.0 & 11.6 & \\
\hline HLP-26 & 300 & 1.0 & 0.85 & -0.03 & 8.0 & 1263.8 & 72.8 & \\
\hline HLP-26 & 300 & 1.5 & 0.85 & -0.04 & 9.0 & 1524.9 & 189.3 & \\
\hline HLP-26 & 300 & 2.0 & 0.85 & -0.03 & 9.0 & 1949.6 & - & \\
\hline HLP-26 & 300 & 2.5 & 0.85 & -0.03 & 8.0 & 1968.2 & - & 1 \\
\hline HLP-27 & 200 & 1.0 & 0.20 & -0.02 & - & 273.8 & 5.3 & 7 \\
\hline HLP-27 & 200 & 1.9 & 0.25 & -0.02 & 10.0 & 1335.4 & 235.4 & \\
\hline HLP-27 & 200 & 4.0 & 0.20 & -0.03 & 10.0 & 1166.7 & 45.8 & 7 \\
\hline HLP-27 & 200 & 5.1 & 0.25 & -0.02 & 10.0 & 1510.5 & 255.9 & \\
\hline HLP-27 & 200 & 5.8 & 0.25 & -0.01 & 10.0 & 1489.7 & 351.4 & \\
\hline HLP-27 & 200 & 8.0 & 0.20 & -0.02 & - & 1408.0 & 681.4 & 7 \\
\hline HLP-27 & 200 & 11.9 & 0.25 & -0.02 & 10.0 & 1998.0 & - & \\
\hline HLP-27 & 200 & 16.0 & 0.25 & -0.03 & 10.0 & 1973.4 & - & 1 \\
\hline HLP-27 & 200 & 21.7 & 0.25 & -0.04 & 10.0 & 2032.2 & - & 1 \\
\hline HLP-28 & 200 & 1.8 & 0.25 & -0.02 & 10.0 & 6.6 & 0.0 & 5 \\
\hline HLP-28 & 200 & 5.8 & 0.26 & -0.02 & 10.0 & 340.2 & 4.3 & \\
\hline HLP-28 & 200 & 11.9 & 0.15 & -0.03 & 10.0 & 375.1 & 3.0 & \\
\hline HLP-28 & 200 & 12.0 & 0.26 & -0.02 & 6.0 & 233.5 & 6.5 & \\
\hline HLP-28 & 200 & 19.0 & 0.24 & -0.04 & 6.0 & 245.3 & 5.2 & \\
\hline HLP-28 & 200 & 19.0 & 0.25 & -0.04 & 6.0 & 355.2 & 7.0 & \\
\hline HLP-28 & 200 & 26.7 & 0.25 & -0.06 & 6.0 & 272.4 & 4.5 & \\
\hline
\end{tabular}




\begin{tabular}{|c|c|c|c|c|c|c|c|c|}
\hline Glass ID & $\mathrm{T}\left({ }^{\circ} \mathrm{C}\right)$ & $t(d)$ & $\mathrm{vH}_{2} \mathrm{O}(\mathrm{mL})$ & & pH Out & $m_{a}\left(g / m^{2}\right)$ & $2 \sigma\left(\mathrm{g} / \mathrm{m}^{2}\right)$ & notes \\
\hline HLP-28 & 200 & 26.7 & 0.26 & -0.06 & 6.0 & 395.2 & 22.4 & \\
\hline HLP-28 & 200 & 96.9 & 0.26 & -0.16 & 8.0 & 485.7 & 10.5 & 3 \\
\hline HLP-28 & 200 & 150.9 & 0.25 & -0.69 & 8.5 & 1348.2 & - & \\
\hline HLP-28 & 200 & 200.0 & 0.25 & 1.91 & 6.0 & 1453.9 & 261.7 & \\
\hline HLP-28 & 200 & 299.7 & 0.25 & -0.25 & - & 443.6 & 21.8 & 3 \\
\hline HLP-28 & 275 & 4.0 & 0.62 & -0.08 & 5.5 & 564.5 & 8.3 & \\
\hline HLP-28 & 275 & 6.0 & 0.62 & -0.09 & 5.5 & 806.4 & 7.3 & \\
\hline HLP-28 & 275 & 8.0 & 0.62 & -1.14 & 5.5 & 923.9 & 16.2 & \\
\hline HLP-28 & 275 & 11.0 & 0.62 & -0.23 & 5.5 & 943.8 & 8.4 & 3 \\
\hline HLP-28 & 275 & 13.0 & 0.62 & -0.31 & 5.5 & 918.6 & 9.9 & 3 \\
\hline HLP-28 & 300 & 2.0 & 0.80 & -0.05 & 5.5 & 717.5 & 10.5 & \\
\hline HLP-28 & 300 & 3.0 & 1.20 & -0.56 & 6.0 & 797.8 & 6.5 & \\
\hline HLP-28 & 300 & 3.0 & 0.80 & -0.06 & 5.5 & 999.1 & 32.7 & \\
\hline HLP-28 & 300 & 5.0 & 0.80 & -0.06 & 5.5 & 1440.9 & 100.4 & \\
\hline HLP-29 & 200 & 3.4 & 0.25 & -0.03 & 6.0 & 843.1 & 17.5 & \\
\hline HLP-29 & 200 & 5.7 & 0.25 & -0.03 & 5.0 & 1022.2 & 22.6 & \\
\hline HLP-29 & 200 & 7.1 & 0.25 & -0.02 & 6.0 & 754.0 & 3.2 & \\
\hline HLP-29 & 200 & 7.8 & 0.25 & -0.04 & 6.0 & 1375.6 & 47.9 & \\
\hline HLP-29 & 200 & 13.2 & 0.25 & -0.01 & 10.0 & 1340.8 & 152.8 & \\
\hline HLP-29 & 200 & 20.8 & 0.25 & -0.04 & 5.0 & 1881.5 & 223.5 & \\
\hline HLP-29 & 200 & 41.8 & 0.24 & -0.06 & 6.0 & 2026.3 & - & 1 \\
\hline HLP-30 & 200 & 1.9 & 0.25 & -0.02 & 6.1 & 90.6 & 0.4 & 5 \\
\hline HLP-30 & 200 & 5.8 & 0.25 & -0.02 & 10.0 & 374.2 & 2.9 & 5 \\
\hline HLP-30 & 200 & 11.9 & 0.25 & -0.02 & - & 300.4 & 3.2 & 5 \\
\hline HLP-30 & 200 & 12.0 & 0.27 & -0.03 & 5.8 & 942.5 & 13.8 & \\
\hline HLP-30 & 200 & 12.9 & 0.26 & -0.03 & 6.0 & 963.9 & 22.5 & \\
\hline HLP-30 & 200 & 23.7 & 0.26 & -0.05 & 6.0 & 1091.7 & 67.7 & \\
\hline HLP-30 & 200 & 23.7 & 0.26 & -0.03 & 6.0 & 1114.7 & 21.1 & \\
\hline HLP-30 & 200 & 41.0 & 0.25 & -0.06 & 8.5 & 1234.5 & 216.3 & \\
\hline HLP-30 & 200 & 70.0 & 0.25 & -0.10 & 9.5 & 1110.0 & 35.6 & 3 \\
\hline HLP-30 & 200 & 100.0 & 0.25 & -0.12 & 10.0 & 943.6 & 39.1 & 3 \\
\hline HLP-30 & 200 & 169.8 & 0.25 & -0.12 & 9.0 & 1064.1 & 42.5 & 3 \\
\hline HLP-30 & 250 & 3.0 & 0.45 & -0.04 & 8.0 & 318.5 & 20.5 & \\
\hline HLP-30 & 250 & 5.0 & 0.45 & -0.05 & 8.5 & 344.0 & 9.8 & \\
\hline HLP-30 & 250 & 7.0 & 0.45 & -0.06 & 5.5 & 461.3 & 28.6 & \\
\hline HLP-30 & 250 & 9.0 & 0.45 & -0.07 & 5.5 & 921.9 & - & \\
\hline HLP-30 & 250 & 11.0 & 0.45 & -0.08 & 5.0 & 861.9 & 83.7 & \\
\hline HLP-31 & 175 & 24.0 & 0.14 & -0.02 & 7.5 & 921.9 & 38.1 & \\
\hline HLP-31 & 175 & 35.0 & 0.14 & -0.04 & 7.5 & 1059.7 & 31.8 & \\
\hline HLP-31 & 175 & 49.0 & 0.14 & -0.03 & 8.0 & 1139.7 & 168.9 & \\
\hline HLP-31 & 175 & 63.0 & 0.14 & -0.05 & 7.5 & 1160.7 & 34.8 & \\
\hline HLP-31 & 175 & 77.0 & 0.14 & -0.04 & 8.5 & 1168.3 & 12.9 & \\
\hline HLP-31 & 200 & 1.8 & 0.25 & -0.02 & 10.0 & 336.1 & 5.4 & 5 \\
\hline HLP-31 & 200 & 3.0 & 0.26 & -0.02 & 6.0 & 1163.8 & 25.3 & \\
\hline HLP-31 & 200 & 3.9 & 0.20 & -0.02 & 7.0 & 718.4 & 12.7 & 7 \\
\hline HLP-31 & 200 & 5.1 & 0.25 & -0.02 & 6.0 & 1432.9 & 71.0 & \\
\hline HLP-31 & 200 & 5.8 & 0.26 & -0.02 & 10.0 & 1139.4 & 11.8 & \\
\hline HLP-31 & 200 & 6.0 & 0.20 & -0.02 & 7.0 & 1372.1 & 70.7 & 7 \\
\hline HLP-31 & 200 & 6.8 & 0.25 & -0.02 & 6.0 & 1507.5 & 26.3 & \\
\hline HLP-31 & 200 & 11.9 & 0.25 & -0.03 & 10.0 & 2033.0 & - & 2 \\
\hline HLP-31 & 200 & 21.7 & 0.25 & -0.03 & 6.0 & 1826.3 & 146.1 & 1 \\
\hline
\end{tabular}




\begin{tabular}{|c|c|c|c|c|c|c|c|c|}
\hline Glass ID & $\mathrm{T}\left({ }^{\circ} \mathrm{C}\right)$ & $t(d)$ & $\mathrm{vH}_{2} \mathrm{O}(\mathrm{mL})$ & & $\mathrm{pH}$ Out & $\mathrm{m}_{\mathrm{a}}\left(\mathrm{g} / \mathrm{m}^{2}\right)$ & $2 \sigma\left(\mathrm{g} / \mathrm{m}^{2}\right)$ & notes \\
\hline HLP-32 & 200 & 7.1 & 0.26 & -0.02 & 6.0 & 25.3 & 0.2 & \\
\hline HLP-32 & 200 & 13.2 & 0.25 & -0.02 & 10.0 & 50.3 & 0.7 & \\
\hline HLP-32 & 200 & 24.0 & 0.26 & -0.03 & 6.0 & 101.7 & 1.9 & \\
\hline HLP-32 & 200 & 70.0 & 0.25 & -0.10 & 6.0 & 64.7 & 0.9 & \\
\hline HLP-32 & 200 & 99.0 & 0.25 & -0.08 & 8.0 & 64.8 & 0.3 & \\
\hline HLP-32 & 200 & 130.0 & 0.25 & -0.17 & 6.0 & 166.6 & 3.3 & 3 \\
\hline HLP-32 & 200 & 180.0 & 0.25 & -0.23 & 7.5 & 51.1 & 0.9 & 3 \\
\hline HLP-32 & 200 & 239.0 & 0.25 & -0.22 & 7.0 & 141.6 & 1.4 & 3 \\
\hline HLP-32 & 275 & 2.0 & 0.62 & -0.07 & 5.5 & 517.7 & 9.8 & \\
\hline HLP-32 & 275 & 2.9 & 0.62 & 0.27 & 5.5 & 816.0 & 24.7 & \\
\hline HLP-32 & 275 & 5.0 & 0.62 & -0.13 & 5.5 & 767.7 & 23.3 & \\
\hline HLP-32 & 275 & 6.0 & 0.62 & -0.21 & 5.5 & 766.5 & 22.8 & \\
\hline HLP-32 & 275 & 7.1 & 0.62 & -0.11 & 5.5 & 1006.6 & - & \\
\hline HLP-32 & 300 & 3.0 & 0.80 & -0.04 & 5.5 & 1433.0 & 43.0 & \\
\hline HLP-33 & 200 & 1.8 & 0.25 & -0.02 & 10.0 & 136.9 & 2.3 & 5 \\
\hline HLP-33 & 200 & 5.8 & 0.25 & -0.02 & 10.0 & 179.9 & 1.8 & 5 \\
\hline HLP-33 & 200 & 8.0 & 0.20 & -0.03 & 7.5 & 1140.6 & 48.0 & \\
\hline HLP-33 & 200 & 11.9 & 0.25 & -0.02 & 10.0 & 113.1 & 2.2 & 5 \\
\hline HLP-33 & 200 & 13.0 & 0.20 & -0.03 & 7.5 & 1311.1 & 52.4 & \\
\hline HLP-33 & 200 & 17.0 & 0.20 & -0.03 & 7.5 & 1528.6 & 120.0 & \\
\hline HLP-33 & 200 & 22.0 & 0.20 & -0.04 & 10.0 & 1421.6 & 130.0 & \\
\hline HLP-33 & 200 & 30.0 & 0.20 & -0.04 & 8.5 & 1656.4 & - & \\
\hline HLP-33 & 200 & 45.0 & 0.20 & -0.06 & 8.5 & 2026.0 & - & 2 \\
\hline HLP-33 & 200 & 50.0 & 0.20 & -0.06 & 7.0 & 1981.2 & - & 1 \\
\hline HLP-33 & 200 & 130.5 & 0.25 & -0.15 & 10.0 & 2073.8 & - & 1 \\
\hline HLP-33 & 200 & 179.7 & 0.25 & -0.18 & 5.5 & 1925.5 & - & 1 \\
\hline HLP-33 & 200 & 259.5 & 0.26 & -0.21 & - & 1984.1 & - & 1 \\
\hline HLP-33 & 200 & 349.6 & 0.26 & -0.23 & - & 2032.4 & - & 1 \\
\hline HLP-33 & 200 & 375.5 & 0.25 & -0.25 & - & 1966.5 & - & 1 \\
\hline HLP-33 & 200 & 379.5 & 0.25 & -0.25 & - & - & - & 1 \\
\hline HLP-33 & 200 & 389.5 & 0.26 & -0.25 & - & - & - & 1 \\
\hline HLP-33 & 250 & 1.0 & 0.45 & -0.03 & 9.5 & 1930.0 & - & 2 \\
\hline HLP-33 & 250 & 2.0 & 0.45 & -0.03 & 9.5 & 1993.0 & - & 1 \\
\hline HLP-33 & 250 & 3.0 & 0.45 & -0.04 & 8.0 & 2030.1 & - & 1 \\
\hline HLP-33 & 250 & 6.0 & 0.45 & -0.07 & 10.0 & 1982.1 & - & 1 \\
\hline HLP-33 & 250 & 8.0 & 0.45 & -0.07 & 7.0 & 1927.6 & - & 1 \\
\hline HLP-33 & 250 & 10.0 & 0.45 & -0.08 & 10.0 & 2049.5 & - & 1 \\
\hline HLP-33 & 250 & 12.0 & 0.45 & -0.10 & 6.0 & 1969.1 & - & 1 \\
\hline HLP-33 & 300 & 1.0 & 0.80 & -0.04 & 7.5 & 2050.0 & - & 2 \\
\hline HLP-33 & 300 & 2.0 & 0.80 & -0.05 & 5.5 & 2050.9 & - & 1 \\
\hline HLP-33 & 300 & 3.0 & 0.80 & -0.30 & 6.0 & 2018.8 & - & 1 \\
\hline HLP-34 & 200 & 7.1 & 0.25 & -0.02 & 10.0 & 152.3 & 0.8 & \\
\hline HLP-34 & 200 & 24.0 & 0.25 & -0.03 & 6.0 & 102.2 & 3.2 & \\
\hline HLP-34 & 200 & 70.0 & 0.25 & -0.10 & 6.0 & 146.4 & 2.0 & \\
\hline HLP-34 & 200 & 99.0 & 0.25 & -0.08 & 6.0 & 132.5 & 2.8 & \\
\hline HLP-34 & 200 & 130.0 & 0.25 & -0.17 & 6.0 & 252.8 & 5.4 & 3 \\
\hline HLP-34 & 200 & 180.0 & 0.25 & -0.23 & 7.5 & 145.6 & 0.8 & 3 \\
\hline HLP-34 & 200 & 239.0 & 0.25 & -0.22 & 7.0 & 79.3 & 1.1 & 3 \\
\hline HLP-34 & 300 & 2.0 & 0.80 & -0.04 & 5.5 & 412.3 & 7.4 & \\
\hline HLP-34 & 300 & 4.0 & 0.80 & -0.06 & 5.5 & 639.9 & 12.8 & \\
\hline HLP-34 & 300 & 6.0 & 0.80 & -0.08 & 5.5 & 764.7 & 10.9 & \\
\hline
\end{tabular}




\begin{tabular}{|c|c|c|c|c|c|c|c|c|}
\hline Glass ID & $\mathrm{T}\left({ }^{\circ} \mathrm{C}\right)$ & $\mathrm{t}(\mathrm{d})$ & $\mathrm{vH}_{2} \mathrm{O}(\mathrm{mL})$ & & $\mathrm{pH}$ Out & $m_{a}\left(g / m^{2}\right)$ & $2 \sigma\left(\mathrm{g} / \mathrm{m}^{2}\right)$ & notes \\
\hline HLP-34 & 300 & 7.0 & 0.85 & -0.85 & - & 857.9 & 30.9 & \\
\hline HLP-34 & 300 & 8.0 & 0.80 & - & 5.5 & 839.8 & 25.2 & 3 \\
\hline HLP-35 & 200 & 2.0 & 0.25 & -0.02 & 10.0 & 394.5 & 14.3 & 5 \\
\hline HLP-35 & 200 & 3.0 & 0.26 & -0.02 & 6.0 & 659.6 & 33.8 & 5 \\
\hline HLP-35 & 200 & 5.1 & 0.25 & -0.02 & 6.0 & 976.1 & 120.0 & \\
\hline HLP-35 & 200 & 5.8 & 0.25 & -0.02 & 10.0 & 958.3 & 114.8 & \\
\hline HLP-35 & 200 & 6.8 & 0.25 & -0.02 & 6.0 & 966.2 & 117.3 & \\
\hline HLP-35 & 200 & 16.0 & 0.25 & -0.01 & 6.0 & 1178.4 & 175.1 & \\
\hline HLP-35 & 200 & 21.7 & 0.25 & -0.03 & 6.0 & 1164.8 & 85.1 & \\
\hline HLP-35 & 200 & 29.9 & 0.20 & -0.04 & 9.5 & 1375.8 & 63.2 & \\
\hline HLP-35 & 200 & 46.8 & 0.20 & -0.04 & 8.0 & 1574.9 & 133.4 & \\
\hline HLP-35 & 200 & 60.8 & 0.20 & -0.06 & 9.0 & 1594.2 & 139.1 & \\
\hline HLP-35 & 200 & 75.0 & 0.15 & -0.08 & 8.5 & 1915.5 & - & 2 \\
\hline HLP-36 & 200 & 8.7 & 0.26 & -0.06 & 6.0 & 26.6 & 0.1 & 5 \\
\hline HLP-36 & 200 & 15.6 & 0.25 & -0.24 & 10.0 & 253.4 & 1.4 & 5 \\
\hline HLP-36 & 200 & 30.6 & 0.25 & -0.08 & 8.0 & 697.3 & 33.5 & \\
\hline HLP-36 & 200 & 50.0 & 0.25 & -0.06 & 10.0 & 575.1 & 7.7 & \\
\hline HLP-36 & 200 & 70.0 & 0.25 & -0.09 & 9.0 & 1329.4 & 187.3 & \\
\hline HLP-36 & 200 & 99.0 & 0.25 & -0.13 & 9.5 & 1490.3 & - & \\
\hline HLP-36 & 200 & 160.0 & 0.25 & -0.15 & 8.0 & 1518.6 & 234.3 & 3 \\
\hline HLP-36 & 200 & 202.0 & 0.25 & -0.19 & 8.0 & 1418.8 & 218.9 & 3 \\
\hline HLP-36 & 250 & 2.0 & 0.45 & -0.03 & 5.5 & 956.4 & 91.8 & \\
\hline HLP-36 & 250 & 3.0 & 0.45 & -0.04 & 5.5 & 1330.4 & - & \\
\hline HLP-36 & 250 & 4.0 & 0.45 & -0.03 & 6.5 & 1522.1 & 178.4 & \\
\hline HLP-36 & 250 & 6.0 & -0.84 & -0.07 & 9.5 & 1927.0 & - & \\
\hline HLP-36H & 250 & 1.0 & 0.45 & -0.03 & 10.0 & 806.5 & 54.4 & \\
\hline HLP-36H & 250 & 2.0 & 0.45 & -0.03 & 8.5 & 1132.6 & 89.4 & \\
\hline HLP-36H & 250 & 3.0 & 0.45 & -0.04 & 5.5 & 1371.9 & 197.6 & \\
\hline HLP-36H & 250 & 4.0 & 0.45 & -0.05 & 5.5 & 1566.6 & 335.3 & \\
\hline HLP-37 & 200 & 7.1 & 0.25 & -0.02 & 10.0 & 16.4 & 0.2 & 5 \\
\hline HLP-37 & 200 & 24.0 & 0.25 & -0.03 & 6.0 & 100.5 & 1.9 & 5 \\
\hline HLP-37 & 200 & 50.0 & 0.25 & -0.06 & 10.0 & 463.0 & 16.5 & \\
\hline HLP-37 & 200 & 70.0 & 0.25 & -0.09 & 9.0 & 531.6 & 24.6 & \\
\hline HLP-37 & 200 & 99.0 & 0.25 & -0.13 & 9.5 & 556.5 & - & \\
\hline HLP-37 & 200 & 160.0 & 0.25 & -0.15 & 8.0 & 692.1 & 20.5 & \\
\hline HLP-37 & 200 & 202.0 & 0.25 & -0.19 & 7.0 & 553.8 & 30.9 & 3 \\
\hline HLP-37 & 250 & 4.0 & 0.45 & -0.04 & 10.0 & 1890.0 & - & 1 \\
\hline HLP-37 & 250 & 6.0 & 0.45 & -0.05 & 8.5 & 2059.0 & - & 1 \\
\hline HLP-37 & 250 & 9.0 & 0.45 & -0.11 & 10.0 & 1991.1 & - & 1 \\
\hline HLP-37 & 250 & 11.0 & 0.45 & -0.09 & 8.5 & 2024.9 & - & 1 \\
\hline HLP-37 & 250 & 14.0 & 0.45 & -0.13 & 6.0 & 2070.9 & - & 1 \\
\hline HLP-37H & 250 & 1.0 & 0.45 & -0.03 & 9.0 & 962.9 & 75.2 & \\
\hline HLP-37H & 250 & 1.0 & 0.45 & -0.03 & 8.5 & 1552.5 & 381.7 & \\
\hline HLP-37H & 250 & 2.0 & 0.14 & -0.03 & 10.0 & 2074.7 & - & 2 \\
\hline HLP-37H & 250 & 3.0 & 0.45 & -3.03 & 9.5 & 2098.7 & - & 1 \\
\hline HLP-37H & 250 & 4.0 & 0.45 & -0.05 & 6.0 & 2082.1 & - & 1 \\
\hline HLP-37Q & 250 & 0.5 & 0.45 & 0.00 & 10.0 & 874.6 & 34.7 & \\
\hline HLP-37Q & 250 & 1.0 & 0.45 & -0.03 & 10.0 & 1774.7 & 425.9 & \\
\hline HLP-37Q & 250 & 1.0 & 0.45 & -1.42 & 9.0 & 2078.8 & - & \\
\hline HLP-37Q & 250 & 1.5 & 0.45 & 1.36 & - & 1970.3 & - & 1 \\
\hline HLP-38 & 200 & 7.1 & 0.26 & -0.02 & 6.0 & 27.3 & 0.4 & 5 \\
\hline HLP-38 & 200 & 13.2 & 0.25 & -0.02 & 10.0 & 469.8 & 18.3 & \\
\hline
\end{tabular}




\begin{tabular}{|c|c|c|c|c|c|c|c|c|}
\hline Glass ID & $\mathrm{T}\left({ }^{\circ} \mathrm{C}\right)$ & $\mathrm{t}(\mathrm{d})$ & $\mathrm{vH}_{2} \mathrm{O}(\mathrm{mL})$ & & pH Out & $\mathrm{m}_{\mathrm{a}}\left(\mathrm{g} / \mathrm{m}^{2}\right)$ & $2 \sigma\left(\mathrm{g} / \mathrm{m}^{2}\right)$ & notes \\
\hline HLP-38 & 200 & 24.0 & 0.26 & -0.03 & 6.0 & 602.2 & 55.9 & \\
\hline HLP-38 & 200 & 40.0 & 0.20 & -0.06 & 10.0 & 205.4 & 4.2 & \\
\hline HLP-38 & 200 & 60.0 & 0.20 & -0.08 & 7.0 & 369.6 & 5.5 & \\
\hline HLP-38 & 200 & 64.9 & 0.26 & -0.12 & 10.0 & 1283.8 & 68.5 & 3 \\
\hline HLP-38 & 200 & 73.0 & 0.26 & -0.07 & 10.0 & 802.2 & 41.3 & \\
\hline HLP-38 & 200 & 84.1 & 0.25 & -0.09 & 10.0 & 1029.9 & 55.6 & \\
\hline HLP-38 & 200 & 92.0 & 0.26 & -0.10 & 8.0 & 1272.3 & 91.6 & \\
\hline HLP-38 & 200 & 120.0 & 0.20 & -0.12 & 7.0 & 912.0 & 15.8 & \\
\hline HLP-38 & 200 & 140.0 & 0.25 & -0.12 & 9.0 & 1297.4 & 33.4 & 3 \\
\hline HLP-38 & 250 & 5.0 & 0.45 & -0.04 & 5.5 & 1475.6 & 151.8 & \\
\hline HLP-38 & 250 & 10.0 & 0.45 & -0.09 & 5.5 & 1955.8 & - & 2 \\
\hline HLP-38 & 250 & 13.0 & 0.45 & -0.11 & 5.5 & 2068.8 & - & 1 \\
\hline HLP-38H & 250 & 2.0 & 0.45 & -0.03 & 7.0 & 785.1 & 34.2 & \\
\hline HLP-38H & 250 & 3.0 & 0.45 & -0.04 & 9.0 & 807.7 & 48.4 & \\
\hline HLP-38H & 250 & 4.0 & 0.45 & -0.05 & 6.0 & 1307.4 & 175.2 & \\
\hline HLP-39 & 200 & 2.0 & 0.25 & -0.02 & 10.0 & 194.8 & 8.7 & 6 \\
\hline HLP-39 & 200 & 3.9 & 0.25 & -0.03 & 6.0 & 13.2 & 0.3 & \\
\hline HLP-39 & 200 & 5.3 & 0.25 & -0.02 & 10.0 & 13.7 & 0.6 & \\
\hline HLP-39 & 200 & 10.0 & 0.20 & -0.03 & 9.0 & 94.1 & 1.8 & \\
\hline HLP-39 & 200 & 14.0 & 0.55 & -0.03 & 8.0 & 93.7 & 1.4 & \\
\hline HLP-39 & 200 & 18.0 & 0.20 & -0.03 & 8.5 & 134.1 & 2.0 & \\
\hline HLP-39 & 200 & 25.0 & 0.20 & -0.03 & 8.5 & 188.5 & 5.8 & \\
\hline HLP-39 & 250 & 0.5 & 0.45 & -0.02 & 8.0 & 878.3 & 33.4 & \\
\hline HLP-39 & 250 & 1.0 & 0.45 & -0.03 & 5.5 & 1449.1 & 122.7 & \\
\hline HLP-39 & 250 & 2.0 & 0.45 & -0.04 & 5.5 & 1985.7 & - & 2 \\
\hline HLP-39 & 250 & 3.0 & 0.45 & -0.03 & 6.0 & 2075.7 & - & 1 \\
\hline HLP-39 & 250 & 5.0 & 0.45 & -0.05 & 6.0 & 1986.9 & - & 1 \\
\hline HLP-39 & 250 & 7.0 & 0.45 & -0.06 & 6.0 & 2093.0 & - & 1 \\
\hline HLP-39 & 300 & 1.0 & 0.80 & -0.06 & 9.0 & 2219.9 & - & 2 \\
\hline HLP-39 & 300 & 1.5 & 0.80 & -0.06 & 9.0 & 2025.2 & - & 1 \\
\hline HLP-39 & 300 & 2.0 & 0.80 & -0.06 & 9.0 & 2114.8 & - & 1 \\
\hline HLP-40 & 200 & 51.1 & 0.25 & -0.10 & 8.0 & 179.0 & 6.5 & \\
\hline HLP-40 & 200 & 88.0 & 0.25 & -0.11 & 10.0 & 199.6 & 8.1 & \\
\hline HLP-40 & 200 & 140.0 & 0.25 & -0.16 & 8.5 & 262.9 & 12.8 & \\
\hline HLP-40 & 200 & 179.0 & 0.25 & -0.20 & 8.5 & 381.0 & 8.7 & \\
\hline HLP-40 & 200 & 220.0 & 0.25 & -0.23 & - & 290.7 & 8.8 & 3 \\
\hline HLP-40 & 300 & 3.0 & 0.80 & -0.08 & 5.5 & 2128.2 & - & 2 \\
\hline HLP-40H & 275 & 5.0 & 0.62 & -0.04 & 8.5 & 0.0 & - & \\
\hline HLP-40H & 275 & 10.0 & 0.62 & -0.05 & 7.5 & 515.8 & - & \\
\hline HLP-40H & 275 & 15.0 & 0.62 & -0.06 & 10.0 & 2043.9 & - & 2 \\
\hline HLP-40H & 275 & 20.0 & 0.62 & -0.08 & 6.0 & 2029.1 & - & 1 \\
\hline HLP-40Q & 275 & 5.0 & 0.62 & -0.04 & 6.0 & 510.3 & 9.2 & \\
\hline HLP-40Q & 275 & 10.0 & 0.62 & -0.05 & 7.5 & 836.2 & 39.3 & \\
\hline HLP-40Q & 275 & 15.0 & 0.62 & -0.06 & 6.0 & 1514.0 & - & \\
\hline HLP-40Q & 275 & 20.0 & 0.62 & -0.09 & 8.0 & 2144.7 & - & 2 \\
\hline HLP-41 & 200 & 2.0 & 0.25 & -0.02 & 10.0 & 11.2 & 0.1 & 5 \\
\hline HLP-41 & 200 & 5.3 & 0.25 & -0.02 & 10.0 & 28.0 & 0.1 & 5 \\
\hline HLP-41 & 200 & 11.9 & 0.25 & -0.03 & 10.0 & 43.7 & 0.8 & 5 \\
\hline HLP-41 & 200 & 35.6 & 0.25 & -0.07 & 8.0 & 215.2 & 5.4 & \\
\hline HLP-41 & 200 & 35.6 & 0.26 & -0.08 & 6.0 & 322.4 & 8.2 & \\
\hline HLP-41 & 200 & 35.6 & 0.26 & -0.08 & 6.0 & 323.7 & 8.6 & \\
\hline HLP-41 & 200 & 50.8 & 0.26 & -0.09 & 6.0 & 349.0 & 15.2 & \\
\hline
\end{tabular}




\begin{tabular}{|c|c|c|c|c|c|c|c|c|}
\hline Glass ID & $\mathrm{T}\left({ }^{\circ} \mathrm{C}\right)$ & $t(d)$ & $\mathrm{vH}_{2} \mathrm{O}(\mathrm{mL})$ & & pH Out & $\mathrm{m}_{\mathrm{a}}\left(\mathrm{g} / \mathrm{m}^{2}\right)$ & $2 \sigma\left(\mathrm{g} / \mathrm{m}^{2}\right)$ & notes \\
\hline HLP-41 & 200 & 50.8 & 0.26 & -0.09 & 6.0 & 355.8 & 11.4 & \\
\hline HLP-41 & 200 & 70.0 & 0.25 & -0.09 & 10.0 & 639.9 & 42.7 & \\
\hline HLP-41 & 200 & 100.0 & 0.25 & -0.11 & 8.0 & 850.2 & 92.1 & \\
\hline HLP-41 & 200 & 123.5 & 0.25 & -0.15 & 8.0 & 1586.5 & 55.7 & 3 \\
\hline HLP-41 & 200 & 140.0 & 0.25 & -0.11 & 6.0 & 1329.5 & 191.4 & \\
\hline HLP-41 & 300 & 1.0 & 0.80 & -0.05 & 9.0 & 2125.9 & - & 2 \\
\hline HLP-41 & 300 & 1.3 & 0.80 & -0.24 & 9.0 & 2055.3 & - & 1 \\
\hline HLP-41 & 300 & 2.0 & 0.80 & -0.06 & 9.0 & 2092.2 & - & 1 \\
\hline HLP-41H & 225 & 2.0 & 0.31 & -0.03 & 10.0 & 72.3 & 0.3 & \\
\hline HLP-41H & 225 & 4.0 & 0.31 & -0.03 & 10.0 & -26.4 & -0.2 & \\
\hline HLP-41H & 225 & 6.0 & 0.31 & -0.03 & 9.0 & 92.7 & 1.1 & \\
\hline HLP-41H & 250 & 3.0 & 0.45 & -0.03 & 10.0 & 2188.4 & - & 2 \\
\hline HLP-41H & 250 & 5.0 & 0.45 & -0.04 & 5.5 & 2107.1 & - & 1 \\
\hline HLP-41H & 250 & 10.0 & 0.45 & -0.07 & 6.0 & 2102.9 & - & 1 \\
\hline HLP-41H & 250 & 12.0 & 0.45 & -0.02 & 10.0 & 2233.9 & - & 1 \\
\hline HLP-41Q & 250 & 3.0 & 0.45 & -0.03 & 10.0 & 2007.2 & - & 2 \\
\hline HLP-41Q & 250 & 5.0 & 0.45 & -0.04 & 5.5 & 2027.4 & - & 1 \\
\hline HLP-41Q & 250 & 10.0 & 0.45 & -0.08 & 6.0 & 2048.4 & - & 1 \\
\hline HLP-41Q & 250 & 12.0 & 0.45 & -0.11 & 5.5 & 1986.8 & - & 1 \\
\hline HLP-42 & 200 & 7.1 & 0.25 & -0.01 & 6.0 & 0.0 & - & 5 \\
\hline HLP-42 & 200 & 13.2 & 0.25 & -0.02 & 6.0 & 143.3 & 2.1 & \\
\hline HLP-42 & 200 & 24.0 & 0.25 & -0.04 & 6.0 & 142.4 & 0.7 & \\
\hline HLP-42 & 200 & 30.8 & 0.25 & -0.05 & 6.0 & 86.1 & 0.8 & \\
\hline HLP-42 & 200 & 49.0 & 0.25 & -0.09 & 7.5 & 115.0 & 1.1 & \\
\hline HLP-42 & 200 & 70.0 & 0.25 & -0.09 & 8.0 & 130.6 & 0.6 & \\
\hline HLP-42 & 200 & 88.0 & 0.25 & -0.10 & 6.5 & 101.8 & 1.0 & \\
\hline HLP-42 & 200 & 120.0 & 0.25 & -0.13 & 5.5 & 101.9 & 1.0 & \\
\hline HLP-42 & 200 & 301.0 & 0.25 & -0.20 & - & 87.6 & 0.4 & 3 \\
\hline HLP-42 & 300 & 3.0 & 0.80 & -0.06 & 6.0 & 2104.2 & - & 2 \\
\hline HLP-42H & 250 & 3.0 & 0.45 & -0.03 & 5.5 & 0.0 & 0.0 & \\
\hline HLP-42H & 250 & 5.0 & 0.45 & -0.06 & 5.5 & 260.8 & 1.3 & \\
\hline HLP-42H & 250 & 10.0 & 0.45 & -0.10 & 5.5 & 260.0 & 3.9 & \\
\hline HLP-42H & 250 & 12.0 & 0.45 & -0.16 & 5.5 & 556.2 & 6.6 & \\
\hline HLP-43 & 200 & 2.0 & 0.25 & -0.02 & 10.0 & 18.3 & 0.1 & 5 \\
\hline HLP-43 & 200 & 5.8 & 0.25 & -0.02 & 10.0 & 142.2 & 0.7 & 5 \\
\hline HLP-43 & 200 & 11.9 & 0.25 & -0.03 & 10.0 & 150.1 & 0.8 & 5 \\
\hline HLP-43 & 200 & 49.0 & 0.20 & -0.07 & 6.0 & 410.3 & 1.7 & \\
\hline HLP-43 & 200 & 70.0 & 0.20 & -0.09 & 7.0 & 454.8 & 3.6 & \\
\hline HLP-43 & 200 & 100.0 & 0.20 & -0.12 & 6.0 & 373.2 & 8.2 & 3 \\
\hline HLP-43 & 200 & 101.0 & 0.20 & -0.09 & 6.5 & 641.4 & 7.4 & \\
\hline HLP-43 & 200 & 150.0 & 0.20 & -0.16 & 6.0 & 382.3 & 3.6 & 3 \\
\hline HLP-43 & 200 & 160.0 & 0.20 & -0.14 & 7.5 & 531.7 & 4.3 & 3 \\
\hline HLP-43 & 200 & 220.0 & 0.20 & -0.19 & 7.0 & 376.1 & 4.7 & 3 \\
\hline HLP-43 & 200 & 225.0 & 0.20 & -0.19 & 7.0 & 318.3 & 4.6 & 3 \\
\hline HLP-43 & 250 & 2.1 & 0.45 & -0.03 & 8.0 & 625.3 & 9.0 & \\
\hline HLP-43 & 250 & 3.0 & 0.45 & -0.04 & 5.5 & 883.5 & 15.3 & \\
\hline HLP-43 & 250 & 4.0 & 0.45 & -0.04 & 7.5 & 1103.5 & 22.1 & \\
\hline HLP-43 & 250 & 5.0 & 0.45 & -0.06 & 8.0 & 1305.3 & 80.0 & \\
\hline HLP-43 & 250 & 5.9 & 0.45 & -0.06 & 6.0 & 1538.6 & 100.7 & \\
\hline HLP-43 & 250 & 10.0 & 0.45 & -0.07 & 7.0 & 1955.2 & - & 1 \\
\hline HLP-43 & 300 & 0.5 & 0.80 & -0.02 & 5.5 & 712.9 & 6.5 & \\
\hline HLP-43 & 300 & 1.0 & 0.85 & -0.03 & 8.0 & 1301.6 & 50.2 & \\
\hline
\end{tabular}




\begin{tabular}{|c|c|c|c|c|c|c|c|c|}
\hline Glass ID & $\mathrm{T}\left({ }^{\circ} \mathrm{C}\right)$ & $t(d)$ & $\mathrm{vH}_{2} \mathrm{O}(\mathrm{mL})$ & & $\mathrm{pH}$ Out & $\mathrm{m}_{\mathrm{a}}\left(\mathrm{g} / \mathrm{m}^{2}\right)$ & $2 \sigma\left(\mathrm{g} / \mathrm{m}^{2}\right)$ & notes \\
\hline HLP-43 & 300 & 1.5 & 0.85 & -0.04 & 9.0 & 1535.0 & 97.5 & \\
\hline HLP-43 & 300 & 2.0 & 0.85 & -0.03 & 9.0 & 2022.0 & - & 2 \\
\hline HLP-44 & 200 & 30.0 & 0.20 & -0.05 & 8.5 & 348.2 & 2.9 & \\
\hline HLP-44 & 200 & 49.0 & 0.20 & -0.08 & 6.0 & 486.8 & 5.0 & \\
\hline HLP-44 & 200 & 61.0 & 0.20 & -0.08 & 7.0 & 525.0 & 23.9 & \\
\hline HLP-44 & 200 & 100.0 & 0.20 & -0.08 & 6.0 & 759.4 & 19.9 & \\
\hline HLP-44 & 200 & 101.0 & 0.20 & -0.10 & 6.0 & 664.4 & 15.2 & \\
\hline HLP-44 & 200 & 120.0 & 0.24 & -0.05 & 8.5 & 1062.7 & 21.4 & 6 \\
\hline HLP-44 & 200 & 150.0 & 0.20 & -0.15 & .6 .5 & 512.7 & 6.8 & 3 \\
\hline HLP-44 & 200 & 201.0 & 0.26 & -0.19 & 8.5 & 688.0 & 6.2 & 3 \\
\hline HLP-44 & 200 & 260.0 & 0.25 & -0.18 & $\sim 9.5$ & 709.1 & 23.0 & 3 \\
\hline HLP-44 & 200 & 271.0 & 0.25 & -0.19 & - & 809.3 & 19.4 & 3 \\
\hline HLP-44 & 200 & 280.0 & 0.37 & -0.25 & 8.5 & 1667.1 & 241.1 & 3 \\
\hline HLP-44 & 250 & 2.0 & 0.45 & -0.03 & 5.5 & 828.3 & 6.8 & \\
\hline HLP-44 & 250 & 3.0 & 0.45 & -0.04 & 8.0 & 1042.0 & 92.5 & \\
\hline HLP-44 & 250 & 4.0 & 0.45 & -0.05 & 8.0 & 1284.4 & 34.3 & \\
\hline HLP-44 & 250 & 5.0 & 0.45 & -0.05 & 8.0 & 1445.2 & 78.0 & \\
\hline HLP-44 & 250 & 5.9 & 0.45 & -0.06 & 6.0 & 1696.3 & 116.3 & \\
\hline HLP-44 & 250 & 10.0 & 0.45 & -0.08 & 8.0 & 1963.6 & - & 1 \\
\hline HLP-45 & 200 & 30.0 & 0.20 & -0.03 & 6.0 & 432.4 & 6.8 & \\
\hline HLP-45 & 200 & 49.0 & 0.20 & -0.07 & 8.5 & 607.0 & 6.3 & \\
\hline HLP-45 & 200 & 61.0 & 0.20 & -0.11 & 6.0 & 476.2 & 21.7 & 3 \\
\hline HLP-45 & 200 & 100.0 & 0.20 & -0.09 & 7.0 & 926.0 & 15.9 & \\
\hline HLP-45 & 200 & 101.0 & 0.20 & -0.09 & 8.5 & 722.6 & 7.8 & \\
\hline HLP-45 & 200 & 120.0 & 0.24 & -0.05 & 8.5 & 928.8 & 23.1 & \\
\hline HLP-45 & 200 & 150.0 & 0.20 & -0.11 & 7.5 & 566.0 & 7.5 & 3 \\
\hline HLP-45 & 200 & 201.0 & 0.26 & -0.19 & 8.5 & 740.3 & 6.6 & 3 \\
\hline HLP-45 & 200 & 260.0 & 0.25 & -0.18 & $\sim 9.5$ & 858.3 & 27.9 & 3 \\
\hline HLP-45 & 200 & 271.0 & 0.25 & -0.19 & - & 656.9 & 15.8 & 3 \\
\hline HLP-45 & 200 & 280.0 & 0.37 & -0.25 & 8.5 & 1679.9 & 243.0 & 3 \\
\hline HLP-45 & 250 & 2.0 & 0.45 & -0.03 & 5.5 & 1145.2 & 25.0 & \\
\hline HLP-45 & 250 & 3.0 & 0.45 & -0.04 & 8.5 & 1462.3 & 27.0 & \\
\hline HLP-45 & 250 & 4.0 & 0.45 & -0.05 & 5.5 & 1695.1 & 166.4 & \\
\hline HLP-45 & 250 & 5.0 & 3.43 & -0.04 & 10.0 & 1878.4 & 405.7 & \\
\hline HLP-45 & 250 & 5.9 & 0.45 & -0.04 & 5.0 & 2011.1 & - & \\
\hline HLP-46 & 90 & 444.5 & 0.07 & -0.01 & 5.5 & 5.1 & 0.1 & 4 \\
\hline HLP-46 & 90 & 502.5 & 0.07 & -0.01 & 8.0 & 26.2 & 0.1 & 4 \\
\hline HLP-46 & 90 & 599.5 & 0.07 & -0.01 & 9.0 & 9.8 & 0.0 & 4 \\
\hline HLP-46 & 90 & 699.5 & 0.07 & -0.03 & 5.5 & 6.4 & 0.1 & 4 \\
\hline HLP-46 & 90 & 800.5 & 0.07 & 0.00 & - & 5.0 & 0.0 & 4 \\
\hline HLP-46 & 90 & 884.7 & 0.06 & -0.02 & 5.5 & 5.1 & 0.1 & 4 \\
\hline HLP-46 & 125 & 91.0 & 0.08 & -0.02 & 5.5 & 5.0 & 0.0 & \\
\hline HLP-46 & 125 & 116.0 & 0.08 & -0.02 & 5.5 & 17.2 & 0.2 & \\
\hline HLP-46 & 125 & 144.0 & 0.08 & -0.02 & 5.5 & 21.3 & 0.2 & \\
\hline HLP-46 & 125 & 168.0 & 0.08 & -0.02 & 6.0 & 12.6 & 0.0 & \\
\hline HLP-46 & 125 & 193.0 & 0.08 & -0.02 & 9.5 & 22.5 & 0.1 & \\
\hline HLP-46 & 125 & 220.0 & 0.08 & -0.03 & 6.5 & 32.0 & 0.1 & \\
\hline HLP-46 & 150 & 5.0 & 0.10 & -0.01 & 5.5 & 124.2 & 2.6 & 5 \\
\hline HLP-46 & 150 & 5.1 & 0.10 & -0.01 & 5.5 & 0.0 & - & 4 \\
\hline HLP-46 & 150 & 7.3 & 0.10 & -0.07 & 5.5 & 176.2 & 1.9 & 5 \\
\hline HLP-46 & 150 & 7.3 & 0.10 & -0.01 & 5.5 & 377.8 & 5.3 & 5 \\
\hline HLP-46 & 150 & 15.0 & 0.10 & -0.01 & 5.8 & 1088.6 & 26.8 & \\
\hline
\end{tabular}




\begin{tabular}{|c|c|c|c|c|c|c|c|c|}
\hline Glass ID & $\mathrm{T}\left({ }^{\circ} \mathrm{C}\right)$ & $t(d)$ & $\mathrm{vH}_{2} \mathrm{O}(\mathrm{mL})$ & & $\mathrm{pH}$ Out & $\mathrm{m}_{\mathrm{a}}\left(\mathrm{g} / \mathrm{m}^{2}\right)$ & $2 \sigma\left(\mathrm{g} / \mathrm{m}^{2}\right)$ & notes \\
\hline HLP-46 & 150 & 15.0 & 0.10 & -0.02 & 5.8 & 1138.2 & 44.0 & \\
\hline HLP-46 & 150 & 20.0 & 0.10 & -0.02 & 10.0 & 942.0 & 96.9 & 6 \\
\hline HLP-46 & 150 & 23.3 & 0.10 & -0.01 & 6.1 & 1402.7 & 76.1 & \\
\hline HLP-46 & 150 & 23.3 & 0.10 & -0.01 & 6.1 & 1585.0 & 128.4 & \\
\hline HLP-46 & 150 & 27.8 & 0.10 & -0.01 & 10.0 & 1556.9 & 112.1 & \\
\hline HLP-46 & 150 & 34.3 & 0.10 & -0.02 & - & 1592.6 & 201.3 & \\
\hline HLP-46 & 150 & 34.3 & 0.10 & -0.02 & - & 1592.4 & 117.0 & \\
\hline HLP-46 & 150 & 41.2 & 0.10 & -0.02 & 5.5 & 1597.5 & 222.0 & \\
\hline HLP-46 & 150 & 41.2 & 0.10 & -0.02 & 5.8 & 1684.9 & 262.4 & \\
\hline HLP-46 & 175 & 1.0 & 0.14 & -0.02 & 4.8 & 0.0 & - & 4 \\
\hline HLP-46 & 175 & 2.0 & 0.14 & -0.02 & 4.8 & 39.0 & - & 5 \\
\hline HLP-46 & 175 & 2.0 & 0.14 & -0.02 & 4.8 & 195.0 & 4.3 & 5 \\
\hline HLP-46 & 175 & 3.1 & 0.15 & -0.02 & 4.7 & 988.9 & 18.5 & \\
\hline HLP-46 & 175 & 5.1 & 0.14 & -0.02 & 5.5 & 1171.2 & 58.2 & \\
\hline HLP-46 & 175 & 6.2 & 0.15 & -0.02 & 5.5 & 1423.7 & 58.7 & \\
\hline HLP-46 & 175 & 6.2 & 0.15 & -0.02 & 5.5 & 1208.3 & 64.3 & \\
\hline HLP-46 & 175 & 8.1 & 0.15 & -0.02 & 10.0 & 1536.9 & 190.3 & \\
\hline HLP-46 & 175 & 8.1 & 0.15 & -0.03 & 5.0 & 1435.5 & 150.6 & \\
\hline HLP-46 & 175 & 10.4 & 0.14 & 0.00 & 8.0 & 1496.7 & 248.7 & \\
\hline HLP-46 & 175 & 11.1 & 0.15 & -0.03 & 5.0 & 1779.2 & 115.4 & \\
\hline HLP-46 & 175 & 11.1 & 0.14 & -0.03 & 5.0 & 1561.9 & 177.8 & \\
\hline HLP-46 & 175 & 12.0 & 0.14 & -0.02 & 5.0 & 1850.7 & 277.8 & \\
\hline HLP-46 & 175 & 12.0 & 0.14 & -0.01 & 10.0 & 1862.3 & 106.7 & \\
\hline HLP-46 & 200 & 1.1 & 0.20 & -0.03 & 5.0 & 891.5 & 19.4 & \\
\hline HLP-46 & 200 & 1.1 & 0.20 & -0.02 & 5.0 & 897.8 & 21.5 & \\
\hline HLP-46 & 200 & 2.1 & 0.20 & -0.02 & 5.0 & 1053.3 & 104.8 & \\
\hline HLP-46 & 200 & 2.1 & 0.20 & -0.02 & 5.0 & 1289.2 & 33.3 & \\
\hline HLP-46 & 200 & 3.0 & 0.20 & -0.02 & 5.3 & 1476.4 & 50.1 & \\
\hline HLP-46 & 200 & 3.0 & 0.20 & -0.02 & 5.0 & 1567.8 & 161.3 & \\
\hline HLP-46 & 200 & 3.9 & 0.20 & -0.03 & 5.0 & 1693.9 & 103.5 & \\
\hline HLP-46 & 200 & 3.9 & 0.20 & -0.03 & 5.0 & 1748.4 & 139.1 & \\
\hline HLP-46 & 200 & 4.9 & 0.20 & -0.03 & 5.0 & 1871.3 & 155.6 & \\
\hline HLP-46 & 200 & 4.9 & 0.20 & -0.03 & 5.0 & 1808.7 & 179.0 & \\
\hline HLP-47 & 200 & 3.0 & -1.80 & -0.05 & 7.5 & 328.8 & 16.5 & Jun-00-B \\
\hline HLP-47 & 200 & 5.0 & 0.25 & -0.02 & 10.0 & 513.3 & 6.9 & Sep-99 \\
\hline HLP-47 & 200 & 5.0 & 0.20 & -0.02 & 6.5 & 913.2 & 117.4 & Jun-00-A \\
\hline HLP-47 & 200 & 5.0 & 0.21 & -0.03 & 10.0 & 571.5 & 7.6 & Jun-00-B \\
\hline HLP-47 & 200 & 10.0 & 0.19 & 0.17 & 6.5 & 1143.8 & 24.6 & Jun-00-A \\
\hline HLP-47 & 200 & 10.0 & 0.20 & -0.03 & 8.5 & 1300.7 & 87.1 & Jun-00-B \\
\hline HLP-47 & 200 & 10.0 & 0.20 & -0.03 & 7.5 & 1441.2 & 54.6 & Jun-00-B \\
\hline HLP-47 & 200 & 10.0 & 0.20 & -0.02 & 8.0 & 1040.6 & 124.9 & Dec-99 \\
\hline HLP-47 & 200 & 15.0 & 0.19 & -0.03 & 6.5 & 1531.4 & 44.1 & Jun-00-A \\
\hline HLP-47 & 200 & 15.0 & 0.25 & -0.03 & 8.0 & 1273.2 & 138.4 & Sep-99 \\
\hline HLP-47 & 200 & 15.0 & 0.21 & -0.03 & 8.5 & 1800.6 & - & Jun-00-B \\
\hline HLP-47 & 200 & 18.0 & 0.20 & -0.03 & 9.0 & 1431.6 & 73.6 & Dec-99 \\
\hline HLP-47 & 200 & 20.0 & 0.20 & -0.07 & 8.0 & 1903.1 & - & Jun-00-A \\
\hline HLP-47 & 200 & 20.0 & 0.19 & -0.03 & 5.5 & 1794.1 & - & Jun-00-B, 1 \\
\hline HLP-47 & 200 & 20.0 & 0.20 & -0.03 & 8.5 & 1797.5 & - & Jun-00-B, 1 \\
\hline HLP-47 & 200 & 22.0 & 0.25 & -0.02 & 6.0 & 1705.3 & 23.0 & Sep-99 \\
\hline HLP-47 & 200 & 29.9 & 0.20 & -0.03 & 8.0 & 2011.9 & - & Sep-99 \\
\hline HLP-47 & 200 & 30.0 & 0.20 & -0.04 & 5.5 & 1703.4 & - & Jun-00-B, 1 \\
\hline HLP-48 & 90 & 719.5 & 0.06 & -0.02 & 5.5 & 58.7 & 0.6 & \\
\hline
\end{tabular}




\begin{tabular}{|c|c|c|c|c|c|c|c|c|}
\hline Glass ID & $\mathrm{T}\left({ }^{\circ} \mathrm{C}\right)$ & $t(d)$ & $\mathrm{vH}_{2} \mathrm{O}(\mathrm{mL})$ & & pH Out & $\mathrm{m}_{\mathrm{a}}\left(\mathrm{g} / \mathrm{m}^{2}\right)$ & $2 \sigma\left(\mathrm{g} / \mathrm{m}^{2}\right)$ & notes \\
\hline HLP-48 & 150 & 72.0 & 0.16 & -0.02 & 6.2 & 441.4 & 6.3 & \\
\hline HLP-48 & 150 & 72.0 & 0.15 & -0.04 & 10.0 & 647.4 & 9.6 & \\
\hline HLP-48 & 150 & 130.8 & 0.10 & -0.05 & 10.0 & 547.9 & 7.0 & \\
\hline HLP-48 & 150 & 188.6 & 0.16 & -0.04 & - & 1058.8 & 51.1 & \\
\hline HLP-48 & 150 & 188.6 & 0.15 & -0.05 & - & 1102.6 & 68.2 & \\
\hline HLP-48 & 150 & 214.7 & 0.15 & -0.04 & 10.0 & 1053.9 & 87.3 & \\
\hline HLP-48 & 150 & 214.7 & 0.16 & -0.10 & 10.0 & 1004.1 & 63.5 & \\
\hline HLP-48 & 150 & 249.7 & 0.16 & -0.05 & - & 1025.1 & 52.7 & \\
\hline HLP-48 & 150 & 249.7 & 0.16 & -0.05 & 10.0 & 1099.8 & 50.3 & \\
\hline HLP-48 & 150 & 299.6 & 0.16 & -0.07 & 10.0 & 852.7 & 82.4 & \\
\hline HLP-48 & 150 & 349.5 & 0.15 & -0.06 & - & 957.8 & 50.5 & \\
\hline HLP-48 & 175 & 14.7 & 0.15 & -0.03 & 5.3 & 633.8 & 7.8 & \\
\hline HLP-48 & 175 & 14.7 & 0.14 & -0.02 & 6.1 & 968.8 & 15.6 & \\
\hline HLP-48 & 175 & 26.1 & 0.14 & -0.08 & 7.5 & 1224.1 & 97.9 & \\
\hline HLP-48 & 175 & 41.9 & 0.15 & -0.03 & 6.1 & 1204.8 & 27.9 & \\
\hline HLP-48 & 175 & 41.9 & 0.15 & -0.03 & 5.8 & 1396.7 & 102.9 & \\
\hline HLP-48 & 175 & 68.9 & 0.15 & -0.05 & 6.1 & 1460.2 & 177.9 & \\
\hline HLP-48 & 175 & 68.9 & 0.14 & -0.04 & 6.1 & 1617.3 & 237.8 & \\
\hline HLP-48 & 175 & 78.6 & 0.15 & -0.05 & 5.8 & 1727.0 & 223.2 & \\
\hline HLP-48 & 175 & 78.6 & 0.15 & -0.05 & 5.8 & 1874.7 & 184.7 & \\
\hline HLP-48 & 200 & 6.2 & 0.25 & -0.03 & 5.5 & 761.5 & 8.7 & 2 samp,May99 \\
\hline HLP-48 & 200 & 6.2 & 0.25 & -0.03 & 5.8 & 880.6 & 25.6 & 2 samp,May99 \\
\hline HLP-48 & 200 & 7.8 & 0.20 & -0.02 & 10.0 & 627.0 & 8.5 & 1 samp, Dec99 \\
\hline HLP-48 & 200 & 10.0 & 0.20 & -0.02 & 10.0 & 789.2 & 12.5 & 1 samp, Dec99 \\
\hline HLP-48 & 200 & 10.0 & 0.20 & -0.03 & 6.0 & 792.0 & 18.2 & 1 samp, Dec99 \\
\hline HLP-48 & 200 & 10.0 & 0.20 & -0.02 & 6.0 & 738.8 & 13.1 & RR-Lab A \\
\hline HLP-48 & 200 & 10.0 & 0.21 & -0.02 & 10.0 & 817.4 & 18.1 & RR-Lab A \\
\hline HLP-48 & 200 & 10.0 & 0.20 & -0.02 & 10.0 & 789.2 & 12.5 & RR-Lab B \\
\hline HLP-48 & 200 & 10.0 & 0.20 & -0.03 & 6.0 & 792.0 & 18.2 & RR-Lab B \\
\hline HLP-48 & 200 & 11.2 & 0.25 & -0.04 & 5.8 & 1057.0 & 10.0 & 2 samp,May99 \\
\hline HLP-48 & 200 & 11.2 & 0.25 & -0.03 & 6.1 & 1272.7 & 49.1 & 2 samp,May99 \\
\hline HLP-48 & 200 & 14.0 & 0.26 & -0.04 & 5.8 & 1278.1 & 46.6 & 2 samp,May99 \\
\hline HLP-48 & 200 & 14.0 & 0.25 & -0.04 & 5.8 & 1371.6 & 153.5 & 2 samp,May99 \\
\hline HLP-48 & 200 & 18.0 & 0.20 & -0.03 & 8.5 & 1222.0 & 103.5 & 1 samp, Dec99 \\
\hline HLP-48 & 200 & 20.0 & 0.20 & -0.02 & 10.0 & 1208.3 & 81.6 & 1 samp, Dec99 \\
\hline HLP-48 & 200 & 20.0 & 0.20 & -0.02 & 8.5 & 1324.0 & 348.3 & 1 samp, Dec99 \\
\hline HLP-48 & 200 & 20.0 & 0.20 & -0.03 & 10.0 & 1141.1 & 36.8 & RR-Lab A \\
\hline HLP-48 & 200 & 20.0 & 0.20 & -0.03 & 6.0 & 1403.8 & 128.3 & RR-Lab A \\
\hline HLP-48 & 200 & 20.0 & 0.20 & -0.02 & 10.0 & 1208.3 & 81.6 & RR-Lab B \\
\hline HLP-48 & 200 & 20.0 & 0.20 & -0.02 & 8.5 & 1324.0 & 348.3 & RR-Lab B \\
\hline HLP-48 & 200 & 22.2 & 0.25 & -0.06 & 5.9 & 1581.9 & 248.5 & 2 samp,May99 \\
\hline HLP-48 & 200 & 22.2 & 0.25 & -0.06 & 5.5 & 1704.4 & 217.8 & 2 samp,May99 \\
\hline HLP-48 & 250 & 1.1 & 0.44 & 0.09 & 10.0 & 976.6 & 17.6 & \\
\hline HLP-48 & 250 & 1.1 & 0.45 & 0.00 & 6.0 & 1049.7 & 70.5 & \\
\hline HLP-48 & 250 & 1.3 & 0.46 & -0.03 & 8.0 & 1243.1 & 46.3 & \\
\hline HLP-48 & 250 & 1.4 & 0.45 & - & 10.0 & 1068.4 & 48.8 & \\
\hline HLP-48 & 250 & 2.1 & 0.46 & -0.03 & 8.0 & 1699.5 & 153.0 & \\
\hline HLP-48 & 250 & 2.2 & 0.45 & -0.03 & 10.0 & 1507.6 & 95.8 & \\
\hline HLP-48 & 250 & 3.0 & 0.46 & -0.03 & 6.0 & 1988.1 & - & 2 \\
\hline HLP-49 & 200 & 7.1 & 0.25 & -0.01 & 6.0 & 167.4 & 1.1 & 5 \\
\hline HLP-49 & 200 & 13.2 & 0.25 & -0.02 & 6.0 & 262.0 & 1.6 & 5 \\
\hline HLP-49 & 200 & 24.0 & 0.25 & -0.04 & 6.0 & 600.5 & 12.2 & \\
\hline
\end{tabular}




\begin{tabular}{|c|c|c|c|c|c|c|c|c|}
\hline Glass ID & $\mathrm{T}\left({ }^{\circ} \mathrm{C}\right)$ & $\mathrm{t}(\mathrm{d})$ & $\mathrm{vH}_{2} \mathrm{O}(\mathrm{mL})$ & & pH Out & $\mathrm{m}_{\mathrm{a}}\left(\mathrm{g} / \mathrm{m}^{2}\right)$ & $2 \sigma\left(\mathrm{g} / \mathrm{m}^{2}\right)$ & notes \\
\hline HLP-49 & 200 & 51.1 & 0.25 & -0.10 & 8.0 & 672.9 & 17.5 & \\
\hline HLP-49 & 200 & 88.0 & 0.25 & -0.11 & 10.0 & 757.5 & 28.5 & \\
\hline HLP-49 & 200 & 140.0 & 0.25 & -0.16 & 8.5 & 670.1 & 74.2 & 3 \\
\hline HLP-49 & 200 & 178.9 & 0.25 & -0.20 & 8.5 & 634.2 & 24.4 & 3 \\
\hline HLP-49 & 200 & 220.0 & 0.25 & -0.23 & - & 639.2 & 15.3 & 3 \\
\hline HLP-49 & 275 & 2.0 & 0.62 & -0.06 & 5.5 & 1992.6 & - & 2 \\
\hline HLP-49 & 275 & 4.0 & 0.62 & -0.06 & 5.5 & 2115.0 & - & 1 \\
\hline HLP-49 & 275 & 5.0 & 0.62 & -0.08 & 5.5 & 2118.9 & - & 1 \\
\hline HLP-49 & 275 & 7.0 & 0.62 & -0.17 & 5.5 & 2150.3 & - & 1 \\
\hline HLP-49 & 275 & 9.0 & 0.62 & -0.30 & 5.5 & 2110.8 & - & 1 \\
\hline HLP-49 & 300 & 3.0 & 0.80 & -0.08 & 5.5 & 2128.2 & - & 2 \\
\hline HLP-49H & I 250 & 8.0 & 0.45 & -0.07 & 10.0 & 1182.0 & 128.9 & \\
\hline HLP-49H & I 250 & 11.0 & 0.45 & -0.09 & 5.5 & 1158.5 & 101.1 & \\
\hline HLP-49Q & 250 & 2.0 & 0.45 & -0.03 & 5.5 & 158.0 & 2.3 & 5 \\
\hline HLP-49Q & 250 & 5.0 & 0.45 & -0.05 & 6.0 & 875.6 & 29.0 & \\
\hline HLP-49Q & 250 & 8.0 & 0.45 & -0.04 & 5.5 & 971.4 & 41.6 & \\
\hline HLP-49Q & 250 & 11.0 & 0.45 & -0.04 & 5.5 & 1480.1 & 331.5 & \\
\hline HLP-51 & 150 & 188.6 & 0.15 & -0.05 & - & 367.0 & 6.1 & \\
\hline HLP-51 & 150 & 214.7 & 0.15 & -0.04 & 10.0 & 468.2 & 41.1 & \\
\hline HLP-51 & 150 & 214.7 & 0.16 & -0.10 & 10.0 & 624.3 & 59.3 & 3 \\
\hline HLP-51 & 150 & 249.7 & 0.16 & -0.05 & - & 555.4 & 11.1 & \\
\hline HLP-51 & 150 & 249.7 & 0.16 & -0.05 & 10.0 & 679.9 & 47.5 & \\
\hline HLP-51 & 150 & 299.6 & 0.16 & -0.07 & - & 515.0 & 16.6 & 6 \\
\hline HLP-51 & 200 & 6.2 & 0.25 & -0.03 & 5.8 & 318.4 & 26.9 & 5 \\
\hline HLP-51 & 200 & 6.2 & 0.25 & -0.03 & 5.5 & 410.5 & 37.3 & \\
\hline HLP-51 & 200 & 11.2 & 0.25 & -0.04 & 5.8 & 499.5 & 66.7 & \\
\hline HLP-51 & 200 & 11.2 & 0.25 & -0.03 & 6.1 & 521.1 & 89.6 & \\
\hline HLP-51 & 200 & 14.0 & 0.25 & -0.04 & 5.8 & 173.4 & 2.5 & 5 \\
\hline HLP-51 & 200 & 22.2 & 0.25 & -0.06 & 5.5 & 337.0 & 18.4 & 5 \\
\hline HLP-51 & 200 & 22.2 & 0.25 & -0.06 & 5.9 & 609.2 & 73.8 & \\
\hline HLP-51 & 200 & 24.9 & 0.25 & -0.05 & 6.0 & 429.4 & 21.6 & \\
\hline HLP-51 & 200 & 27.0 & 0.25 & -0.05 & 10.0 & 538.7 & 101.9 & \\
\hline HLP-51 & 200 & 33.2 & 0.25 & -0.05 & 10.0 & 484.4 & 53.8 & \\
\hline HLP-51 & 200 & 99.9 & 0.25 & -0.14 & 6.0 & 775.2 & 47.0 & 3 \\
\hline HLP-51 & 200 & 100.0 & 0.18 & -0.09 & 6.0 & 836.9 & 226.9 & \\
\hline HLP-51 & 200 & 155.0 & 0.20 & -0.14 & 5.5 & 843.6 & 331.3 & 3 \\
\hline HLP-51 & 200 & 179.4 & 0.20 & -0.12 & 7.0 & 406.7 & 6.6 & 3 \\
\hline HLP-51 & 200 & 188.6 & 0.25 & -0.22 & 6.0 & 580.6 & 56.3 & 3 \\
\hline HLP-51 & 200 & 213.0 & 0.20 & -0.17 & 7.0 & 875.3 & 254.5 & 3 \\
\hline HLP-51 & 200 & 289.6 & 0.25 & -0.22 & - & 995.9 & 188.23 & 3 \\
\hline HLP-51 & 200 & 370.5 & 0.25 & -0.25 & - & 809.7 & 89.2 & 3 \\
\hline HLP-51 & 200 & 374.5 & 0.25 & -0.24 & - & 527.0 & 18.2 & 3 \\
\hline HLP-51 & 200 & 379.5 & 0.25 & -0.24 & - & 773.8 & 200.7 & 3 \\
\hline HLP-51 & 250 & 5.0 & 0.45 & -0.05 & 10.0 & 440.0 & 5.9 & 5 \\
\hline HLP-51 & 250 & 7.0 & 0.45 & -0.06 & 10.0 & 928.6 & 33.0 & \\
\hline HLP-51 & 250 & 10.0 & 0.39 & -0.08 & 5.5 & 1277.2 & 69.4 & \\
\hline HLP-51 & 250 & 12.0 & 0.45 & -0.09 & 5.5 & 1407.0 & 74.1 & \\
\hline HLP-51 & 250 & 15.4 & 0.45 & -0.15 & 5.5 & 1516.4 & 60.7 & \\
\hline HLP-51 & 250 & 18.0 & 0.45 & -0.12 & 5.5 & 1771.3 & 212.6 & \\
\hline HLP-51 & 250 & 22.0 & 0.45 & -0.23 & 9.5 & 1735.3 & 288.3 & \\
\hline HLP-51 & 250 & 25.0 & 0.45 & -0.19 & 6.0 & 1844.1 & 0.0 & \\
\hline HLP-51 & 250 & 28.3 & 0.45 & -0.16 & 10.0 & 2088.1 & - & 2 \\
\hline
\end{tabular}




\begin{tabular}{|c|c|c|c|c|c|c|c|c|}
\hline Glass ID & $\mathrm{T}\left({ }^{\circ} \mathrm{C}\right)$ & $t(d)$ & $\mathrm{vH}_{2} \mathrm{O}(\mathrm{mL})$ & & $\mathrm{pH}$ Out & $\mathrm{m}_{\mathrm{a}}\left(\mathrm{g} / \mathrm{m}^{2}\right)$ & $2 \sigma\left(\mathrm{g} / \mathrm{m}^{2}\right)$ & notes \\
\hline HLP-51 & 250 & 30.3 & 0.45 & -0.18 & 5.5 & 2060.1 & - & 2 \\
\hline HLP-51 & 275 & 2.0 & 0.62 & -0.04 & 10.0 & 797.8 & 12.2 & \\
\hline HLP-51 & 275 & 3.0 & 0.62 & -0.04 & 10.0 & 997.6 & 19.4 & \\
\hline HLP-51 & 275 & 4.0 & 0.62 & -0.07 & 10.0 & 1083.4 & 45.2 & \\
\hline HLP-51 & 275 & 5.2 & 0.63 & -0.09 & 9.0 & 1468.7 & 108.5 & \\
\hline HLP-51 & 275 & 6.9 & 0.62 & -0.13 & 5.5 & 1605.7 & 210.2 & \\
\hline HLP-51 & 275 & 9.2 & 0.62 & -0.23 & 5.5 & 1790.5 & 184.2 & \\
\hline HLP-51 & 275 & 11.0 & 0.62 & -0.39 & 5.5 & 1976.8 & - & 2 \\
\hline HLP-51 & 300 & 1.0 & 0.79 & -0.05 & 6.0 & 647.2 & 18.8 & \\
\hline HLP-51 & 300 & 1.0 & 0.80 & -0.06 & 6.0 & 700.0 & 38.3 & \\
\hline HLP-51 & 300 & 1.5 & 0.81 & -0.11 & 6.0 & 895.2 & 35.8 & \\
\hline HLP-51 & 300 & 2.0 & 0.80 & -0.10 & 6.0 & 1071.2 & 25.7 & \\
\hline HLP-51 & 300 & 2.0 & 0.80 & -0.09 & 6.0 & 1071.4 & 20.6 & \\
\hline HLP-51 & 300 & 2.4 & 0.80 & -0.35 & - & 978.3 & 19.6 & \\
\hline HLP-51 & 300 & 3.1 & 0.80 & -0.39 & 6.0 & 1188.6 & 24.1 & \\
\hline HLP-51 & 300 & 4.0 & 0.85 & -0.12 & 5.5 & 1877.7 & 135.2 & \\
\hline HLP-51 & 300 & 5.1 & 0.80 & -0.09 & 6.0 & 2005.4 & - & 2 \\
\hline HLP-52 & 125 & 20.0 & 0.08 & -0.01 & 10.0 & 88.6 & 0.3 & 5 \\
\hline HLP-52 & 125 & 31.0 & 0.08 & -0.02 & $>7.5$ & 1007.2 & 138.9 & \\
\hline HLP-52 & 125 & 40.0 & 0.08 & -0.02 & - & 1416.6 & 173.6 & \\
\hline HLP-52 & 125 & 50.0 & 0.08 & -0.01 & - & 1406.9 & 138.1 & \\
\hline HLP-52 & 125 & 79.0 & 0.08 & -0.02 & - & 1844.5 & 550.2 & \\
\hline HLP-52 & 150 & 3.0 & 0.10 & -0.02 & 10.0 & 26.0 & 0.3 & 5 \\
\hline HLP-52 & 150 & 6.0 & 0.15 & -0.02 & - & 484.0 & 34.5 & 5 \\
\hline HLP-52 & 150 & 8.0 & 0.10 & -0.02 & - & 1068.5 & 55.0 & \\
\hline HLP-52 & 150 & 9.0 & 0.10 & -0.02 & - & 1276.8 & 153.2 & \\
\hline HLP-52 & 150 & 11.0 & 0.10 & -0.02 & 8.0 & 1660.3 & 259.9 & \\
\hline HLP-52 & 150 & 18.0 & 0.10 & -0.02 & 8.0 & 2002.3 & - & 1 \\
\hline HLP-52 & 150 & 20.0 & 0.10 & -0.01 & - & 1993.0 & - & 1 \\
\hline HLP-52 & 200 & 0.5 & 0.25 & -0.02 & 10.0 & 485.0 & 6.1 & \\
\hline HLP-52 & 200 & 1.0 & 0.25 & -0.02 & - & 1512.0 & 124.4 & \\
\hline HLP-52 & 200 & 1.6 & 0.25 & -0.01 & 10.0 & 1791.2 & 129.0 & \\
\hline HLP-52 & 200 & 4.0 & 0.20 & -0.02 & 5.5 & 2032.5 & 332.0 & 1 \\
\hline HLP-52 & 200 & 7.0 & 0.20 & -0.02 & 6.5 & 2010.7 & - & 1 \\
\hline HLP-53 & 175 & 2.1 & 0.14 & -0.02 & 10.0 & 106.4 & 1.1 & 5 \\
\hline HLP-53 & 175 & 3.9 & 0.14 & -0.02 & 10.0 & 184.9 & 0.9 & 5 \\
\hline HLP-53 & 175 & 3.9 & 0.14 & -0.01 & 10.0 & 412.7 & 4.6 & 5 \\
\hline HLP-53 & 175 & 5.0 & 0.14 & -0.01 & 10.0 & 1404.3 & - & \\
\hline HLP-53 & 175 & 5.9 & 0.14 & -0.03 & 10.0 & 949.8 & 144.0 & \\
\hline HLP-53 & 175 & 6.0 & 0.14 & -0.02 & 10.0 & 1894.7 & - & \\
\hline HLP-53 & 175 & 7.0 & 0.14 & -0.02 & 10.0 & 1774.0 & - & \\
\hline HLP-53 & 175 & 7.9 & 0.14 & -0.02 & 10.0 & 2022.3 & - & 2 \\
\hline HLP-53 & 200 & 0.9 & 0.20 & -0.07 & 10.0 & 184.7 & 3.1 & 5 \\
\hline HLP-53 & 200 & 1.5 & 0.20 & -0.01 & 10.0 & 149.0 & 0.7 & 5 \\
\hline HLP-53 & 200 & 2.0 & 0.20 & -0.03 & 10.0 & 1376.1 & 89.3 & \\
\hline HLP-53 & 200 & 2.9 & 0.20 & -0.02 & 10.0 & 1892.2 & 0.0 & \\
\hline HLP-54 & 200 & 6.9 & 0.24 & -0.02 & 6.0 & 537.2 & 7.9 & 5 \\
\hline HLP-54 & 200 & 10.1 & 0.24 & -0.03 & 6.0 & 950.8 & 50.7 & 8 \\
\hline HLP-54 & 200 & 14.0 & 0.24 & -0.03 & 5.0 & 1103.3 & 49.3 & 8 \\
\hline HLP-54 & 200 & 15.6 & 0.24 & -0.05 & 8.0 & 1133.3 & 149.4 & 8 \\
\hline HLP-54 & 200 & 20.0 & 0.20 & -0.03 & 6.0 & 842.3 & 58.9 & 8 \\
\hline HLP-54 & 200 & 25.0 & 0.20 & -0.04 & 6.0 & 927.6 & 61.9 & 8 \\
\hline HLP-54 & 200 & 28.6 & 0.25 & -0.06 & 10.0 & 1373.0 & 272.1 & 8 \\
\hline
\end{tabular}




\begin{tabular}{|c|c|c|c|c|c|c|c|c|}
\hline Glass ID & $\mathrm{T}\left({ }^{\circ} \mathrm{C}\right)$ & $t(d)$ & $\mathrm{vH}_{2} \mathrm{O}(\mathrm{mL})$ & & pH Out & $\mathrm{m}_{\mathrm{a}}\left(\mathrm{g} / \mathrm{m}^{2}\right)$ & $2 \sigma\left(\mathrm{g} / \mathrm{m}^{2}\right)$ & notes \\
\hline HLP-55 & 200 & 5.0 & 0.20 & -0.02 & 6.0 & 181.9 & 1.6 & 5 \\
\hline HLP-55 & 200 & 6.9 & 0.24 & -0.02 & 6.0 & 458.3 & 11.8 & 8 \\
\hline HLP-55 & 200 & 8.1 & 0.24 & -0.03 & 6.0 & 606.2 & 31.5 & 8 \\
\hline HLP-55 & 200 & 8.7 & 0.25 & -0.05 & 8.0 & 716.9 & 18.7 & 8 \\
\hline HLP-55 & 200 & 11.0 & 0.20 & -0.03 & 6.0 & 986.6 & 66.3 & 8 \\
\hline HLP-55 & 200 & 14.0 & 0.24 & -0.03 & 5.0 & 733.1 & 32.0 & 8 \\
\hline HLP-55 & 200 & 14.0 & 0.20 & -0.03 & 6.0 & 1335.5 & 48.3 & 8 \\
\hline HLP-55 & 200 & 17.0 & 0.20 & -0.03 & 6.5 & 1391.3 & 30.2 & 8 \\
\hline HLP-55 & 200 & 21.0 & 0.20 & -0.04 & 6.0 & 1631.8 & 120.1 & 8 \\
\hline HLP-55 & 200 & 28.0 & 0.20 & -0.04 & 6.5 & 1752.1 & 249.2 & 8 \\
\hline HLP-55 & 200 & 28.6 & 0.25 & -0.06 & 10.0 & 1841.1 & - & 2 \\
\hline HLP-55 & 200 & 33.9 & 0.23 & -0.04 & 8.0 & 1100.6 & 89.5 & 7 \\
\hline HLP-55 & 200 & 41.2 & 0.25 & -0.07 & 6.0 & 1433.0 & 151.7 & 8 \\
\hline HLP-56 & 200 & 34.8 & 0.20 & -0.05 & 5.5 & 24.7 & 0.2 & \\
\hline HLP-56 & 200 & 49.8 & 0.20 & -0.07 & 7.0 & 62.3 & 0.5 & \\
\hline HLP-56 & 200 & 69.0 & 0.20 & -0.07 & 9.0 & 115.4 & 1.3 & \\
\hline HLP-56 & 200 & 87.0 & 0.20 & -0.11 & 6.0 & 130.3 & 1.1 & \\
\hline HLP-56 & 200 & 107.0 & 0.20 & -0.11 & 7.0 & 145.2 & 0.9 & \\
\hline HLP-56 & 200 & 122.0 & 0.20 & -0.12 & 7.0 & 215.8 & 2.3 & \\
\hline HLP-56 & 200 & 146.0 & 0.20 & -0.15 & 5.5 & 156.2 & 4.9 & 3 \\
\hline HLP-56 & 200 & 181.0 & 0.20 & -0.14 & 6.5 & 240.9 & 4.3 & 3 \\
\hline HLP-56 & 200 & 187.9 & 0.20 & -0.18 & 6.5 & 134.4 & 1.3 & 3 \\
\hline HLP-56 & 250 & 3.0 & 0.45 & -0.04 & 9.5 & 422.4 & 24.9 & 5 \\
\hline HLP-56 & 250 & 5.3 & 0.45 & -0.05 & 10.0 & 812.9 & 6.3 & \\
\hline HLP-56 & 250 & 7.0 & 0.45 & -0.08 & 7.5 & 1080.7 & 136.7 & \\
\hline HLP-56 & 250 & 7.8 & 0.45 & -0.06 & 7.0 & 1147.6 & 72.9 & \\
\hline HLP-56 & 250 & 9.9 & 0.45 & -0.07 & 6.0 & 1298.1 & 96.7 & \\
\hline HLP-56 & 250 & 12.0 & 0.45 & -0.11 & 5.0 & 1437.2 & 53.1 & \\
\hline HLP-56 & 250 & 12.1 & 0.45 & -0.09 & 6.0 & 1409.1 & 94.4 & \\
\hline HLP-56 & 250 & 14.0 & 0.45 & -0.12 & 5.5 & 1526.6 & 256.5 & \\
\hline HLP-56 & 300 & 1.0 & 0.80 & -0.03 & 8.0 & 980.9 & 17.9 & \\
\hline HLP-56 & 300 & 1.5 & 0.80 & -0.04 & 6.0 & 1255.8 & 31.7 & \\
\hline HLP-56 & 300 & 2.0 & 0.80 & -0.04 & 5.5 & 1581.5 & - & \\
\hline HLP-56 & 300 & 2.5 & 0.80 & -0.06 & 5.5 & 1878.0 & 90.1 & \\
\hline HLP-58 & 200 & 15.0 & 0.20 & -0.03 & 6.5 & 39.8 & 0.4 & \\
\hline HLP-58 & 200 & 30.0 & 0.20 & -0.05 & 6.5 & 43.6 & 0.1 & \\
\hline HLP-58 & 200 & 44.0 & 0.20 & -0.05 & 6.5 & 148.8 & 4.9 & \\
\hline HLP-58 & 200 & 49.0 & 0.20 & -0.08 & 6.0 & 136.0 & 1.9 & \\
\hline HLP-58 & 200 & 101.0 & 0.20 & -0.12 & 6.0 & 225.6 & 4.0 & \\
\hline HLP-58 & 200 & 150.0 & 0.20 & -0.15 & 6.5 & 83.5 & 0.8 & 3 \\
\hline HLP-59 & 200 & 14.0 & 0.20 & -0.03 & 7.5 & 44.6 & 0.2 & \\
\hline HLP-59 & 200 & 28.0 & 0.20 & -0.05 & 7.0 & 60.7 & 0.4 & \\
\hline HLP-59 & 200 & 44.0 & 0.20 & -0.06 & 7.5 & 177.0 & 1.9 & \\
\hline HLP-60 & 200 & 14.0 & 0.20 & -0.04 & 5.5 & 34.3 & 0.38 & \\
\hline HLP-60 & 200 & 28.0 & 0.20 & -0.04 & 5.5 & 48.4 & 0.15 & \\
\hline HLP-60 & 200 & 44.0 & 0.20 & -0.07 & 5.5 & 332.3 & 3.70 & \\
\hline HLP-61 & 200 & 15.0 & 0.20 & -0.03 & 7.5 & 60.3 & 0.7 & \\
\hline HLP-61 & 200 & 30.0 & 0.20 & -0.05 & 8.5 & 229.4 & 3.9 & \\
\hline HLP-61 & 200 & 44.0 & 0.20 & -0.06 & 9.0 & 375.4 & 6.9 & \\
\hline HLP-61 & 200 & 50.0 & 0.20 & -0.09 & 8.0 & 837.0 & 44.0 & 6 \\
\hline HLP-61 & 200 & 54.1 & 0.20 & -0.08 & 8.5 & 501.3 & 5.2 & \\
\hline
\end{tabular}




\begin{tabular}{|c|c|c|c|c|c|c|c|c|}
\hline Glass ID & $\mathrm{T}\left({ }^{\circ} \mathrm{C}\right)$ & $t(d)$ & $\mathrm{vH}_{2} \mathrm{O}(\mathrm{mL})$ & & $\mathrm{pH}$ Out & $\mathrm{m}_{\mathrm{a}}\left(\mathrm{g} / \mathrm{m}^{2}\right)$ & $2 \sigma\left(\mathrm{g} / \mathrm{m}^{2}\right)$ & notes \\
\hline HLP-61 & 200 & 78.9 & 0.20 & -0.14 & 6.5 & 694.6 & 9.6 & \\
\hline HLP-61 & 200 & 100.0 & 0.20 & -0.12 & 7.5 & 422.3 & 19.7 & 3 \\
\hline HLP-61 & 200 & 149.0 & 0.20 & -0.14 & 9.0 & 533.2 & 54.73 & 3 \\
\hline HLP-62 & 200 & 15.0 & 0.20 & -0.04 & 6.0 & 7.9 & 0.0 & \\
\hline HLP-62 & 200 & 30.0 & 0.20 & -0.06 & 6.0 & 6.6 & 0.1 & \\
\hline HLP-62 & 200 & 44.0 & 0.20 & -0.07 & 6.0 & 7.9 & 0.1 & \\
\hline HLP-62 & 200 & 56.1 & 0.20 & -0.10 & 5.5 & 19.6 & 0.3 & \\
\hline HLP-63 & 200 & 1.0 & 0.20 & -0.02 & 10.0 & 313.4 & 26.4 & \\
\hline HLP-63 & 200 & 2.0 & 0.20 & -0.03 & 10.0 & 2021.0 & - & 2 \\
\hline HLP-64 & 200 & 15.0 & 0.20 & -0.04 & 6.0 & 57.5 & 0.2 & \\
\hline HLP-64 & 200 & 30.0 & 0.20 & -0.05 & 7.5 & 269.1 & 2.3 & \\
\hline HLP-64 & 200 & 44.0 & 0.20 & -0.07 & 6.0 & 334.1 & 5.5 & \\
\hline HLP-64 & 200 & 50.0 & 0.20 & -0.09 & 6.0 & 548.7 & 7.5 & \\
\hline HLP-64 & 200 & 149.0 & 0.20 & -0.13 & 6.0 & 778.6 & 14.3 & 3 \\
\hline HLP-65 & 200 & 14.0 & 0.20 & -0.04 & 6.5 & 106.8 & 0.6 & \\
\hline HLP-65 & 200 & 28.0 & 0.20 & -0.05 & 6.0 & 142.5 & 1.6 & \\
\hline HLP-65 & 200 & 43.0 & 0.20 & -0.05 & 6.0 & 216.4 & 1.9 & \\
\hline HLP-65 & 200 & 55.1 & 0.20 & -0.09 & 6.0 & 279.0 & 4.2 & \\
\hline HLP-66 & 200 & 1.0 & 0.20 & -0.02 & 8.0 & 1336.9 & 26.1 & \\
\hline HLP-66 & 200 & 3.0 & 0.20 & -0.02 & 10.0 & 1670.4 & - & 1 \\
\hline HLP-66 & 200 & 3.0 & 0.20 & -0.02 & 7.0 & - & - & 1 \\
\hline HLP-66 & 200 & 5.0 & 0.20 & -0.02 & 10.0 & 1751.4 & - & 1 \\
\hline HLP-66 & 200 & 5.0 & 0.20 & -0.02 & 9.5 & - & - & 1 \\
\hline HLP-66 & 200 & 5.1 & 0.20 & - & - & - & - & 1 \\
\hline HLP-66 & 200 & 15.0 & 0.20 & -0.03 & 10.0 & - & - & 1 \\
\hline HLP-66 & 200 & 22.0 & 0.20 & -0.04 & 10.0 & - & - & 1 \\
\hline HLP-66 & 200 & 27.0 & 0.20 & -0.04 & 10.0 & - & - & 1 \\
\hline HLP-67 & 200 & 1.0 & 0.20 & -0.02 & 9.0 & 1056.1 & 21.96 & \\
\hline HLP-67 & 200 & 2.0 & 0.20 & -0.02 & 10.0 & 1408.3 & 50.05 & \\
\hline HLP-67 & 200 & 3.0 & 0.20 & -0.02 & 8.5 & 1517.2 & 99.31 & \\
\hline HLP-67 & 200 & 5.0 & 0.20 & -0.02 & 10.0 & 1891.8 & - & 1 \\
\hline HLP-67 & 200 & 8.0 & 0.20 & -0.02 & 8.5 & 1852.6 & - & 1 \\
\hline HLP-67 & 200 & 15.0 & 0.20 & -0.03 & 9.0 & 1931.5 & - & 1 \\
\hline HLP-67 & 200 & 16.0 & 0.20 & -0.03 & 9.0 & 1953.3 & - & 1 \\
\hline HLP-67 & 200 & 22.0 & 0.20 & -0.04 & 9.0 & 2043.9 & - & 1 \\
\hline HLP-68 & 200 & 14.0 & 0.20 & -0.03 & 7.5 & 121.3 & 1.5 & \\
\hline HLP-68 & 200 & 28.0 & 0.20 & -0.04 & 8.0 & 286.9 & 5.1 & \\
\hline HLP-68 & 200 & 43.0 & 0.20 & -0.07 & 7.5 & 331.6 & 12.4 & \\
\hline HLP-68 & 200 & 54.1 & 0.20 & -0.09 & 9.0 & 360.5 & 15.3 & \\
\hline HLP-69 & 200 & 14.0 & 0.20 & -0.04 & 6.0 & 154.6 & 2.7 & \\
\hline HLP-69 & 200 & 28.0 & 0.20 & -0.08 & 6.0 & 150.0 & 1.4 & \\
\hline HLP-69 & 200 & 42.0 & 0.20 & -0.08 & 6.0 & 305.4 & 1.5 & \\
\hline HLP-69 & 200 & 54.1 & 0.20 & -0.10 & 6.0 & 272.5 & 5.5 & \\
\hline HLP-71 & 200 & 14.0 & 0.20 & -0.03 & 10.0 & -58.5 & -0.4 & 6 \\
\hline HLP-72 & 200 & 15.0 & 0.20 & -0.03 & 6.0 & 131.2 & 1.1 & 5 \\
\hline HLP-72 & 200 & 22.0 & 0.20 & -0.04 & 6.0 & 438.8 & 16.0 & \\
\hline HLP-72 & 200 & 27.0 & 0.20 & -0.05 & 6.5 & 524.4 & 14.4 & \\
\hline HLP-72 & 200 & 50.0 & 0.20 & -0.06 & 6.0 & 766.7 & 65.1 & \\
\hline HLP-72 & 200 & 52.2 & 0.20 & -0.08 & 6.0 & 705.9 & 107.5 & \\
\hline
\end{tabular}




$\begin{array}{lrrrrrrrr}\text { Glass ID } & \mathrm{T}\left({ }^{\circ} \mathrm{C}\right) & \mathrm{t}(\mathrm{d}) & \mathrm{vH}_{2} \mathrm{O}(\mathrm{mL}) & & \mathrm{pH} \mathrm{Out} \mathrm{m}_{\mathrm{a}}\left(\mathrm{g} / \mathrm{m}^{2}\right) & 2 \sigma\left(\mathrm{g} / \mathrm{m}^{2}\right) & \text { notes } \\ \mathrm{HLP}-72 & 200 & 99.0 & 0.20 & -0.12 & 6.5 & 624.9 & 31.2 & 3 \\ \mathrm{HLP}-72 & 200 & 151.0 & 0.20 & -0.13 & 6.0 & 574.4 & 34.1 & 3 \\ \mathrm{HLP}-74 & 200 & 14.0 & 0.20 & -0.04 & 6.5 & 340.5 & 4.45 & \\ \mathrm{HLP}-74 & 200 & 28.0 & 0.20 & -0.04 & 6.5 & 505.3 & 7.79 & \\ \mathrm{HLP}-74 & 200 & 42.0 & 0.20 & -0.03 & 7.0 & 630.0 & 16.23 & \\ \mathrm{HLP}-74 & 200 & 52.2 & 0.20 & -0.08 & 7.5 & 757.2 & 38.07 & \\ \mathrm{HLP}-74 & 200 & 80.0 & 0.20 & -0.10 & 7.0 & 867.1 & 27.94 & \\ \mathrm{HLP}-75 & 200 & 14.0 & 0.20 & -0.03 & 8.5 & 344.1 & 14.0 & \\ \text { HLP-75 } & 200 & 28.0 & 0.20 & -0.04 & 8.5 & 428.3 & 28.3 & \\ \text { HLP-75 } & 200 & 42.0 & 0.20 & -0.03 & 8.5 & 608.2 & 29.2 & \\ \mathrm{HLP-75} & 200 & 52.2 & 0.20 & -0.08 & 9.0 & 617.5 & 47.0 & \\ \mathrm{HLP-76} & 200 & 5.0 & 0.20 & -0.03 & 7.0 & 518.1 & 6.48 & \\ \text { HLP-76 } & 200 & 10.0 & 0.20 & -0.03 & 7.0 & 1245.2 & 18.73 & \\ \text { HLP-76 } & 200 & 14.0 & 0.20 & -0.03 & 8.5 & 1784.3 & - & 2 \\ \text { HLP-76 } & 200 & 28.0 & 0.20 & -0.04 & 8.0 & 1834.2 & - & 1 \\ \text { HLP-76 } & 200 & 42.0 & 0.20 & -0.05 & 8.0 & 1763.4 & - & 1 \\ \text { HLP-76 } & 200 & 52.2 & 0.20 & -0.08 & 8.0 & 1920.8 & - & 1 \\ \text { HLP-77 } & 200 & 5.0 & 0.20 & -0.03 & 7.0 & 343.4 & 4.32 & \\ \text { HLP-77 } & 200 & 10.0 & 0.20 & -0.03 & 7.0 & 1338.9 & 41.11 & \\ \text { HLP-77 } & 200 & 14.0 & 0.20 & -0.03 & 9.0 & 1922.1 & - & 2 \\ \text { HLP-77 } & 200 & 28.0 & 0.20 & -0.03 & 8.0 & 1757.8 & - & 1 \\ \text { HLP-77 } & 200 & 42.0 & 0.20 & -0.04 & 8.5 & 1782.0 & - & 1 \\ \text { HLP-77 } & 200 & 52.2 & 0.20 & -0.08 & 7.0 & 1931.4 & - & 1\end{array}$

Notes

1 Sample is fully dissolved - not used to estimate rate

2 Sample is fully dissolved - used to estimate rate

$3 \quad$ Water loss was too high from vessel - not used to estimate rate

$4 \quad$ No detectable corrosion

5 Reaction amount was too low - not used to estimate rate (before linear portion of $m_{a}-t$ curve)

6 Sample was found to be outlier - not used to estimate rate

7 Test performed at a different amount of water than most other data - not used to estimate rate

8 Test performed at a different amount of water than most other data - used to estimate rate

9 Sample appeared different from others (possibly mislabeled) - not used to estimate rate 
Appendix D

\section{VHT Data from Literature}




\section{Appendix D: VHT Data from Literature}

Table D-1. VHT Data From Literature

\begin{tabular}{|c|c|c|c|c|c|c|c|c|}
\hline Glass ID & Reported Glass ID & Method & $\begin{array}{c}\mathrm{T} \\
{\left[{ }^{\circ} \mathrm{C}\right]}\end{array}$ & $\begin{array}{c}\mathrm{t} \\
{[\mathrm{d}]}\end{array}$ & $\begin{array}{c}\text { Reported } \\
d_{a}(\mu \mathrm{m})\end{array}$ & $\begin{array}{l}\text { Estimated } \\
m_{a}\left(\mathrm{~g} / \mathrm{m}^{2}\right)\end{array}$ & Reference & Comment \\
\hline HLP-01 & TFA-BASE & $\mathrm{C}$ & 200 & 23.5 & 86 & 224 & Muller et al. 2001 & \\
\hline HLP-46 & LD6-5412 & A & 70 & 56 & 0 & 0 & Feng et al. 1996 & \\
\hline HLP-46 & LD6-5412 & A & 120 & 28 & 0 & 0 & Feng et al. 1996 & \\
\hline HLP-46 & LD6-5412 & A & 120 & 56 & 0 & 0 & Feng et al. 1996 & \\
\hline HLP-46 & LD6-5412 & A & 150 & 3 & 0 & 0 & Feng et al. 1996 & \\
\hline HLP-46 & LD6-5412 & A & 150 & 7 & 0 & 0 & Feng et al. 1996 & \\
\hline HLP-46 & LD6-5412 & A & 150 & 11 & 200 & 240 & Feng et al. 1996 & \\
\hline HLP-46 & LD6-5412 & A & 150 & 14 & 200 & 240 & Feng et al. 1996 & \\
\hline HLP-46 & LD6-5412 & A & 150 & 18 & - & 1300 & Feng et al. 1996 & Completely altered \\
\hline HLP-46 & LD6-5412 & A & 150 & 21 & - & 1300 & Feng et al. 1996 & Completely altered \\
\hline HLP-46 & LD6-5412 & A & 175 & 1 & 200 & 240 & Feng et al. 1996 & \\
\hline HLP-46 & LD6-5412 & A & 175 & 2 & 800 & 960 & Feng et al. 1996 & \\
\hline HLP-46 & LD6-5412 & A & 175 & 3 & 1000 & 1200 & Feng et al. 1996 & \\
\hline HLP-46 & LD6-5412 & A & 175 & 5 & 800 & 960 & Feng et al. 1996 & \\
\hline HLP-46 & LD6-5412 & A & 175 & 7 & - & 1300 & Feng et al. 1996 & Completely altered \\
\hline HLP-46 & LD6-5412 & A & 200 & 3 & - & 1300 & Feng et al. 1996 & Completely altered \\
\hline HLP-46 & LD6-5412 & A & 200 & 7 & - & 1300 & Feng et al. 1996 & Completely altered \\
\hline HLP-48 & LAWA33 & $\mathrm{C}$ & 150 & 10 & 3 & 8 & Muller et al. 2001 & \\
\hline HLP-48 & LAWA33 & A & 150 & 14 & 0 & 0 & McGrail et al. 1999 & \\
\hline HLP-48 & LAWA33 & $\mathrm{C}$ & 150 & 20 & 44.2 & 115 & Muller et al. 2001 & \\
\hline HLP-48 & LAWA33 & $\mathrm{C}$ & 150 & 22 & 49.6 & 129 & Muller et al. 2001 & $1 / 3$ excess $\mathrm{H} 2 \mathrm{O}$ \\
\hline HLP-48 & LAWA33 & $\mathrm{C}$ & 150 & 22 & 55.7 & 145 & Muller et al. 2001 & normal \\
\hline HLP-48 & LAWA33 & $\mathrm{C}$ & 150 & 22 & 81.4 & 212 & Muller et al. 2001 & 1/3 less H2O \\
\hline HLP-48 & LAWA33 & A & 150 & 28 & 5 & 6.5 & McGrail et al. 1999 & \\
\hline HLP-48 & LAWA33 & A & 150 & 57 & 40 & 52 & McGrail et al. 1999 & \\
\hline HLP-48 & LAWA33 & A & 150 & 77 & 300 & 390 & McGrail et al. 1999 & \\
\hline HLP-48 & LAWA33 & A & 175 & 6 & 1 & 1.3 & McGrail et al. 1999 & \\
\hline HLP-48 & LAWA33 & A & 175 & 14 & 50 & 65 & McGrail et al. 1999 & \\
\hline HLP-48 & LAWA33 & A & 175 & 28 & 250 & 325 & McGrail et al. 1999 & \\
\hline HLP-48 & LAWA33 & $\mathrm{C}$ & 200 & 23.5 & 541 & 1407 & Muller et al. 2001 & \\
\hline HLP-51 & LAWABP1 & $\mathrm{C}$ & 200 & 23.5 & 46 & 120 & Muller et al. 2001 & \\
\hline HLP-53 & LAWA23 & $\mathrm{C}$ & 150 & 10 & 7.3 & 19 & Muller et al. 2001 & \\
\hline HLP-53 & LAWA23 & $\mathrm{C}$ & 150 & 20 & 52.3 & 136 & Muller et al. 2001 & \\
\hline HLP-53 & LAWA23R & $\mathrm{C}$ & 200 & 23.5 & - & 2600 & Muller et al. 2001 & Completely altered \\
\hline HLP-54 & L4-912 & $\mathrm{A}$ & 150 & 7 & 0 & 0 & Feng et al. 1996 & \\
\hline HLP-54 & L4-912 & A & 150 & 14 & 0 & 0 & Feng et al. 1996 & \\
\hline HLP-54 & L4-912 & A & 150 & 28 & 0 & 0 & Feng et al. 1996 & \\
\hline HLP-55 & L4-99 & A & 150 & 7 & 0 & 0 & Feng et al. 1996 & \\
\hline HLP-55 & L4-99 & A & 150 & 14 & 0 & 0 & Feng et al. 1996 & \\
\hline HLP-55 & L4-99 & A & 150 & 28 & 0 & 0 & Feng et al. 1996 & \\
\hline HLP-56 & LAWA44-1 & $\mathrm{C}$ & 150 & 25 & 2.1 & 5 & Muller et al. 2001 & \\
\hline HLP-56 & LAWA44-3 & $\mathrm{C}$ & 200 & 23.5 & 9 & 23 & Muller et al. 2001 & \\
\hline HLP-56 & LAWA44-3 & $\mathrm{C}$ & 200 & 55 & 7.6 & 20 & Muller et al. 2001 & \\
\hline HLP-56 & LAWA44-3 & $\mathrm{C}$ & 200 & 102 & 14.7 & 38 & Muller et al. 2001 & \\
\hline HLP-56 & LAWA44-3 & $\mathrm{C}$ & 200 & 206 & 12.1 & 31 & Muller et al. 2001 & \\
\hline
\end{tabular}




\section{Appendix E}

\section{XRD Scans from VHT Samples}




\section{Appendix E: XRD Scans from VHT Samples}
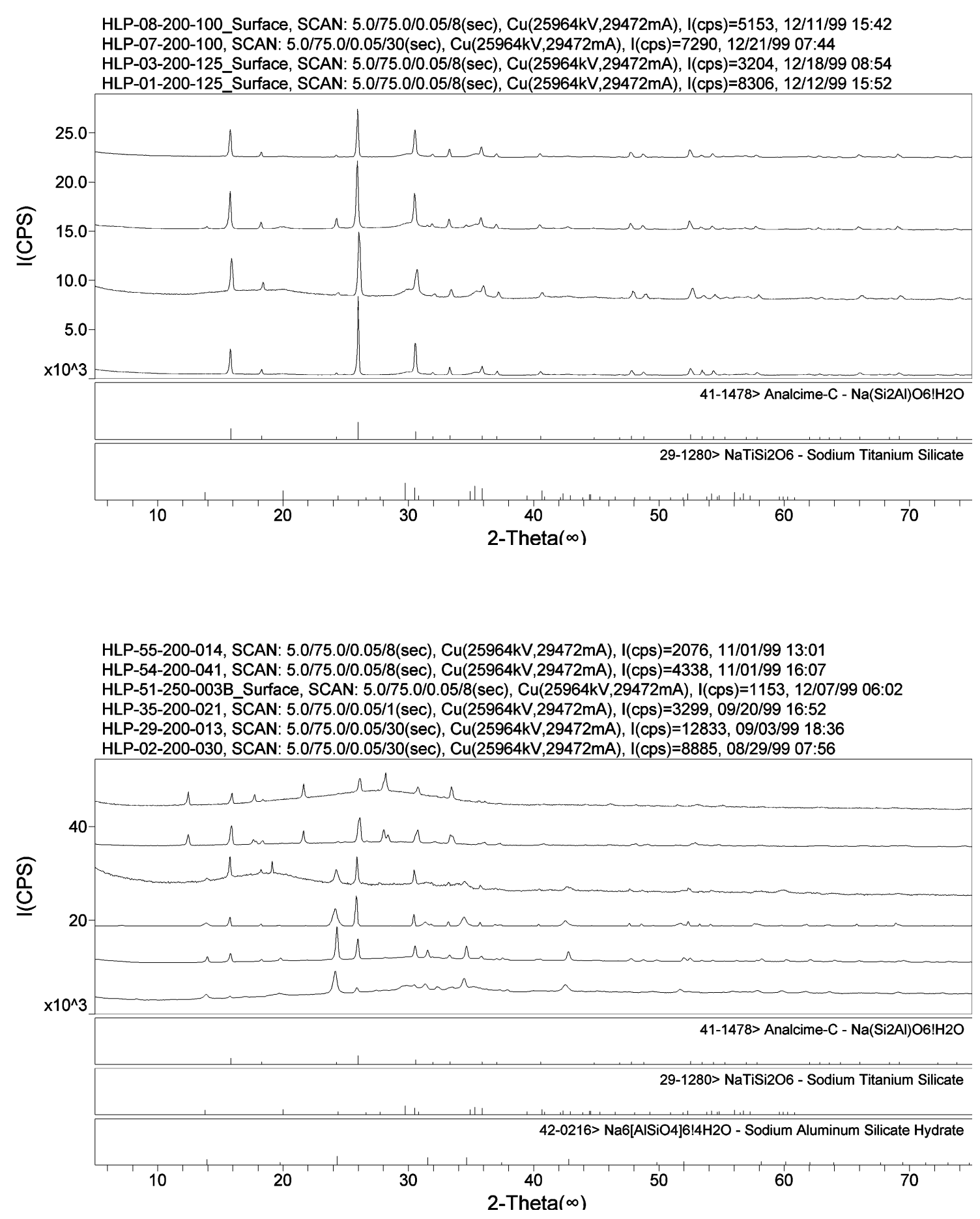

E.1 


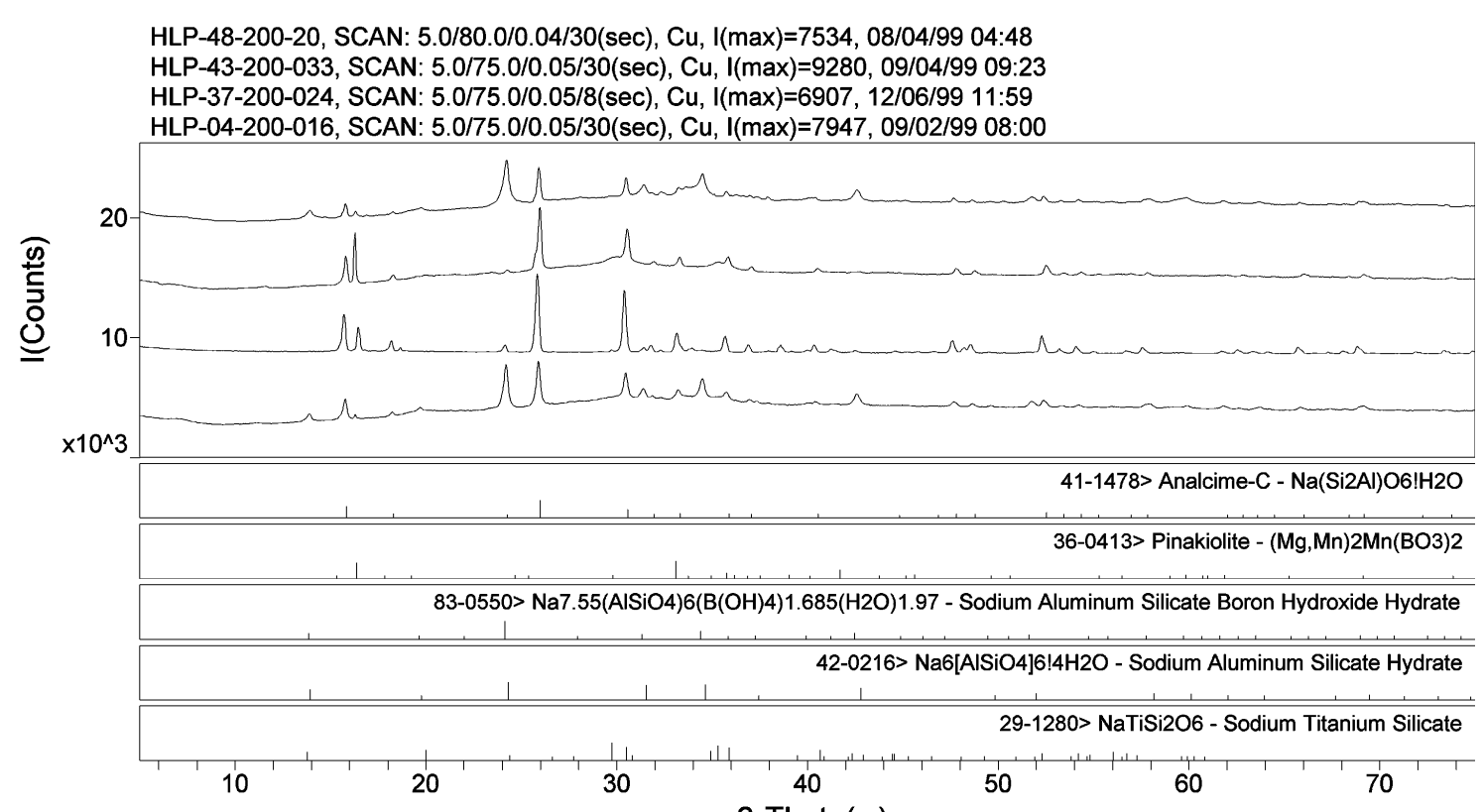

2-Theta( $\infty)$

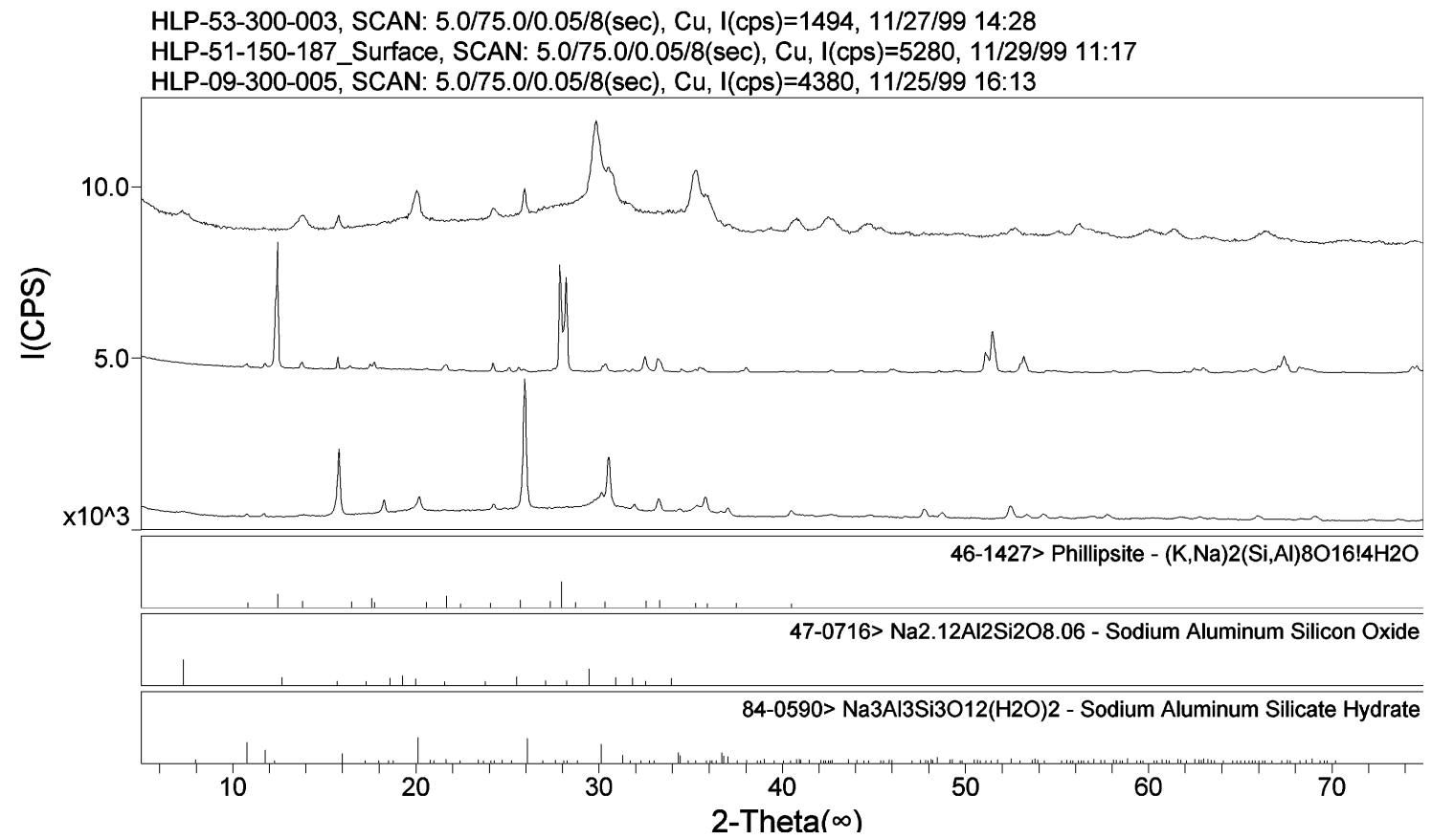

E.2 
-13-200-080 Surface, SCAN: 5.0/75.0/0.05/8(sec), Cu(25964kV,29472mA), I(cps)=6152, 12/21/99 18:33

HLP-12-300-002, SCAN: 5.0/75.0/0.05/8(sec), Cu(25964kV,29472mA), I(cps)=1944, 11/26/99 08:18

HLP-12-200-105, SCAN: 5.0/75.0/0.05/8(sec), Cu(25964kV,29472mA), I(cps)=3268, 11/28/99 15:42

HLP-10-200-129_Surface, SCAN: 5.0/75.0/0.05/8(sec), Cu(25964kV,29472mA), I(cps)=7906, 12/20/99 15:56

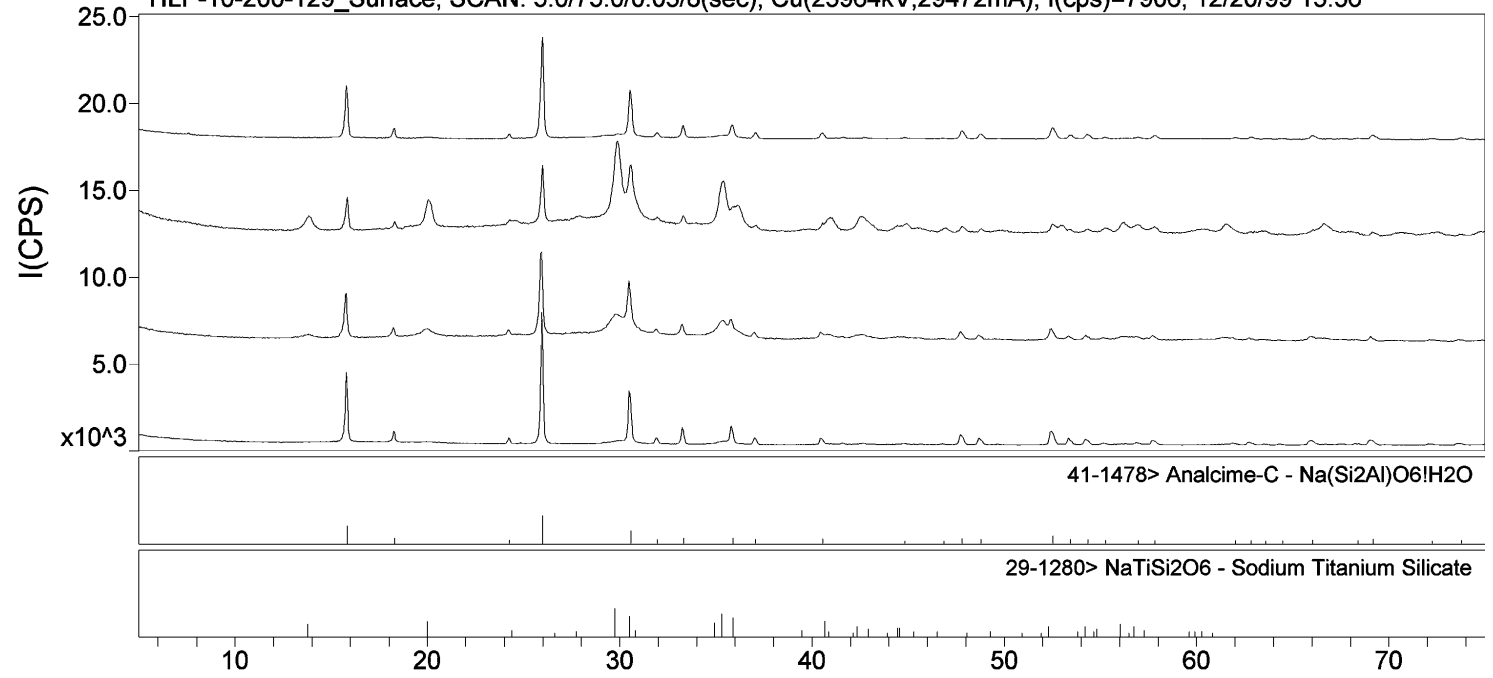

2-Theta $\infty)$

HLP-18-200-032-103199c, SCAN: 5.0/75.0/0.05/8(sec), Cu(25964kV,29472mA), I(cps)=4542, 10/31/99 21:20 HLP-17-200-075_Surface, SCAN: 5.0/75.0/0.05/8(sec), Cu(25964kV,29472mA), I(cps)=5559, 12/18/99 15:41 HLP-16-200-075_Surface, SCAN: 5.0/75.0/0.05/8(sec), Cu(25964kV,29472mA), I(cps)=8646, 12/11/99 18:57

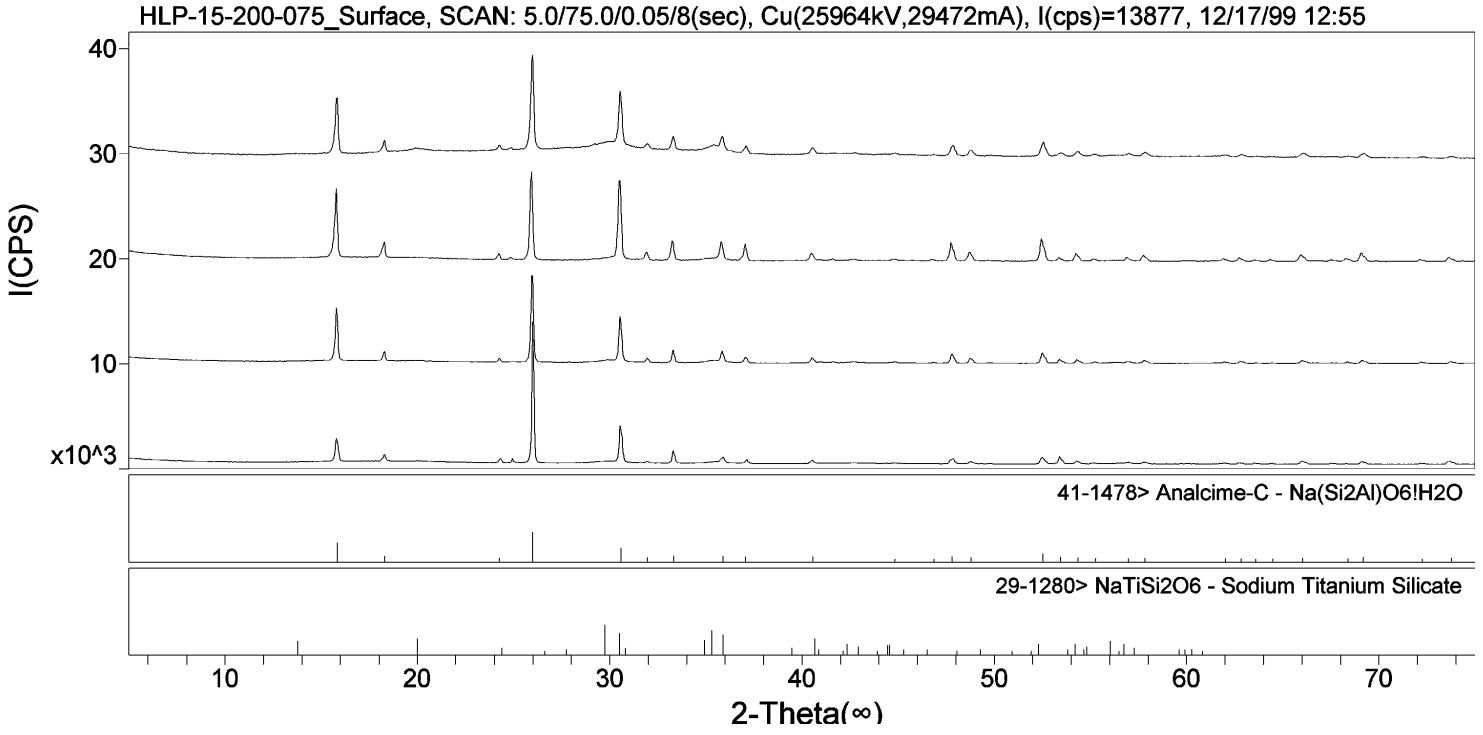


HLP-32-200-024_Surface, SCAN: 5.0/75.0/0.05/8(sec), Cu(25964kV,29472mA), I(cps)=1251, 12/20/99 19:12 HLP-31-200-010, SCAN: 5.0/75.0/0.05/30(sec), Cu(25964kV,29472mA), I(cps)=1038, 12/12/99 09:02

HLP-24-200-032_Surface, SCAN: 5.0/75.0/0.05/8(sec), Cu(25964kV,29472mA), I(cps) $=3087,12 / 19 / 9908: 30$

HLP-20-200-075_Surface, SCAN: 5.0/75.0/0.05/8(sec), Cu(25964kV,29472mA), I(cps)=2042, 12/17/99 16:16

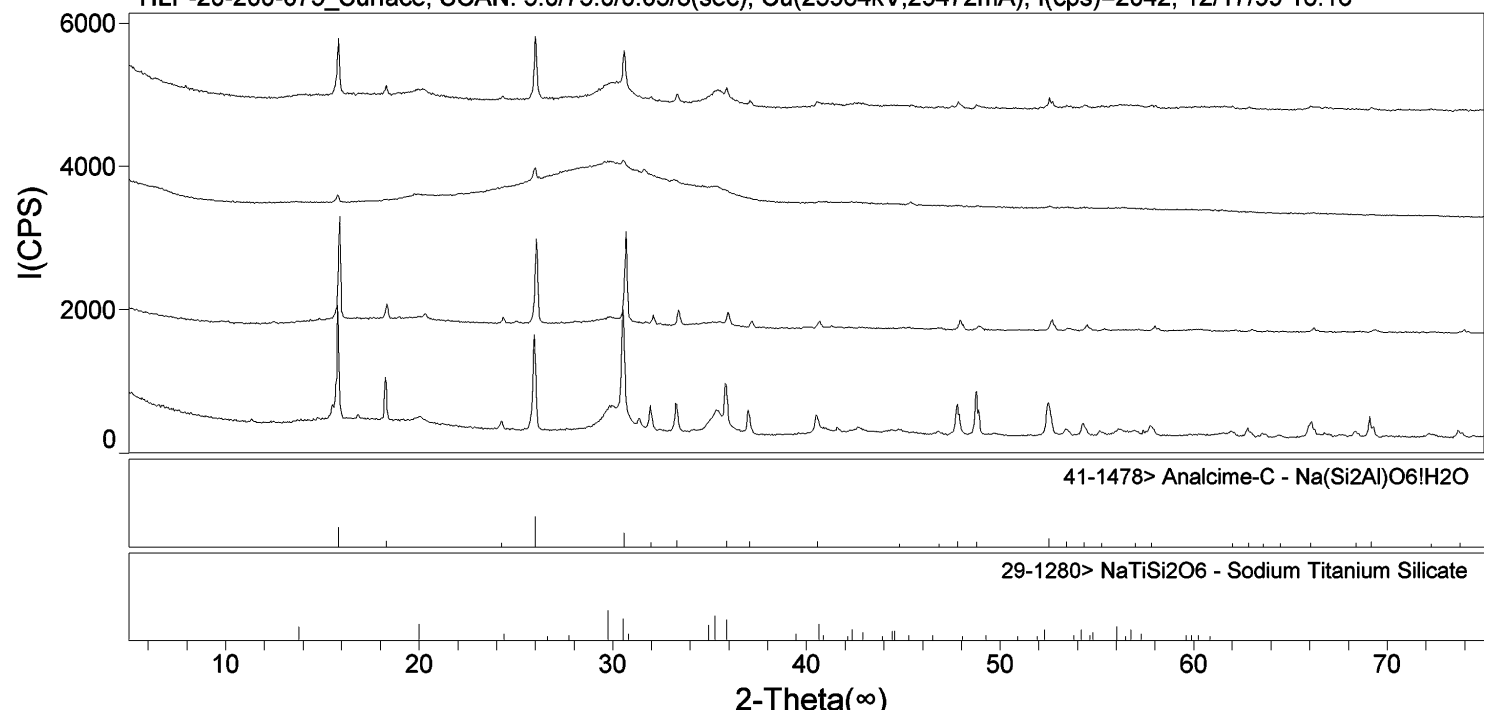

HLP-49-200-050, SCAN: 5.0/75.0/0.05/8(sec), Cu(24934kV,25955mA), I(cps)=1927, 12/04/99 11:25 HLP-21-200-032_Surface, SCAN: 5.0/75.0/0.05/8(sec), Cu(24934kV,25955mA), I(cps)=1546, 12/21/99 14:58

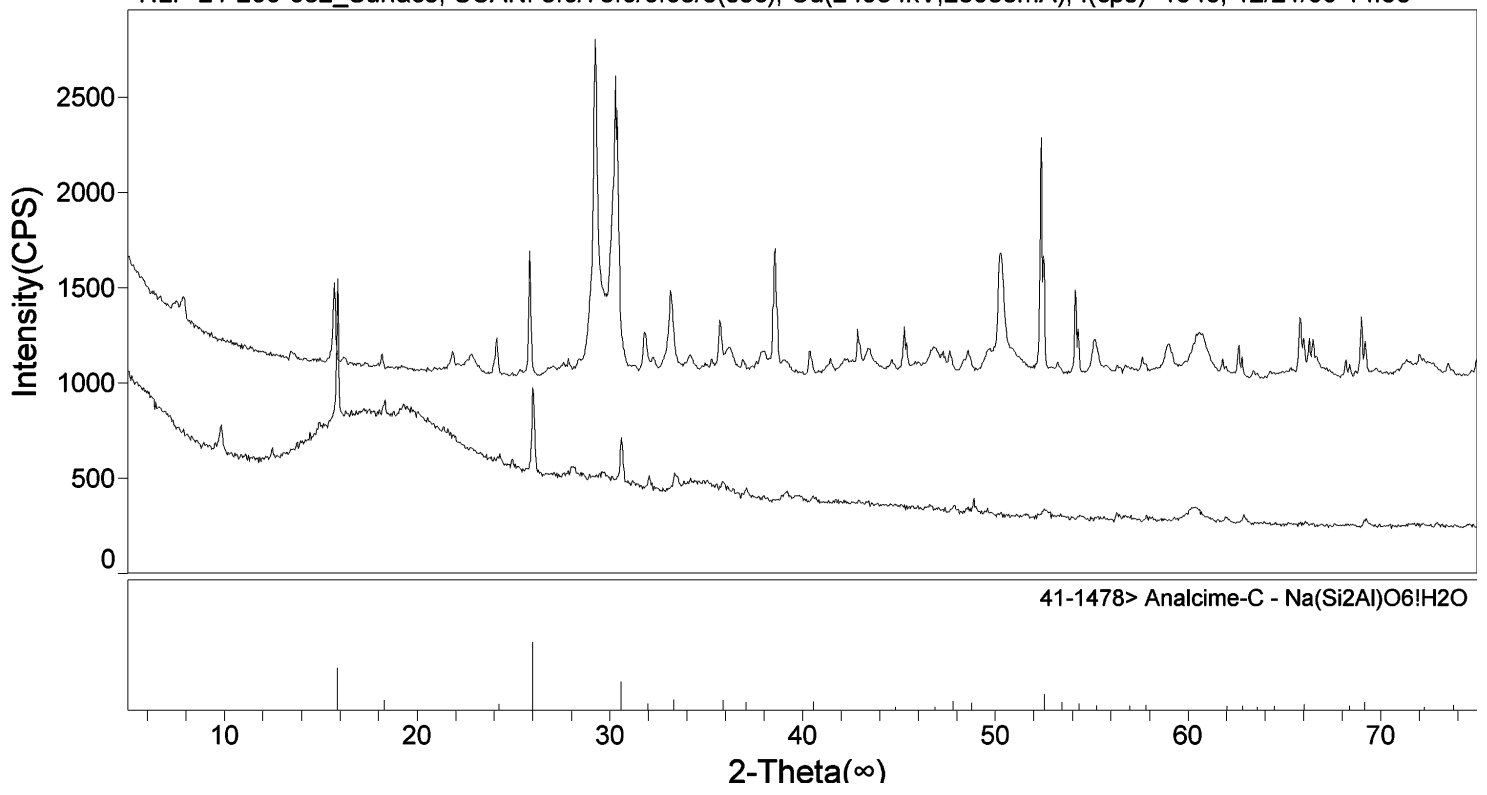



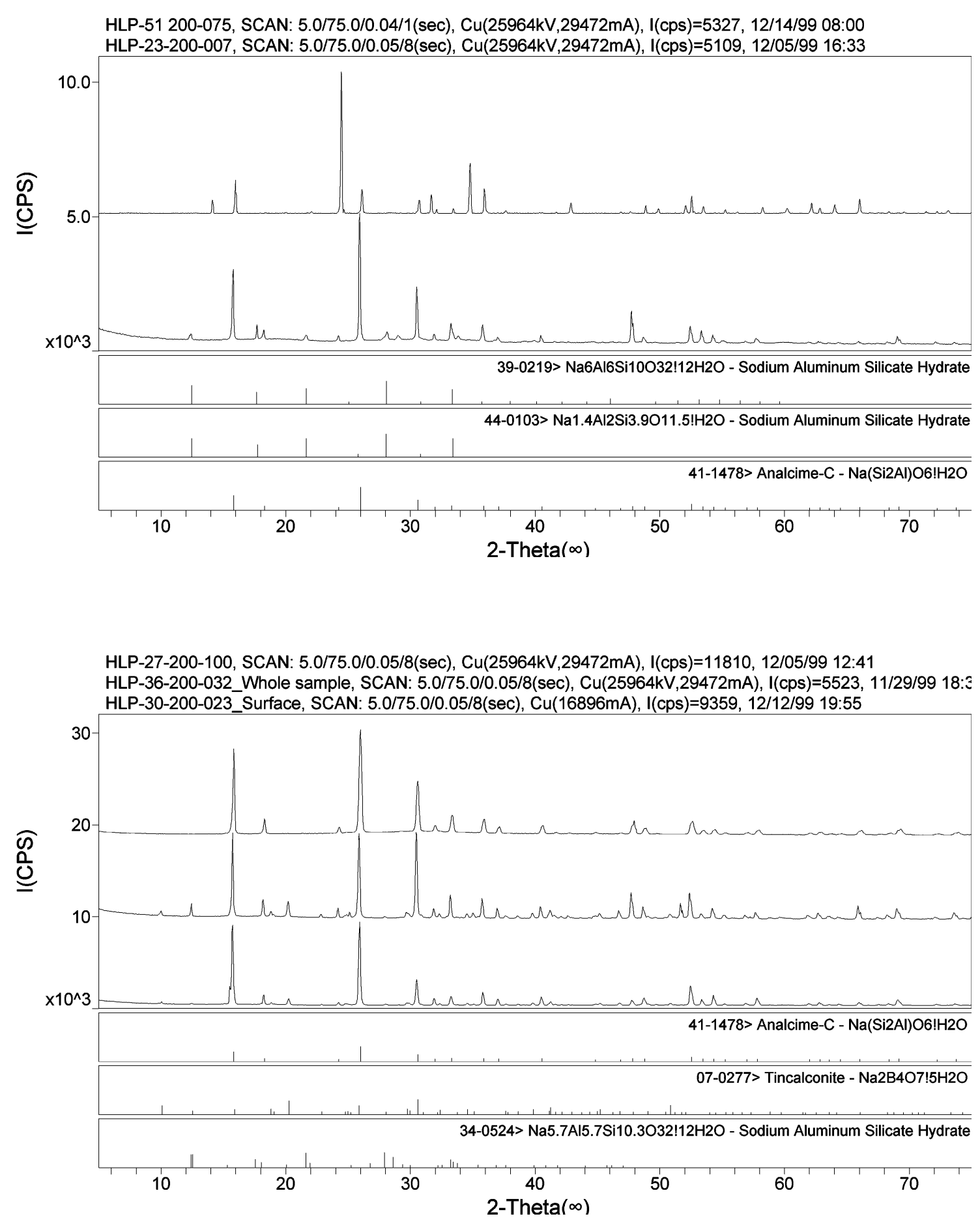


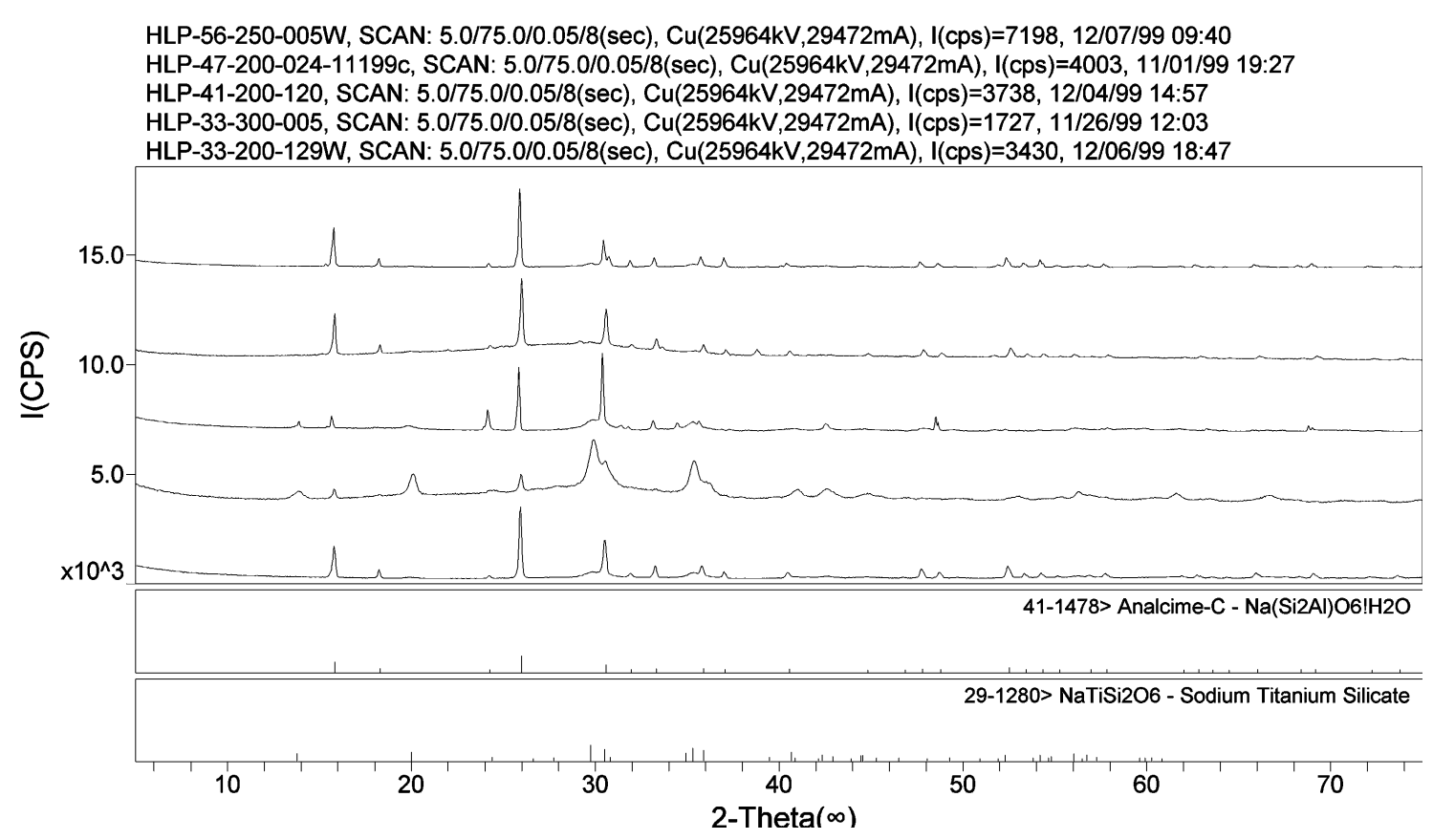

HLP-42-200-068_Surface, SCAN: 5.0/75.0/0.05/8(sec), Cu, I(cps)=2979, 12/21/99 11:01 HLP-38-200-064, SCAN: 5.0/75.0/0.05/8(sec), Cu, I(cps)=3794, 11/27/99 21:28 HLP-38-200-024, SCAN: 5.0/75.0/0.05/30(sec), Cu, I(cps)=12597, 09/06/99 20:05
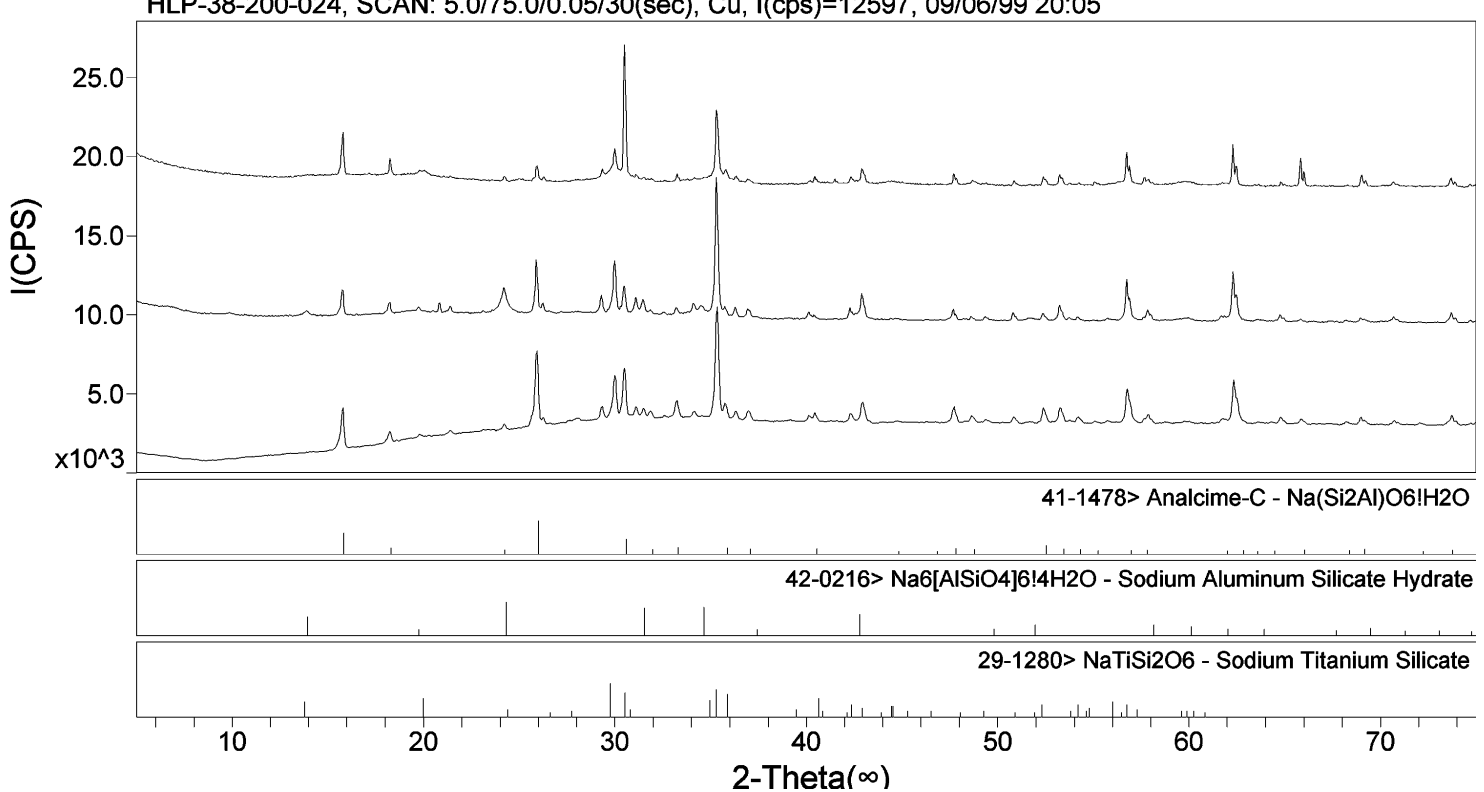


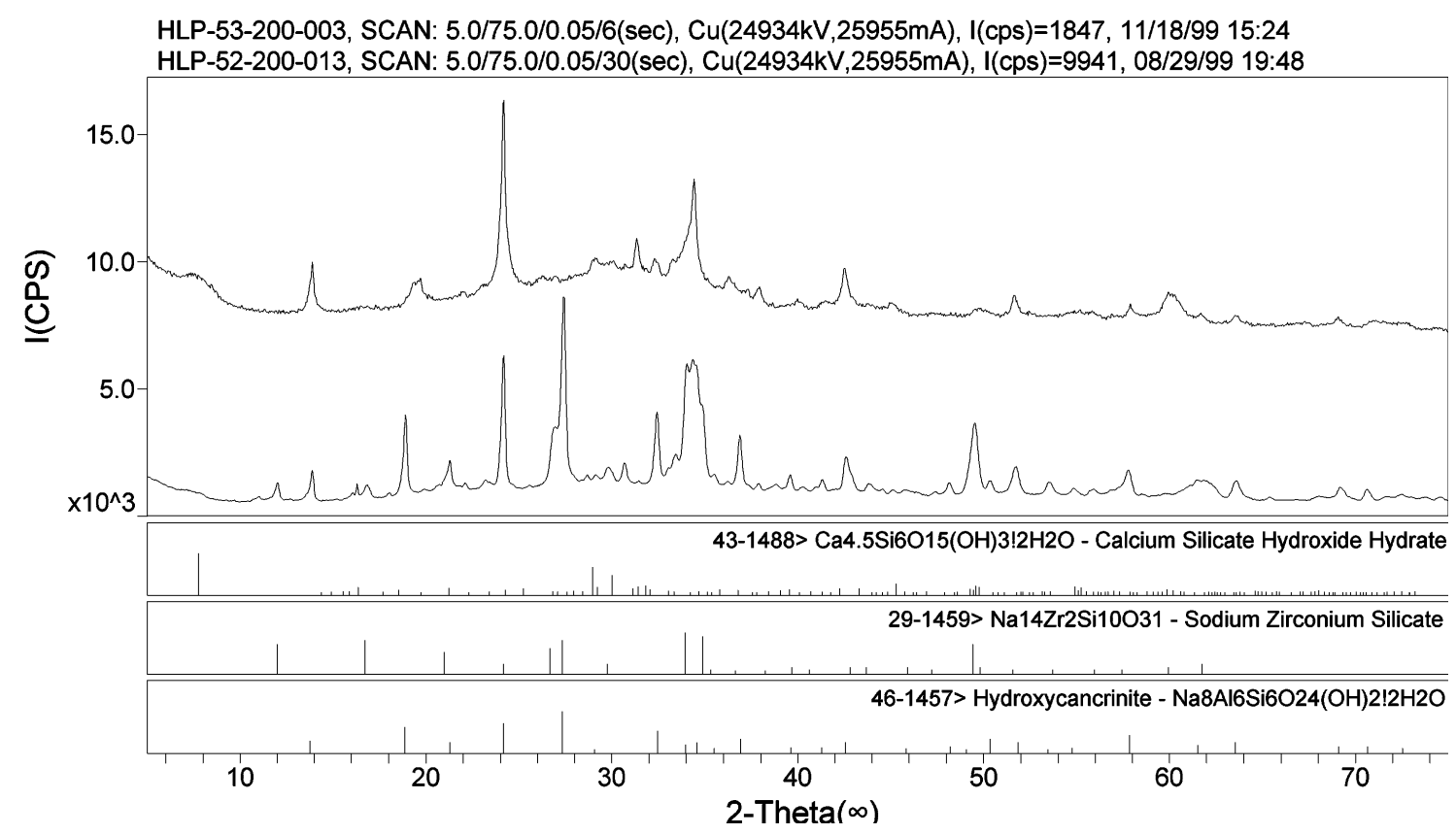

\section{Time and Temperature}

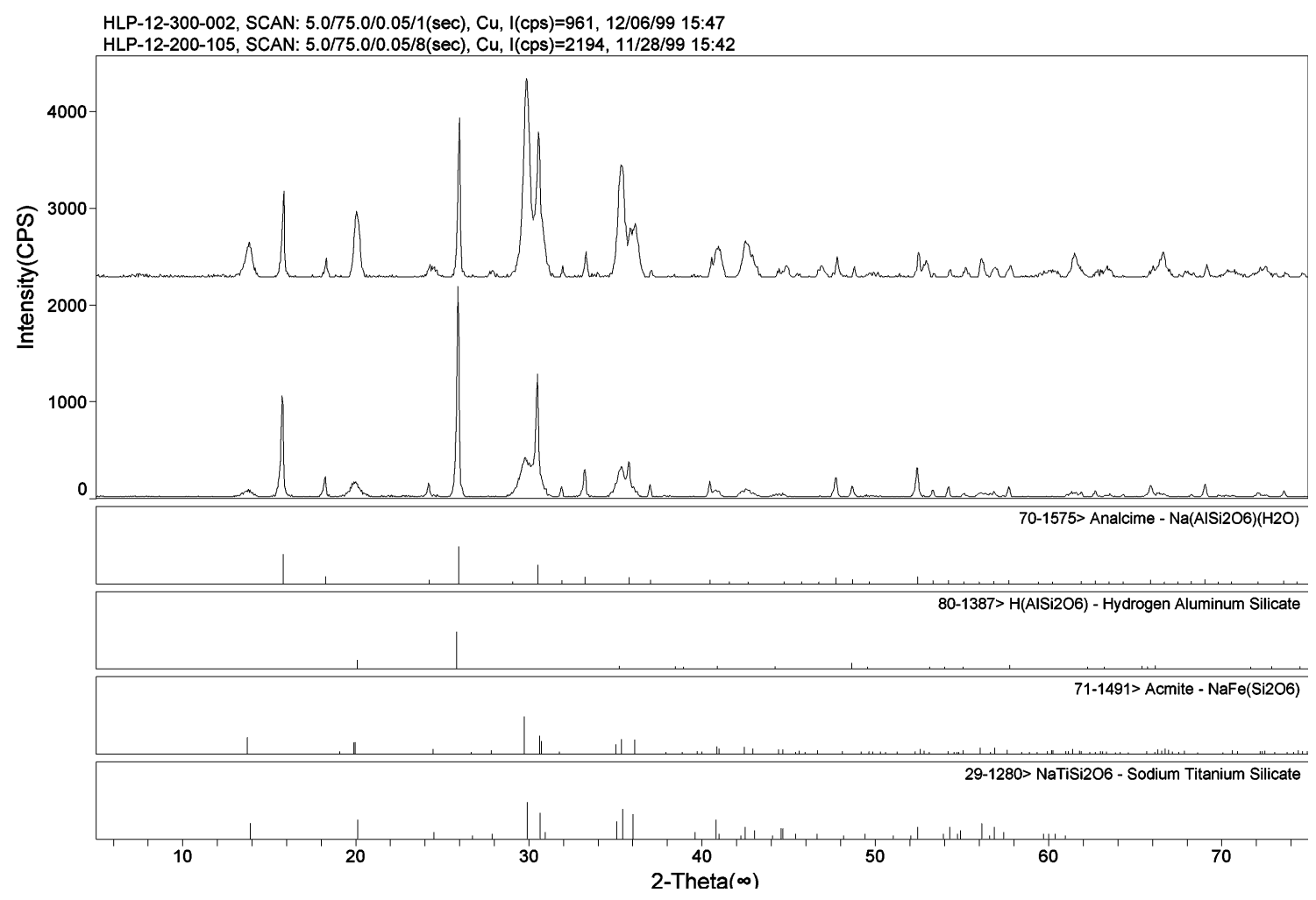

E.7 

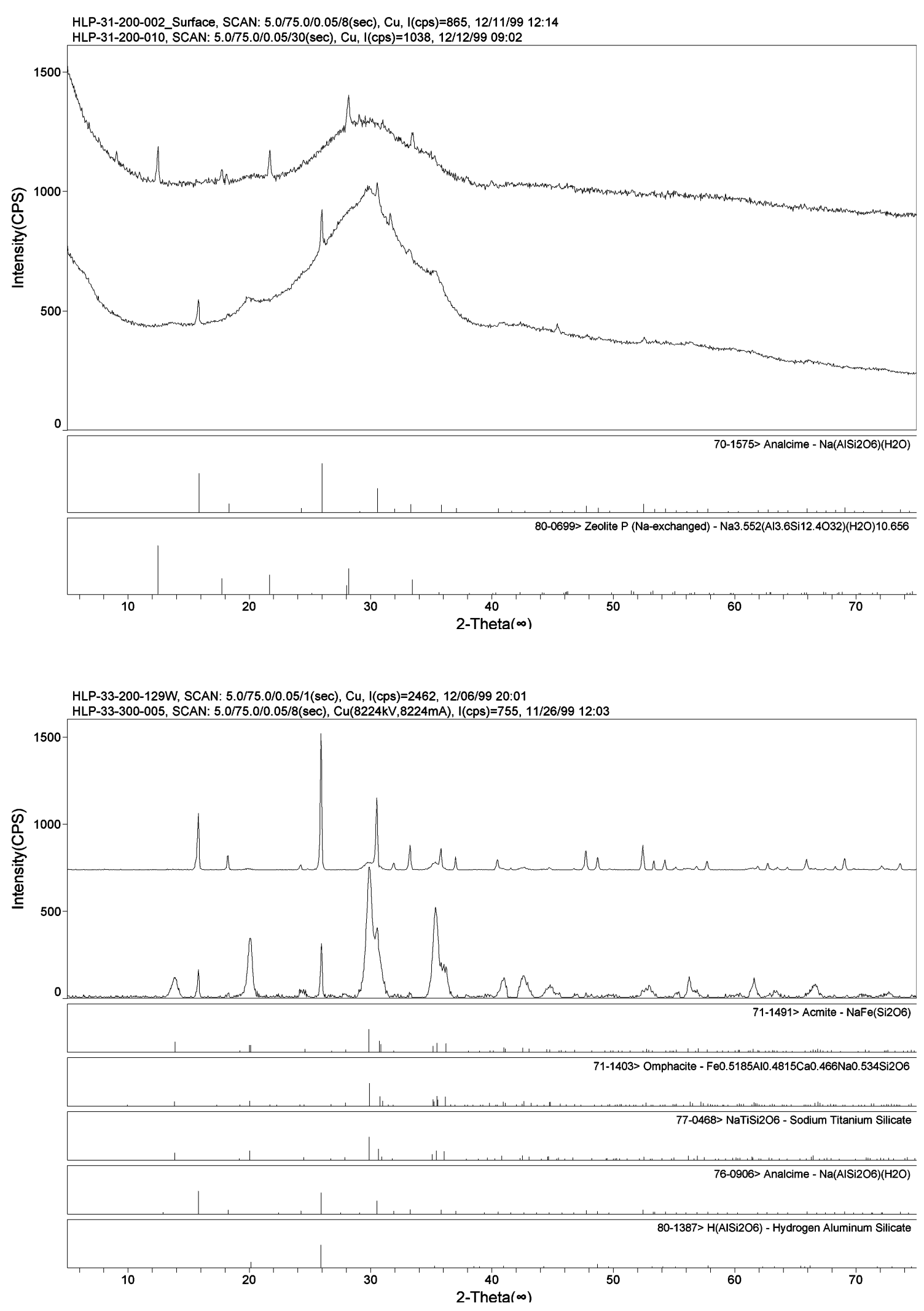

E. 8 

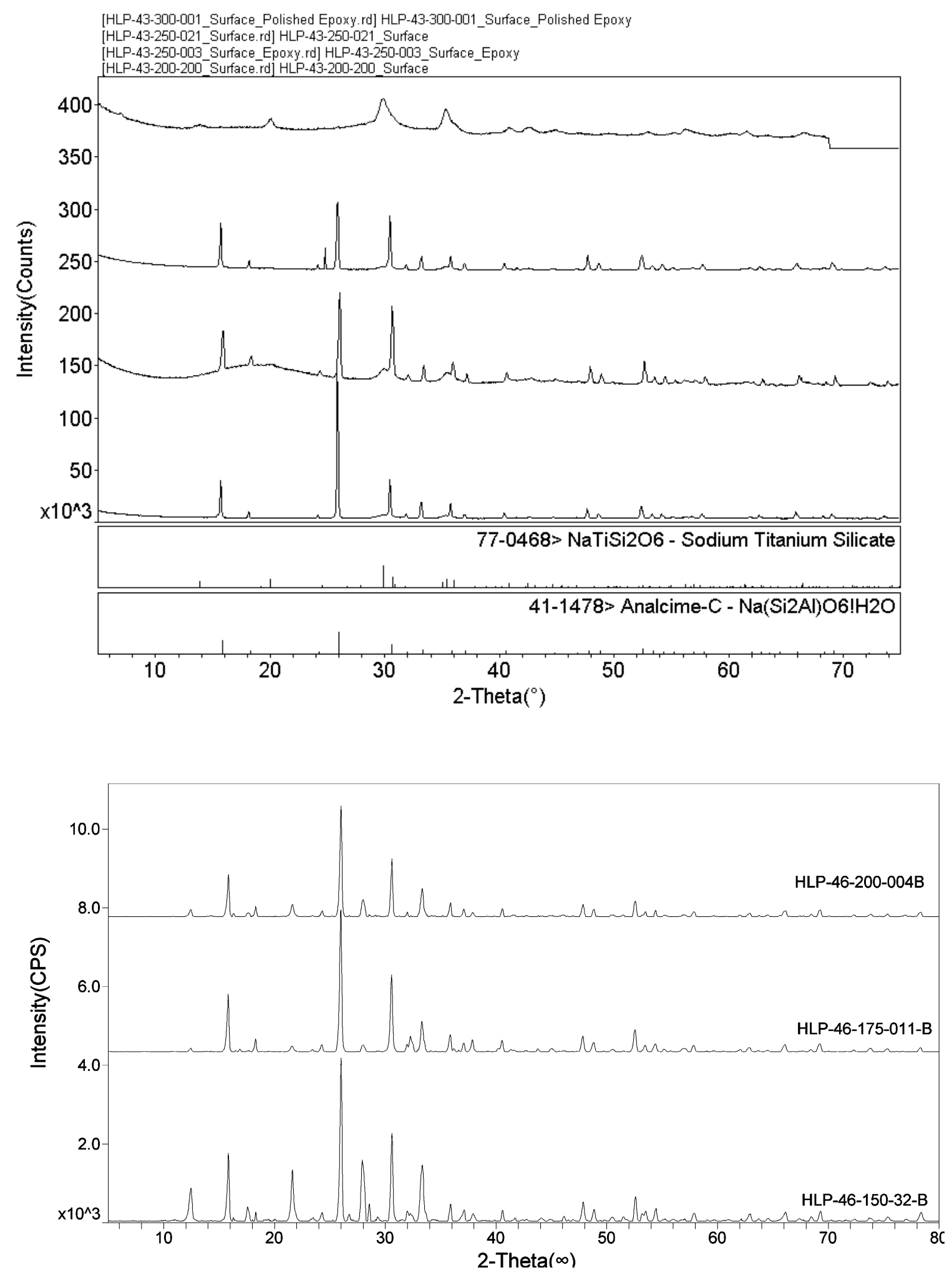

E.9 

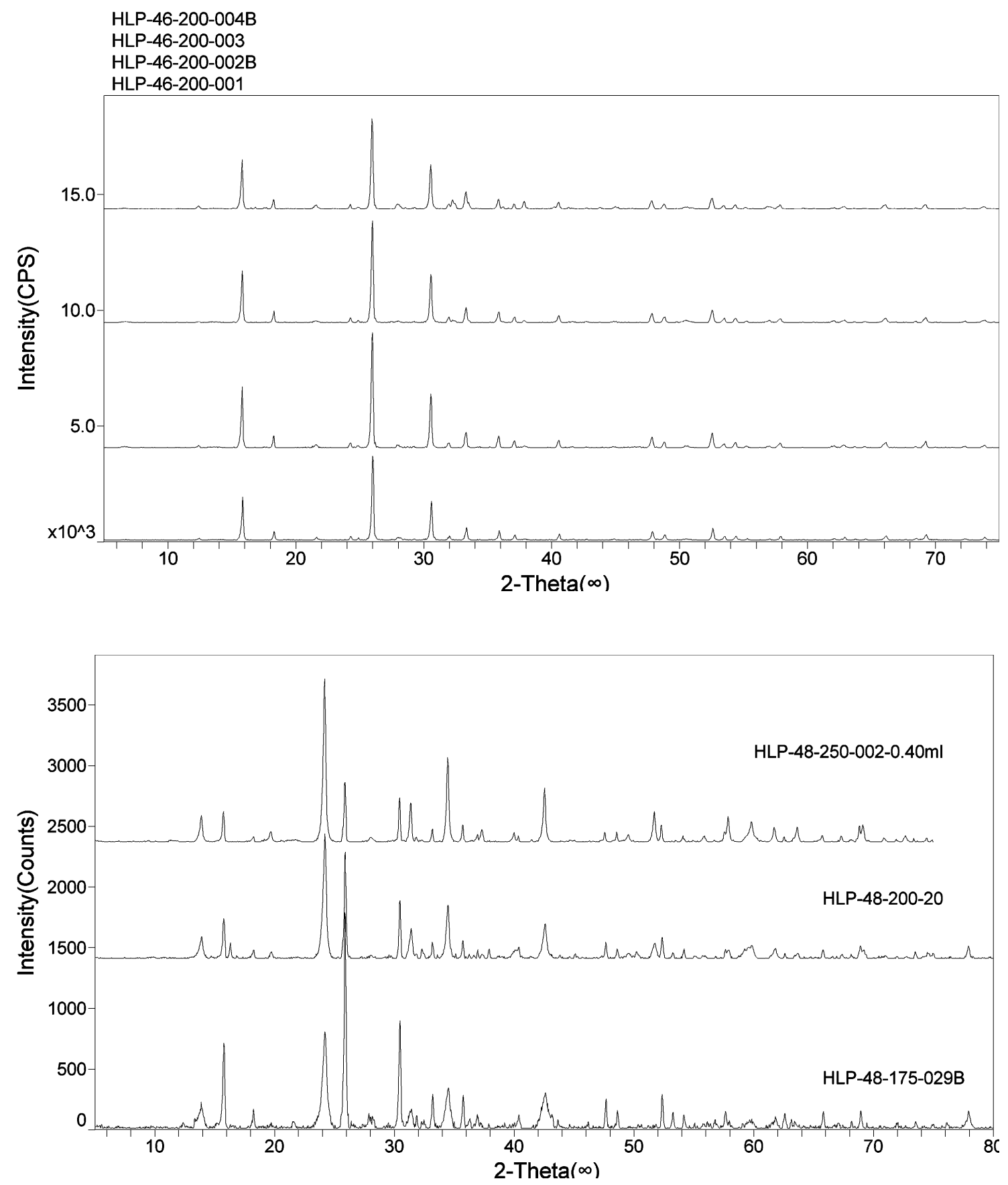

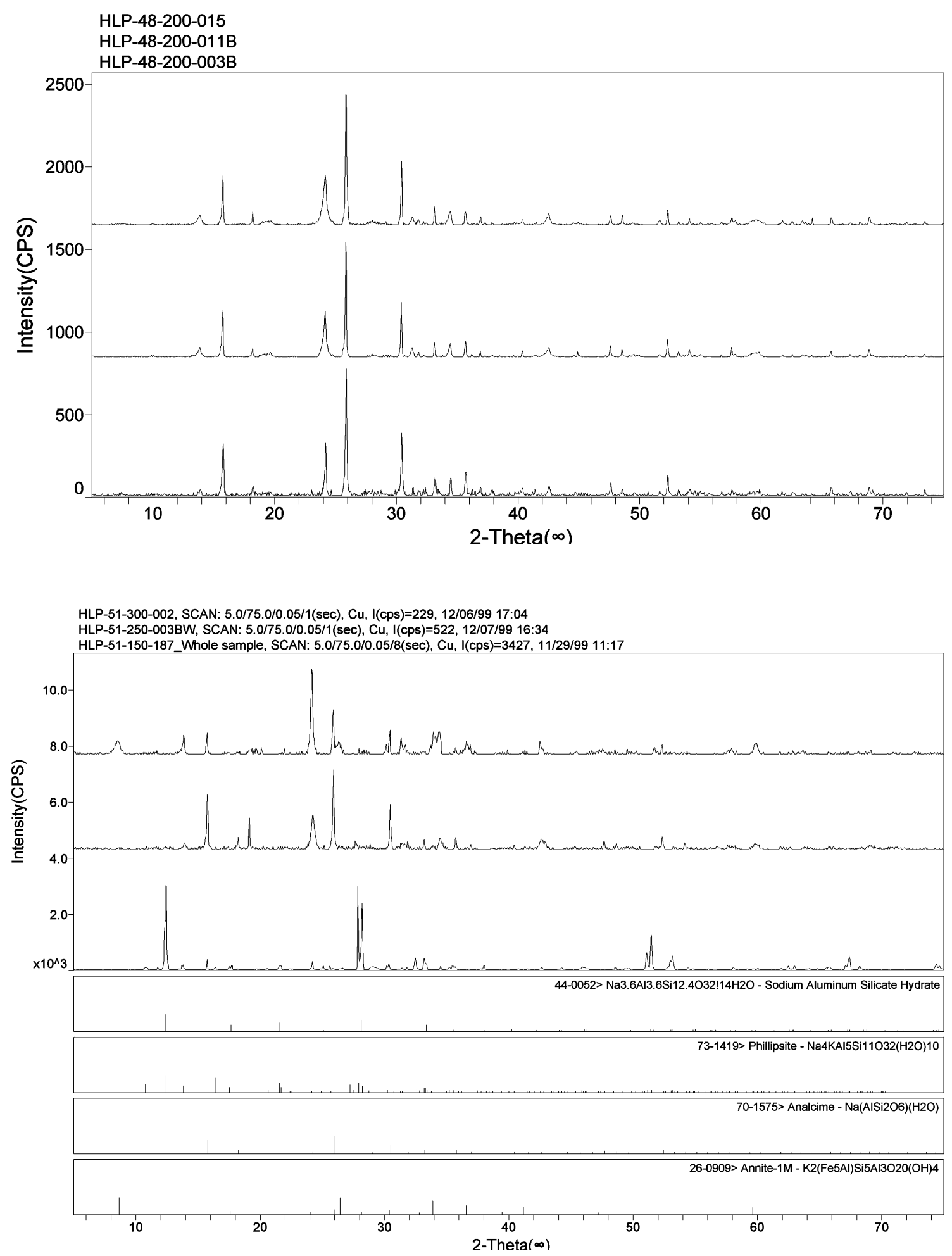

E.11 


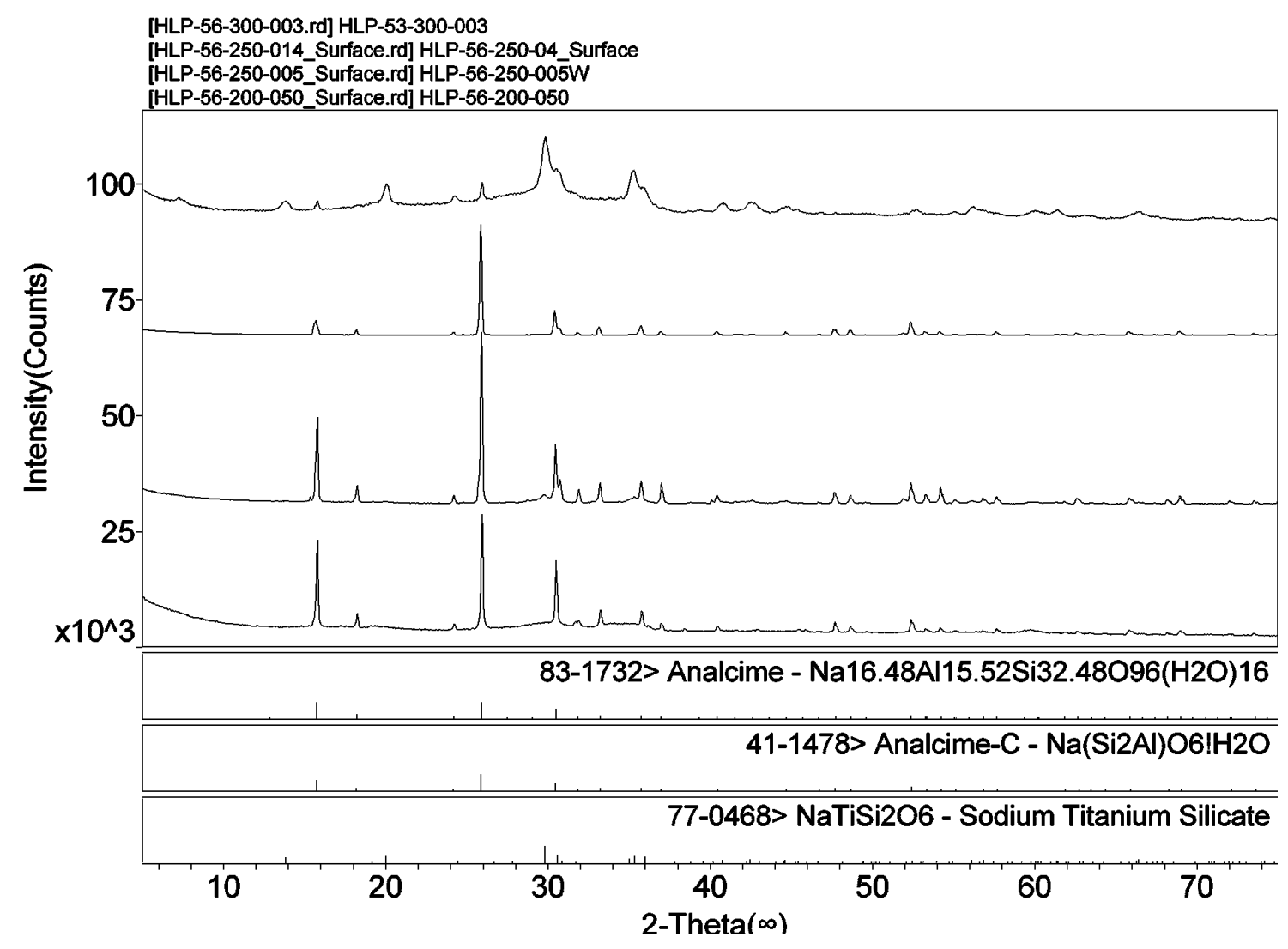

Solo Spectra

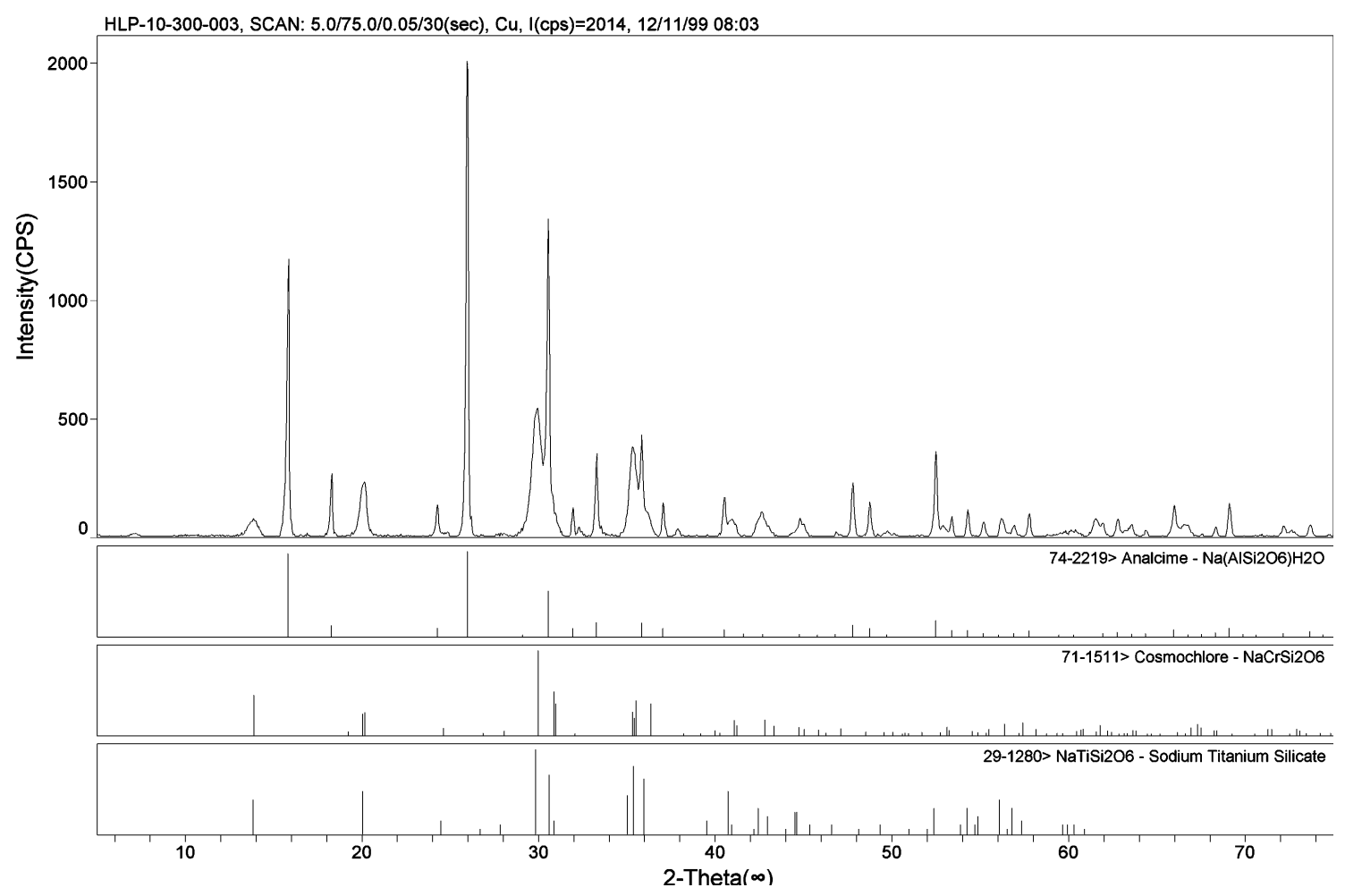

E. 12 

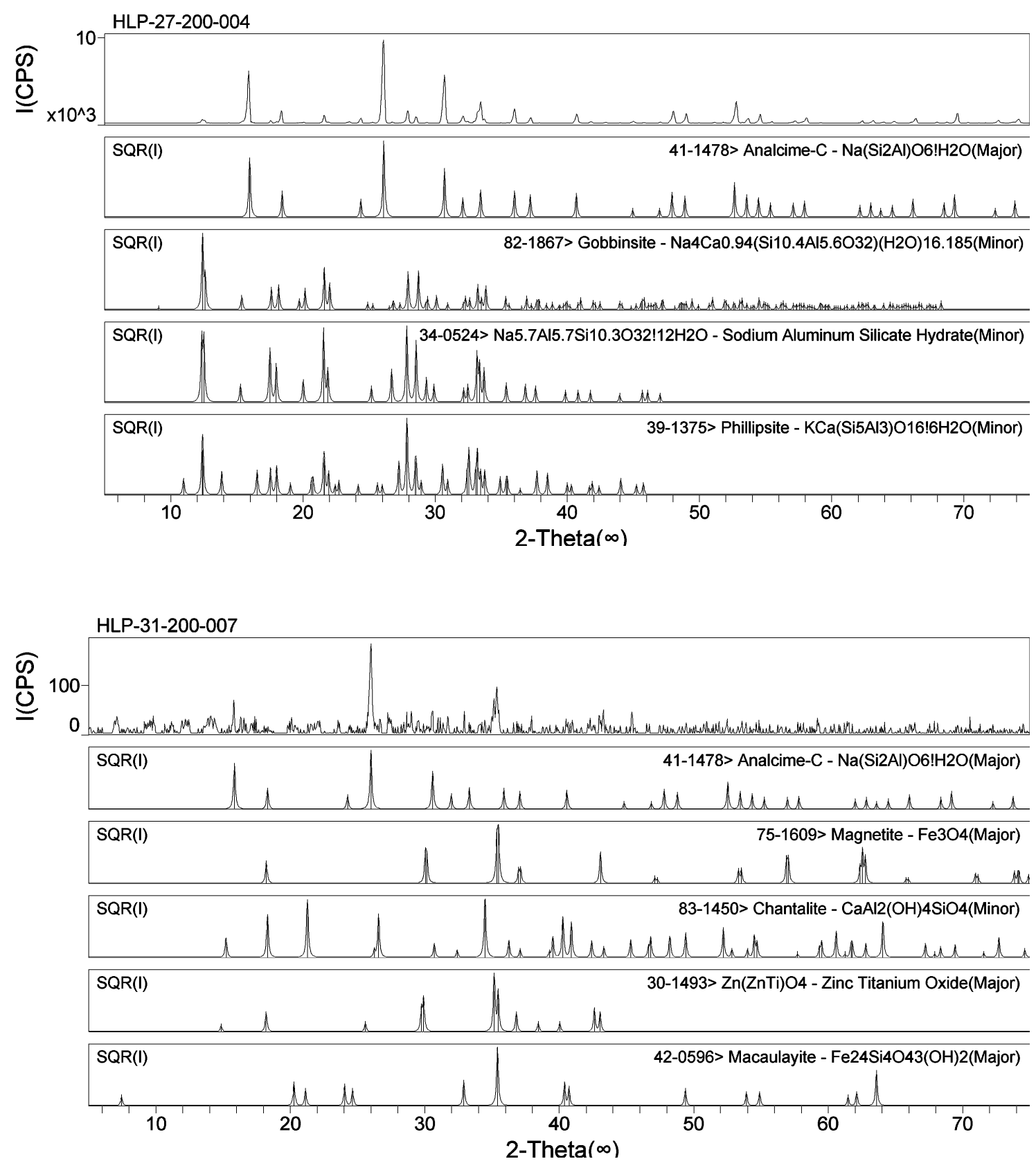


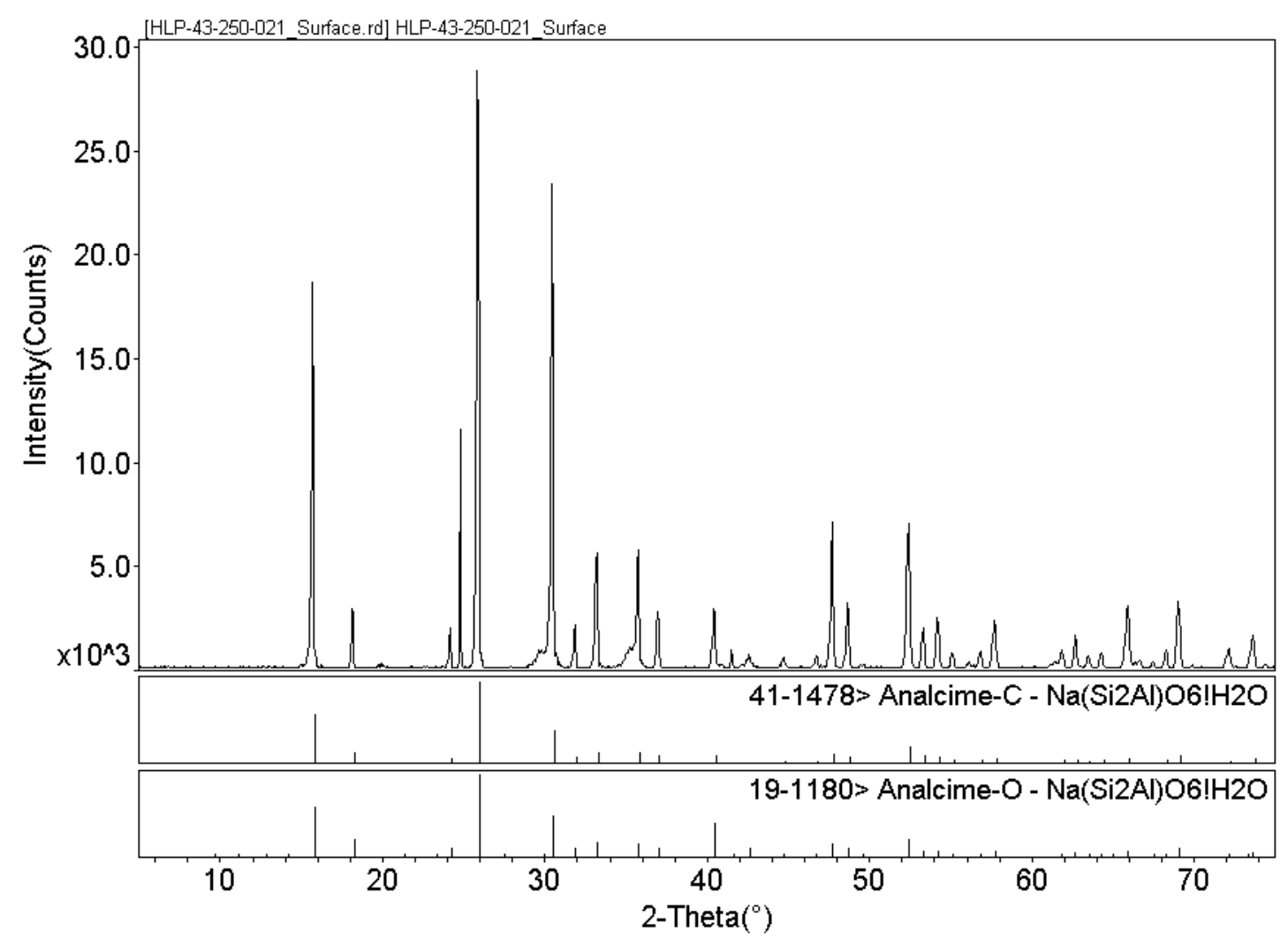

E. 14 

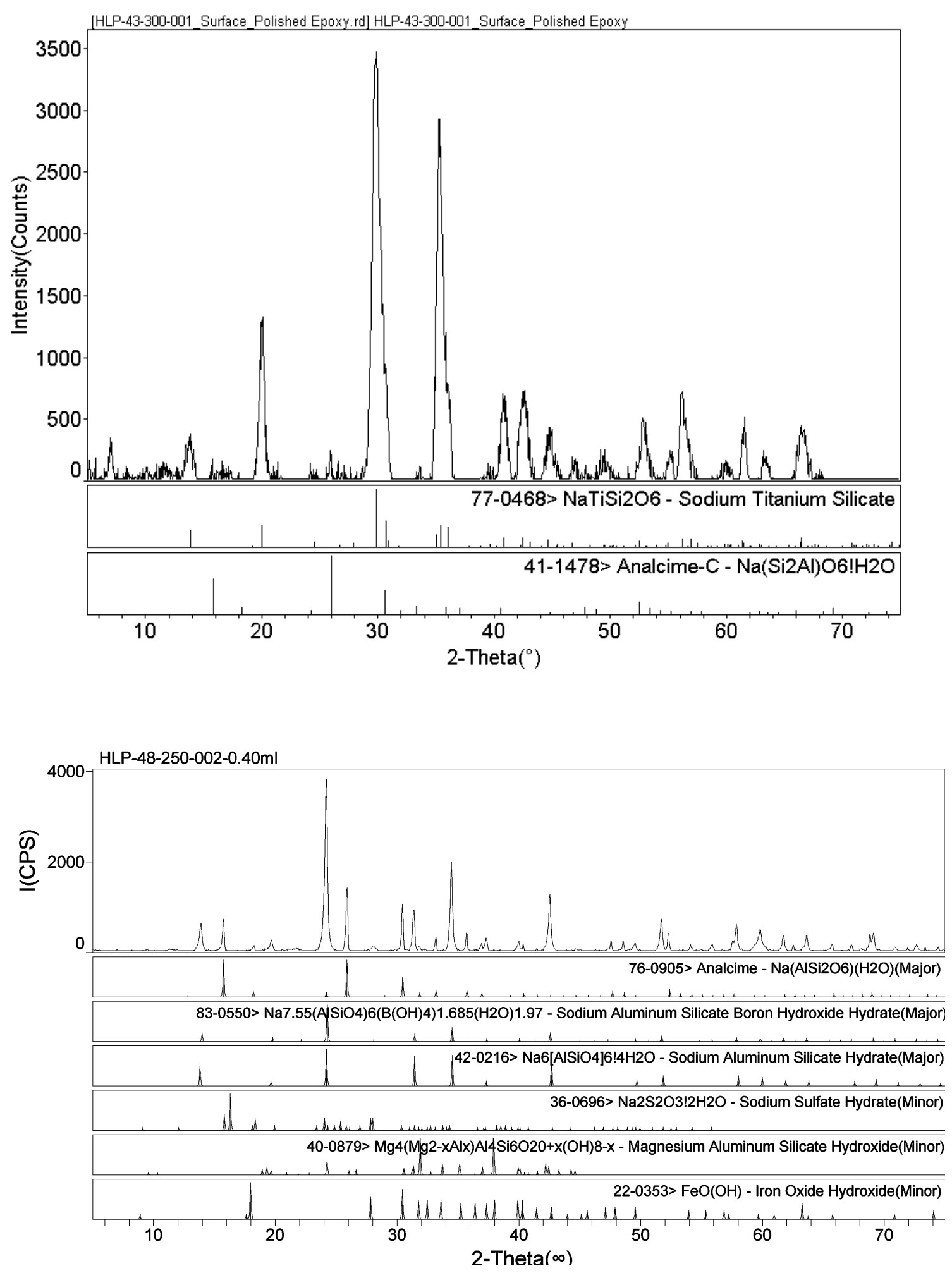

E. 15 

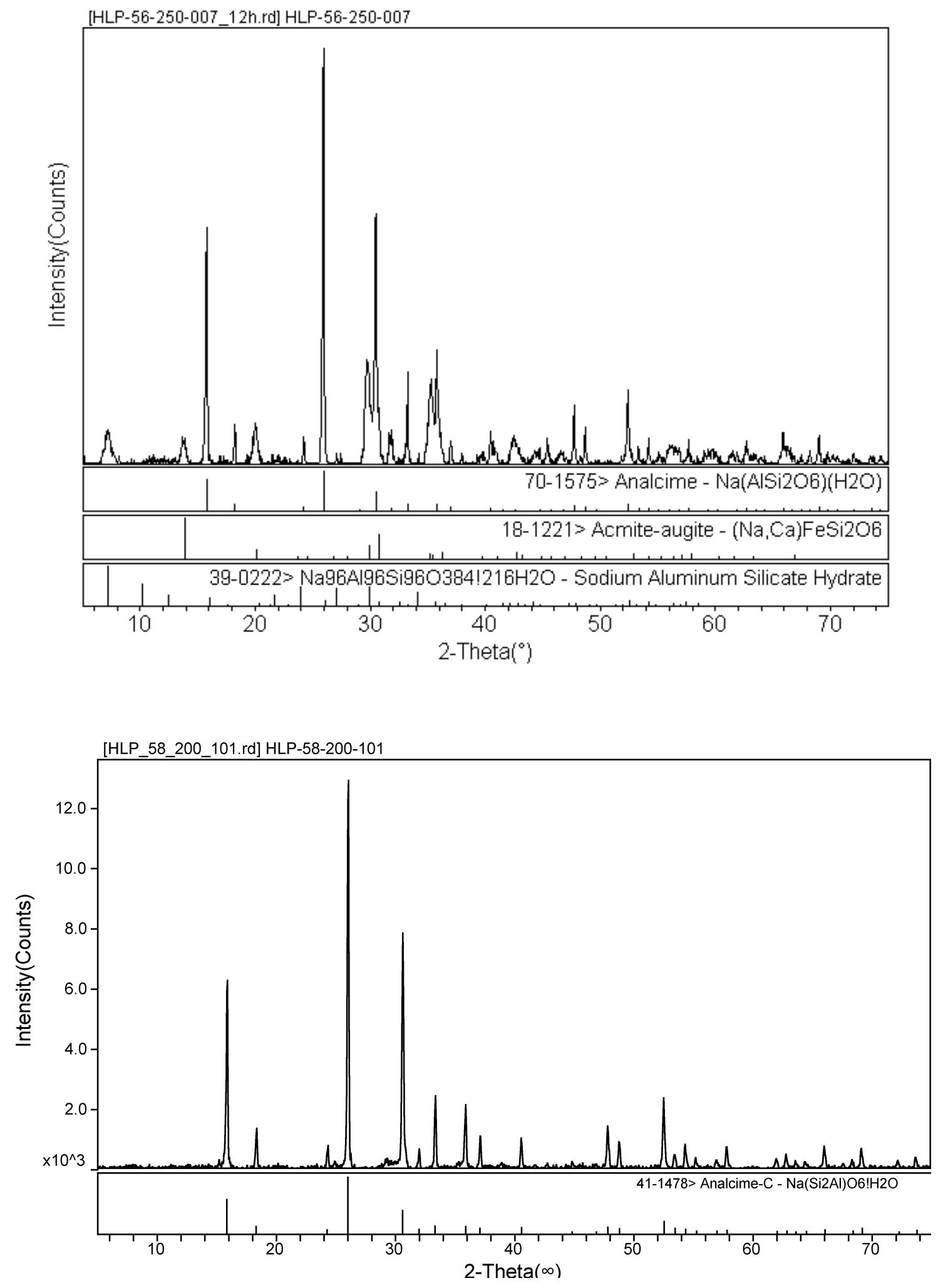

E.16 

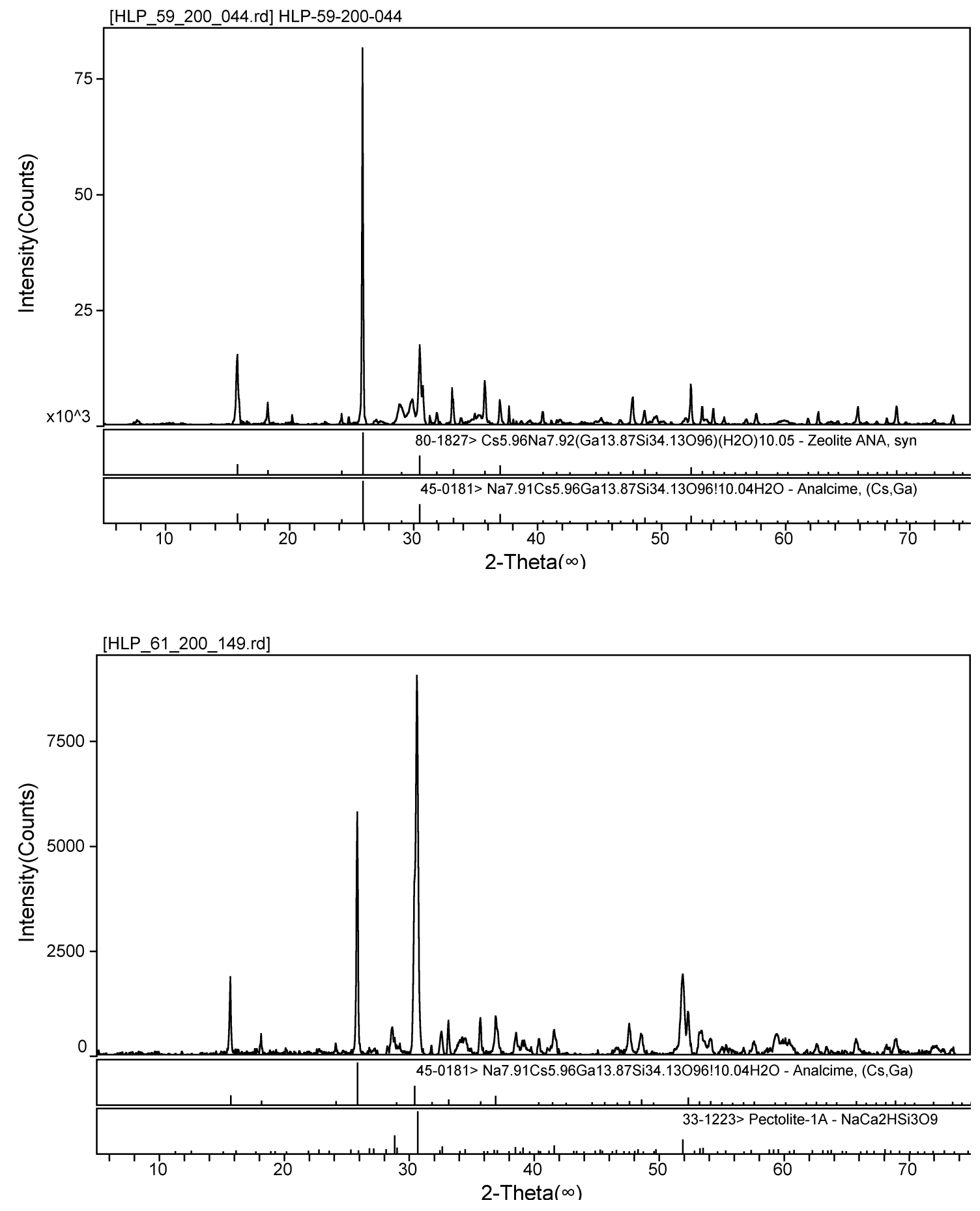

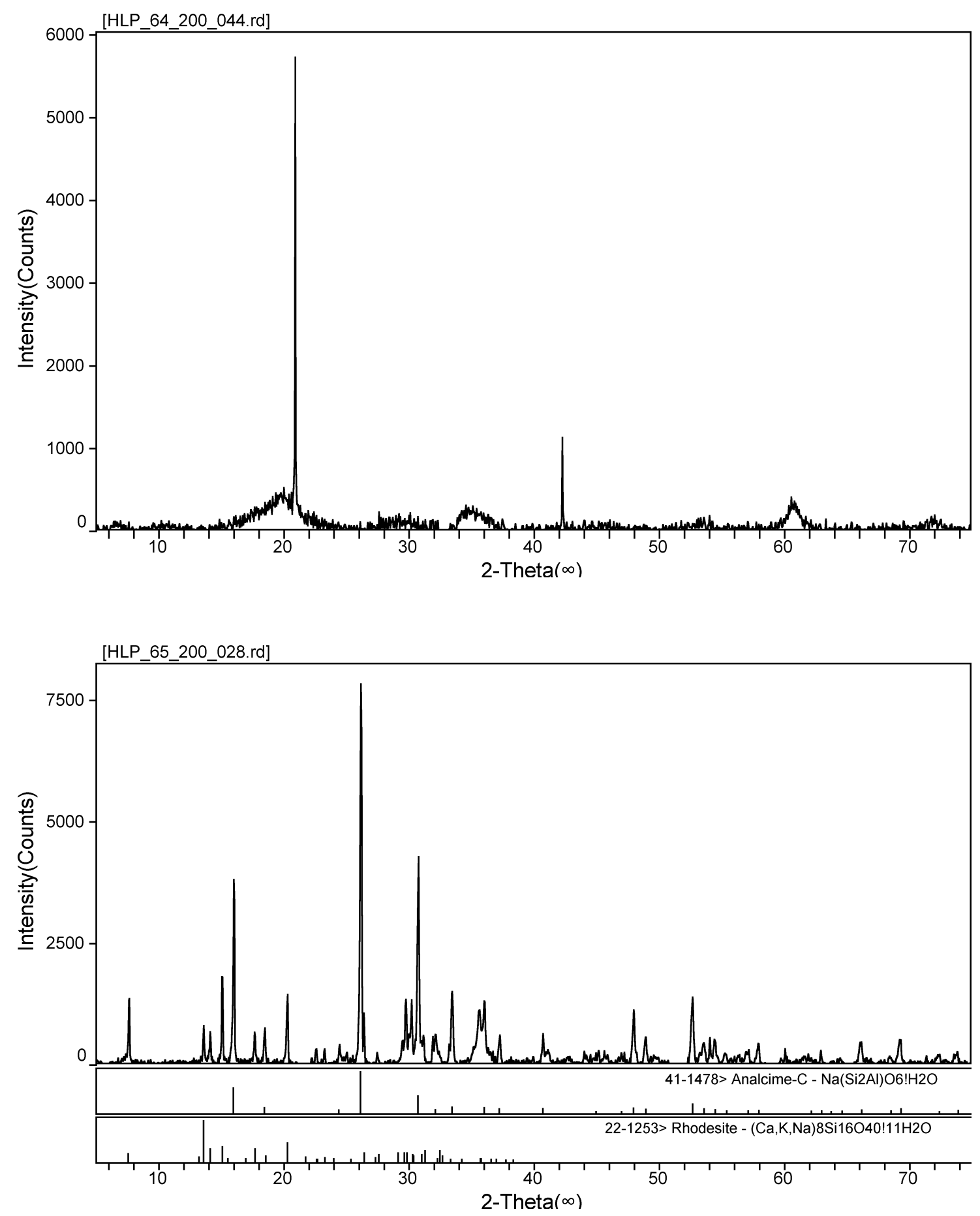

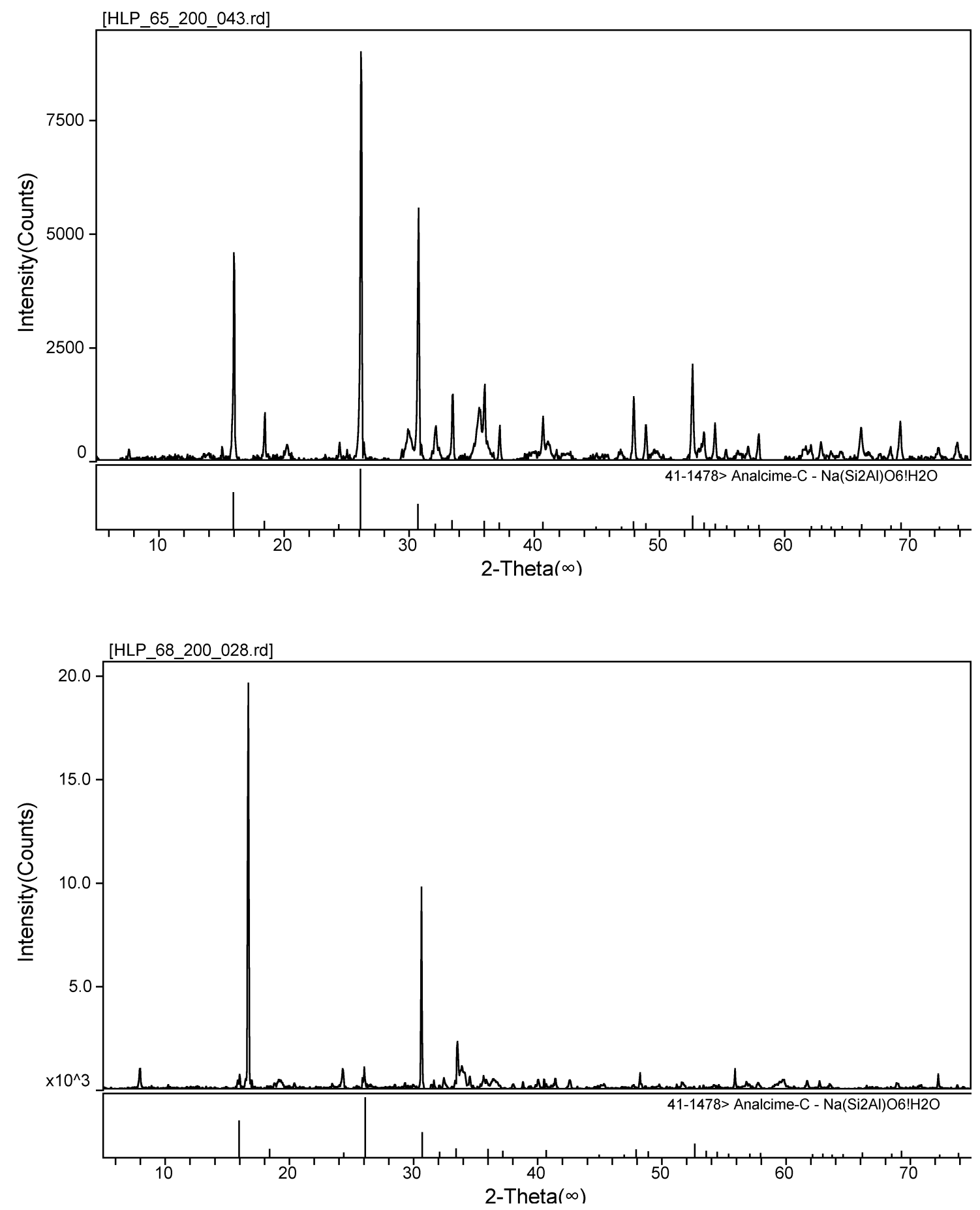

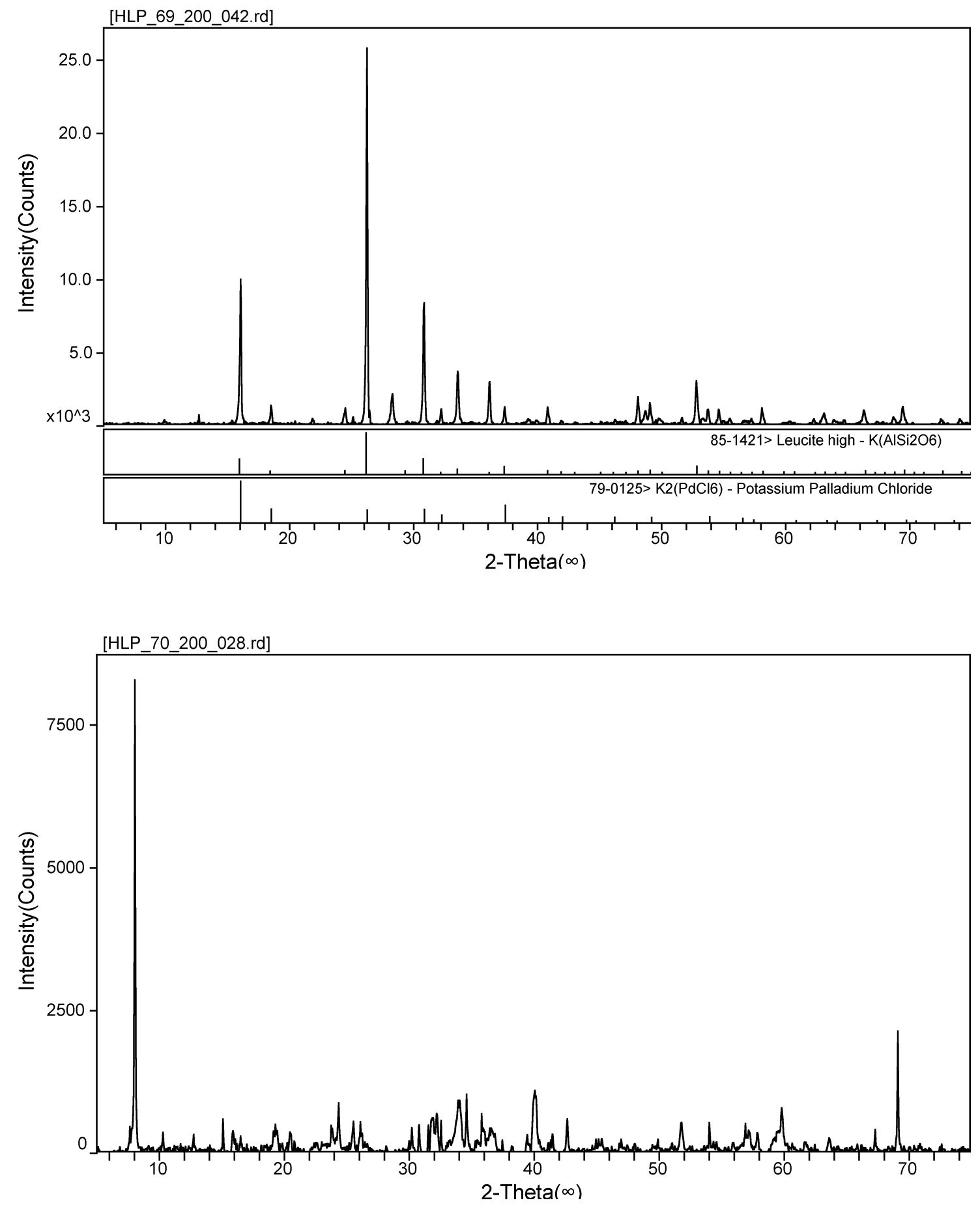

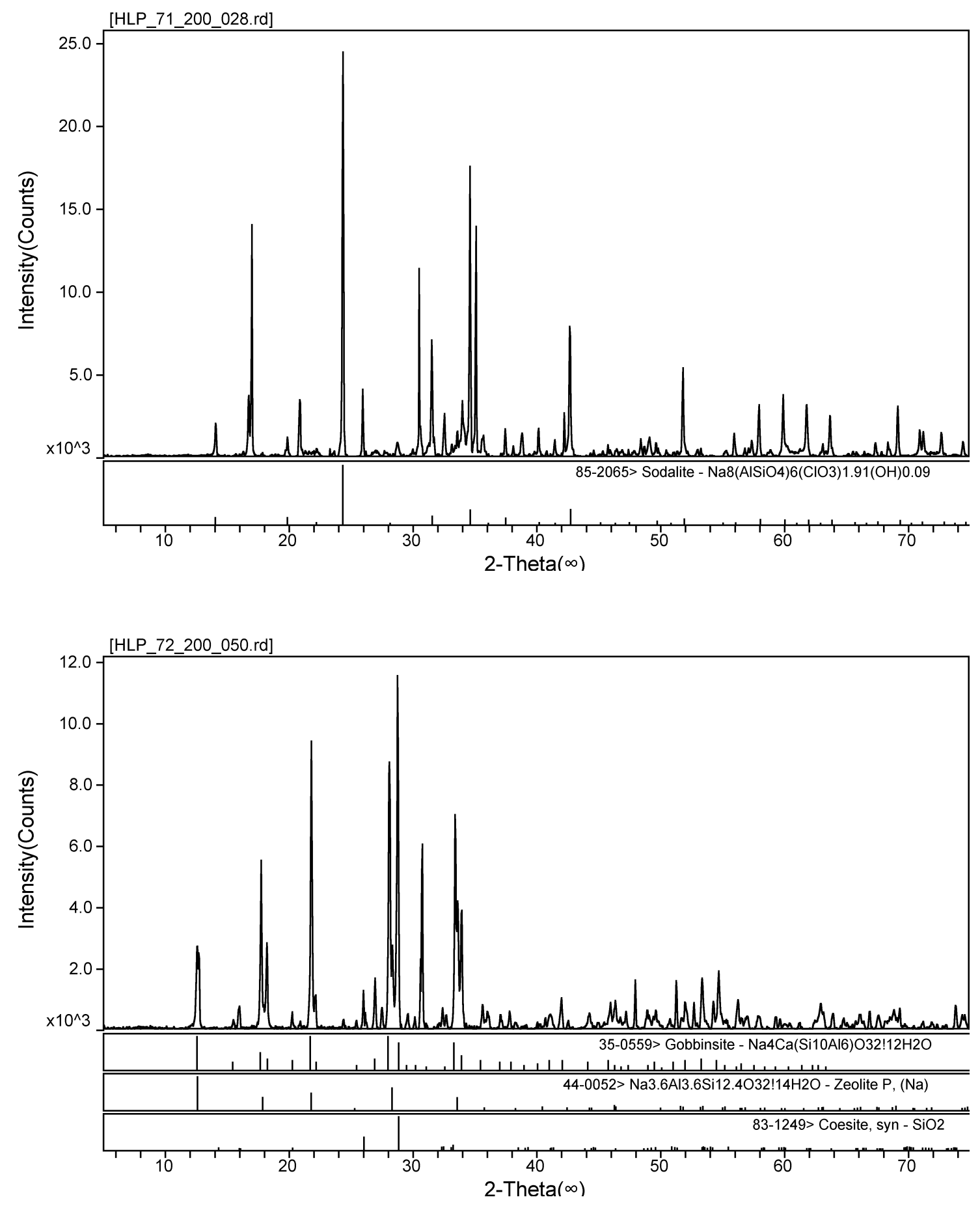

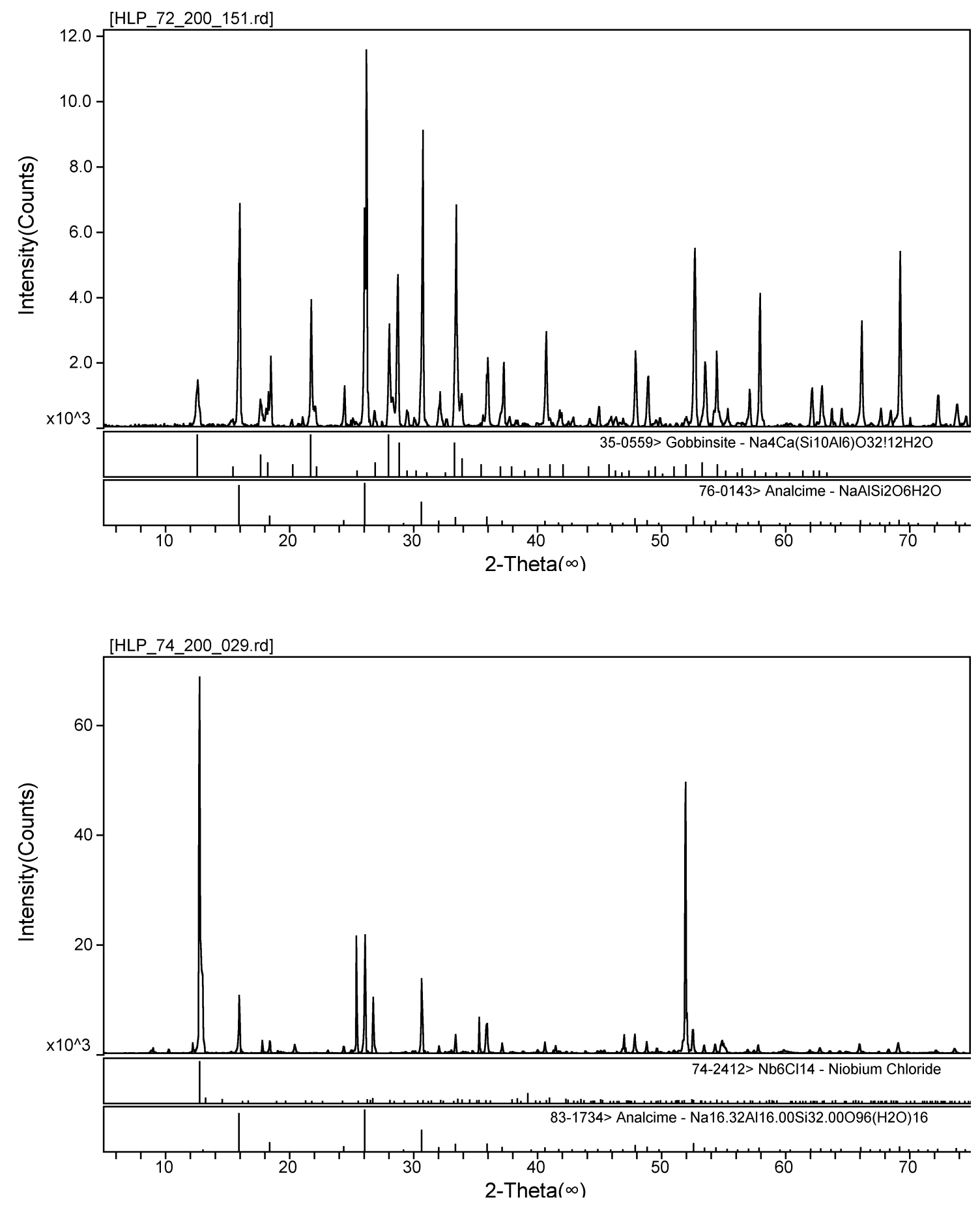

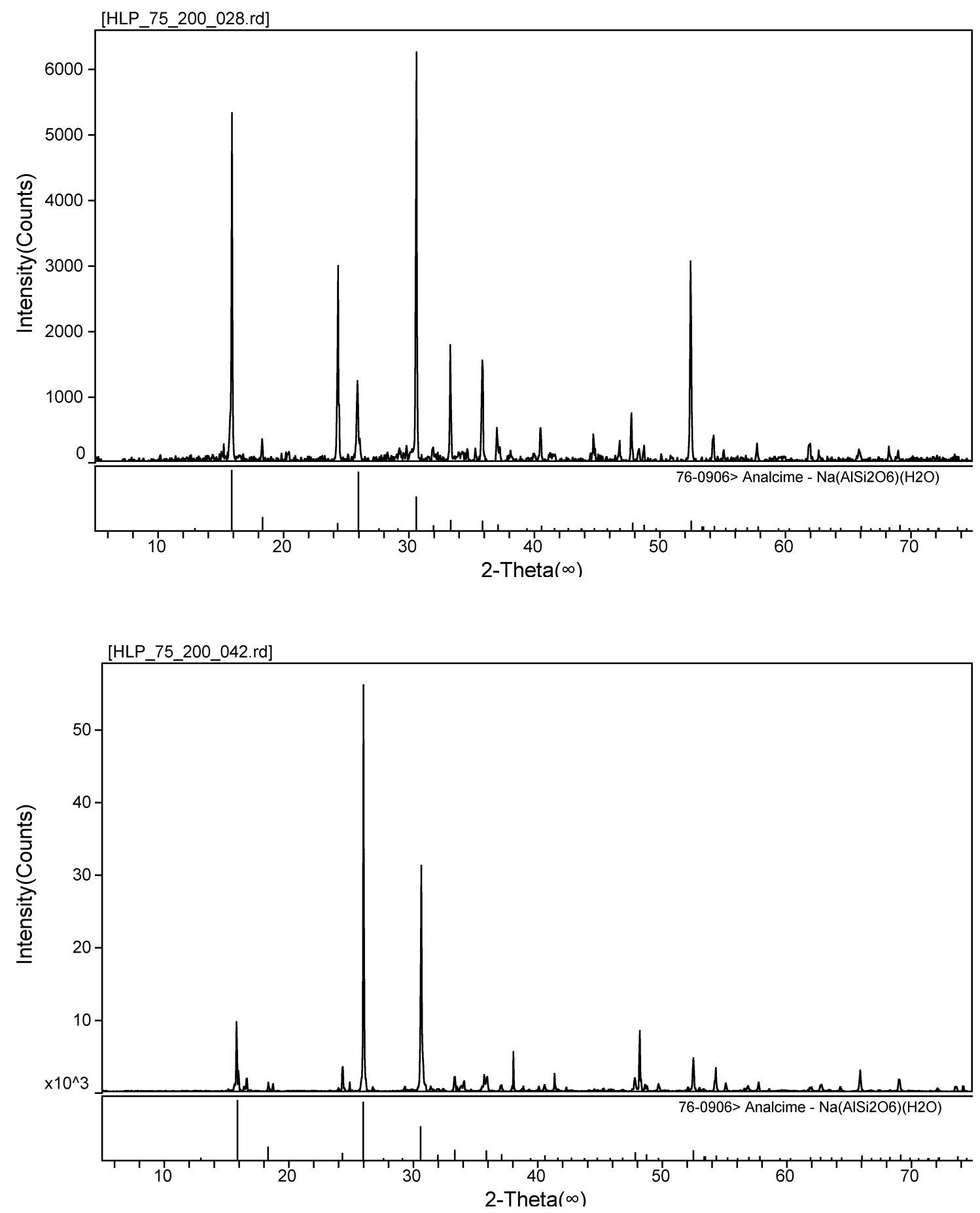

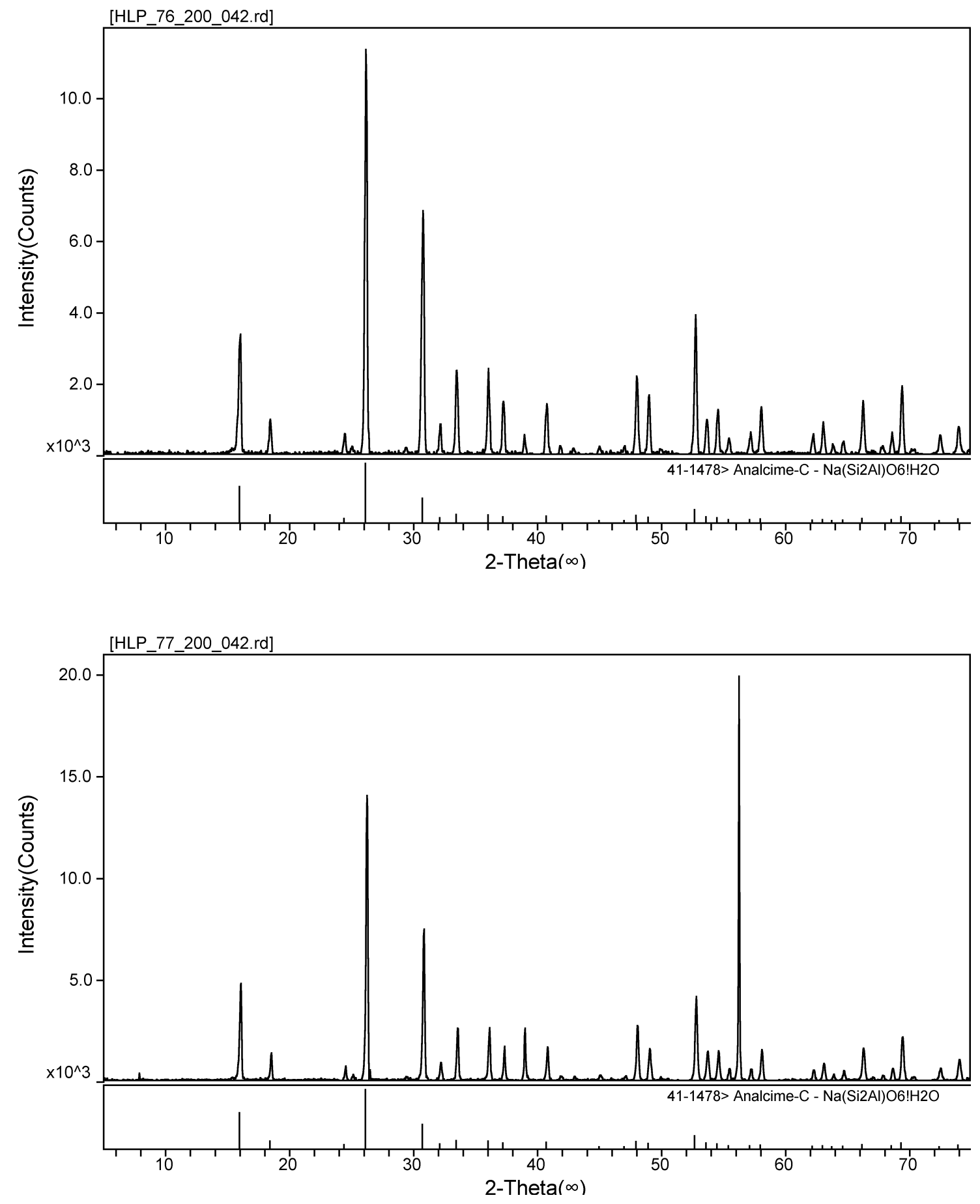


\section{Report Distribution List}

No. of

Copies

\section{$\underline{\text { OFFSITE }}$}

1 Argonne National Laboratory Argonne, Illinois 60439, Attn: W. L. Ebert

2 Catholic University of America Vitreous State Laboratory 620 Michigan Ave., N. E.

Washington, D. C. 20064, Attn:
A. C. Buechele
I. L. Pegg
Hannon Hall
Hannon Hall

1 CEA-Valrho / Marcoule

SCD/LEBM

Bâtiment 208, BP 171

30207 BAGNOLS - SUR - CEZE CEDEX, FRANCE, Attn:

J. L. Dussossoy

2 VSCHT

Ustav Skla a Keramiky

Technicka 5

16628 Praha 6

Czech Republic, Attn:

Ales Helebrant

Antonin Jiricka

11 Westinghouse Savannah River Company

Aiken, South Carolina 29808, Attn:
K. G. Brown
$773-42 \mathrm{~A}$
E. W. Holtzscheiter
773-A
C. M. Jantzen
T. L. Lorier (5)
S. L. Marra
D. K. Peeler
G. W. Wicks
$773-\mathrm{A}$
999-W
999-W
999-W
773-A

No. of

Copies

\section{$\underline{\text { ONSITE }}$}

4 DOE/Office of River Protection

C. A. Babel

H6-60

R. Carreon

H6-60

P. E. Lamont

H6-60

E. H. Randklev

H6-60

1 DOE/Richland Operations Office

T. E. Pietrok

K8-50

2 Washington Group

J. R. Harbour

H4-02

J. R. Cook

$\mathrm{H} 4-02$

2 CH2M Hill Hanford Group

J. O. Honeyman

H6-18

K. A. Gasper

L4-07

1 Fluor Daniel Northwest

F. M. Mann

$\mathrm{H} 0-22$

35 Pacific Northwest National Laboratory

$\begin{array}{ll}\text { W. F. Bonner } & \text { K9-14 } \\ \text { W. C. Cosby } & \text { K7-62 } \\ \text { J. V. Crum } & \text { K6-24 } \\ \text { P. R. Hrma } & \text { K6-24 } \\ \text { L. K. Holton } & \text { H6-61 } \\ \text { B. R. Johnson } & \text { K6-24 } \\ \text { D. S. Kim } & \text { K6-24 } \\ \text { D. E. Kurath } & \text { P7-28 } \\ \text { B. P. McGrail } & \text { K6-81 } \\ \text { L. M. Peurrung } & \text { K6-24 } \\ \text { M. J. Schweiger } & \text { K6-24 } \\ \text { D. E. Smith } & \text { K6-24 } \\ \text { G. L. Smith } & \text { K6-24 } \\ \text { D. M. Strachan } & \text { K6-24 } \\ \text { J. D. Vienna (10) } & \text { K6-24 } \\ \text { J. H. Westsik } & \text { K9-91 } \\ \text { B. J. Williams -- TFA (8) } & \text { K9-69 } \\ \text { Technical Report Files (2) } & \text { P8-55 }\end{array}$

